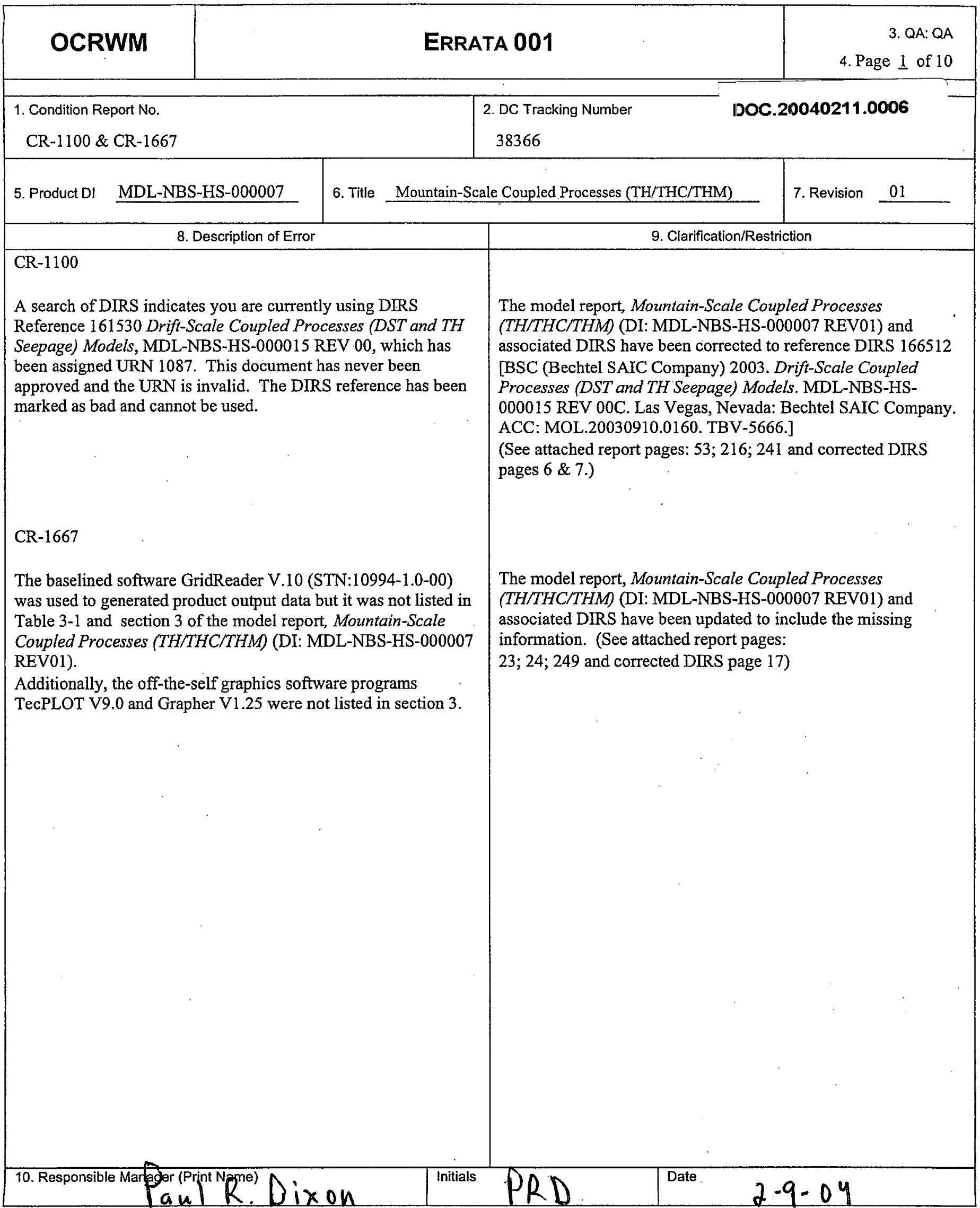


will accompany these drying (drainage) and rewetting (imbibition) processes. This leads to different curves of relative permeability and capillary pressures for describing drainage and imbibing processes, respectively. In this work, hysteresis effects are ignored because they are small compared to the uncertainty inherent to the development of the capillary pressure and relative permeability relationships.

The ignoring of THM/THC coupling and hysteresis effects results partially from the limitations of available field data and constitutive relations to describe these phenomena. However, these effects are considered negligible when compared with the uncertainty of the rock properties existing in the collected data. The results of THC and THM analyses presented in Sections 6.4 and 6.5, and summarized in Sections 8.2 and 8.3, support this approach.

\subsection{2-D MOUNTAIN-SCALE TH MODEL RESULTS AND ANALYSES}

TH processes occur at different spatial and temporal scales. During the early part of the heating period, important TH processes occur near the emplacement drifts. These are the drift-scale processes. At this scale, variability in heat output from individual waste packages and different times of waste emplacement may give rise to variability in the extent of dry-out, rewetting, and water flux along drifts and at different drift locations. Also at this scale, the availability of additional water in the condensation zone may lead to an augmented fracture liquid flux much greater than the ambient fracture flux. This increased fracture liquid flux may result in thermal seepage into the emplacement drifts. The issue of thermal seepage has been investigated in the Drift-Scale (DST and TH Seepage) Coupled Processes report (BSC 2003 [166512]). This Model Report will not address thermal seepage. However, it will analyze the expected magnitude of fracture flux augmentation caused by long-term heating at the repository. This may assist in determining the mountain-scale effect on thermal seepage.

At later times following waste emplacement, TH coupled processes at the mountain scale, i.e., the perturbation in temperature, and in fracture and matrix liquid saturation, take place over a much larger space domain compared to drift-scale effects (Haukwa et al. 2003 [165165]). These mountain-scale TH processes include repository edge effects, large-scale enhanced water and gas flow, and temperature elevation in the far field. In this section, we will present model results and analyses of the mountain-scale TH effects from the 2-D TH model. Results from the 3-D TH model will be presented in Section 6.3. As shown in Figure 6.1-1, the 2-D model vertical cross section is nearly perpendicular to the direction of the repository drifts. Therefore, it cannot simulate fluid and heat flow that occurs into or from the eastern and western directions (i.e., parallel to the drift axis). In particular, water-vapor transport and associated heat transfer along drift tunnels, and their effect on TH conditions near the repository, cannot be described by the 2$\mathrm{D}$ model. Water-vapor migrating into the cooler regions (such as the access tunnel) and then condensing, occurring while the boiling front is expanding, is considered to be unimportant with respect to long-term prediction(s) of mountain-scale thermohydrology. The reason this is considered true is because the maximum extent of boiling occurs in a few tens of years after 50 years of ventilation, whereas the mountain-scale $\mathrm{TH}$ prediction time frame is hundreds to thousands of years. Therefore, water-vapor migration predicted by the 2-D TH model for short time frames cannot have a significant effect on long-term and mountain-scale $\mathrm{TH}$ behavior. Furthermore, the boiling front returns to the drift wall in approximately 800 to 1,000 years so 
provided validation of the mountain-scale $\mathrm{TH}$ Model for their accuracy and reliability in describing TH conditions under proposed thermal loading in the Yucca Mountain UZ.

\subsubsection{Validation of the Physical Processes}

Two-phase fluid flow and heat transfer in a fractured geological medium are the main focus of this Model Report. Such fluid flow and heat-transfer processes consist of some or all of the following physical processes: heat conduction, convective heat transfer, flow of liquid water and air/water vapor, vaporization and condensation, drainage through fractures and imbibition into matrix, and capillary effects. These processes have been routinely modeled and numerically simulated in the geothermal and petroleum reservoir engineering disciplines. Such numerical models of geothermal and petroleum systems have also been validated against a wealth of fieldscale tests and production data.

Aside from this, these same processes have been modeled at a smaller (space and time) scale in the Drift-Scale Coupled Processes (DST and TH Seepage) Model Report (BSC 2003 [166512]). The model results in that AMR were compared with measured temperature and saturation data from the Drift Scale Test (DST) at Yucca Mountain. The DST is the largest of the three thermal field tests performed at Yucca Mountain. The heating phase in the DST lasted slightly more than four years, and a large volume of rock was heated to temperatures close to and above boiling. Considerable high-quality TH/THM/THC data were collected from the DST. These data gave an adequate representation of the likely $\mathrm{TH} / \mathrm{THM} / \mathrm{THC}$ processes to be encountered in the nearfield of the emplacement drifts. Through a detailed comparison of measured and simulated TH/THM/THC data, it was concluded in BSC 2003 [166512] that the physical processes were adequately represented by the model. This builds confidence into the mountain-scale coupledprocesses models, since the underlying flow and heat transfer processes are identical both in the drift-scale and in the mountain-scale of this AMR. However, the thermal tests (including the DST) provide only limited data for calibration and validation of the numerical models. The small spatial and temporal scales limit validation of the mountain-scale models. The validation is also limited by the uncertainties arising from parameter estimates in a geologically complex system and the upscaling of drift-scale results to the UZ Mountain-Scale Model.

\subsubsection{Validation of the Numerical Modeling Approach}

In the absence of direct data to validate the mountain-scale coupled-processes models, validations of the modeling approach must rely mainly on the conceptual and mathematical validity of models. The analyses conducted in this AMR are intended to provide the mountainscale response to thermal loading under the proposed thermal-loading conditions. The numerical models are used to determine the effect of thermal loading on mountain-scale liquid and gas flux, temperature, and moisture distribution in the UZ. In these models, the relevant thermal-hydrological conditions at the potential repository are explicitly represented over the applicable time and space scale. Contemporary practice in modeling fluid-flow and heat-transfer processes has been incorporated in our approach. The formulation of simulation code TOUGH2 V1.6 (LBNL 2003 [161491]) allows numerical modeling of such processes. The following few paragraphs provide evidence of successful application of TOUGH2 in modeling two-phase flow and heat transfer in an unsaturated geological medium. 
160146 BSC (Bechtel SAIC Company) 2002. Total System Performance Assessment-License Application Methods and Approach. TDR-WIS-PA-000006 REV 00. Las Vegas, Nevada: Bechtel SAIC Company. ACC: MOL.20020923.0175.

160975 BSC (Bechtel SAIC Company) 2002. Ventilation Model. ANL-EBS-MD-000030 REV 01 ICN 01. Las Vegas, Nevada: Bechtel SAIC Company. ACC: MOL.20021106.0055.

161773 BSC (Bechtel SAIC Company) 2003. Analysis of Hydrologic Properties Data. MDL-NBS-HS-000014 REV 00. Las Vegas, Nevada: Bechtel SAIC Company. ACC: DOC.20030404.0004.

160240 BSC (Bechtel SAIC Company) 2003. Calibrated Properties Model. MDL-NBS-HS000003 REV 01. Las Vegas, Nevada: Bechtel SAIC Company. ACC:

DOC.20030219.0001.

160109 BSC (Bechtel SAIC Company) 2003. Development of Numerical Grids for UZ Flow and Transport Modeling. ANL-NBS-HS-000015 REV 01. Las Vegas, Nevada: Bechtel SAIC Company. ACC: DOC.20030404.0005.

162711 BSC (Bechtel SAIC Company) 2003. Drift Degradation Analysis. ANL-EBS-MD000027 REV 02. Las Vegas, Nevada: Bechtel SAIC Company. ACC: DOC.20030709.0003.

164890 BSC (Bechtel SAIC Company) 2003. Drift Scale THM Model. MDL-NBS-HS000017 REV 00 ICN 01. Las Vegas, Nevada: Bechtel SAIC Company. ACC: DOC.20031014.0009.

166512 BSC (Bechtel SAIC Company) 2003. Drift-Scale Coupled Processes (DST and TH Seepage) Models. MDL-NBS-HS-000015 REV 00 C. Las Vegas, Nevada: Bechtel SAIC Company. ACC: MOL.20030910.0160.TBV-5666.

162050 BSC (Bechtel SAIC Company) 2003. Drift-Scale Coupled Processes (DST and THC Seepage) Models. MDL-NBS-HS-000001 REV 02. Las Vegas, Nevada: Bechtel SAIC Company. ACC: DOC.20030804.0004.

164873 BSC (Bechtel SAIC Company) 2003. Features, Events, and Processes in UZ Flow and Transport. ANL-NBS-MD-000001 REV 02A. Las Vegas, Nevada: Bechtel SAIC Company. ACC: MOL.20031016.0004. TBV-5483

165692 BSC (Bechtel SAIC Company) 2003. Multiscale Thermohydrologic Model Report. ANL-EBS-MD-000049 REV 01E. Las Vegas, Nevada: Bechtel SAIC Company. ACC: MOL.20031009.0227. TBV-5533

165179 BSC (Bechtel SAIC Company) 2003. Q-List. TDR-MGR-RL-000005 REV 00. Las Vegas, Nevada: Bechtel SAIC Company. ACC: DOC.20030930.0002. 


\begin{tabular}{|c|c|c|c|c|c|c|}
\hline 23 & $\begin{array}{l}\text { NBS-HS-000015 REV 01. Las Vegas, } \\
\text { Nevada: Bechtel SAIC Company. } \\
\text { ACC: DOC.20030404.0005. } \\
160109\end{array}$ & |Table 11 & $\mid \begin{array}{l}\text { Reference } \\
\text { Only }\end{array}$ & Table 6.1-1 & $\begin{array}{l}\text { Provide hydrogeologic unit } \\
\text { information }\end{array}$ & N/A \\
\hline \multirow{3}{*}{24} & \multirow{3}{*}{$\begin{array}{l}\text { BSC (Bechtel SAIC Company) } 2003 . \\
\text { Drift Degradation Analysis. ANL-EBS- } \\
\text { MD-000027 REV 02. Las Vegas, } \\
\text { Nevada: Bechtel SAIC Company. } \\
\text { ACC: DOC.20030709.0003. } \\
162711\end{array}$} & 6.1 .4 .1 & \begin{tabular}{|l|} 
Reference \\
Only
\end{tabular} & 6.5 .5 & $\begin{array}{l}\text { Reference to mapped fracture } \\
\text { distribution }\end{array}$ & N/A \\
\hline & & Table 34 & $\begin{array}{l}\text { Reference } \\
\text { Only }\end{array}$ & 6.5 .8 & $\begin{array}{l}\text { Reference to rock classification } \\
\text { developed in the Drift } \\
\text { Degradation Analysis }\end{array}$ & N/A \\
\hline & & \begin{tabular}{|l} 
Tables \\
IV-1, IV- \\
2 \\
\end{tabular} & \begin{tabular}{|l|} 
Reference \\
Only
\end{tabular} & 6.5 .3 & $\begin{array}{l}\text { Reference to mapped fracture } \\
\text { distribution }\end{array}$ & $\mathrm{N} / \mathrm{A}$ \\
\hline \multirow{9}{*}{25} & \multirow{9}{*}{$\begin{array}{l}\text { BSC (Bechtel SAIC Company) } 2003 . \\
\text { Drift Scale THM Model. MDL-NBS-HS- } \\
\text { 000017 REV 00 ICN 01. Las Vegas, } \\
\text { Nevada: Bechtel SAIC Company. } \\
\text { ACC: DOC. } 20031014.0009 . \\
164890\end{array}$} & \begin{tabular}{|l|} 
Figure \\
$6.5 .2-1$ \\
\end{tabular} & \begin{tabular}{|l|} 
Reference \\
Only
\end{tabular} & 6.5 .10 & $\begin{array}{l}\text { Shows consistency with the } \\
\text { Drift Scale THM Model results } \\
\end{array}$ & $\mathrm{N} / \mathrm{A}$ \\
\hline & & 6.5 .2 & \begin{tabular}{|l|} 
Reference \\
Only
\end{tabular} & 6.5 .11 & $\begin{array}{l}\text { Shows consistency with the } \\
\text { Drift Scale THM Model results }\end{array}$ & N/A \\
\hline & & \begin{tabular}{|l|}
6.6 .1 \\
Figure \\
$7.4 .3-2$ \\
\end{tabular} & $\begin{array}{l}\text { Reference } \\
\text { Only }\end{array}$ & 6.5 .12 & $\begin{array}{l}\text { Shows consistency with the } \\
\text { Drift Scale THM Model results }\end{array}$ & $\mathrm{N} / \mathrm{A}$ \\
\hline & & $\begin{array}{l}6.6 .2 \\
6.6 .6\end{array}$ & \begin{tabular}{|l|} 
Reference \\
Only
\end{tabular} & 6.5 .13 & $\begin{array}{l}\text { Shows consistency with the } \\
\text { Drift Scale THM Model results }\end{array}$ & N/A \\
\hline & & 7 & \begin{tabular}{|l} 
Reference \\
Only
\end{tabular} & 6.5 .5 & $\begin{array}{l}\text { Refer to model validation in the } \\
\text { Drift Scale THM Model Report }\end{array}$ & N/A \\
\hline & & 4.1 .1 .1 & \begin{tabular}{|l|} 
Reference \\
Only
\end{tabular} & 6.5 .8 & $\begin{array}{l}\text { Shows consistency with the } \\
\text { Drift Scale THM Model input }\end{array}$ & N/A \\
\hline & & Entire & $\begin{array}{l}\text { Reference } \\
\text { Only }\end{array}$ & $\begin{array}{l}6.5,6.5 .9 \\
6.5 .15,7.3 \\
8.4\end{array}$ & \begin{tabular}{|l|} 
Reference to Drift Scale TM \\
and HM rock properties; \\
Reference to uncertainty \\
discussion in the Drift Scale \\
THM Model; Refer to model \\
validation in the Drift Scale \\
THM Model Report; Refer to \\
model validation in the Drift \\
Scale THM Model Report \\
\end{tabular} & N/A \\
\hline & & \begin{tabular}{|l|} 
Table \\
$6.4-1$ \\
\end{tabular} & \begin{tabular}{|l|} 
Reference \\
Only
\end{tabular} & \begin{tabular}{|l|} 
Table \\
$6.5 .9-1$ \\
\end{tabular} & $\begin{array}{l}\text { Reference to Drift Scale TM } \\
\text { and HM rock properties } \\
\end{array}$ & N/A \\
\hline & & Table 6-2 & \begin{tabular}{|l} 
Reference \\
Only
\end{tabular} & Table 6.6-1 & $\begin{array}{l}\text { Discussion of the effects of } \\
\text { thermo-mechanical stresses on } \\
\text { fracture characteristics near } \\
\text { waste emplacement drifts } \\
\end{array}$ & N/A \\
\hline & BSC (Bechtel SAIC Company) 2003. & Entire & Reference & $6.2,7.1 .1$ & Discussion of thermal seepage & N/A \\
\hline
\end{tabular}




\begin{tabular}{|c|c|c|c|c|c|c|}
\hline 26 & \begin{tabular}{|l} 
Drift-Scale Coupled Processes (DST and \\
TH Seepage) Models. MDL-NBS-HS- \\
000015 REV 00C. Las Vegas, Nevada: \\
Bechtel SAIC Company. ACC: \\
MOL.20030910.0160. TBV-5666 \\
166512 \\
\end{tabular} & & Only & & issues & \\
\hline \multirow{4}{*}{27} & \multirow{4}{*}{$\begin{array}{l}\text { BSC (Bechtel SAIC Company) } 2003 . \\
\text { Drift-Scale Coupled Processes (DST and } \\
\text { THC Seepage) Models. MDL-NBS-HS- } \\
\text { 000001 REV 02. Las Vegas, Nevada: } \\
\text { Bechtel SAIC Company. ACC: } \\
\text { DOC.20030804.0004. } \\
162050\end{array}$} & Entire & \begin{tabular}{|l|} 
Reference \\
Only \\
\end{tabular} & \begin{tabular}{|l|}
$1,5.2,6.4$ \\
6.4 .2 .4 \\
6.4 .2 .5 \\
$7.2,7.2 .2$ \\
7.2 .3 .3 \\
7.2 .3 .5 \\
\end{tabular} & $\begin{array}{l}\text { Drift-Scale THC Model } \\
\text { Processes }\end{array}$ & N/A \\
\hline & & \begin{tabular}{|l|} 
Figure \\
$7.1-2$
\end{tabular} & \begin{tabular}{|l|} 
Reference \\
Only
\end{tabular} & 7.2 .1 .1 & $\begin{array}{l}\text { Locations of the hydrology } \\
\text { boreholes, sampling intervals, } \\
\text { and temperature sensors }\end{array}$ & N/A \\
\hline & & $\begin{array}{l}\text { Table } \\
6.2-2\end{array}$ & \begin{tabular}{|l|} 
Reference \\
Only
\end{tabular} & Table 6.4-1 & $\begin{array}{l}\text { Information on Minerals, } \\
\text { Aqueous Species, and Gaseous } \\
\text { Species }\end{array}$ & $\mathrm{N} / \mathrm{A}$ \\
\hline & & \begin{tabular}{|l|} 
Table \\
$6.2-1$ \\
\end{tabular} & \begin{tabular}{|l|} 
Reference \\
Only
\end{tabular} & Table 6.4-2 & $\begin{array}{l}\text { Information on initial Pore- } \\
\text { Water and Gas Compositions }\end{array}$ & N/A \\
\hline 28 & \begin{tabular}{|l|} 
BSC (Bechtel SAIC Company) 2003. \\
Features, Events, and Processes in UZ \\
Flow and Transport. ANL-NBS-MD- \\
000001 REV 02A. Las Vegas, Nevada: \\
Bechtel SAIC Company. ACC: \\
MOL.20031016.0004. TBV-5483 \\
164873 \\
\end{tabular} & Entire & $\begin{array}{l}\text { Reference } \\
\text { Only }\end{array}$ & 6.6 & $\begin{array}{l}\text { Documentation of some } \\
\text { excluded FEPs }\end{array}$ & N/A \\
\hline 29 & \begin{tabular}{|l|} 
BSC (Bechtel SAIC Company) 2003. \\
Multiscale Thermohydrologic Model \\
Report. ANL-EBS-MD-000049 REV \\
01E. Las Vegas, Nevada: Bechtel SAIC \\
Company. ACC: MOL.20031009.0227. \\
TBV-5533 \\
165692 \\
\end{tabular} & Entire & \begin{tabular}{|l|} 
Reference \\
Only
\end{tabular} & 8.1 & $\begin{array}{l}\text { Information on peak } \\
\text { temperature estimated by } \\
\text { Multiscale Thermohydrologic } \\
\text { Model }\end{array}$ & N/A \\
\hline 30 & $\begin{array}{l}\text { BSC (Bechtel SAIC Company) 2003. Q- } \\
\text { List. TDR-MGR-RL-000005 REV 00. } \\
\text { Las Vegas, Nevada: Bechtel SAIC } \\
\text { Company. ACC: DOC.20030930.0002. } \\
165179 \\
\end{array}$ & Entire & \begin{tabular}{|l|} 
Reference \\
Only
\end{tabular} & 2 & Safety category & N/A \\
\hline & \begin{tabular}{|l|} 
BSC (Bechtel SAIC Company) 2003. \\
Repository Design Project, RDP/PA IED
\end{tabular} & Entire & $\begin{array}{l}\text { Product } \\
\text { Output }\end{array}$ & $\begin{array}{l}6.1 .5 ; \\
\text { Tables 4.1- }\end{array}$ & $\begin{array}{l}\text { Time dependent thermal line } \\
\text { load (decay with time) for } 1.45\end{array}$ & N/A \\
\hline
\end{tabular}




\section{USE OF SOFTWARE}

The software and routines used in this study are listed in Table 3-1. These are appropriate for the intended application, were obtained from Software Configuration Management, and were used only within the range of validation. These codes have been qualified in accordance with AP-SI.1Q, Software Management.

Table 3-1. Qualified Software Used in this Report

\begin{tabular}{|c|c|c|c|}
\hline Software Name & Version & $\begin{array}{l}\text { Software Tracking Number } \\
\text { (STN): }\end{array}$ & Citations \\
\hline TOUGH2 & 1.6 & $10007-1.6-01$ & LBNL 2003 [161491] \\
\hline TOUGHREACT & 3.0 & $10396-3.0-00$ & LBNL 2002 [161256] \\
\hline FLAC3D & 2.0 & $10502-2.0-00$ & LBNL 2001 [154783] \\
\hline EXT & 1.1 & $10005-1.1-00$ & LBNL 1999 [160768] \\
\hline EXT & 1.0 & $10047-1.0-00$ & LBNL 1999 [140944] \\
\hline Infil2grid & 1.7 & $10077-1.7-00$ & LBNL 2002 [154793] \\
\hline Wingridder & 2.0 & $10024-2.0-00$ & LBNL 2002 [154785] \\
\hline GridReader & 1.0 & 10994-10.-00 & LBNL 2003 [167237] \\
\hline \multicolumn{4}{|c|}{ Pre and Post Processing Software } \\
\hline GPZones.dat & 1.0 & $10509-1.0-00$ & LBNL 2001 [154792] \\
\hline tin & 1.1 & 10899-1.1-00 & LBNL 2002 [162038] \\
\hline Delb.dat & 1.0 & $10507-1.0-00$ & LBNL 2001 [154791] \\
\hline 2KGRIDV1.f & 1.0 & $10244-1.0-00$ & LBNL 1999 [147553] \\
\hline 2kgridv1a.for & 1.0 & $10382-1.0-00$ & LBNL 2000 [153067] \\
\hline GEN-INCON-VO.F & 1.0 & $10220-1.0-00$ & LBNL 2000 [147023] \\
\hline GET_A_LAYER_V0.F & 1.0 & $10221-1.0-00$ & LBNL 2000 [147025] \\
\hline GET_TEMP_VO.F & 1.0 & $10222-1.0-00$ & LBNL 2000 [147027] \\
\hline TOPTEMP_V0.F & 1.0 & $10224-1.0-00$ & LBNL 2000 [147030] \\
\hline HSOURCE_VO.F & 1.0 & $10225-1.0-00$ & LBNL 2000 [147031] \\
\hline 2 kgrid8.for & 1.0 & $10503-1.0-00$ & LBNL 2002 [154787] \\
\hline
\end{tabular}

The TH aspects of the numerical simulations in this Model Report were performed with the computer program TOUGH2 V1.6 (LBNL 2003 [161491]), using equation-of-state module EOS3. The THC and THM simulations were carried out with TOUGHREACT V3.0 (LBNL 2002 [161256]) and TOUGH2 V1.6 (LBNL 2003 [161491])/FLAC3D V2.0 (LBNL 2001 [154783]), respectively. To process the TOUGH2 V1.6 (LBNL 2003 [161491]) and FLAC3D V2.0 (LBNL 2001 [154783]) output for plotting, the codes EXT V1.0 (LBNL 1999 [140944]) and EXT V1.1 (LBNL 1999 [160768]), postprocessors for the TOUGH2 family of codes are used. The software infil2grid V1.7 LBNL 2002 [154793] is used to map the infiltration flux from the infiltration maps onto the numerical grid. The code Wingridder V2.0 (LBNL 2002 [154785]) 
was used to generate numerical grids used here and is documented in a separate Model Report. The code GridReader V1.0 (LBNL 2003 [167237]) was used to convert the 8 character mesh files to 5 character mesh files. All these codes have been qualified under AP-SI.IQ, Software Management.

Standard, commercially available spreadsheet and graphics software programs (TecPLOT V8.0, TecPLOT V9.0, Grapher V1.25, and EXCEL 97 SR-1) were also used for post-processing simulations results in Sections of 6.2, 6.3, 6.4, and 6.5. Details and procedures for using the standard functions of TecPLOT and EXCEL in post-processing and simulation extraction for plotting are documented in Wang (2003 [165927]) as well as in Attachment IV.

This Model Report documents the mountain-scale TH/THC/THM models. Input and output files for the model simulations documented in this Model Report have been submitted to the TDMS as summarized in Table 8-1 and discussed under each modeled scenario in Section 6. 
147027 LBNL (Lawrence Berkeley National Laboratory) 2000. Software Routine: get_temp_v0.f. V1.0. DEC Alpha w/OSF1 V4.0. 10222-1.0-00.

147031 LBNL (Lawrence Berkeley National Laboratory) 2000. Software Routine: hsource_v0.f. V1.0. DEC Alpha w/OSF1 V4.0. 10225-1.0-00.

147030 LBNL (Lawrence Berkeley National Laboratory) 2000. Software Routine: toptemp_v0.f. V1.0. DEC Alpha w/OSF1 V4.0. 10224-1.0-00.

154783 LBNL (Lawrence Berkeley National Laboratory) 2001. Software Code: FLAC3D. V2.0. PC. STN: 10502-2.0-00.

154791 LBNL (Lawrence Berkeley National Laboratory) 2001. Software Routine: Delb.dat. V1.0. PC. STN: 10507-1.0-00.

154792 LBNL (Lawrence Berkeley National Laboratory) 2001. Software Routine: Gpzones.dat. V1.0. PC. STN: 10509-1.0-00.

154793 LBNL (Lawrence Berkeley National Laboratory) 2002. Software Code: infil2grid. V1.7. DEC-Alpha, PC. 10077-1.7-00.

162038 LBNL (Lawrence Berkeley National Laboratory) 2002. Software Code: Tin. V1.1. PC Windows 98. 10899-1.1-00.

161256 LBNL (Lawrence Berkeley National Laboratory) 2002. Software Code: TOUGHREACT. V3.0. DEC-Alpha with Unix OSF1 V5.1 and OSF1 V5.0, Sun UltraSparc w/Solaris 5.5.1, PC with Linux Redhat 7.2. 10396-3.0-00.

154785 LBNL (Lawrence Berkeley National Laboratory) 2002. Software Code: WINGRIDDER. V2.0. PC. 10024-2.0-00.

154787 LBNL (Lawrence Berkeley National Laboratory) 2002. Software Routine: 2kgrid8.for. V1.0. DEC-Alpha, PC. 10503-1.0-00.

161491 LBNL (Lawrence Berkeley National Laboratory) 2003. Software Code: TOUGH2. V1.6. PC/MS-DOS under Windows 98, Sun UltraSparc OS 5.5.1, DEC-Alpha OSF1 V4.0. 10007-1.6-01.

167237 LBNL (Lawrence Berkeley National Laboratory) 2003. Software Code: GridReader. V1.0. PC/WINDOWS NT 4.0. 10994-1.0-00.

\subsection{CODES, STANDARDS, REGULATIONS, AND PROCEDURES}

15667166 FR 55732. Disposal of High-Level Radioactive Wastes in a Proposed Geologic Repository at Yucca Mountain, NV. Final Rule 10 CFR Part 63. Readily available.

AP-2.22Q, Rev. 1, ICN 0. Classification Analyses and Maintenance of the Q-List. Washington, D.C.: U.S. Department of Energy, Office of Civilian Radioactive Waste Management. ACC: DOC.20030807.0002. 


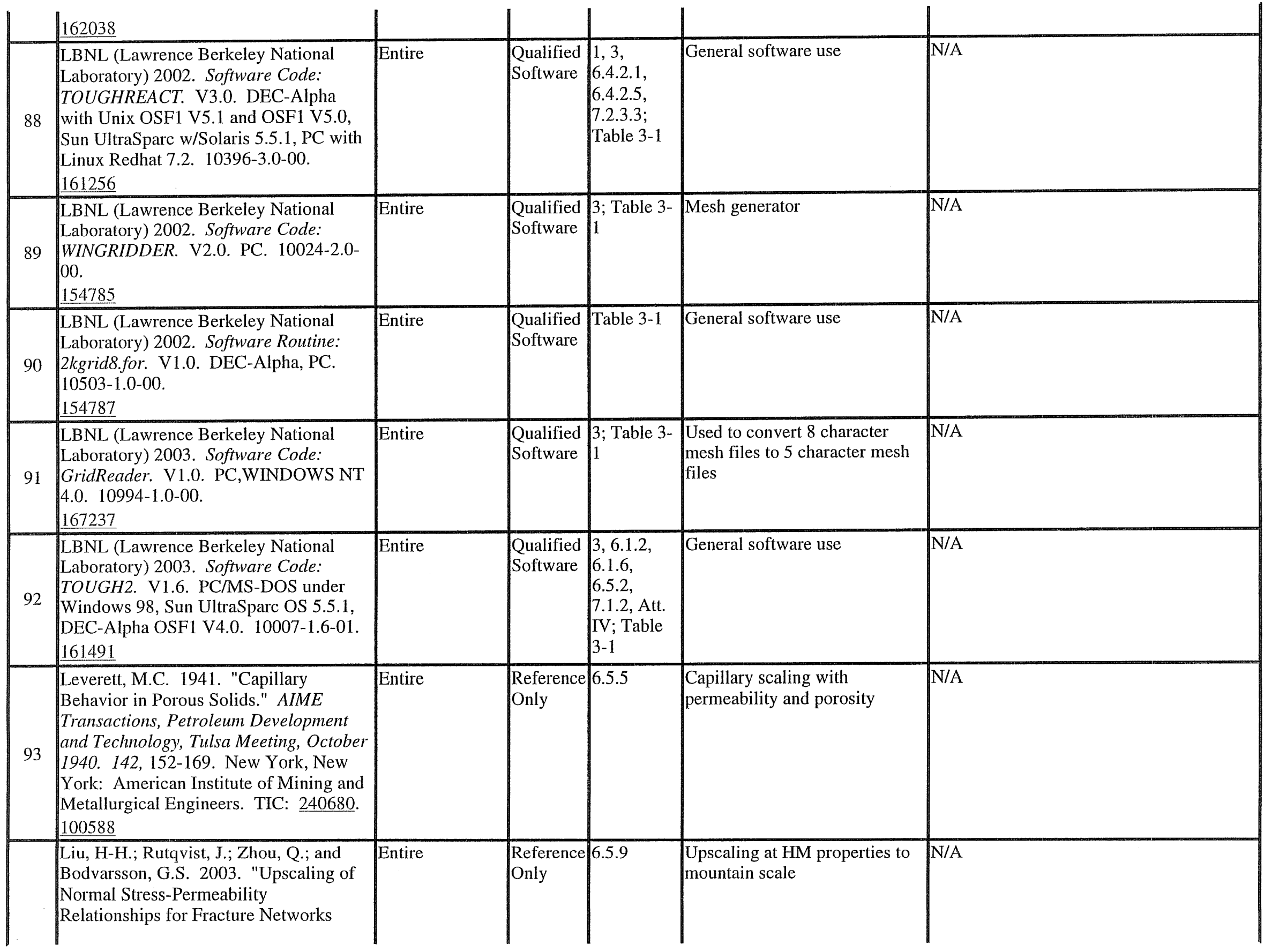


2 Type of Madnamalical Model

Provosu Model

Alsgration Madal

$\square$ Systam Model

Deserba lntendod Uae of Modal

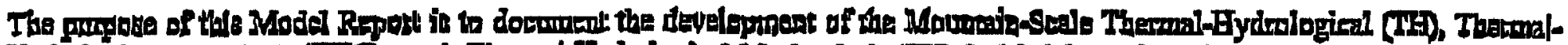

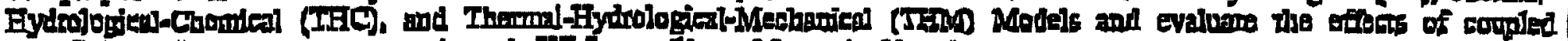

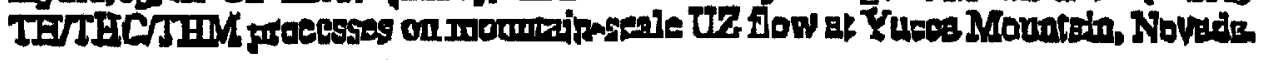

\section{a. Tilla}

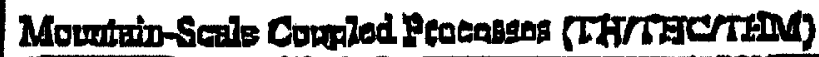

4. DI (nnoluding Rev. No. and Thange Na, il appllealelej:

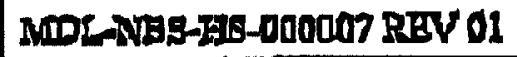

\begin{tabular}{|c|c|}
\hline $\begin{array}{l}\text { 5. Tolal autarihments } \\
4\end{array}$ & 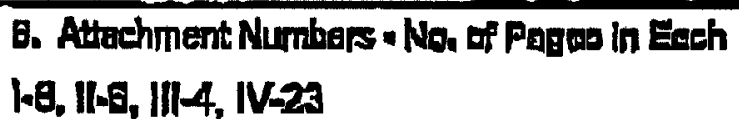 \\
\hline
\end{tabular}

\begin{tabular}{|c|c|c|}
\hline & Prinfed Nome & Bignakung \\
\hline 7. Originator & $y-8.7 n$ & 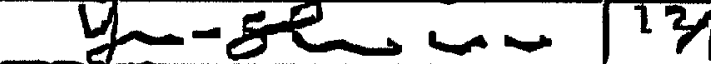 \\
\hline a. $\operatorname{cso}$ & B. Kinstefio & 12 \\
\hline 6. Cheaker & P. Pexcof & \\
\hline 10. AER . & E Gillensm & $12 / 4$ \\
\hline 11. Regponsilbla Mongger/Laad & 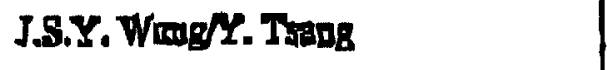 & \\
\hline 12. Reapandilala Menagar & P. Dixon & 127 \\
\hline
\end{tabular}

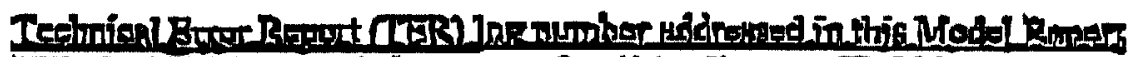

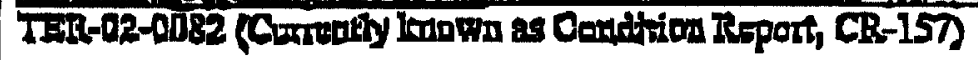




\section{OFFICE OF CIVILIAN RADIOACTIVE WASTE MANAGEMENT \\ MODEL REVISION RECORD}

1. Page: 2

of: 252

2. Model Title:

Mountain-Scale Coupled Processes (TH/THC/THM)

3. DI (including Rev. No. and Change No., if applicable):

MDL-NBS-HS-000007 REV01

\begin{tabular}{|l|l}
\hline \multicolumn{1}{|c|}{ 4. Revision/Change No. } & \multicolumn{1}{c}{ 5. Description of Revision/Change } \\
\hline REV 00 & Initial Issue \\
REV 01 & The entire model documentation was revised. Side bars are not used because the changes were too
\end{tabular}

extensive to use Step 5.8d)1) per AP-SIII.10Q, Rev. 2/ICN 0. 


\section{TABLE OF CONTENTS}

ACRONYMS .17

1. PURPOSE .19

2. QUALITY ASSURANCE. .21

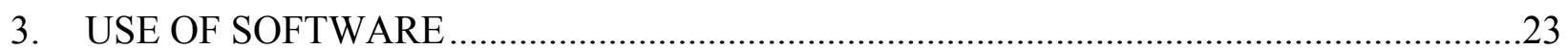

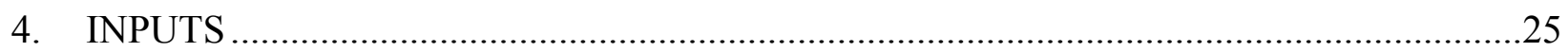

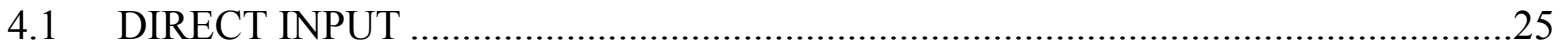

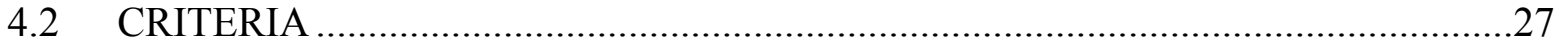

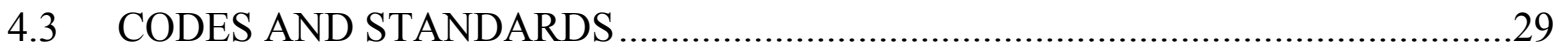

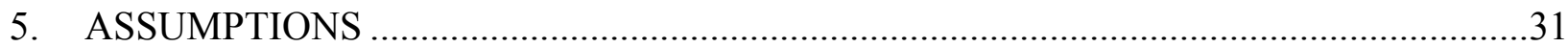

5.1 ASSUMPTIONS FOR THE MOUNTAIN-SCALE TH MODEL ……………..............

5.2 ASSUMPTIONS FOR THE MOUNTAIN-SCALE THC MODEL …………...............31

5.3 ASSUMPTIONS FOR THE MOUNTAIN-SCALE THM MODEL ............................31

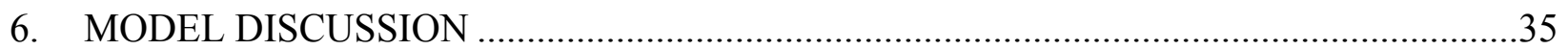

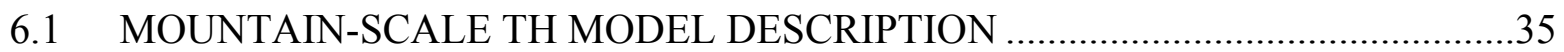

6.1.1 Geological Model and Numerical Grids ....................................................36

6.1.2 Numerical Codes and TH Modeling Approach..............................................40

6.1.3 TH Model Boundary and Initial Conditions ..............................................42

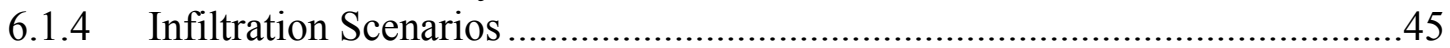

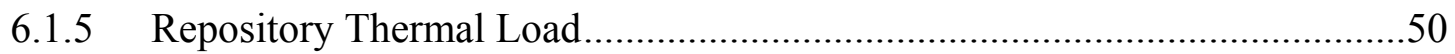

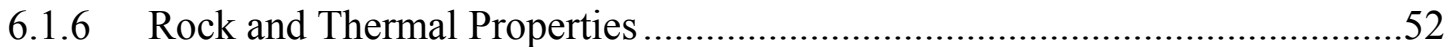

6.2 2-D MOUNTAIN-SCALE TH MODEL RESULTS AND ANALYSES ...................53

6.2.1 Base-Case Model Results and Analyses ......................................................54

6.2.1.1 Contours of Temperature and Fracture Saturation ..........................54

6.2.1.2 Temperature along the North-South Axis.......................................55

6.2.1.3 Matrix Liquid Saturation along the North-South Axis ...................68

6.2.1.4 Fracture Liquid Saturation along the North-South Axis..................70

6.2.1.5 Vertical Profile of Temperature, Liquid Saturation, and

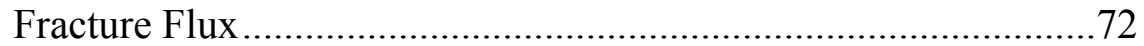

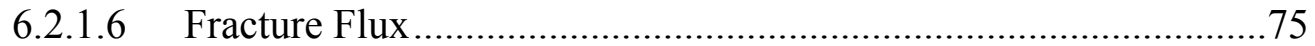

6.2.2 The No-Ventilation Case Model Results and Analyses ..................................77

6.2.2.1 Comparison of the TH Changes near the Repository …….............77

6.2.2.2 Comparison of the TH Changes at the Bottom of the PTn .............79

6.2.2.3 Comparison of Fracture Fluxes........................................................ 81 


\section{TABLE OF CONTENTS (Continued)}

6.3 3-D MOUNTAIN-SCALE TH MODEL RESULTS AND ANALYSES .................82

6.3.1 Base-Case Model Results and Analyses ................................................83

6.3.1.1 Temperature .......................................................................8 84

6.3.1.2 Liquid Saturation ........................................................ 100

6.3.1.3 Percolation Flux ......................................................................106

6.3.2 No-Ventilation Model Results and Analyses ...........................................115

6.4 MOUNTAIN-SCALE THC MODEL.............................................................. 135

6.4.1 Conceptual Model For Mountain-Scale THC Processes..............................135

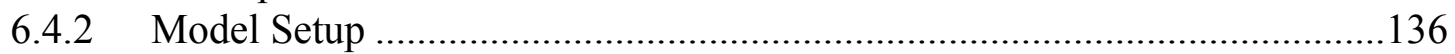

6.4.2.1 Numerical Mesh.................................................................136

6.4.2.2 Rock Properties....................................................................138

6.4.2.3 Hydrological and Thermal Boundary and Initial Conditions ......138

6.4.2.4 Initial and Boundary Geochemical Conditions..........................139

6.4.2.5 Numerical Code and Simulation Methods.................................142

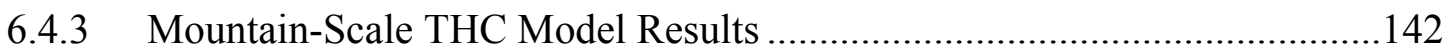

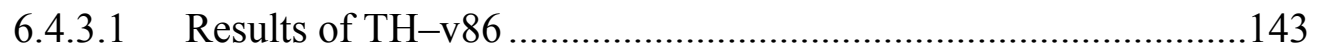

6.4.3.2 Chemical Steady State for Aqueous and Gaseous Species..........152

6.4.3.3 Effects of Thermal Loading on Aqueous and Gaseous

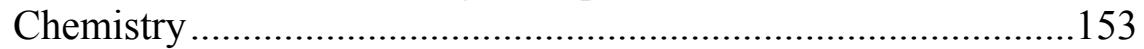

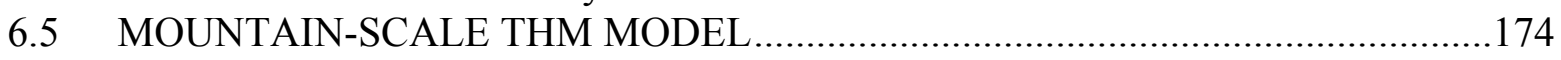

6.5.1 Introduction to Coupled THM Analysis....................................................174

6.5.2 Description of the Coupled THM Simulator .............................................174

6.5.3 Dual-Permeability Model for Analysis of THM Processes at Yucca

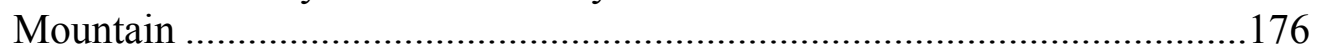

6.5.4 TOUGH2 to FLAC3D Link for Yucca Mountain .....................................176

6.5.5 FLAC3D to TOUGH2 Link for Yucca Mountain ........................................177

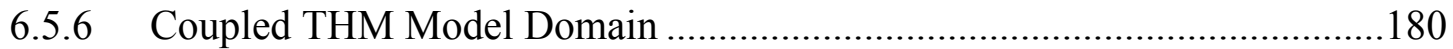

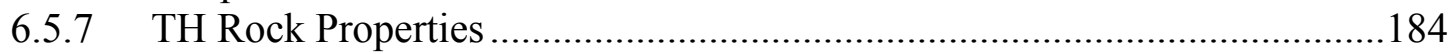

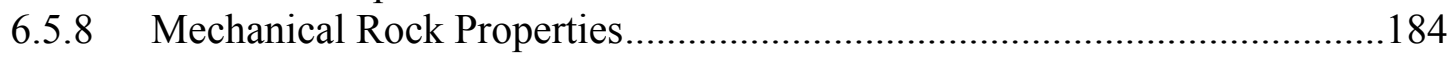

6.5.9 Coupled TM and HM Rock Properties......................................................185

6.5.10 Evolution of Temperature at Yucca Mountain.........................................187

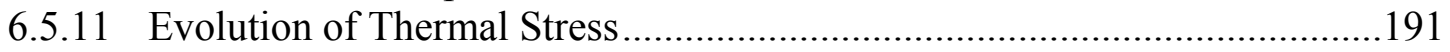

6.5.12 Evolution of Hydraulic Properties............................................................193

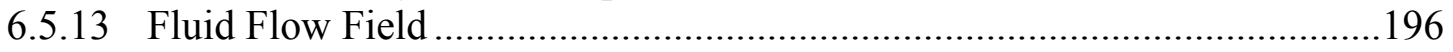

6.5.14 Impact of Possible Fracturing and Shear Slip near Ground Surface ............204

6.5.15 Discussion of Uncertainties in the Mountain-Scale THM Results ..............208

6.6 FEPS ADDRESSED IN THIS MODEL REPORT .......................................210

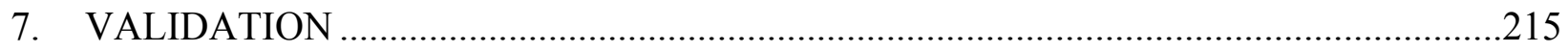

7.1 VALIDATION OF THE MOUNTAIN-SCALE TH MODEL ...........................215

7.1.1 Validation of the Physical Processes...............................................................216

7.1.2 Validation of the Numerical Modeling Approach.......................................216

7.1.3 Confidence Building through Publication.............................................218 


\section{TABLE OF CONTENTS (Continued)}

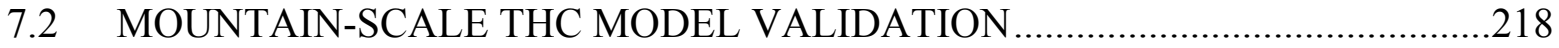

7.2.1 Model Validation Methods, Criteria, and Limitations .................................219

7.2.1.1 Validation Method 1-Corroboration with Experimental Data ..219

7.2.1.2 Confidence Building through Publication in Peer-Reviewed Journals .................................................................................221

7.2.2 Summary of Validation to DST Geochemical Data and Lab Experiments..221

7.2.3 Summary of the DST THC Model and Validation to Measured Data .........222

7.2.3.1 Conceptual Model for THC Processes...........................................222

7.2.3.2 Numerical Grid and Properties ...................................................222

7.2.3.3 Geochemical Model ...............................................................223

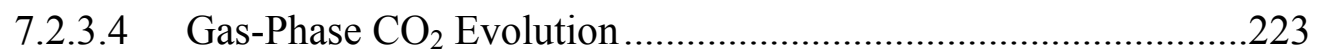

7.2.3.5 Aqueous Species Evolution ........................................................225

7.2.3.6 Mineral Precipitation and Dissolution.........................................226

7.2.4 Summary of DST Model Validation Results .............................................227

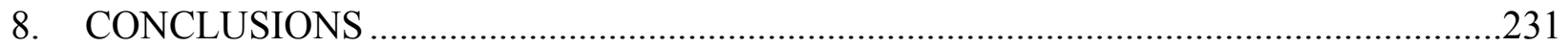

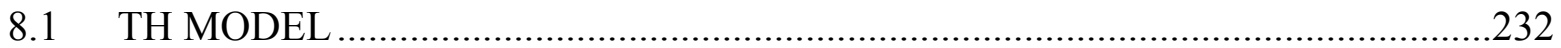

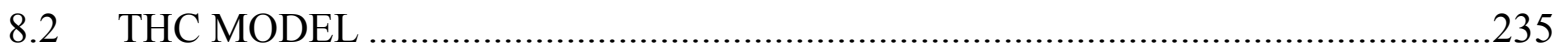

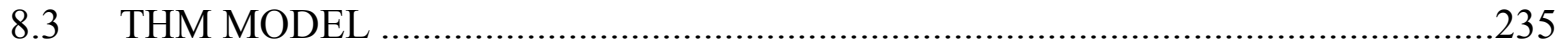

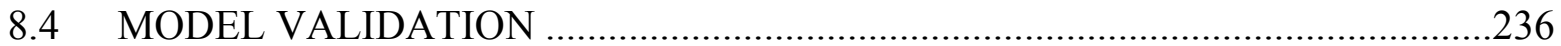

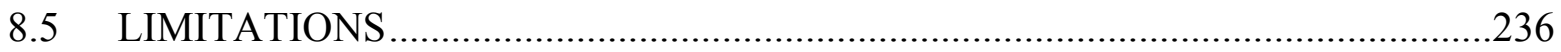

8.6 SATISFACTION OF ACCEPTANCE CRITERIA …….....................................237

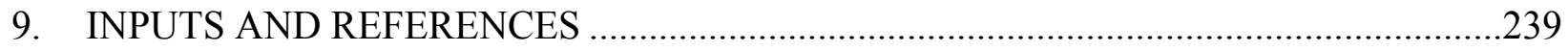

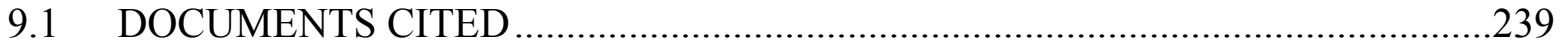

9.2 CODES, STANDARDS, REGULATIONS, AND PROCEDURES ………….........239

9.3 SOURCE DATA, LISTED BY DATA TRACKING NUMBER ………...................249

9.4 OUTPUT DATA, LISTED BY DATA TRACKING NUMBER ................................250

ATTACHMENT I-INITIAL MINERAL VOLUME FRACTIONS........................................... I-1

ATTACHMENT II-INITIAL MINERAL REACTIVE SURFACE AREAS $\left(\mathrm{cm}^{2} / \mathrm{g}\right.$ FOR MATRIX, $\mathrm{m}^{2} / \mathrm{m}^{3}$ FOR FRACTURES)........................................................................... II-1

ATTACHMENT III—PERMEABILITY MODEL PARAMETERS ........................................ III-1

ATTACHMENT IV—PREPARATIONS AND CALCULATIONS FOR POST-PROCESSING TH/THC/THM MODEL RESULTS. 


\section{INTENTIONALLY LEFT BLANK}




\section{LIST OF FIGURES}

6.1-1. Plan View of the 3-D TH Model Grid, Showing the Model Domain, Faults Incorporated, Several Borehole Locations, and TH Model Boundaries

6.1-2. 2-D N-S Cross Sectional Model domain and Grid, showing Lateral and Vertical Discretization, Hydrogeological Layers, Repository Layout, and a Fault

6.1-3. Plan View of Net Infiltration Distributed over the 3-D TH Model Grid for the Present-Day Mean Infiltration Scenario for the First 600 Years of Thermal Load .....

6.1-4. Plan View of Net Infiltration Distributed over the 3-D TH Model Grid for the Monsoon Mean Infiltration Scenario for the 600-2,000 Years of Thermal Load.......48

6.1-5. Plan View of Net Infiltration Distributed over the 3-D TH Model Grid for the Glacial Transition Mean Infiltration Scenario for the 2,000 Years and Beyond of Thermal Load

6.2-1a. Contours of Temperature in the 2-D North-South Cross Section of the UZ Model Grid at 100 Years with Base-Case Thermal Loading. .56

6.2-1b. Contours of Fracture Liquid Saturation in the 2-D North-South Cross Section of the UZ Model Grid at 100 Years with Base-Case Thermal Loading.... .57

6.2-2a. Contours of Temperature in the 2-D North-South Cross Section of the UZ Model Grid at 500 Years with Base-Case Thermal Loading. . .58

6.2-2b. Contours of Fracture Liquid Saturation in the 2-D North-South Cross Section of the UZ Model Grid at 500 Years with Base-Case Thermal Loading. .59

6.2-3a. Contours of Temperature in the 2-D North-South Cross Section of the UZ Model Grid at 1,000 Years with Base-Case Thermal Loading...

6.2-3b. Contours of Fracture Liquid Saturation in the 2-D North-South Cross Section of the UZ Model Grid at 1,000 Years with Base-Case Thermal Loading.....

6.2-4a. Contours of Temperature in the 2-D North-South Cross Section of the UZ Model Grid at 5,000 years with Base-Case Thermal Loading

6.2-4b. Contours of Fracture Liquid Saturation in the 2-D North-South Cross Section of the UZ Model Grid at 5,000 Years with Base-Case Thermal Loading....

6.2-5a. Contours of Temperature in the 2-D North-South Cross Section of the UZ Model Grid at 8,000 Years with Base-Case Thermal Loading.....

6.2-5b. Contours of Fracture Liquid Saturation in the 2-D North-South Cross Section of the UZ Model Grid at 8,000 Years with Base-Case Thermal Loading.....

6.2-6a. Temperature Just Above the Emplacement Drifts with Base-Case Thermal Loading

6.2-6b. Temperature at the Bottom of PTn with Base-Case Thermal Loading ........................66

6.2-6c. Temperature at the Bottom of TSw with Base-Case Thermal Loading........................67

6.2-7a. Matrix Liquid Saturation Just above the Repository with Base-Case Thermal

Loading

6.2-7b. Matrix Liquid Saturation at the Bottom of PTn with Base-Case Thermal Loading

6.2-7c. Matrix Liquid Saturation at the Bottom of TSw with Base-Case Thermal Loading..... 


\section{LIST OF FIGURES (Continued)}

6.2-8a. Fracture Liquid Saturation Just above the Emplacement Drifts with Base-Case Thermal Loading.....

6.2-8b. Fracture Liquid Saturation Just below the Emplacement Drifts with Base-Case Thermal Loading.

6.2-8c. Fracture Liquid Saturation at the Bottom of PTn with Base-Case Thermal Loading

6.2-8d. Fracture Liquid Saturation at the Bottom of TSw with Base-Case Thermal Loading

6.2-9a. Temperature along a Vertical Column ("b62") from the Ground Surface to Water Table with Base-Case Thermal Loading..... .73

6.2-9b. Matrix Liquid Saturation along a Vertical Column ("b62") from Ground Surface to Water Table with Base Thermal Loading....................................................74

6.2-9c. Fracture Liquid Saturation along a Vertical Column ("b62") from Ground Surface to Water Table with Base-Case Thermal Loading .........................................74

6.2-9d. Vertical Fluxes in Fractures Along Column B62 At Various Times............................75

6.2-10a. Vertical Downward Fluxes in the Fractures Just above the Emplacement Drifts with Base-Case Thermal Loading.

6.2-10b. Vertical Downward Fluxes in Fractures over the Pillar Regions with Base-Case Thermal Loading. .76

6.2-11a. Comparison of Temperatures Just above the Emplacement Drifts Arising from No-Ventilation Thermal-Loading Scenario

6.2-11b. Matrix Liquid Saturation Just above the Emplacement Drifts Arising from the No-Ventilation Thermal-Loading Scenario . .78

6.2-11c. Fracture Liquid Saturation Just above the Emplacement Drifts Arising from the No-Ventilation Case Thermal-Loading Scenario

6.2-12a. Comparison of Temperature at the Bottom of PTn Arising from the Base-Case (Solid Lines) and No-Ventilation Case (Dotted Lines) Thermal-Loading Scenario

6.2-12b. Comparison of Matrix Liquid Saturation at the Bottom of PTn Arising from the Base-Case (Solid Lines) and the No-Ventilation Case (Dotted Lines) ThermalLoading Scenarios.

6.2-12c. Comparison of Fracture Liquid Saturation at the Bottom of PTn Arising from the Base-Case (Solid Lines) and the No-Ventilation (Dotted Lines) ThermalLoading Scenarios.

6.2-13. Vertical Fracture Liquid Fluxes Into the Pillar Regions from Top, Comparison of the Base-Case (Solid Line) and No-Ventilation Case (Dotted Line) Thermal Loading Scenarios during Peak Thermal Periods.

6.3.1-1a. Model-Predicted Rock Temperature Distribution at Repository Horizon at Time of 100 Years after Nuclear Waste Emplacement (the Base-Case Model with Ventilation).

6.3.1-1b. Model-Predicted Temperature Distribution at the N-S Cross Section at 100

Years after Nuclear Waste Emplacement (the Base-Case Model with Ventilation). 


\section{LIST OF FIGURES (Continued)}

6.3.1-2a. Model-Predicted Rock Temperature Distribution at Repository Horizon at 500 Years after Nuclear Waste Emplacement (the Base-Case Model with Ventilation)

6.3.1-2b. Model-Predicted Rock Temperature Distribution at the Bottom of PTn Unit at 500 years after Nuclear Waste Emplacement (Base-Case Model with Ventilation)

6.3.1-2c. Model-Predicted Rock Temperature Distribution at the Top of CHn Unit at 500 Years after Nuclear Waste Emplacement (the Base-Case Model with Ventilation)

6.3.1-3a. Model-Predicted Rock Temperature Distribution at Repository Horizon at 1,000 Years after Nuclear Waste Emplacement (the Base-Case Model with Ventilation)

6.3.1-3b. Model-Predicted Rock Temperature Distribution at the Bottom of PTn Unit at 1,000 Years after Nuclear Waste Emplacement (Base-Case Model with Ventilation)

6.3.1-3c. Model-Predicted Rock Temperature Distribution at the Top of CHn Unit at Time of 1,000 Years after Nuclear Waste Emplacement (the Base-Case Model with Ventilation)

6.3.1-3d. Model-Predicted Temperature Distribution at the N-S Cross Section at 1,000 Years after Nuclear Waste Emplacement (the Base-Case Model with Ventilation)

6.3.1-4a. Model-Predicted Rock Temperature Distribution at Repository Horizon at 2,000 Years after Nuclear Waste Emplacement (the Base-Case Model with Ventilation)

6.3.1-4b. Model-Predicted Rock Temperature Distribution at the Bottom of PTn Unit at 2,000 Years after Nuclear Waste Emplacement (Base-Case Model with Ventilation)

6.3.1-4c. Model-Predicted Rock Temperature Distribution at the Top of CHn Unit at 2,000 Years after Nuclear Waste Emplacement (Base-Case Model with Ventilation)

6.3.1-5a. Model-Predicted Rock Temperature Distribution at Repository Horizon at 5,000 Years after Nuclear Waste Emplacement (the Base-Case Model with Ventilation)

6.3.1-5b. Model-Predicted Temperature Distribution at the N-S Cross Section at 5,000 Years after Nuclear Waste Emplacement (the Base-Case Model with Ventilation)

6.3.1-6. Model-Predicted Temperature Profiles at Different Times along Observation Columns A (Southern Repository Block Center) and F (Northern, Main Repository Block Center) (Base-Case Model with Ventilation).

6.3.1-7. Model-Predicted Temperature Changes with Times at Repository Horizon, Bottom PTn (Elevation of 1,307.5 m), and Top CHn (Elevation of $961 \mathrm{~m}$ ) along the Observation Column F (Northern or Main Repository Block Center) (Base-Case Model with Ventilation) 


\section{LIST OF FIGURES (Continued)}

6.3.1-8. Model-Predicted Matrix Liquid Saturation Distribution at Repository Horizon at 500 Years after Nuclear Waste Emplacement (the Base-Case Model with Ventilation)

6.3.1-9. Model-Predicted Matrix Liquid Saturation Distribution at Repository Horizon at 1,000 Years after Nuclear Waste Emplacement (the Base-Case Model with Ventilation)

6.3.1-10. Model-Predicted Matrix Liquid Saturation Distribution at Repository Horizon at 2,000 Years after Nuclear Waste Emplacement (the Base-Case Model with Ventilation)

6.3.1-11a. Model-Predicted Matrix Liquid Saturation Distribution at the N-S Cross Section at 500 Years after Nuclear Waste Emplacement (the Base-Case Model with Ventilation)

6.3.1-11b. Model-Predicted Matrix Liquid Saturation Distribution at the N-S Cross Section at the Ambient Condition with the Present-Day, Mean infiltration Rates.

6.3.1-12. Model-Predicted Matrix Liquid Saturation Distribution at the N-S Cross Section at 1,000 Years after Nuclear Waste Emplacement (the Base-Case Model with Ventilation).

6.3.1-13. Model-Predicted Matrix Liquid Saturation Distribution along Observation Column $\mathrm{H}$ at Different Times (the Base-Case Model with Ventilation)...

6.3.1-14a. Model-Predicted Total Vertical Flux Distribution at the Bottom of PTn Unit at the Ambient Condition with the Present-Day, Mean Infiltration Rates

6.3.1-14b. Model-Predicted Total Vertical Flux Distribution at the Bottom of PTn Unit at 500 Years after Nuclear Waste Emplacement (the Base-Case Model with Ventilation)

6.3.1-15a. Model-Predicted Total Vertical Flux Distribution at Repository Horizon at the Ambient Condition with the Present-Day, Mean Infiltration Rates.

6.3.1-15b. Model-Predicted Total Vertical Flux Distribution at Repository Horizon at 500 Years after Nuclear Waste Emplacement (the Base-Case Model with Ventilation)

6.3.1-16a. Model-Predicted Total Vertical Flux Distribution at the Top of CHn Unit at the Ambient Condition with the Present-Day, Mean Infiltration Rates

6.3.1-16b. Model-Predicted Total Vertical Flux Distribution at the Top of CHn unit at 500 Years after Nuclear Waste Emplacement (the Base-Case Model with Ventilation)

6.3.1-17. Model-Predicted Total Vertical Flux Distribution along Observation Column F (Center of the Northern Repository Block) at Different Times (the Base-Case Model with Ventilation).

6.3.1-18. Model Predicted Total Vertical Flux Distribution along the Observation Column C (Outside the Northern Repository Block) at Different Times (the Base-Case Model with Ventilation).

6.3.2-1. Model-Predicted Rock Temperature Distribution at Repository Horizon at 100 years after Nuclear Waste Emplacement (the No-Ventilation Model). 


\section{LIST OF FIGURES (Continued)}

6.3.2-2a. Model-Predicted Rock Temperature Distribution at Repository Horizon at 500 Years after Nuclear Waste Emplacement (the No-Ventilation Model).

6.3.2-2b. Model-Predicted Rock Temperature Distribution at the Bottom of PTn Unit at Time of 500 Years after Nuclear Waste Emplacement (the No-Ventilation Model)

6.3.2-2c. Model-Predicted Rock Temperature Distribution at the Top of CHn Unit at 500 Years after Nuclear Waste Emplacement (the No-Ventilation Model).

6.3.2-3a. Model-Predicted Rock Temperature Distribution at Repository Horizon at 1,000 Years after Nuclear Waste Emplacement (the No-Ventilation Model) ..........120

6.3.2-3b. Model-Predicted Rock Temperature Distribution at the Bottom of PTn Unit at 1,000 Years after Nuclear Waste Emplacement (the No-Ventilation Model)

6.3.2-3c. Model-Predicted Rock Temperature Distribution at the Top of CHn Unit at 1,000 Years after Nuclear Waste Emplacement (the No-Ventilation Model)

6.3.2-3d. Model-Predicted Temperature Distribution at the N-S Cross Section at 1,000 Years after Nuclear Waste Emplacement (the No-Ventilation Model)....

6.3.2-4a. Model-Predicted Rock Temperature Distribution at Repository Horizon at 2,000 Years after Nuclear Waste Emplacement (the No-Ventilation Model) ..........124

6.3.2-4b. Model-Predicted Rock Temperature Distribution at the Bottom of PTn Unit at 2,000 Years after Nuclear Waste Emplacement (the No-Ventilation Model). 125

6.3.2-4c. Model-Predicted Rock Temperature Distribution at the Top of CHn Unit at 2,000 Years after Nuclear Waste Emplacement (the No-Ventilation Model) ...........126

6.3.2-5. Model-Predicted Rock Temperature Distribution at Repository Horizon at 5,000 Years after Nuclear Waste Emplacement (the No-Ventilation Model)

6.3.2-6a. Model-Predicted Temperature Profiles at Different Times along Observation Column F (the Center of the Northern, Main Repository Block) (the NoVentilation Model)

6.3.2-6b. Temperature Changes over Time at Three Elevations of the Lower PTn Unit (Elevation 1,307.5 m), Repository Horizon, and the Upper CHn Unit (Elevation of $961 \mathrm{M}$ ) along Column F (Center of the Northern Repository Block) (the No-Ventilation Model) .

6.3.2-7. Model-Predicted Matrix Liquid Saturation Distribution at the N-S Cross Section at 1,000 Years after Nuclear Waste Emplacement (the No-Ventilation Model).

6.3.2-8. Comparison of Simulated Matrix Liquid Saturation Distributions along Observation Column F at 10-8,000 Years after Nuclear Waste Emplacement, Using the No-Ventilation Model

6.3.2-9. Model-Predicted Total Vertical Flux Distribution at Repository Horizon at 500

Years after Nuclear Waste Emplacement (the No-Ventilation Model)

6.3.2-10. Predicted Total Vertical Flux Distribution along Observation Column F (the Center of the Northern Repository Block) at 10-8,000 Years Using the NoVentilation Model (downward flux is represented in positive).

6.3.2-11. Predicted Total Vertical Flux Distribution along Observation Column I (the Center of the Northern Repository Block) at 10-8,000 Years Using the NoVentilation Model..... 


\section{LIST OF FIGURES (Continued)}

6.4-1. Schematic East-West Cross Section through the Geological Framework Model (GFM) Showing Potential Mountain-Scale THC Processes.

6.4-2. Map View of the 2-D Cross Section of the THC Model Grid Mesh (Black Window) .

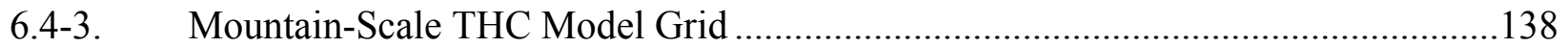

6.4-4. Short-Term Temperature Evolution Curves at Different Locations ............................144

6.4-5. Long-Term Temperature Evolution Curves at Different Locations ............................145

6.4-6. Temperature Spatial Distribution at Different Times (86\% Ventilation) ...................146

6.4-7. Matrix Saturation Evolution Curves at Different Locations (86\% Ventilation)........147

6.4-8. Matrix Saturation Distribution Maps at Different Times (86\% Ventilation) .............148

6.4-9. Fracture Saturation Distribution Maps at Different Times (86\% Ventilation)...........149

6.4-10. Percolation Fluxes at the Drift Horizon at Different Times (Simulated by Different Model Setups) .....................................................................................151

6.4-11. Distribution of $\mathrm{pH}$ under Chemical Steady State (No Mineral-Water Reactions) ....152

6.4-12. Gas Phase $\mathrm{CO}_{2}$ Concentrations in Fractures over 100,000 Years (Thermal Loading with 86\% Heat Removal by Ventilation) ..................................................154

6.4-13. Matrix Pore Water pH Evolution under Thermal Impact without Mineral-Water

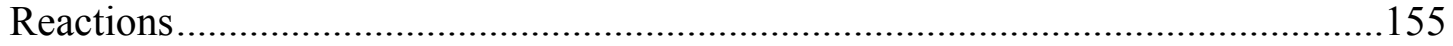

6.4-14. Fracture pH Evolution under Thermal Loading without Mineral-Water

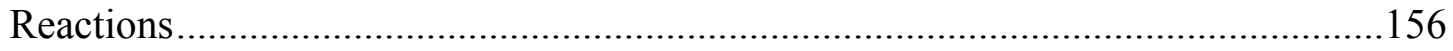

6.4-15. Chloride Concentrations in Fracture Water at 200; 600; 1,000; 2,000; 3,000;

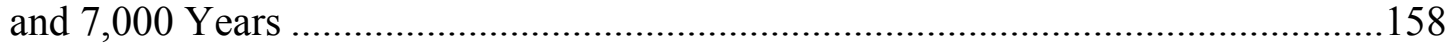

6.4-16. Fracture $\mathrm{Gas} \mathrm{CO}_{2}$ Concentrations and Temperatures at 200;600;1,000;2,000;

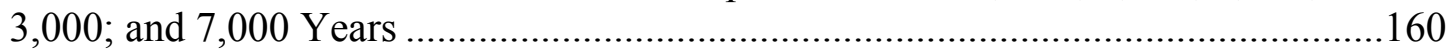

6.4-17. Fracture Water $\mathrm{pH}$ and Temperature at 200; 600; 1,$000 ; 2,000 ; 3,000$; and 7,000 Years

6.4-18. Calcite Precipitation (Volume \%) in Fractures at 1,000; 3,000; 5,000; and 7,000 Years .

6.4-19. Amorphous Silica Precipitated (Volume \%) in Fractures around Drifts after 1,000 and 2,000 Years

6.4-20. Volcanic Glass Dissolved (Volume \%) in the Rock Matrix after 1,000; 2,000; 3,000; and 7,000 Years 166

6.4-21. Stellerite Precipitation (Volume \%) in the Rock Matrix after 1,000; 2,000; 3,000; and 7,000 Years

6.4-22. Potassium Feldspar (Microcline) Precipitation (Above) and Dissolution (Below) (Volume \%) in the Rock Matrix after 2,000 and 7,000 Years.. 168

6.4-23. Albite Precipitation (Above) and Dissolution (Below) (Volume \%) in the Rock Matrix after 2,000 and 7,000 Years

6.4-24. Clinoptilolite Precipitation (Above) and Dissolution (Below) (Volume \%) in the Rock Matrix after 2,000 and 7,000 Years....

6.4-25. Fracture and Matrix Porosity Changes after 7,000 Years..........................................171

6.4-26. Fracture and Matrix Permeability after 7,000 Years ...............................................171

6.4-27. Percolation Fluxes at the Repository Horizon from the TH and THC Models .........172

6.5.2-1. Schematic of Coupling between TOUGH2 and FLAC3D ......................................175 


\section{LIST OF FIGURES (Continued)}

6.5.5-1. Conceptual Model Used for Calculation of Stress-Induced Changes in Hydraulic Properties ..... 180

6.5.5-2. Schematic for Normal Stress vs. Aperture Relation ...........................

6.5.6-1. Domain and Boundary Conditions for the Mountain-Scale THM Model ...................184

6.5.10-1. Calculated Evolution of Thermal Power from Waste Package (a) and Temperature at Two Points on the Level of the Emplacement Drifts (b)..................188

6.5.10-2. Calculated Temperature Distribution......................................................................189

6.5.10-3. Temperature Profiles through the Repository for TH (solid red line) and THM (dashed blue line) Analyses ...................................................................................190

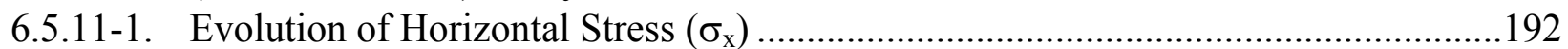

6.5.12-1. Evolution of Vertical Permeability Correction Factor $\left(\mathrm{F}_{\mathrm{kz}}=\mathrm{k}_{z} / \mathrm{ki}\right)$ Relative to Pre-Emplacement Permeability

6.5.12-2. Evolution of Horizontal Permeability Correction Factor $\left(\mathrm{F}_{\mathrm{kx}}=\mathrm{k}_{\mathrm{x}} / \mathrm{k}_{\mathrm{I}}\right)$ Relative to Pre-Emplacement Permeability.

6.5.12-3. Vertical Permeability at 1,000 Years along a Vertical Column at the Left Boundary of the Mountain-Scale THM Model Representing the Interior of the Repository: (a) Vertical Permeability Correction Factor $\left(\mathrm{F}_{\mathrm{kz}}=\mathrm{k}_{\mathrm{z}} / \mathrm{k}_{\mathrm{i}}\right)$ at 1,000 Years Relative to Pre-emplacement, (b) Vertical Permeability at 1,000 Years Compared to Pre-Emplacement (Initial) Permeability

6.5.13-1. Distribution of Vertical Percolation Flux $\left(\mathrm{Q}_{z}\right)$ at 100 Years after Emplacement for TH and THM Solutions

6.5.13-2. Distribution of Vertical Percolation Flux $\left(\mathrm{Q}_{\mathrm{z}}\right)$ at 1,000 Years after Emplacement for TH and THM Solutions....

6.5.13-3. Distribution of Vertical Percolation Flux $\left(\mathrm{Q}_{\mathrm{z}}\right)$ at 10,000 Years after Emplacement for a TH and THM Solutions

6.5.13-4. Distribution of Vertical Percolation Flux near four Emplacement Drifts in the Interior of the Repository $\left(\mathrm{Q}_{\mathrm{z}}\right)$ at 100 Years after Emplacement for TH and THM Solutions

6.5.13-5. Distribution of Vertical Percolation Flux near Four Emplacement Drifts in the Interior of the Repository $\left(\mathrm{Q}_{z}\right)$ at 1,000 Years after Emplacement for TH and THM Solutions

6.5.13-6. Distribution of Vertical Percolation Flux near Four Emplacement Drifts in the Interior of the Repository $\left(\mathrm{Q}_{\mathrm{z}}\right)$ at 10,000 Years after Emplacement for TH and THM Solutions

6.5.13-7. Vertical Percolation Flux $\left(\mathrm{Q}_{\mathrm{z}}\right)$ across the Repository Horizon near Four Emplacement Drifts for a TH Simulation (solid red lines) and a THM Simulation (blue dashed line)

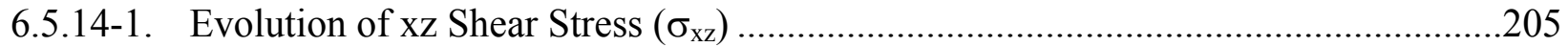

6.5.14-2. Ratio of $\sigma_{s /} \sigma_{n}$ from Stresses Acting on Vertical and Horizontal Fractures ................206

6.5.14-3. Vertical Permeability at 10,000 Years along a Vertical Column at the Left Boundary of the Mountain-Scale THM Model, with an Imposed Three-Orderof-Magnitude Permeability Increase in Zone of Possible Fracturing near the Ground Surface 


\section{LIST OF FIGURES (Continued)}

6.5.13-4. Comparison of the Vertical Percolation Flux (Qz) across the Repository Horizon near Four Emplacement Drifts for a TH Simulation (solid red lines) and a Coupled THM Simulation, with Imposed Three-Order-of-Magnitude Permeability Change in Zone of Stress Relief Near Ground Surface (blue dashed line)

7.2-1. Enlargement of 2-D Numerical Mesh for the DST Showing Locations of Central Canister Heater (Red Circle), Wing Heater Locations (Purple Diamonds and Red Squares), Concrete Invert (Green Squares), and Drift Wall Blocks (Small Red Squares)

7.2-2. Modeled $\mathrm{CO}_{2}$ Concentrations in Fractures after 3 years of Heating ....

7.2-3. Modeled Gas Phase $\mathrm{CO}_{2}$ Concentrations in Fractures Compared to Measured Values (corrected for vapor condensation):(a) Borehole Interval 74-3 (average of bounding gridblocks); (b) Borehole Interval 75-3; (c) Borehole Interval 763

7.2-4. Measured and Modeled pH for Samples Collected from Borehole Interval 60-3,

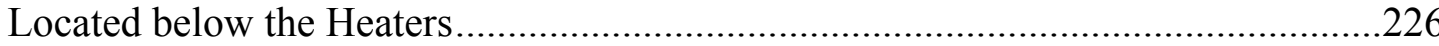

7.2-5. Volume Percent Change in Amorphous Silica Abundance ....................................227

7.2-6. Volume Percent Change in Amorphous Silica Abundance ...................................227 


\section{LIST OF TABLES}

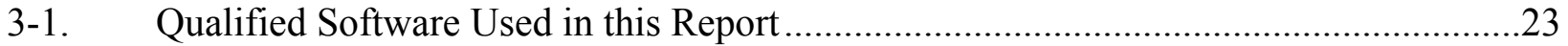

4.1-1. Input Data and Design Parameter Source and Data Tracking Numbers.......................26

4.2-1. Project Requirements and YMRP Acceptance Criteria Applicable to This Model

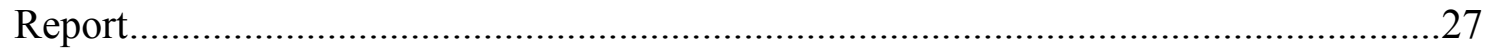

6-1. $\quad$ Model Development Documentation Scientific Notebooks .....................................35

6.1-1. GFM2000 Lithostratigraphy, TH Model Layer, and Hydrogeologic Unit Correlation Used in the Mountain-Scale TH Model......................................................37

6.1-2. Averaged Infiltration Rates (mm/year) and Time Period over the UZ Model

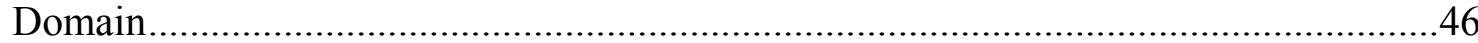

6.3-1. Observation Cells, Grid Columns, and Coordinates of the 3-D TH Model..................83

6.4-1. Minerals, Aqueous Species, and Gaseous Species in the Mountain-Scale THC Model.......

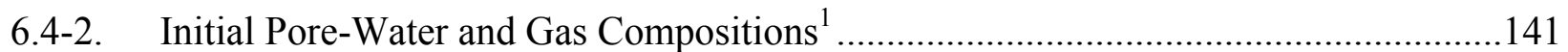

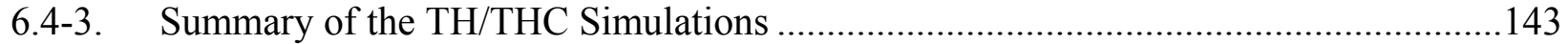

6.5.6-1. THM Model Boundary Conditions ........................................................................183

6.5.9-1. Summary of HM Parameters Developed in the Model Report..................................187

6.6-1. FEPs Relevant to This AMR and Included into TSPA-LA ....................................211

8-1. $\quad$ Output Data and Data Tracking Numbers ........................................................232 


\section{INTENTIONALLY LEFT BLANK}




\section{ACRONYMS}

2-D two-dimensional, two dimensions

3-D three-dimensional, three dimensions

ACC Accession Number

AMR Analysis/Model Report

AP Administrative Procedure

BSC Bechtel SAIC Company

CFR Code of Federal Regulations

$\mathrm{CFu} \quad$ Crater Flat undifferentiated hydrolgeologic unit

CHn Calico Hills nonwelded hydrogeologic unit

DOE Department of Energy

DST Drift-scale test

DTN Data Tracking Number

ECM Effective Continuum Model

ESE East South East

ESF Exploratory Studies Facility

GFM Geological Framework Model

HLW High Level Waste

HM Hydrological-Mechanical

IFDM Integral Finite Difference Method

LA License Application

LBNL Lawrence Berkeley National Laboratory

M\&O Management and Operating Contractor

masl Meters above sea level

MINC Multiple interacting continua

MR Model Report

NRC U.S. Nuclear Regulatory Commission

NS North South 


\section{ACRONYMS (Continued)}

PA Performance Assessment

PTn Paintbrush nonwelded hydrogeologic unit

QARD Quality Assurance Requirements and Description

SN Scientific Notebook

SRR Software Routine Report

STN Software Tracking Number

TBD To Be Determined

TBV To Be Verified

TDMS Technical Data Management System

TH Thermal-Hydrogical

THC Thermal-Hydrological-Chemical

THM Thermal-Hydrological-Mechanical

TM Thermal Mechanical

TSw Topopah Spring welded hydrogeologic unit

TSPA Total System Performance Assessment

TWP Technical Work Plan

UZ Unsaturated Zone

WNW West North West

WP Work Package

YMP Yucca Mountain Project

YMRP Yucca Mountain Review Plan, Final Report 


\section{PURPOSE}

The purpose of this Model Report is to document the development of the Mountain-Scale Thermal-Hydrological (TH), Thermal-Hydrological-Chemical (THC), and ThermalHydrological-Mechanical (THM) Models and evaluate the effects of coupled TH/THC/THM processes on mountain-scale UZ flow at Yucca Mountain, Nevada. This Model Report was planned in Technical Work Plan (TWP) for: Performance Assessment Unsaturated Zone (BSC 2002 [160819], Section 1.12.7), and was developed in accordance with AP-SIII.10Q, Models. In this Model Report, any reference to "repository" means the nuclear waste repository at Yucca Mountain, and any reference to "drifts" means the emplacement drifts at the repository horizon. This Model Report provides the necessary framework to test conceptual hypotheses for analyzing mountain-scale hydrological/chemical/mechanical changes and predict flow behavior in response to heat release by radioactive decay from the nuclear waste repository at the Yucca Mountain site.

The mountain-scale coupled TH/THC/THM processes models numerically simulate the impact of nuclear waste heat release on the natural hydrogeological system, including a representation of heat-driven processes occurring in the far field. The TH simulations provide predictions for thermally affected liquid saturation, gas- and liquid-phase fluxes, and water and rock temperature (together called the flow fields). The main focus of the TH Model is to predict the changes in water flux driven by evaporation/condensation processes, and drainage between drifts. The TH Model captures mountain-scale three dimensional (3-D) flow effects, including lateral diversion at the PTn/TSw interface and mountain-scale flow patterns. The MountainScale THC Model evaluates TH effects on water and gas chemistry, mineral dissolution/precipitation, and the resulting impact to UZ hydrological properties, flow and transport. The THM Model addresses changes in permeability due to mechanical and thermal disturbances in stratigraphic units above and below the repository host rock. The Mountain-Scale THM Model focuses on evaluating the changes in 3-D UZ flow fields arising out of thermal stress and rock deformation during and after the thermal periods.

The mountain-scale TH/THC/THM simulations are carried out using the UZ Flow and Transport Model (UZ Model) (BSC 2003 [163045]). These simulations provide mountain-scale thermally perturbed flow fields that directly incorporate thermal effects on UZ flow into the TSPA. The flow fields are developed with a spatially varying mean infiltration rate and varying climates during the compliance period. The simulations use the base case thermal load and ventilation scenario.

Predictions of thermal-loading effects in such models in turn require establishment and acceptance of mathematical models that accurately represent the physics of heat and fluid transport in the UZ. In this Model Report, the mathematical formulation employed in the TOUGH2 family of codes (Pruess 1987 [100684]; Pruess 1991 [100413]), the continuum models, and the van Genuchten capillary pressure and relative permeability relationships are relied upon to adequately describe the behavior of the UZ under thermal-loading conditions. This formulation is based on the traditional energy and mass conservation relationships, together with appropriate constitutive equations. In addition to the formulations for UZ flow employed in TOUGH2, the THC models rely on the equations describing aqueous and gaseous species 
advective and diffusive transport, and gas-water-mineral reactions via kinetic and equilibrium relations, as incorporated in TOUGHREACT V3.0 (LBNL 2002 [161256]) and described in Drift-Scale Coupled Processes (DST and THC Seepage) Models (BSC 2003 [162050]). The THM modeling relies upon equations describing the mechanical stresses resulting from thermal expansion, and the changes in fracture permeability resulting from changes in mechanical stress, as incorporated in FLAC3D and TOUGH2. The results of these coupled processes models are used to support the exclusion of certain features, events, or processes (FEPs) from the TSPA-LA model, on the basis of low consequence.

As indicated in the TWP (BSC 2002 [160819], Section 2.7.3), Level I validation is sufficient for the mountain-scale TH/THC/THM models. During model development, confidence is built into the mountain-scale TH/THC/THM models by adhering to sound, contemporary scientific principles, and by justification of the use of input parameters as well as initial and boundary conditions. All input data are taken from the TDMS or prescribed by planned repository operating conditions. Confidence in mountain-scale TH/THC/THM models is also gained during model development by examining all model results for heat, mass, and force balance, and conformity with known physical principles of energy and mass transport. No data exist yet that can be used to validate the mountain-scale TH/THC/THM models against direct experimental measurements; see the TWP by BSC (2002 [160819], Section I-3-1). Therefore, confidence in the Mountain-Scale TH/THC/THM models is gained by reviewing the validation of the corresponding drift-scale models. The mountain-scale TH/THC/THM models use the same conceptual models as those of the drift-scale TH/THC/THM models. Thus, since the drift-scale TH/THC/THM models are validated by comparison with measured data, the conceptual model underlying the mountain-scale TH/THC/THM models can be considered valid. Further validation of the mountain-scale $\mathrm{TH} / \mathrm{THC} / \mathrm{THM}$ models is provided by publications in peerreviewed journals.

The limitations of the mountain-scale TH/THC/THM models, and for any predictive model, are defined by the underlying conceptual model and the associated assumptions listed in Section 5 or included with model development in Section 6. For example, the mountain-scale TH/THC/THM models are continuum models with some average hydrological and thermal properties of the constituent stratigraphic units (owing mainly to lack of extensive data in 3-D). The outputs from the mountain-scale TH/THC/THM models can be used as inputs (for example as boundary conditions) to drift scale process models. However, they should not be construed as simulations of any drift-scale process. 


\section{QUALITY ASSURANCE}

Development of this model report and the supporting modeling activities have been determined to be subject to the Yucca Mountain Project's quality assurance (QA) program as defined in the Quality Assurance Requirements and Description (DOE 2003 [162903]) and as indicated in Technical Work Plan for: Performance Assessment Unsaturated Zone, TWP-NBS-HS-000003 REV 02 (BSC 2002 [160819], Section 8.2, Work Package (WP) AUZM08). Approved QA procedures identified in the TWP (BSC 2002 [160819], Section 4) have been used to conduct and document the activities described in this model report. The TWP also identifies the methods used to control the electronic management of data (BSC 2002 [160819], Section 8.4, WP AUZM08) during the modeling and documentation activities.

This model report provides model predictions of repository thermal effects on mountain-scale $\mathrm{TH}, \mathrm{THC}$, and THM processes in the Yucca Mountain UZ which is a natural barrier and is classified in the Q-List (BSC 2003 [165179]) as Safety Category because it is important to waste isolation, as defined in AP-2.22Q, Classification Analyses and Maintenance of the Q-List. The results of this report are important to the demonstration of compliance with the post-closure performance objectives prescribed in 10 CFR 63.113 [156671]. The report contributes to the analysis data used to support post-closure performance assessment; the conclusions do not directly impact engineered features important to preclosure safety, as defined in AP-2.22Q. 


\section{INTENTIONALLY LEFT BLANK}




\section{USE OF SOFTWARE}

The software and routines used in this study are listed in Table 3-1. These are appropriate for the intended application, were obtained from Software Configuration Management, and were used only within the range of validation. These codes have been qualified in accordance with AP-SI.1Q, Software Management.

Table 3-1. Qualified Software Used in this Report

\begin{tabular}{|l|l|l|l|}
\hline \multicolumn{1}{|c|}{ Software Name } & Version & \multicolumn{1}{c|}{$\begin{array}{c}\text { Software Tracking Number } \\
\text { (STN): }\end{array}$} & Citations \\
\hline TOUGH2 & 1.6 & $10007-1.6-01$ & LBNL 2003 [161491] \\
\hline TOUGHREACT & 3.0 & $10396-3.0-00$ & LBNL 2002 [161256] \\
\hline FLAC3D & 2.0 & $10502-2.0-00$ & LBNL 2001 [154783] \\
\hline EXT & 1.1 & $10005-1.1-00$ & LBNL 1999 [160768] \\
\hline EXT & 1.0 & $10047-1.0-00$ & LBNL 1999 [140944] \\
\hline Infil2grid & 1.7 & $10077-1.7-00$ & LBNL 2002 [154793] \\
\hline Wingridder & 2.0 & $10024-2.0-00$ & LBNL 2002 [154785] \\
\hline & & Routines & \\
\hline GPZones.dat & 1.0 & $10509-1.0-00$ & LBNL 2001 [154792] \\
\hline tin & 1.1 & $10899-1.1-00$ & LBNL 2002 [162038] \\
\hline Delb.dat & 1.0 & $10507-1.0-00$ & LBNL 2001 [154791] \\
\hline 2KGRIDV1.f & 1.0 & $10244-1.0-00$ & LBNL 1999 [147553] \\
\hline 2kgridv1a.for & 1.0 & $10382-1.0-00$ & LBNL 2000[153067] \\
\hline GEN-INCON-V0.F & 1.0 & $10220-1.0-00$ & LBNL 2000 [147023] \\
\hline GET_A_LAYER_V0.F & 1.0 & $10221-1.0-00$ & LBNL 2000 [147025] \\
\hline GET_TEMP_V0.F & 1.0 & $10222-1.0-00$ & LBNL 2000 [147027] \\
\hline TOPTEMP_V0.F & 1.0 & $10224-1.0-00$ & LBNL 2000 [147030] \\
\hline HSOURCE_V0.F & 1.0 & $10225-1.0-00$ & LBNL 2000 [147031] \\
\hline 2kgrid8.for & 1.0 & $10503-1.0-00$ & LBNL 2002 [154787] \\
\hline
\end{tabular}

The TH aspects of the numerical simulations in this Model Report were performed with the computer program TOUGH2 V1.6 (LBNL 2003 [161491]), using equation-of-state module EOS3. The THC and THM simulations were carried out with TOUGHREACT V3.0 (LBNL 2002 [161256]) and TOUGH2 V1.6 (LBNL 2003 [161491])/FLAC3D V2.0 (LBNL 2001 [154783]), respectively. To process the TOUGH2 V1.6 (LBNL 2003 [161491]) and FLAC3D V2.0 (LBNL 2001 [154783]) output for plotting, the codes EXT V1.0 (LBNL 1999 [140944]) and EXT V1.1 (LBNL 1999 [160768]), postprocessors for the TOUGH2 family of codes are used. The software infil2grid V1.7 LBNL 2002 [154793] is used to map the infiltration flux from the infiltration maps onto the numerical grid. The code Wingridder V2.0 (LBNL 2002 [154785]) 
was used to generate numerical grids used here and is documented in a separate Model Report. All these codes have been qualified under AP-SI.IQ, Software Management.

The documentation for the routines listed in Table 3-1 is provided in the Software Routine Reports (SRR) submitted under the STNs in Table 3-1. These were used for pre- and postprocessing of files.

Standard, commercially available spreadsheet and graphics software programs (TecPLOT V8.0 and EXCEL 97 SR-1) were also used for post-processing simulations results in Sections of 6.2, 6.3, 6.4, and 6.5. Details and procedures for using the standard functions of TecPLOT and EXCEL in post-processing and simulation extraction for plotting are documented in Wang (2003 [165927]) as well as in Attachment IV.

This Model Report documents the mountain-scale TH/THC/THM models. Input and output files for the model simulations documented in this Model Report have been submitted to the TDMS as summarized in Table 8-1 and discussed under each modeled scenario in Section 6. 


\section{INPUTS}

\subsection{DIRECT INPUT}

Key input data and parameters used in TH/THC/THM model development are listed in Table 4.1-1 and include the parameters discussed below. The THC and THM Models require all of the same inputs as the TH Model, plus the additional inputs listed for each model.

\section{All Mountain-Scale TH/THC/THM Models}

- Fracture properties (frequency, permeability, van Genuchten $\alpha$ and $m$ parameters, porosity, and interface area) for each UZ model layer

- Matrix properties (porosity, permeability, van Genuchten $\alpha$ and $m$ ) for each UZ model layer

- Thermal properties (grain density, wet and dry thermal conductivity, and grain specific heat) for each model layer

- Fault properties (matrix and fracture) for each hydrogeologic unit

- Repository thermal-load and ventilation efficiency

- Infiltration maps for present and future climates.

- Numerical model grids

$\underline{\text { THC Model }}$

- Mineralogy (volume fractions and reactive surface areas in each layer)

- Water and gas chemistry (initial and boundary)

- Thermodynamic and kinetic data for mineral-water-gas reactions

- Transport properties for aqueous and gaseous species

- Fracture aperture and spacing for calculating changes to fracture permeability

\section{$\underline{\text { THM Model }}$}

- Mechanical properties (bulk modulus and shear modulus)

- TM properties (thermal expansion coefficient)

- HM properties (parameters for the stress dependency of hydraulic properties) 
Specific input data sets and associated Data Tracking Numbers (DTNs) are provided in Table 4.1-1. Complete references are also presented in Section 9.3.

Table 4.1-1. Input Data and Design Parameter Source and Data Tracking Numbers

\begin{tabular}{|c|c|}
\hline Current DTN & Data Description \\
\hline GS000308311221.005 [147613] & $\begin{array}{l}\text { Net infiltration maps-mean, upper, and lower } \\
\text { boundaries }\end{array}$ \\
\hline LB03013DSSCP3I.001 [162379] & Calibrated 3-D hydrologic properties \\
\hline LB0303THERMESH.001 [165168] & 3-D thermal model grid \\
\hline $\begin{array}{l}\text { 800-IED-WISO-00204-000-00A [Design } \\
\text { Parameter] (BSC } 2003 \text { [164136]) }\end{array}$ & Repository thermal load and decay data ${ }^{1}$ \\
\hline $\begin{array}{l}\text { ANL-EBS-MD-000030 REV } 03 \text { ICN } 01 \\
\text { [Design Parameter] (BSC } 2003 \text { [166343]). }\end{array}$ & Ventilation efficiency \\
\hline LB0210THRMLPRP.001 [160799] & Thermal properties for model layers \\
\hline LB0205REVUZPRP.001 [159525] & Fracture properties for model layers \\
\hline LB0208UZDSCPMI.002 [161243] & $\begin{array}{l}\text { Calibrated fracture and matrix properties sets } \\
\text { for mean infiltration }\end{array}$ \\
\hline LB0307KNTDBRTM.001 [164433] & Kinetic data \\
\hline LB0307THMDBRTM.001 [164434] & Thermodynamic data \\
\hline LA9908JC831321.001 [113495] & $\begin{array}{l}\text { Model input and output files for Mineralogical } \\
\text { Model "MM3.0" Version 3.0. }\end{array}$ \\
\hline LA9912SL831151.001 [146447] & Drift-Scale test and single heater Test fracture \\
\hline LA9912SL831151.002 [146449] & mineralogy \\
\hline MO9911SEPGRP34.000 [148524] & Mechanical rock-mass properties \\
\hline LB0303THERMSIM.001 [165167] & Boundary and initial conditions \\
\hline LB030432DGRIDS.001 [163937] & Vertical geological layering for THM model \\
\hline
\end{tabular}

The data used as direct input for the TH/THC/THM models are all qualified in accordance with the requirements of QARD. The data listed in table 4.1-1 are appropriate for this study because they represent fracture, matrix, and thermal properties calibrated for the UZ model at Yucca Mountain. The technical product outputs listed in Table 4.1-1 are also appropriate for this study because they represent the planned operating conditions (repository thermal load) and the calculated efficiency of planned ventilation. The appropriateness of the data is also discussed in Sections 6 and 7 when they are used for modeling and validation efforts. 


\subsection{CRITERIA}

Technical requirements to be satisfied by performance assessment (PA) are based on 10 CFR 63.114 and 63.115 (66 FR 55732 [156671], Requirements for Performance Assessment) and identified in the Yucca Mountain Project Requirements Document (Canori and Leitner 2003 [161770]). The acceptance criteria that will be used by the Nuclear Regulatory Commission (NRC) to determine whether the technical requirements have been met are identified in the Yucca Mountain Review Plan, Final Report (YMRP; NRC 2003 [163274]). The pertinent requirements and acceptance criteria for this Model Report are summarized in Table 4.2-1.

Table 4.2-1. Project Requirements and YMRP Acceptance Criteria Applicable to This Model Report

\begin{tabular}{|c|c|c|c|}
\hline $\begin{array}{l}\text { Requirement } \\
\text { Number }^{\mathrm{a}}\end{array}$ & Requirement Title $^{a}$ & 10 CFR 63 Link & YMRP Acceptance Criteria \\
\hline PRD-002/T-015 & $\begin{array}{l}\text { Requirements for } \\
\text { Performance Assessment }\end{array}$ & $\begin{array}{l}10 \text { CFR } 63.114(\mathrm{a}-\mathrm{c}) \\
{[156671]}\end{array}$ & $\begin{array}{l}\text { Criteria } 1 \text { to } 4 \text { for Flow Paths in the } \\
\text { Unsaturated Zone }\end{array}$ \\
\hline PRD-002/T-016 & $\begin{array}{l}\text { Requirements for Multiple } \\
\text { Barriers }\end{array}$ & $\begin{array}{l}10 \text { CFR } 63.115(a-c) \\
{[156671]}\end{array}$ & $\begin{array}{l}\text { Criteria } 1 \text { to } 3 \text { for Demonstration of } \\
\text { Multiple Barriers }\end{array}$ \\
\hline
\end{tabular}

NOTES: ${ }^{a}$ from Canori and Leitner (2003 [161770])

b from NRC (2003 [163274], Section 2.2.1.3.6.3)

c from NRC (2003 [163274], Section 2.2.1.1.3)

The acceptance criteria identified in Section 2.2.1.3.6.3 of the YMRP (NRC 2003 [163274]) are given below, followed by a short description of their applicability to this Model Report:

- Acceptance Criterion 1, System Description and Model Integration Are Adequate:

The total system performance assessment adequately incorporates important design features, physical phenomena, and couplings, and uses consistent and appropriate assumptions throughout the flow paths in the unsaturated zone process-level model. Couplings include thermal-hydrological effects.

The aspects of geology, hydrology, physical phenomena, and couplings that may affect flow paths in the unsaturated zone are adequately considered. Conditions and assumptions in the abstraction of flow paths in the unsaturated zone are readily identified and consistent with the body of data presented in the description.

Sufficient data and technical bases to assess the degree to which features, events, and processes have been included in this abstraction are provided.

Adequate spatial and temporal variability of model parameters and boundary conditions are employed in process-level models to estimate flow paths in the unsaturated zone, including percolation flux.

Average parameter estimates used in process-level models are representative of the temporal and spatial discretizations considered in the model. 
The TH, THC, and THM systems are described in Sections 6.1, 6.4, and 6.5, respectively.

- Acceptance Criterion 2, Data Are Sufficient for Model Justification:

Hydrological and thermal-hydrological values used in the safety case are adequately justified. Adequate descriptions of how data were used, interpreted, and appropriately synthesized into the parameters are provided. Estimates of deep-percolation flux rates constitute an upper bound, or are based on a technically defensible unsaturated zone flow model that reasonably represents the physical system.

Sensitivity or uncertainty analyses are performed to assess data sufficiency, and determine the possible need for additional data;

Accepted and well-documented procedures are used to construct and calibrate numerical models. Reasonably complete process-level conceptual and mathematical models are used in the analyses. Mathematical models are provided that are consistent with conceptual models and site characteristics; and the robustness of results from different mathematical models is compared.

The data are identified in Table 4.1-1, and their sufficiency is demonstrated by the model validation in Section 7.

- Acceptance Criterion 3, Data Uncertainty Is Characterized and Propagated Through the Model Abstraction:

Models use parameter values, and probability distributions, that are technically defensible, and reasonably account for uncertainties and variabilities. The initial conditions, boundary conditions, and computational domain used in sensitivity analyses and/or similar analyses are consistent with available data. Parameter values are consistent with the initial and boundary conditions and the assumptions of the conceptual models for the Yucca Mountain site. Coupled processes are adequately represented. Uncertainties in the characteristics of the natural system are considered.

The hydrological and thermal properties used in the TH/THC/THM Models are identified in Table 4.1-1. Uncertainty in these properties is captured by calibrating them using different infiltration maps (BSC 2003 [163045]).

- Acceptance Criterion 4, Model Uncertainty Is Characterized and Propagated Through the Model Abstraction:

Alternative modeling approaches of features, events, and processes, consistent with available data and current scientific understanding, are investigated. The selected model is consistent with available data and current scientific understanding. The results and limitations are appropriately considered in the abstraction. 
The modeling approach for $\mathrm{TH}$ is described in Section 6.1.2, with consideration of alternative models. For THC and THM, modeling approaches are described in Sections 6.4.1 and 6.5.3, respectively. FEPs are discussed in Section 6.6

The acceptance criteria identified in Sections 2.2.1.1.3 of the YMRP (NRC 2003 [163274]) are given below, followed by a short description of their applicability to this Model Report:

- Acceptance Criterion 1, Identification of Barriers is Adequate:

The unsaturated rocks above the repository (and below surficial soils) and the unsaturated rocks below the repository (and above the water table) are natural barriers important to waste isolation. They function by diverting and retarding percolating groundwater above the repository and their barrier capability is determined by their hydrological properties as implemented in this model for flow in the UZ.

The natural barrier is identified in Section 6.1.1.

- Acceptance Criterion 2, Description of Barrier Capability to Isolate Waste Is Acceptable:

The capability of the identified barriers to prevent or substantially delay the movement of water is adequately identified and described. The uncertainty associated with barrier capabilities is adequately described.

Sections $6.1,6.2,6.3,6.4$, and 6.5 discuss the effectiveness of the natural barriers under thermal loading conditions.

- Acceptance Criterion 3, Technical Basis for Barrier Capability Is Adequately Presented:

The technical bases are consistent with the technical basis for the performance assessment. The technical basis for assertions of barrier capability is commensurate with the importance of each barrier's capability and the associated uncertainties.

The technical basis for barrier capability is presented in Sections 6.1, 6.2, 6.3, 6.4, and 6.5.

In the TWP (BSC 2002 [160819], Table 3-1), only one of these acceptance criteria (Criterion 1 for Flow Paths in the UZ) was identified for this model report. The other criteria also identified are appropriate for this model report (see also Section 6).

\subsection{CODES AND STANDARDS}

No specific formally established standards have been identified as applying to this modeling activity. 


\section{INTENTIONALLY LEFT BLANK}




\section{ASSUMPTIONS}

Assumptions are only listed in this section if they are necessitated by lack of data. Modeling approaches, approximations, and idealizations that form part of the models are documented in the respective model development sections: Sections 6.1-6.3 for the TH models, in Section 6.4 for the THC model, and in Section 6.5 for the THM Model.

This section presents the rationale and justification for assumptions; discusses whether further confirmation is needed, and references the sections in the Model Report where these assumptions are used.

\subsection{ASSUMPTIONS FOR THE MOUNTAIN-SCALE TH MODEL}

No assumptions are needed for the mountain-scale TH model. Modeling approaches, approximations, and idealizations that form part of the TH model are documented in the Section 6.1 .

\subsection{ASSUMPTIONS FOR THE MOUNTAIN-SCALE THC MODEL}

The geochemical model for the Mountain-Scale THC Model is based on the THC Seepage Model discussed in BSC (2003 [162050]). Therefore, the one assumption made for that Model Report has also been made for the Mountain-Scale THC Model: A value of 0.2 is assumed for matrix tortuosity of the tuff matrix at Yucca Mountain. Because this is a factor applied along with the porosity to the diffusion coefficient, the effect on reaction-transport processes of a deviation in this number from the true value would be small. Therefore, no further justification or confirmation is necessary. Because reactions involving $\mathrm{CO}_{2}$ are minimal in the drift, the diffusivity of $\mathrm{CO}_{2}$ within in-drift components has a negligible effect on THC processes outside of the drift. Therefore, this assumption needs no further justification or confirmation.

The THC model also adopts the modeling approaches of the TH Model discussed in Section 6.1.

\subsection{ASSUMPTIONS FOR THE MOUNTAIN-SCALE THM MODEL}

This section contains a list of assumptions specific for the Mountain-Scale THM Model used in Section 6.5 of this Model Report. Each statement of an assumption is followed by the rationale for why the assumption is considered valid or reasonable.

1. The initial vertical stress field (units of $\mathrm{Pa}$ ) is assumed to be $\sigma_{\mathrm{v}}=-\rho g z_{\mathrm{d}}=-2,200 \times$ $9.81 \times \mathrm{z}_{\mathrm{d}}=-21,582 \times \mathrm{z}_{\mathrm{d}}$, where $\mathrm{z}_{\mathrm{d}}$ is depth $(\mathrm{m})$. Horizontal stresses are assumed to be $\sigma_{\mathrm{H}}=0.5 \times \sigma_{\mathrm{v}}$ (least compressive horizontal stress) and $\sigma_{\mathrm{h}}=0.6 \times \sigma_{\mathrm{v}}$ (maximum compressive horizontal stress). This assumption is used for all geological layers in all THM simulations in Section 6.5 of this Model Report.

Basis: The assumed initial stress field represents the best estimate of the stress field at the repository horizon. Vertical stress is estimated based on the weight of the overburden rock, with an average density of $2,200 \mathrm{~kg} / \mathrm{m}^{3}$ (See Section 6.5.6). The assumed ratios of the horizontal stresses to the vertical (0.5 and 0.6) are average 
values representing the best estimate at the repository horizon given in the Yucca Mountain Site Geotechnical Report (CRWMS M\&O 1997 [103564], Table 3-2, p. 323). According to Table 3-2 of the Site Geotechnical Report, the minimum horizontal/vertical stress ratio is estimated to range from 0.3 to 0.8 with an average value of 0.5 , whereas maximum horizontal/vertical stress ratio is estimated to range from 0.3 to 1.0 with an average value of 0.6 . A few additional stress measurements conducted in 1996 to 1998 indicates stress ratios of about 0.4 and 0.7 for minimum and maximum horizontal stresses, respectively (MO0007RIB00077.000 [154087], Tables 4 and 5). These values (0.4 and 0.7) are within the ranges and close to the average values of previous estimates, but indicate a slightly more anisotropic stress field. The assumed initial stress field is considered sufficiently accurate because this Model Report concerns itself with thermally induced stresses, which are largely independent of the initial stress field. Moreover, the initial stresses are small compared to the thermally induced stresses. This assumption is considered adequate and requires no further confirmation.

2. The TSw3 TM unit is assigned rock-mass mechanical properties (Young's modulus and Poisson's ratio) that are equal to that of the TSw2 TM unit. This assumption is needed for complete definition of mechanical material properties (Section 6.5.8).

Basis: Rock-mass properties of the TSw3 TM unit are not listed in the qualified data source (DTN: MO9911SEPGRP34.000 [148524], Tables 10 and 11) and have to be derived. Assigning the TSw3 TM unit to have mechanical properties equivalent to the TSw2 TM unit is considered to be a good estimate for the following reasons: (1) the Young's modulus measured on intact rock samples from TSw3 and TSw2 TM units are similar (DTN: MO9911SEPGRP34.000 [148524], Table 8); and (2) the mean fracture spacing of the two TM units are similar (See DTN: LB0205REVUZPRP.001 [159525], where layers tsw34-37 and tsw38-39 are equivalent to TSw2 and TSw3 TM units, respectively). This assumption is considered adequate and requires no further confirmation.

3. The rock-mass mechanical properties (Young's modulus and Poisson's ratio) of the CHn TM unit are assumed to be equivalent to the intact rock mechanical properties (Young's modulus and Poisson's ratio). This assumption is needed for complete definition of mechanical material properties (Section 6.5.8).

Basis: Rock-mass properties of the CHn TM unit are not listed in the qualified data source (DTN: MO9911SEPGRP34.000 [148524], Tables 10 and 11) and have to be derived. Assuming the rock properties of the CHn TM unit to be equal to its intact rock properties is justified as follows: (a) for the CHn TM unit, the measured values of Young's modulus of intact rock samples is very low (5.63 GPa with $1.55 \mathrm{GPa}$ standard deviation according to DTN: MO9911SEPGRP34.000 [148524], Table 8). This indicates that the rock-mass deformability is controlled by the deformability of the intact rock matrix rather than by the deformability of rock fractures; (b) The intact rock modulus provides an upper limit for the rock-mass modulus of deformation, which can be considered a conservative estimate giving the maximum possible TM 
impact. This estimate is considered sufficient, considering that the CHn TM unit is located far below the repository units. For the THM analysis, concern is focused on THM processes primarily in the repository units and secondarily in units located above the repository. This assumption is considered adequate and requires no further confirmation. 


\section{INTENTIONALLY LEFT BLANK}




\section{MODEL DISCUSSION}

As discussed in Section 1, this Model Report documents the development of and the results from using the Mountain-Scale Coupled Processes TH/THC/THM Models. This section describes conceptual and numerical models developed, numerical grids and model parameters used, and model results for these coupled-processes models (TH/THC/THM models). It consists of the following sections:

- Mountain-Scale TH Model Description (Section 6.1)

- 2-D Mountain-Scale TH Model Results and Analyses (Section 6.2)

- 3-D Mountain-Scale TH Model Results and Analyses (Section 6.3)

- Mountain-Scale THC Model (Section 6.4)

- Mountain-Scale THM Model (Section 6.5).

Key scientific notebooks used to document modeling activities described in this Model Report are listed in Table 6-1.

Table 6-1. Model Development Documentation Scientific Notebooks

\begin{tabular}{|l|l|l|l|}
\hline \multicolumn{1}{|c|}{$\begin{array}{c}\text { LBNL Scientific } \\
\text { Notebook ID }\end{array}$} & \multicolumn{1}{|c|}{$\begin{array}{c}\text { M\&O Scientific } \\
\text { Notebook ID }\end{array}$} & \multicolumn{1}{|c|}{ Page Numbers } & \multicolumn{1}{c|}{ Citations } \\
\hline YMP-LBNL-YSW-3 & SN-LBNL-SCl-199-V1 & pp. 105-108, 215-232 & Wang 2003 [165927] \\
\hline YMP-LBNL-YSW-KZ-1 & SN-LBNL-SCI-202-V1 & pp. 134, 141-151 & Wang 2003 [165927] \\
\hline YMP-LBNL-YSW-3.1 & SN-LBNL-SCl-199-V2 & pp. 7-140 & Wang 2003 [165927] \\
\hline YMP-LBNL-ELS-GL-2 & SN-LBNL-SCl-219-V2 & pp. 67-73 & Wang 2003 [165927] \\
\hline YMP-LBNL-YSW-KZ-2 & SN-LBNL-SCl-202-V2 & pp. 6-10 & Wang 2003 [165927] \\
\hline YMP-LBNL-JR-2 & SN-LBNL-SCI-204-V2 & pp. 185-235, 271-273 & Wang 2003 [165927] \\
\hline YMP-LBNL-THC-GZ-1 & SN-LBNL-SCl-238-V1 & pp. 7-92 & Wang 2003 [165927] \\
\hline
\end{tabular}

In the TWP (BSC 2002 [160819], Table 2-5), simulations for upper and lower bounds of infiltration under the present and two future climate states were planned. However, simulations have been done only for the mean present and future infiltration maps (see also Section 4.2).

\subsection{MOUNTAIN-SCALE TH MODEL DESCRIPTION}

The conceptual models used for the Mountain-Scale TH Model are documented in this Model Report as well as in the Model Report, UZ Flow Models and Submodels (BSC 2003 [163045], Section 6.3). The conceptual and numerical models are presented in this section so that a complete discussion of the model is provided. 


\subsubsection{Geological Model and Numerical Grids}

The geological model used for developing the TH Model is the Geological Framework Model (GFM2000; DTN: MO0012MWDGFM02.002 [153777]). Based on this geological model, two grids, one 3-D and one 2-D, are developed and used in the Mountain-Scale TH Model. The development of the 3-D TH model grid was documented in the Scientific Analysis Report $U Z$ Flow Models and Submodels (BSC 2003 [163045]). The development of the 2-D TH model grid is described in the present report. Table 6.1-1 lists the geological units/layers for different hydrogeologic units and the associations with the TH Model numerical grid-layer information. These geological formations have been organized into layered hydrogeologic units, based primarily on the degree of welding (Montazer and Wilson 1984 [100161]). These units are the Tiva Canyon welded (TCw) hydrogeologic unit, the Paintbrush nonwelded unit (PTn), the Topopah Spring welded (TSw) unit, the Calico Hills nonwelded unit (CHn), and the Crater Flat undifferentiated $(\mathrm{CFu})$ units. 
Table 6.1-1. GFM2000 Lithostratigraphy, TH Model Layer, and Hydrogeologic Unit Correlation Used in the Mountain-Scale TH Model

\begin{tabular}{|c|c|c|c|}
\hline $\begin{array}{c}\text { Major Unit } \\
\text { (Modified from Montazer and } \\
\text { Wilson 1984 [100161]) }\end{array}$ & $\begin{array}{l}\text { Lithostratigraphic } \\
\text { Nomenclature }\end{array}$ & $\begin{array}{l}\text { TH Model Grid } \\
\text { Layer* }^{*}\end{array}$ & Hydrogeologic Unit \\
\hline \multirow{5}{*}{$\begin{array}{l}\text { Tiva Canyon welded } \\
(\mathrm{TCw})\end{array}$} & Tpcr & tcw11 & CCR, CUC \\
\hline & Трср & \multirow[t]{2}{*}{ tcw12 } & \multirow[t]{2}{*}{ CUL, CW } \\
\hline & TpcLD & & \\
\hline & Tpcpv3 & \multirow[t]{2}{*}{ tcw13 } & \multirow[t]{2}{*}{ CMW } \\
\hline & Tpcpv2 & & \\
\hline \multirow{10}{*}{$\begin{array}{l}\text { Paintbrush nonwelded } \\
\text { (PTn) }\end{array}$} & Tpcpv1 & ptn21 & CNW \\
\hline & Tpbt4 & \multirow[t]{2}{*}{ ptn22 } & \multirow[t]{2}{*}{ BT4 } \\
\hline & \multirow[t]{3}{*}{ Tpy (Yucca) } & & \\
\hline & & ptn23 & TPY \\
\hline & & \multirow[t]{2}{*}{ ptn24 } & \multirow[t]{2}{*}{ BT3 } \\
\hline & Tpbt3 & & \\
\hline & Tpp (Pah) & ptn25 & TPP \\
\hline & Tpbt2 & \multirow[t]{3}{*}{ ptn26 } & \multirow[t]{3}{*}{ BT2 } \\
\hline & Tptrv3 & & \\
\hline & Tptrv2 & & \\
\hline \multirow{11}{*}{$\begin{array}{l}\text { Topopah Spring welded } \\
\text { (TSw) }\end{array}$} & Tptrv1 & \multirow[t]{2}{*}{ tsw31 } & \multirow[t]{2}{*}{ TTC } \\
\hline & \multirow[t]{2}{*}{ Tptrn } & & \\
\hline & & tsw32 & TR \\
\hline & Tptrl, Tptf & \multirow[t]{2}{*}{ tsw33 } & \multirow[t]{2}{*}{ TUL } \\
\hline & Tptpul, RHHtop & & \\
\hline & Tptpmn & tsw34 & TMN \\
\hline & Tptpll & tsw35 & TLL \\
\hline & \multirow[t]{2}{*}{ Tptpln } & tsw36 & TM2 (upper 2/3 of Tptpln) \\
\hline & & tsw37 & TM1 (lower 1/3 of Tptpln) \\
\hline & Tptpv3 & tsw38 & PV3 \\
\hline & Tptpv2 & tsw39 (vit, zeo) & PV2 \\
\hline
\end{tabular}


Table 6.1-1. GFM2000 Lithostratigraphy, TH Model Layer, and Hydrogeologic Unit Correlation Used in the Mountain-Scale TH Model (continued)

\begin{tabular}{|c|c|c|c|}
\hline $\begin{array}{c}\text { Major Unit } \\
\text { (Modified from Montazer and } \\
\text { Wilson 1984 [100161]) }\end{array}$ & $\begin{array}{l}\text { Lithostratigraphic } \\
\text { Nomenclature }\end{array}$ & $\begin{array}{l}\text { UZ Model Grid } \\
\text { Layer* }\end{array}$ & Hydrogeologic Unit \\
\hline \multirow[t]{14}{*}{$\begin{array}{l}\text { Calico Hills nonwelded } \\
(\mathrm{CHn})\end{array}$} & Tptpv1 & \multirow[t]{2}{*}{ ch1 (vit, zeo) } & \multirow[t]{2}{*}{$\begin{array}{l}\text { BT1 or } \\
\text { BT1a (altered) }\end{array}$} \\
\hline & Tpbt1 & & \\
\hline & \multirow{4}{*}{$\begin{array}{l}\text { Tac } \\
\text { (Calico) }\end{array}$} & ch2 (vit, zeo) & \multirow{4}{*}{$\begin{array}{l}\mathrm{CHV} \text { (vitric) } \\
\text { or } \\
\mathrm{CHZ} \text { (zeolitic) }\end{array}$} \\
\hline & & ch3 (vit, zeo) & \\
\hline & & ch4 (vit, zeo) & \\
\hline & & ch5 (vit, zeo) & \\
\hline & Tacbt (Calicobt) & ch6 (vit, zeo) & BT \\
\hline & Tcpuv (Prowuv) & pp4 & PP4 (zeolitic) \\
\hline & Tcpuc (Prowuc) & pp3 & PP3 (devitrified) \\
\hline & Tcpmd (Prowmd) & \multirow[t]{2}{*}{ pp2 } & \multirow[t]{2}{*}{ PP2 (devitrified) } \\
\hline & Tcplc (Prowlc) & & \\
\hline & Tcplv (Prowlv) & \multirow[t]{3}{*}{$\mathrm{pp} 1$} & \multirow[t]{3}{*}{ PP1 (zeolitic) } \\
\hline & Tcpbt (Prowbt) & & \\
\hline & Tcbuv (Bullfroguv) & & \\
\hline \multirow{11}{*}{$\begin{array}{l}\text { Crater Flat undifferentiated } \\
\text { (CFu) }\end{array}$} & Tcbuc (Bullfroguc) & bf3 & BF3 (welded) \\
\hline & Tcbmd (Bullfrogmd) & & \\
\hline & Tcblc (Bullfroglc) & & \\
\hline & Tcblv (Bullfroglv) & \multirow[t]{3}{*}{ bf2 } & \multirow[t]{3}{*}{ BF2 (nonwelded) } \\
\hline & Tcbbt (Bullfrogbt) & & \\
\hline & Tctuv (Tramuv) & & \\
\hline & Tctuc (Tramuc) & \multirow[t]{3}{*}{ tr3 } & \multirow[t]{3}{*}{ Not Available } \\
\hline & Tctmd (Trammd) & & \\
\hline & Tctlc (Tramlc) & & \\
\hline & Tctlv (Tramlv) & \multirow[t]{2}{*}{$\operatorname{tr} 2$} & \multirow[t]{2}{*}{ Not Available } \\
\hline & Tctbt (Trambt) and below & & \\
\hline
\end{tabular}

Source: BSC 2003 [160109], Table 11.

NOTE: *Defined as a rock material type, represented by the code name, for grid blocks belonging to the rock unit.

The 3-D TH Model grid is shown in the plan view of Figure 6.1-1. The 3-D TH Model grid has been developed to be consistent with the engineering layout of the repository, including the orientation of the emplacement drifts: see, for reference, Figure 11 in Underground Layout Configuration (BSC 2003 [165572]) for a schematic drawing of the repository layout. The thermal model grid domain covers approximately $20 \mathrm{~km}^{2}$ of the area and uses a refined mesh in the vicinity of the repository. The thermal model domain is selected to focus on geothermal conditions and thermal-loading effects at and near the repository area. The TH model domain is considered to provide sufficient accuracy for such studies because of the small impact of the thermal effect expected in the lateral directions. In particular, the thermal grid incorporates every repository drift explicitly by taking into account orientations, lengths, elevations, and spacing of the repository drifts. Specifically, a grid spacing of $81 \mathrm{~m}$ is used in the direction perpendicular to drifts. At the repository horizon, a segment of a $5.5 \mathrm{~m}$ diameter cylinder represents waste 
emplacement drifts for thermal-loading TH studies. (In the 2-D mountain-scale TH model, by contrast, drift elements are square in shape.) Drift elements have the same hydrological properties as the surrounding matrix, except for zero capillarity and slightly less than 100\% porosity. Heat sources will be introduced into the drift elements. In the 3-D TH Model grid, faults are represented in the model by vertical or inclined $30 \mathrm{~m}$ wide zones.

The 3-D TH Model grid of Figure 6.1-1 consists of 980 mesh columns of both fracture and matrix continua, 86,440 gridblocks, and 343,520 connections in a dual-permeability grid. Vertically, the thermal grid has an average of 45 computational grid layers. Note that the 3-D thermal grid uses relatively coarse vertical grid spacing and a smaller grid domain than the UZ Flow Model grid (BSC 2003 [163045]) to reduce the total number of gridblocks and thus reduce the computational intensity required for $\mathrm{TH}$ modeling.

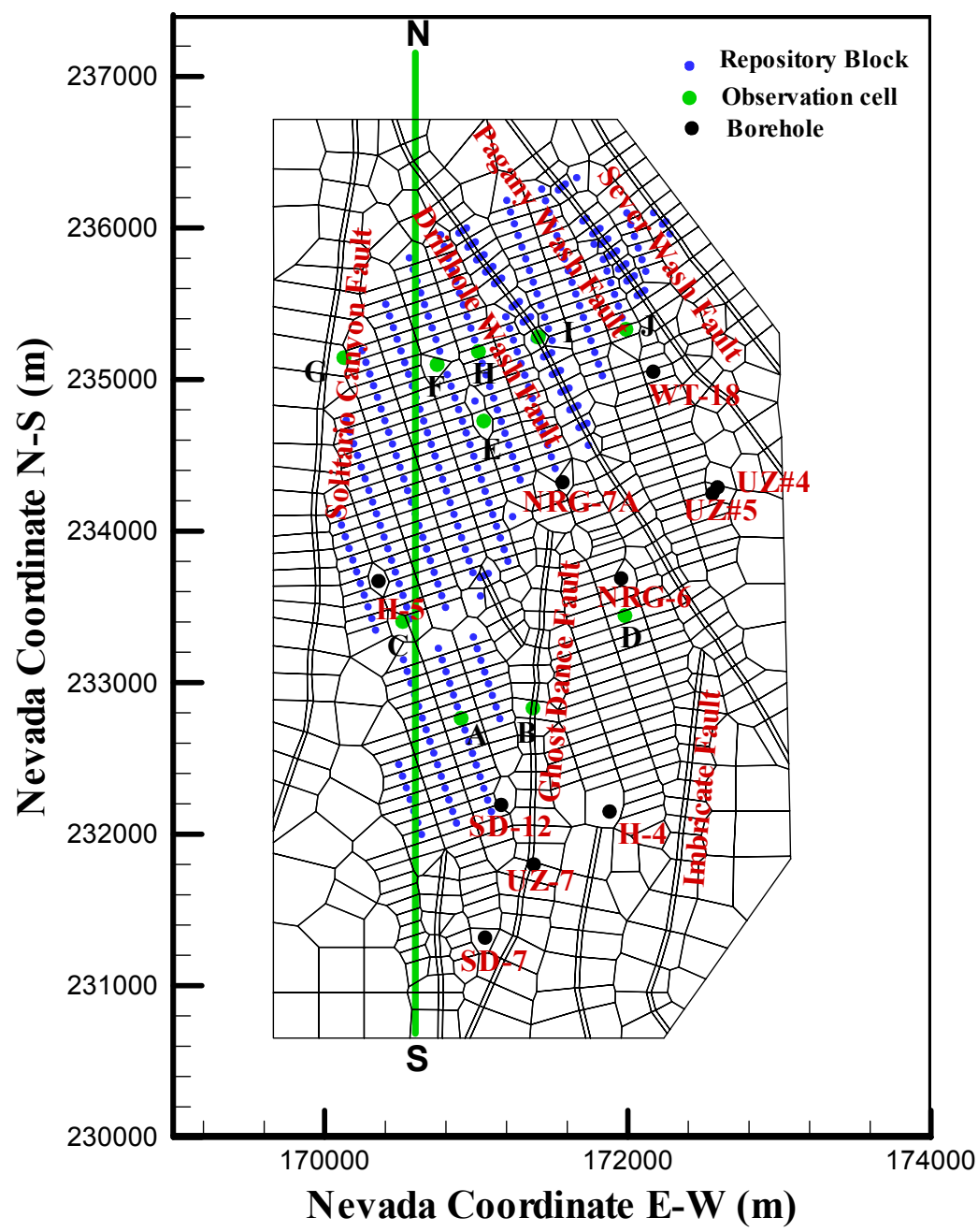

DTN: LB0303THERMESH.001 [165168]

NOTE: North-South green line is trace of 2-D model grid shown in Figure 6.1-2. The THC Model uses a subset of the green line; see Figure 6.4-2.

Figure 6.1-1. Plan View of the 3-D TH Model Grid, Showing the Model Domain, Faults Incorporated, Several Borehole Locations, and TH Model Boundaries 
In addition to the 3-D model grid, the TH Model also uses a north-south 2-D cross-sectional grid, with the plan location (N-S) shown in Figure 6.1-1. The 2-D TH model grid is shown in Figure 6.1-2. The 2-D cross-sectional grid is a refined north-south grid (Figure 6.1-1) and is specifically developed for detailed study of TH processes. The 2-D grid has a total of 306 grid columns and an average of 64 grid layers, resulting in 39,000 gridblocks and 100,000 connections in a dualpermeability grid. The 2-D grid has a more refined spatial resolution (Figure 6.1-2) than the 3-D TH model grid, with a uniform horizontal grid spacing of $21.297 \mathrm{~m}(=85.188 / 4$; here, $85.188 \mathrm{~m}$ is the drift spacing along the N-S direction of Figure 6.1-1).

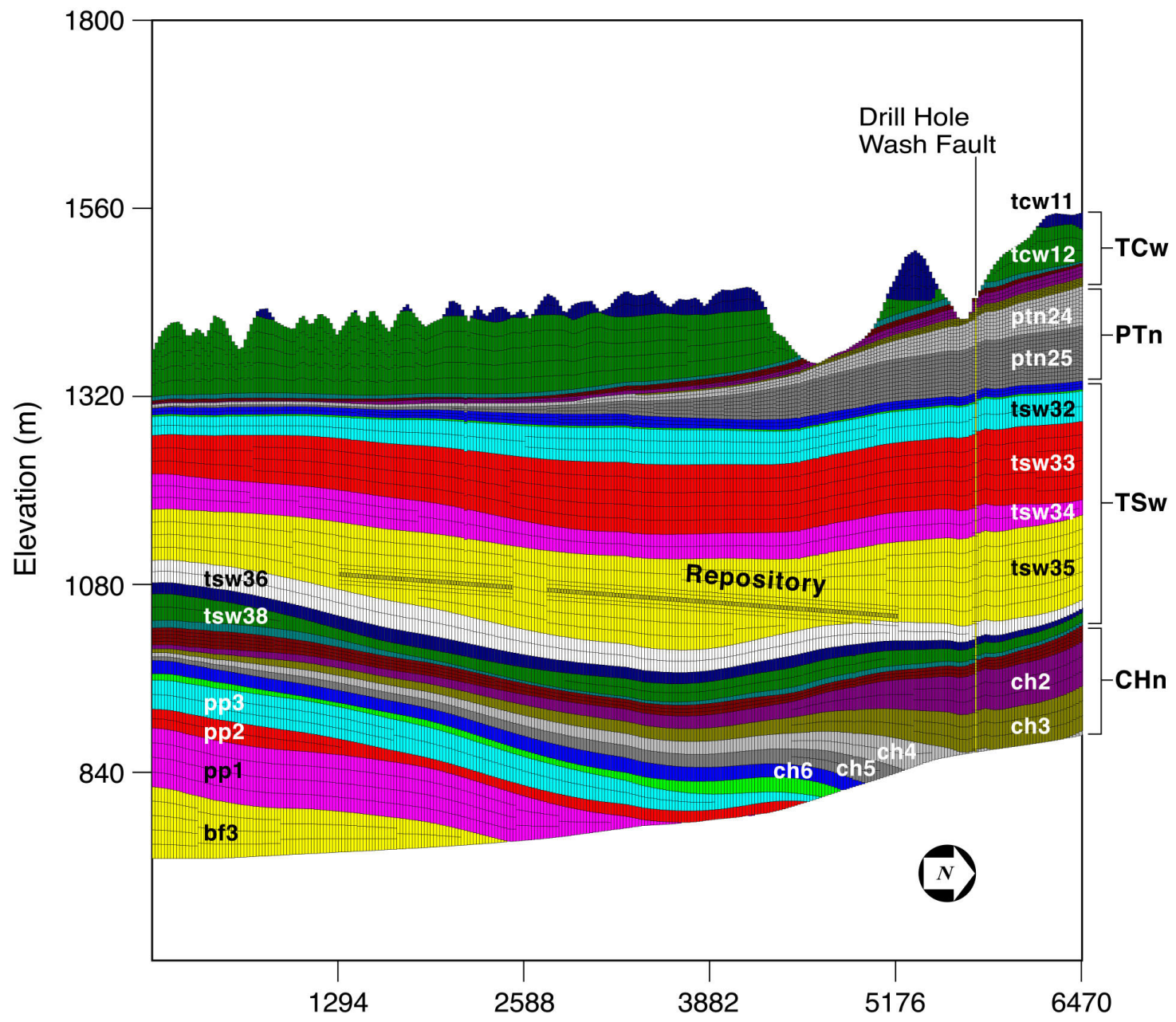

Horizontal Distance (m) from point(170600,230673)

DTN: LB0310MTSCLTH2.001

Figure 6.1-2. 2-D N-S Cross Sectional Model domain and Grid, showing Lateral and Vertical Discretization, Hydrogeological Layers, Repository Layout, and a Fault

\subsubsection{Numerical Codes and TH Modeling Approach}

The model simulation results presented in this Model Report were carried out using TOUGH2 V1.6 (LBNL 2003 [161491]) for TH simulations. To model TH processes in the UZ system at Yucca Mountain, mathematical models or governing equations are needed to describe the 
physical processes quantitatively. The physical processes associated with flow and transport in porous media are governed by the fundamental conservation laws (i.e., conservation of mass, momentum, and energy), which govern the behavior of fluid flow, chemical migration, and heat transfer through fractured porous media. The macroscopic continuum approach has been most commonly used in practical applications (Bear 1972 [156269]). In this approach, the physical laws governing flow of several fluids, transport of multicomponents, and heat transfer in porous media are represented mathematically on the macroscopic level by a set of partial differential or integral equations. Fluid and heat flow and chemical-transport processes in fracture and matrix systems in the UZ are described using a macroscopic, dual-permeability continuum approach.

In addition to the conservation or continuity equations of mass and thermal energy in fracture and matrix systems, specific relationships or mechanisms are needed that describe how fluid flow, solute/tracer transport, and heat transfer occur in porous and fractured media. The following specific constitutive laws act as such mechanisms by governing local fluid flow, component transport, and heat-transfer processes in porous and fractured media:

- Darcy's law is applied to describe the two-phase flow of gas and water in both fractures and matrix (Pruess et al. 1999 [160778], pp. 144-161). In particular, the two-phase equation of the TOUGH2 EOS9 module is used in describing nonisothermal liquid and gas flow through the UZ at Yucca Mountain. Relative permeability and capillary functions of both fractures and matrix follow the model of van Genuchten (1980 [100610]).

- The generalized Fourier's law (Wu and Pruess 2000 [153972], pp. 704-707), including heat conduction and advection transfer in a multiphase porous and fractured system, is used to evaluate heat transfer processes. This includes transfer of latent heat by vapor.

In both research and application, the multiphase extension of Darcy's law (Pruess et al. 1999 [160778], pp. 144-161), and the generalized Fourier's law (Wu and Pruess 2000 [153972], pp. 704-707) have been used as fundamental laws that govern multiphase fluid and heat flow processes within porous-medium and fractured rocks. These fundamental laws or correlations, based on theory, experiment, and field studies, reflect our current understanding of porousmedium physics.

In the mountain-scale TH model, perched-water effects are ignored. The occurrence of perched water and its effects on the UZ flow fields are discussed in a separate Model Report (BSC 2003 [163045]). Perched-water conditions are confined mainly to the lower units of the Topopah Spring welded (TSw) hydrogeological unit and on top of the Calico Hills nonwelded unit (CHn). Over the repository domain, perched water locations are typically 100-150 m below the repository horizon (Wu et al. 1999 [117167]). Because the dominant heat-transfer mechanism at these locations is heat conduction and boiling conditions are not attained, the effect of repository thermal load on perched-water bodies is ignored.

Another key issue for simulating fluid and heat flow in the fractured-porous rock of Yucca Mountain is how to handle fracture and matrix interaction under multiphase and nonisothermal conditions. The available methods for treating fluid flow in fractures and the rock matrix using a numerical approach include: (1) an explicit discrete-fracture and matrix representation; (2) the 
dual-continuum method, including double- and multiporosity, dual-permeability, or the more general "multiple interacting continua" (MINC) method (Pruess and Narasimhan 1985 [101707]); and (3) the generalized effective continuum method (ECM). For the work documented in this Model Report, the dual-permeability conceptual model is applied to evaluate fluid and heat flow in the fracture-matrix system of the Yucca Mountain UZ.

The dual-continuum conceptualization provides an appropriate representation of the UZ processes within the UZ at Yucca Mountain (Doughty 1999 [135997]) and is much less demanding in computational effort or in data requirements than the discrete-fracture-modeling approach. Therefore, the dual-continuum method has become the main approach used in the modeling studies of the Yucca Mountain Project (Wu et al. 1999 [117161]; 2002 [160195]). In this report, the dual-permeability formulation is considered to be appropriate for simulating flow and transport through fractured tuffs of the Yucca Mountain UZ. As applied in this Model Report the traditional dual-permeability concept is first modified using an active fracture model (Liu et al. 1998 [105729]) to represent fingering effects of liquid flow through fractures. The active fracture model as validated in the Model Report Calibrated Properties Model (BSC 2003 [160240]) provides calibrated properties. In addition, the dual-permeability model is further modified by adding additional global fracture-matrix connections at the interfaces of TCw-PTn, PTn-TSw, and vitric-nonvitric units to better simulate fracture-matrix flow at these transitions.

Use of the discrete fracture or weeps-type model as an alternative is limited by (1) large uncertainties in the distribution of fractures within the mountain and (2) an extensive computational burden owing to the large amount of data required to describe the fracture system. On the other hand, the ECM approach, although computationally the most efficient, may not capture important nonequilibrium fracture-matrix $\mathrm{TH}$ processes under thermal loading conditions.

\subsubsection{TH Model Boundary and Initial Conditions}

In TOUGH2, boundary conditions are generally specified by means of appropriately chosen volume elements and flow connections. Boundary conditions can be of two basic types. Dirichlet conditions prescribe thermodynamic conditions, such as pressure or temperature on the boundary, while Neumann conditions prescribe fluxes of mass or heat crossing boundary surfaces (Pruess 1991 [100413], pp. 33-37). A special case of the Neumann boundary conditions is the no-flux boundary. In the Integral Finite Difference Method (IFDM) used in TOUGH2, this case is handled by not specifying any flow conditions across the boundary. Dirichlet-type boundary conditions, such as constant pressures or temperatures, can be specified by introducing appropriate boundary elements and connections. This approach has been implemented as follows:

1. Thermal conditions at the top and bottom boundaries are represented using temperatures that are fixed in time, but variable in space. In addition, top and bottom model boundaries are also subject to constant pressure and saturation conditions.

The use of constant temperature, pressure, and saturation boundaries has been discussed extensively (e.g., Wu et al. 1999 [117161]). The fixed temperature condition at the top and bottom boundaries is a simplified representation of the heat exchange on 
the boundary "surfaces" between the model domain and the atmosphere or the water table. The top boundary of the model, made up of the land surface or tuff-alluvial contact, is controlled mainly by the atmosphere, whereas temperatures at the water table are determined by the ambient geothermal gradients and infiltration flux. The two boundaries are both far away from the repository horizon; therefore, the effects of specified temperatures on thermal behavior at or near the repository are expected to be small. As a result, constant temperatures, estimated from field-measured values along these boundaries, will provide a good approximation of the TH system to be simulated.

2. An equivalent heat load is evenly distributed within emplacement drifts and released from time zero after waste emplacement, according to the predicted heat load history (thermal decay curve).

Actual thermal load at the repository will be discretely distributed in both space and time. The approach of evenly distributing the thermal source over all the drifts will have little effect on far-field $\mathrm{TH}$ processes on the mountain-scale, because detailed thermal-load distributions affect only drift-scale processes and are limited to the first few years of thermal load.

3. Waste emplacement drifts are assigned matrix permeabilities, zero capillary pressures, and other properties of the hydrogeological unit in which they are located.

Excavation of the drifts will substantially affect only the near-field environment. Mountain-scale TH models are designed to evaluate the TH processes primarily on the large scale of the UZ system, as well as averaged behavior near the drifts over tens of thousands of years. Over this period, the near-drift processes are expected to have little impact on mountain-scale TH processes.

4. Ventilation removes thermal energy only. The amount of water vapor and air removed by ventilation is ignored.

When ventilation is used to remove most of the heat generated by the emplaced waste, ventilation is treated as removing the heat only; the effects of ventilation and associated air circulation on water vapor and air at the repository are ignored. Although ventilation may remove some water vapor from the drifts and surrounding rock, the amount removed is negligible because for most of the 50 -year ventilated period, the ventilation is carried out by forced air or gas flow along completely dry drifts.

The TH model boundary and initial conditions are specified in the same way as in the ambient TH model: UZ Flow Models and Submodels (BSC 2003 [163045]). In particular, the ambient TH model results (DTN: LB0303THERMSIM.001 [165167]) are directly used for specification of the boundary and initial conditions of the 3-D TH model. In general, the ground surface of the mountain (or the tuff-alluvium contact in areas of significant alluvial cover) is taken as the top model boundary; the water table is treated as the bottom model boundary. Both the top and bottom boundaries of the model are treated as Dirichlet-type conditions with specified constant but spatially varying temperature and gas pressure. A constant liquid saturation value of 0.999 was set for the bottom boundary. Surface infiltration, as discussed below in Section 6.1.4, is 
applied using a source term in the fracture gridblocks within the second grid layer from the top. This method was adopted because the first layer is treated as a Dirichlet-type boundary, with constant pressure, saturation, and temperature, to represent average atmospheric conditions at the mountain.

The water table is used as the bottom model boundary, a surface where the water pressure is a fixed, single value. Within the numerical models for gas and heat flow simulations, the bottom model boundary representing the water table has a fixed gas pressure, equal to the atmospheric pressure at the elevation. All lateral boundaries, as shown in Figure 6.1-1, are treated as no-flow (closed) boundaries, which allow flow only along the vertical plane. This treatment is reasonable for the eastern boundary, which is along or near the Bow Ridge Fault, because high vertical permeability and lower capillary forces are expected within the faults (see fault properties estimated in BSC (2003 [160240])). The western and northern lateral boundaries have little effect on moisture flow within and near the repository areas, because these boundaries are separated from the repository by faults. The southern lateral boundary also has little influence, because it is located far from the repository (Figure 6.1-1).

The spatially distributed values of temperatures along the top and bottom boundaries are based on field observation. This treatment is corroborated by data reported by Sass et al. (1988 [100644]) and the calibrated temperature distribution along the water table (BSC 2003 [163045]).

Pressure conditions at both top and bottom boundaries of the model are based on observed gaspressure values. The water table, which is the bottom boundary of the mountain-scale TH model, is shown to be a relatively flat, stable surface in most of the model domain, increasing its elevation only in the north (BSC 2003 [160109], Section 6.4). For most areas in the middle and southern part of the model domain, the flat portion of the water table is about $730 \mathrm{~m}$ above sea level (masl) (BSC 2003 [160109]). The rise in the water table elevation near the northern end of the model domain is explicitly included by raising the bottom boundary accordingly at that location. The elevated water table at the northern end of the model domain is unlikely to have significant impact on temperatures near the repository, because the repository is still far from the water table. The elevation in water table may have some impact, however, on regional groundwater flow. Analysis of saturated zone groundwater flow is beyond the scope of this Model Report. The gas pressures are estimated using a pressure value of $92 \mathrm{kPa}$ at an elevation of $730 \mathrm{~m}$. Surface gas pressures are determined by running the TOUGH2 code, EOS3 module to steady-state under given temperature, bottom pressure, and surface-infiltration conditions. This is necessary to generate a steady-state, equilibrated gas-pressure boundary to avoid artificial airflow or circulation, which may occur if nonequilibrated pressures are imposed on the groundsurface boundaries.

To account for variations in atmospheric temperature with surface elevations in the mountain, measured mean surface temperatures and a linear equation that correlates surface temperature with elevation are used. The annual-average temperature was measured for near-surface sensors in boreholes NRG-6 and NRG-7a (DTNs: GS960308312232.001 [105573]; GS951108312232.008 [106756]; and GS950208312232.003 [105572]), with several years of continuous temperature monitoring data. The surface temperatures $T_{\mathrm{s}}$ at any elevation $\mathrm{Z}$ are then 
computed using the routine toptemp_v0.f V1.0 (LBNL 2000 [147030]) and are treated as constants according to the following equation (Wu et al. 1999 [117161], Eq. 4):

$$
\mathrm{T}_{\mathrm{s}}=\mathrm{T}_{\mathrm{ref}}-\lambda\left[\mathrm{Z}-\mathrm{Z}_{\mathrm{ref}}\right]
$$

where $T_{\text {ref }}$ is mean surface temperature at reference elevation $Z_{\text {ref }}$ and $\lambda$ is the dry adiabatic atmospheric lapse rate in ${ }^{\circ} \mathrm{C} / \mathrm{m}$. This lapse is $0.01^{\circ} \mathrm{C} / \mathrm{m}$ (Driscoll 1986 [116801], p. 50). In this formulation, the surface reference temperature used and the mean lapse rate are estimated based on the field measurements in the Model Report, UZ Flow Models and Submodels (BSC 2003 [163045]).

The temperature distributions at the bottom boundary of the 3-D TH Model were taken from the ambient TH model (BSC 2003 [163045]). Note that the ambient TH model also provides a database for estimate of water table temperatures with DTN: LB0303THERMSIM.001 [165167]. This database is used to obtain bottom-temperature boundary conditions for the 2-D TH model. The software routine GET_TEMP_V0.F V1.0 (LBNL 2000 [147027]) was first used to estimate temperatures for a flat surface at an elevation of $730 \mathrm{~m}$. Because the water table is no longer flat with the current UZ and TH models, the actual estimates of the water table or bottom-modelboundary temperatures were interpolated between the values at $730 \mathrm{~m}$ elevation and the model surface boundary. Note that the bottom temperature boundaries of both 2-D and 3-D TH models are not extended $1,000 \mathrm{~m}$ below the water table, as done for the previous mountain-scale $\mathrm{TH}$ models (CRWMS M\&O 2000 [144454]). This approximation is justified as follows: during the entire thermal-loading period, the changes in water table temperatures are not expected to produce any significant impact on UZ percolation and $\mathrm{TH}$ behavior near the repository. However, neglecting changes in temperature at the water table may have some impact on temperature evolution in stratigraphic units near the water table after 1,000 years or later (CRWMS M\&O 2000 [144454]). It is also to be noted that temperature rise at water table in previous mountain-scale TH model (CRWMS M\&O 2000 [144454]) may have been overestimated because that model did not account for convective cooling by regional groundwater flow. This cooling effect may indeed give rise to constant water temperature at the water table.

\subsubsection{Infiltration Scenarios}

Water entering the UZ as net infiltration from precipitation at the land surface is the major control on overall hydrological and thermal-hydrological conditions within the UZ at Yucca Mountain. This is because net infiltration is the ultimate source of percolation through the UZ. Water percolating downward through the UZ will be the principal means by which radionuclides may be transported from the repository to the water table. Such percolation could be also have a direct impact on the evolution of $\mathrm{TH}$ processes near the waste emplacement drifts.

The Mountain-Scale TH Model uses net infiltration rates as surface-water-recharge boundary conditions. The net infiltration rates consist of present-day and future scenarios, determined by studies of modern and future climates. Three mean net infiltration maps (DTN: GS000308311221.005 [147613]) implemented with the TH Model are documented in the following reports: Future Climate Analysis (USGS 2001 [158378]) and Simulation of Net 
Infiltration for Modern and Potential Future Climates (USGS 2001 [160355]) for climate and infiltration models. They include present-day (modern), monsoon, and glacial transition mean infiltration rates. The actual schedule and the averages of the three infiltration rates in the $\mathrm{TH}$ models are shown in Table 6.1-2, indicating average values over the model domain for three time periods. Table 6.1-2 shows that the Mountain-Scale TH Model implements three infiltration rates over three time periods for the thermal-loading investigation. The future climates are considered to act sequentially over the modeled period: present (0-600 years), monsoon (600-2,000 years), and then glacial transition (2,000 years and beyond).

Table 6.1-2. Averaged Infiltration Rates (mm/year) and Time Period over the UZ Model Domain

\begin{tabular}{|c|c|c|}
\hline Scenario & Time Period & Mean Infiltration $(\mathbf{m m} / \mathbf{y r})$ \\
\hline Present-Day/Modern & $0-600$ Years & 3.58 \\
\hline Monsoon & $600-2,000$ Years & 10.43 \\
\hline Glacial Transition & 2,000 and beyond & 16.09 \\
\hline
\end{tabular}

Values averaged from DTN: GS000308311221.005 [147613]

As shown in Table 6.1-2, with the UZ Model grid the average rate over the model domain for present-day mean infiltration is $3.58 \mathrm{~mm} / \mathrm{yr}$ (Wang 2003 [165927], SN-LBNL-SCI-199-V1, p. 107), which is considered as a base-case infiltration scenario. The two future climatic scenarios, the monsoon and glacial transition periods, are used to account for projected climate-induced changes in precipitation and net infiltration. The average values in Table 6.1-2 are estimated using the 3-D TH model grid, shown in Figure 6.1-1 for infiltration maps (DTN: GS000308311221.005 [147613]), and the software routine infil2grid V1.7 (LBNL 2002 [154793]). Net infiltration is handled in a consistent manner in this report, i.e., mapping the USGS infiltration maps to model grids.

A plan view of the spatial distribution for the three mean infiltration maps, as interpolated onto the 3-D UZ TH model grid, is shown in Figures 6.1-3, 6.1-4 and 6.1-5 respectively, for the present-day (0-600 years), monsoon (600-2,000 years), and glacial transition (2,000 and beyond) mean infiltration scenarios. The figures show similar patterns of flux distributions for the three infiltration rates, with higher infiltration rates in the northern part of the model domain and along the mountain ridge east of the Solitario Canyon fault. For the 2-D TH model, infiltration at the top boundary was extracted from the infiltration map discussed above. The average (over the 2-D TH Model grid) infiltration during present-day, monsoon, and glacial transition climatic periods are $5.8043 \mathrm{~mm} /$ year, $16.9535 \mathrm{~mm} / \mathrm{year}$, and $28.8198 \mathrm{~mm} / \mathrm{year}$, respectively. 


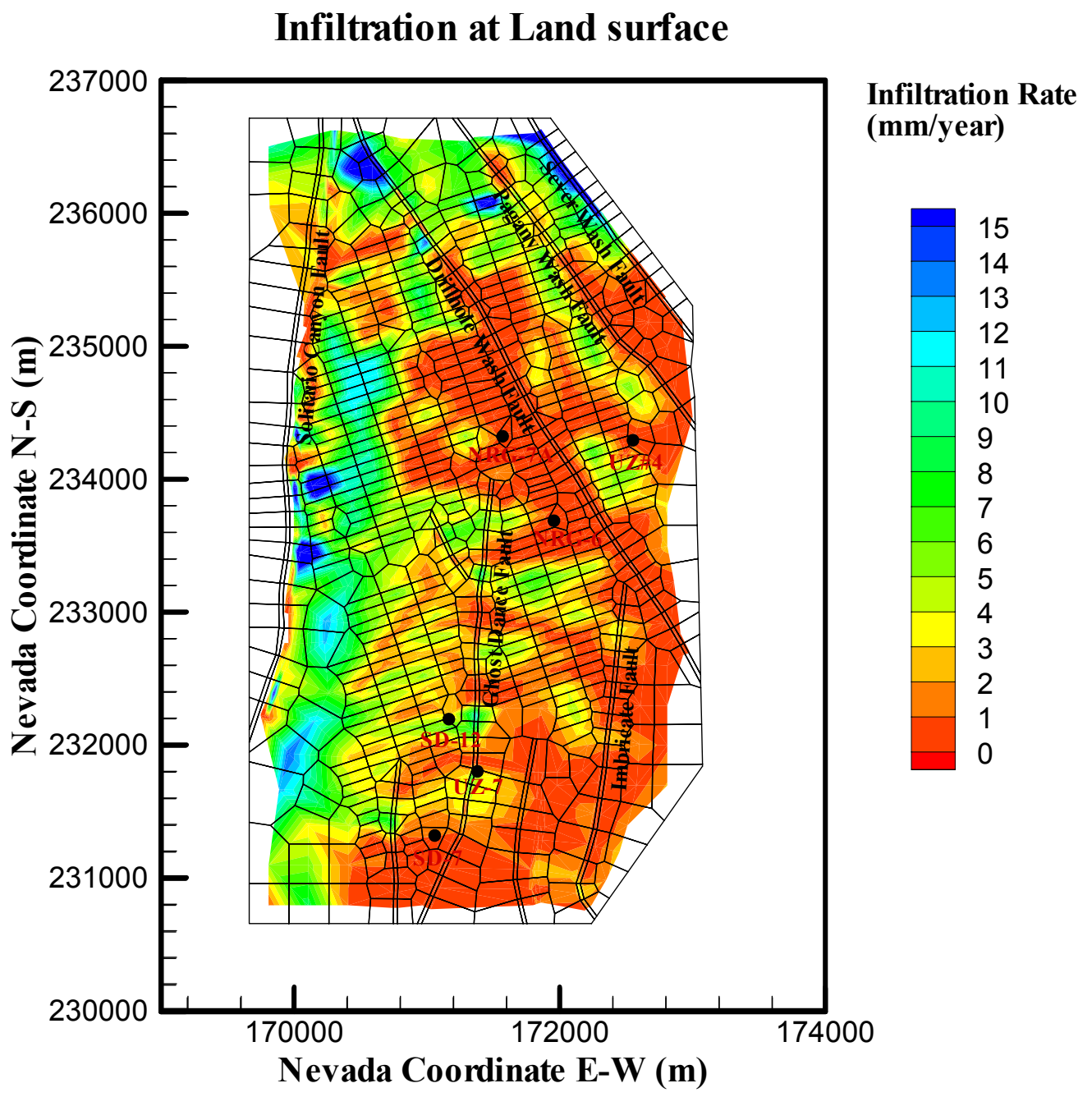

DTN: GS000308311221.005 [147613]

Figure 6.1-3. Plan View of Net Infiltration Distributed over the 3-D TH Model Grid for the Present-Day Mean Infiltration Scenario for the First 600 Years of Thermal Load 


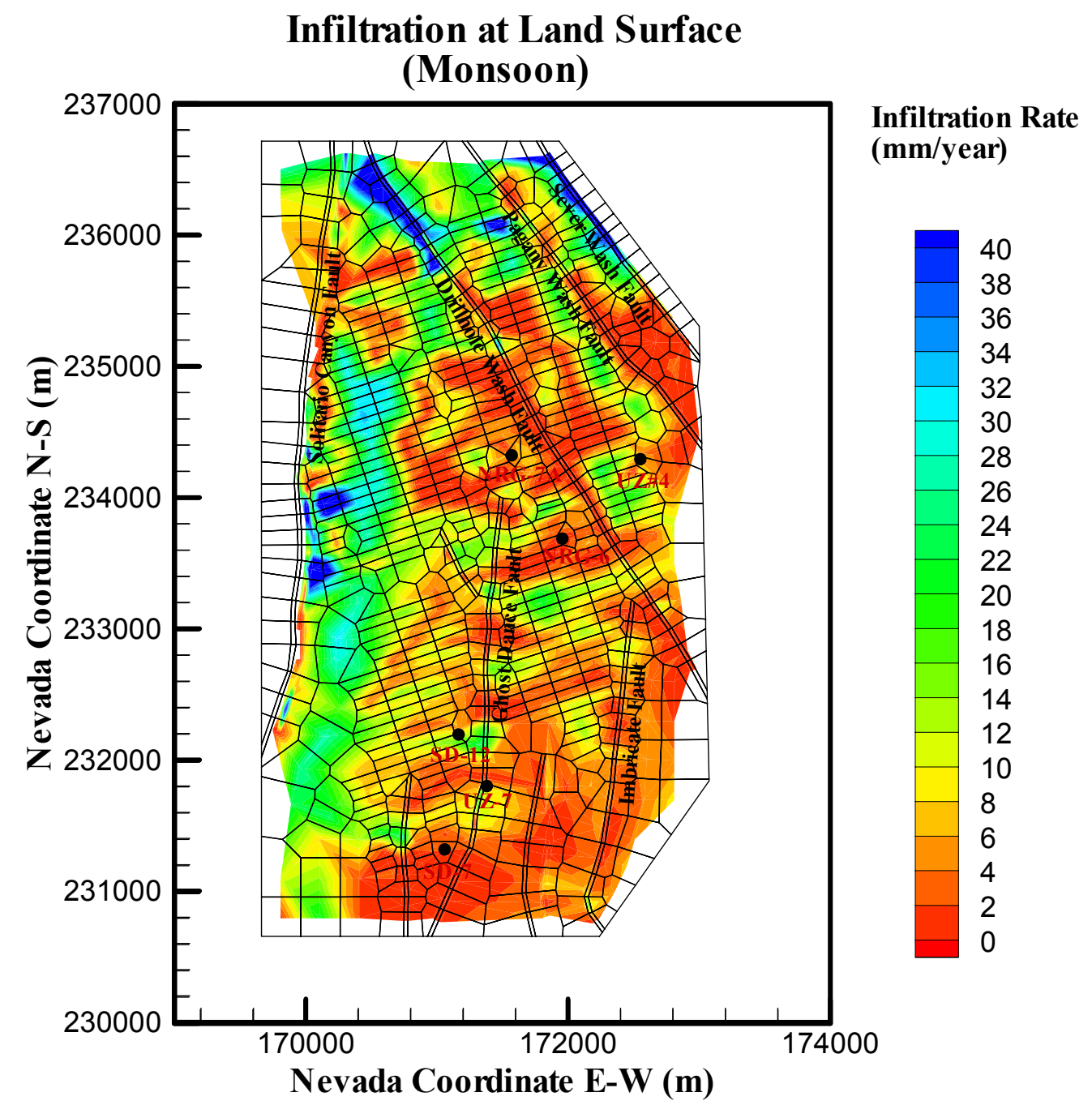

DTN: GS000308311221.005 [147613]

Figure 6.1-4. Plan View of Net Infiltration Distributed over the 3-D TH Model Grid for the Monsoon Mean Infiltration Scenario for the 600-2,000 Years of Thermal Load 


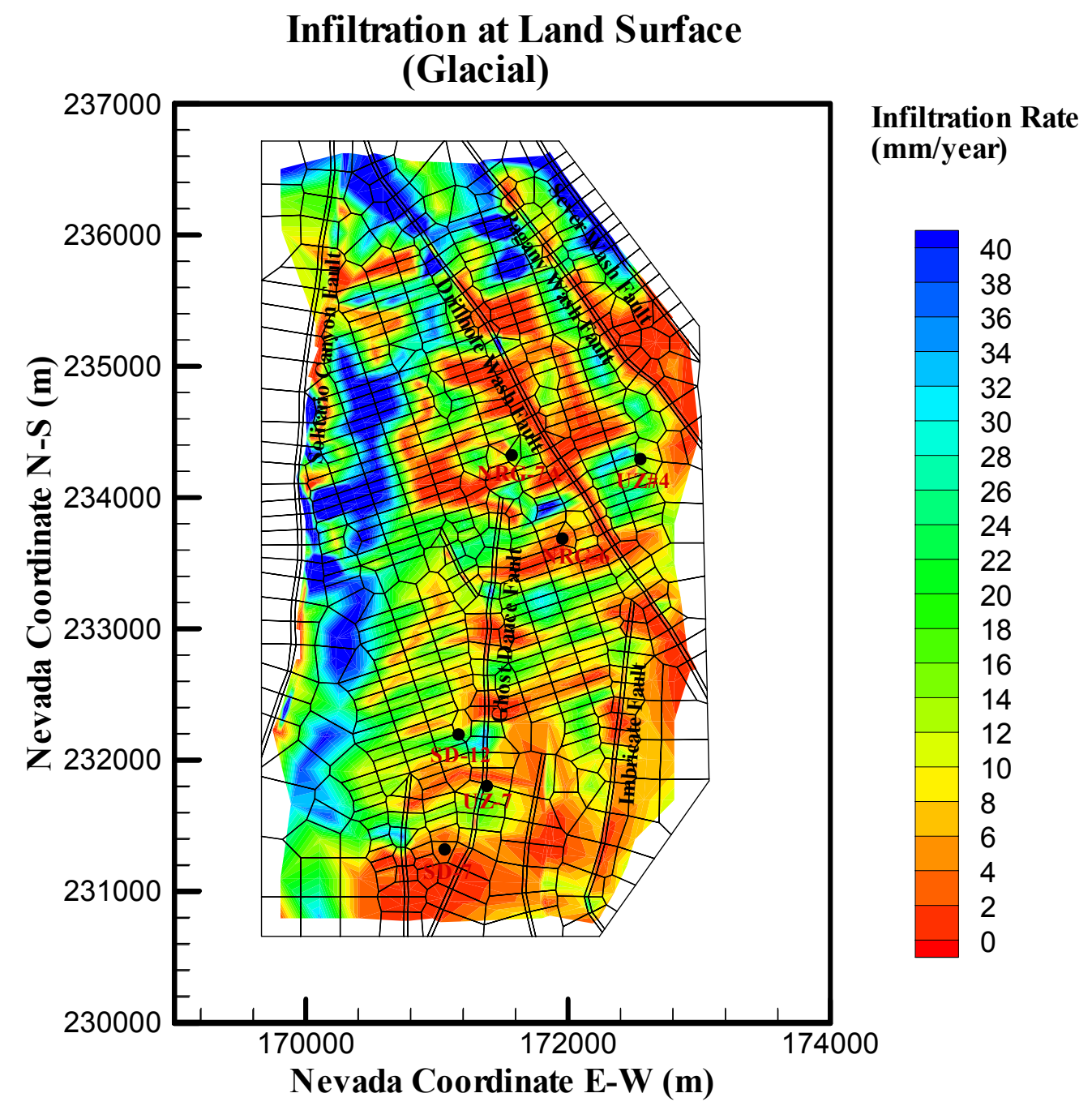

DTN: GS000308311221.005 [147613]

Figure 6.1-5. Plan View of Net Infiltration Distributed over the 3-D TH Model Grid for the Glacial Transition Mean Infiltration Scenario for the 2,000 Years and Beyond of Thermal Load 


\subsubsection{Repository Thermal Load}

The reference-mode heat load used in the mountain-scale TH models in this Model Report is $1.45 \mathrm{~kW} / \mathrm{m}$, measured along the axis of an emplacement drift (BSC 2003 [164069]). The value of $1.45 \mathrm{~kW} / \mathrm{m}$ refers to the initial thermal line load that decreases with time as a result of radioactive decay. The time-varying heat-load values are given in 800-IED-WISO-00204-00000A, RDP/PA Typical Waste Package Components Assembly [4] (BSC 2003 [164136]), which is the controlled source of data. Since the controlled source was not available at the time of the simulations, the actual heat-load decay data used in the TH modeling was obtained from 800IED-EBS0-00403-000-00B, Repository/PA IED Subsurface Facilities (BSC 2003 [161731]). There appears to be no difference in the thermal decay data between the controlled source and the actual source. During the preclosure period, ventilation in the drifts will remove a significant amount of heat. Heat removal by ventilation has been calculated (BSC 2003 [166343], Figures 6-7 and 6-8) as a function of time and drift length, and summarized (BSC 2003 [166343], Table 6-7) for $600 \mathrm{~m}$ and $800 \mathrm{~m}$ long drifts, integrated over 50 years of ventilation. Values shown there range from $85.8 \%$ to $88.3 \%$ heat removal (less efficient for longer drifts). The value $86.3 \%$, originally reported in BSC 2002 ([160975], Table 6-6), falls within this range toward the lower end (i.e., a more conservative estimate of heat-removal efficiency). Accordingly, this value has been used to represent the fraction of the time-varying line load that is effectively removed from the repository. In other words, only $13.7 \%$ of the given line load curve is used for the first 50 years after emplacement. After 50 years, the full line load is implemented. This will be referred to as the base-case thermal loading.

The thermal load and the resulting temperature field may have a large influence on many THrelated processes. These processes can directly impact the performance of the repository. For example, emplacement of heat-generating high-level waste (HLW) will elevate the temperature and cause the redistribution of in situ moisture at the repository, and in the unsaturated zone. As heat is released from the waste unit and transferred to the surrounding host rock, the temperature near the waste packages will approach or exceed the boiling point of water (approximately $97^{\circ} \mathrm{C}$ at ambient pressure). Boiling of formation water will then take place, with the associated increase in vapor pressure and overall gas-phase pressure. This will result in forced convection of the gas phase, with a redistribution of water accompanied by large latent heat effects. With favorable conditions, this may result in "heat-pipe" conditions, the steady counter-current flow of liquid towards the repository and vapor-phase away from the repository. The liquid-phase and gas-phase flow will perturb the in situ fluid saturation in both fractures and matrix, and may result in a large two-phase zone above the repository, as well as an increase in the potential for changes in the flow properties within the condensation zones. The impact of heat on TH processes will depend on the thermal load and its distribution at the repository.

Each repository drift is represented by a single element and is modeled with the properties of the UZ Model layer in which the element is located. The distribution of the heat source at the repository horizon depends on the discrete representation of the drifts within the repository nodes and the grid spacing.

Because the grid spacing within the repository is equal to the drift spacing, a laterally continuous (smeared heat source) is modeled across the repository. This approach cannot provide detailed 
resolution of $\mathrm{TH}$ processes in terms of temperature, saturation, and flux for the intervening space between the drifts. However, this coarse-grid model allows for simple and fast estimation of the long-term, average response to thermal load. Except for the early time, heat distribution is sufficiently diffused at the repository such that a smeared heat source model presents a good approximation of the heat-source distribution. The major advantage of this modeling approach is that it allows for direct comparison of fluid, temperature, and flux distribution between the 3-D ambient flow field models (BSC 2003 [163045]) and the TH model over the repository domain. The impact of TH on flow and transport can then be directly estimated using flow fields extracted from the TH model.

Although the repository thermal load is computed based on the total acreage of the repository, the heat-generating radioactive waste will be stored in the drifts within the repository at a discrete spacing. The current repository design has drifts of $5.5 \mathrm{~m}$ diameter, spaced $81 \mathrm{~m}$ apart in a WNW-ESE direction (Figure 6.1-1). Because of the large spacing between the drifts and the disparity in infiltration across the model, a potential for large differences or gradients in temperature, saturation, and flux exists between the heated drifts. The discrete (drift-by-drift) model attempts to provide a refined-grid model that accounts for such phenomena to investigate their importance and effect on mountain-scale TH processes.

To address some of these issues, a 2-D grid was designed with the repository nodes subdivided to explicitly include an element that approximates the dimensions of the drift in both 2-D and 3D TH models. To model a more physically accurate heat distribution at the repository horizon, a $5.5 \mathrm{~m}$ drift element is inserted for every $81 \mathrm{~m}$ of lateral spacing along the repository in the 3-D grid. For the 2-D grid, a $5.0 \mathrm{~m}$ drift element is inserted for every repository gridblock along the $\mathrm{N}-\mathrm{S}$ cross-sectional grid with a spacing of $85.188 / 4=21.297 \mathrm{~m}$. This is equivalent to a $81 \mathrm{~m}$ lateral spacing along the direction perpendicular to repository drifts (Figure 6.1-1). This is because the repository drifts are designed not exactly in the east-west direction, i.e., they are not perpendicular to the N-S cross section. The thermal load for the 3-D TH Model is computed based on the initial thermal-line-load value of $1.45 \mathrm{~kW} / \mathrm{m}$ and the length of the inserted drift cylinders, and applied to the discrete drift elements.

A $5.0 \times 5.0 \mathrm{~m}$ drift element is used (close to the $5.5 \mathrm{~m}$ drift diameter to represent a drift tunnel) in the 2-D grid, because $5.0 \mathrm{~m}$ layers are used in the numerical grid. In the 2-D grid, this drift element is bordered laterally by two equal subelements (grid spacing of $(21.297-5) / 2=8.149 \mathrm{~m}$ ) of the original repository element. Above and below the repository, the three elements in each repository element are connected to the overlying and underlying elements within the same column and laterally between themselves and the laterally adjacent elements. This locally refined grid of the 2-D TH Model allows for flow between drifts. However, since the refinement is limited to the repository level, the applied surface infiltration is based on the original grid with spacing of 21.297. In this refined grid, each drift element is laterally separated by five elements between the drifts. The N-S 2-D model represents a section $1 \mathrm{~m}$ wide, but because the drifts are not E-W, each element contains more than 1 meter of drift length. The thermal load is computed based on the initial thermal line load value of $1.45 \mathrm{~kW} / \mathrm{m}$, divided by the cosine of the angle between the drift orientation and true E-W, and applied to the discrete drift elements. 


\subsubsection{Rock and Thermal Properties}

The key input rock and fluid-flow parameters and thermal properties in this AMR are summarized in Section 4. These rock and fluid-flow parameters were provided in the AMR: $U Z$ Flow Models and Submodels (BSC 2003 [163045]) (DTN: LB03013DSSCP3I.001 [162379]). Thermal properties include grain density, wet and dry thermal conductivity, grain specific heat for each model grid layer (DTN: LB0210THRMLPRP.001 [160799]).

The rock and thermal parameter specification in the TH model is, in general, layer-wise uniform layer by layer, following the UZ Flow Model (BSC 2003 [163045]). However, certain portions of grid layers representing the $\mathrm{CHn}$ unit are partly altered from vitric to zeolitic. In these altered layers, different rock properties are specified for vitric or zeolitic zones. All the geological units, including those representing fault zones, are treated as fracture-matrix systems using a dualpermeability approach, except the $\mathrm{CHn}$ vitric zones, which are treated as single-porosity matrix. To model transition from single continuum to fracture-matrix dual continuum, global fracturematrix connections are added across interfaces between TCw-PTn, PTn-TSw, and vitricnonvitric $\mathrm{CHn}$ units. The van Genuchten relative permeability and capillary pressure functions (van Genuchten 1980 [100610]) are used to describe flow in both fractures and matrix. This is primarily because the van Genuchten functions have been traditionally used for analyzing unsaturated flow through Yucca Mountain tuffs, from core sample analysis to model parameter estimation. Note that the van Genuchten relations were developed for porous soils rather than fracture networks. Therefore, it is justified to use them for matrix flow. For describing fracture flow, the van Genuchten model may or may not be appropriate in general. However, a recent study (Liu and Bodvarsson 2001 [160110]) found that the van Genuchten model is approximately valid under lower fracture saturation conditions in the UZ of Yucca Mountain.

THC and THM effects are ignored in the TH model. These effects are modeled in Sections 6.4 and 6.5. Flow and transport properties can be affected by changes in temperature through THM effects. Similarly, dissolution, precipitation, adsorption, and other geochemical reactions resulting from THC coupling can alter flow and transport properties. Many of the temperaturedependent properties, such as fluid density, viscosity, and specific enthalpy, are incorporated in the formulation of the TOUGH2 V1.6 (LBNL 2003 [161491]) code. However, the effects of THM and THC on rock properties (such as permeability, relative permeability, and the relationship between capillary pressure and liquid saturation) have not been considered in the TH models. Specifically, for the TH model, the following effects are ignored:

1. The effects of THM and THC on rock properties as a result of thermal load are ignored.

THC and THM effects may have a significant impact on TH processes only at or near drifts during the first few years of the thermal-loading period. On the mountain-scale domain, in long-term analyses, the effects of THM and THC on flow and transport properties are expected to be small.

2. Hysteresis effects are negligible.

In addition to THM and THC effects, the thermal load will create significant dryout and rewetting phenomena in the nearby ( $\sim 10$ meters) regions of tuffs. Hysteresis effects 
will accompany these drying (drainage) and rewetting (imbibition) processes. This leads to different curves of relative permeability and capillary pressures for describing drainage and imbibing processes, respectively. In this work, hysteresis effects are ignored because they are small compared to the uncertainty inherent to the development of the capillary pressure and relative permeability relationships.

The ignoring of THM/THC coupling and hysteresis effects results partially from the limitations of available field data and constitutive relations to describe these phenomena. However, these effects are considered negligible when compared with the uncertainty of the rock properties existing in the collected data. The results of THC and THM analyses presented in Sections 6.4 and 6.5, and summarized in Sections 8.2 and 8.3, support this approach.

\subsection{2-D MOUNTAIN-SCALE TH MODEL RESULTS AND ANALYSES}

TH processes occur at different spatial and temporal scales. During the early part of the heating period, important TH processes occur near the emplacement drifts. These are the drift-scale processes. At this scale, variability in heat output from individual waste packages and different times of waste emplacement may give rise to variability in the extent of dry-out, rewetting, and water flux along drifts and at different drift locations. Also at this scale, the availability of additional water in the condensation zone may lead to an augmented fracture liquid flux much greater than the ambient fracture flux. This increased fracture liquid flux may result in thermal seepage into the emplacement drifts. The issue of thermal seepage has been investigated in the Drift-Scale (DST and TH Seepage) Coupled Processes report (BSC 2003 [161530]). This Model Report will not address thermal seepage. However, it will analyze the expected magnitude of fracture flux augmentation caused by long-term heating at the repository. This may assist in determining the mountain-scale effect on thermal seepage.

At later times following waste emplacement, TH coupled processes at the mountain scale, i.e., the perturbation in temperature, and in fracture and matrix liquid saturation, take place over a much larger space domain compared to drift-scale effects (Haukwa et al. 2003 [165165]). These mountain-scale TH processes include repository edge effects, large-scale enhanced water and gas flow, and temperature elevation in the far field. In this section, we will present model results and analyses of the mountain-scale TH effects from the 2-D TH model. Results from the 3-D TH model will be presented in Section 6.3. As shown in Figure 6.1-1, the 2-D model vertical cross section is nearly perpendicular to the direction of the repository drifts. Therefore, it cannot simulate fluid and heat flow that occurs into or from the eastern and western directions (i.e., parallel to the drift axis). In particular, water-vapor transport and associated heat transfer along drift tunnels, and their effect on TH conditions near the repository, cannot be described by the 2$\mathrm{D}$ model. Water-vapor migrating into the cooler regions (such as the access tunnel) and then condensing, occurring while the boiling front is expanding, is considered to be unimportant with respect to long-term prediction(s) of mountain-scale thermohydrology. The reason this is considered true is because the maximum extent of boiling occurs in a few tens of years after 50 years of ventilation, whereas the mountain-scale $\mathrm{TH}$ prediction time frame is hundreds to thousands of years. Therefore, water-vapor migration predicted by the 2-D TH model for short time frames cannot have a significant effect on long-term and mountain-scale $\mathrm{TH}$ behavior. Furthermore, the boiling front returns to the drift wall in approximately 800 to 1,000 years so 
that any early, tens-of-year phenomenon should have no lasting effect on long-term $\mathrm{TH}$ responses.

\subsubsection{Base-Case Model Results and Analyses}

As discussed in Section 6.1.5 and above, the base-case TH Model uses only 13.7\% (BSC 2002 [160975], see Section 6.1.5 for more details) of the total thermal load in the first 50 years after waste emplacement. After 50 years, 100\% thermal load is introduced into repository drifts. As discussed in the opening paragraphs of this section, the important mountain-scale $\mathrm{TH}$ changes are perturbations in temperature, fracture and matrix liquid saturation, and fracture fluxes. First, contours of temperature and fracture liquid saturation at different times will be shown. These contour plots will provide the reader with an overall picture of the TH perturbation in the entire 2-D mountain-scale TH model domain. Second, line plots of temperature, fracture and matrix liquid saturation, and fracture fluxes at various locations and times will be analyzed to develop a more specific understanding of the TH processes. The locations of interest in the 2-D TH model domain are the north-south axis just above and below the repository, the bottom of the PTn stratigraphic unit $(\sim 125-150 \mathrm{~m}$ above the emplacement drifts) and the bottom of the TSw stratigraphic unit ( 75-100 m below the emplacement drifts). Analyzing the TH responses at these locations will help us in determining the extent of TH perturbation both near and far away from the emplacement drifts.

\subsubsection{Contours of Temperature and Fracture Saturation}

The predicted TH conditions in the rock 100 years after emplacement of the wastes are shown in Figures 6.2-1a and 6.2-1b. These figures, generated from the base-case simulations (data extraction and plotting procedures are summarized in Attachment IV, Section IV.1), show the contours of temperature and fracture liquid saturation, respectively, in the 2-D N-S refined grid of the UZ model grid. Note that the thick, blue layer, indicating higher $(\sim 80 \%)$ saturation, in the lower, southern portion of Figure 6.2-1b shows matrix saturation, not fracture saturation, because this layer is vitric and simulated as a nonfractured zone (i.e., without a fracture continuum). At this early time, the model results also show that there is little change in matrix liquid saturation along the cross section, and the TH changes are limited to the near field. After 100 years of heating, because of the elevated temperature around the drifts, some amount of drying is going on. This is further evident from Figure 6.2-1b. The contours of fracture liquid saturation in the figure shows drying (reduction from ambient saturation condition) around the drifts. It is obvious that the impact of heat 100 years after emplacement is realized only within a few meters (in terms of saturation, Figure 6.2-1b) to a few tens of meters (in terms of temperature, Figure 6.21a). While the regions immediately surrounding the drifts are reaching almost boiling conditions $\left(\sim 96^{\circ} \mathrm{C}\right)$ at 100 years, the space between two adjacent drifts (i.e., the pillar region) is predicted to reach a temperature of about $60^{\circ} \mathrm{C}$ at this time.

With the progress of heating, TH changes occur over a larger space domain. This can be seen from Figures 6.2-2a and 6.2-2b, where the contours of temperature and fracture saturation, respectively, are shown at 500 years of emplacement. At this time, perturbations in temperature are expected at least $150 \mathrm{~m}$ above and below the repository. Temperature at the pillar region, even at this time, is still expected to remain well below boiling conditions. As far as matrix liquid saturation is concerned, perturbations (in the form of drying) are expected to be still 
restricted within a few meters of the drift at 500 years of heating. At this time, matrix liquid saturation in the pillar region is predicted to be ambient, i.e., no drying is evident in the pillar region. Drying around the emplacement drifts is also evident in the fracture liquid saturation (Figure 6.2-2b). Drying in the fractures is more prominent below the emplacement drifts than above. Laterally, the extent of drying in the fractures is not observed beyond a few meters from the emplacement drifts. Fractures in the pillar region are predicted to be at ambient conditions after 500 years of heating. These same trends in temperature, matrix, and fracture liquid saturation are observable even at 1,000 years of heating (see Figures 6.2-3a and 6.2-3b).

At 5,000 years of heating, however, temperatures have cooled down considerably (see Figure 6.2-4a), even close to the emplacement drifts. Though temperature perturbation exists at a large spatial scale in the mountain, nowhere in the mountain is it predicted to be more than $70-80^{\circ} \mathrm{C}$. As far as saturation is concerned, both the rock matrix and the fractures (Figure 6.2-4b) have returned to mostly ambient conditions at 5,000 years. Figures $6.2-5 \mathrm{a}$ and $6.2-5 \mathrm{~b}$ show the temperature and fracture liquid saturation, respectively at 8,000 years. With continuous radioactive decay, temperatures have declined further and are below $55^{\circ} \mathrm{C}$ everywhere in the mountain. Matrix and fracture liquid saturation has also returned to their preheating conditions. It is clear that the thermal regime in the mountain does not last much longer than 8,000 years. Beyond this time, conditions are essentially ambient in the mountain.

\subsubsection{Temperature along the North-South Axis}

In Figure 6.2-6a, temperatures at different times are shown along the north-south axis just above the emplacement drifts for the base-case thermal-loading scenario. At 100 years, the locations just above the drift reaches a maximum temperature of about $96^{\circ} \mathrm{C}$ (the green line). The sharp peaks in temperature are for those locations that are directly above the emplacement drifts. The troughs immediately following the sharp peaks represent the temperature profiles in the pillar region. Observe that the middle of the pillar regions is predicted to be around $60^{\circ} \mathrm{C}$ at 100 years. At 500 years (the black line), the locations just above the drifts are still at around $96^{\circ} \mathrm{C}$ but the mid-pillar regions have reached a temperature of about $84^{\circ} \mathrm{C}$. The peak mid-pillar temperature is predicted to be around $88^{\circ} \mathrm{C}$ at 1,000 years (the yellow line). After this, temperatures start to decline, and the sharp difference in temperature between the drifts and the mid-pillar regions begin to disappear. For example, at 3,000 years (the orange line), both the locations directly above the drift and the mid-pillar regions have declined below $80^{\circ} \mathrm{C}$, and the difference between the peaks (directly above drifts) and the troughs (mid-pillar regions) is no more than $3-4^{\circ} \mathrm{C}$. After 8,000 years (the cyan line), temperatures just above the drift across the north-south axis of the repository are predicted to decline below $55^{\circ} \mathrm{C}$. 


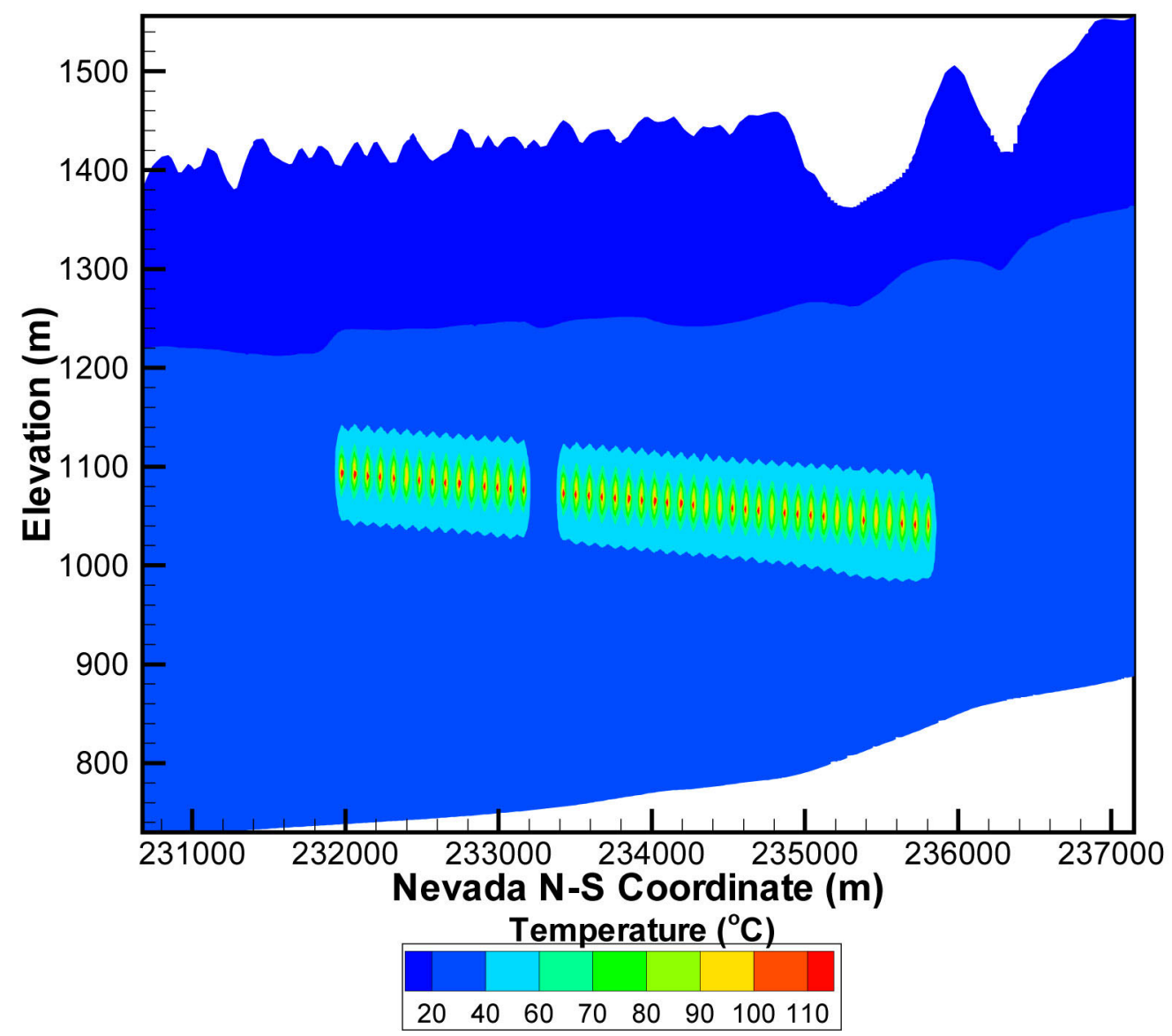

DTN: LB0310MTSCLTH2.001

Figure 6.2-1a. Contours of Temperature in the 2-D North-South Cross Section of the UZ Model Grid at 100 Years with Base-Case Thermal Loading 


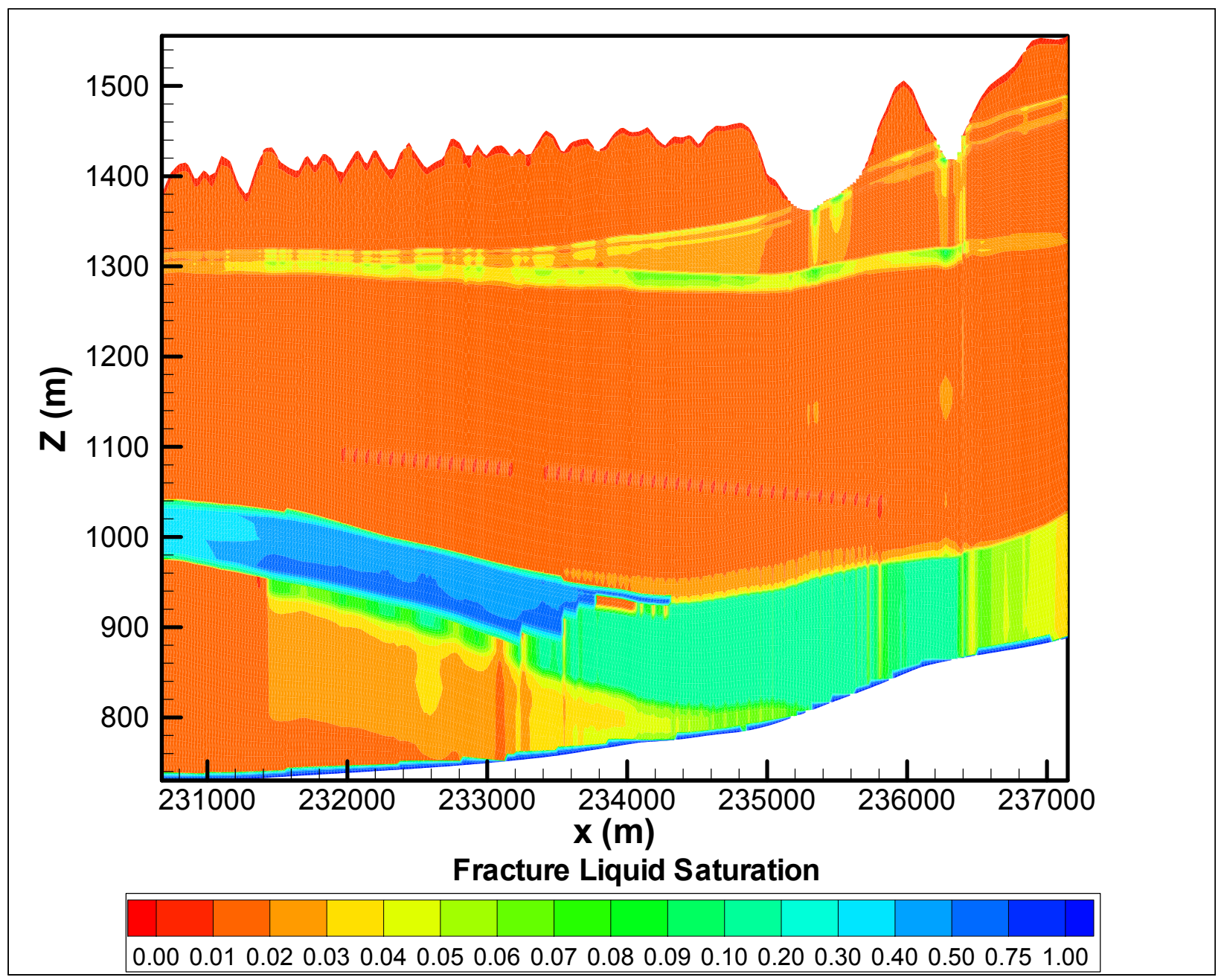

DTN: LB0310MTSCLTH2.001

NOTE: The thick, blue layer at lower, left side of the figure represents matrix saturation, as the vitric layer in that region is simulated as non-fractured (i.e. the fracture continuum is absent in that region).

Figure 6.2-1b. Contours of Fracture Liquid Saturation in the 2-D North-South Cross Section of the UZ Model Grid at 100 Years with Base-Case Thermal Loading 


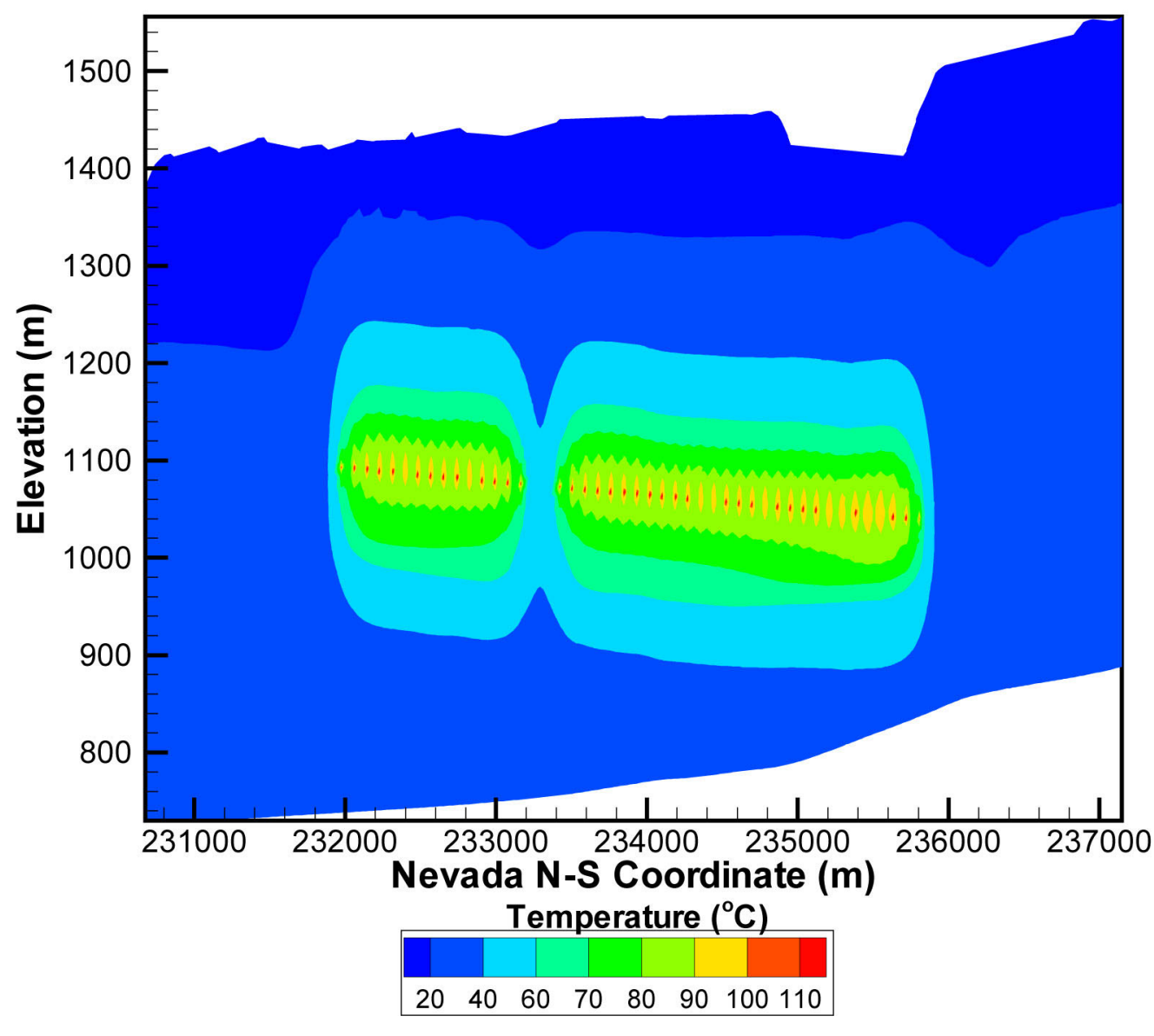

DTN: LB0310MTSCLTH2.001

Figure 6.2-2a. Contours of Temperature in the 2-D North-South Cross Section of the UZ Model Grid at 500 Years with Base-Case Thermal Loading 


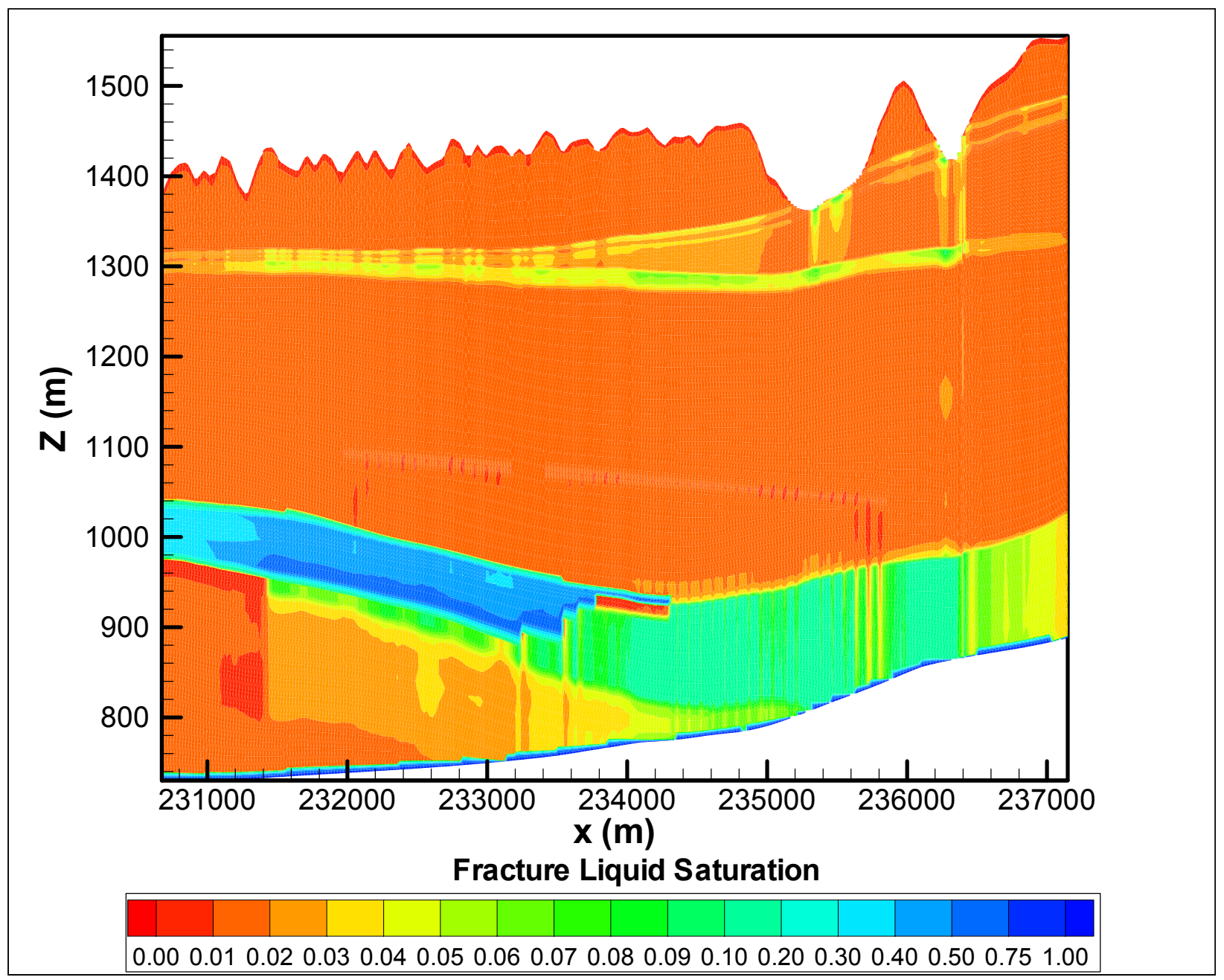

DTN: LB0310MTSCLTH2.001

NOTE: The thick, blue layer at lower, left side of the figure represents matrix saturation, as the vitric layer in that region is simulated as non-fractured (i.e. the fracture continuum is absent in that region).

Figure 6.2-2b. Contours of Fracture Liquid Saturation in the 2-D North-South Cross Section of the UZ Model Grid at 500 Years with Base-Case Thermal Loading 


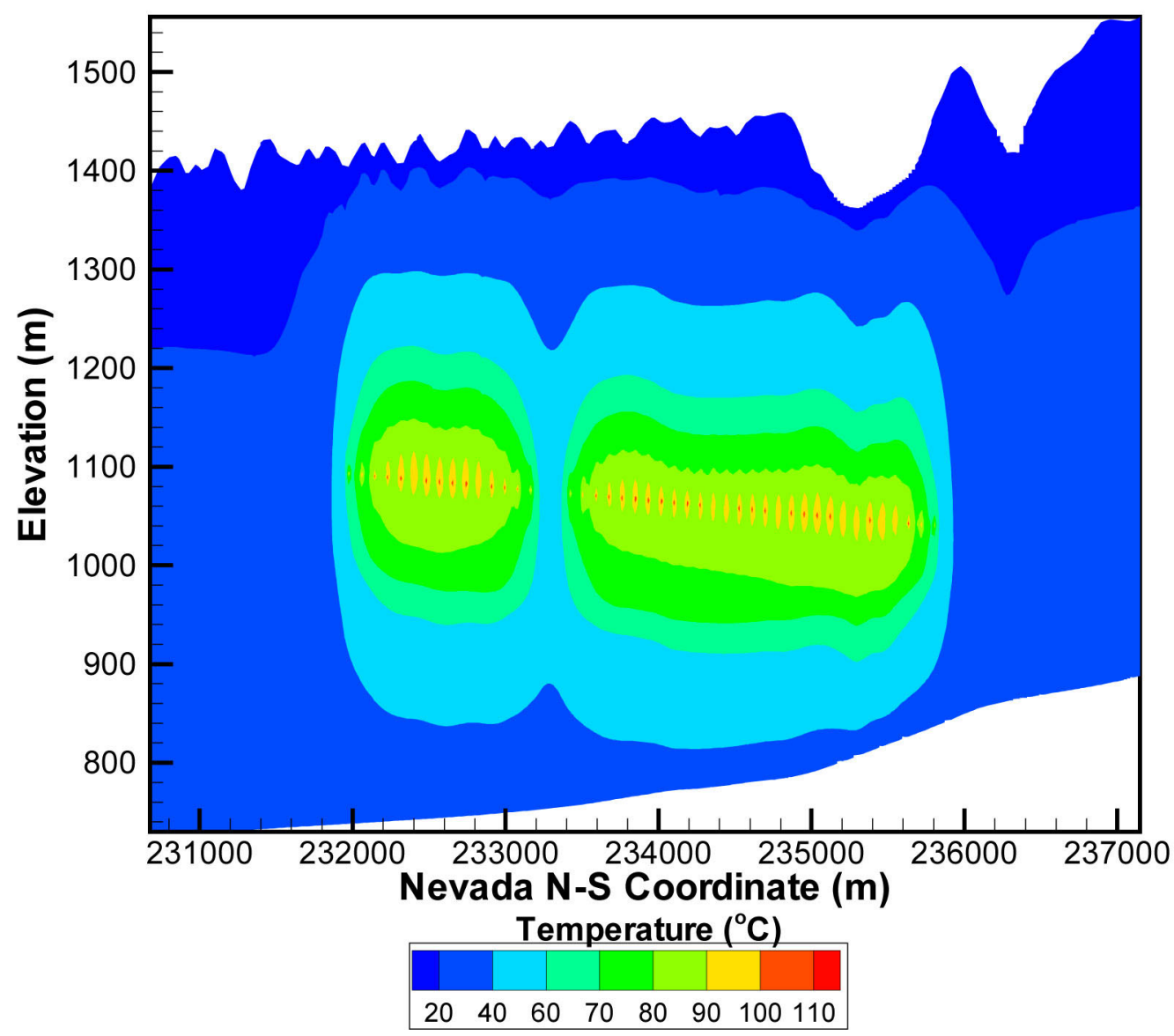

DTN: LB0310MTSCLTH2.001

Figure 6.2-3a. Contours of Temperature in the 2-D North-South Cross Section of the UZ Model Grid at 1,000 Years with Base-Case Thermal Loading 


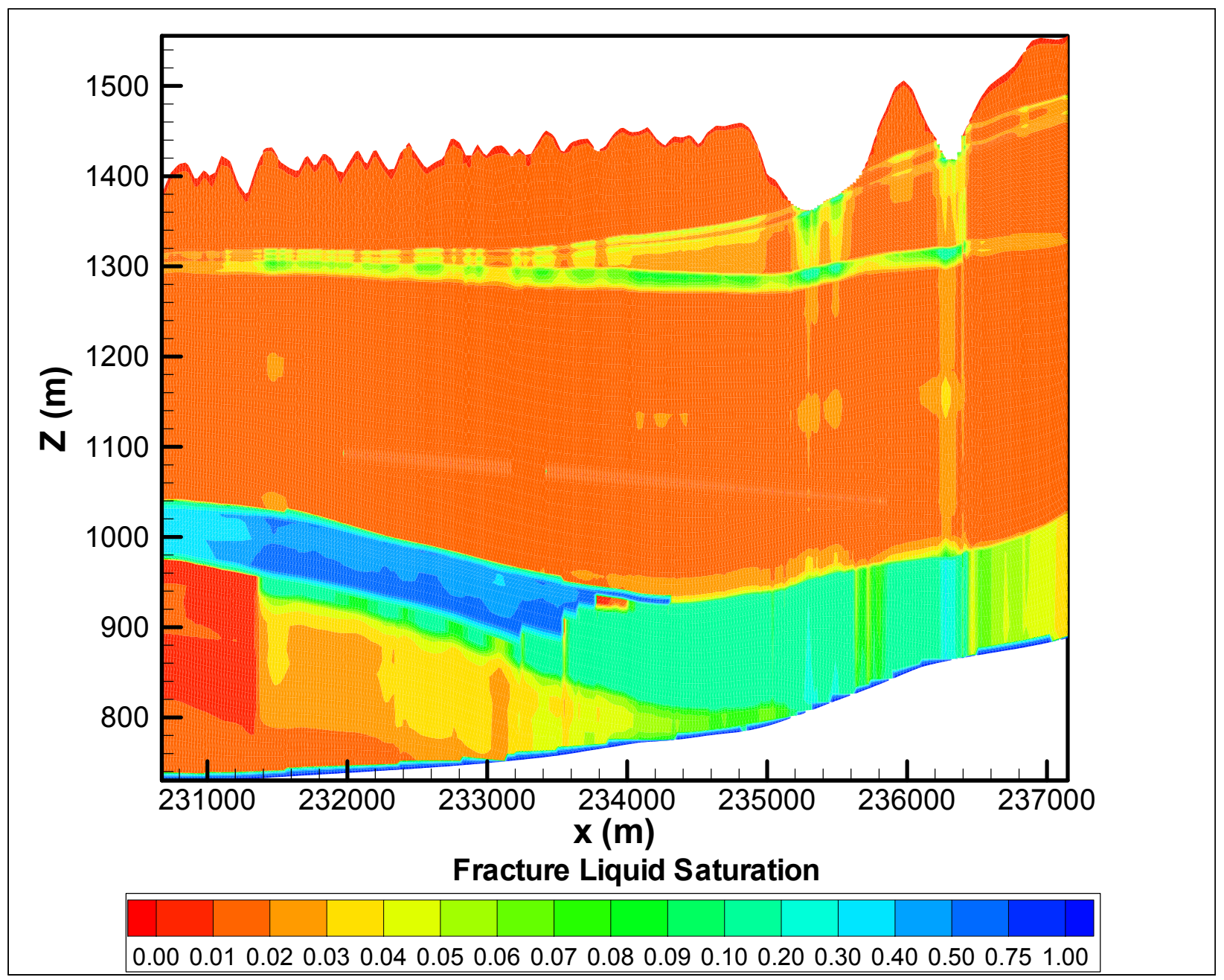

DTN: LB0310MTSCLTH2.001

NOTE: The thick, blue layer at lower, left side of the figure represents matrix saturation, as the vitric layer in that region is simulated as non-fractured (i.e. the fracture continuum is absent in that region).

Figure 6.2-3b. Contours of Fracture Liquid Saturation in the 2-D North-South Cross Section of the UZ Model Grid at 1,000 Years with Base-Case Thermal Loading 


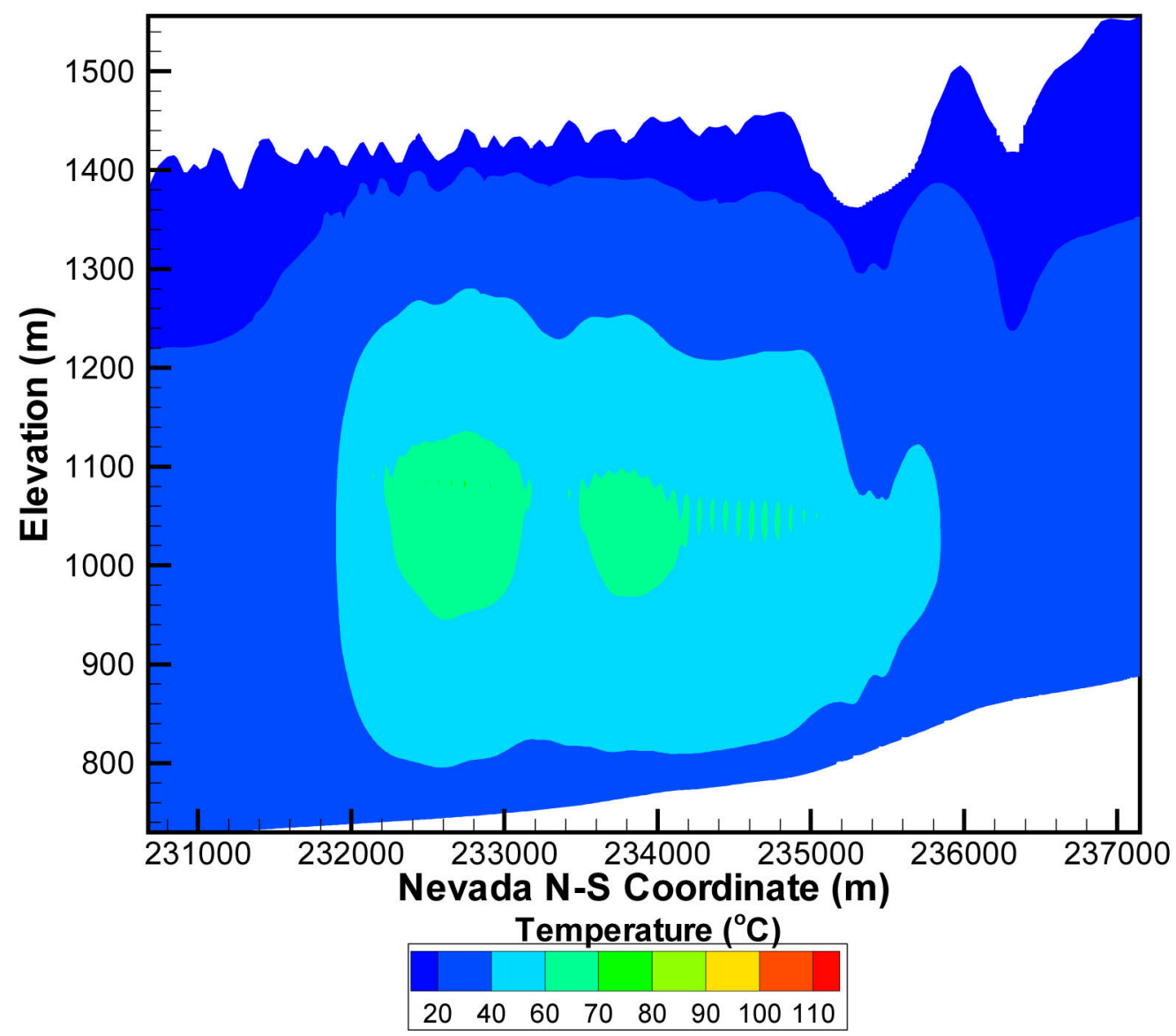

DTN: LB0310MTSCLTH2.001

Figure 6.2-4a. Contours of Temperature in the 2-D North-South Cross Section of the UZ Model Grid at 5,000 years with Base-Case Thermal Loading 


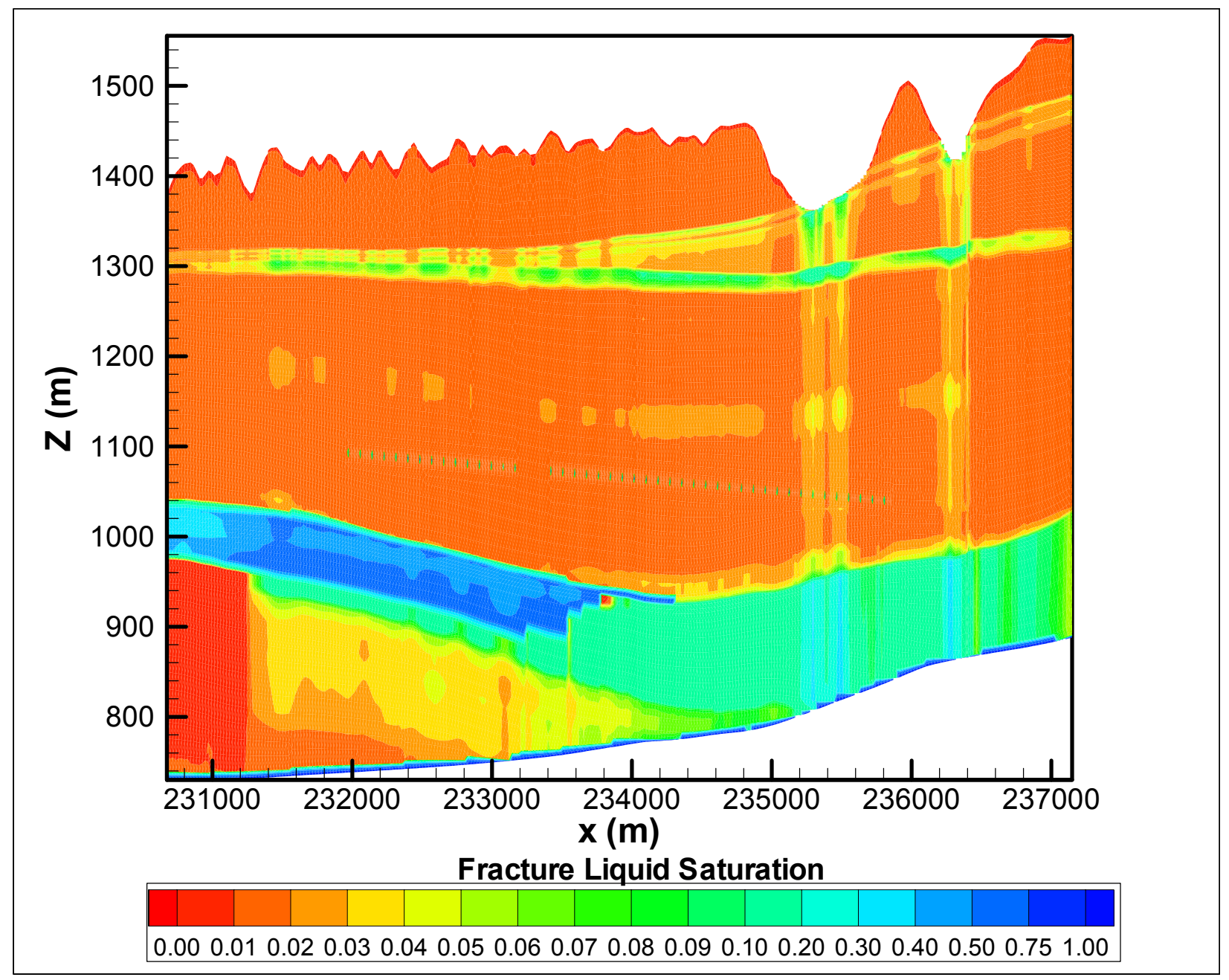

DTN: LB0310MTSCLTH2.001

NOTE: The thick, blue layer at the lower left side of the figure represents matrix saturation, as the vitric layer in that region is simulated as nonfractured (i.e., the fracture continuum is absent in that region).

Figure 6.2-4b. Contours of Fracture Liquid Saturation in the 2-D North-South Cross Section of the UZ Model Grid at 5,000 Years with Base-Case Thermal Loading 


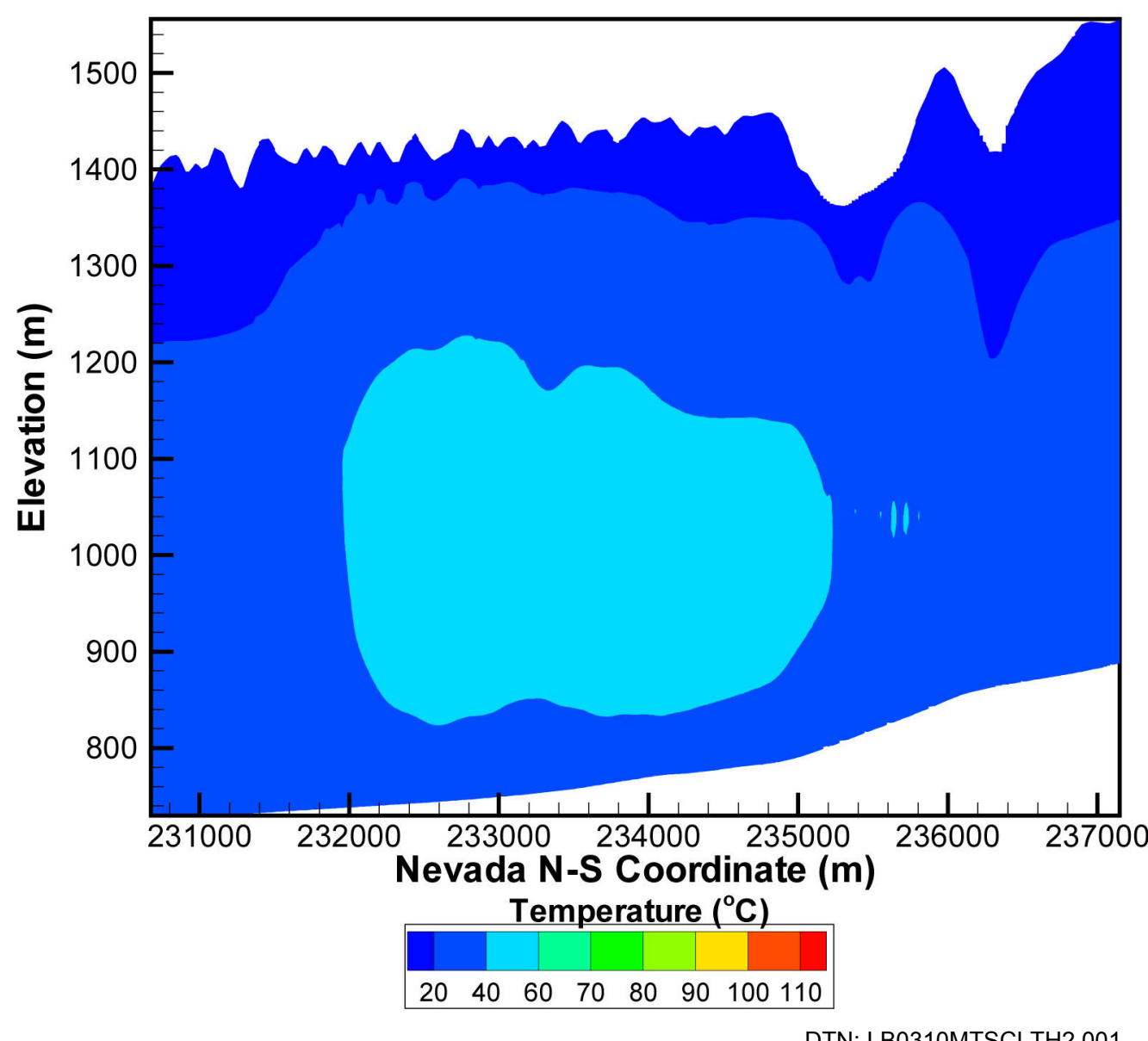

Figure 6.2-5a. Contours of Temperature in the 2-D North-South Cross Section of the UZ Model Grid at 8,000 Years with Base-Case Thermal Loading 


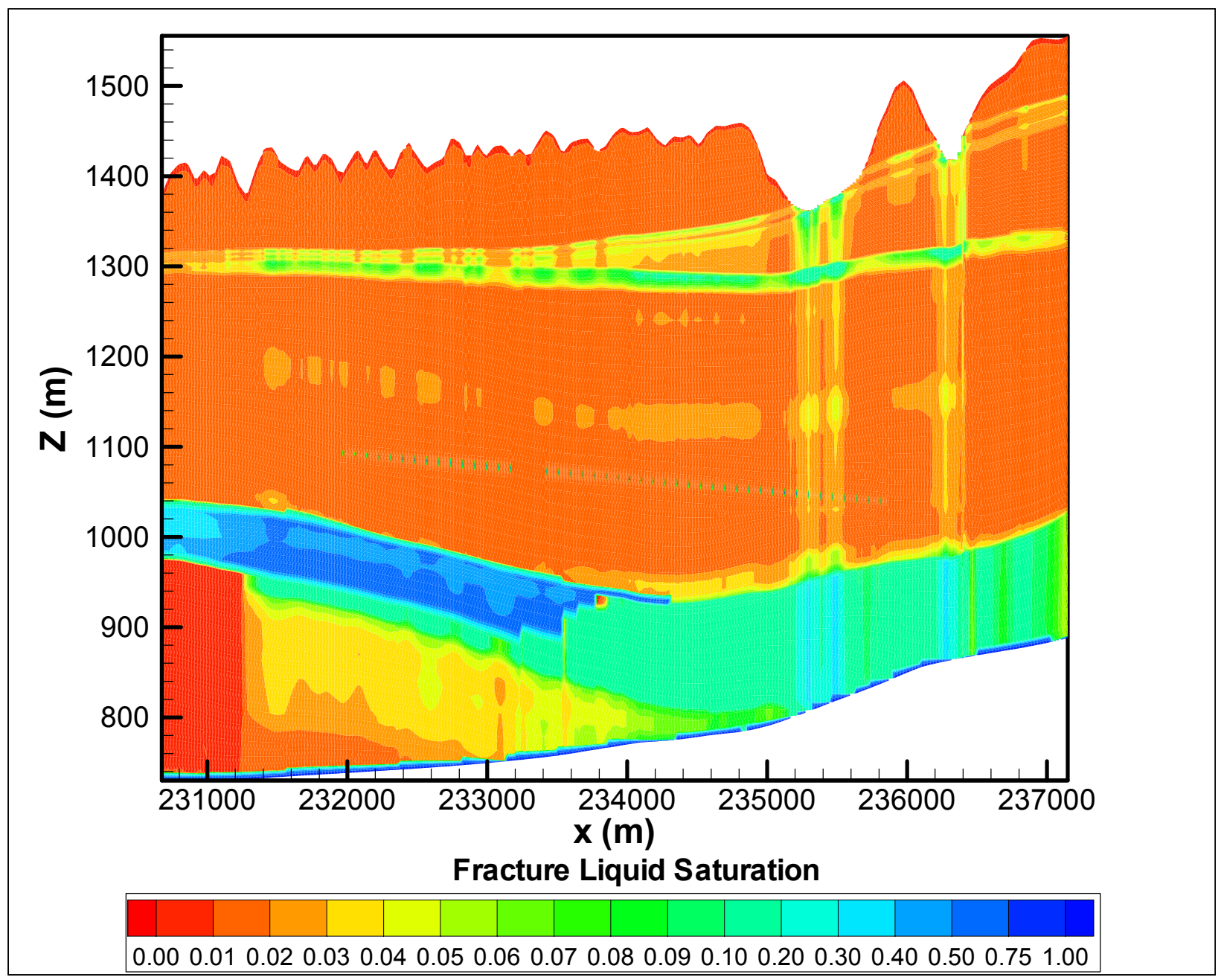

DTN: LB0310MTSCLTH2.001

NOTE: The thick, blue layer at lower, left side of the figure represents matrix saturation, as the vitric layer in that region is simulated as non-fractured (i.e. the fracture continuum is absent in that region).

Figure 6.2-5b. Contours of Fracture Liquid Saturation in the 2-D North-South Cross Section of the UZ Model Grid at 8,000 Years with Base-Case Thermal Loading 


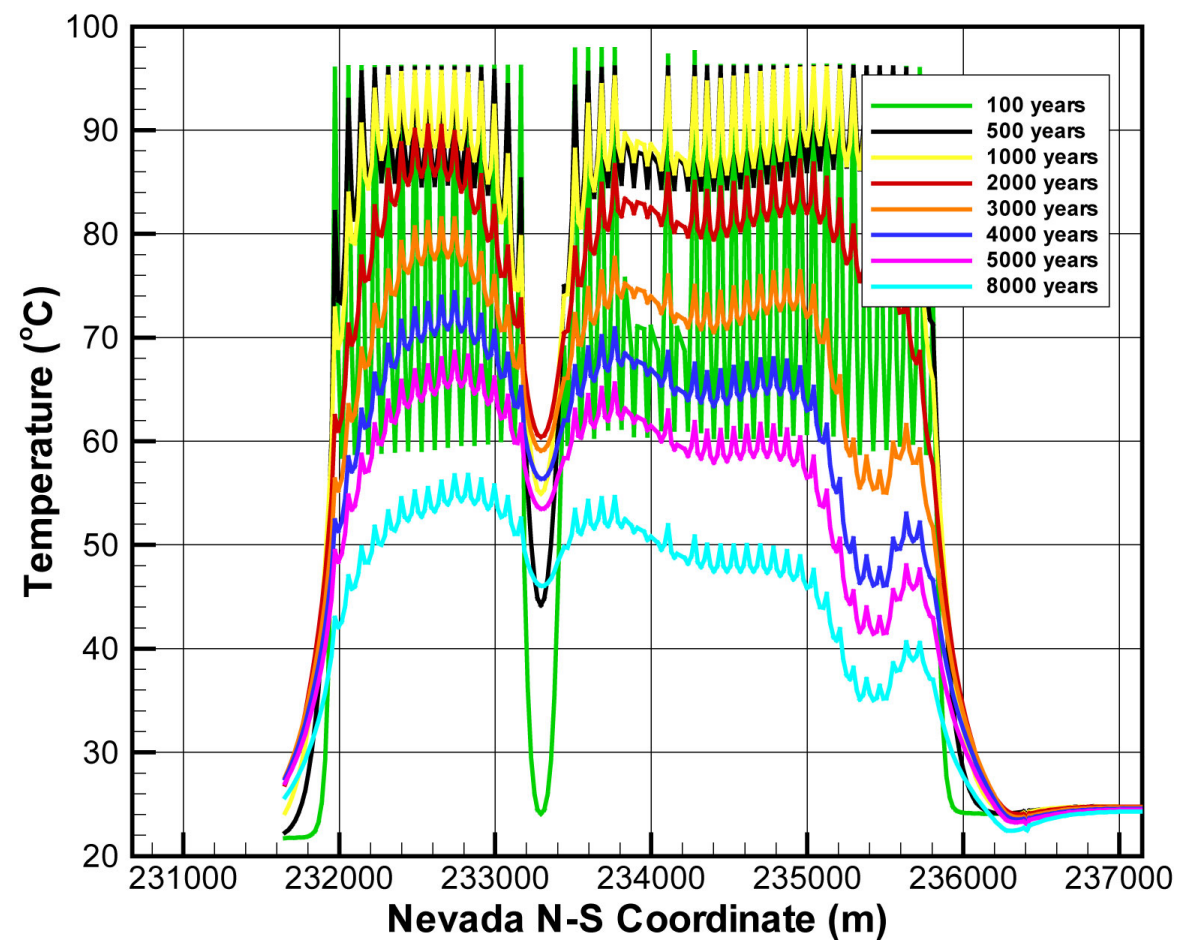

DTN: LB0310MTSCLTH2.001

Figure 6.2-6a. Temperature Just Above the Emplacement Drifts with Base-Case Thermal Loading

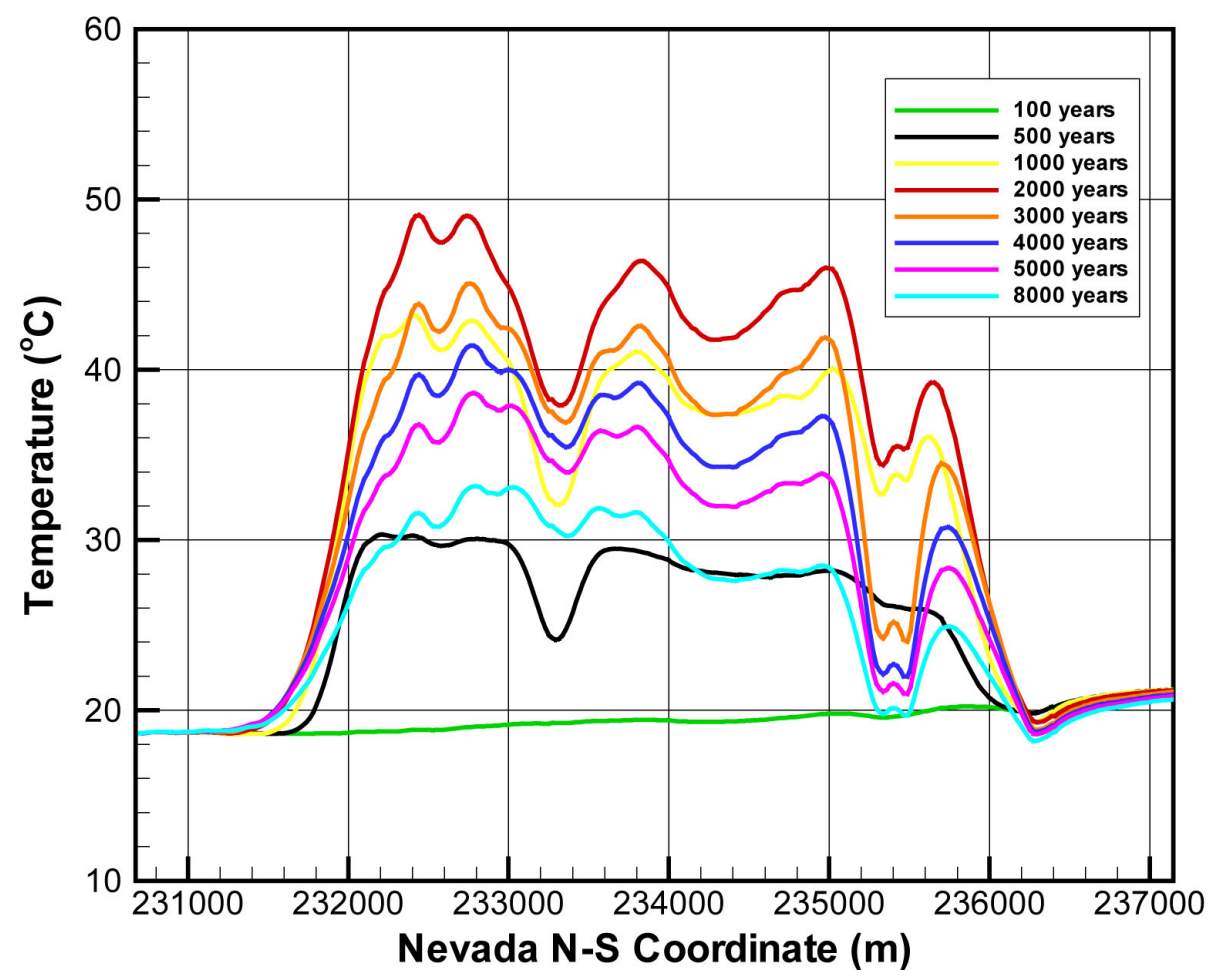

DTN: LB0310MTSCLTH2.001

Figure 6.2-6b. Temperature at the Bottom of PTn with Base-Case Thermal Loading 


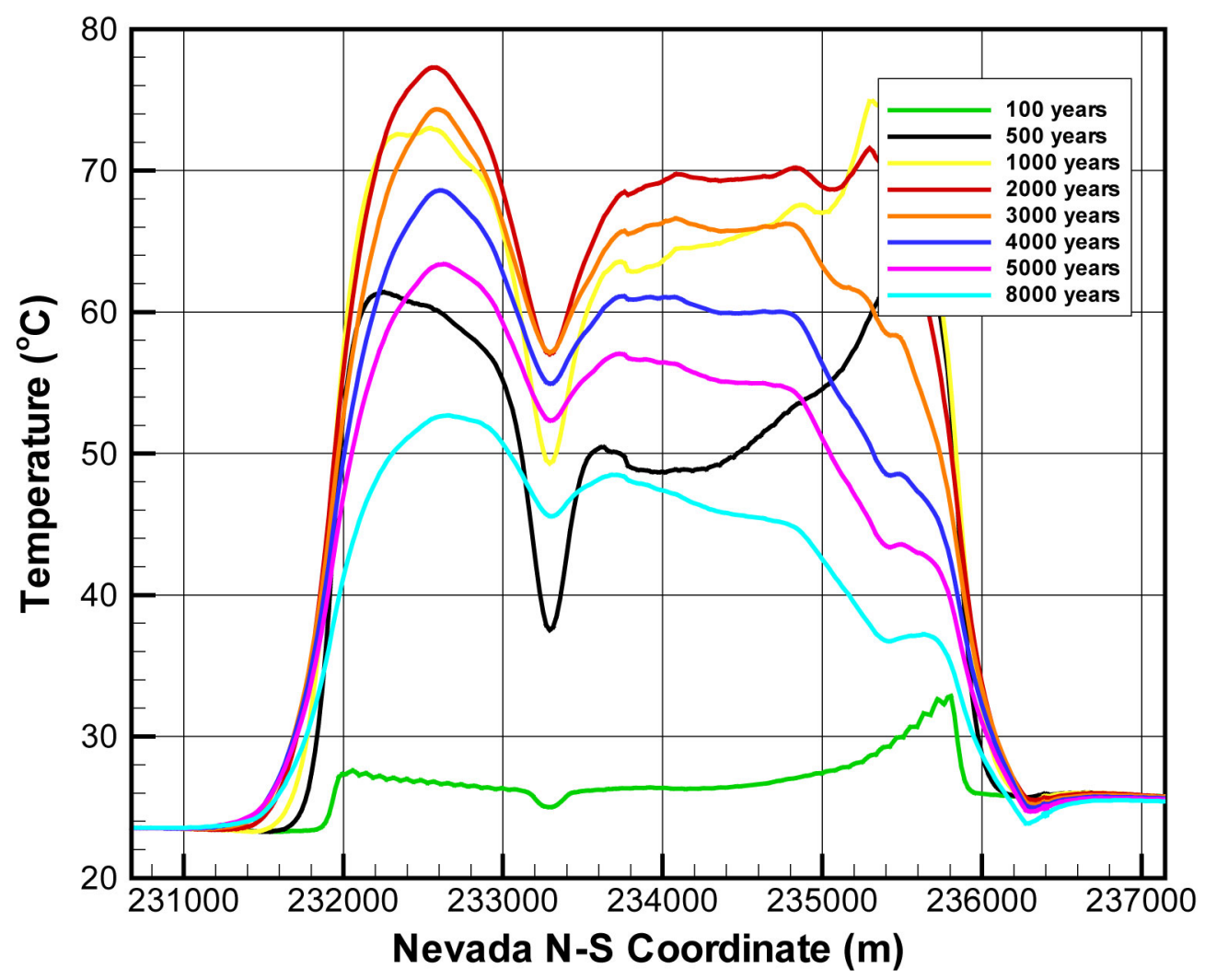

DTN: LB0310MTSCLTH2.001

Figure 6.2-6c. Temperature at the Bottom of TSw with Base-Case Thermal Loading

Figure 6.2-6b is similar to Figure 6.2-6a except that it shows temperature at the bottom of the PTn. At 100 years (the green line), temperatures at the bottom of the PTn are still below $20^{\circ} \mathrm{C}$. In other words, temperatures are still ambient, and the impact of heat has not extended up to the bottom of the PTn. At 500 years (the black line), however, temperatures at the bottom of the PTn have started to increase due to heat from the emplaced wastes. Temperatures at the bottom of the PTn are predicted to reach a maximum of $50^{\circ} \mathrm{C}$ at 2,000 years (the red line). After that, temperatures start to decline. By 8,000 years, temperatures at the PTn bottom have steadily cooled to just above $30^{\circ} \mathrm{C}$ and are predicted to return to ambient conditions soon after this. In other words, the bottom of the PTn experiences a thermal perturbation not more than $30^{\circ} \mathrm{C}$ above ambient conditions, and the thermal regime is not expected to last any more than 10,000 years.

The extent and duration of the thermal perturbation below the repository can be seen from Figure 6.2-6c. In Figure 6.2-6c, temperatures are shown at the bottom of the TSw along the north-south axis of the repository. The pattern of temperature rise and decline in this figure is similar to that in Figure 6.2-6b. Here, however, the maximum predicted temperature is about $75^{\circ} \mathrm{C}$ at 2,000 years (the red line in Figure 6.2-6c). After that, temperatures are expected to gradually decline to about a maximum of $50^{\circ} \mathrm{C}$ at 8,000 years (the cyan line). The higher peak temperature at the bottom of TSw compared to the bottom of PTn can be attributed to its location close to the repository horizon. Also, since the water table in the present $\mathrm{TH}$ model is maintained at a constant temperature, the predicted increase in temperature at the bottom of the TSw is expected to be somewhat underestimated. The smaller peak temperatures at the northern side of the 
repository can be attributed to higher infiltration rates at those areas compared to the southern sides.

\subsubsection{Matrix Liquid Saturation along the North-South Axis}

Figures $6.2-7 \mathrm{a}$ to $6.2-7 \mathrm{c}$ shows the matrix liquid saturation at different times for three different locations. Figure 6.2-7a shows the matrix liquid saturation along the north-south axis just above the repository. At locations just above the emplacement drifts, drying associated with a heated drift occurs (Figure 6.2-7a), reducing near-drift saturation to a minimum between 500-1,000 years after emplacement of wastes. After 1,000 years, resaturation commences, and the matrix saturation just above the drift returns to ambient condition at or around 5,000 years. The slight increase in matrix saturation above the present-day saturation during later times results from increased infiltration after climate change (around 2,000 years). Matrix liquid saturation at the bottom of the PTn is shown in Figure 6.2-7b. Since the peak temperature at the bottom of the PTn was never higher than $50^{\circ} \mathrm{C}$ and never approached boiling, the changes in matrix saturation at the PTn bottom caused by heating are negligible. The step-wise increase in matrix saturation at 1,000 years and 3,000 years in Figure 6.2-7b results from climate changes at 600 years and 2,000 years, respectively. Figure 6.2-7c similarly shows the matrix liquid saturation at the bottom of the TSw. Because of the below-boiling conditions prevailing at this location, changes in matrix liquid saturation from ambient saturation values are minimal at any time. The significantly different matrix saturations for the northern and southern ends of the repository at the bottom of TSw result from vitric-zeolitic transition.

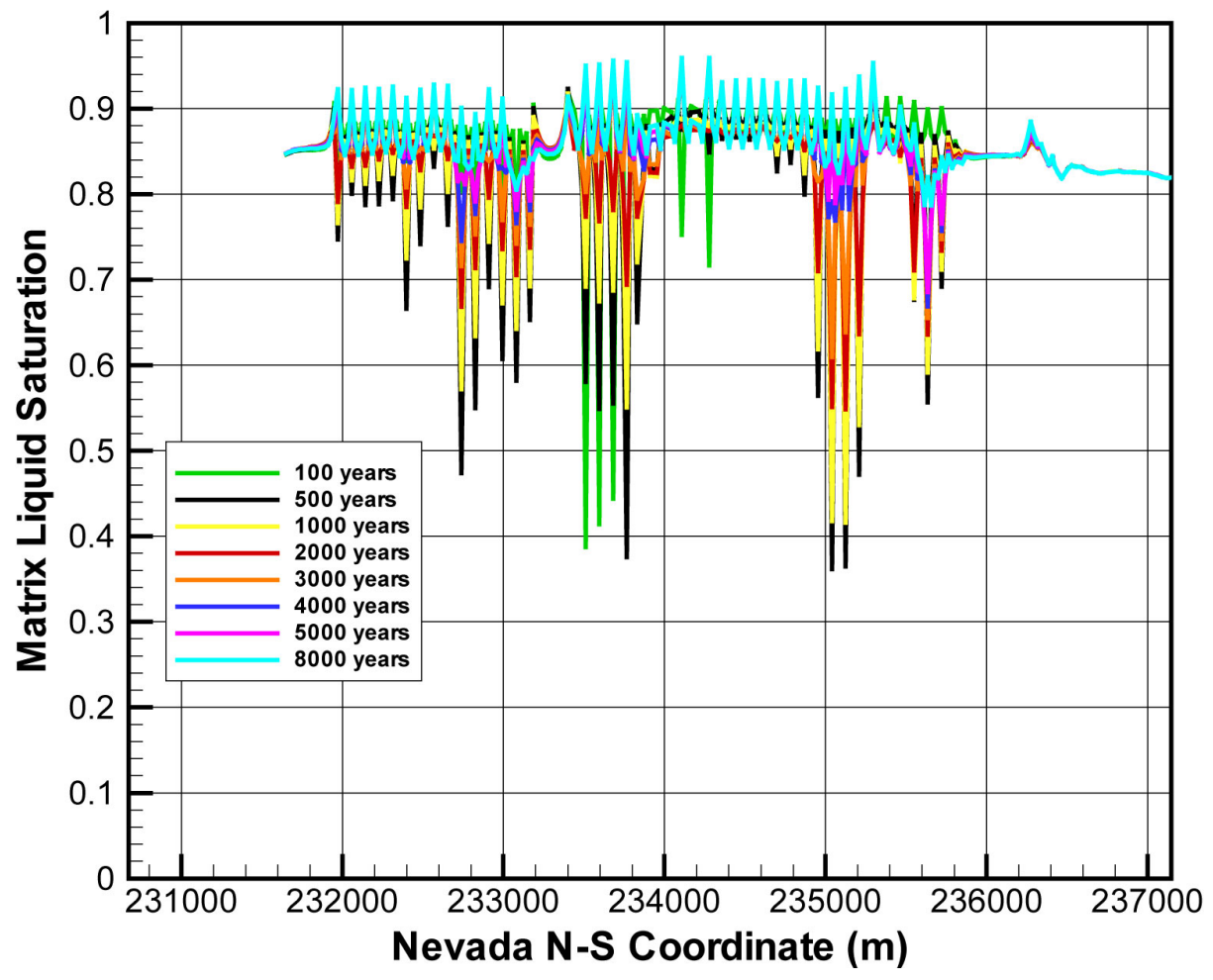

DTN: LB0310MTSCLTH2.001

Figure 6.2-7a. Matrix Liquid Saturation Just above the Repository with Base-Case Thermal Loading 


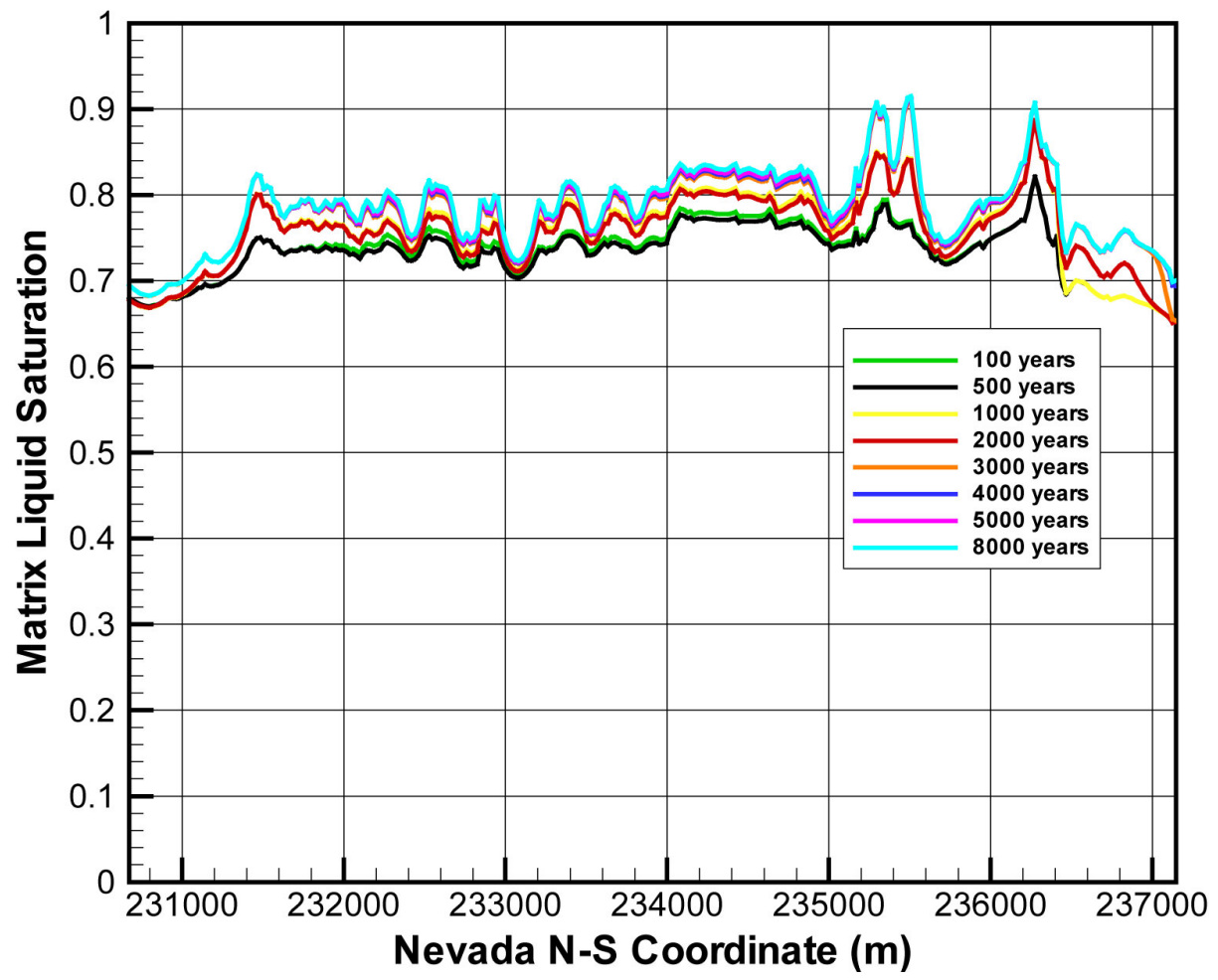

DTN: LB0310MTSCLTH2.001

Figure 6.2-7b. Matrix Liquid Saturation at the Bottom of PTn with Base-Case Thermal Loading

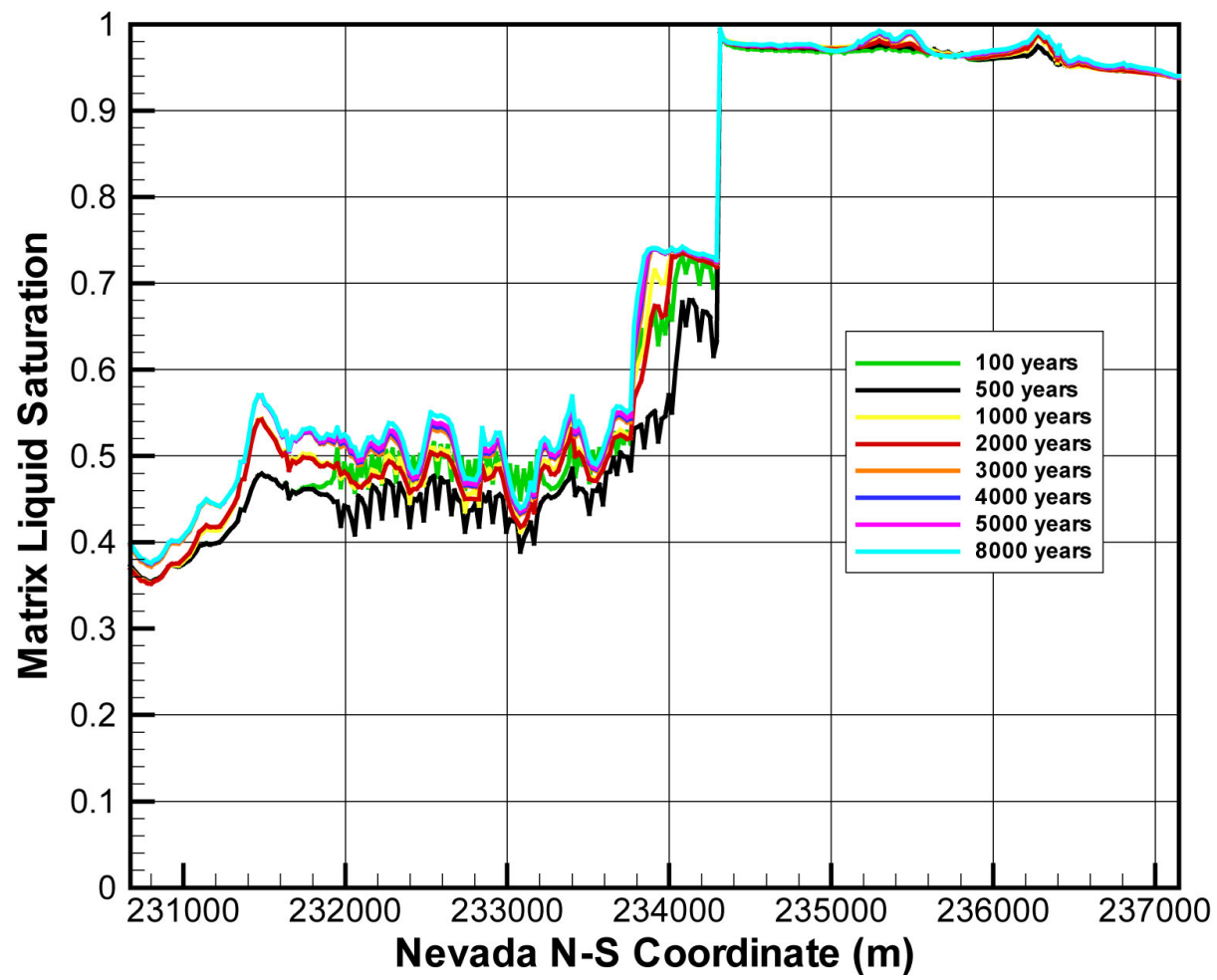

DTN: LB0310MTSCLTH2.001

Figure 6.2-7c. Matrix Liquid Saturation at the Bottom of TSw with Base-Case Thermal Loading 


\subsubsection{Fracture Liquid Saturation along the North-South Axis}

Figures $6.2-8 \mathrm{a}$ to $6.2-8 \mathrm{~d}$ illustrate fracture liquid saturation during the thermal regime. Figure 6.2-8a shows fracture liquid saturation along the north-south axis just above the repository. Under ambient conditions, fractures in Yucca Mountain are extremely dry compared to the matrix because of the large fracture apertures and relatively smaller capillary suction in the fractures compared to the rock matrix. Heating during the thermal period is expected to mobilize some of the matrix pore water through the fractures after condensation of the boiled water. However, since no large-scale boiling is evident with the base-case thermal loading, fractures remain essentially dry and retain their ambient conditions. Fractures just above the emplacement drifts show limited drying. Fractures in the pillar region show almost no sign of drying. Also, because of climate changes, fractures are expected to be more saturated in the future than at present. Figure 6.2-8b similarly shows the fracture liquid saturation along the north-south axis just below the repository. The patterns are similar to those in Figure 6.2-8a, except that drying is more extensive below the drifts than above, mostly because of the capillary barrier effects of the emplacement drifts. The increase in fracture saturation at future times is attributed to climate changes. Figures $6.2-8 \mathrm{c}$ and $6.2-8 \mathrm{~d}$ similarly illustrate that perturbations in fracture liquid saturation at the bottom of the PTn and the bottom of the TSw, respectively, are minimal at any time during the thermal regime.

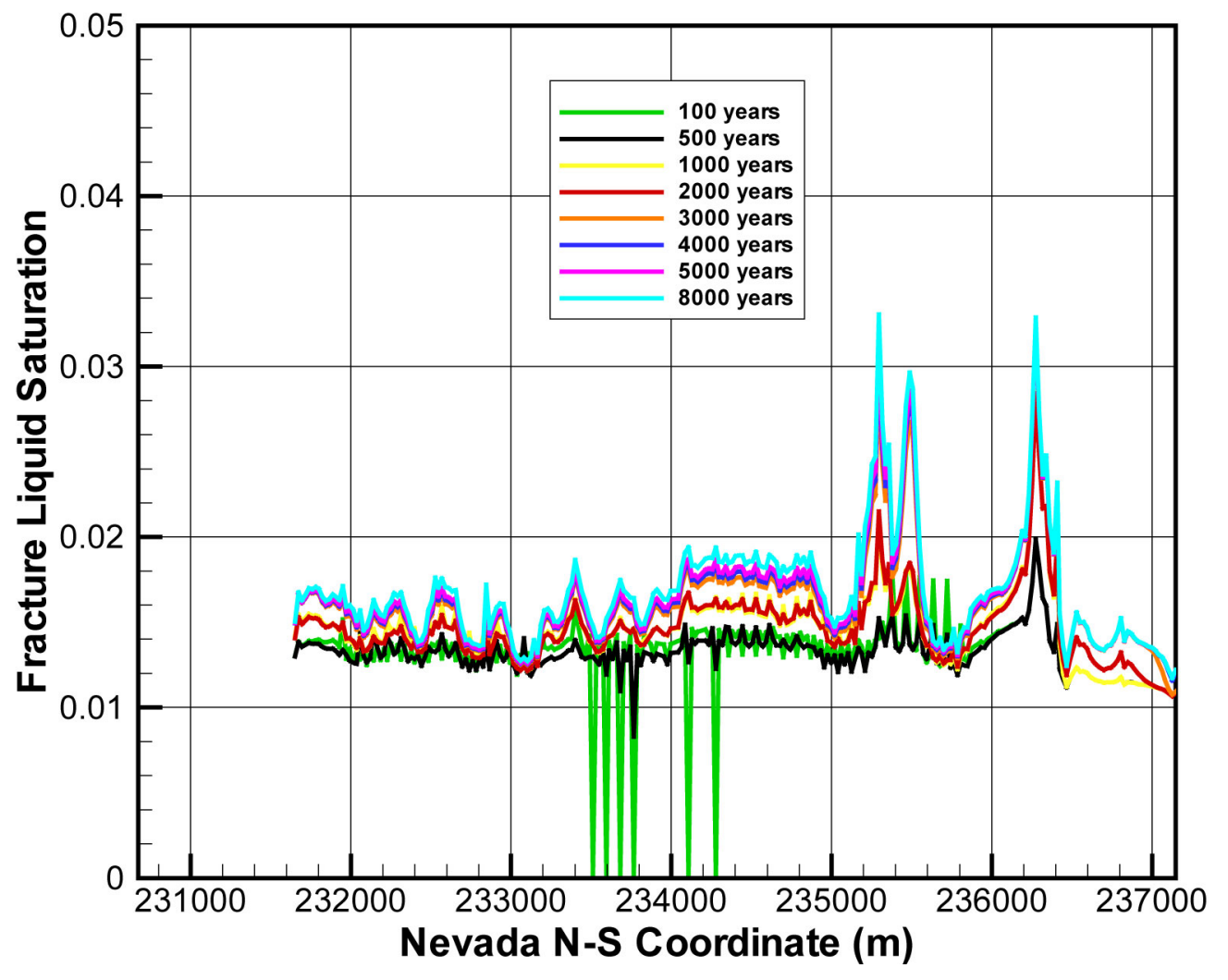

DTN: LB0310MTSCLTH2.001

Figure 6.2-8a. Fracture Liquid Saturation Just above the Emplacement Drifts with Base-Case Thermal Loading 


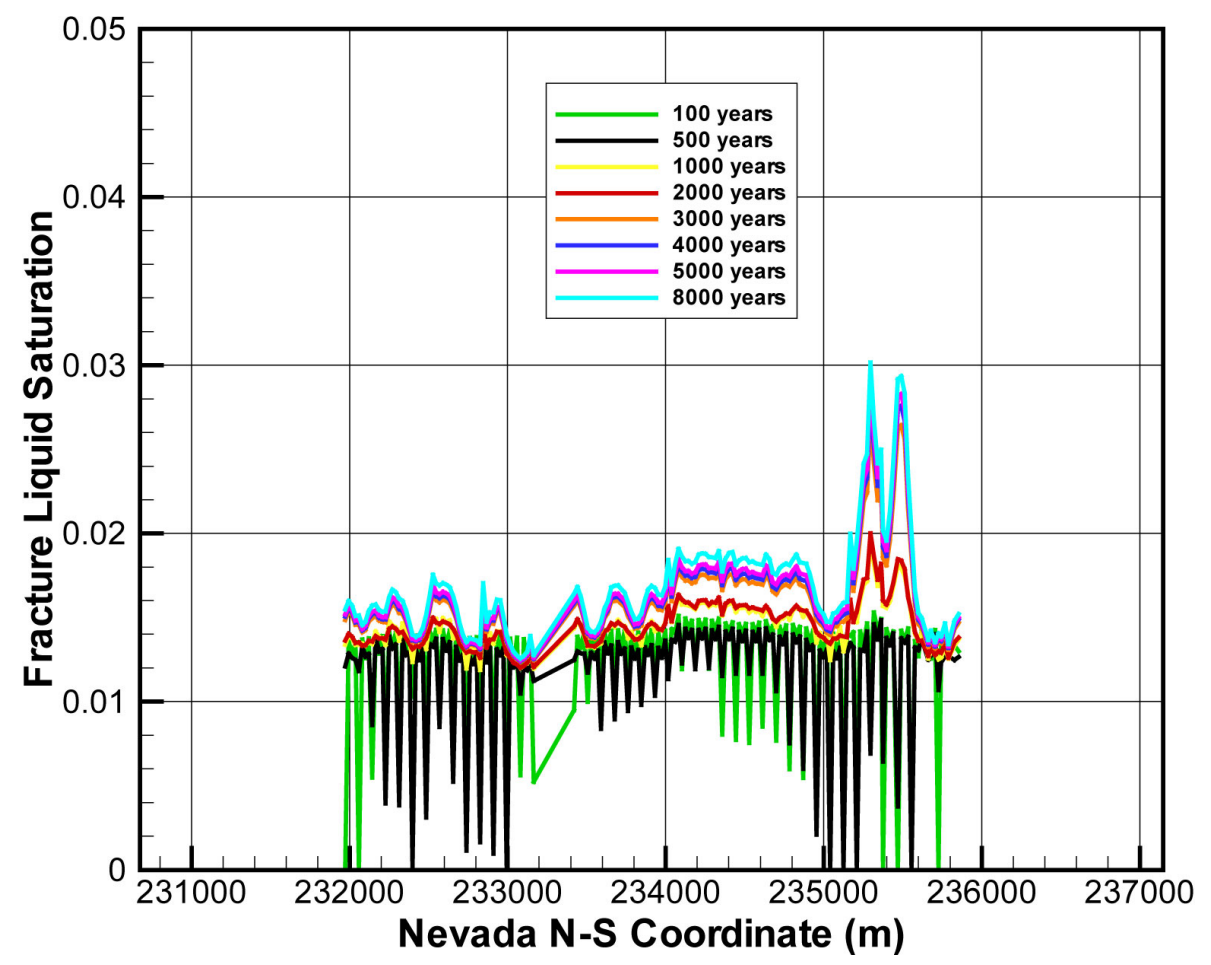

DTN: LB0310MTSCLTH2.001

Figure 6.2-8b. Fracture Liquid Saturation Just below the Emplacement Drifts with Base-Case Thermal Loading

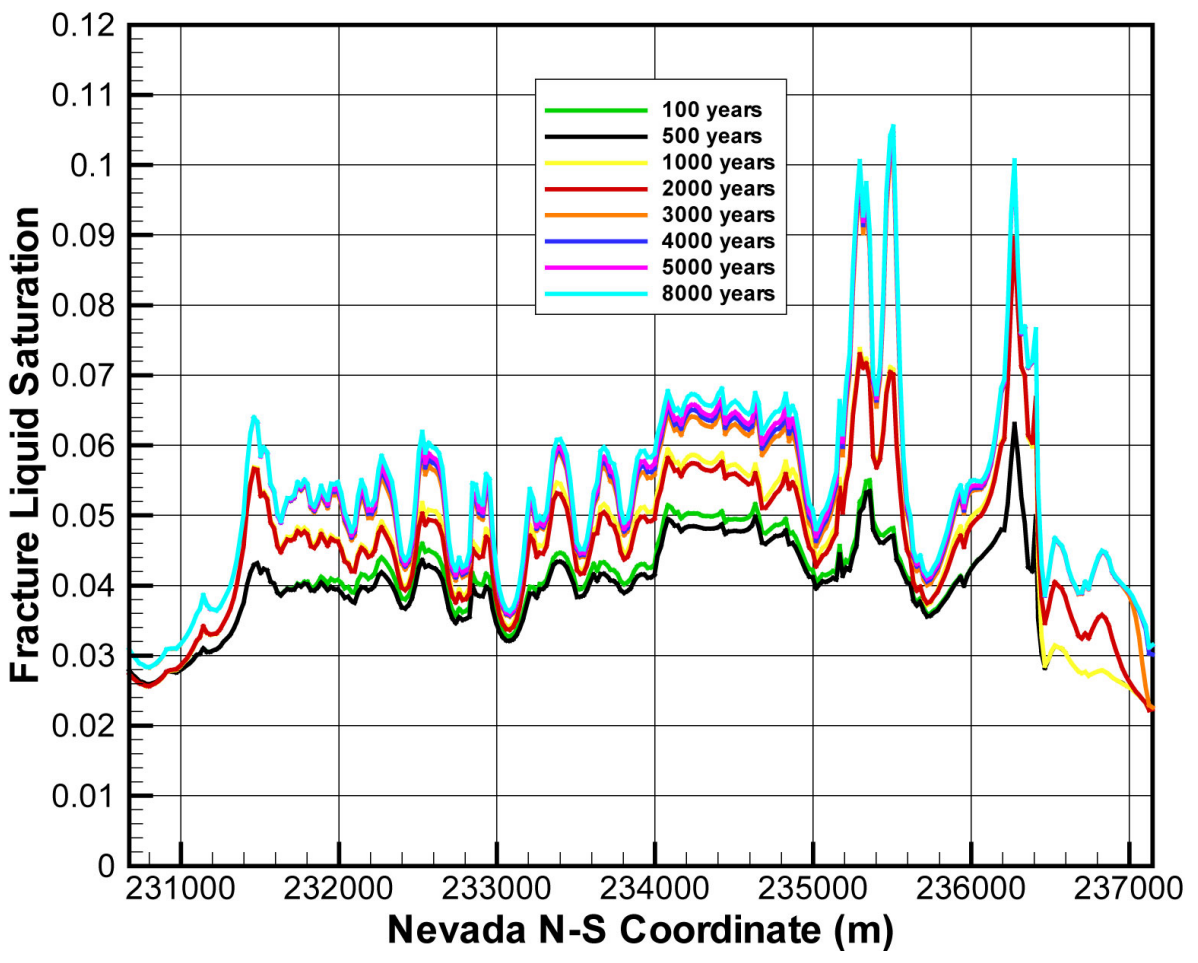

DTN: LB0310MTSCLTH2.001

Figure 6.2-8c. Fracture Liquid Saturation at the Bottom of PTn with Base-Case Thermal Loading 


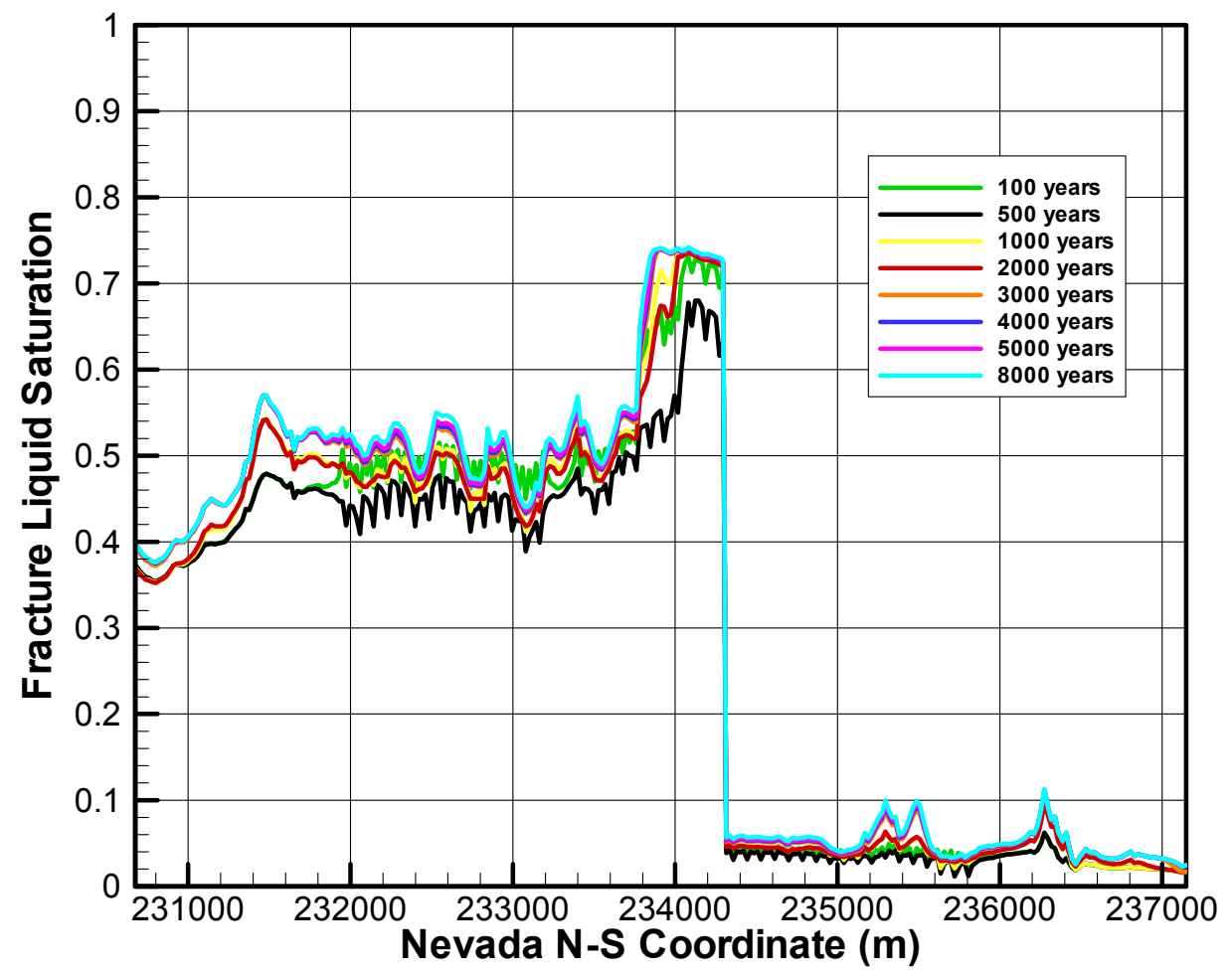

DTN: LB0310MTSCLTH2.001

Figure 6.2-8d. Fracture Liquid Saturation at the Bottom of TSw with Base-Case Thermal Loading

\subsubsection{Vertical Profile of Temperature, Liquid Saturation, and Fracture Flux}

A further estimate of the extent of perturbation in temperature and saturation can be obtained by observing the vertical profiles of these variables. Figures 6.2-9a to 6.2-9d shows the temperature, matrix liquid saturation, and fracture liquid saturation along Column "b62" of the 2-D N-S crosssectional grid. Column "b62" is situated approximately at $234100 \mathrm{~m}$ and runs from the surface to the water table. From Figure 6.2-9a, it is seen that the temperature reaches a maximum of about $96^{\circ} \mathrm{C}$ at the repository horizon at 100 years. Temperatures drop off symmetrically as one moves up or down along the column away from the repository horizon. With the progress of time, the peak temperatures (and temperatures along the vertical column) decline gradually. At 8,000 years, peak temperature in this column has already declined to about $50^{\circ} \mathrm{C}$ and is expected to return to ambient conditions soon after that. As expected, matrix liquid saturation (Figure 6.2-9b) along the vertical column shows little variation from its ambient condition, except for limited drying close to the repository horizon during peak thermal perturbation regime. Figure 6.2-9c shows fracture liquid saturation along column "b62." At almost every location, particularly above the repository horizon, there is very little change in fracture liquid saturation from ambient conditions through the thermal regime. However, just above the repository, considerable build-up of saturation occurs. This is partly a result of the capillary barrier effect, which prevents water from entering the repository, resulting in some build-up in saturation just above the repository. Another source of this build-up is the increased surface infiltration rates during the monsoon and glacial transition climates. Evidence of gravity-induced drainage through the pillar regions is also evident in the fracture saturation profile of Figure 6.2-9c. The increase in 
saturation below about $925 \mathrm{~m}$ (and no build-up at all above the repository horizon) is a result of fast gravity drainage through the highly conductive fractures.

Figure 6.2-9d shows the vertical fluxes in fractures as a function of elevation along column b62. In this figure, vertical fluxes in fractures, expressed as millimeters per year, are shown at various times. In this column, the vertical fracture flux at the ground surface (elevation 1450 masl) is about $9 \mathrm{~mm} /$ year. At 100 years, there is a significant $(\sim 100 \mathrm{~mm} /$ year $)$ build-up of fluxes just above the emplacement drift (at 1063 masl). Because of the capillary barrier effects of the emplacement drifts, vertical fluxes immediately below the drift are nonexistent. This results in a spike in vertical fracture fluxes just above and below the drift. On the other hand, the spike in vertical fracture fluxes at $\sim 940$ masl results from the modeling approach adopted in this study. Recall that the vitric layer present at that location has been modeled as a nonfractured matrix continuum. Since there are no fractures present at that location, vertical fractures are represented as zero. The quantum jump in vertical fracture fluxes at 1,000 years and 3,000 years in Figure $6.2-9 \mathrm{~d}$ results from the changes in climatic conditions at 600 years (transition from present-day to monsoon climate) and 2,000 years (transition from monsoon to glacial transition climate), respectively.

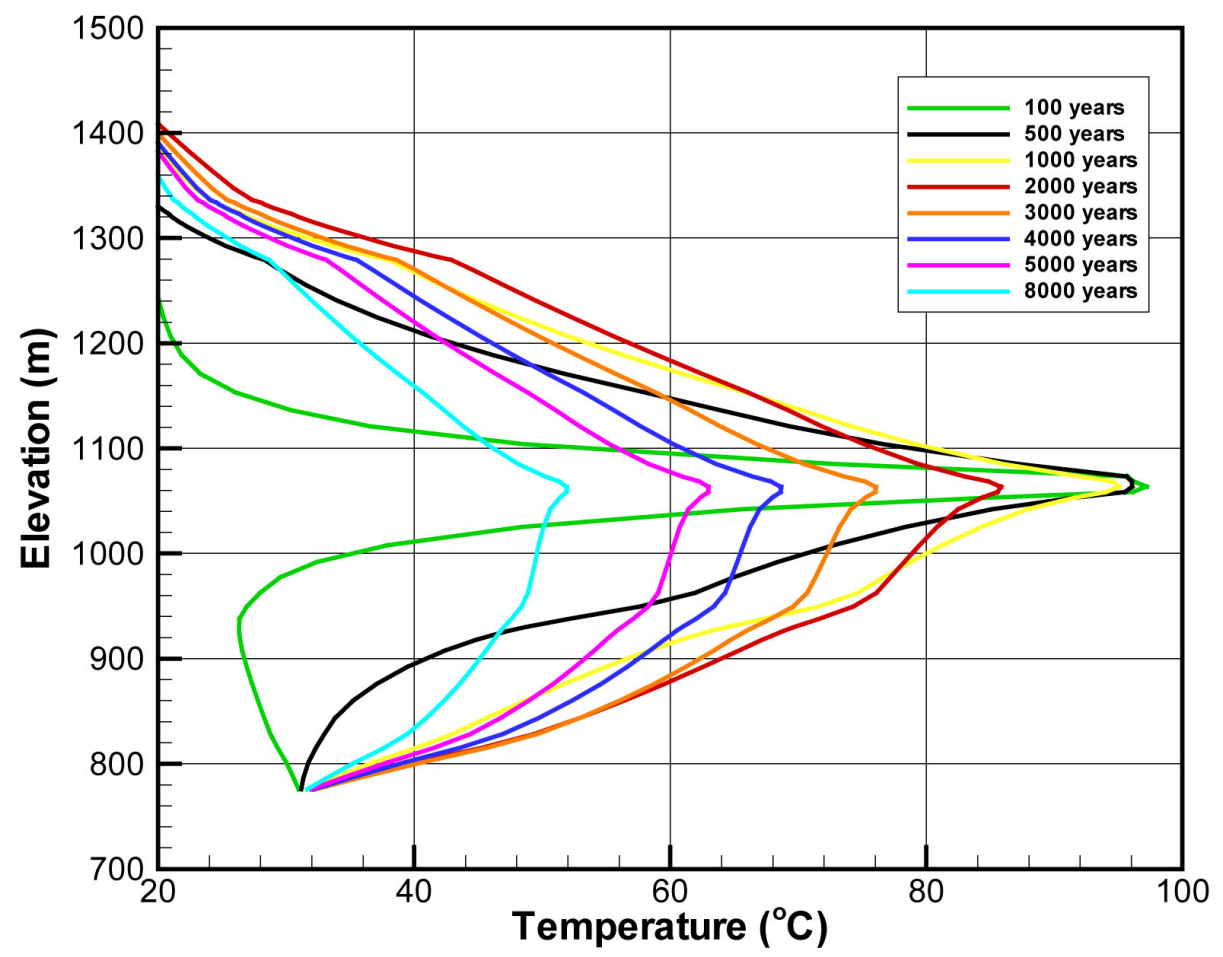

DTN: LB0310MTSCLTH2.001

Figure 6.2-9a. Temperature along a Vertical Column ("b62") from the Ground Surface to Water Table with Base-Case Thermal Loading 


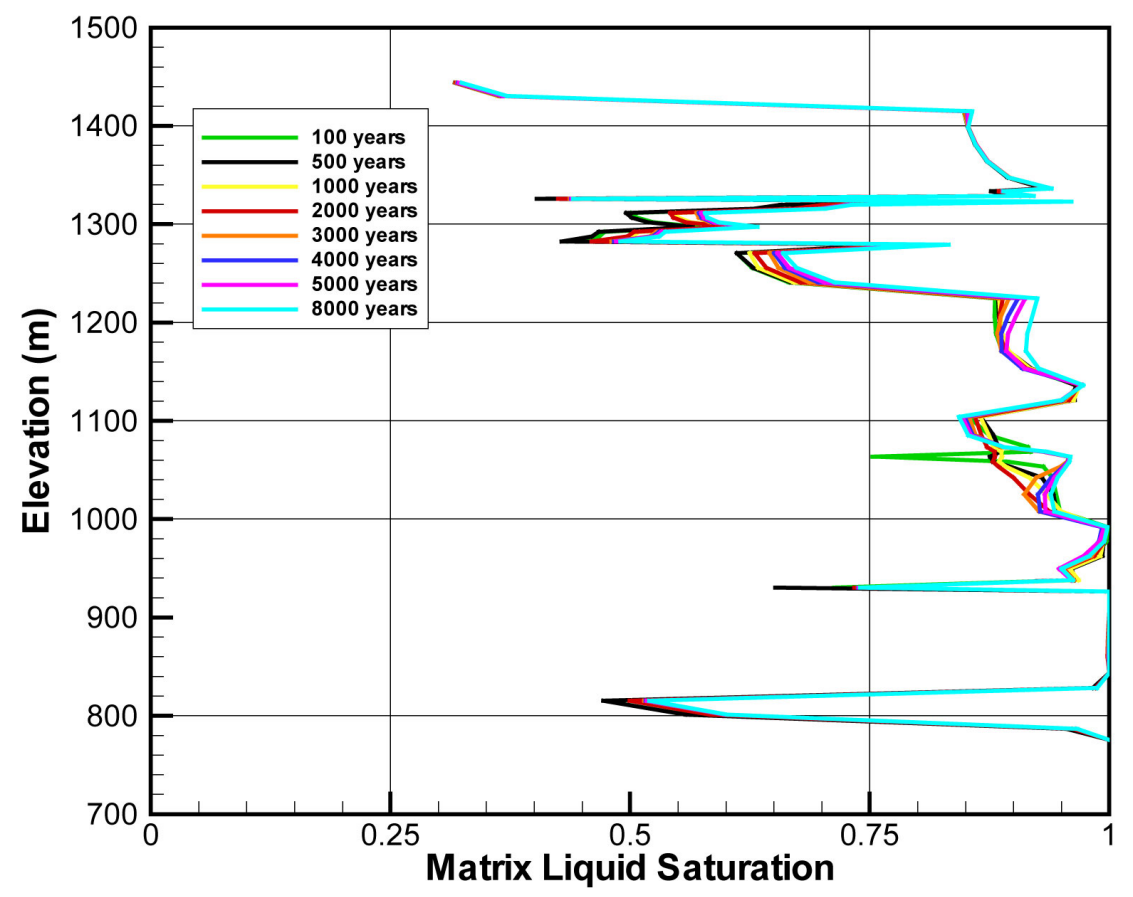

DTN: LB0310MTSCLTH2.001

Figure 6.2-9b. Matrix Liquid Saturation along a Vertical Column ("b62") from Ground Surface to Water Table with Base Thermal Loading

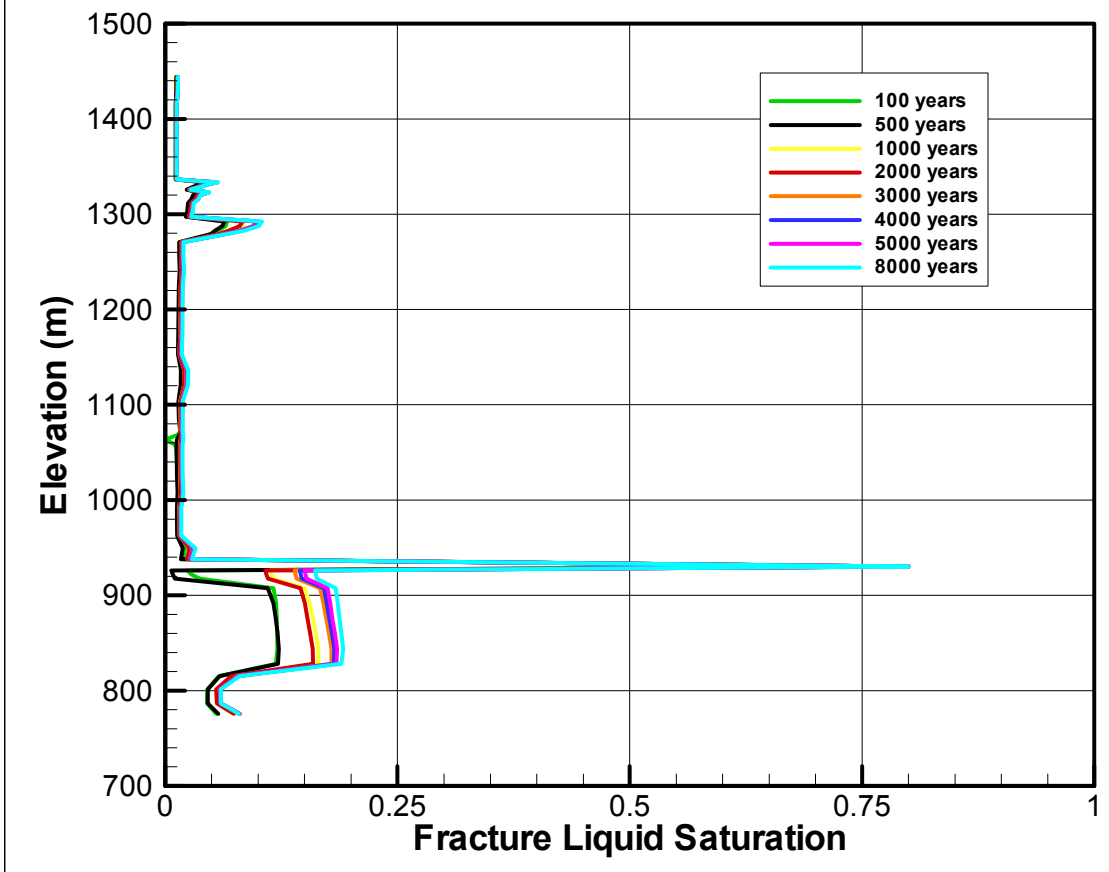

DTN: LB0310MTSCLTH2.001

NOTE: The spike in the fracture liquid saturation at $940 \mathrm{~m}$ is due to the presence of the vitric layer, which was simulated as a nonfractured matrix continuum (i.e., no fracture continuum present for that layer).

Figure 6.2-9c. Fracture Liquid Saturation along a Vertical Column ("b62") from Ground Surface to Water Table with Base-Case Thermal Loading 


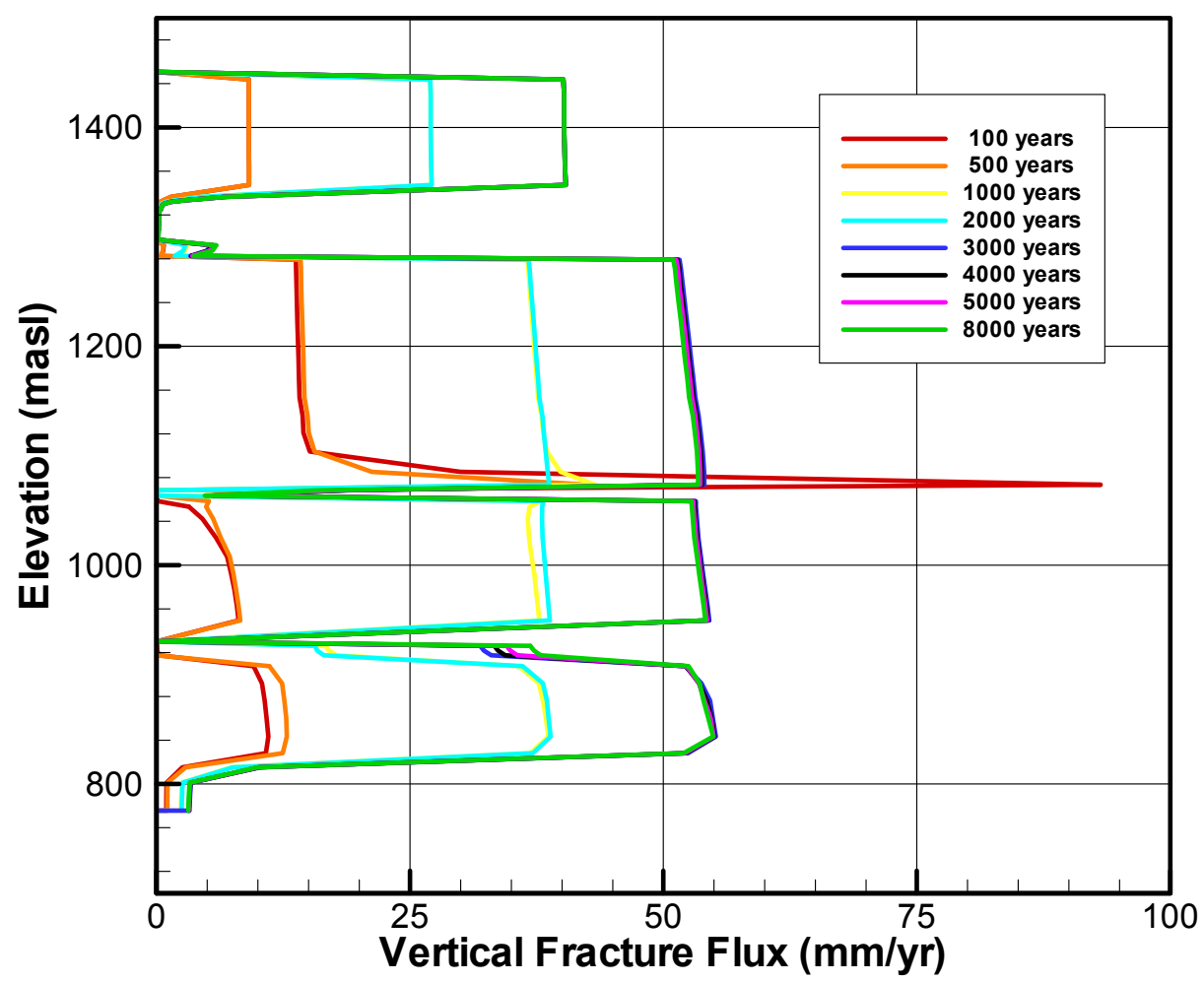

DTN: LB0310MTSCLTH2.001

NOTE: The "'zero" fracture flux at $~ 940$ masl results from the vitric layer in that location being modeled as a nonfractured matrix continuum (i.e., the fracture continuum is absent there, resulting in a zero fracture flux)

Figure 6.2-9d. Vertical Fluxes in Fractures Along Column B62 At Various Times

\subsubsection{Fracture Flux}

Drainage through fractures is illustrated in Figure 6.2-10a. This figure shows the magnitude of vertical liquid flux in fractures along the north-south axis just above the repository. The vertical fracture fluxes are shown by solid lines at 100 (green), 500 (cyan), 1,000 (yellow), 3,000 (orange), and 5,000 (red) years after emplacement of wastes. Figure 6.2-10a also shows the surface infiltration maps along the north-south axis for present day (black), monsoon (purple), and glacial transition (blue) periods by dotted lines. Fracture fluxes appear to be elevated in the pillar regions. This is further clarified in Figure 6.2-10b, where a close up of the vertical fracture fluxes in the pillar regions is shown. Though a more refined numerical grid would have provided a clearer picture of drainage through pillars, Figure $6.2-10 \mathrm{~b}$ is sufficiently informative. First, no fracture liquid fluxes are observed directly above the emplacement drifts. Because of drying (thermal barrier) and capillarity (capillary barrier) effects, water is diverted away from locations just above the emplacement drifts, resulting in elevated fluxes in the pillar region. However, the elevation in fracture fluxes in the pillar region is not very significant in the base-case because only limited displacement of water by boiling takes place in this thermal-loading scenario. 


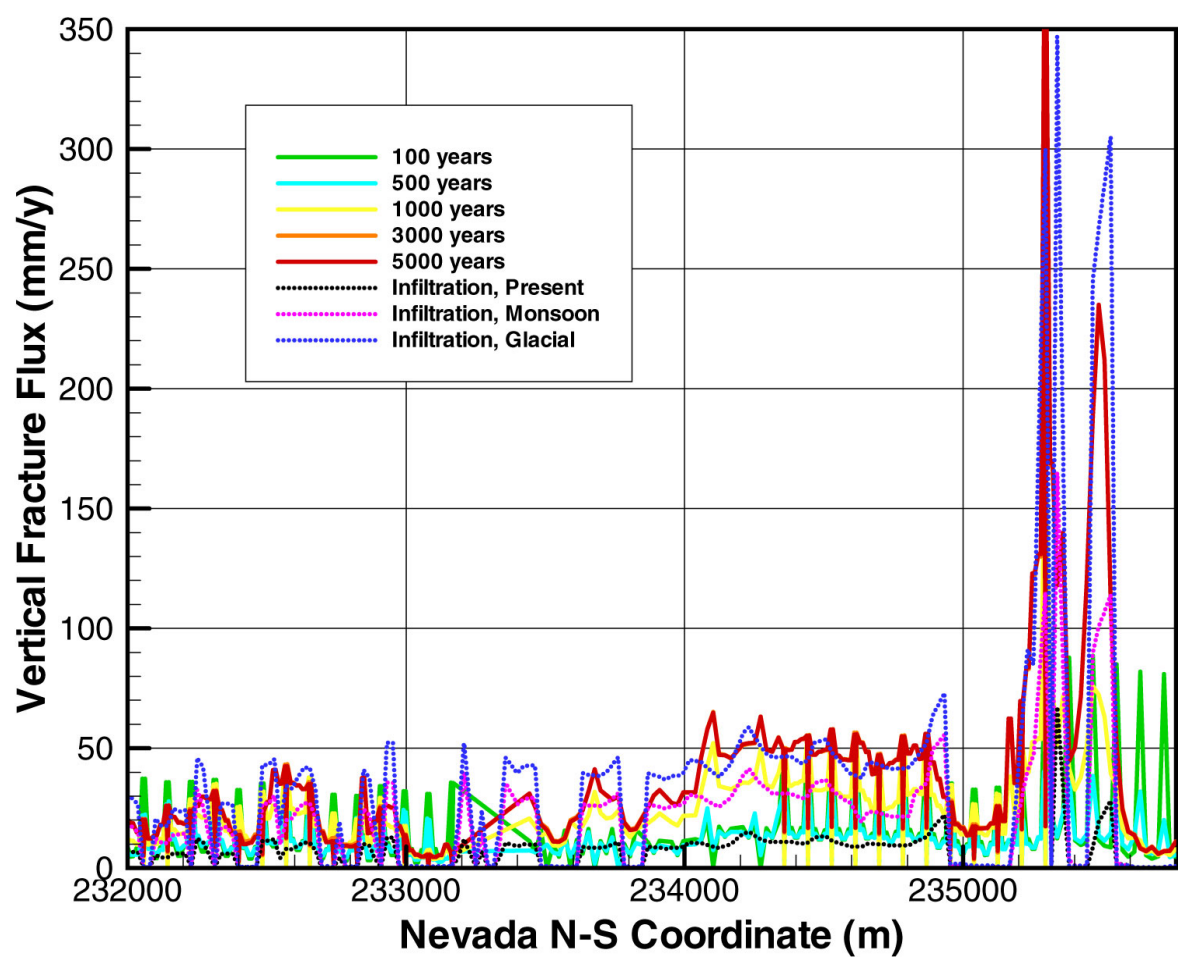

DTN: LB0310MTSCLTH2.001

Figure 6.2-10a. Vertical Downward Fluxes in the Fractures Just above the Emplacement Drifts with Base-Case Thermal Loading

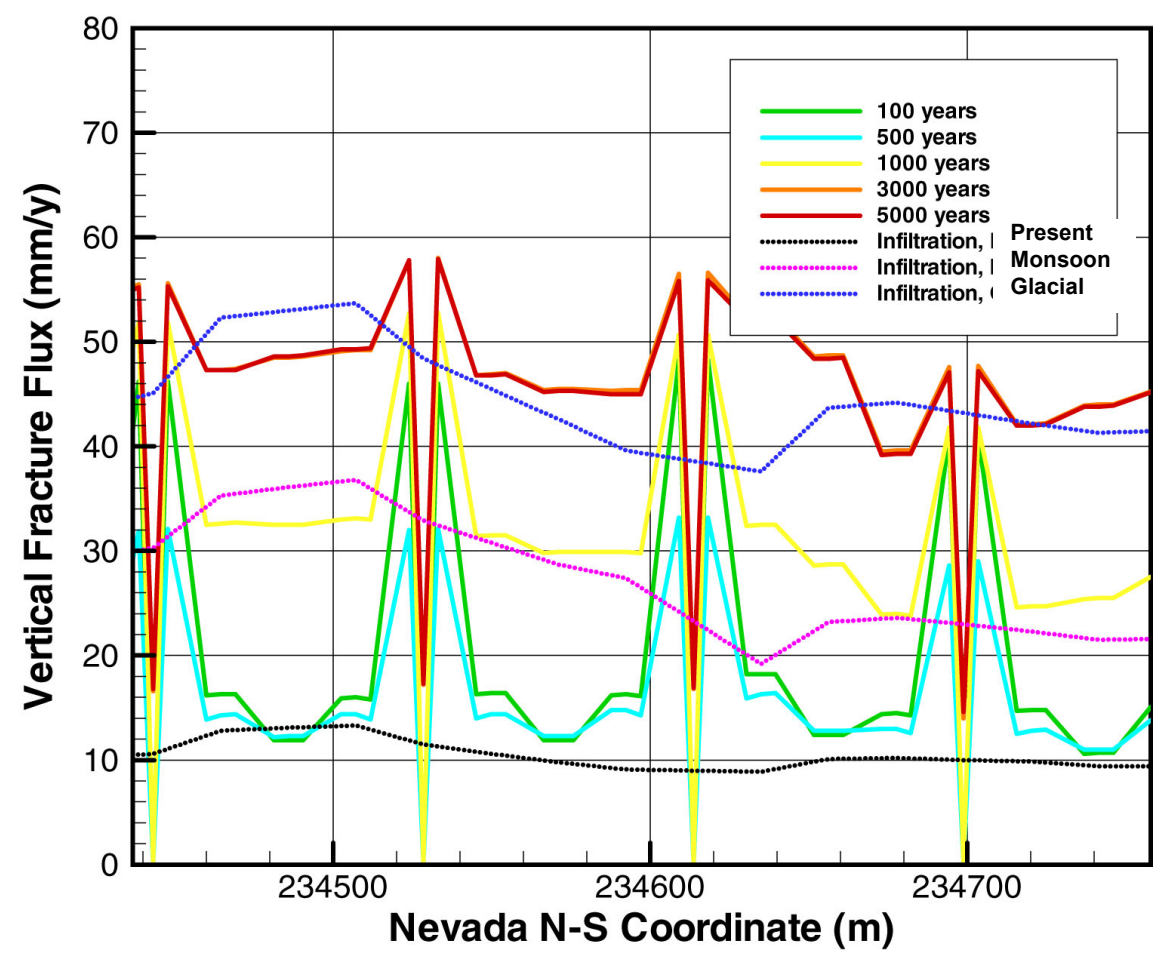

DTN: LB0310MTSCLTH2.001

Figure 6.2-10b. Vertical Downward Fluxes in Fractures over the Pillar Regions with Base-Case Thermal Loading 


\subsubsection{The No-Ventilation Case Model Results and Analyses}

The extent of thermal and hydrological perturbation in the mountain, however, may be considerably altered if the thermal loading is significantly different from the base-case scenario. Only a small perturbation in temperature, liquid saturation, and fracture fluxes occurs in the base-case scenario because mostly below-boiling conditions are maintained in the mountain. This is because a significant part (86.3\%, BSC 2002 [160975], see Section 6.1.5 for more details) of the heat is removed during the first 50 years by ventilation. A no-ventilation case has run to investigate the influence of ventilation on the extent and duration of the thermal perturbation in the mountain, a sensitivity analysis was performed where no heat was removed by ventilation. This sensitivity analysis helps in bracketing the extent of TH changes in the mountain caused by emplacement of the heat-generating wastes. In the following, a comparison is made between the base-case thermal loading scenario and a "no-ventilation" thermal-loading scenario. The sensitivity cases studied in the drift-scale $\mathrm{TH}$ model indicated that the $\mathrm{TH}$ perturbations were not significantly different from the base-case.

\subsubsection{Comparison of the TH Changes near the Repository}

Figure 6.2-11a shows the temperature from the no-ventilation scenario along the north-south axis just above the repository horizon. This figure should be compared with Figure 6.2-6a, which shows temperature at the same location from the base-case scenario. While the patterns of temperature rise and decline are similar for both the cases, the peak temperatures for the noventilation case are significantly higher than the base-case. The peak temperature in the noventilation case at 100 years is close to $130^{\circ} \mathrm{C}$, i.e., substantially above the boiling point of water. The mid-pillar region, however, still does not reach boiling temperatures. After 500 years, even the peak temperatures of the no-ventilation scenario have mostly fallen below boiling. Though the difference in temperature between the base case and the no-ventilation case is substantial during the initial phases of heating, the difference decreases as heat load decreases with time. At 8,000 years, the base-case and no-ventilation case are almost indistinguishable as far as temperature is concerned. Thus, even if the entire heat from the wastes were available, the thermal regime in the mountain is not expected to last much longer than 10,000 years.

The matrix liquid saturations just above the repository for the no-ventilation scenario are shown in Figure 6.2-11b. This figure should be compared with Figure 6.2-7a. Clearly, because of the significantly higher-than-boiling temperature in the no-ventilation case, there is extensive drying in the matrix for this case. This implies that significantly more water has been displaced from the matrix pores by heating in the no-ventilation case. During the later phases, rewetting of the matrix pores takes place, and the saturation profiles for the two cases are comparable. Fracture liquid saturation in that same location for the no-ventilation scenario is shown in Figure 6.2-11c (compare with Figure 6.2-8a). The trends in fracture saturation are similar to those for matrix liquid saturation. 


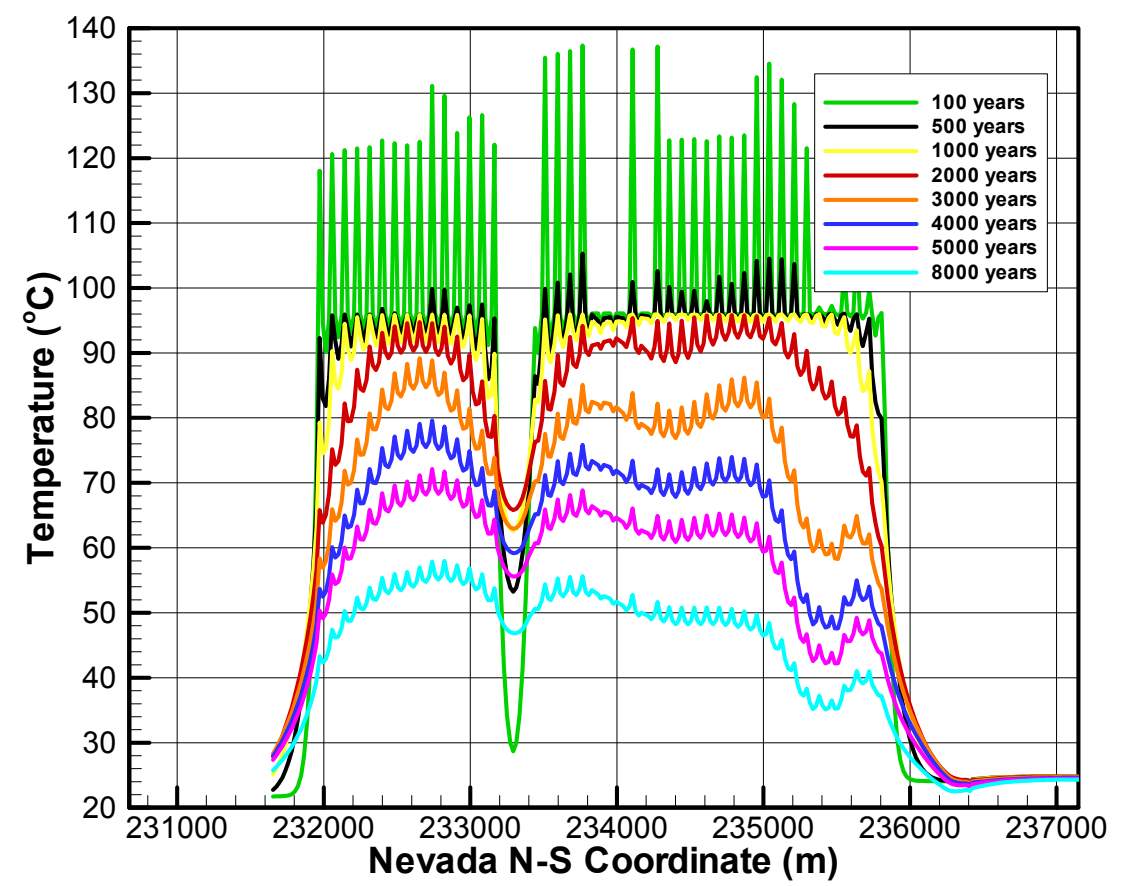

NOTE: Compare This Figure with Figure 6.2-6a.

Figure 6.2-11a. Comparison of Temperatures Just above the Emplacement Drifts Arising from NoVentilation Thermal-Loading Scenario

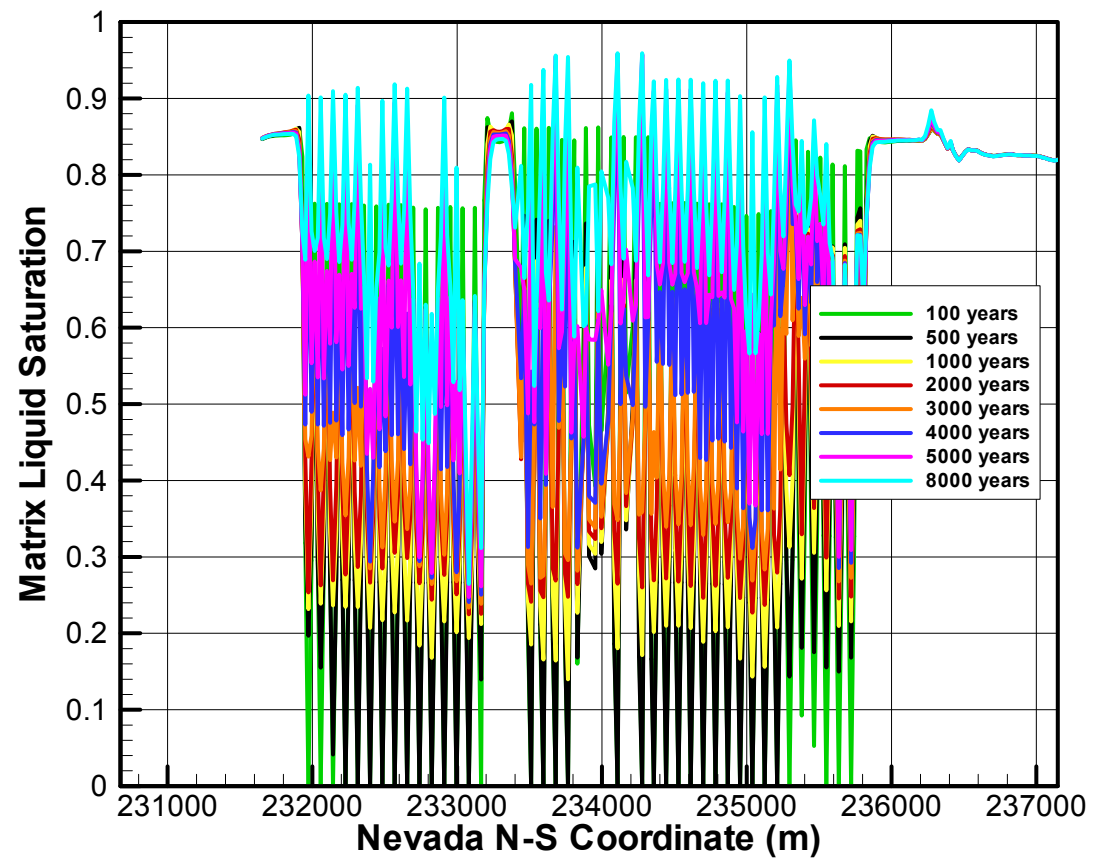

NOTE: Compare This Figure with Figure 6.2-7a.

DTN: LB0310MTSCLTH2.001

Figure 6.2-11b. Matrix Liquid Saturation Just above the Emplacement Drifts Arising from the NoVentilation Thermal-Loading Scenario 


\subsubsection{Comparison of the TH Changes at the Bottom of the PTn}

Stronger thermal loading in the no-ventilation case produces a larger perturbation in temperature and liquid saturation in the vicinity of the emplacement drifts (Figures 6.2-11a-c). Figures 6.212a-c compare the thermal perturbation produced by the base-case and the no-ventilation case at the bottom of the PTn. These figures demonstrate how the TH regime far away from the repository is influenced by the thermal-loading at the repository. Figure 6.2-12a shows temperature for the two thermal-loading scenarios at the bottom of the PTn. Recall that (Figure 6.2-6b) with the base-case thermal loading, temperature at the bottom of the PTn reached a maximum of about $50^{\circ} \mathrm{C}$ at 2,000 years. In the no-ventilation thermal-loading scenario, a peak temperature of approximately $65^{\circ} \mathrm{C}$ is realized at the bottom of the PTn. However, this peak is reached earlier (at 1,000 years) compared to the base-case. Thereafter, the difference in temperatures from the two thermal-loading scenarios continues to decrease, and at 8,000 years, there is no noticeable difference in the temperatures predicted by these two scenarios. Stronger heat loading causes about $10-15^{\circ} \mathrm{C}$ (up to $20^{\circ} \mathrm{C}$ ) higher peak temperature at the bottom of the PTn in the first 1,000 or so years, and the difference between the temperatures continues to decrease thereafter (becoming similar by 8,000 years). One inference from this is that the impact of heat loading is the largest close to the repository (drift-scale), and the maximum impact is limited to the first 1,000 years or so elsewhere in the mountain.

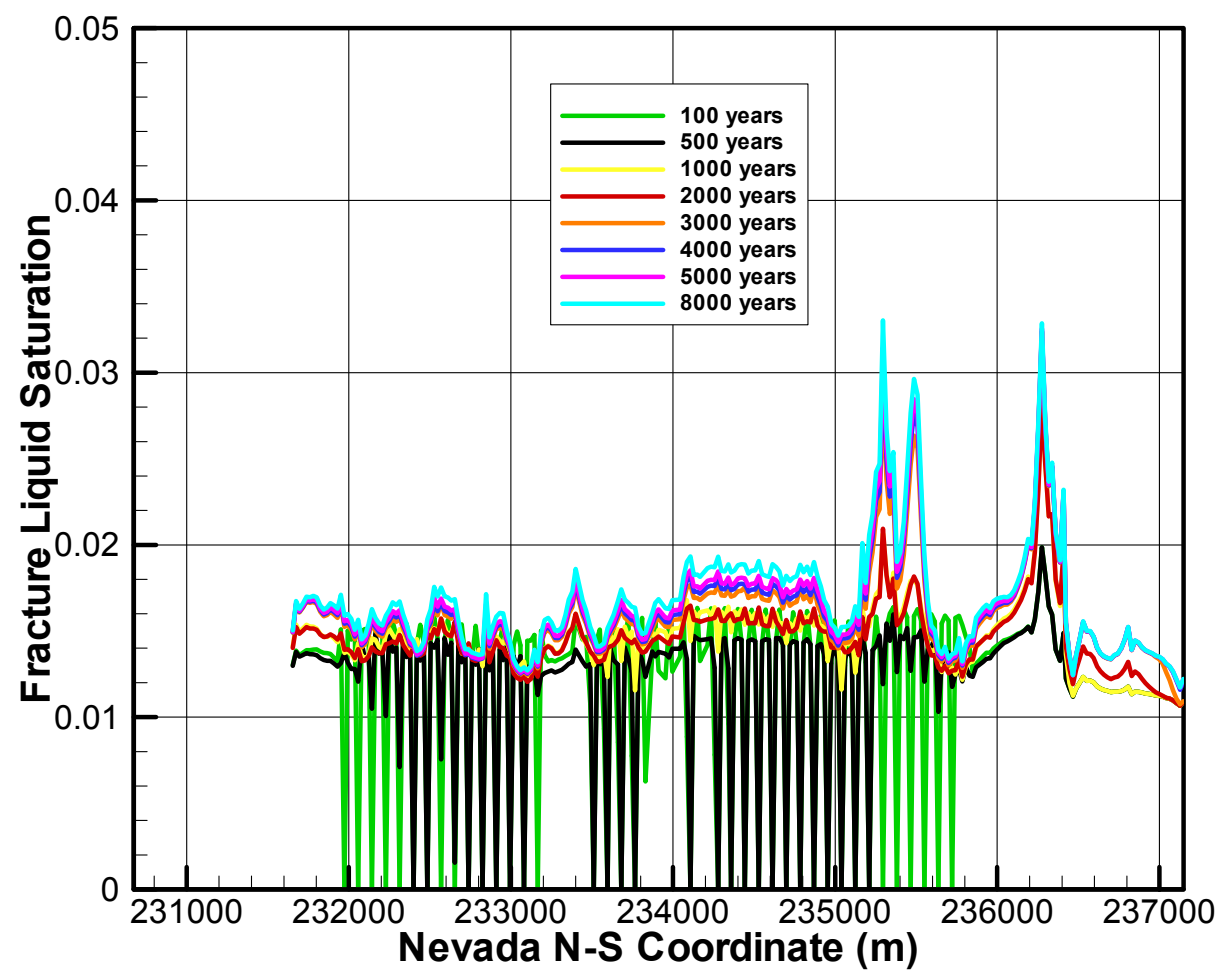

DTN: LB0310MTSCLTH2.001

NOTE: See Figure 6.2-8a for fracture liquid saturation just above the emplacement drifts arising from the base-case thermal-loading scenerio.

Figure 6.2-11c. Fracture Liquid Saturation Just above the Emplacement Drifts Arising from the NoVentilation Case Thermal-Loading Scenario 


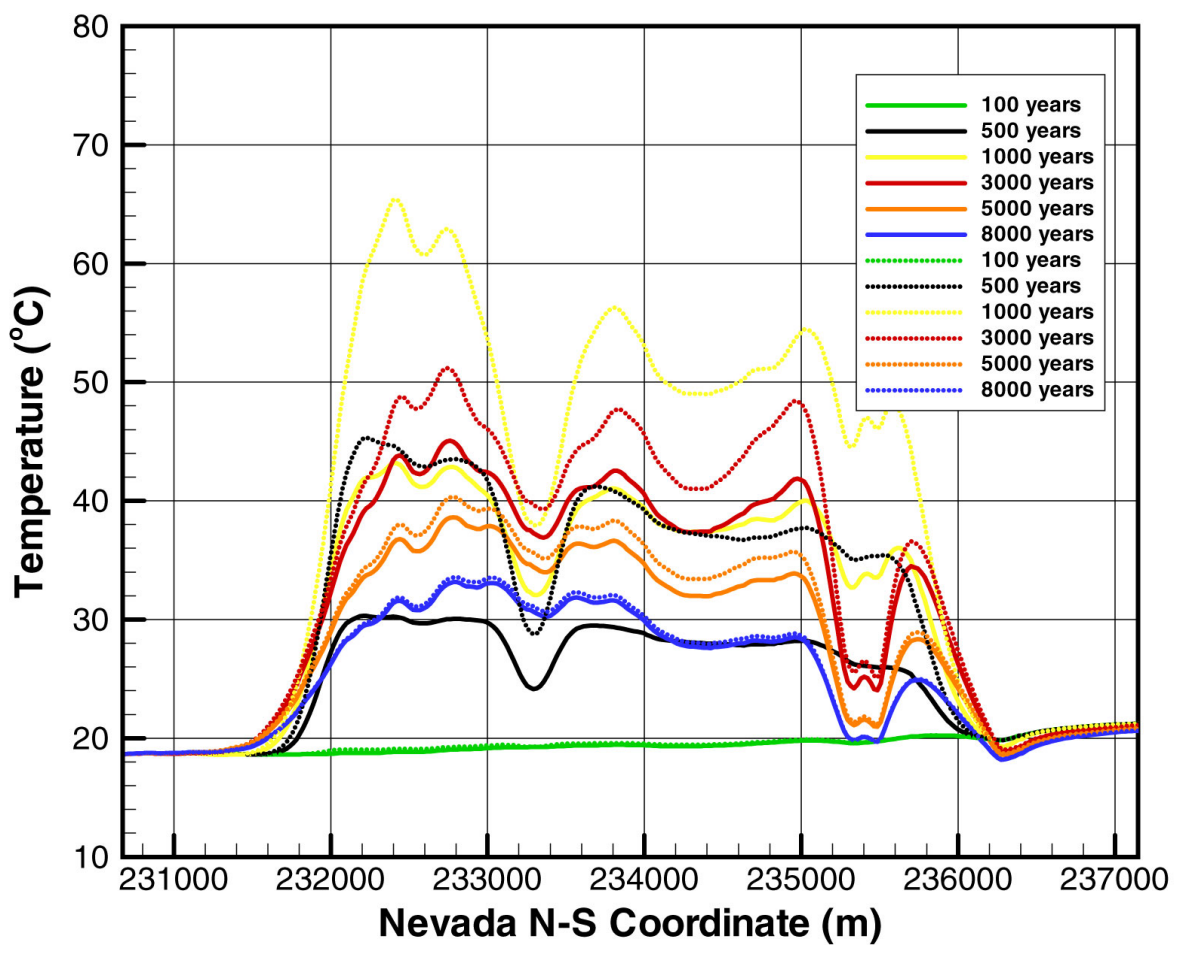

DTN: LB0310MTSCLTH2.001

Figure 6.2-12a. Comparison of Temperature at the Bottom of PTn Arising from the Base-Case (Solid Lines) and No-Ventilation Case (Dotted Lines) Thermal-Loading Scenario

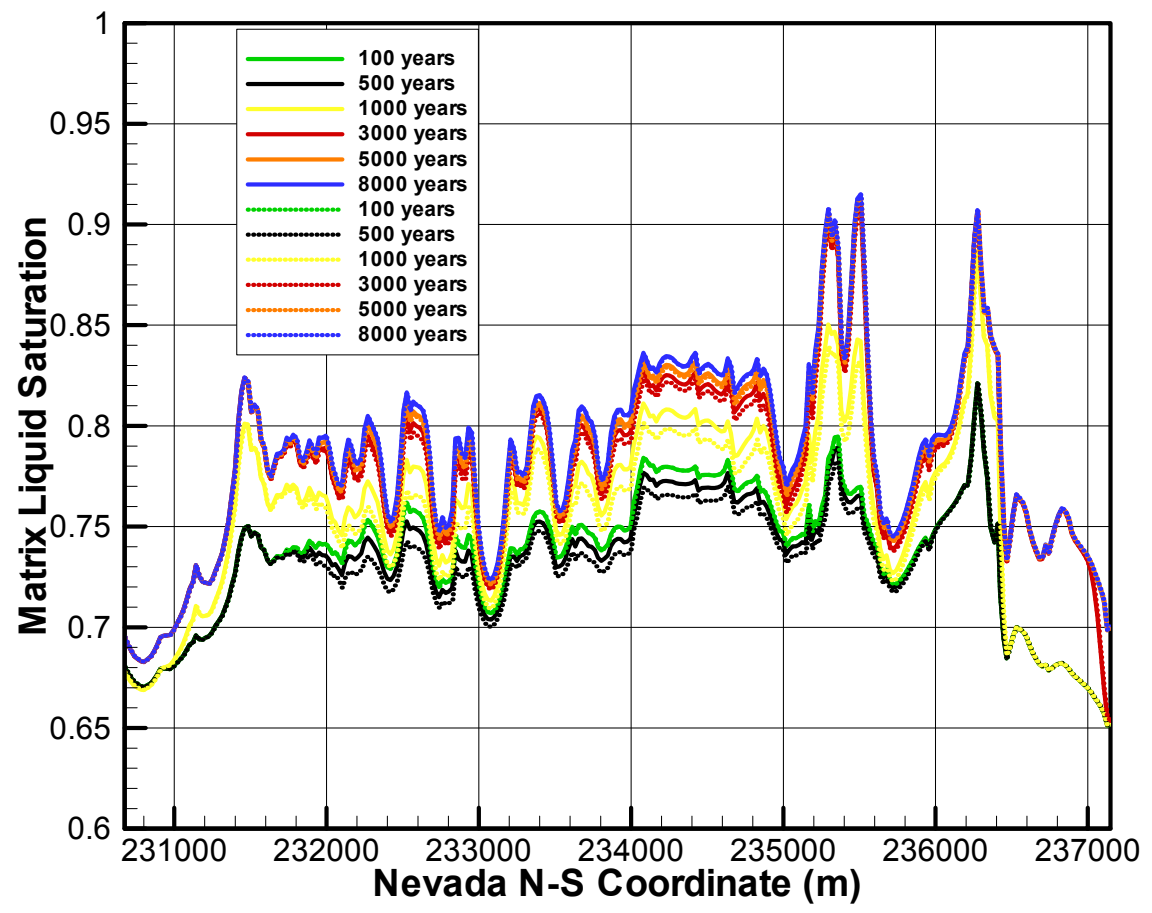

DTN: LB0310MTSCLTH2.001

Figure 6.2-12b. Comparison of Matrix Liquid Saturation at the Bottom of PTn Arising from the BaseCase (Solid Lines) and the No-Ventilation Case (Dotted Lines) Thermal-Loading Scenarios 
That inference is also substantiated by Figure $6.2-12 \mathrm{~b}$, where the matrix liquid saturation for the two different thermal-loading scenarios at the bottom of PTn is compared. While a stronger thermal loading in the no-ventilation case resulted in extensive drying in the near-repository area (compared to the base case), the matrix liquid saturation is relatively unaltered at the bottom of PTn by the change in thermal loading. This is because in both cases, temperatures at the bottom of PTn are below boiling, so that very little drying or rewetting occurs there. As a result, matrix liquid saturation is similar for the two cases at the bottom of PTn. The same holds for fracture liquid saturation at the bottom of PTn (Figure 6.2-12c). The bottom of the PTn stratigraphic unit is only minimally impacted by the change in thermal loading. Similar response is predicted for the bottom of the TSw, which is located approximately $100 \mathrm{~m}$ below the repository. These models predict that ventilation has limited impact on mountain-scale TH conditions beyond 100$150 \mathrm{~m}$ above or below the repository.

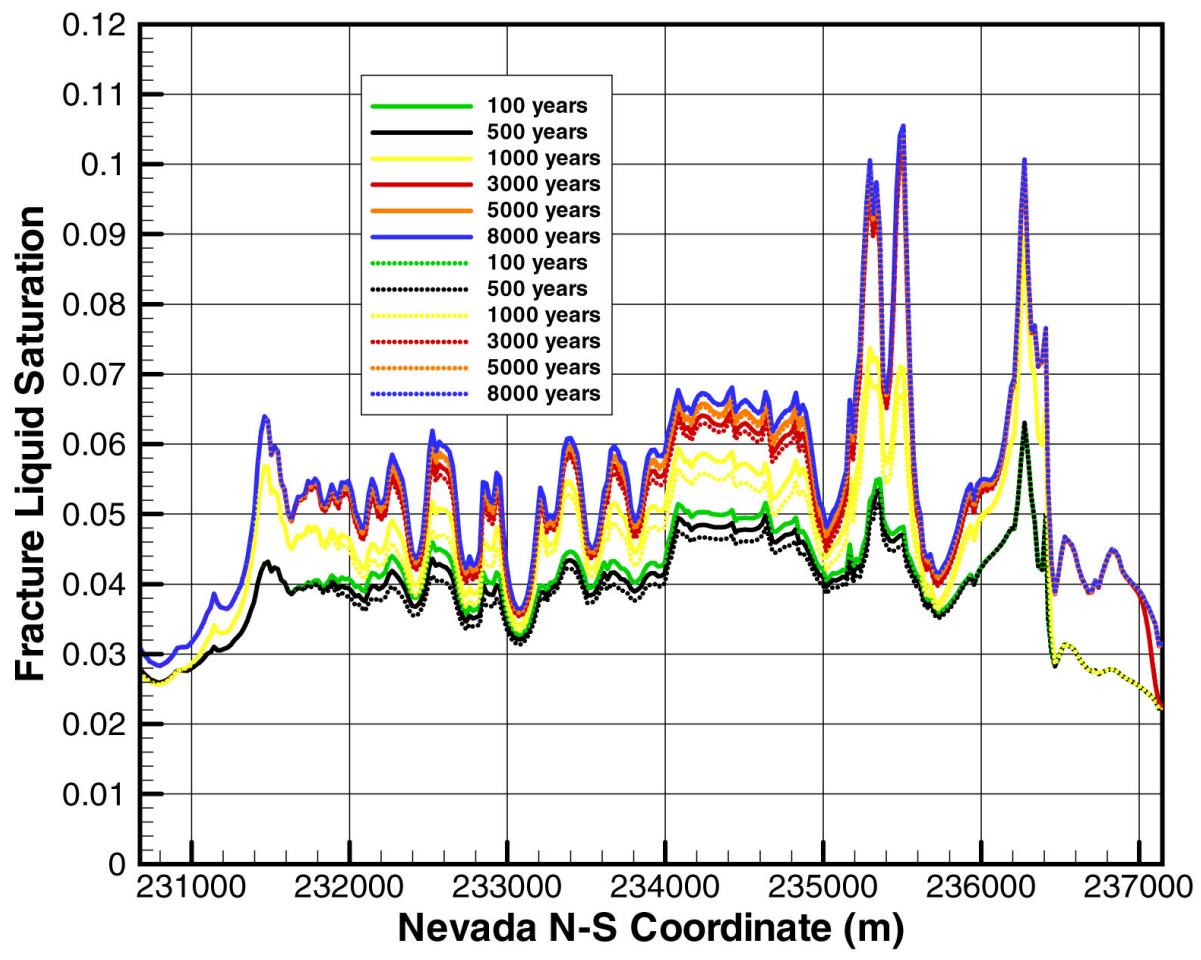

DTN: LB0310MTSCLTH2.001

Figure 6.2-12c. Comparison of Fracture Liquid Saturation at the Bottom of PTn Arising from the BaseCase (Solid Lines) and the No-Ventilation (Dotted Lines) Thermal-Loading Scenarios

\subsubsection{Comparison of Fracture Fluxes}

Figure 6.2-13 shows vertical liquid fluxes in the fractures for the two thermal-loading scenarios at 100 years and 500 years (the peak thermal perturbation times) just above the repository. In this figure, the solid lines refer to the base-case thermal-loading scenario, and the dotted lines correspond to the no-ventilation thermal-loading scenario. The vertical fluxes are not shown along the entire north-south axis of the repository but over a distance covering a few typical emplacement drifts. The figure shows detailed evolution of fracture fluxes in the pillar regions between adjacent drifts. Observe that, both at 100 years and 500 years, the vertical fracture 
fluxes in the pillar region for the no-ventilation case are twice as large as those for the base-case. This is because more water is displaced by boiling in the no-ventilation case than in the base case. Additionally, because of higher temperatures and more extensive boiling in the noventilation case, the thermal barrier is larger both in spatial and temporal extent compared to the base-case. This results in a larger diversion of water through the pillar region for the noventilation case. This also indicates that, even during peak thermal perturbation (resulting from the higher heat load in the no-ventilation case), drainage takes place through the pillar region. Fracture fluxes just above the repository arising out of the two thermal-loading scenarios are similar once the thermal regime ends, i.e., after about 5,000 years.

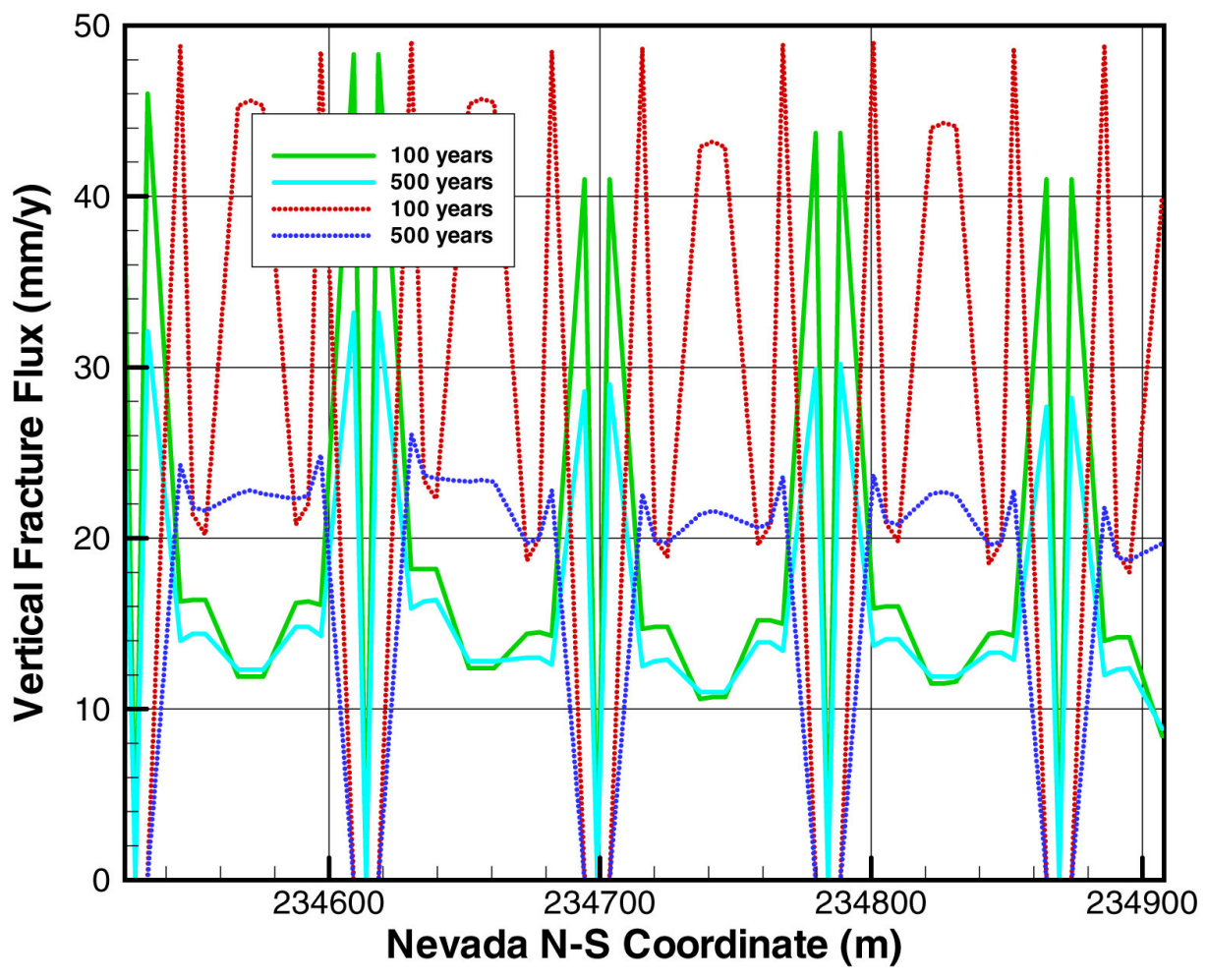

DTN: LB0310MTSCLTH2.001

Figure 6.2-13. Vertical Fracture Liquid Fluxes Into the Pillar Regions from Top, Comparison of the Base-Case (Solid Line) and No-Ventilation Case (Dotted Line) Thermal Loading Scenarios during Peak Thermal Periods

\subsection{3-D MOUNTAIN-SCALE TH MODEL RESULTS AND ANALYSES}

Mountain-scale TH effects caused by thermal load at the repository are 3-D phenomena lasting hundreds to thousands of years after waste emplacement. Thus, 3-D models provide the most accurate approach to predicting $\mathrm{TH}$ effects. In this section, 3-D TH simulations are used to analyze the evolution of temperature, saturation, and percolation flux under thermal-loading conditions. As discussed in Sections 6.1.5, the 3-D TH Model uses the same two thermal-loading scenarios over the entire repository drift blocks as those in the 2-D TH Model (Section 6.2). The first thermal-loading scenario, the base-case, considers that $86.3 \%$ of the heat load is removed by ventilation in the first 50 years after initial waste emplacement. In the second scenario, heat removal by ventilation is ignored. Similarly, the net infiltration rates over the 3-D model domain 
consist of three time periods for future climates, as given in Table 6.1-2. The future climates in both thermal-loading scenarios are represented by the same three sequential modeled periods: present (0-600 years), monsoon (600-2,000 years), and then glacial transition (2,000 years and beyond). These results in a step increase in net surface infiltration rates supplied over the model top boundary.

The results of 3-D TH model simulations of the two thermal-loading scenarios are presented and discussed in terms of a number of 2-D contour plots of temperature, saturation, and flux at the bottom of PTn, the top of $\mathrm{CHn}$, the repository horizon, and a north-south (NS) vertical cross section. Plots of the evolution of temperature, saturation, and vertical flux are provided for several 1-D observation columns, selected from the 3-D model grid. Coordinates and corresponding columns for these selected observation cells along the 1-D grid columns are listed in Table 6.3-1, and the locations of these observation cells are also shown in Figure 6.1-1 in plan view. For this mountain-scale TH model, this Model Report is primarily concerned with the extent of the thermally disturbed zone and the predicted mountain-scale changes in the temperature, saturation, and percolation flux under the influence of repository thermal load. Attachment IV (Section IV.2) documents the procedures of data extraction and plotting of 3-D $\mathrm{TH}$ model simulation results.

Table 6.3-1. Observation Cells, Grid Columns, and Coordinates of the 3-D TH Model

\begin{tabular}{|l|l|l|l|}
\hline \multicolumn{1}{|c|}{ Observation Cell } & \multicolumn{1}{c|}{ Column } & \multicolumn{1}{|c|}{$\mathbf{X}(\mathbf{m})$} & \multicolumn{1}{c|}{$\mathbf{Y ( m )}$} \\
\hline A & d 3 & 170901.9 & 232754.1 \\
\hline B & B58* & 171376.6 & 232822.1 \\
\hline C & h57 & 170516.1 & 233394.2 \\
\hline D & e42 & 171983.8 & 233432.5 \\
\hline E & h50 & 171051.3 & 234717.3 \\
\hline F & h47 & 170743.5 & 235090.3 \\
\hline G & a71 & 170127.5 & 235135.7 \\
\hline H & b60 & 171016.5 & 235176.1 \\
\hline I & A41 & 171411.7 & 235271.2 \\
\hline J & b72 & 171991 & 235322.4 \\
\hline
\end{tabular}

DTN: LB0310MTSCLTH3.001

NOTE: $\quad$ *Fault columns.

\subsubsection{Base-Case Model Results and Analyses}

As discussed in Section 6.1.5 and above, the base-case TH Model uses only $13.7 \%$ of the total thermal load in the first 50 years after waste emplacement (BSC 2003 [166343]). After 50 years, $100 \%$ thermal load is introduced into repository drifts. The base-case $\mathrm{TH}$ model results are displayed using several (2-D) plots along selected horizontal layers, the NS vertical cross section, and 1-D vertical columns of Table 6.3-1 (Figure 6.1-1) to discuss the changes of temperature, saturation, and flux near the repository and the UZ system under the effect of repository thermal load. 


\subsubsection{Temperature}

Figures 6.3.1-1-6.3.1-5 show the 3-D TH model simulated temperatures at the repository horizon, bottom of the PTn, and top of the CHn, at 100, 500, 1,000, 2,000, and 5,000 years after emplacement. Note that in the 3-D model, the grid layers, such as the selected repository horizon, PTn bottom, and CHn top layers, are not exactly horizontal (see Figure 6.1-2 for the stratigraphic layers and their spatial distributions along the NS cross section), and they have varying thickness and elevations over the model domain, designed following the geological model. These temperature distribution contours indicate how $\mathrm{TH}$ conditions along these layers are impacted by the repository thermal load at different times. The simulated temperatures at repository horizon, as shown in Figures 6.3.1-1a, 6.3.1-2a, 6.3.1-3a, 6.3.1-4a, and 6.3.1-5a, indicate that after 100 years, a boiling condition at the ambient atmospheric pressure is reached in many drift elements located at or near the center of the northern repository layout block. (Note that temperatures shown in these figures are for the rock surrounding the drift and not for the drift itself, where boiling temperatures are reached.) The boiling condition lasts up to 1,000 years along the central portion of drifts away from the repository layout boundary. These temperature contours also show that at the repository, the highest-temperature period or the strongest thermal effect is from 500 to 1,000 years. After 1,000 years, the thermal effect of repository heating starts decreasing. After 2,000 years, the temperatures at and near the repository are significantly cooled down. At 5,000 years, Figures 6.3.1-5a and 6.3.1-5b show that majority of the system returns almost to ambient conditions, and temperatures at the remaining hottest spots within the repository area are $60^{\circ} \mathrm{C}$ only or less.

At earlier times (up to 100 years), the simulation results (Figures 6.3.1-1a and 6.3.1-1b) show very limited spatial thermal disturbance from repository heating. During this period, repository thermal load has little impact on the TH conditions at the bottom of PTn and the top of CHn. As repository heating continues, the thermal impact on far-field thermal conditions appears more evident. Figures 6.3.1-2b, 6.3.1-3b, and 6.3.1-4b display the increase in temperature along the bottom of the PTn unit, which rises from the ambient $20^{\circ} \mathrm{C}$ to above $40^{\circ} \mathrm{C}$ at 500 years, to more than $50^{\circ} \mathrm{C}$ in certain areas at 1,000 years, and even higher at 2,000 years. Similarly, the temperatures below the repository (Figures 6.3.1-2c, 6.3.1-3c, and 6.3.1-4c), along the top of the $\mathrm{CHn}$, also increase from their ambient $27^{\circ} \mathrm{C}$ to above $50^{\circ} \mathrm{C}$ at 500 years, to $65^{\circ} \mathrm{C}$ at 1,000 years, and to $75^{\circ} \mathrm{C}$ at 2,000 years, respectively. These changes in far-field temperature, predicted by the 3-D TH model, reach their peak values about 2,000 years after waste emplacement, which is consistent with those temperatures simulated by the 2-D model, discussed in the last section (Section 6.2). Also note that since the water table in the 3-D TH model is maintained at a constant temperature, the predicted increase in temperature at the top of the $\mathrm{CHn}$ is expected to be somewhat underestimated. In general, the $\mathrm{TH}$ model results indicate that a larger increase in temperature (or stronger TH impact) occurs at the top of CHn than at the bottom of PTn, since the top of $\mathrm{CHn}$ is much closer to the repository horizon than the PTn bottom (See Figure 6.1-2).

The vertical spatial variations in temperature along the NS cross section of the 3-D model (Figure 6.1-1) at 1,000 years are shown in Figure 6.3.1-3d. At this time, the heated zones around the repository start cooling down, and the predicted maximum temperatures are $95^{\circ} \mathrm{C}$ at repository rock, which is below the ambient boiling point. As Figures 6.3.1-5a and 6.3.1-5b 
indicate, at 5,000 years after waste replacement, the highest temperatures within the repository horizon are only at $60^{\circ} \mathrm{C}$.

\section{Temperature Distribution at Repository Horizon (100 years)}

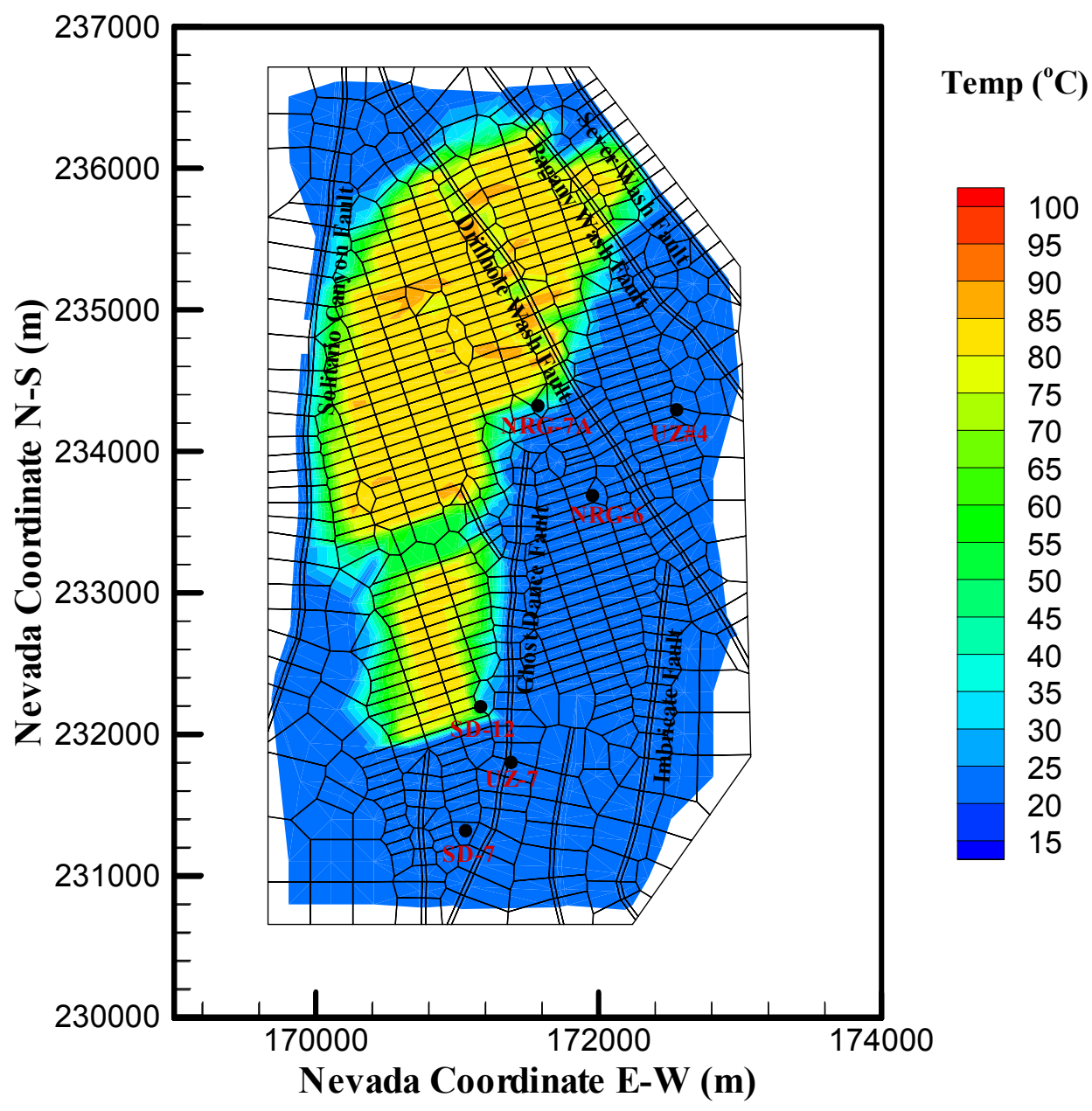

DTN: LB0310MTSCLTH3.001

Figure 6.3.1-1a. Model-Predicted Rock Temperature Distribution at Repository Horizon at Time of 100 Years after Nuclear Waste Emplacement (the Base-Case Model with Ventilation). 
Temperature at $\mathrm{N}-\mathrm{S}$ cross section at time 100 years

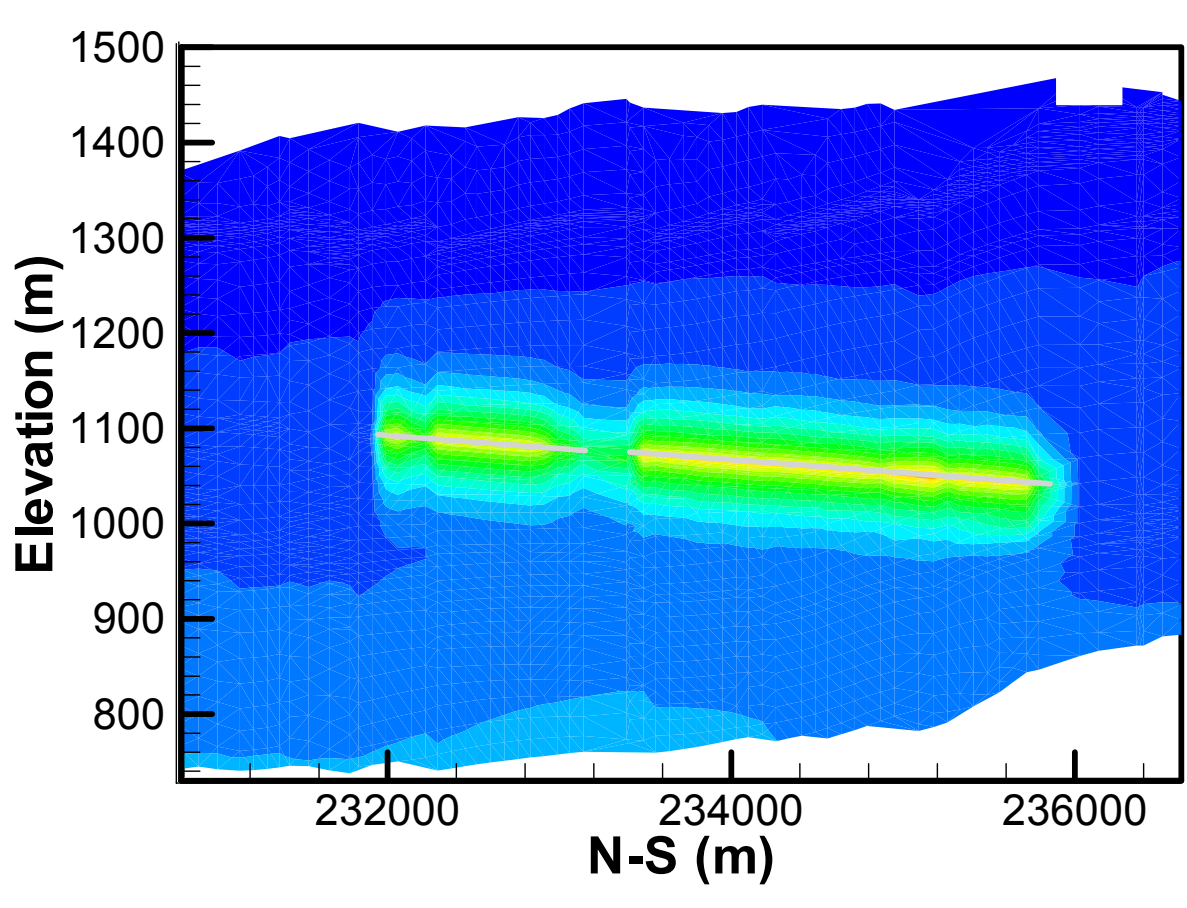

Temp $\left({ }^{\circ} \mathrm{C}\right)$

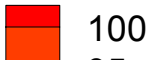

95

90

85

80

75

70

65

60

55

50

45

40

35

30

25

20

DTN: LB0310MTSCLTH3.001

Figure 6.3.1-1b. Model-Predicted Temperature Distribution at the N-S Cross Section at 100 Years after Nuclear Waste Emplacement (the Base-Case Model with Ventilation). 


\section{Temperature Distribution at Repository Horizon (500 years)}

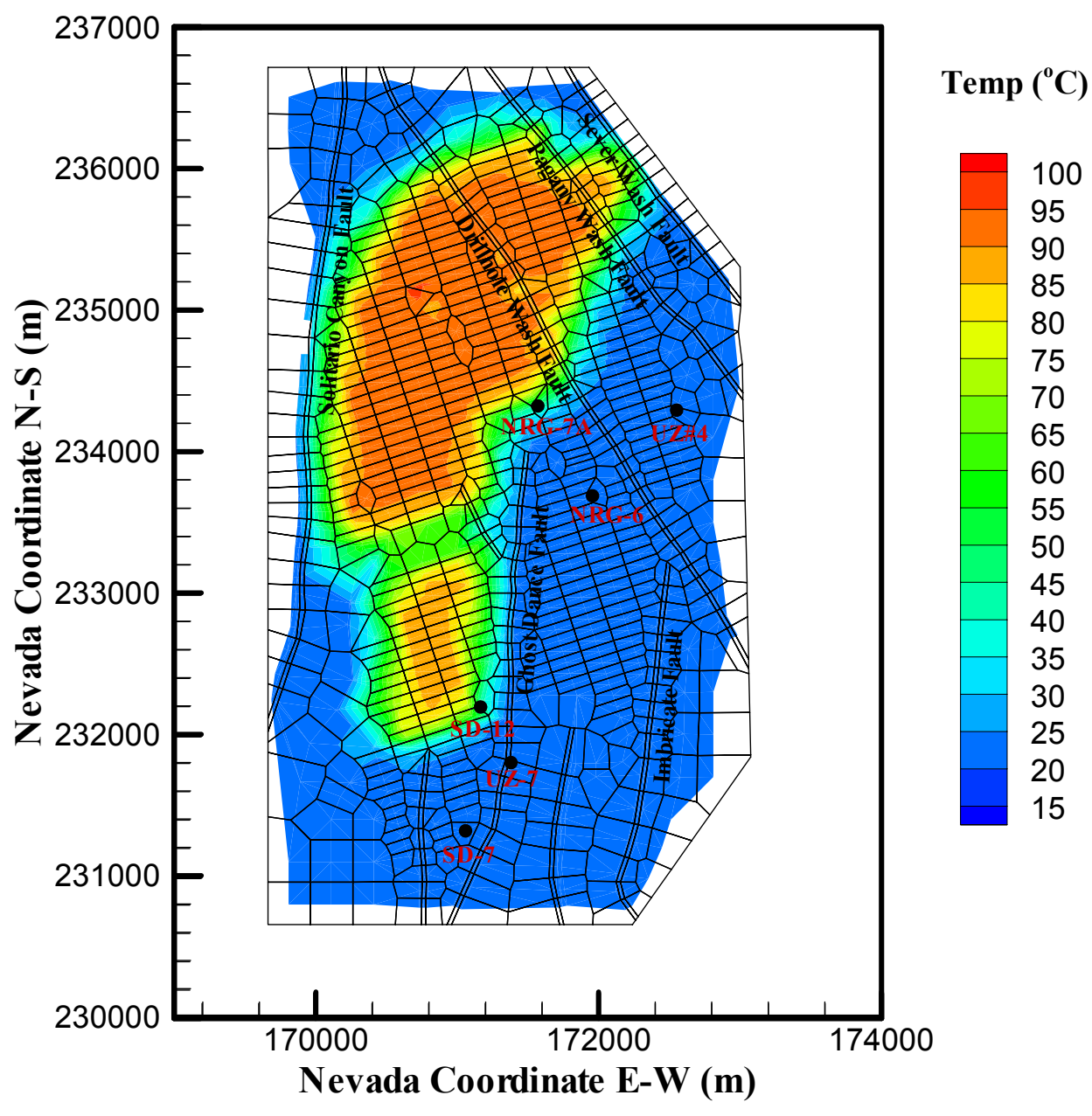

DTN: LB0310MTSCLTH3.001

Figure 6.3.1-2a. Model-Predicted Rock Temperature Distribution at Repository Horizon at 500 Years after Nuclear Waste Emplacement (the Base-Case Model with Ventilation) 


\section{Temperature Distribution at PTn bottom (500 years)}

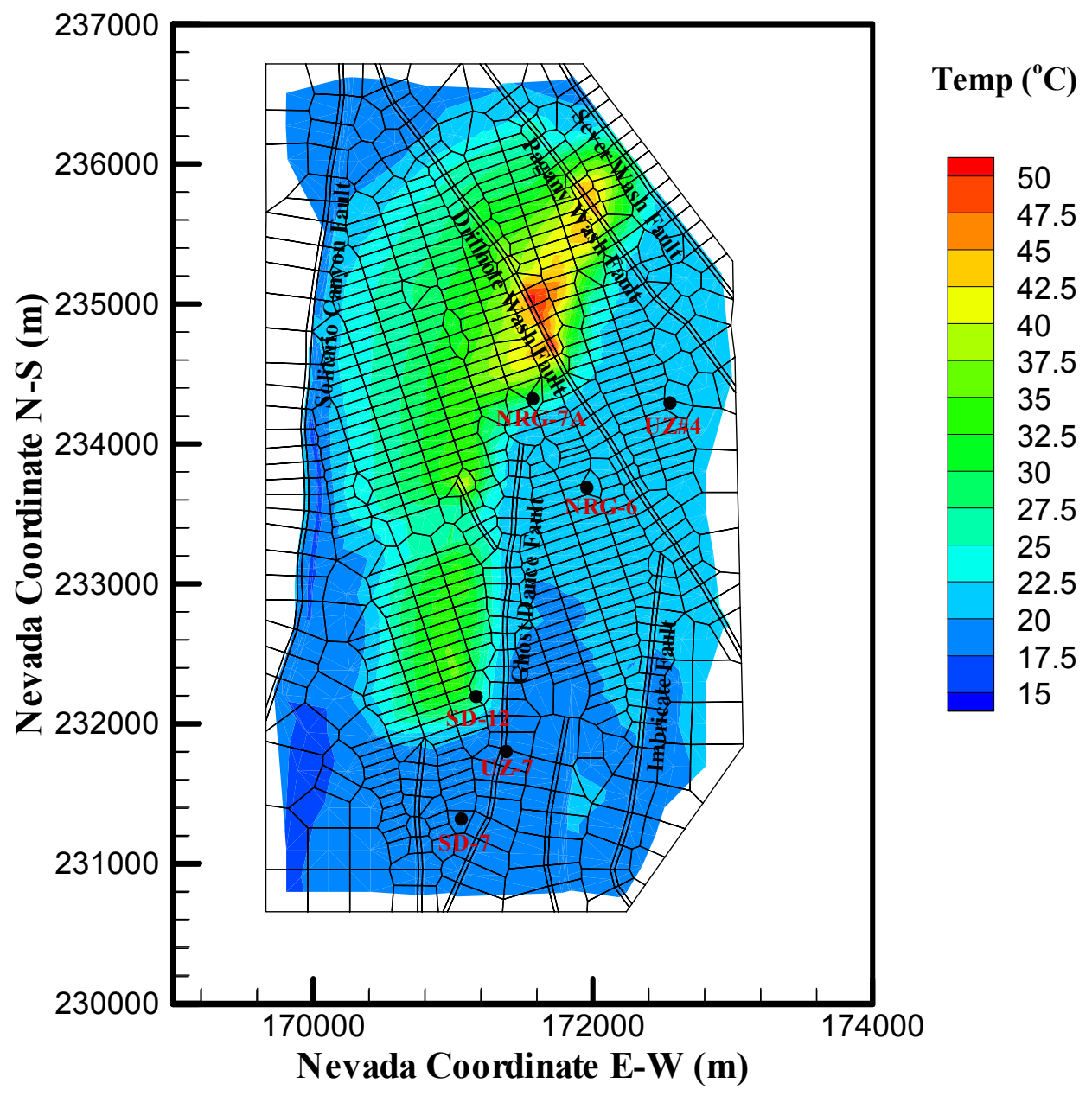

DTN: LB0310MTSCLTH3.001

Figure 6.3.1-2b. Model-Predicted Rock Temperature Distribution at the Bottom of PTn Unit at 500 years after Nuclear Waste Emplacement (Base-Case Model with Ventilation) 


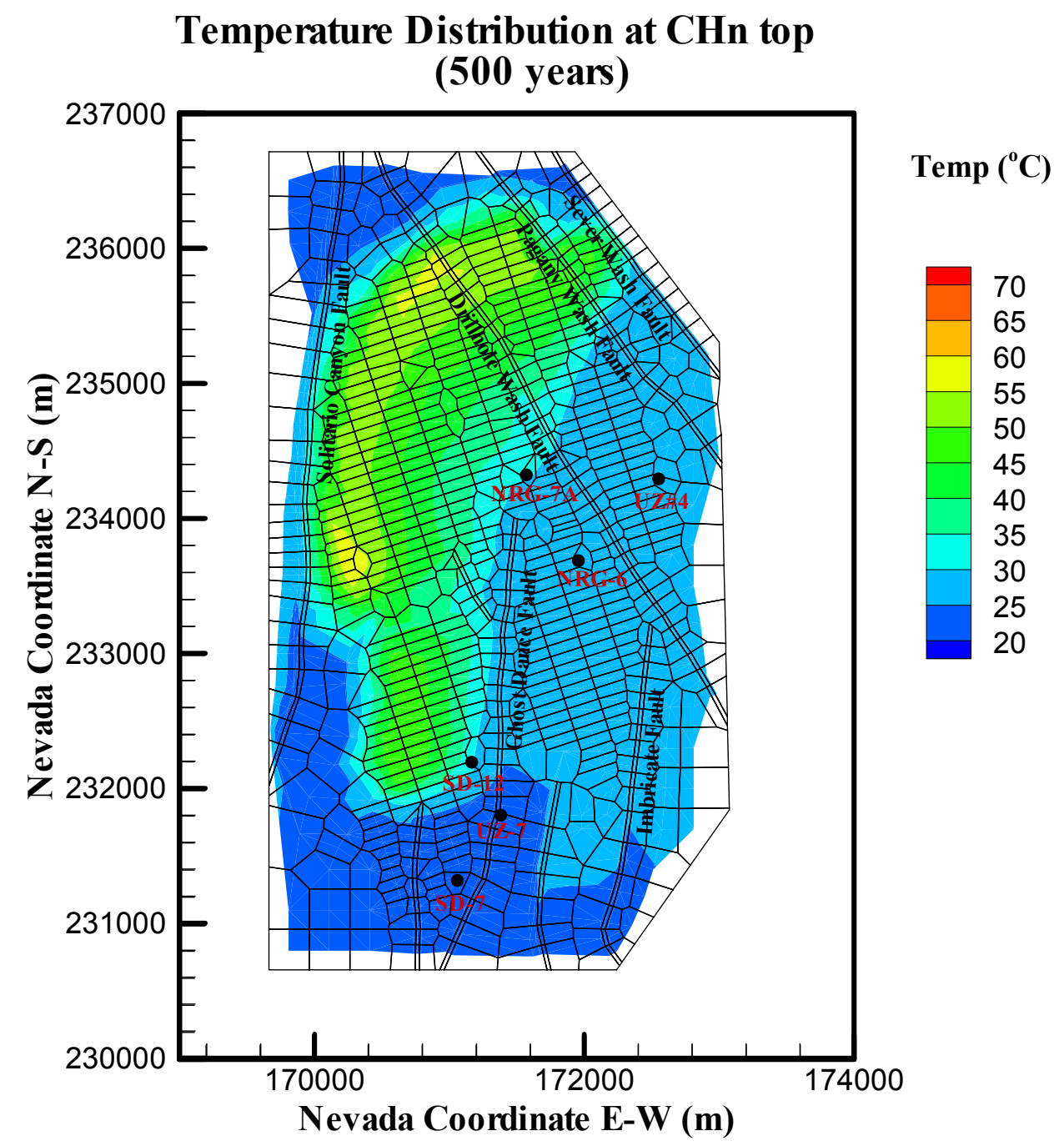

DTN: LB0310MTSCLTH3.001

Figure 6.3.1-2c. Model-Predicted Rock Temperature Distribution at the Top of CHn Unit at 500 Years after Nuclear Waste Emplacement (the Base-Case Model with Ventilation) 


\section{Temperature Distribution at Repository Horizon (1000 year, $v)$}

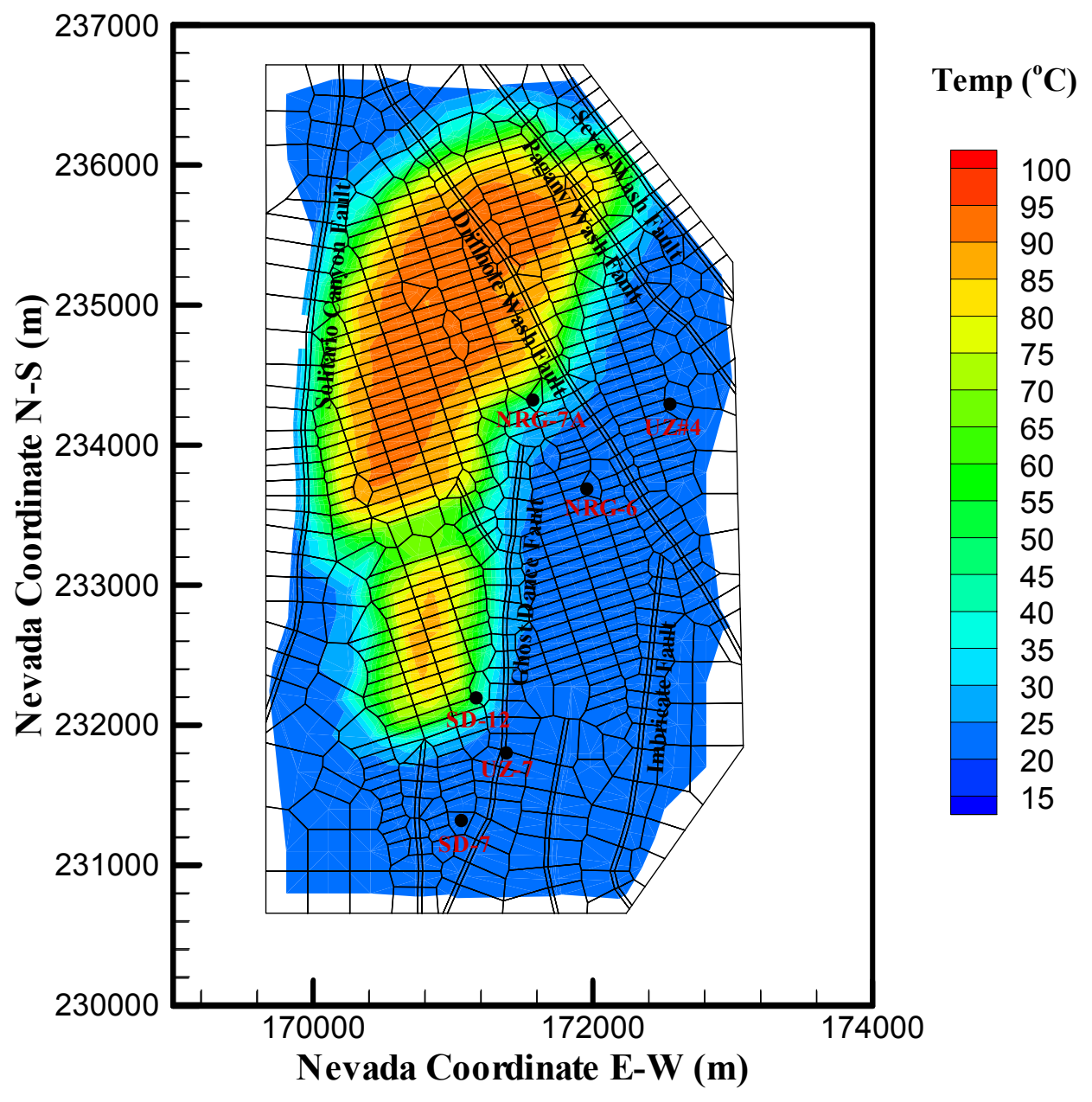

DTN: LB0310MTSCLTH3.001

Figure 6.3.1-3a. Model-Predicted Rock Temperature Distribution at Repository Horizon at 1,000 Years after Nuclear Waste Emplacement (the Base-Case Model with Ventilation) 


\section{Temperature Distribution at PTn bottom (1000 year, $v)$}

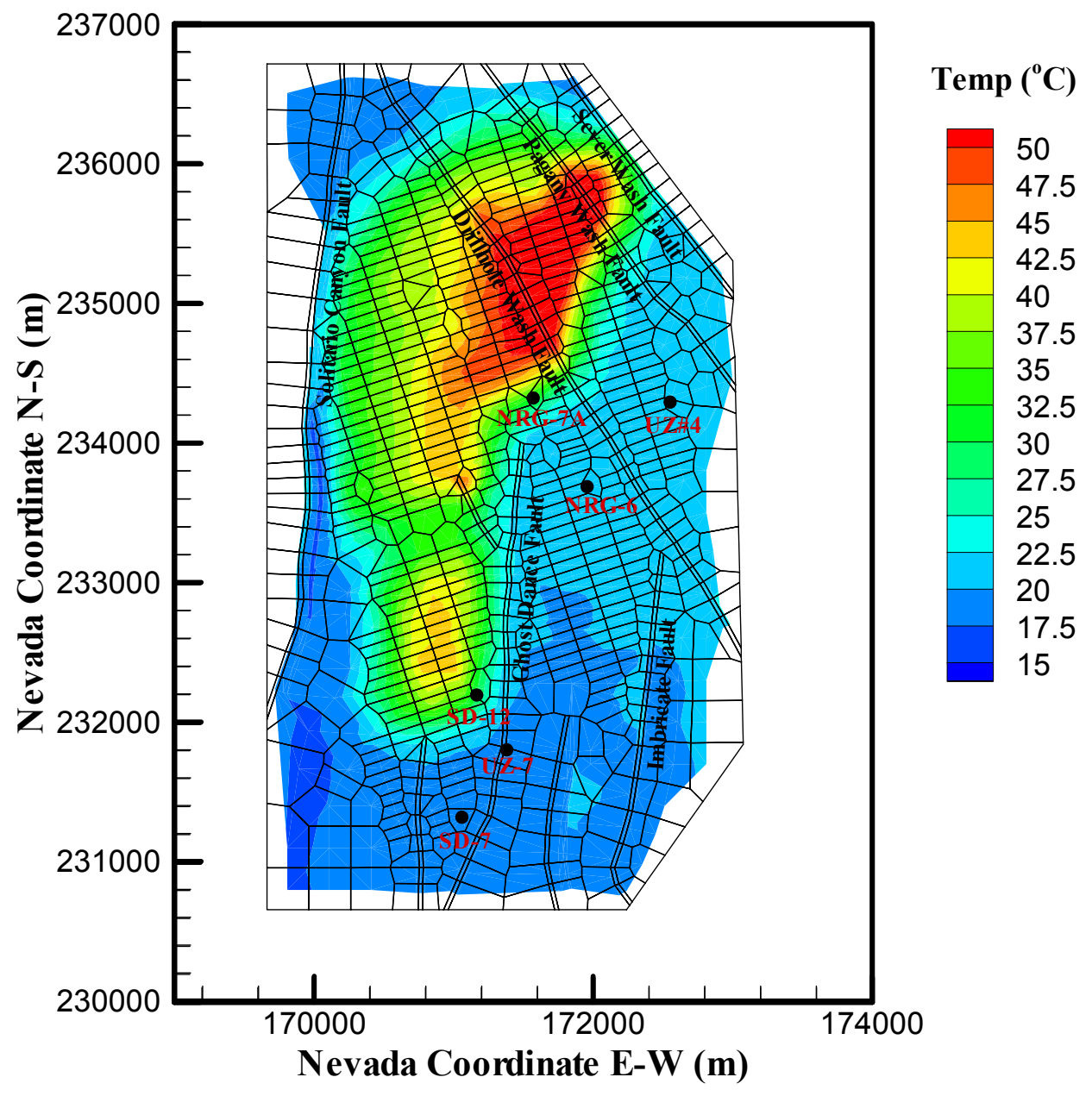

DTN: LB0310MTSCLTH3.001

Figure 6.3.1-3b. Model-Predicted Rock Temperature Distribution at the Bottom of PTn Unit at 1,000 Years after Nuclear Waste Emplacement (Base-Case Model with Ventilation) 


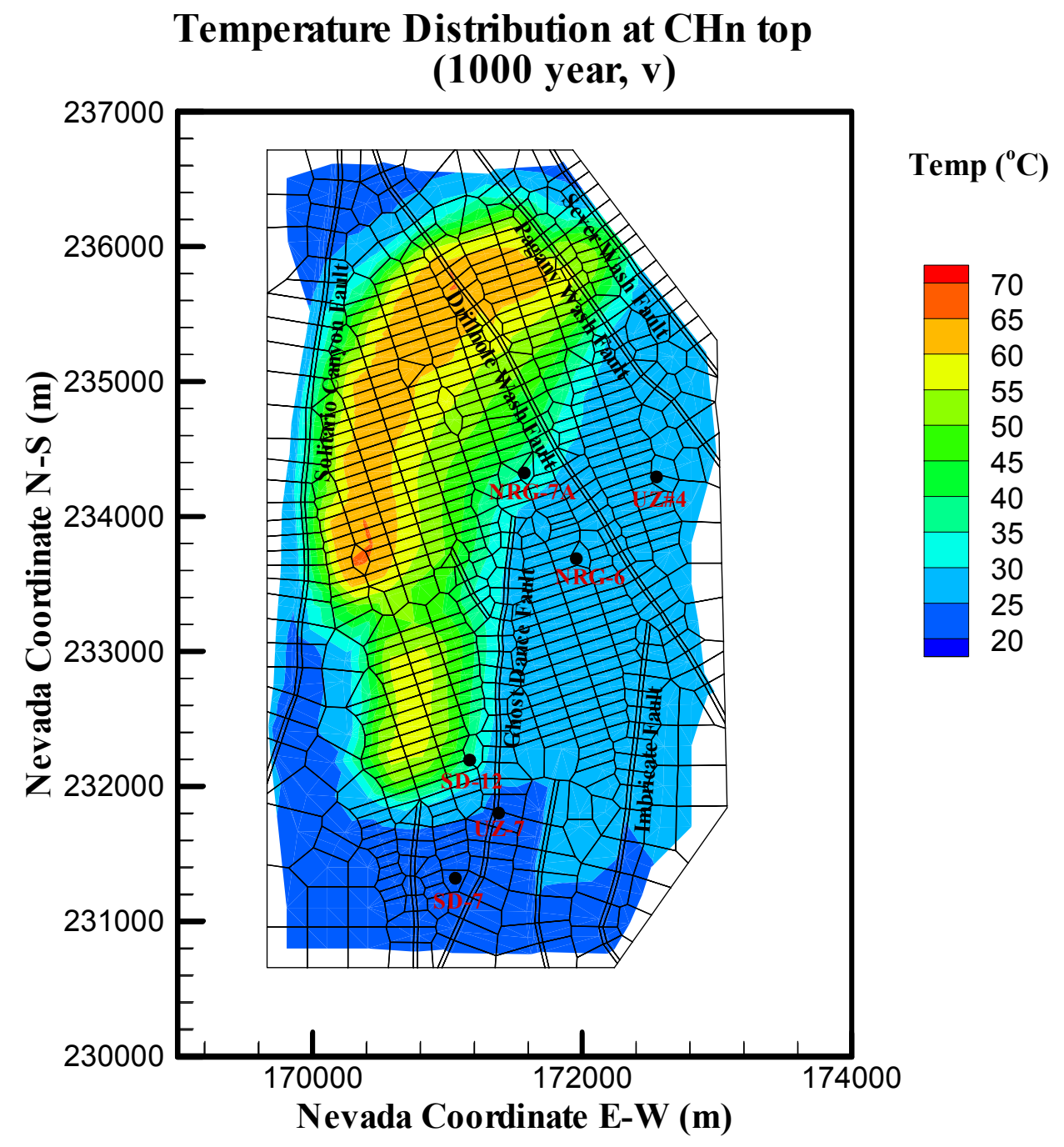

DTN: LB0310MTSCLTH3.001

Figure 6.3.1-3c. Model-Predicted Rock Temperature Distribution at the Top of CHn Unit at Time of 1,000 Years after Nuclear Waste Emplacement (the Base-Case Model with Ventilation) 
Temperature at $\mathrm{N}-\mathrm{S}$ cross section at time 1000 years

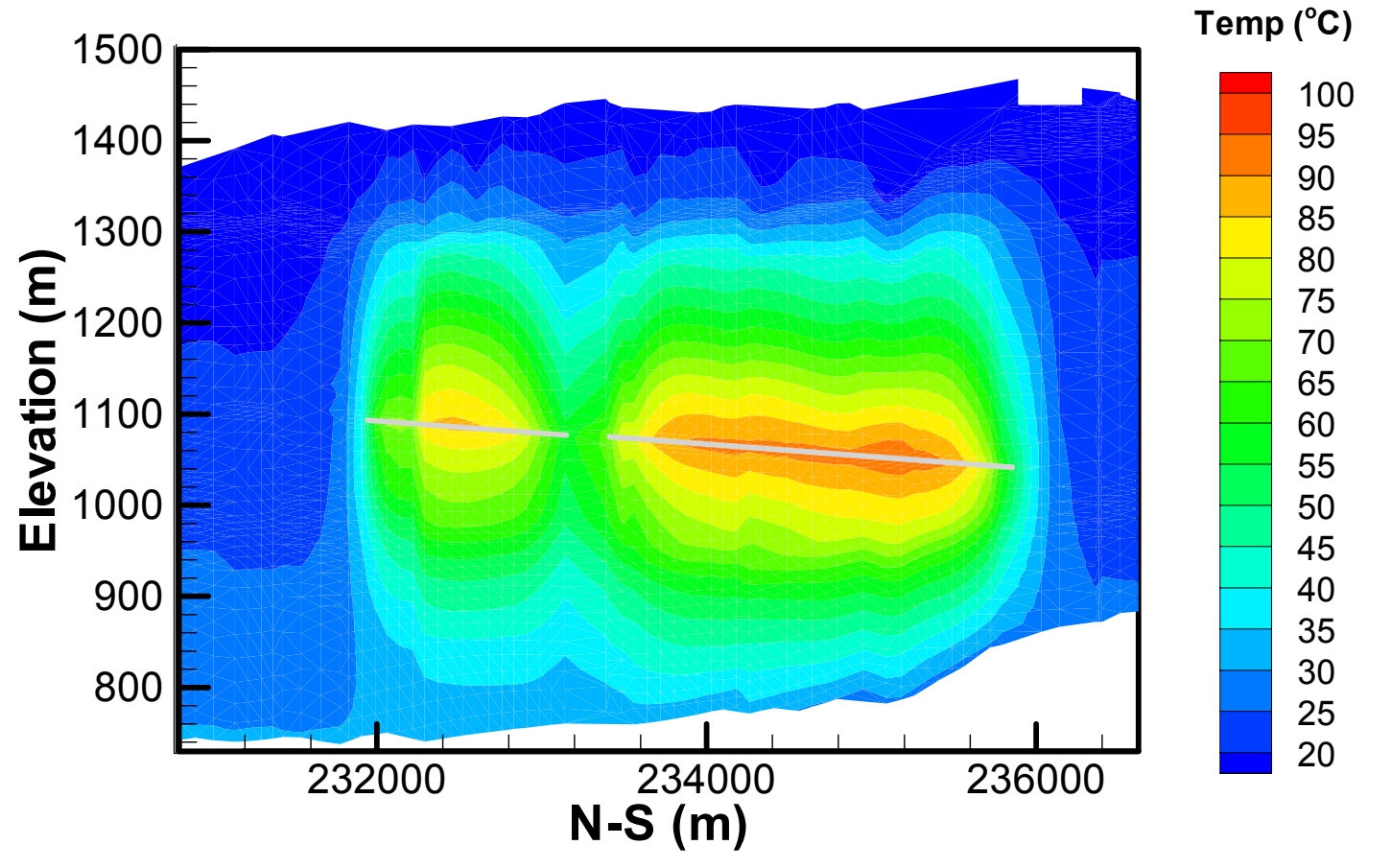

DTN: LB0310MTSCLTH3.001

Figure 6.3.1-3d. Model-Predicted Temperature Distribution at the N-S Cross Section at 1,000 Years after Nuclear Waste Emplacement (the Base-Case Model with Ventilation) 


\section{Temperature Distribution at Repository Horizon (2000 years, $v)$}

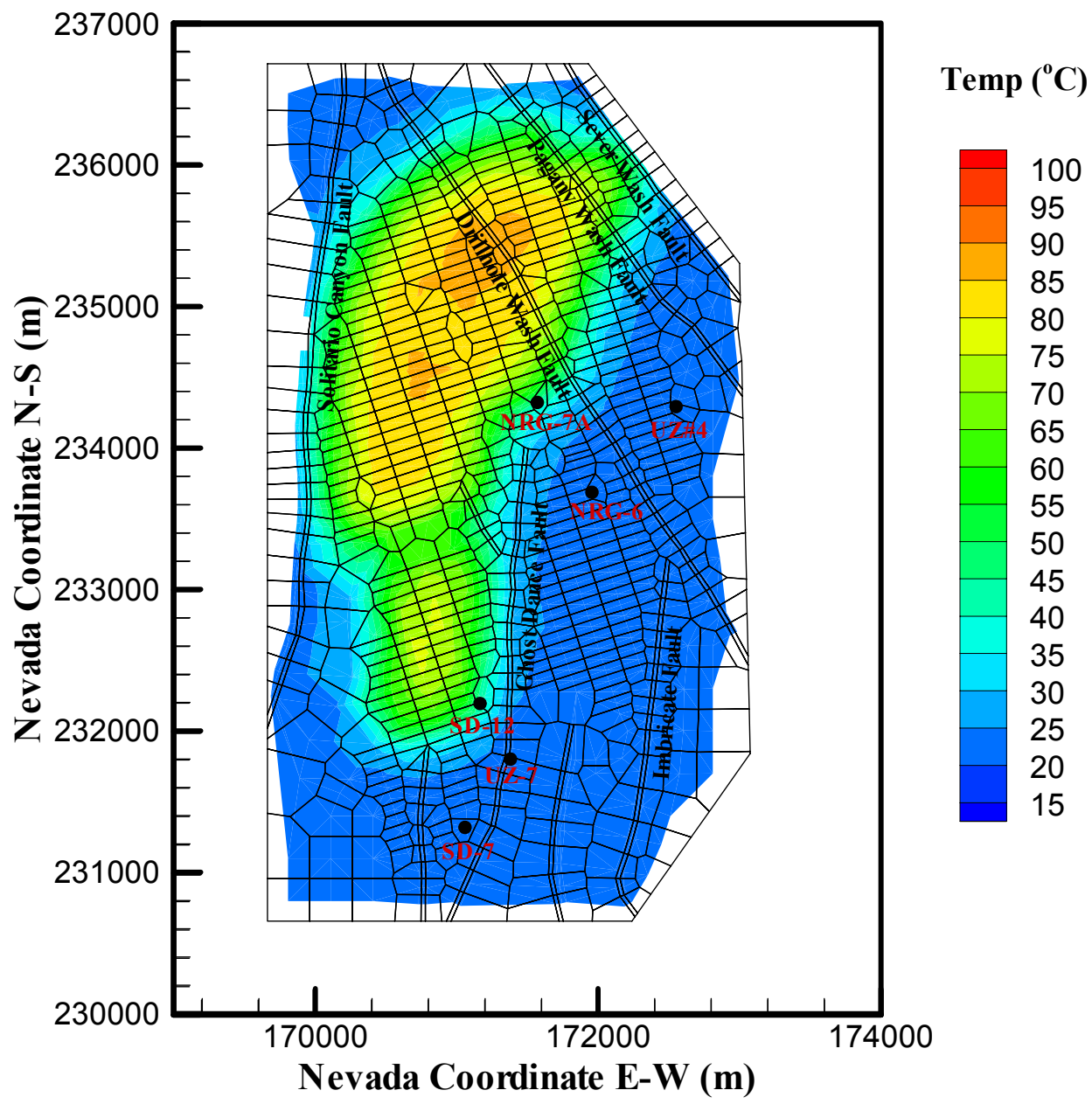

DTN: LB0310MTSCLTH3.001

Figure 6.3.1-4a. Model-Predicted Rock Temperature Distribution at Repository Horizon at 2,000 Years after Nuclear Waste Emplacement (the Base-Case Model with Ventilation) 


\section{Temperature Distribution at PTn bottom $(2000$ years, $v)$}

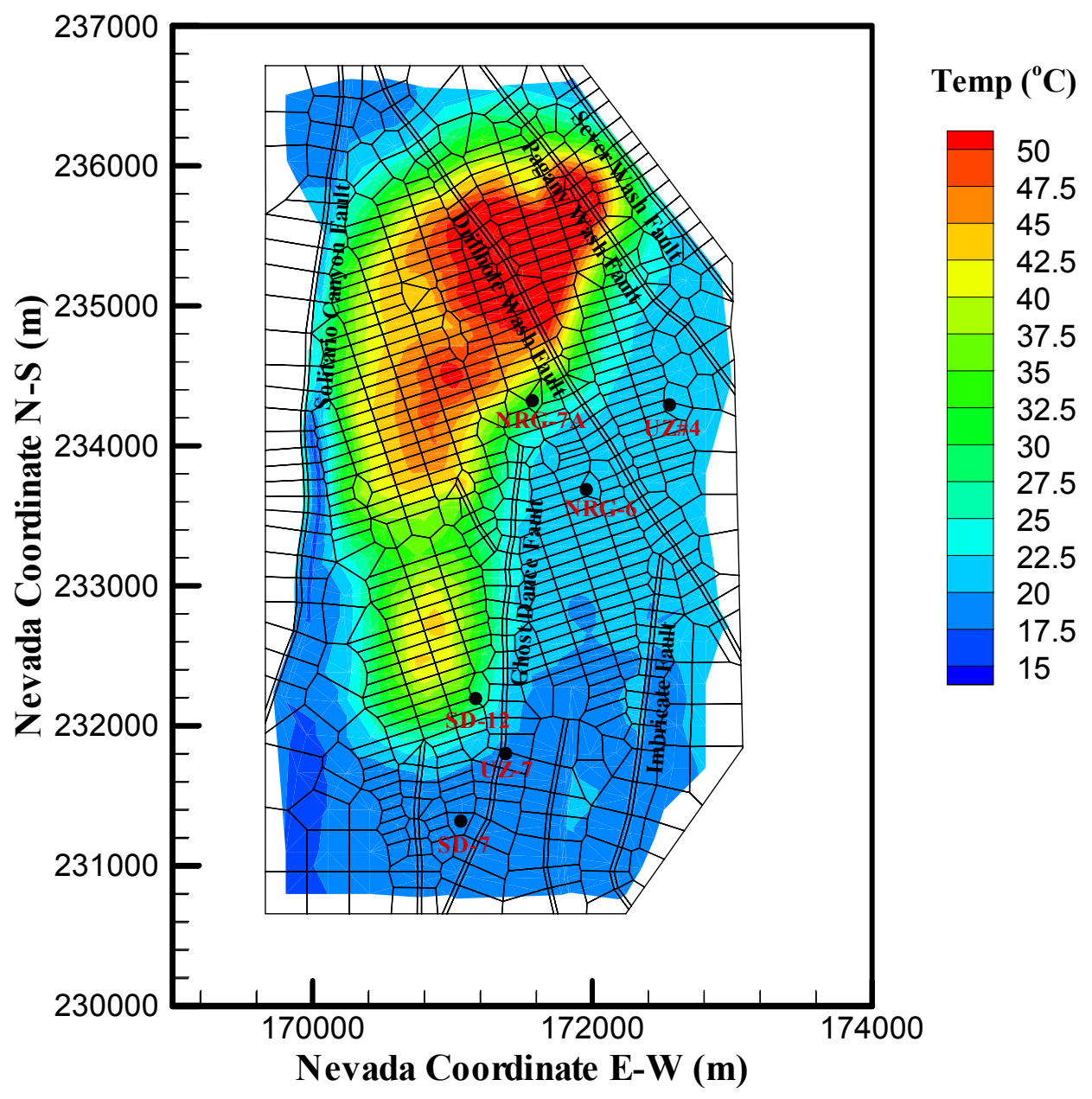

DTN: LB0310MTSCLTH3.001

Figure 6.3.1-4b. Model-Predicted Rock Temperature Distribution at the Bottom of PTn Unit at 2,000 Years after Nuclear Waste Emplacement (Base-Case Model with Ventilation) 


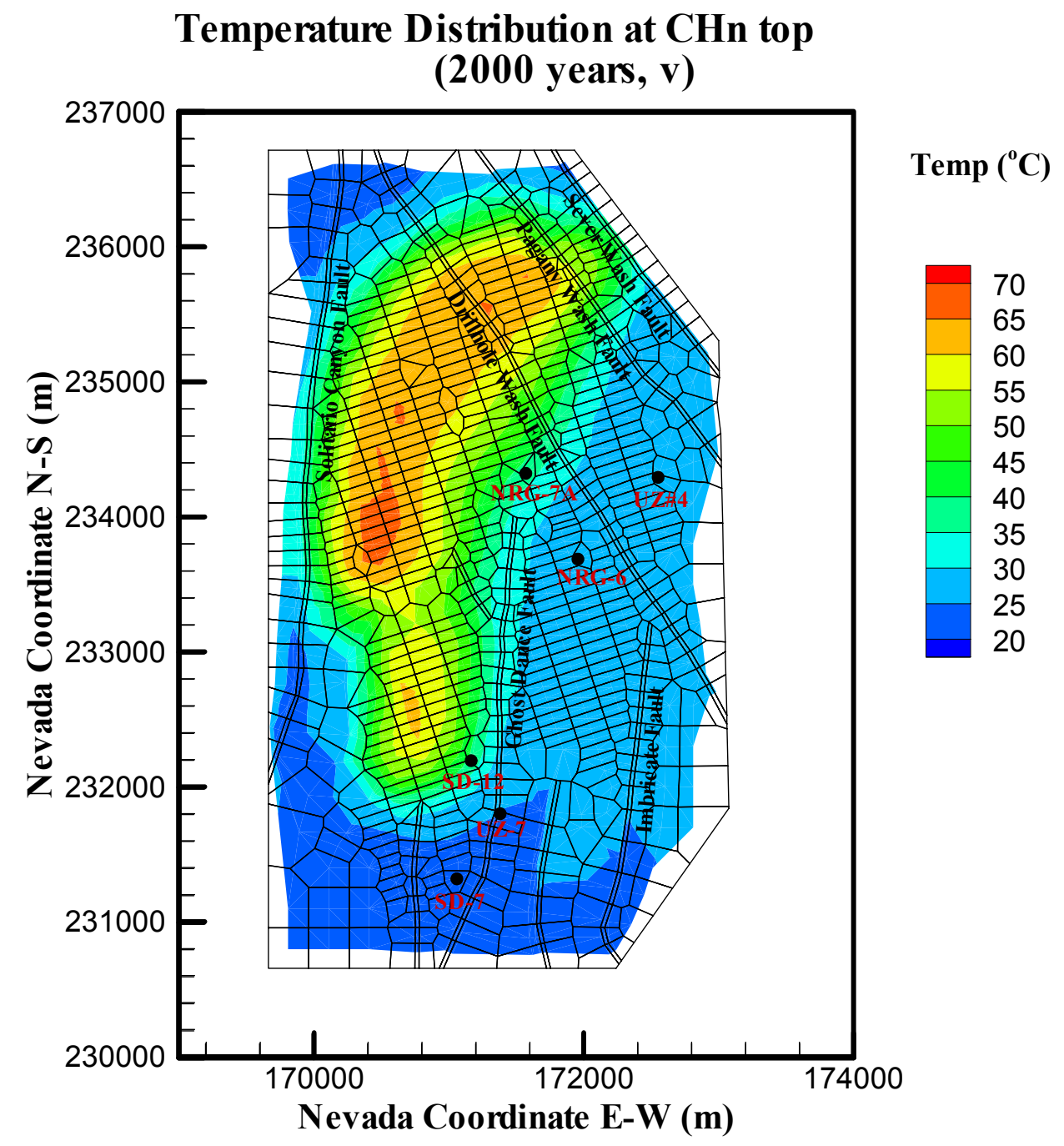

DTN: LB0310MTSCLTH3.001

Figure 6.3.1-4c. Model-Predicted Rock Temperature Distribution at the Top of $\mathrm{CHn}$ Unit at 2,000 Years after Nuclear Waste Emplacement (Base-Case Model with Ventilation) 


\section{Temperature Distribution at Repository Horizon (5000 years, $v)$}

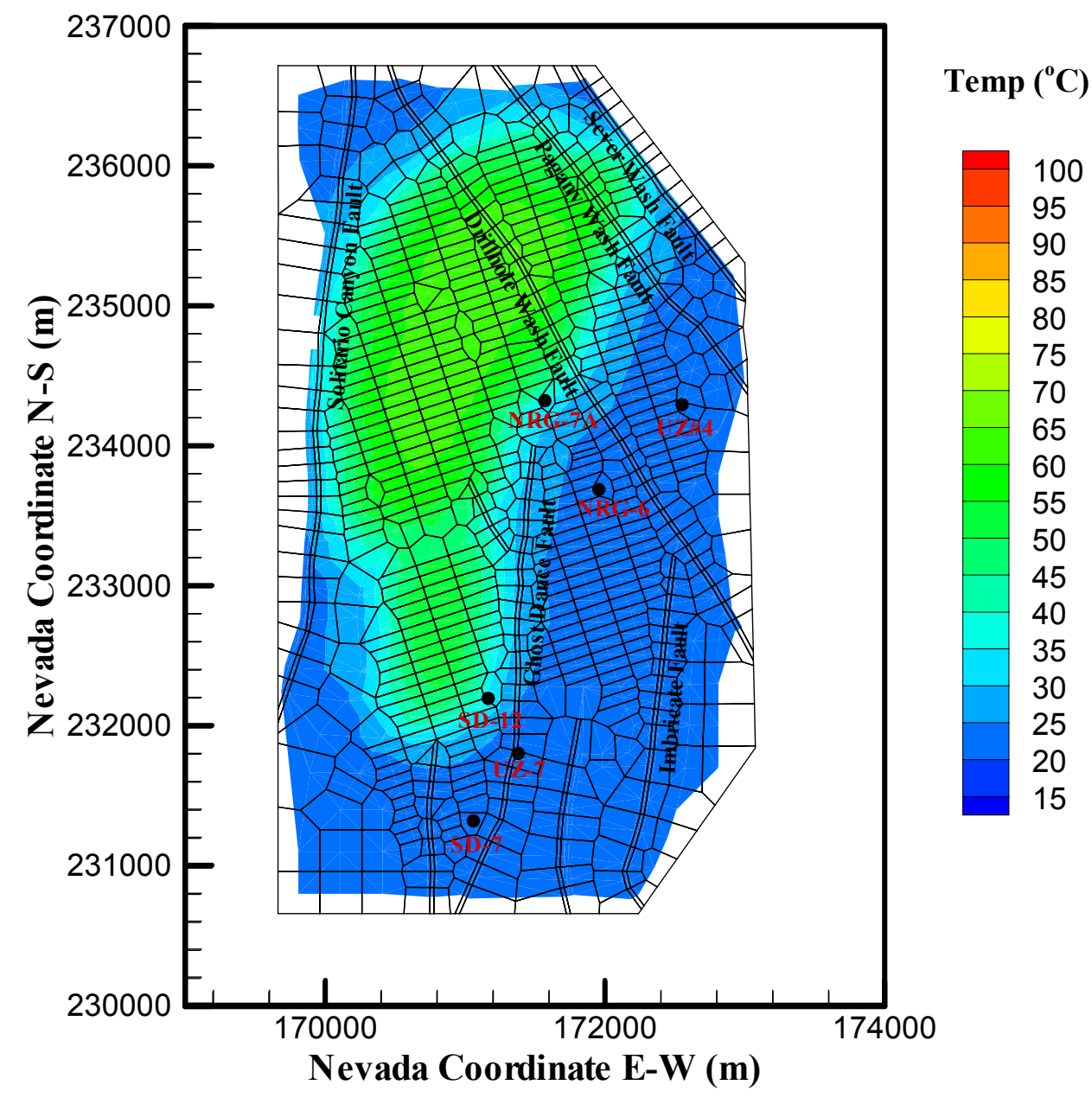

DTN: LB0310MTSCLTH3.001

Figure 6.3.1-5a. Model-Predicted Rock Temperature Distribution at Repository Horizon at 5,000 Years after Nuclear Waste Emplacement (the Base-Case Model with Ventilation) 


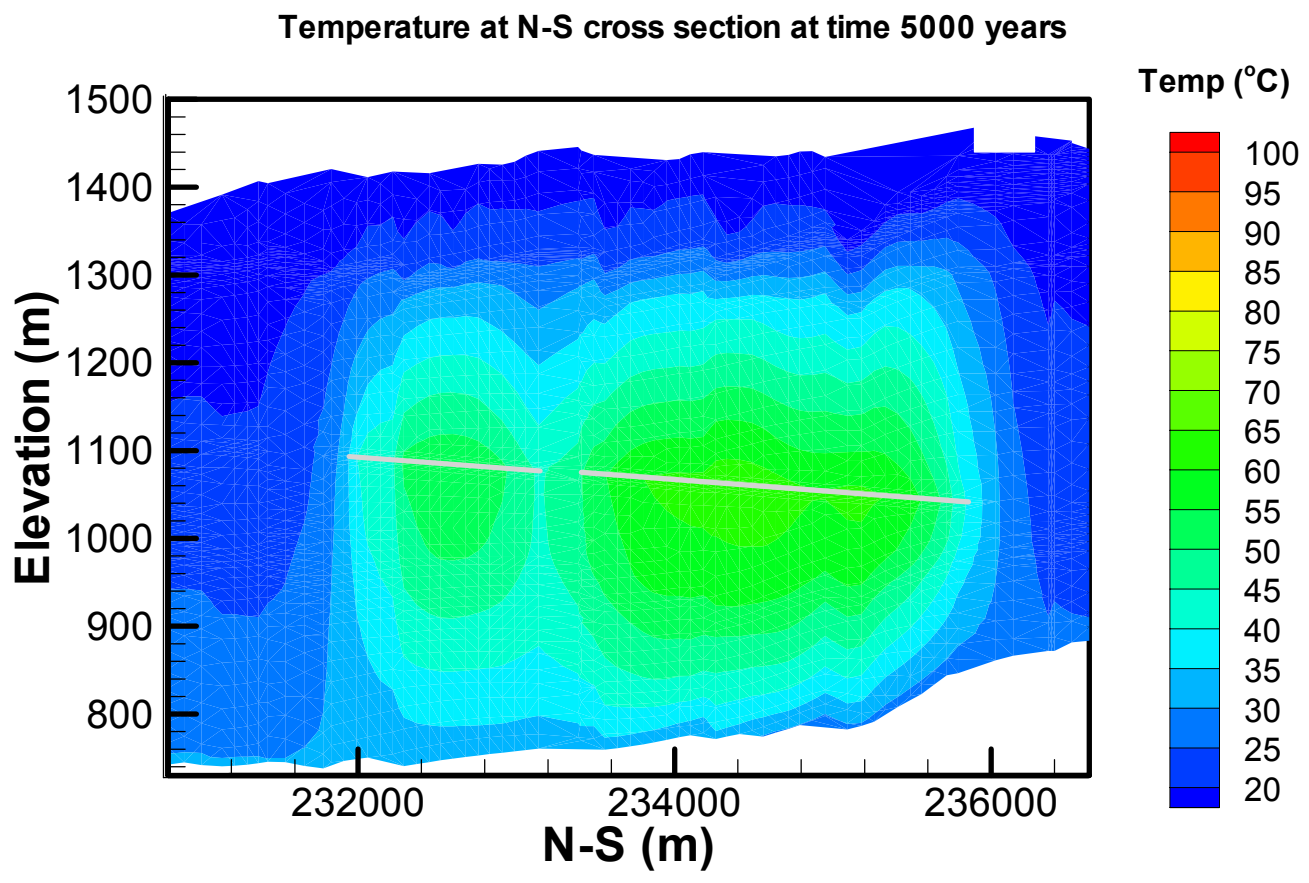

DTN: LB0310MTSCLTH3.001

Figure 6.3.1-5b. Model-Predicted Temperature Distribution at the N-S Cross Section at 5,000 Years after Nuclear Waste Emplacement (the Base-Case Model with Ventilation)

Figure 6.3.1-6 displays two 1-D vertical profiles of simulated temperatures in Observation Columns A (the center of the southern or small repository block, Figure 6.1-1) and F (the center of the northern, main repository block, Figure 6.1-1) at different times (10, 100, 500, 800, 2,000, $3,000,5,000$, and 8,000 years). Both horizontal and vertical cross-sectional temperature contours above show that the boiling zones are limited for the most part to inside the northern, main repository boundary. The vertical temperature distributions at Observation Column A and Column $\mathrm{F}$ in Figure 6.3.1-6 indicate a sharp temperature peak (or jump) to boiling conditions, which develops at the repository horizon at column F, i.e., the center of the northern or main repository block during a period of 100-500 years in this particular location. In the southern repository, the peak temperature is lower than the local boiling point during the entire thermalloading period. The temperature profiles along the two columns of Figure 6.3.1-6 also indicate that the strongest thermal impact on the far-field regions, e.g., PTn or CHn units, occurs at about 2,000 years.

Figure 6.3.1-7 displays variations of simulated temperatures with time at three elevations along Column F, the repository level, the lower portion of the PTn, and the upper CHn. The simulated results show that the maximum temperature at the repository horizon of this location is about $100^{\circ} \mathrm{C}$, reached at 130 years. At this location, temperatures at the repository drift rise to boiling condition shortly before 100 years. The figure shows near-constant temperature at the repository drift between 100-600 years, indicating boiling conditions. The cool-down phase almost coincides with the change of climate at 600 years, and temperature drops below boiling after 1,000 years. Figure 6.3.1-7 also shows that temperatures near the PTn bottom and upper CHn portion reach their highest values at about 2,000 years after waste emplacement. 
Temperature distribution at Observation Column A

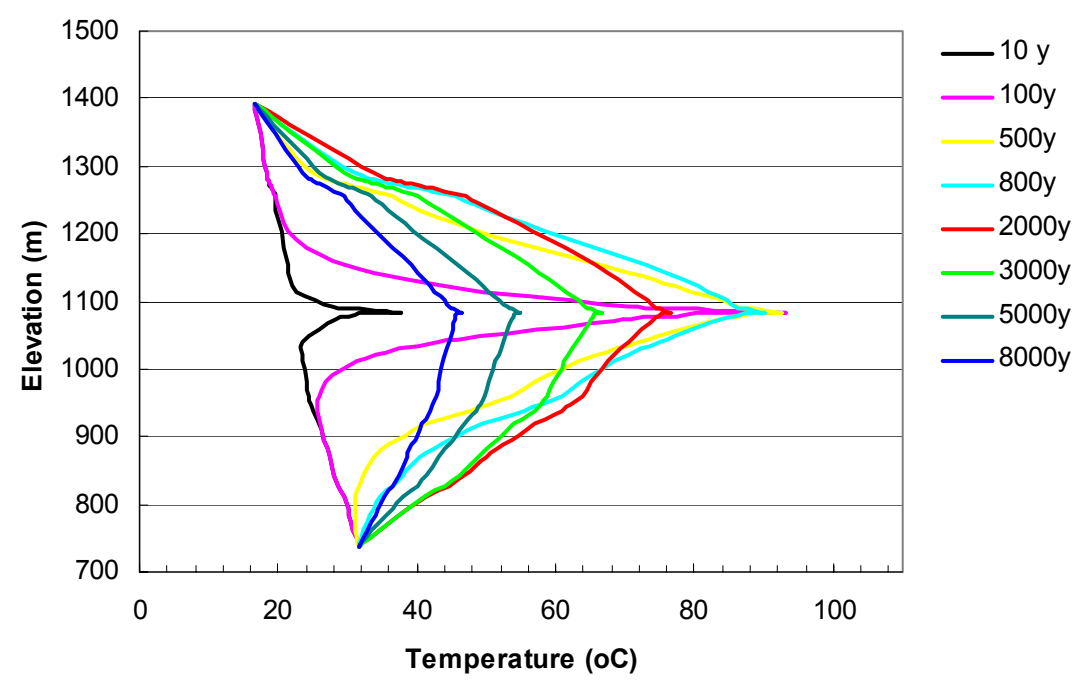

Temperature distribution at Observation Column F

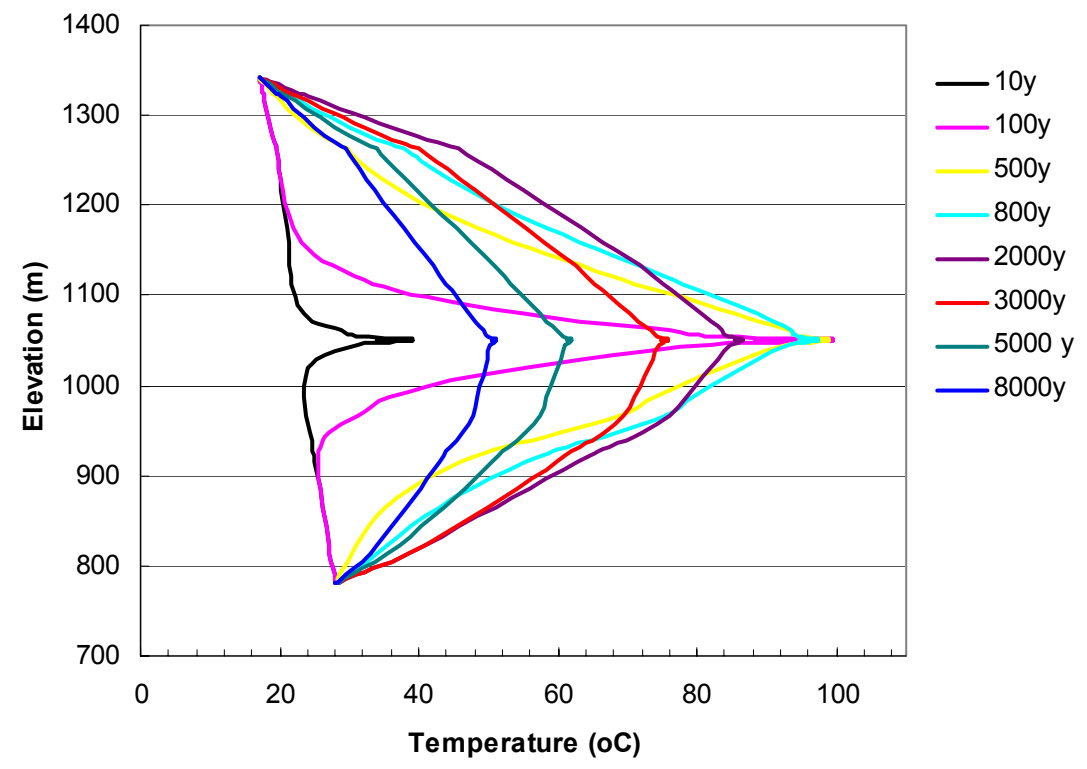

DTN: LB0310MTSCLTH3.001

Figure 6.3.1-6. Model-Predicted Temperature Profiles at Different Times along Observation Columns A (Southern Repository Block Center) and F (Northern, Main Repository Block Center) (Base-Case Model with Ventilation) 


\section{Temperature Change at Gridblock DP12h47 (F)} (with ventilation)

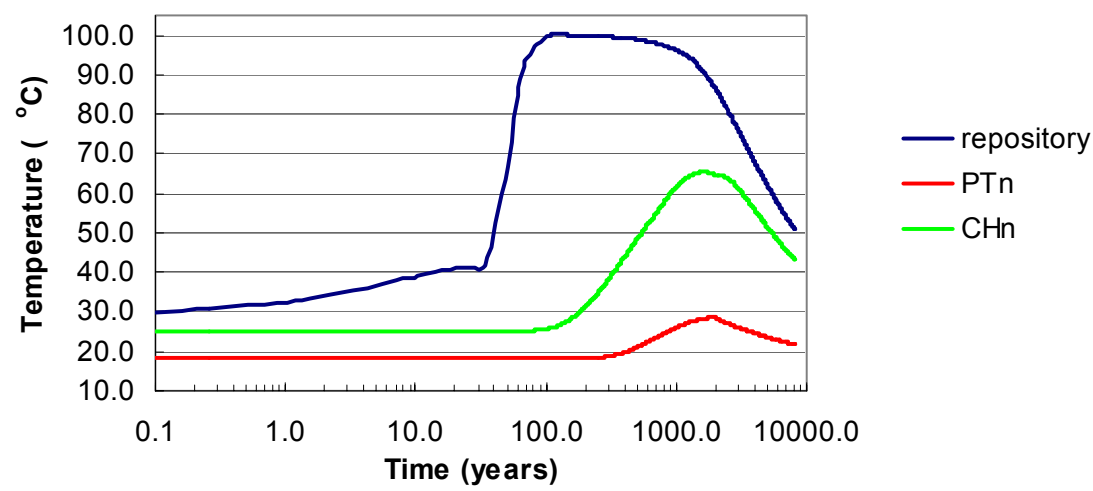

DTN: LB0310MTSCLTH3.001

Figure 6.3.1-7. Model-Predicted Temperature Changes with Times at Repository Horizon, Bottom PTn (Elevation of 1,307.5 m), and Top CHn (Elevation of $961 \mathrm{~m}$ ) along the Observation Column F (Northern or Main Repository Block Center) (Base-Case Model with Ventilation)

\subsubsection{Liquid Saturation}

Changes in liquid saturation in the host rock at and near repository drifts are important for several reasons. They determine the period during which the repository remains dry. They are also used to assess the potential desaturation-induced changes in porosity and hydraulic conductivity (for example, in the zeolitic units). Liquid saturation also quantifies the thermally induced flow mobilization and focusing that may affect UZ flow and the potential for seepage into drifts. Finally, they also help identify the onset of rewetting processes and the subsequent potential for possible waste package corrosion at the repository horizon.

Figures 6.3.1-8 through 6.3.1-10 show the plots of matrix liquid saturation at the repository horizon at times of 500,1,000, and 2,000 years, respectively. The contour plots of the matrix liquid saturation at 500 and 1,000 years after initial thermal load along the N-S cross section are shown in Figures 6.3.1-11 and 6.3.1-12. In addition, Figure 6.3.1-13 presents the matrix liquid saturation in Observation Column $\mathrm{H}$ (near the center of the northern repository block) at different times.

Comparing the simulated matrix liquid saturations at the same locations for different times and with their initial values, it is found that the 3-D model in general predicts small changes in matrix liquid saturation on the large, mountain scale under the base-case thermal-load scenario. Therefore, no large spatial-scale mobilization of liquid by vaporization is created by the designed repository heating. Figures 6.3.1-8-6.3.1-10 indicate that the predicted matrix liquid saturations at the repository horizon are scarcely different for the three different times. They are also almost identical to the ambient saturation distribution at the repository horizon. The distribution of liquid saturation at the $\mathrm{N}-\mathrm{S}$ cross section at 500 years and 1,000 years of thermal load (Figures 6.3.1-11 and 6.3.1-12) are also very similar at the two times. Note that Figure 6.3.1-11a presents 
vertical saturation distributions at 500 years after waste emplacement along the N-S cross section of the 3-D model, showing little difference from the ambient or initial condition of Figure 6.3.1$11 \mathrm{~b}$ for the same cross section.

Figures 6.3.1-13 shows a slight change of matrix saturation along the vertical column. However, these changes result mainly from changes in climates, i.e., from the increase in net infiltration rates. Note the repository elevation is at about $1,050 \mathrm{~m}$ at this location. The 3-D numerical model does not predict extensive dryout zones or zero saturation in matrix blocks near the repository drifts within the 3-D domain. This is primarily because of (1) the relatively low thermal load for the base-case with ventilation; (2) the coarse gridding around the drifts with large volume average; and (3) the increase in infiltration rates at 600 and 2,000 years. Note that drifts are simulated as an equivalent porous material with zero capillary pressure and zero initial liquid saturation, i.e., completely dry, and are not included in these plots.

\section{Saturation Distribution at Repository Horizon (500 year, in matrix)}

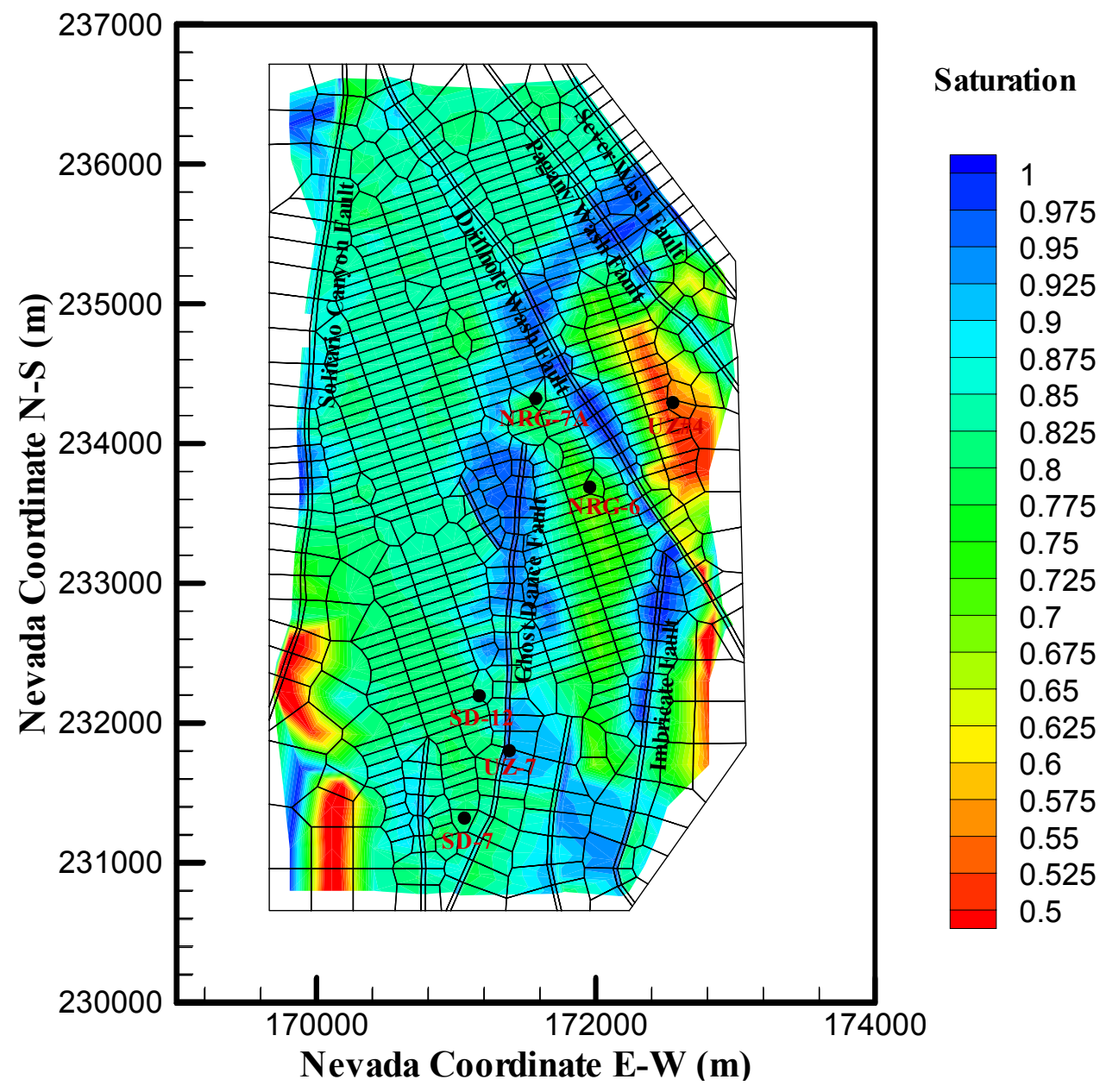

DTN: LB0310MTSCLTH3.001

Figure 6.3.1-8. Model-Predicted Matrix Liquid Saturation Distribution at Repository Horizon at 500 Years after Nuclear Waste Emplacement (the Base-Case Model with Ventilation) 


\section{Saturation Distribution at Repository Horizon (1000 year, in matrix)}

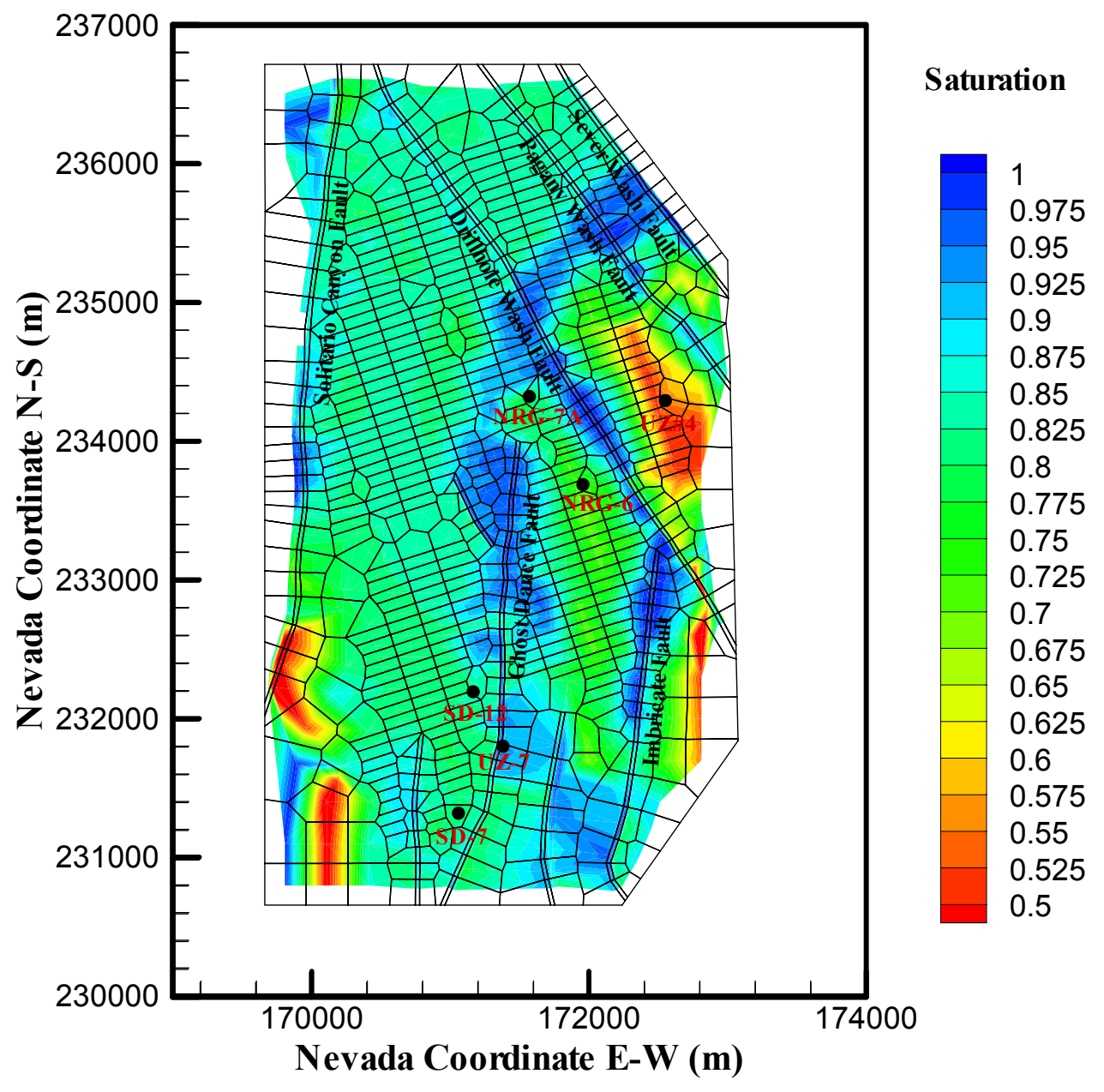

DTN: LB0310MTSCLTH3.001

Figure 6.3.1-9. Model-Predicted Matrix Liquid Saturation Distribution at Repository Horizon at 1,000 Years after Nuclear Waste Emplacement (the Base-Case Model with Ventilation) 


\section{Saturation Distribution at Repository Horizon (2000 year, in matrix)}

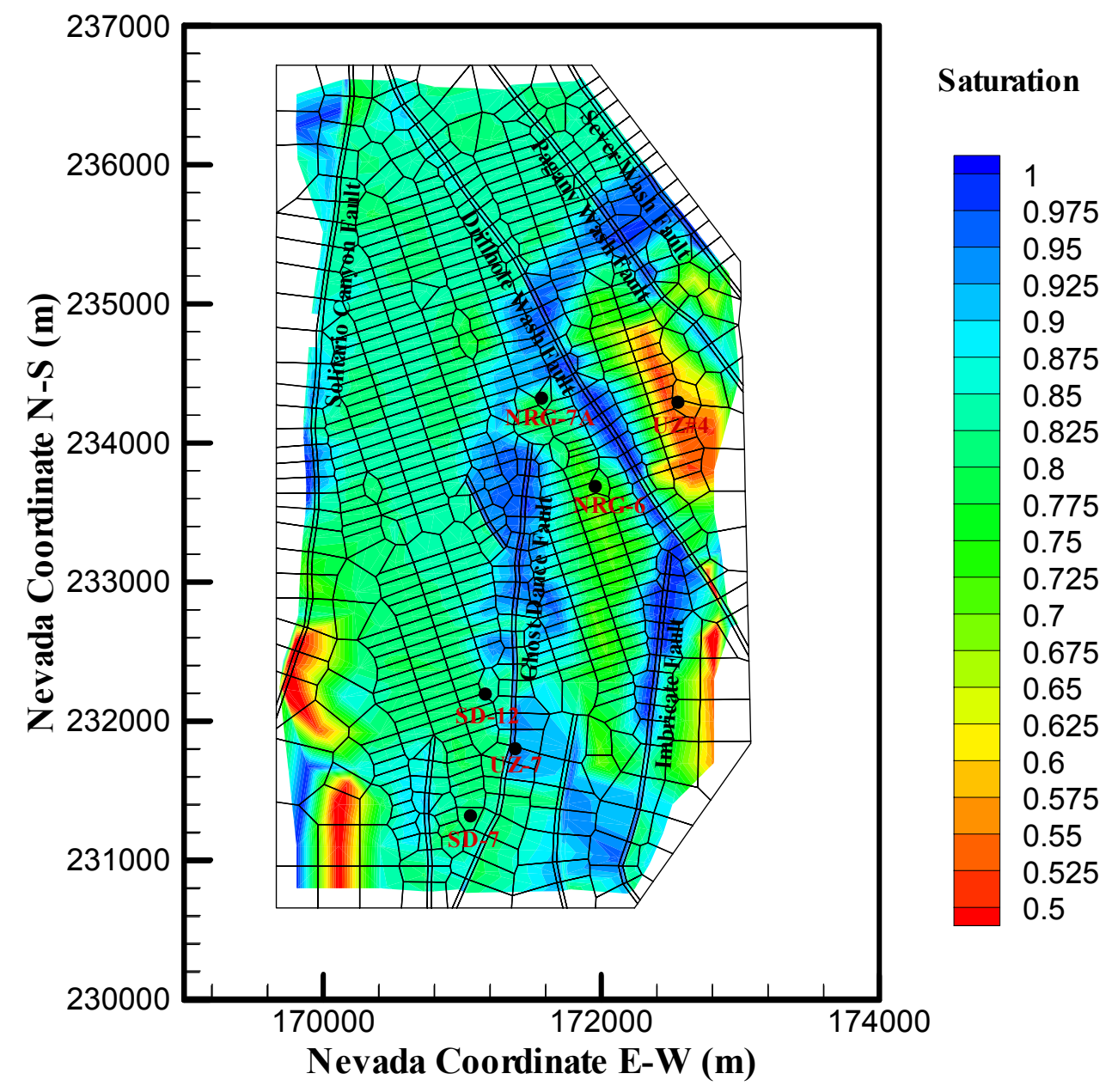

DTN: LB0310MTSCLTH3.001

Figure 6.3.1-10. Model-Predicted Matrix Liquid Saturation Distribution at Repository Horizon at 2,000 Years after Nuclear Waste Emplacement (the Base-Case Model with Ventilation) 
Saturation distribution at $\mathrm{N}-\mathrm{S}$ cross section at time $\mathbf{5 0 0}$ years (with ventilation)

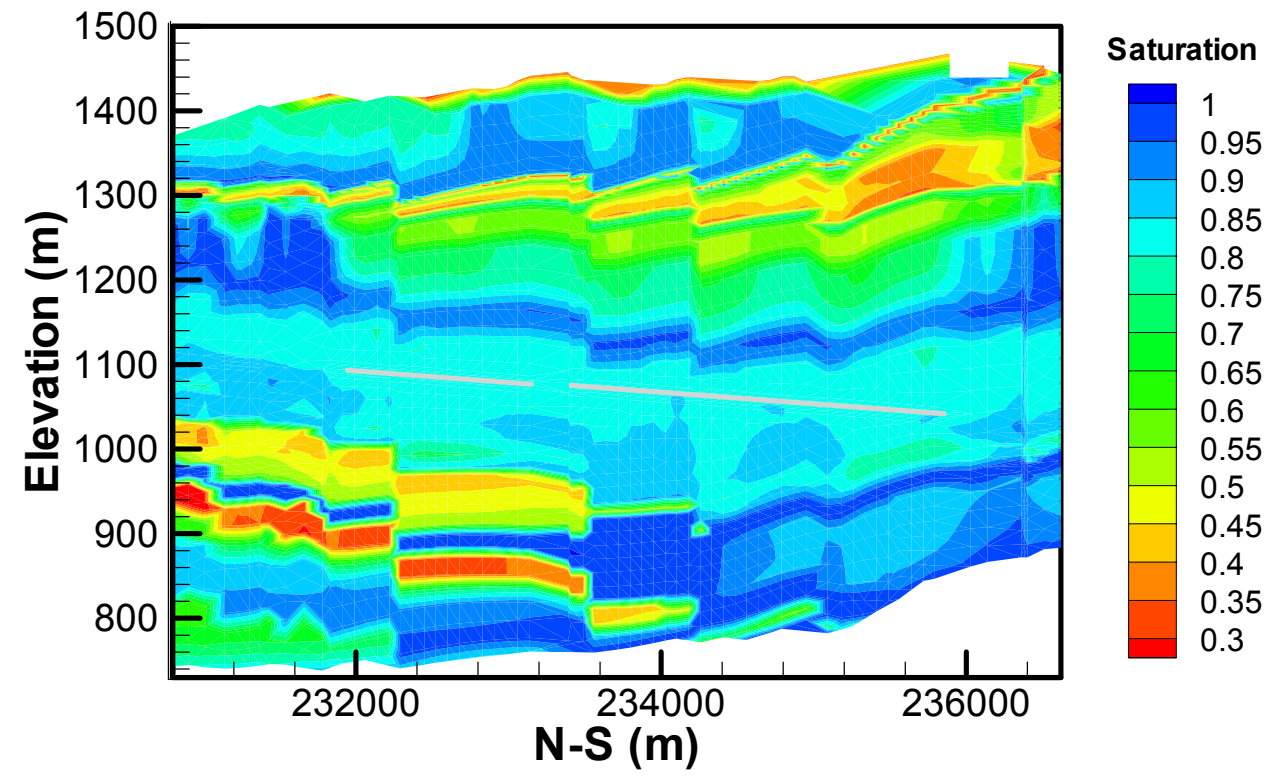

DTN: LB0310MTSCLTH3.001

Figure 6.3.1-11a.Model-Predicted Matrix Liquid Saturation Distribution at the N-S Cross Section at 500 Years after Nuclear Waste Emplacement (the Base-Case Model with Ventilation)

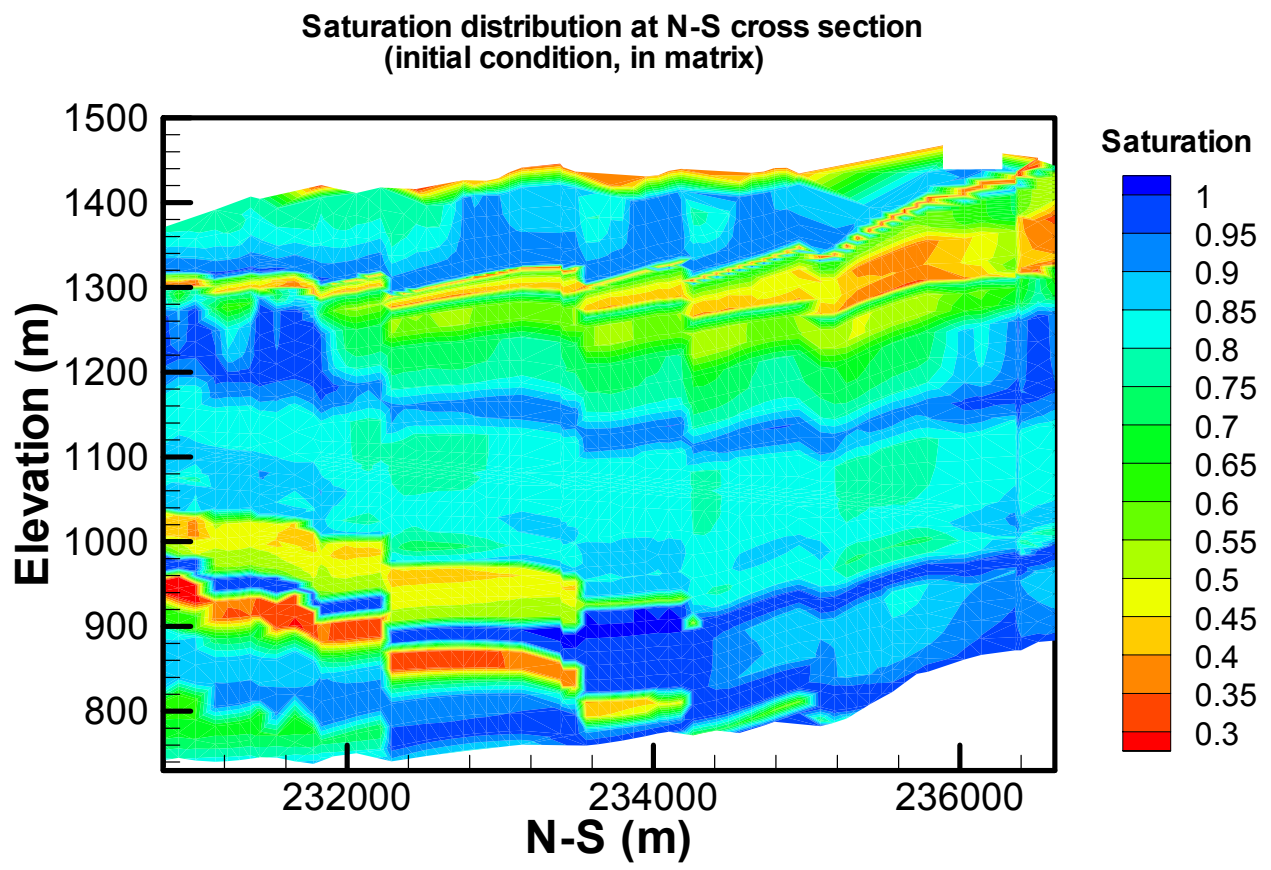

DTN: LB0310MTSCLTH3.001

Figure 6.3.1-11b.Model-Predicted Matrix Liquid Saturation Distribution at the N-S Cross Section at the Ambient Condition with the Present-Day, Mean infiltration Rates. 
Saturation distribution at $\mathrm{N}-\mathrm{S}$ cross section at time 1000 years (with ventilation)

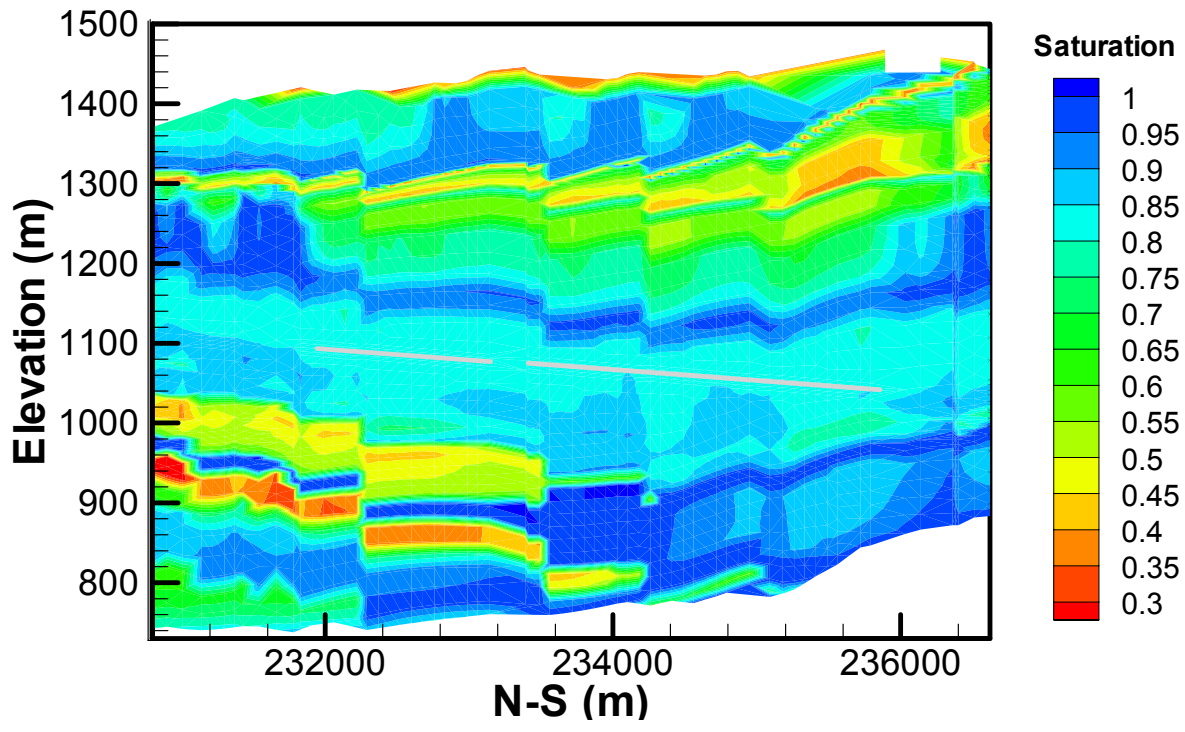

DTN: LB0310MTSCLTH3.001

Figure 6.3.1-12. Model-Predicted Matrix Liquid Saturation Distribution at the N-S Cross Section at 1,000 Years after Nuclear Waste Emplacement (the Base-Case Model with Ventilation)

Saturation distribution at Observation Column H

(in matrix)

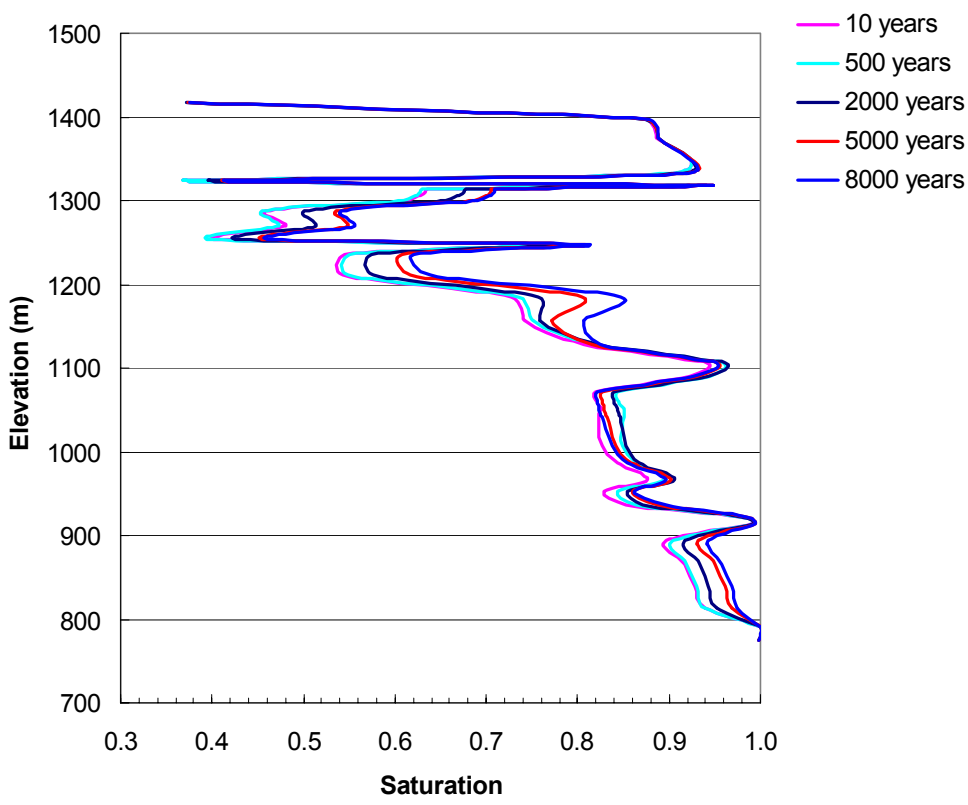

DTN: LB0310MTSCLTH3.001

NOTE: Infiltration rates at the top of column H are: Present day $6.558 \mathrm{~mm} / \mathrm{yr}$; Monsoon $20.451 \mathrm{~mm} / \mathrm{yr}$; and Glacial transition $29.920 \mathrm{~mm} / \mathrm{yr}$.

Figure 6.3.1-13. Model-Predicted Matrix Liquid Saturation Distribution along Observation Column $\mathrm{H}$ at Different Times (the Base-Case Model with Ventilation) 


\subsubsection{Percolation Flux}

Thermally induced flux evolution can also be analyzed using the 3-D TH model results. Figures 6.3.1-14-6.3.1-16 show the vertical liquid fluxes in the fracture continuum initially and 500 years after emplacement at the PTn bottom, repository horizon, and top of CHn. Figures 6.3.1$14 \mathrm{~b}, 6.3 .1-15 \mathrm{~b}$, and 6.3.1-16b show the effect of the thermal load, after 500 years, on the percolation fluxes above the repository, at the repository horizon, and below the repository. Figures 6.3.1-14a, 6.3.1-15a, and 6.3.1-16a show their corresponding ambient fluxes. In general, percolation flux increases within the repository gridblocks, or at the PTn bottom and at the CHn top, only in areas directly above or below the repository. The maximum increase is observed at the repository horizon (Figure 6.3.1-15b versus Figure 6.3.1-15a), because of the strongest thermal impact from repository heating. The flux increase at the bottom of the PTn (Figures 6.3.1-14b and 6.3.1-14a) is small and caused mainly by vapor condensation. Below the repository horizon, the increase in flux at the top of CHn (Figures 6.3.1-16b and 6.3.1-16a) is also relatively small and caused by drainage through the pillars.

Because of the strong capillary barrier effect in drifts (which is simulated with zero capillary pressure), no liquid flow into drifts has been predicted at any locations over the period of thousands of years (Output-DTNs: LB0310MTSCLTH2.001; LB0310MTSCLTH3.001). Because of the large gridblocks in the 3-D TH model, simulated liquid flux is continuously downward through pillar regions between drifts over the entire thermal-loading period. 


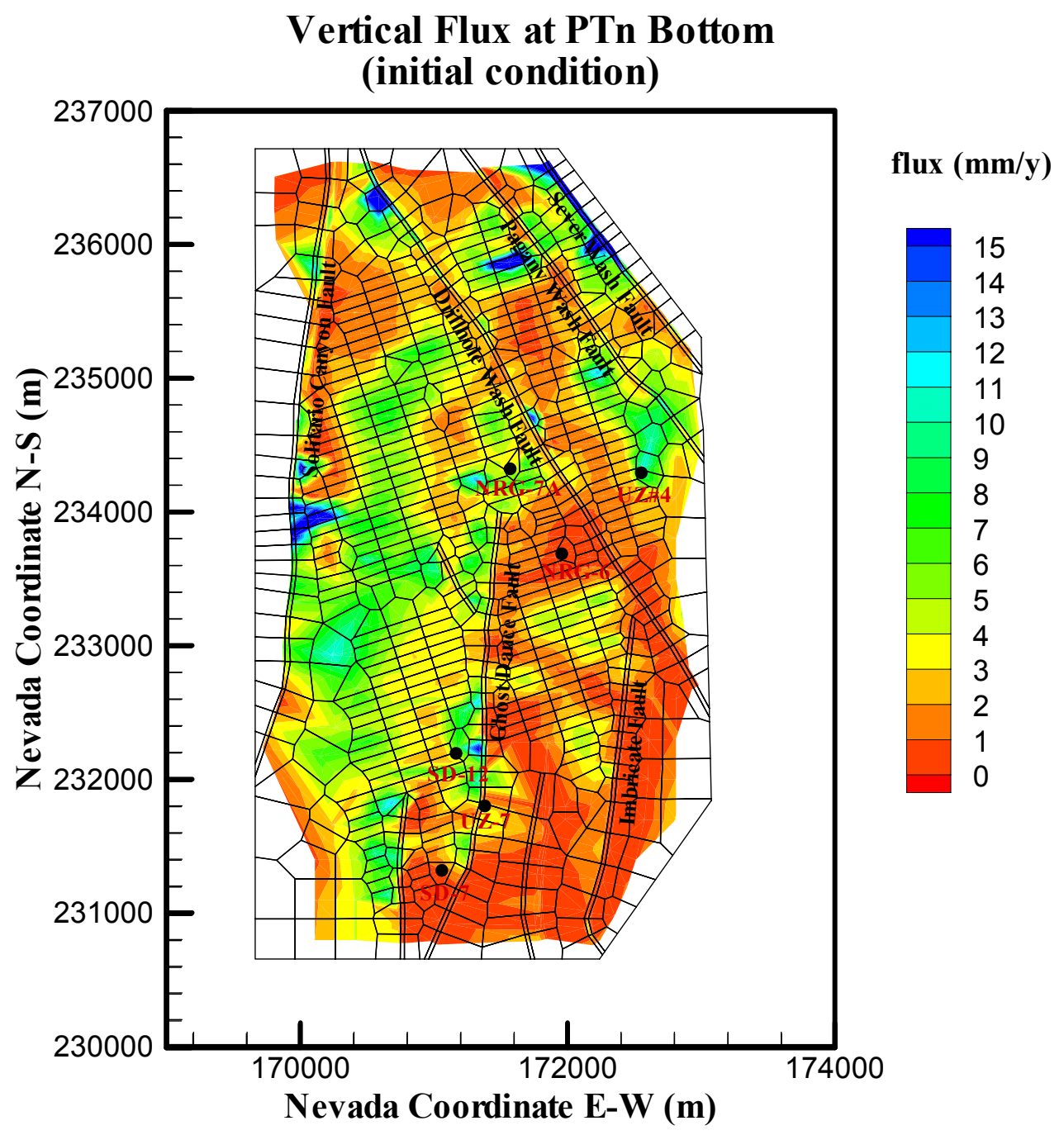

DTN: LB0310MTSCLTH3.001

Figure 6.3.1-14a. Model-Predicted Total Vertical Flux Distribution at the Bottom of PTn Unit at the Ambient Condition with the Present-Day, Mean Infiltration Rates 


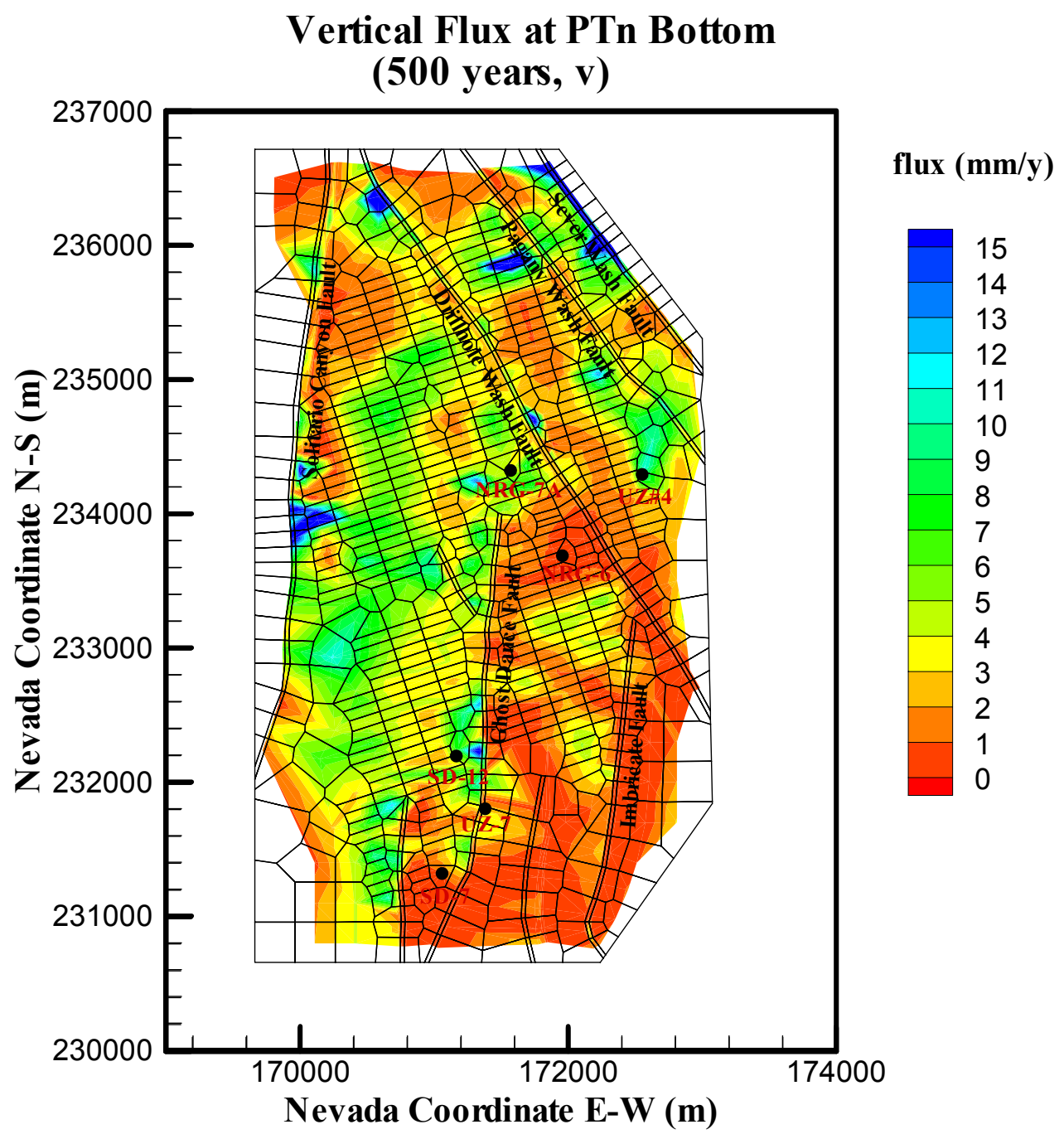

DTN: LB0310MTSCLTH3.001

Figure 6.3.1-14b. Model-Predicted Total Vertical Flux Distribution at the Bottom of PTn Unit at 500 Years after Nuclear Waste Emplacement (the Base-Case Model with Ventilation) 


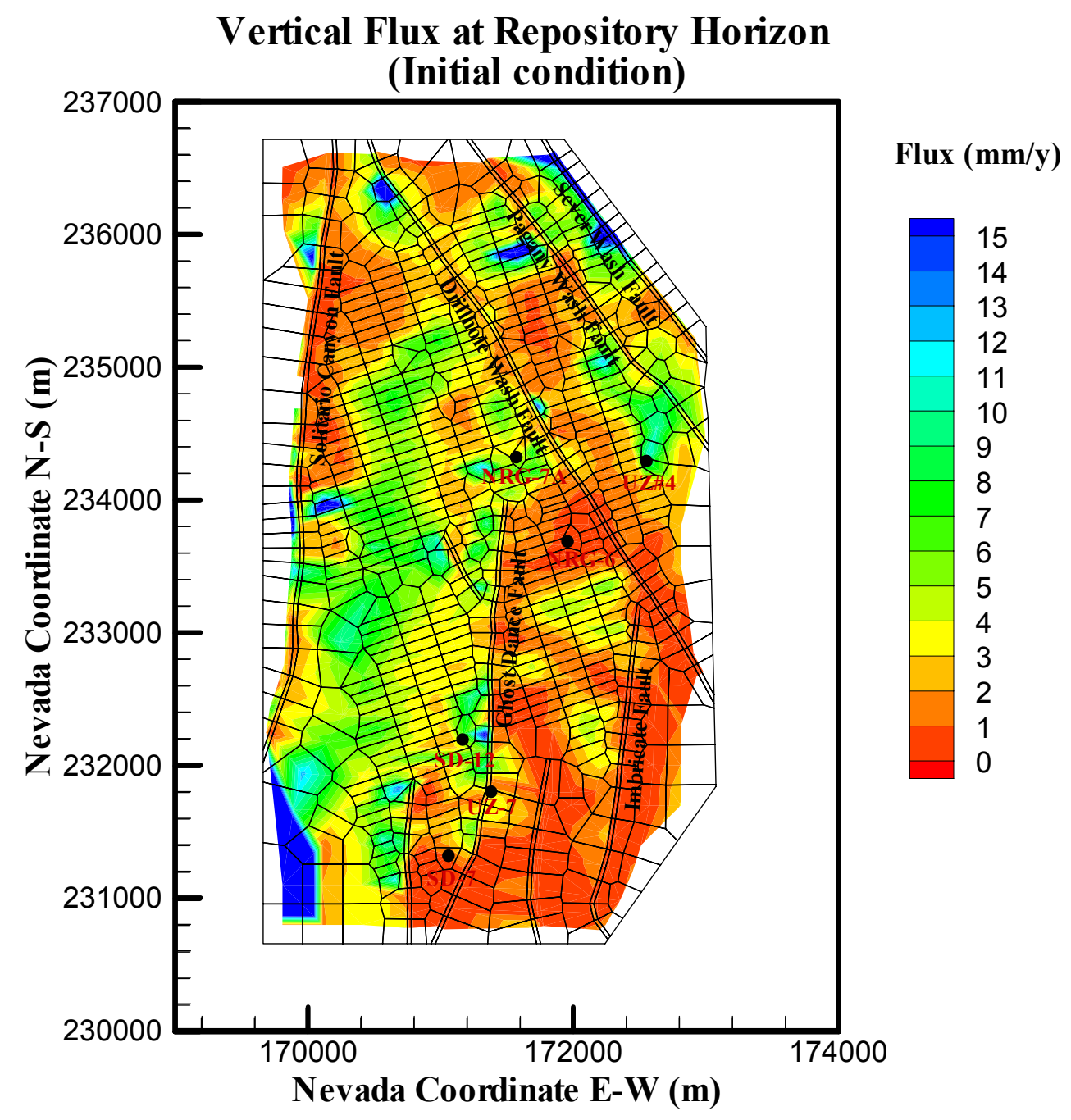

DTN: LB0310MTSCLTH3.001

Figure 6.3.1-15a. Model-Predicted Total Vertical Flux Distribution at Repository Horizon at the Ambient Condition with the Present-Day, Mean Infiltration Rates. 


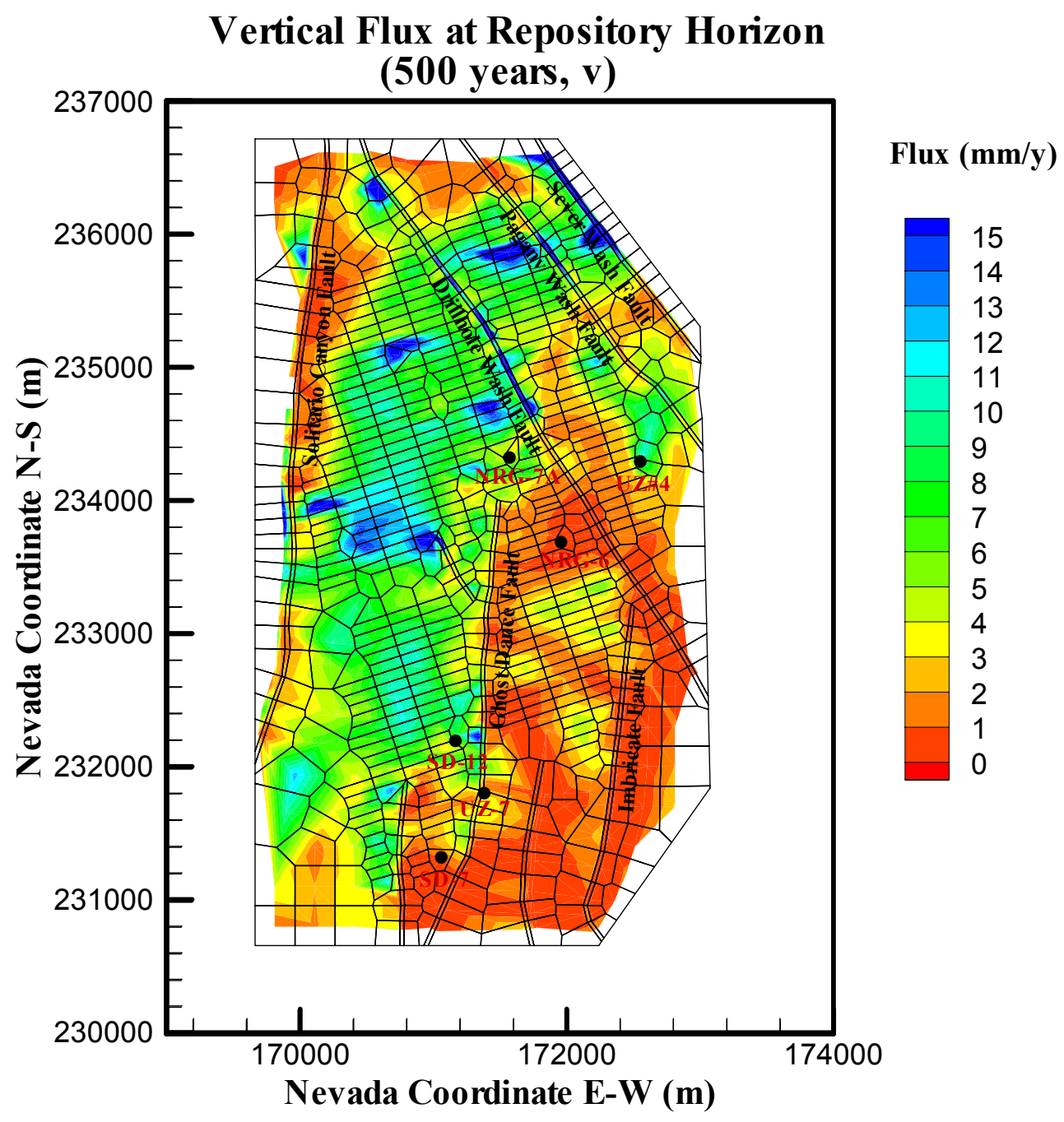

DTN: LB0310MTSCLTH3.001

Figure 6.3.1-15b. Model-Predicted Total Vertical Flux Distribution at Repository Horizon at 500 Years after Nuclear Waste Emplacement (the Base-Case Model with Ventilation) 


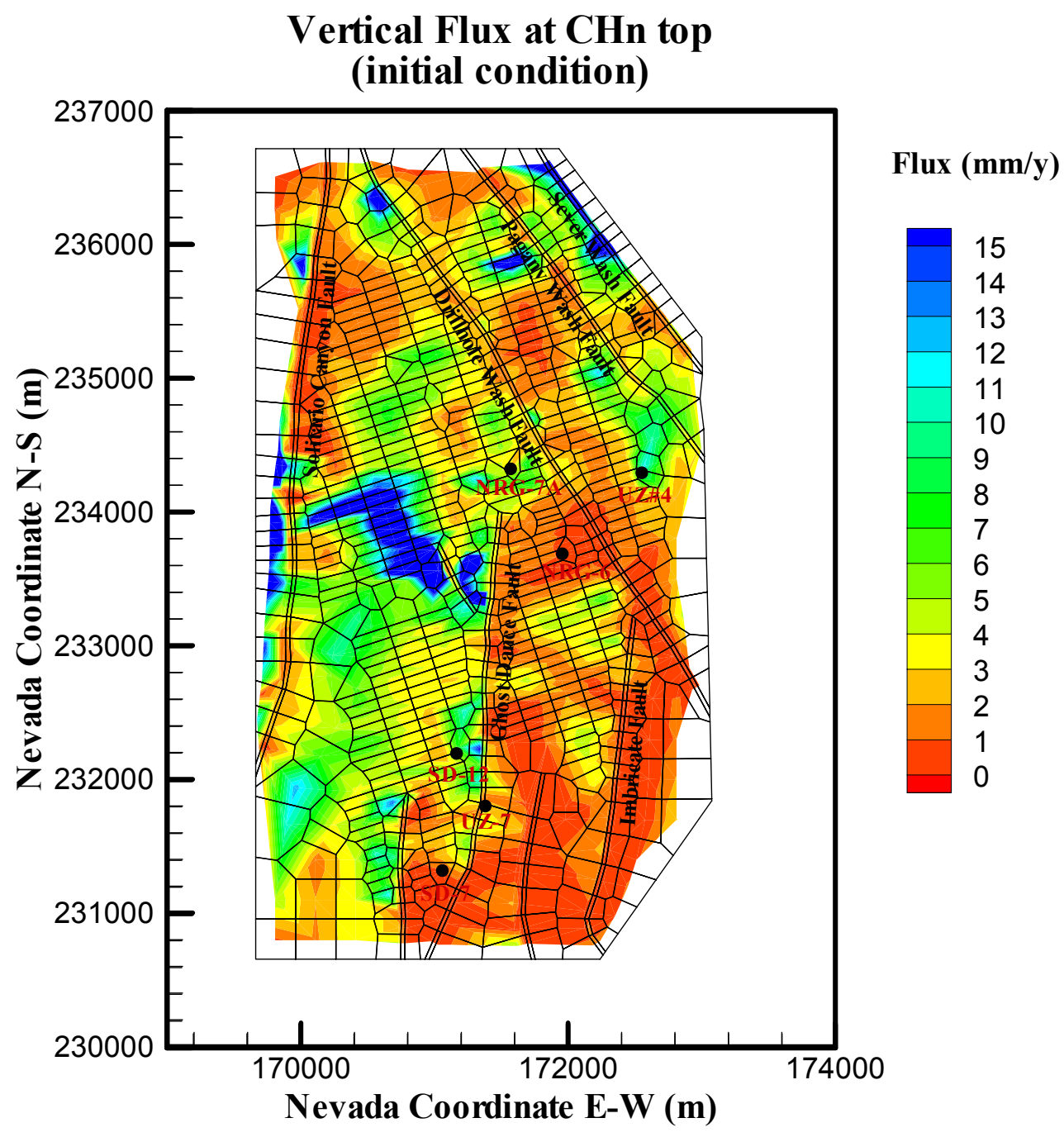

DTN: LB0310MTSCLTH3.001

Figure 6.3.1-16a. Model-Predicted Total Vertical Flux Distribution at the Top of CHn Unit at the Ambient Condition with the Present-Day, Mean Infiltration Rates 


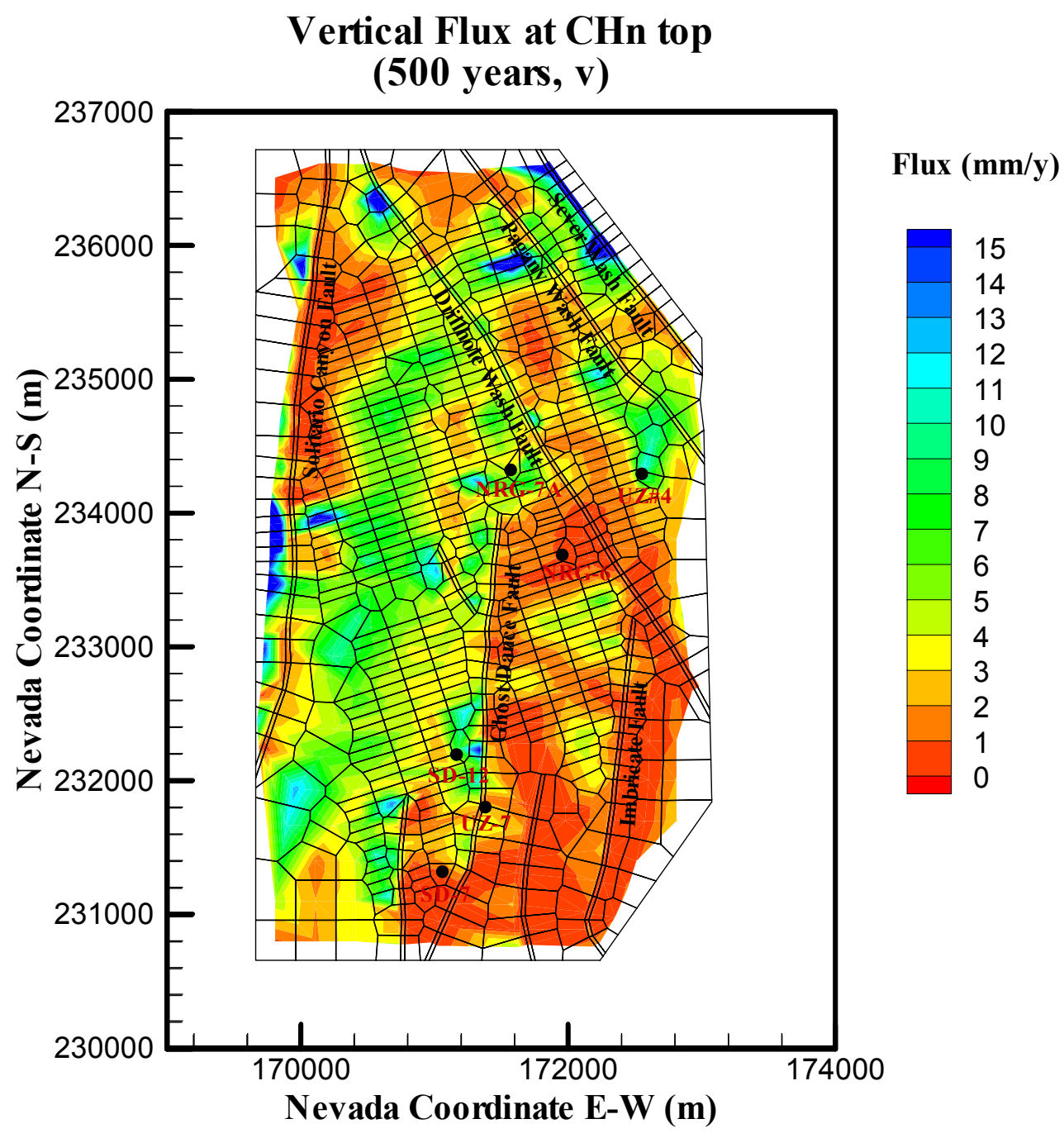

DTN: LB0310MTSCLTH3.001

Figure 6.3.1-16b. Model-Predicted Total Vertical Flux Distribution at the Top of $\mathrm{CHn}$ unit at 500 Years after Nuclear Waste Emplacement (the Base-Case Model with Ventilation) 
Figures 6.3.1-17 and 6.3.1-18 show vertical liquid fluxes and their thermally induced variation along Observation Columns F and $\mathrm{C}$ (Figure 6.1-1) at different times from 10 to 8,000 years. As shown in Figure 6.1-1, Column F crosses the center of the northern, main repository block, and Column $\mathrm{C}$ is located just outside of the southern edge of the northern repository block. The surface infiltration rate at Column $\mathrm{F}$ is approximately $4.5 \mathrm{~mm} /$ year. Along Column F, Figure 6.3.1-17 shows that there are three distinctly different vertical percolation fluxes, which are corresponding to changes in infiltration rate from present day (less than 600 years), monsoon (600-2,000 years), and glacial transition (greater than 2,000 years) climates. The figure indicates that significant impact of repository heating on percolation fluxes occurs only during the first 1,000 years. The maximum increase (factor of 3 ) in repository percolation fluxes is at 500 years of waste emplacement. Above and below the repository horizon, Figure 6.3.1-17 indicates that percolation fluxes are only elevated slightly by the repository thermal loading at early times (less than 1,000 years). After 2,000 years, however, as repository heat decreases, the thermal effect on percolation fluxes diminishes.

Vertical percolation fluxes and their variations with time at Location $\mathrm{C}$ are shown in Figure 6.3.1-18. Note that Column $\mathrm{C}$ is located just outside and very close to the repository boundary. The ambient infiltration rates at Column $\mathrm{C}$ are about $8 \mathrm{~mm} / \mathrm{year}$, which is almost twice as high as that in Column F. Yet Figure 6.3.2-18 shows only a slight effect of repository heating on vertical fluxes, i.e., the vertical flux distribution in Column $\mathrm{C}$ remains similar to ambient distribution through the entire thermal-loading period. This is expected, as Column $\mathrm{C}$ is located outside the repository area. Boiling front never reaches this location; hence no thermal effects on flux are predicted in Column $\mathrm{C}$. 
Total Vertical Liquid flux in Observation Column F

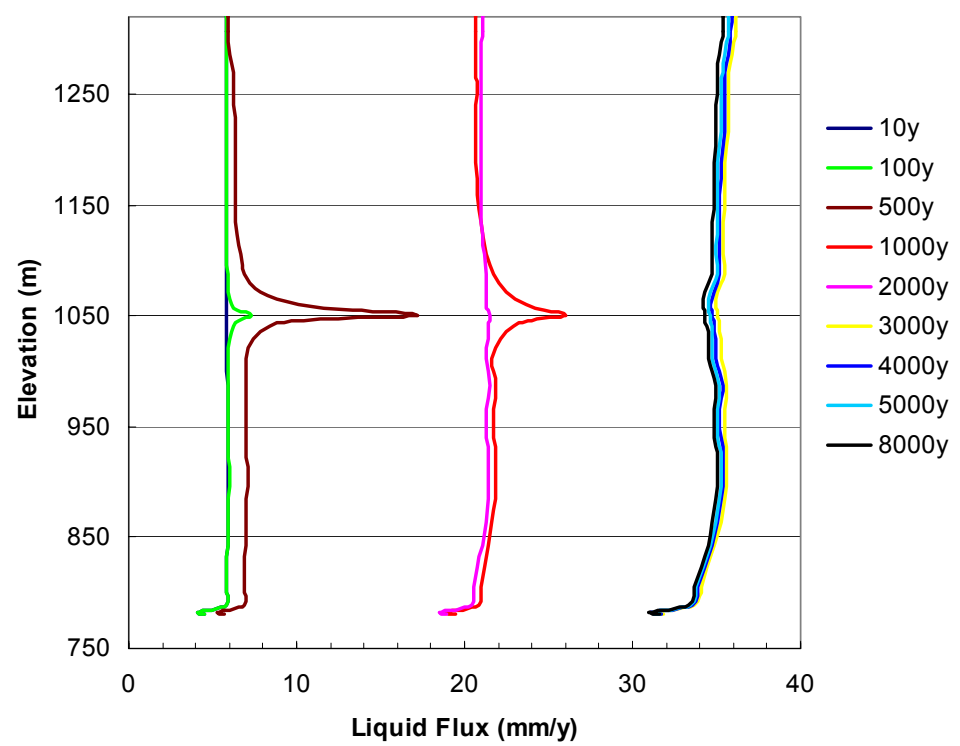

DTN: LB0310MTSCLTH3.001

Figure 6.3.1-17. Model-Predicted Total Vertical Flux Distribution along Observation Column F (Center of the Northern Repository Block) at Different Times (the Base-Case Model with Ventilation).

Total Vertical Liquid flux in Observation Column C

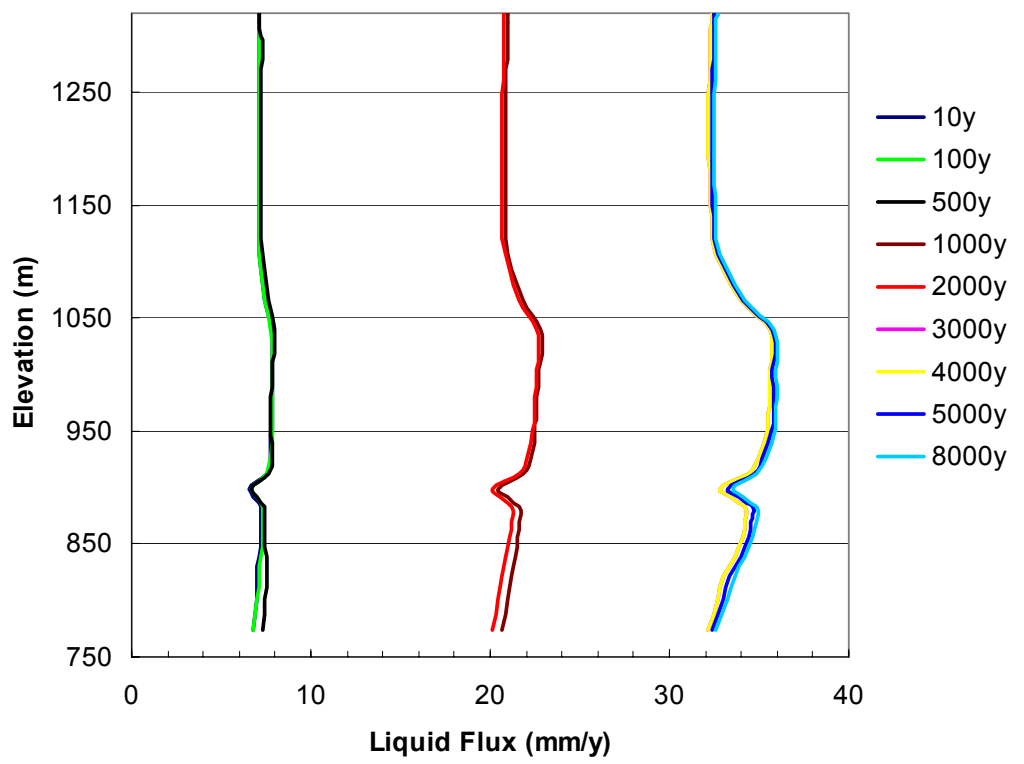

DTN: LB0310MTSCLTH3.001

Figure 6.3.1-18. Model Predicted Total Vertical Flux Distribution along the Observation Column C (Outside the Northern Repository Block) at Different Times (the Base-Case Model with Ventilation). 


\subsubsection{No-Ventilation Model Results and Analyses}

The difference between the no-ventilation case and the base-case model, as discussed in Sections 6.1.5 and 6.3.1, is that in the no-ventilation case, $100 \%$ of radioactive-decay heat is released into the host rock at the repository for the entire thermal period. This scenario is not a design under the current thermal-load management strategy, but rather, it is used for sensitivity analysis. The modeling approach, numerical model grid, input parameters, boundary, and initial conditions are the same as those discussed above for the base case. The results of the 3-D no-ventilation model are also presented using 2-D and 1-D plots of the evolution of temperature, saturation, and vertical percolation flux.

\section{Temperature}

Figures 6.3.2-1-6.3.2-5 show the simulated temperature contours at the repository horizon, the bottom of the PTn, and top of the CHn unit, as well as along the NS vertical cross section after $100,500,1,000,2,000$, and 5,000 years of thermal load. Compared with their counterparts of the ventilation model results of Figures 6.3.1-1-6.3.1-5, the no-ventilation TH model results show a qualitatively similar pattern of temperature distributions along these 2-D planes, though higher temperatures and larger TH effects, particularly in the first 100 years. Without ventilation, the 3-D TH Model indicates that boiling in the repository will occur after 2 years of thermal loading, while the base-case model (with first 50-year ventilation) estimates that boiling will not develop until 100 years after waste replacement.

The no-ventilation model results show, however, that the significant impact of ventilation on $\mathrm{TH}$ behavior at the repository and its surrounding areas lasts only for a couple of hundred years. Comparison of temperatures at 100 years, modeled with and without ventilation (Figure 6.3.1-1 versus Figure 6.3.2-1), show a more than $10^{\circ} \mathrm{C}$ difference between the two model results and much more widespread boiling. At 500 years, the temperature difference is less than $5^{\circ} \mathrm{C}$ (Figures 6.3.1-2a and 6.3.2-2a), and the difference further decreases $1-2{ }^{\circ} \mathrm{C}$ at 1,000 years.

In contrast, the no-ventilation model simulation results predict larger effects of ventilation on the far-field thermal conditions for the time $<1,000$ years, when compared to the results with ventilation (Haukwa et al. 2003 [165165]). At 500 years, the temperatures at the bottom of PTn (Figure $6.3 .2-2 \mathrm{~b}$ ) rise to $60^{\circ} \mathrm{C}$ without ventilation (versus only $40^{\circ} \mathrm{C}$ with ventilation except for localized low-infiltration areas near the Drillhole Wash fault, Figure 6.3.1-2b). The temperatures at the PTn bottom reach as high as $70-80^{\circ} \mathrm{C}$ without ventilation (Figures $6.3 .2-3 \mathrm{~b}$ and $6.3 .2-4 \mathrm{~b}$ ) in localized areas after 1,000-2,000 years, compared to $55^{\circ} \mathrm{C}$ for the case with ventilation (Figures 6.3.1-3b and 6.3.1-4b). In contrast, the temperatures during the first 1,000-2,000 years at the top of $\mathrm{CHn}$ for the no-ventilation case are only slightly higher than in the ventilation case (Figures 6.3.2-3c, 6.3.2-4c, 6.3.1-3c and 6.3.1-4c). Note in the no-ventilation case that temperatures in localized areas at the bottom of PTn are higher than at the top of CHn. This indicates that without the first 50-year ventilation, the stronger vaporization may create a stronger heat convection transfer to the PTn unit above the repository horizon, increasing the potential for thermally induced changes in PTn properties.

After 2,000 years, there is little difference in temperature conditions predicted by the two models (Figures 6.3.1-5 and 6.3.2-5). Although the boiling starts as early as two years after waste 
emplacement with the no-ventilation model, the boiling condition lasts to about 1,000 years for both cases, with or without ventilation.

\section{Temperature Distribution at Repository Horizon (100 years, nv)}

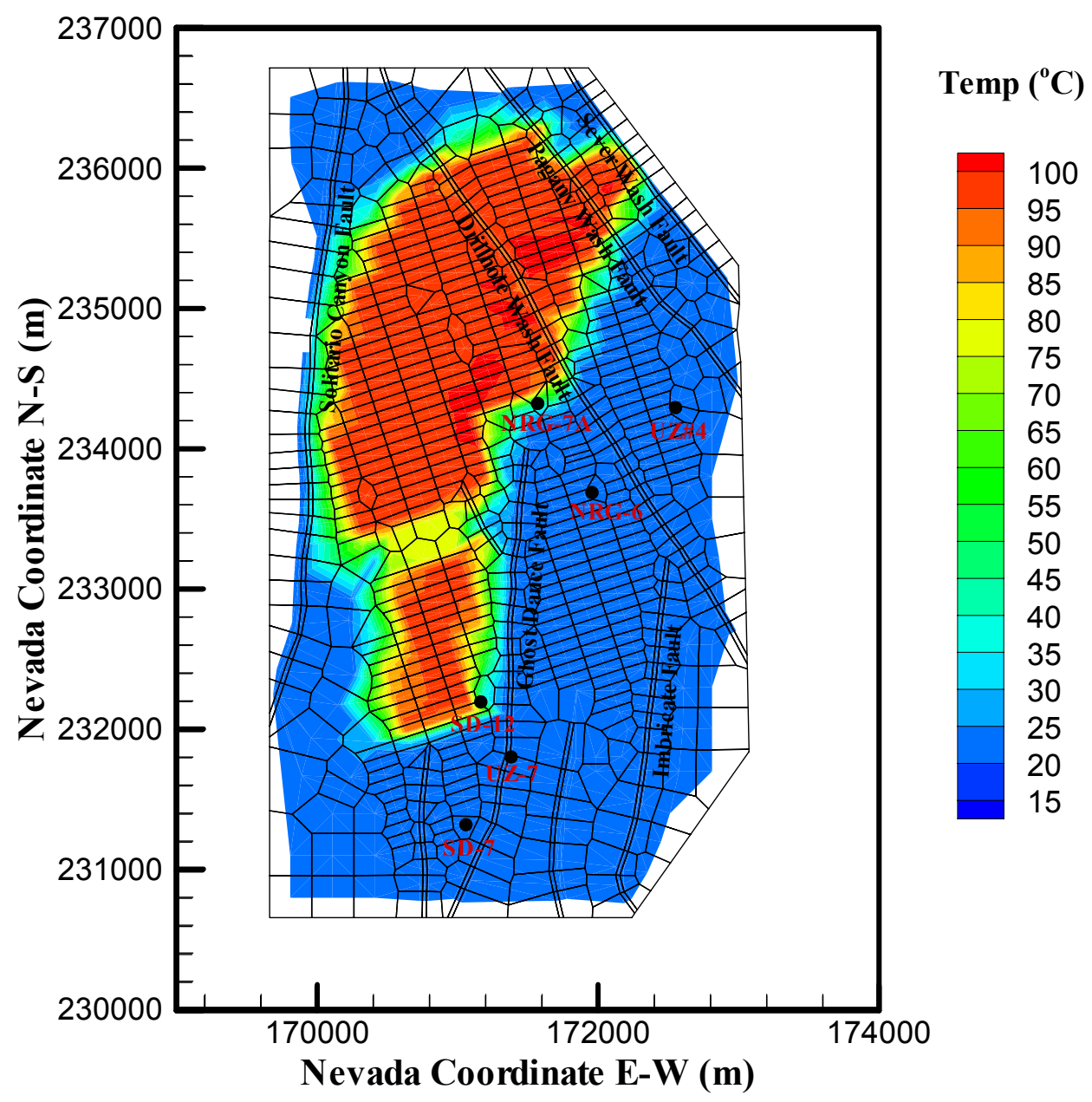

DTN: LB0310MTSCLTH3.001

Figure 6.3.2-1. Model-Predicted Rock Temperature Distribution at Repository Horizon at 100 years after Nuclear Waste Emplacement (the No-Ventilation Model) 


\section{Temperature Distribution at Repository Horizon (500 years, nv)}

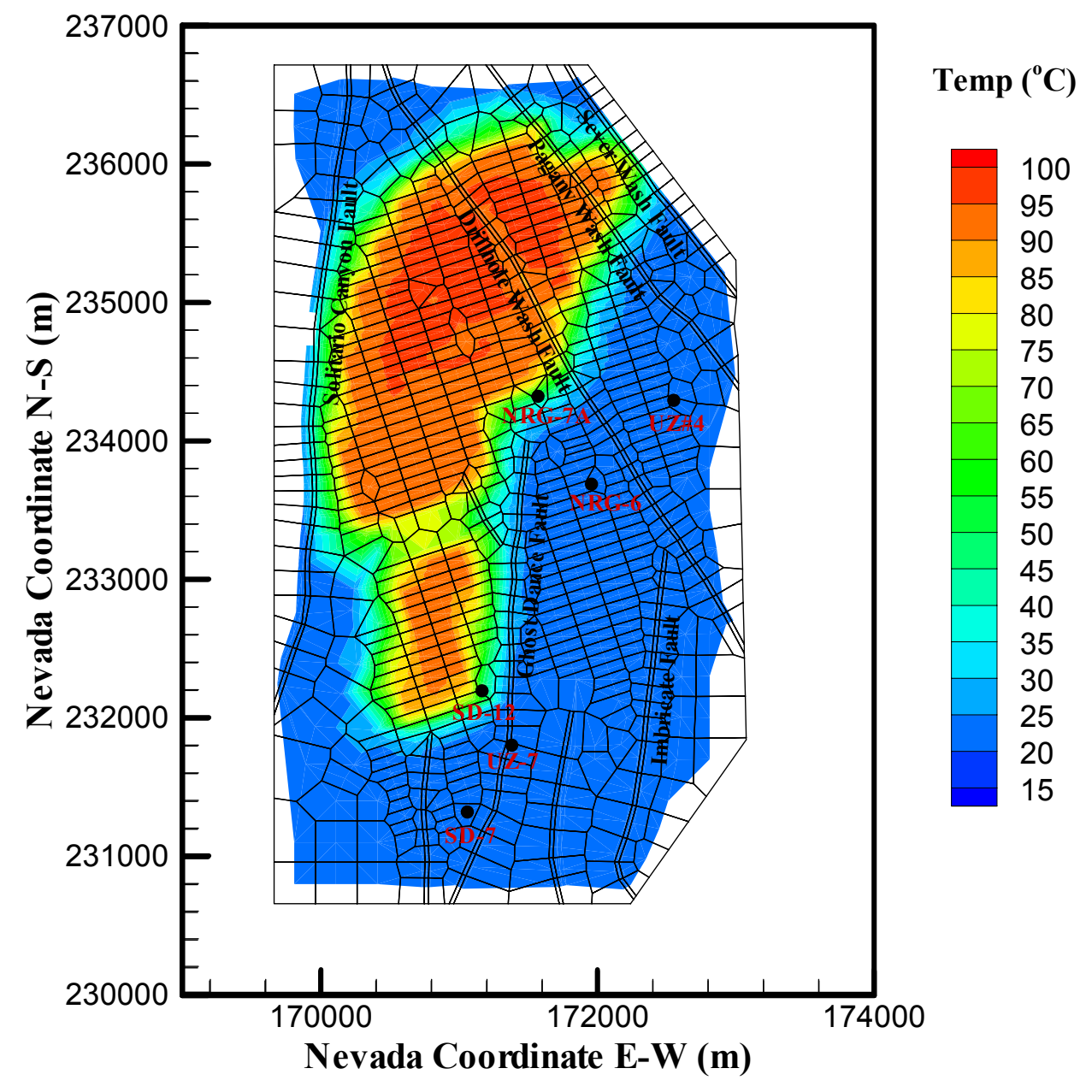

DTN: LB0310MTSCLTH3.001

Figure 6.3.2-2a. Model-Predicted Rock Temperature Distribution at Repository Horizon at 500 Years after Nuclear Waste Emplacement (the No-Ventilation Model) 


\section{Temperature Distribution at PTn bottom (500 years, nv)}

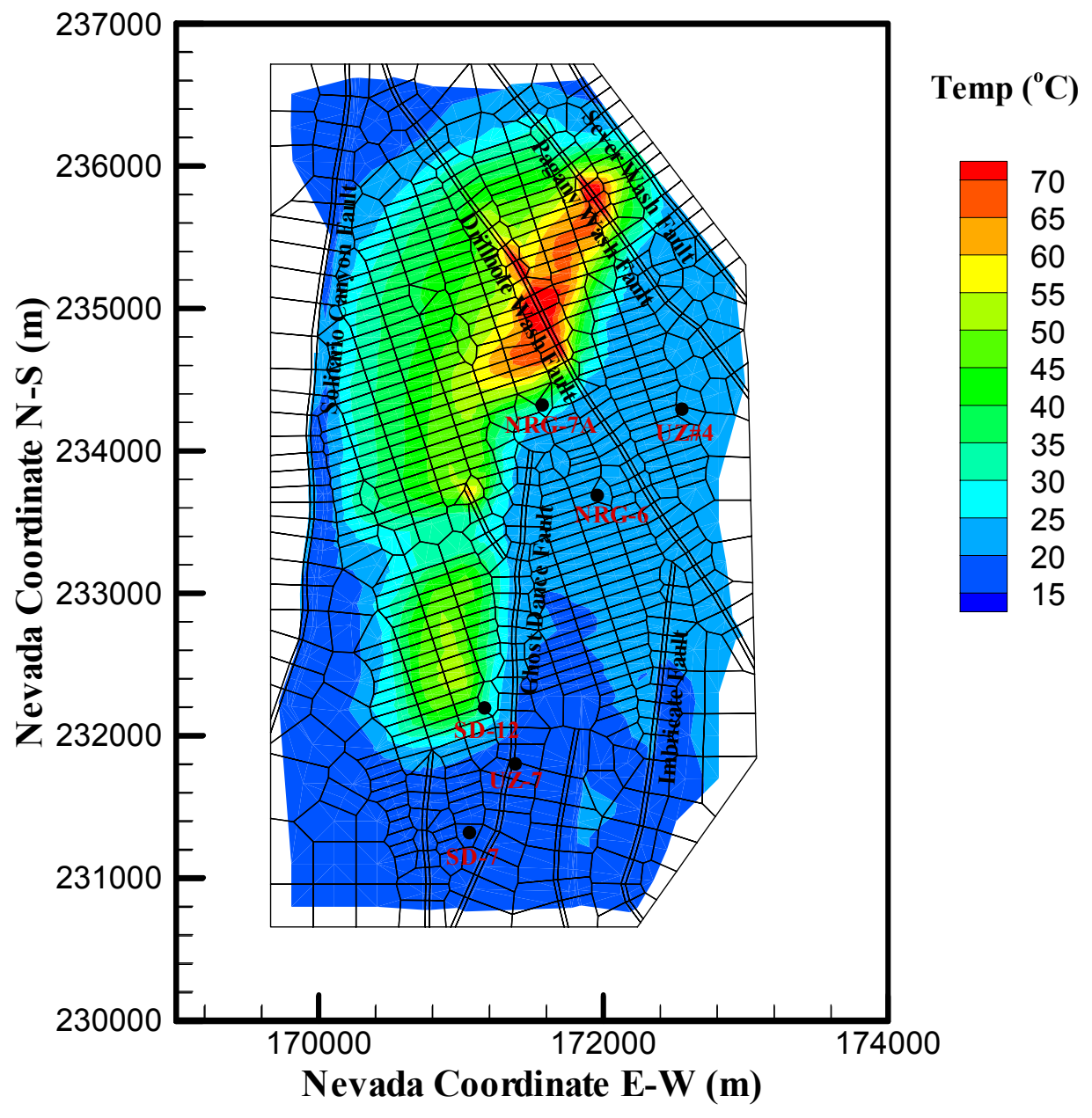

DTN: LB0310MTSCLTH3.001

Figure 6.3.2-2b. Model-Predicted Rock Temperature Distribution at the Bottom of PTn Unit at Time of 500 Years after Nuclear Waste Emplacement (the No-Ventilation Model) 


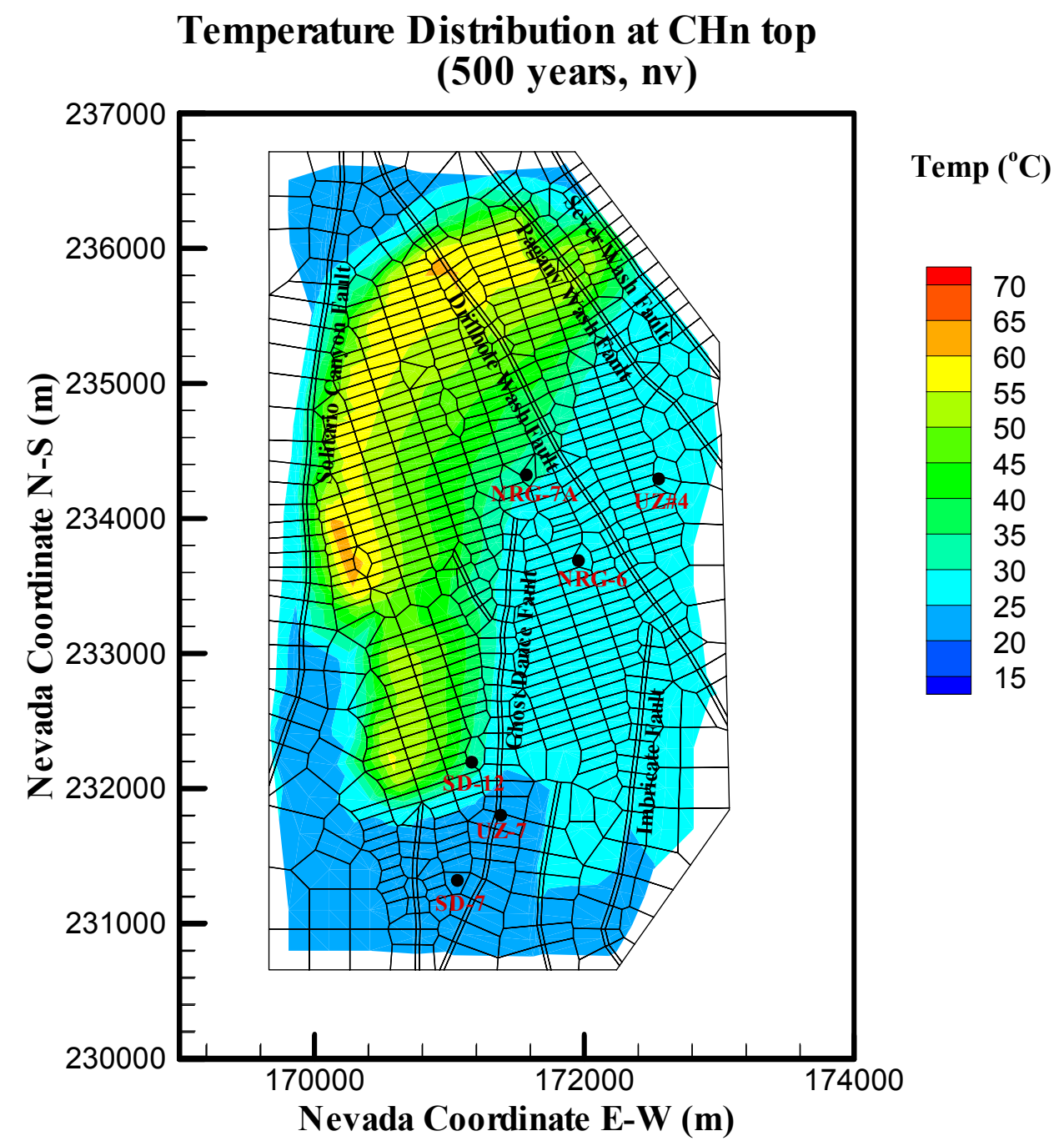

DTN: LB0310MTSCLTH3.001

Figure 6.3.2-2c. Model-Predicted Rock Temperature Distribution at the Top of CHn Unit at 500 Years after Nuclear Waste Emplacement (the No-Ventilation Model) 


\section{Temperature Distribution at Repository Horizon (1000 year, nv)}

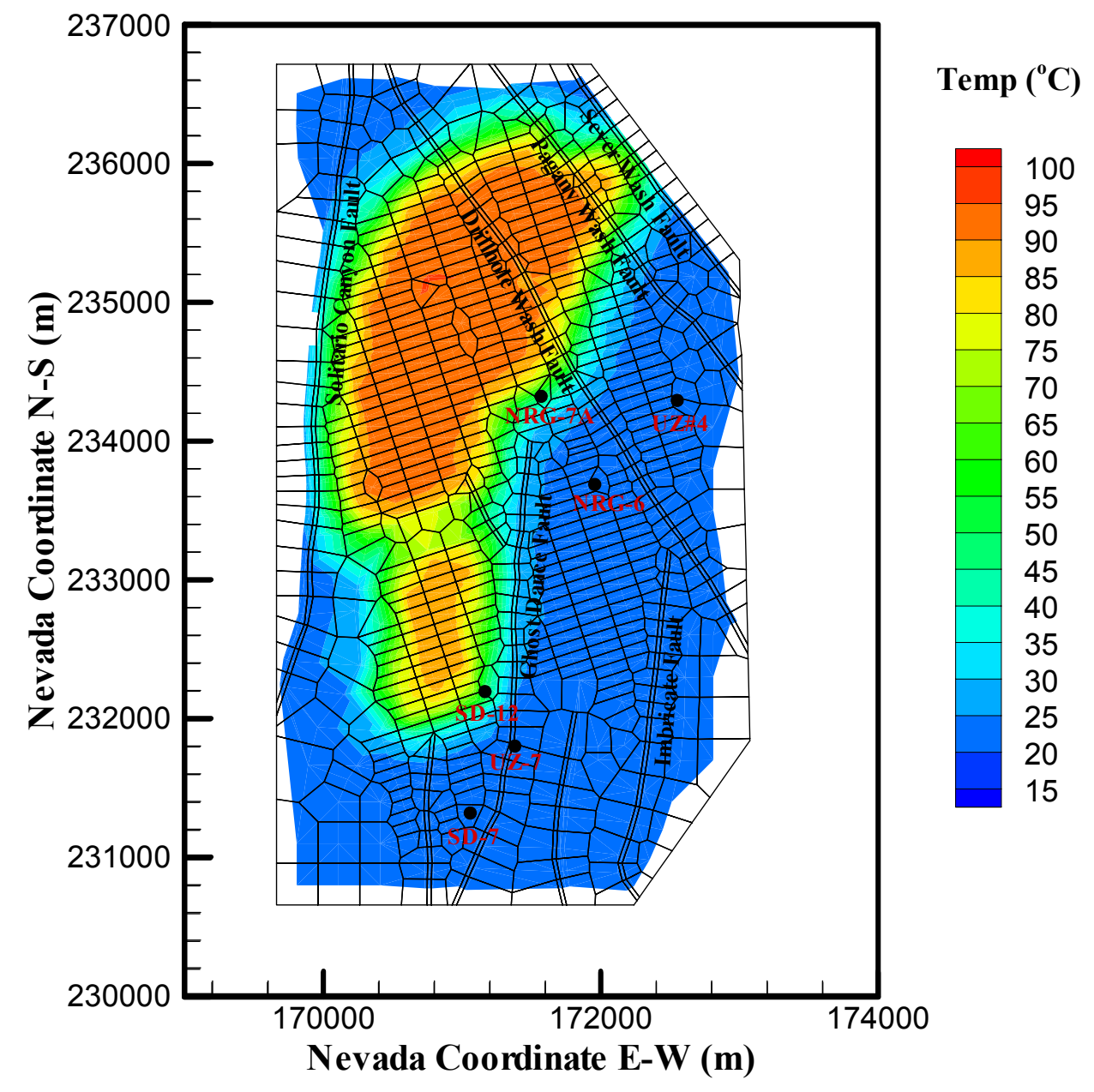

DTN: LB0310MTSCLTH3.001

Figure 6.3.2-3a. Model-Predicted Rock Temperature Distribution at Repository Horizon at 1,000 Years after Nuclear Waste Emplacement (the No-Ventilation Model) 


\section{Temperature Distribution at PTn bottom (1000 years, nv)}

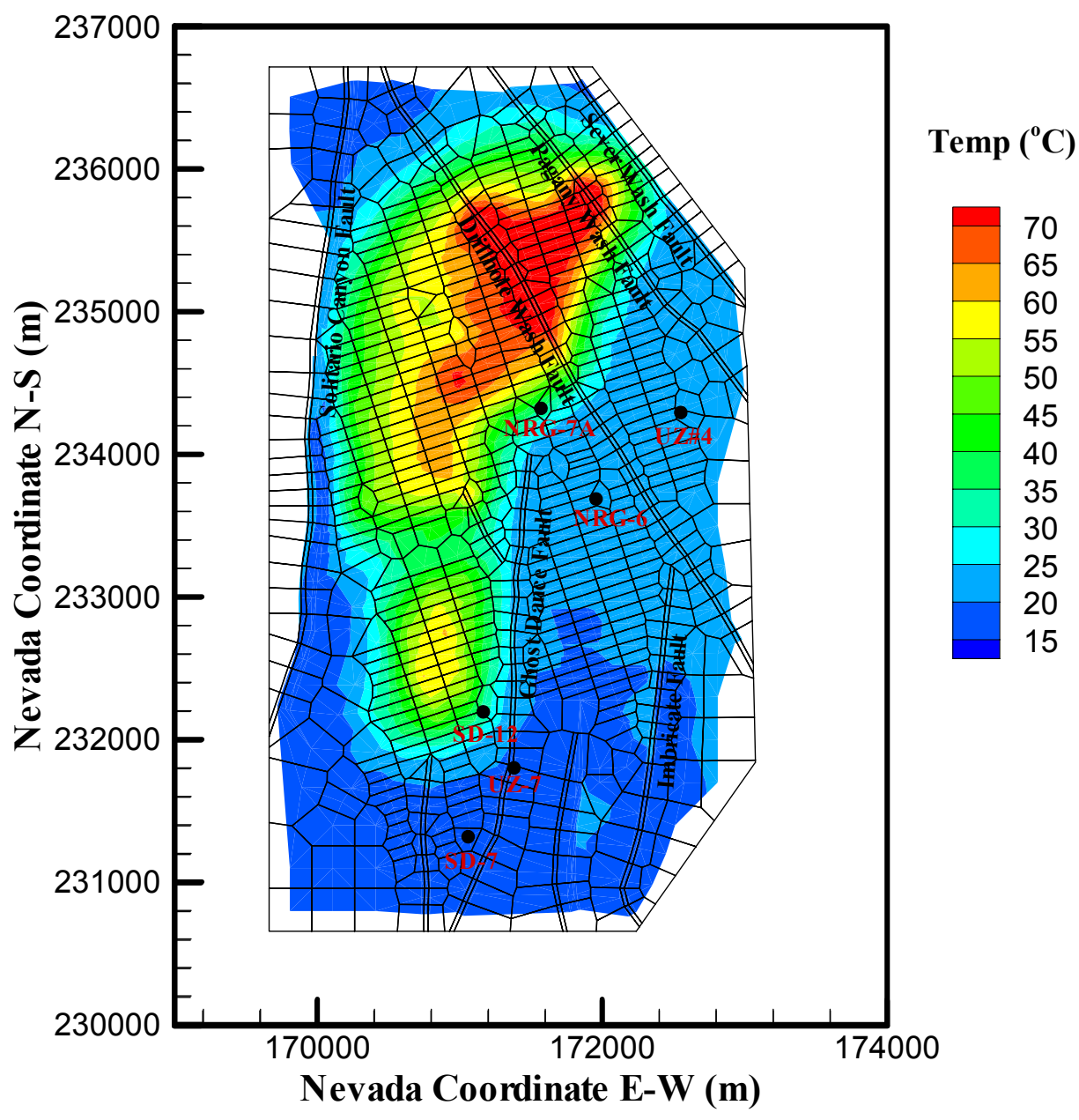

DTN: LB0310MTSCLTH3.001

Figure 6.3.2-3b. Model-Predicted Rock Temperature Distribution at the Bottom of PTn Unit at 1,000 Years after Nuclear Waste Emplacement (the No-Ventilation Model) 


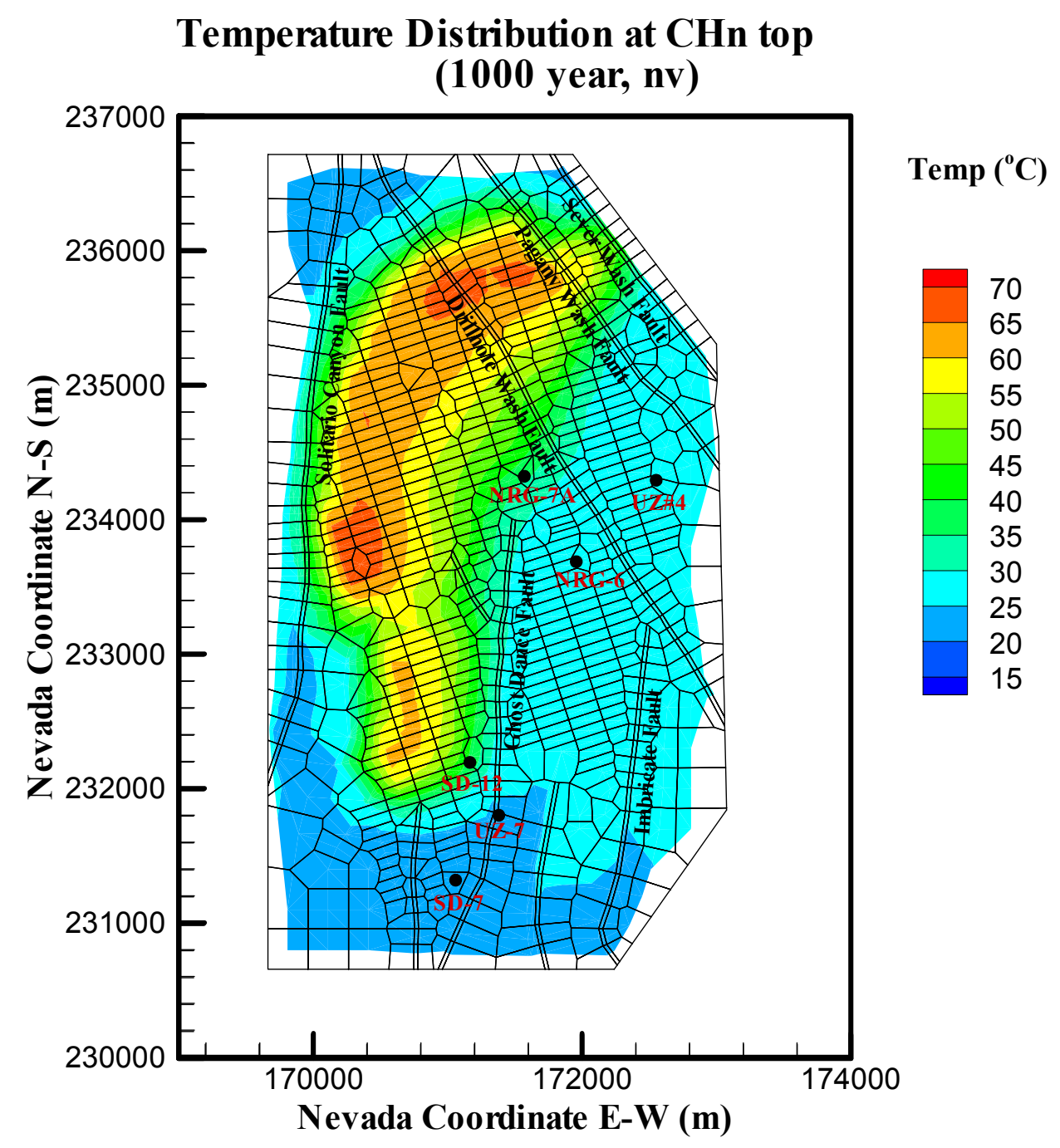

DTN: LB0310MTSCLTH3.001

Figure 6.3.2-3c. Model-Predicted Rock Temperature Distribution at the Top of $\mathrm{CHn}$ Unit at 1,000 Years after Nuclear Waste Emplacement (the No-Ventilation Model) 


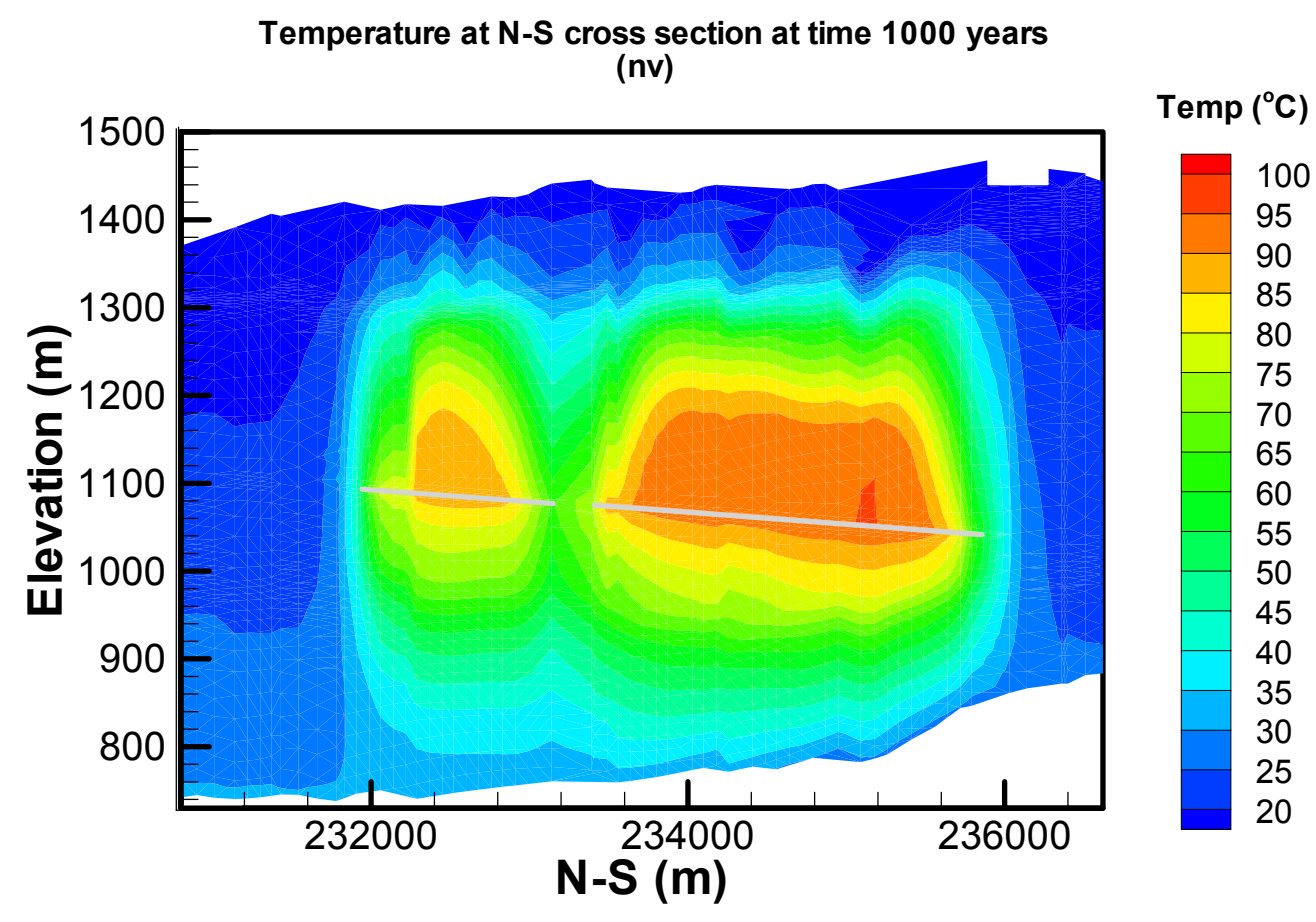

DTN: LB0310MTSCLTH3.001

Figure 6.3.2-3d. Model-Predicted Temperature Distribution at the N-S Cross Section at 1,000 Years after Nuclear Waste Emplacement (the No-Ventilation Model) 


\section{Temperature Distribution at Repository Horizon \\ (2000 years, nv)}

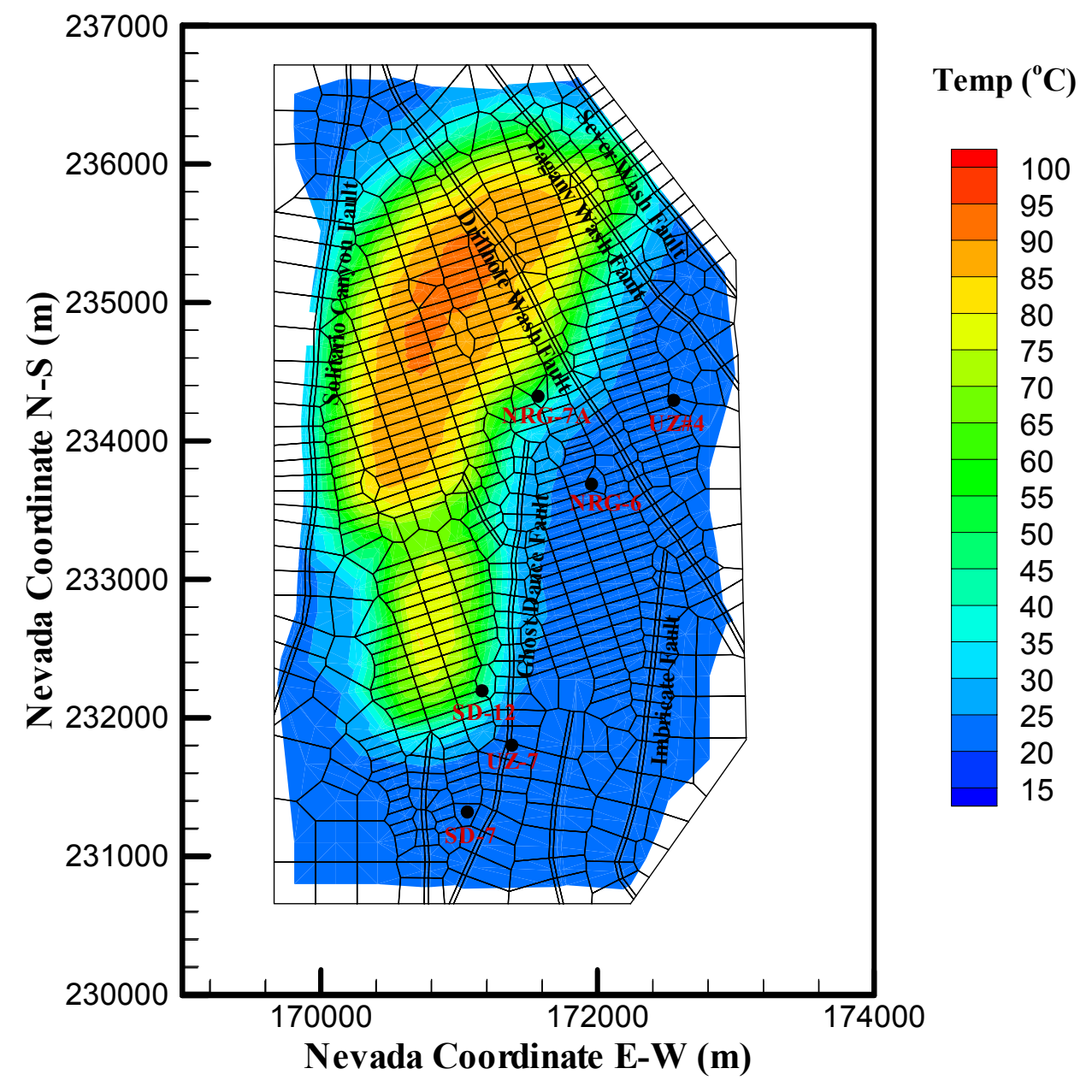

DTN: LB0310MTSCLTH3.001

Figure 6.3.2-4a. Model-Predicted Rock Temperature Distribution at Repository Horizon at 2,000 Years after Nuclear Waste Emplacement (the No-Ventilation Model) 


\section{Temperature Distribution at PTn bottom \\ (2000 years, $\mathrm{nv})$}

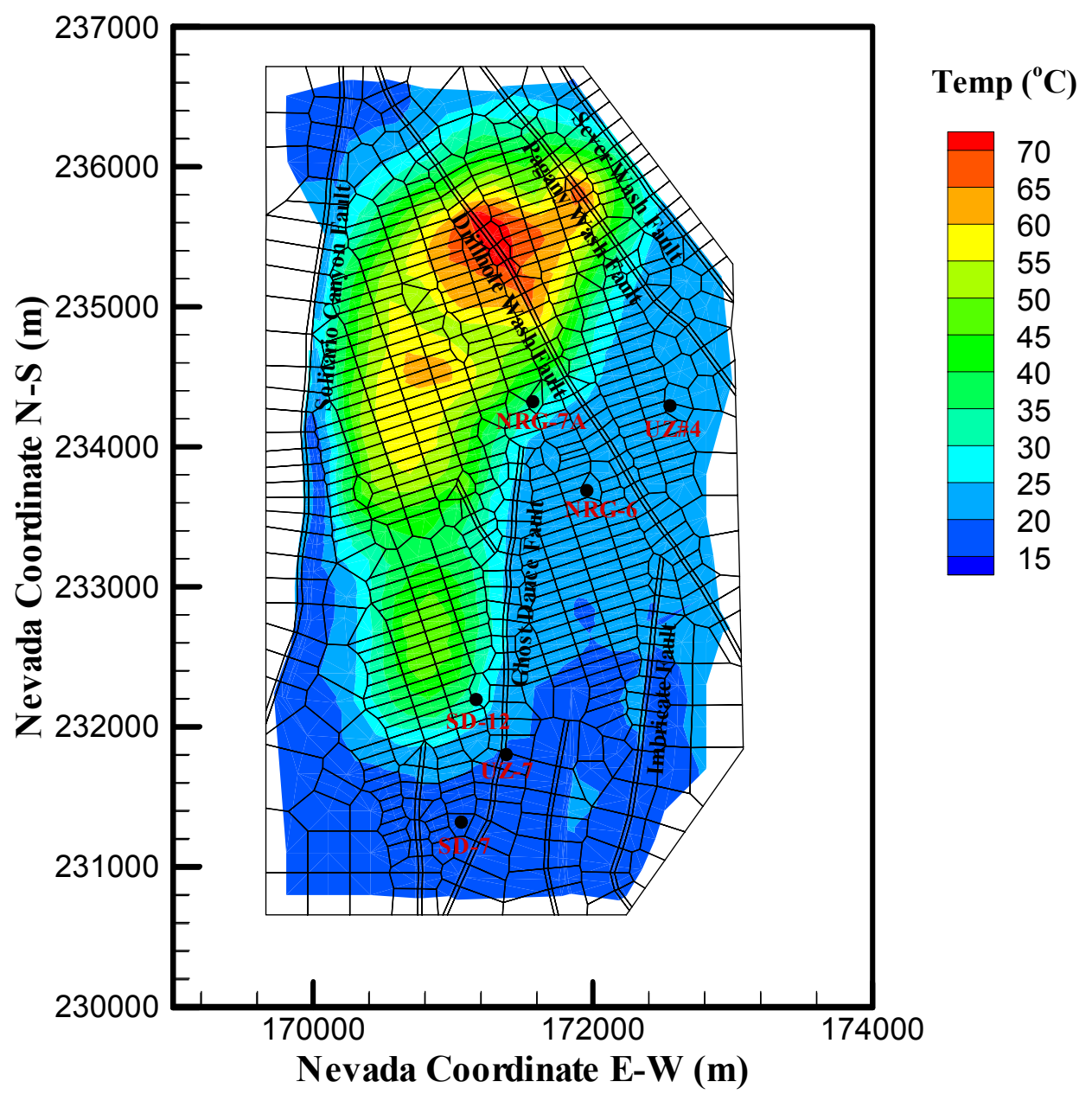

DTN: LB0310MTSCLTH3.001

Figure 6.3.2-4b. Model-Predicted Rock Temperature Distribution at the Bottom of PTn Unit at 2,000 Years after Nuclear Waste Emplacement (the No-Ventilation Model) 


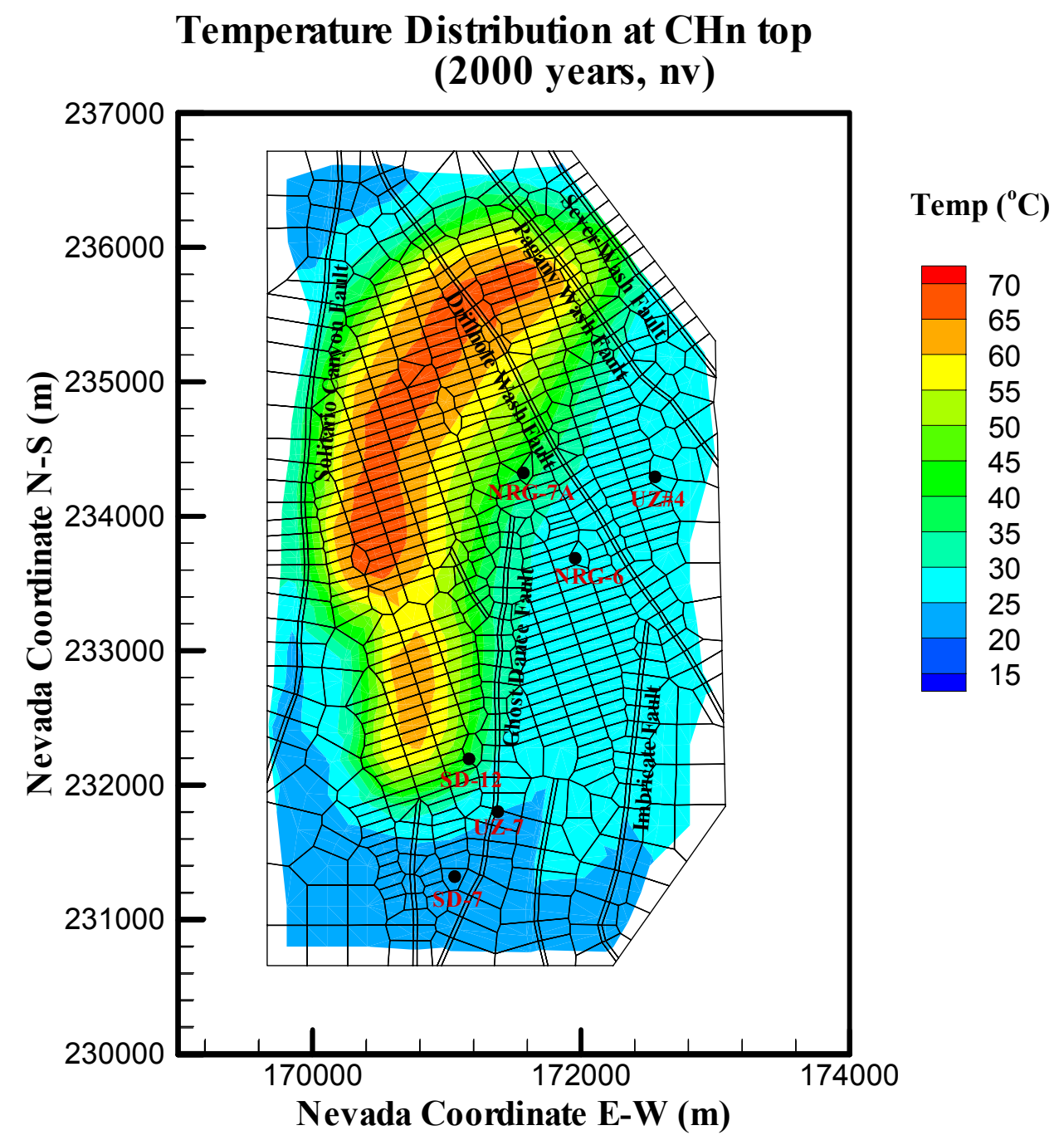

DTN: LB0310MTSCLTH3.001

Figure 6.3.2-4c. Model-Predicted Rock Temperature Distribution at the Top of $\mathrm{CHn}$ Unit at 2,000 Years after Nuclear Waste Emplacement (the No-Ventilation Model) 


\section{Temperature Distribution at Repository Horizon (5000 years, nv)}

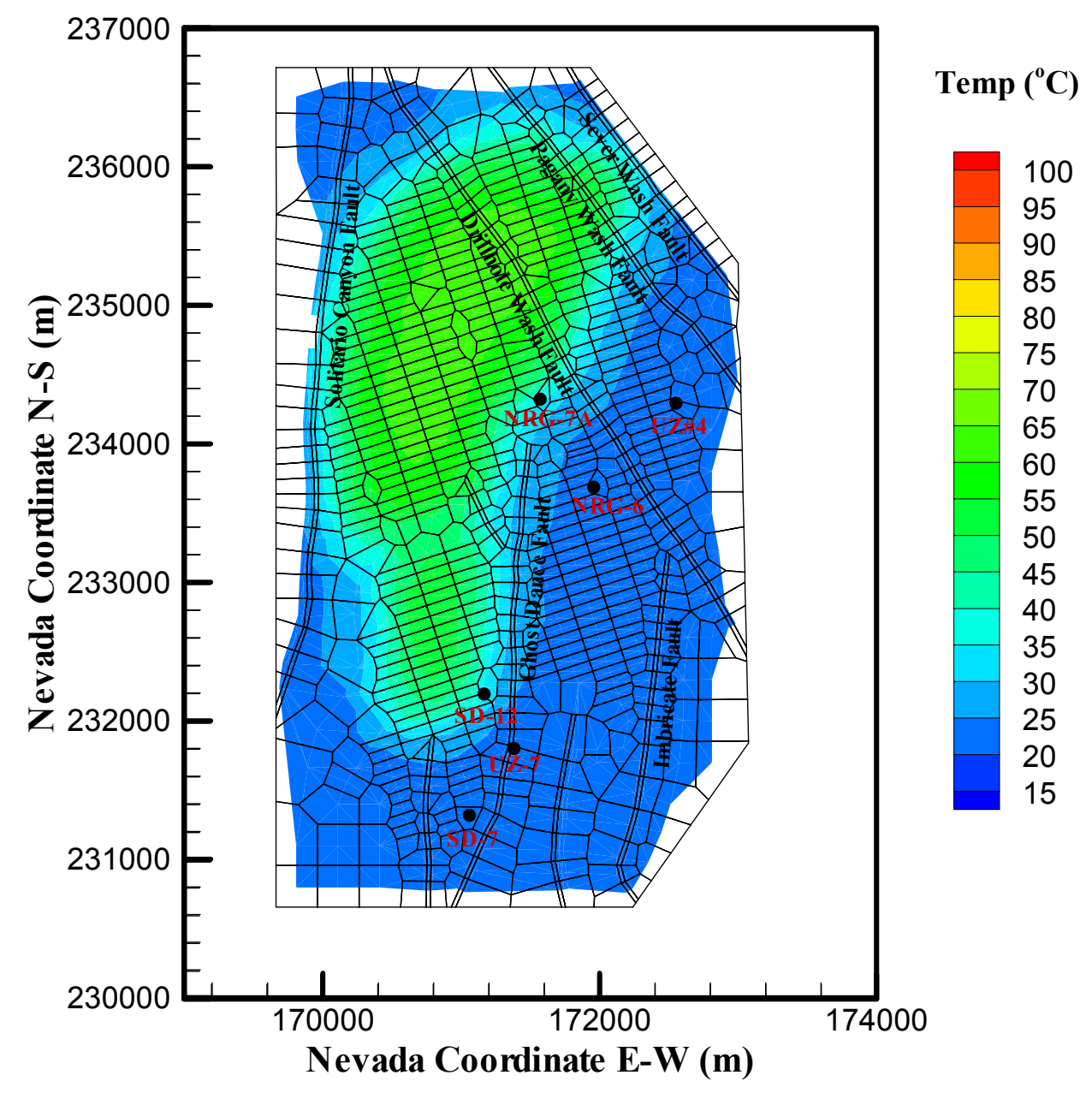

DTN: LB0310MTSCLTH3.001

Figure 6.3.2-5. Model-Predicted Rock Temperature Distribution at Repository Horizon at 5,000 Years after Nuclear Waste Emplacement (the No-Ventilation Model) 
Several temperature profiles at different times along the vertical Column $\mathrm{F}$ (near the center of the northern repository block), as shown in Figure 6.3.2-6a. Compared with Figure 6.3.1-6 for the ventilation case, Figure 6.3.2-6a shows a higher temperature at the repository horizon (more than $130^{\circ} \mathrm{C}$ versus $100^{\circ} \mathrm{C}$ of Figure $6.3 .1-6$ ). Moreover, boiling zones directly above the repository are thicker, indicating stronger TH effects without ventilation. Note that a heat pipe develops, lasting beyond 1,000 years for this no-ventilation case (6.3.2-6a). The heat-pipe phenomena are characterized by zero temperature gradient at boiling temperatures in the areas immediately above the repository horizon.

The simulated temperatures and their variations versus time at three elevations (lower PTn, repository horizon, and upper $\mathrm{CHn}$ ) along Observation Column F (Figure 6.1-1) are presented in Figure 6.3.2-6b. At the repository horizon, Figure 6.3.2-6b shows that without ventilation, temperatures at the repository increase rapidly and reach boiling in about two years, reach a maximum value of about $130^{\circ} \mathrm{C}$ at $8-34$ years after waste emplacement. For the same time period, by comparison, the predicted highest temperatures with the base-case or ventilation model (Figure 6.3.1-7) are still below $50^{\circ} \mathrm{C}$, well below the ambient boiling temperatures, which is not reached until about 80 years. These results confirm that the ventilation is effective in preventing temperatures from rising rapidly at the repository for the first hundreds of years. Figure 6.3.2-6b also shows that boiling conditions last up to 1,000 years.

The maximum impact of repository heating on the far-field rock, as shown in Figure 6.3.2-6b, occurs at about 2,000 years after waste emplacement, which is similar to the case with ventilation (Figure 6.3.1-7), for the lower portion of the PTn unit and the upper CHn.

Temperature distribution at Observation Column F

(nv)

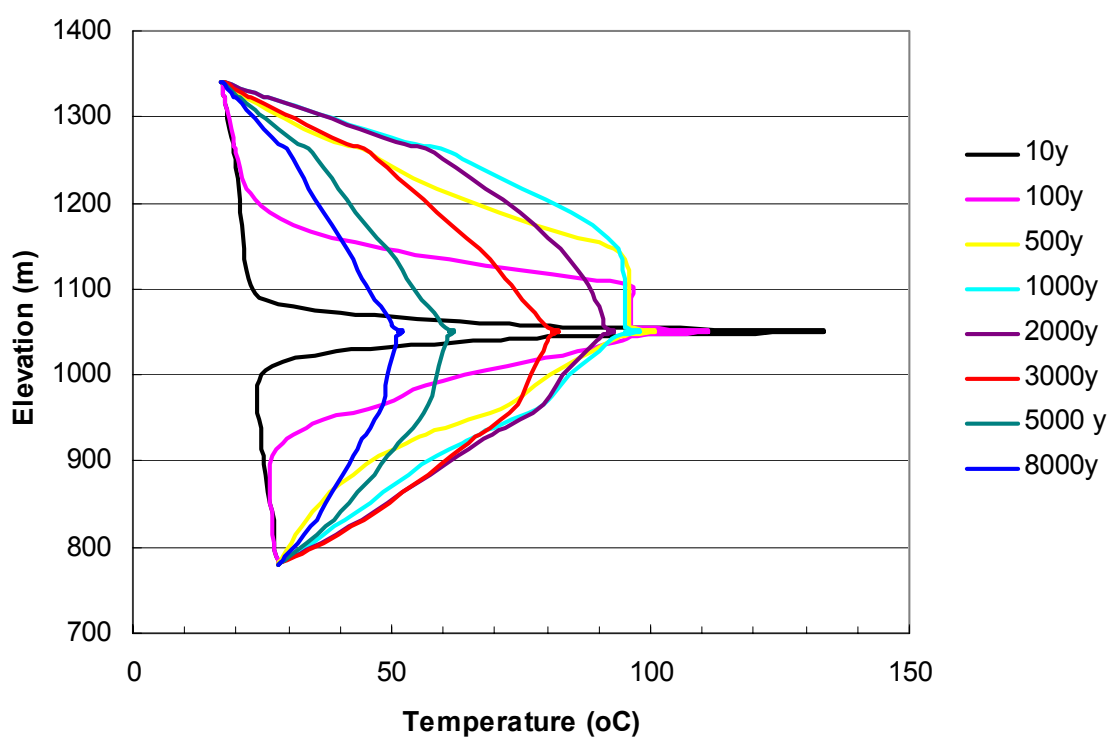

DTN: LB0310MTSCLTH3.001

Figure 6.3.2-6a. Model-Predicted Temperature Profiles at Different Times along Observation Column F (the Center of the Northern, Main Repository Block) (the No-Ventilation Model) 


\section{Temperature Change at Observation Column F (no ventilation)}

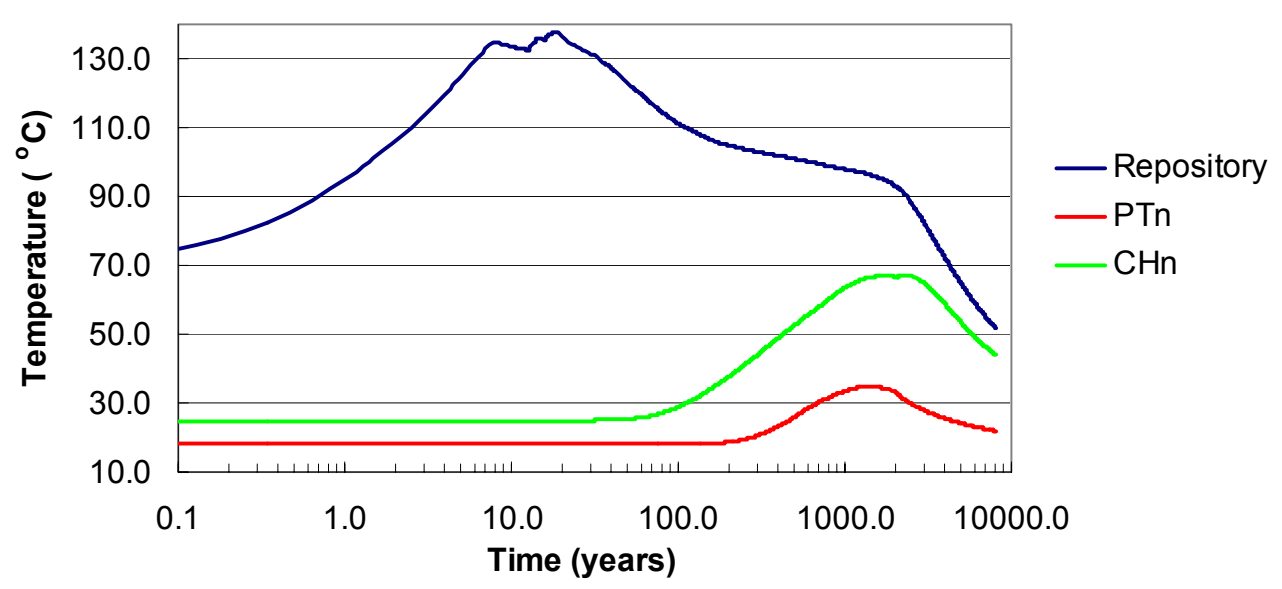

DTN: LB0310MTSCLTH3.001

Figure 6.3.2-6b. Temperature Changes over Time at Three Elevations of the Lower PTn Unit (Elevation $1,307.5 \mathrm{~m}$ ), Repository Horizon, and the Upper CHn Unit (Elevation of $961 \mathrm{M}$ ) along Column F (Center of the Northern Repository Block) (the No-Ventilation Model)

\section{Liquid Saturation}

Figure 6.3.2-7 shows the contour plot of matrix liquid saturation along the N-S cross section at 1,000 years with no ventilation. Because the majority of reduction in matrix liquid saturation by repository heating occurs at areas immediately near repository drifts (Haukwa et al. 2003 [165165]), the figure shows that, for the most part, the liquid saturations in the far fields of the cross section are nearly identical to those shown in Figure 6.3.1-12. The difference is in localized areas around the repository horizon where predicted matrix liquid saturation for the noventilation case is much lower than the corresponding saturation from the base case model. This observation can also be confirmed by examining Figure 6.3.2-8, which shows the evolution of saturation in Column $F$ between 10 and 8,000 years. The lowest saturation $(\sim 0.2)$ is at the repository horizon after 100 years, owing to increased vaporization. The large thermal input leads to more evaporation near drifts and condensation in the units above. The effects of enhanced condensation can be seen in Figure 6.3.2-7, which shows a small increase in liquid saturation above the repository compared with the base case (Figure 6.3.1-12). After 2,000 years, saturation increases are mainly caused by changes in climate. 
Saturation distribution at $\mathrm{N}-\mathrm{S}$ cross section at time 1000 years

(No Ventilation)

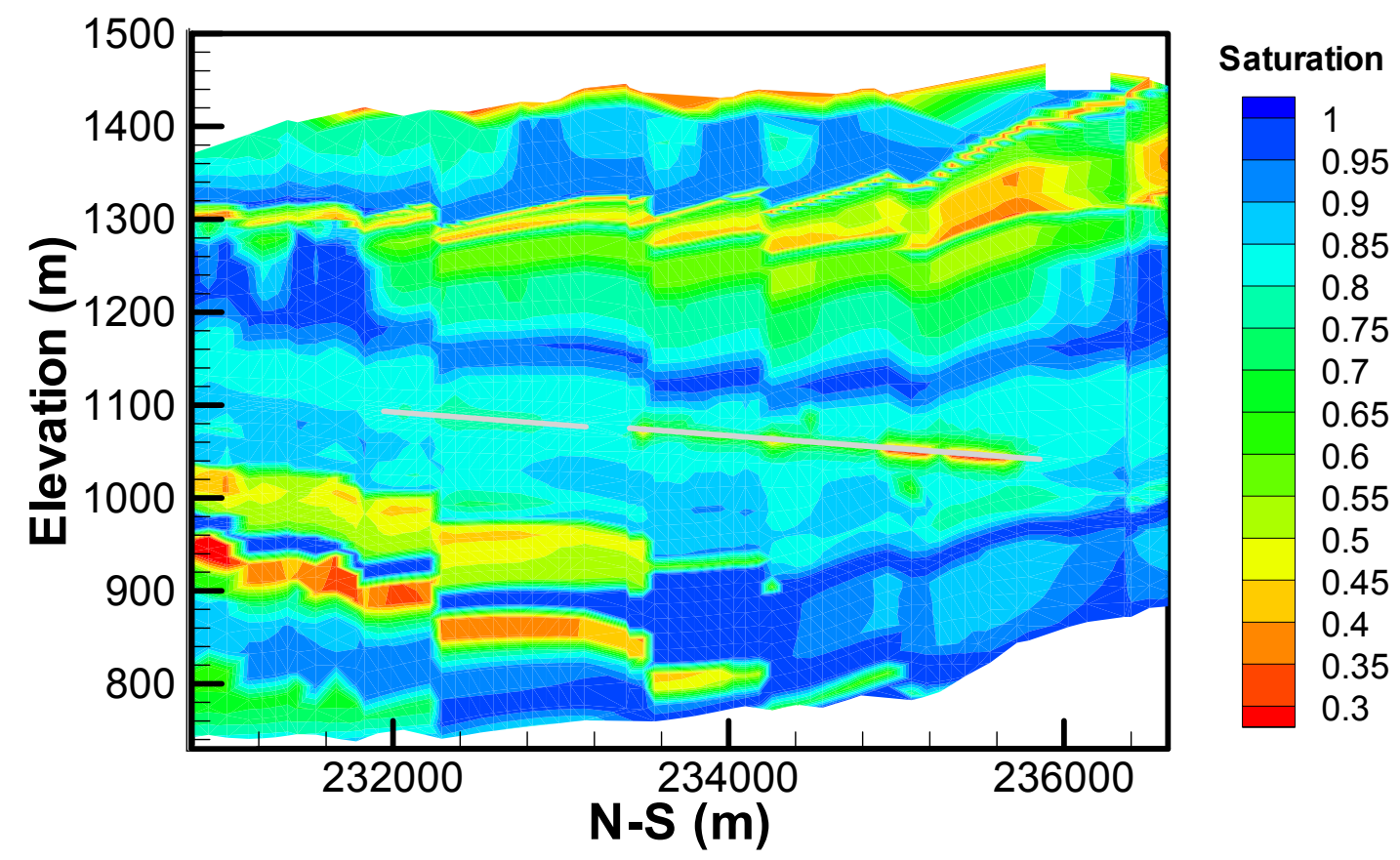

DTN: LB0310MTSCLTH3.001

Figure 6.3.2-7. Model-Predicted Matrix Liquid Saturation Distribution at the N-S Cross Section at 1,000 Years after Nuclear Waste Emplacement (the No-Ventilation Model) 


\section{Saturation distribution at Observation Column F}

(nv)

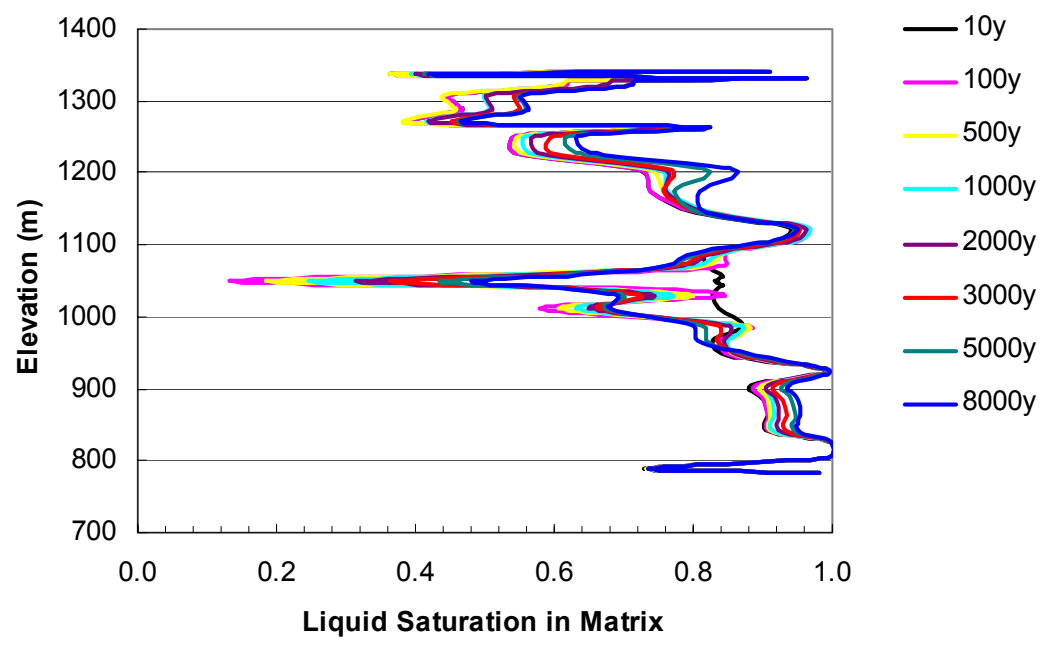

DTN: LB0310MTSCLTH3.001

Figure 6.3.2-8. Comparison of Simulated Matrix Liquid Saturation Distributions along Observation Column $\mathrm{F}$ at 10-8,000 Years after Nuclear Waste Emplacement, Using the NoVentilation Model

\section{Percolation Flux}

As discussed above in the temperature and liquid saturation subsections of Section 6.3.2, boiling in this scenario will last longer, resulting in drier conditions in the rock matrix near the repository and larger condensation zones in the units above drifts. These drier matrix blocks create large capillary pressure gradients, which will enhance reflux back to the drier rock. On the other hand, if boiling does not take place, percolation flux is not significantly affected by local variation of temperature alone.

Figure 6.3.2-9 shows vertical liquid-flux distributions at the repository horizon at 500 years. It shows some difference and large fluxes, as compared with Figure 6.3.1-15b for the case with ventilation. In general, Figure 6.3.2-9 displays larger percolation fluxes at the repository horizon at 500 years compared to ambient conditions (Figure 6.3.1-15a).

Figure 6.3.2-10 provides a comparison of simulated vertical fluxes at different times along Observation Column F (the center of the northern repository block), simulated using the noventilation model, indicating significant different fluxes under TH effect. At 10 years, large downward fluxes (positive values for downward flow in the figure) develop immediately above drifts. The peak flux value reaches $85 \mathrm{~mm} / \mathrm{y}$. At the same time, Figure 6.3.2-10 also shows that upward flow (negative flux value) towards repository drifts from below occurs at the bottom of the drift block, at a rate of more than $20 \mathrm{~mm} / \mathrm{y}$. Upward flow occurs because the strong capillary suction overcomes the local gravitational effect at these earlier times. As repository heat decreases, both downward and upward flux at top and bottom of drifts decreases. At 100 years, 
downward flow at top of drifts decreases to $50 \mathrm{~mm} / \mathrm{yr}$ whereas upward flow at bottom of drifts reduces to less than $10 \mathrm{~mm} / \mathrm{yr}$. Note that after 500 years, upward flow stops and high-flux downward flow zones widen in the region directly above the drift block, indicating enlarged dryout zones and continuing strong condensation effect.

Figure 6.3.2-10 shows that after 2,000 years, thermal impact on vertical percolation fluxes becomes less significant, and the UZ flow is controlled primarily by infiltration flux imposed on the surface boundary, as it changes in response to climate change.

Thermally enhanced percolation flux along a fault column (I) is shown in Figure 6.3.2-11. Similar to the ventilation case (as shown in Figure 6.3.1-18), there is a more profound impact on flow in faults from repository heating (note that the fault column here intersects repository gridblocks) than on less permeable zones above repository drifts. This is because of the much larger vapor flow, with condensation effects occurring in faults. For example, percolation fluxes at 100 years increase by an order of magnitude above their ambient value. 


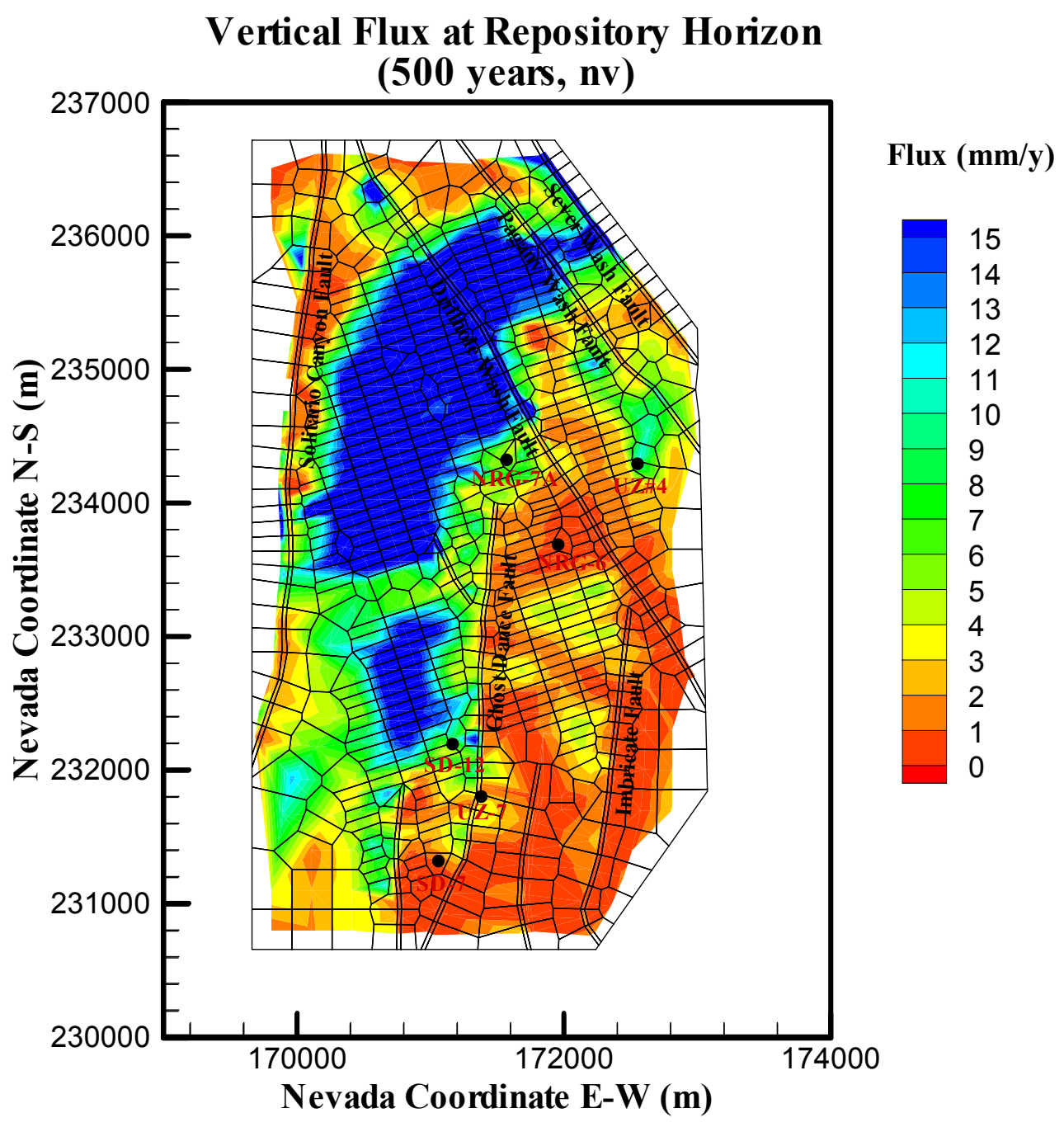

DTN: LB0310MTSCLTH3.001

Figure 6.3.2-9. Model-Predicted Total Vertical Flux Distribution at Repository Horizon at 500 Years after Nuclear Waste Emplacement (the No-Ventilation Model) 

(in Fracture, nv)

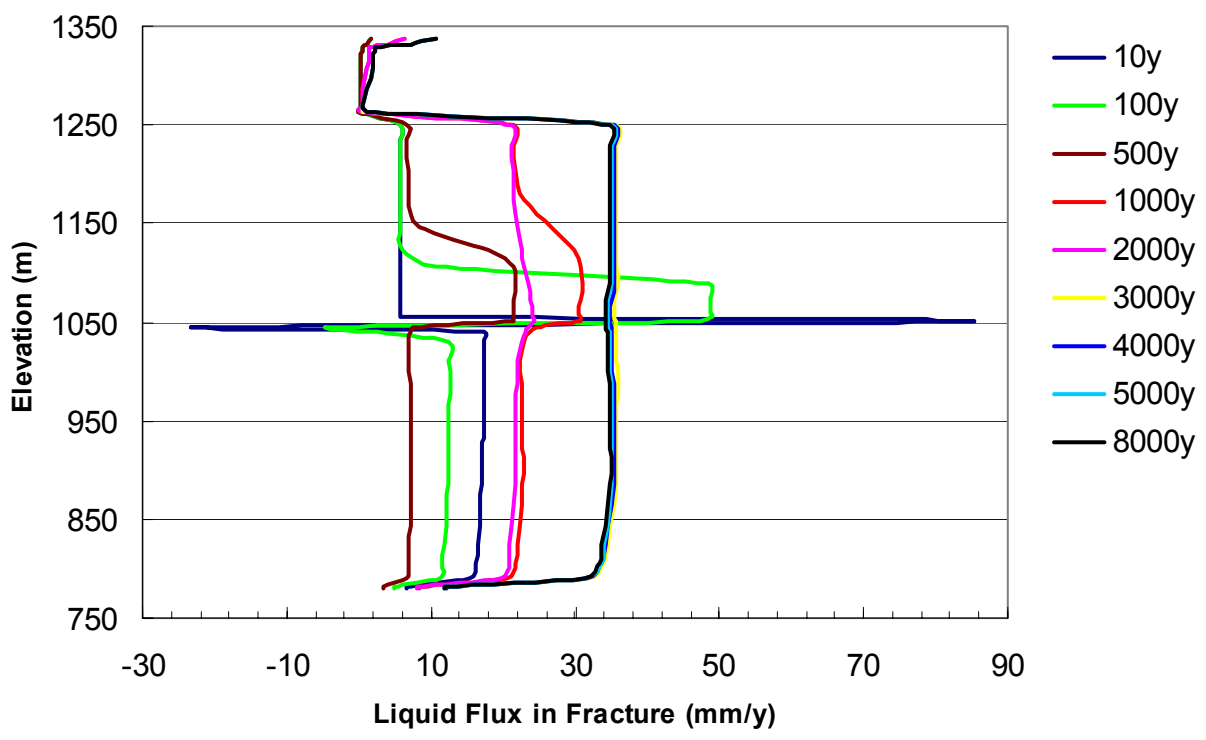

DTN: LB0310MTSCLTH3.001

Figure 6.3.2-10. Predicted Total Vertical Flux Distribution along Observation Column $\mathrm{F}$ (the Center of the Northern Repository Block) at 10-8,000 Years Using the No-Ventilation Model (downward flux is represented in positive).

\section{Total Vertical Liquid flux in Observation Column I}

(nv)

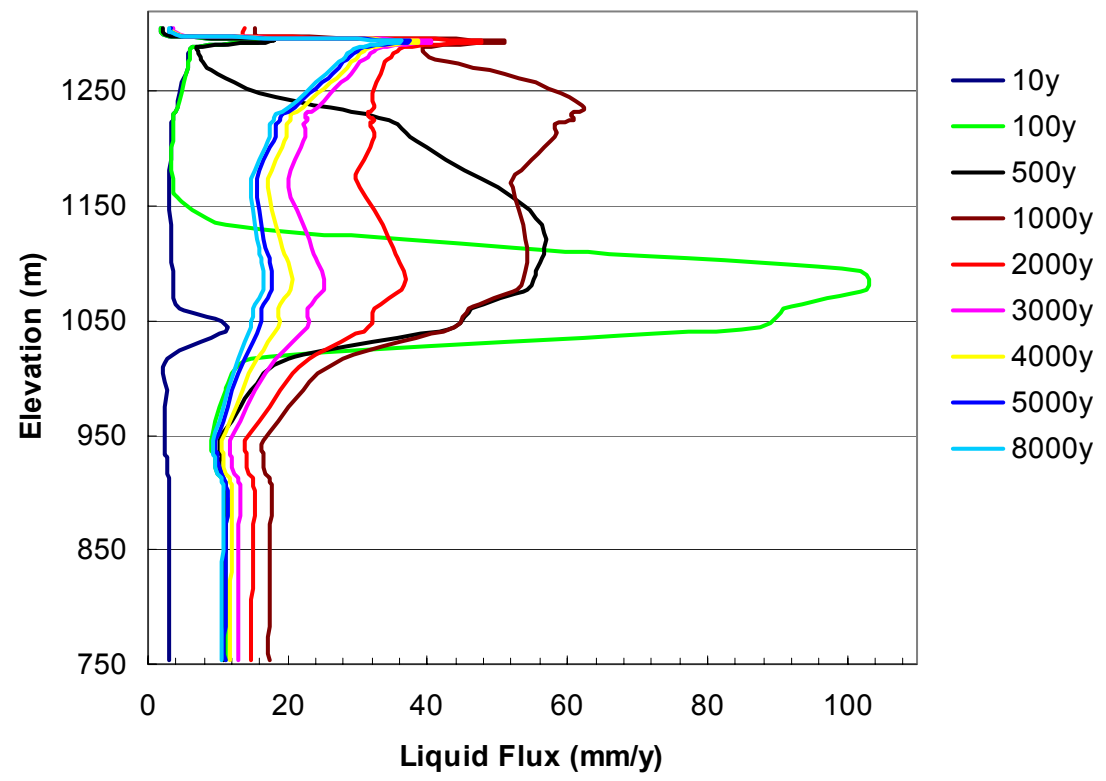

DTN: LB0310MTSCLTH3.001

Figure 6.3.2-11. Predicted Total Vertical Flux Distribution along Observation Column I (the Center of the Northern Repository Block) at 10-8,000 Years Using the No-Ventilation Model 


\subsection{MOUNTAIN-SCALE THC MODEL}

This section summarizes the modeling and uncertainty studies performed for the evaluation of thermal-hydrological-chemical (THC) effects on flow and chemistry in the UZ at the mountain scale. This section addresses the following issues: (1) mountain-scale effects of THC processes on flow and transport, and (2) mountain-scale THC effects on the variability of water chemistry entering drifts under thermal-loading conditions. The Mountain-Scale THC Model is a 2-D model based on the Mountain-Scale TH Model documented in Section 6.2 (the 2-D grid used for the Mountain-Scale THC Model is a subset of the 2-D TH model grid shown in Figures 6.1-1 and 6.1-2), and the conceptual models and data for THC processes documented in Drift-Scale Coupled Processes (DST and THC Seepage) Models (BSC 2003 [162050]). Many of the uncertainties in the conceptual models, and data used for input and model validation, are identical to those discussed in the latter AMRs. However, the drift-scale THC models are focused primarily on processes that affect seepage (and the chemistry of potential seepage) into drifts. On the other hand, the Mountain-Scale THC Model provides predictions of the effect of THC processes on flow in the Paintbrush hydrogeologic unit (PTn), the basal vitrophyre of the Topopah Spring tuff, and in the vitric and zeolitic zones in the Calico Hills unit below the repository. These far-field changes are not of particular concern for the drift-scale THC models.

The purpose of the Mountain-Scale THC Model is to evaluate the coupled THC processes that are caused by variations in geology (structure and lithology), infiltration rate, and temperature at a mountain or repository scale. These are processes that affect the percolation flux to the repository horizon (relevant to seepage), and flow below the repository (relevant to radionuclide transport in the UZ). Small-scale and localized processes, such as mineral precipitation in the boiling zone, can only be captured in finely gridded drift-scale models. Thus, the MountainScale THC Model is focused on larger-scale changes in chemistry and flow that are not localized to very small regions adjacent to the drift. Large-scale gas-phase convection and lateral flow are not represented in the drift-scale THC models, and therefore, the Mountain-Scale THC Model can also address uncertainties in phenomena that may not arise in the drift-scale "chimney" models.

\subsubsection{Conceptual Model For Mountain-Scale THC Processes}

The conceptual model for THC processes provides a comprehensive basis for modeling the pertinent mineral-water-gas reactions in the host rock, under thermal loading conditions, as they influence the chemistry of water and gas in the mountain and associated changes in mineralogy. The data incorporated in the model include hydrological and thermal properties from the calibrated property sets, geological layering from the UZ 3-D Flow and Transport Model, geochemical data (fracture and matrix mineralogy, aqueous geochemistry, and gas chemistry) derived from various sources, thermodynamic data (minerals, gases, and aqueous species), data for mineral-water reaction kinetics, and transport data. Simulations of THC processes include coupling among heat, water, and vapor flow, aqueous and gaseous species transport, kinetic and equilibrium mineral-water reactions, and feedback of mineral precipitation/dissolution on porosity, permeability, and capillary pressure for a dual permeability (fracture-matrix) system.

The potentially important mountain-scale coupled THC processes are illustrated schematically in Figure 6.4-1. Some UZ processes, such as the distribution of net infiltration, may affect THC 
processes. The effect of THC processes on UZ flow may include modification of the percolation flux in the nonwelded tuffs above the repository in the Paintbrush hydrogeologic unit (PTn) and alteration of flow paths (lateral flow) below the repository in the Calico Hills unit vitric and zeolitic layers $(\mathrm{CHn})$, and on the basal vitrophyre of the Topopah Spring tuff. Diversion of water around drifts and percolation fluxes through the pillars may also be influenced by porosity and permeability changes owing to mineral precipitation and dissolution. In addition, small-scale processes, such as fracture-matrix interaction, have a strong effect on the chemical evolution of the system and the distribution of mineral precipitation in fractures and the matrix. These issues are dealt with specifically in Section 6.4.3, where comparisons to simulation results are made.

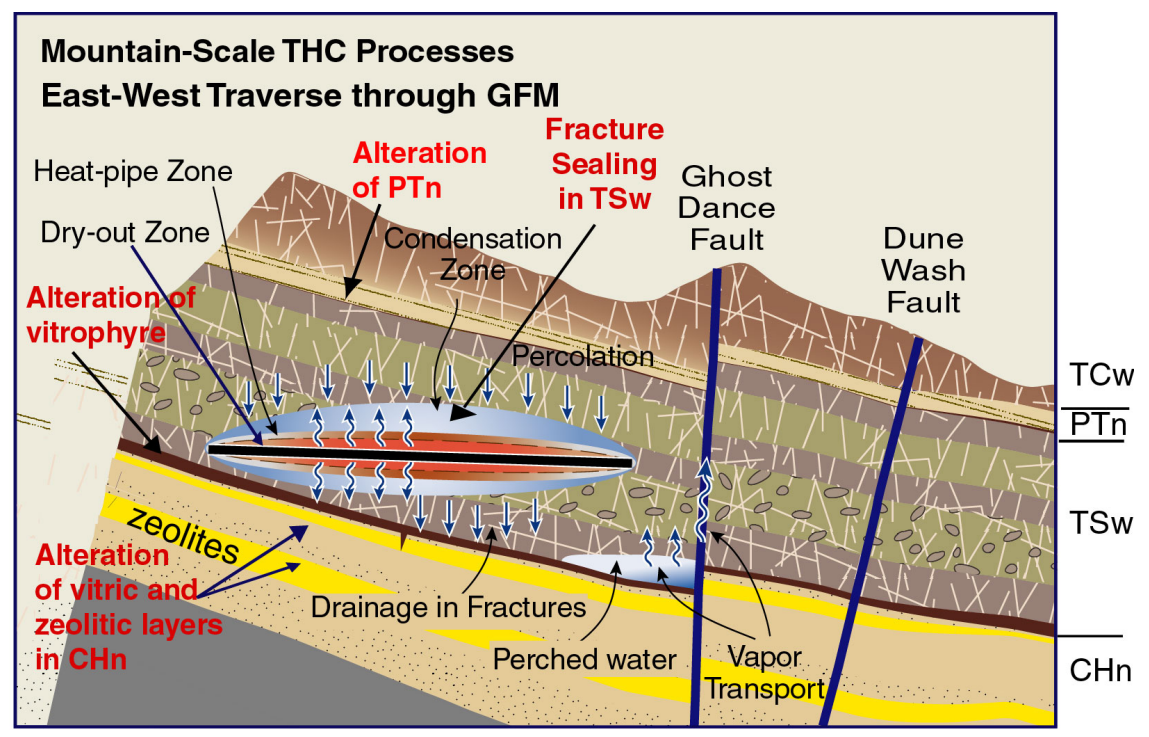

Figure 6.4-1. Schematic East-West Cross Section through the Geological Framework Model (GFM) Showing Potential Mountain-Scale THC Processes

\subsubsection{Model Setup}

\subsubsection{Numerical Mesh}

A $1 \mathrm{~km}$ long North-South vertical cross section (Figure 6.4-2) was selected for the 2-D THC model based on the following rationale: (1) the North-South 2-D vertical cross section is approximately perpendicular to the repository drifts (Figure 6.4-2) and thus better represents the spatial variance of the THC evolution than any other direction; and (2) the maximum number of gridblocks for a TOUGHREACT V3.0 (LBNL 2002 [161256]) simulation must be limitedotherwise computational times would be excessively large (at least several months for the entire cross section). This partial North-South vertical cross section contains 7,410 gridblocks (fracture and matrix) and 8 repository drifts (Figure 6.4-2). The length between two lateral borders of the 2-D cross section is $1193.212 \mathrm{~m}$. The mesh was derived from the 2-D mesh discussed in Section 6.2. A large part of the mesh is outside the repository footprint, so that edge effects can be evaluated. The range in temperatures produced by this model is consistent with the TH model (see Section 6.4.3.1.1). 


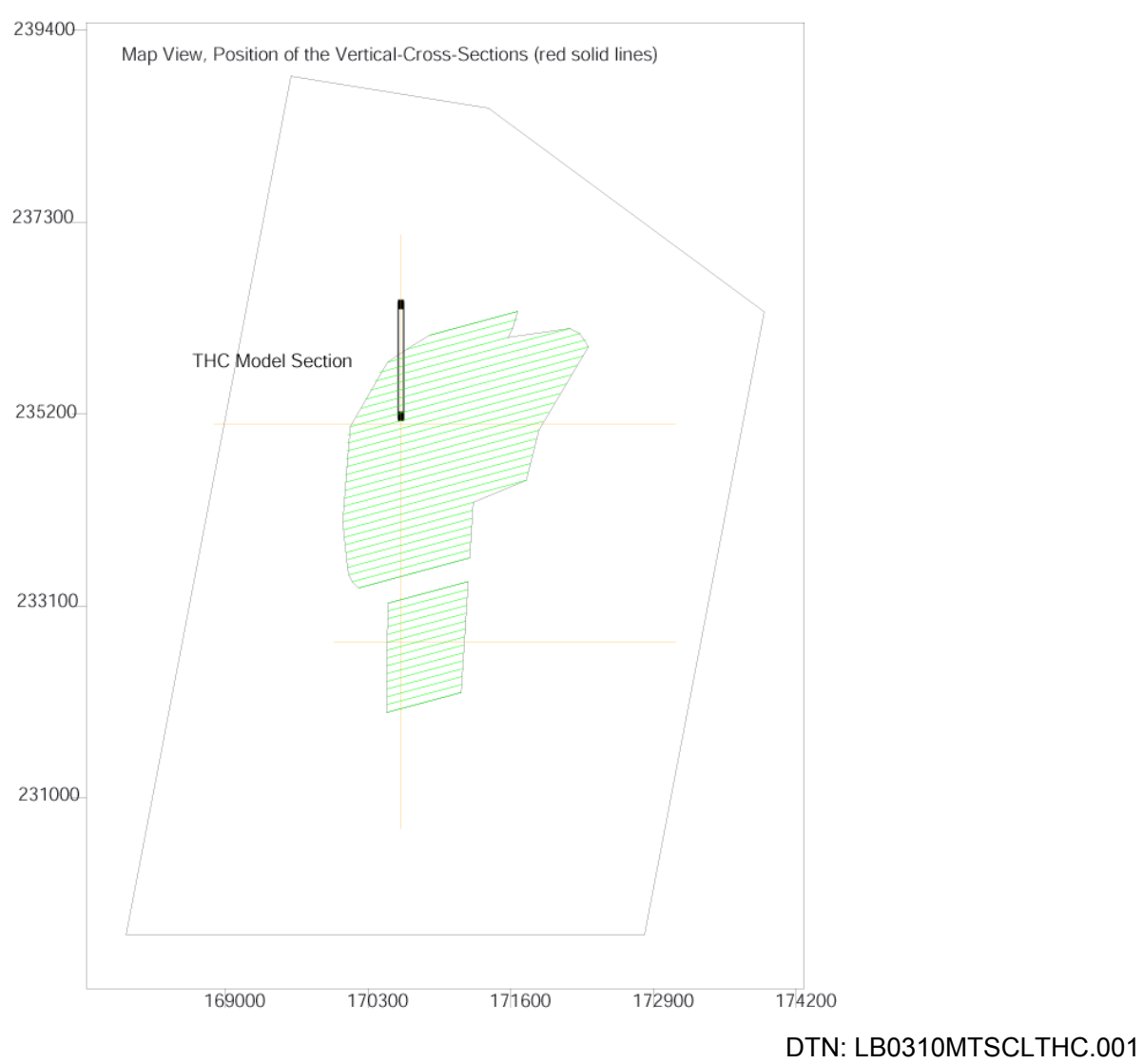

NOTE: The THC model grid is created by cutting the South-North cross-sectional mesh and is shown in the thin black window in the figure. This 2-D mesh is a subset of the 2-D mesh shown in Figure 6.1-2 extending only from Northing 235200 to 236392.7.

Figure 6.4-2. Map View of the 2-D Cross Section of the THC Model Grid Mesh (Black Window)

The upper boundary of the domain is the ground surface; the lower boundary is the groundwater table. The lateral boundaries are set exactly vertical. The northern boundary is the Drill Hole Wash fault and the southern boundary does not correspond to any geological interface. The gridblocks are mostly tetragonal, with average length of $21.4 \mathrm{~m}$ in the horizontal dimension. Vertically, the thickness of the gridblocks is restricted by the thickness of the stratigraphic layers, which vary from $1.6 \mathrm{~m}$ to $20 \mathrm{~m}$. Gridblocks representing the repository drifts are set to be $5 \mathrm{~m} \times 5 \mathrm{~m}$ each. 


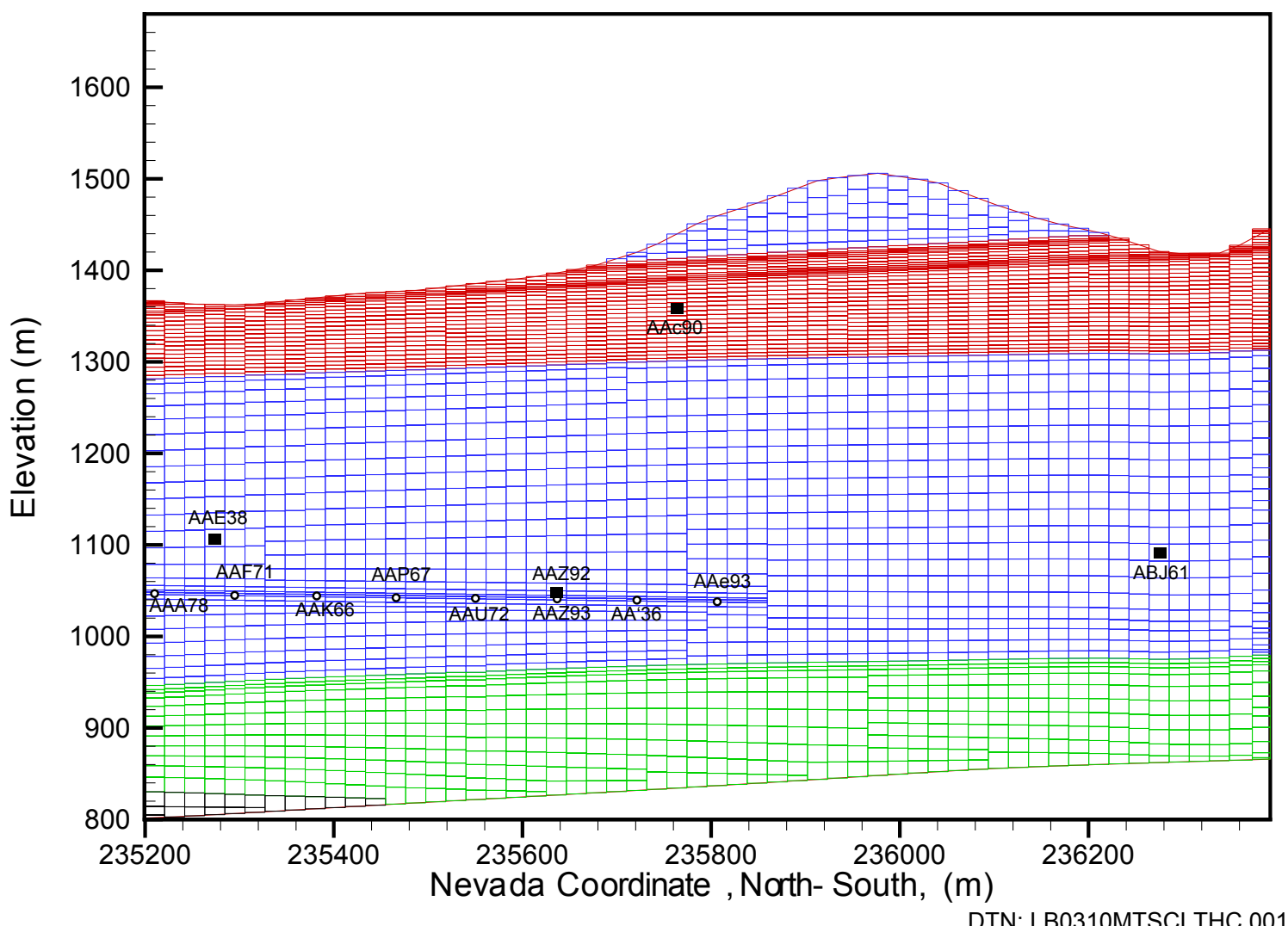

NOTE: (1) The small black circles represent the repository drifts and the black squares represent observation points. The labels are names of the corresponding representative gridblocks of the drifts and observation points; (2) the actual repository blocks are not plotted, because they could hardly be seen on such a small scale.

Figure 6.4-3. Mountain-Scale THC Model Grid

\subsubsection{Rock Properties}

Rock hydraulic properties are from DTNs: LB0208UZDSCPMI.002 [161243] and LB0205REVUZPRP.001 [159525]. Thermal properties are from DTN: LB0210THRMLPRP.001 [160799].

\subsubsection{Hydrological and Thermal Boundary and Initial Conditions}

The infiltration is applied to the top ground surface gridblocks. The infiltration rates were derived from the infiltration map (DTN: GS000308311221.005 [147613]) and is a locationspecific distribution for this model domain extracted from the 2-D infiltration distribution. The climate change scenario consists of three infiltration-rate periods. The present day mean is applied to $0-600$ years of the simulation time, the monsoon mean from 600-2,000 years, and the glacial transition mean for 2,000 years and beyond. The infiltration rates are spatially variable (for each of the climatic periods), owing mainly to the topographic condition. The average (over the THC model grid in this AMR) infiltration for the present-day, monsoon, and glacial transition climatic conditions are $8.7 \mathrm{~mm} /$ year, $32.3 \mathrm{~mm} /$ year and $101.6 \mathrm{~mm} /$ year, respectively. The lower boundary is the ground water table, for which a fixed pressure is assigned. Both lateral boundaries are modeled as no-flux for mass because vertical flow is dominant in the UZ. 
The temperature at the ground surface is set as a constant (in time), because both the infiltration rate and the enthalpy of the infiltrating water are treated as constant. Temperature of the groundwater table is constant (Section 6.1.3). The two lateral boundaries are considered as noflux for heat as well as mass.

A steady-state flow and thermal field is required for THC simulations as initial conditions. A TH simulation under ambient conditions was performed to produce the steady-state flow and thermal field with the present-day mean infiltration rate. Estimated temperature and pressure distributions, as initial conditions, were used for this TH simulation under ambient conditions. This simulation lasted 100 million years and the steady-state TH field was achieved. The steady-state $\mathrm{TH}$ field is therefore used as the initial condition for the $\mathrm{TH}$ simulations (with thermal loading) and THC simulations (with thermal loading and geochemistry).

\subsubsection{Initial and Boundary Geochemical Conditions}

The model of the geochemical system includes the major aqueous species, minerals, and gaseous components in the unsaturated zone. Additionally, minor species, such as $\mathrm{F}^{-}$, are included for their relevance to waste package corrosion. The minerals and aqueous and gaseous species in the model geochemical system are listed in Table 6.4-1, and are the same as those in the "extendedcase" geochemical system described in Drift-Scale Coupled Processes (DST and THC Seepage) Models (BSC 2003 [162050]).

The geochemical model consists of the following primary aqueous species: $\mathrm{H}^{+}, \mathrm{Na}^{+}, \mathrm{K}^{+}, \mathrm{Ca}^{2+}$, $\mathrm{Mg}^{2+}, \mathrm{AlO}_{2}^{-}, \mathrm{NO}_{3}^{-}, \mathrm{SO}_{4}^{2-}, \mathrm{F}^{-}, \mathrm{Cl}^{-}, \mathrm{HCO}_{3}^{-}, \mathrm{SiO}_{2}$ (aq), and $\mathrm{HFeO}_{2}$ (aq). Gaseous components include air, $\mathrm{H}_{2} \mathrm{O}$, and $\mathrm{CO}_{2}$. The initial mineralogy of the tuff matrix and fracture coatings is represented by the following assemblage (some as endmembers of an ideal solid-solution phase): $\alpha$ cristobalite, opal, tridymite, quartz, K-feldspar, albite, anorthite, Ca-smectite, Na-smectite, Mgsmectite, illite, calcite, fluorite, gypsum, rhyolitic glass, hematite, stellerite, clinoptilolite, mordenite, and heulandite. Several other secondary phases are also considered (e.g., amorphous silica, kaolinite, and sepiolite), as well as a set of potential salt phases that can precipitate during the complete dryout of a gridblock. A complete description of the rationale for these phases/components, thermodynamic (DTN: LB0307THMDBRTM.001 [164434]) and kinetic data (DTN: LB0307KNTDBRTM.001 [164433]), derivation of various properties, and sources for all data can be found in BSC 2003 ([162050], Section 6.2.2.2). DTNs of other input dataare given in Table 4.1-1.

Simulations have previously shown a very strong effect on the $\mathrm{pH}$ and $\mathrm{CO}_{2}$ concentrations of waters reacting with anorthite at low temperatures, and some effect at elevated temperatures (BSC 2003 [162050], Section 7.1). To allow for an approximately steady-state initial water and gas chemistry, using the thermodynamic and kinetic data as derived, the surface area of anorthite was reduced by three orders of magnitude for the THC Seepage Model initial conditions. Although this reduction seems large, experimental studies comparing the dissolution rates of plagioclase feldspars have shown that the dissolution rate of anorthite is at least three to four orders of magnitude faster than all other composition plagioclase feldspars (Blum and Stillings 1995 [126590], Figure 7, p. 307). In this Model Report, the dissolution rate constant for anorthite was reduced by three orders of magnitude, which is equivalent to reducing the initial surface area of a dissolving phase. 
In the case of a complete dryout of a gridblock, the remaining aqueous components are redistributed among a group of various salt phases as well as those mineral phases already considered. First, components such as silica and calcium are assigned to phases typically forming in the dryout zones, such as amorphous silica and calcite. Then the aqueous components are redistributed to various salt phases, so that mass conservation is achieved for these components in the case of rewetting of a gridblock. The salt phases are then allowed to redissolve kinetically at an arbitrarily fast rate (BSC 2003 [162050], Section 6.4.6.1).

Table 6.4-1. Minerals, Aqueous Species, and Gaseous Species in the Mountain-Scale THC Model

\begin{tabular}{|c|c|}
\hline Aqueous Species (primary): & Minerals \\
\hline $\mathrm{H}_{2} \mathrm{O}$ & Calcite \\
\hline $\mathrm{H}^{+}$ & Tridymite \\
\hline $\mathrm{Na}^{+}$ & $\alpha-$ Cristobalite \\
\hline$\overline{K^{+}}$ & Quartz \\
\hline $\mathrm{Ca}^{+2}$ & Amorphous Silica \\
\hline $\mathrm{Mg}^{+2}$ & Hematite \\
\hline $\mathrm{SiO}_{2}$ & Fluorite \\
\hline $\mathrm{AlO}_{2}^{-}$ & Gypsum \\
\hline $\mathrm{HFeO}_{2}^{-2}$ & Sepiolite \\
\hline $\mathrm{HCO}_{3}^{-}$ & Albite \\
\hline $\mathrm{Cl}^{-}$ & K-Feldspar \\
\hline $\mathrm{SO}_{4}^{-2}$ & Anorthite \\
\hline $\mathrm{F}^{-}$ & Ca-Smectite \\
\hline $\mathrm{NO}_{3}^{-}$ & Mg-Smectite \\
\hline Gaseous Species: & Na-Smectite \\
\hline $\mathrm{CO}_{2}$ & Opal \\
\hline $\mathrm{H}_{2} \mathrm{O}$ & Illite \\
\hline \multirow[t]{6}{*}{ Air } & Kaolinite \\
\hline & Rhyolitic Glass \\
\hline & Stellerite \\
\hline & Heulandite \\
\hline & Mordenite \\
\hline & Clinoptilolite \\
\hline
\end{tabular}

Source: Modified from Table 6.2-2, BSC 2003 [162050]

The initial and infiltrating water chemistry was set to match that from the matrix pore water collected from the Topopah Spring middle nonlithophysal unit (Tptpmn) in Alcove 5, near the ongoing drift-scale test (DST) ("HD-PERM" water; BSC 2003 [162050], Table 6.2-1). Although this water may not be characteristic of all pore waters in the UZ, it has been used successfully in validation studies with the DST, as shown in BSC (2003 [162050], Section 7) and also as summarized in Section 7 of this Model Report. 
Table 6.4-2. Initial Pore-Water and Gas Compositions ${ }^{1}$

\begin{tabular}{|c|c|c|}
\hline \multicolumn{2}{|c|}{ Sample ID: } & HD-PERM ${ }^{4}$ \\
\hline \multicolumn{3}{|c|}{ Water Input Type: } \\
\hline \multicolumn{3}{|c|}{ Units } \\
\hline Temperature & ${ }^{\circ} \mathrm{C}$ & 25 \\
\hline $\mathrm{pH}$ (measured) & $\mathrm{pH}$ & 8.31 \\
\hline $\mathrm{Na}^{+}$ & $\mathrm{mg} / \mathrm{L}$ & 61.5 \\
\hline $\mathrm{K}^{+}$ & $\mathrm{mg} / \mathrm{L}$ & 8 \\
\hline $\mathrm{Ca}^{2+}$ & $\mathrm{mg} / \mathrm{L}$ & 101 \\
\hline $\mathrm{Mg}^{2+}$ & $\mathrm{mg} / \mathrm{L}$ & 17 \\
\hline $\mathrm{SiO}_{2 \text { (aq) }}$ & $\mathrm{mg} / \mathrm{L}$ & 70.5 \\
\hline $\mathrm{Cl}^{-}$ & $\mathrm{mg} / \mathrm{L}$ & 117 \\
\hline $\mathrm{SO}_{4}{ }^{2-}$ & $\mathrm{mg} / \mathrm{L}$ & 116 \\
\hline $\mathrm{HCO}_{3}^{-}(\mathrm{calc})^{2}$ & $\mathrm{mg} / \mathrm{L}$ & 200 \\
\hline $\mathrm{NO}_{3}^{-}$ & $\mathrm{mg} / \mathrm{L}$ & 6.5 \\
\hline$F^{-}$ & $\mathrm{mg} / \mathrm{L}$ & 0.86 \\
\hline $\mathrm{Al}^{3+}(\mathrm{calc})^{2}$ & Molal & $6.173 \mathrm{E}-10$ \\
\hline $\mathrm{Fe}^{3+}(\text { calc })^{2}$ & Molal & 1.155E-12 \\
\hline $\log \left(\mathrm{PCO}_{2}\right)^{2}$ & Bar & -3.1 \\
\hline $\mathrm{CO}_{2}(\text { approx })^{3}$ & ppmv & $\sim 900$ \\
\hline \multicolumn{3}{|c|}{$\begin{array}{l}\text { NOTES: (1) Source: Table 6.2-1 in BSC } 2003 \text { [162050] } \\
\text { (2) Calculated (see Table 6.2-1 in BSC } 2003 \text { [162050]) } \\
\text { (3) Converted to ppmv using total pressure equal to one bar }\end{array}$} \\
\hline
\end{tabular}

Initial mineral abundances were assigned to each hydrogeologic unit based on data from the 3-D Mineralogical Model V3.0 (DTN: LA9908JC831321.001 [113495]) from a single column taken near the center of the repository footprint. Therefore, each model layer is characterized by uniform mineralogical abundances, although some layers may change from zeolitic to vitric along strike. There is no other lateral geologic variability in this model, except for changes in the thicknesses of the layers. Mineral abundances were converted from weight percent to volume fraction and normalized to $100 \%$. Some minerals were given arbitrarily small amounts (such as fluorite) because of their observed occurrence. Mineral abundances for each rock layer are presented in Attachment I. Fracture mineralogy data are derived from DTN: LA9912SL831151.001 [146447] and DTN: LA9912SL831151.002 [146449].

Reactive surface areas for mineral phases were calculated based on the geometric properties of the fracture and matrix media, and the consideration of the extent of pre-existing alteration of the rock. The methodology for the calculation of reactive surface areas is given in BSC (2003 [162050], Section 6.4.3.2). Fracture and matrix mineral reactive surface areas for each rock layer 
are given in Attachment II. Permeability coupling parameters (see BSC 2003 [162050]) are given in Attachment III.

\subsubsection{Numerical Code and Simulation Methods}

Simulations were performed using TOUGHREACT V3.0 (LBNL 2002 [161256]) that coupled multiphase fluid flow (water and air), heat flow, aqueous and gaseous species transport, and kinetic and equilibrium mineral-water-gas reactions. The simulations used the equation of state module EOS3, considering water and gas flow under nonisothermal conditions with vapor-air diffusion. Effects of vapor-pressure lowering were not considered in these simulations because comparison simulations in BSC (2003 [162050]) showed only minor differences in the chemical compositions of waters around drifts, and computational times can be significantly greater.

\subsubsection{Mountain-Scale THC Model Results}

This section discusses a stepwise approach to evaluation of coupled THC processes under thermal-loading conditions at the mountain scale. This stepwise approach introduces increasing levels of transport and reaction, as well as thermal loading conditions, to better distinguish the roles of the various coupled-processes occurring simultaneously. The series of simulation steps was performed as follows:

- Steady-state flow of water and heat under ambient conditions

- Thermal-hydrological (TH) simulation under thermal loading conditions (with $86.3 \%$ heat removal by ventilation for the first 50 years) and the climate change scenario (Section 6.4.3.1). Simulations made with and without vapor diffusion.

- Steady-state aqueous and gaseous species transport, $\mathrm{CO}_{2}$-water equilibration under ambient temperatures (Section 6.4.3.2)

- Aqueous and gaseous species transport, $\mathrm{CO}_{2}$-water equilibration under thermal loading and climate change scenario (Section 6.4.3.3.1)

- Aqueous and gaseous species transport, $\mathrm{CO}_{2}$-water equilibration, mineral-water reactions under thermal loading and climate change scenario (Sections 6.4.3.3.26.4.3.3.4)

In this Model Report, results from all the simulations except the initial steady-state flow field (used for initial conditions only) are presented. Table 6.4-3 summarizes the specific aspects of the simulations. 
Table 6.4-3. Summary of the TH/THC Simulations

\begin{tabular}{|c|c|c|c|c|c|c|c|}
\hline Model & Case Name & Infiltration & $\begin{array}{l}\text { Thermal } \\
\text { Load }\end{array}$ & $\begin{array}{c}\text { Heat- } \\
\text { Removal } \\
\text { by } \\
\text { Ventilation }\end{array}$ & $\begin{array}{l}\text { Aqueous } \\
\text { Chemistry }\end{array}$ & Minerals & Section \\
\hline 1 & Steady state & $\begin{array}{l}\text { Present-day } \\
\text { mean }\end{array}$ & None & $\mathrm{N} / \mathrm{A}$ & No & No & \\
\hline 2 & $\begin{array}{l}\text { Chemical steady } \\
\text { state }\end{array}$ & $\begin{array}{l}\text { Present-day } \\
\text { mean }\end{array}$ & None & $\mathrm{N} / \mathrm{A}$ & Yes & No & 6.4 .3 .2 \\
\hline 3 & $\begin{array}{l}\text { TH-v86 (harmonic } \\
\text { weighting on absolute } \\
\text { permeability, no vapor } \\
\text { diffusion) }\end{array}$ & \multirow{4}{*}{$\begin{array}{l}\text { Present day } \\
\text { mean }(0-600 \\
\text { years) Monsoon } \\
\text { mean (600- } \\
2000 \text { years) } \\
\text { Glacial } \\
\text { transition mean } \\
\text { (2000-100,000 } \\
\text { years) }\end{array}$} & Yes & $86 \%$ & No & No & \multirow[t]{2}{*}{6.4 .3 .1} \\
\hline 4 & $\begin{array}{l}\text { TH-v86 (upstream } \\
\text { weighting on absolute } \\
\text { permeability, vapor } \\
\text { diffusion) }\end{array}$ & & Yes & $86 \%$ & No & No & \\
\hline 5 & THC-v86a & & Yes & $86 \%$ & Yes & No & 6.4.3.3.1 \\
\hline 6 & THC_86_5 & & Yes & $86 \%$ & Yes & Yes & $\begin{array}{l}\text { 6.4.3.3.2- } \\
6.4 .3 .3 .4\end{array}$ \\
\hline
\end{tabular}

NOTE: $\quad$ Sources listed in Section 6.1.5.

As given in Table 6.4-3, three infiltration scenarios were combined to produce a transient infiltration scenario for the $\mathrm{TH}$ (with thermal loading) and THC simulations. The simulation period from 0-600 years was modeled with the present-day mean infiltration rate, 600-2,000 years with the monsoon mean infiltration rate, and 2,000-10,000 years with the glacial transition mean infiltration rate. Two alternative TH simulations were considered. The first one omitted vapor diffusion and used harmonic weighting for the absolute permeability. The second simulation used upstream weighting for the absolute permeability (as well as for the relative permeability) and considered vapor-air diffusion. The THC runs with all aqueous, gaseous species, and minerals used the latter TH setup.

\subsubsection{Results of $\mathrm{TH}-\mathrm{v86}$}

Results from the TH simulations with two different model setups (3 and 4 in Table 6.4-3) show very similar temperature and saturation but different percolation flux through the repository horizon. Simulation with upstream weighting on absolute permeability and consideration of vapor diffusion gives larger percolation fluxes through the repository horizon. Here we plot temperatures and saturations calculated with the model setup of harmonic weighting of permeability and without consideration of vapor diffusion (the temperature and saturation obtained with another model setup are very similar). This setup is consistent with the 2-D TH model in Section 6.2. We also compare the percolation fluxes through the repository horizon calculated with different model setups.

\subsection{Temperature}

Results from the $\mathrm{TH}$ simulation ( $86 \%$ heat removal by ventilation) show that the temperature at representative gridblocks of the drift wall increased immediately after the thermal power loading imposition (see Section IV.3 of Attachment IV for procedures of postprocessing and plotting of 
the THC model results). During the ventilation period, the temperature at the drift wall reaches a peak value, $47.6^{\circ} \mathrm{C}$, at year 22 . After the peak temperature is reached, the drift-wall temperature drops to around $45^{\circ} \mathrm{C}$ (Figure 6.4-4). Once the ventilation ends, the drift-wall temperature increases sharply and reaches its peak, $100.6^{\circ} \mathrm{C}$, at year 73 , then drops to $96.3^{\circ} \mathrm{C}$ and tends thereafter to slowly decrease. The drop in the drift-wall temperature becomes more rapid due to an increase in the infiltration rate at year 600. At locations above the drift, the temperature is strongly affected by the increase of the infiltration rate (see curve AAE38 in Figure 6.4-5). The drift-wall temperatures at different drifts are slightly different from each other. These differences are smaller than $3^{\circ} \mathrm{C}$ and correspond to the spatial variation of the infiltration rate. The temperature approaches close to the ambient value in 100,000 years (Figure 6.4-5). Figure 6.4-6 shows the temperature spatial distribution at different times. The simulated temperature is consistent with the 2-D TH model results shown in Figures 6.2-1a, 6.2-2a, 6.2-3a, 6.2-4a, and 6.2-5a.

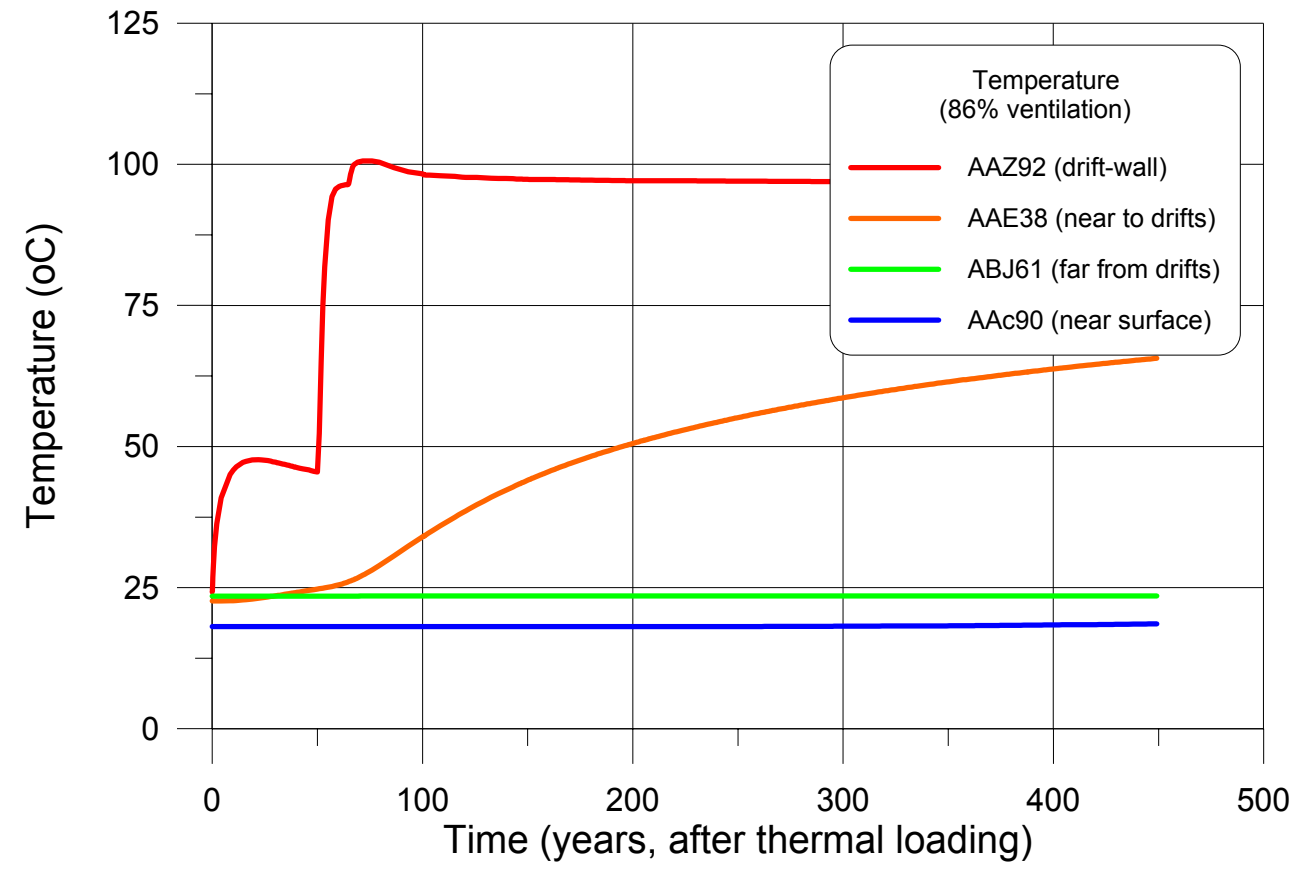

DTN: LB0310MTSCLTHC.002

NOTES: The locations are shown in Figure 6.4-3.

Distance from the nearest drift: AAE38: $64.25 \mathrm{~m}$, ABJ61: $492.54 \mathrm{~m}$, AAc90: $323.94 \mathrm{~m}$.

Figure 6.4-4. Short-Term Temperature Evolution Curves at Different Locations 


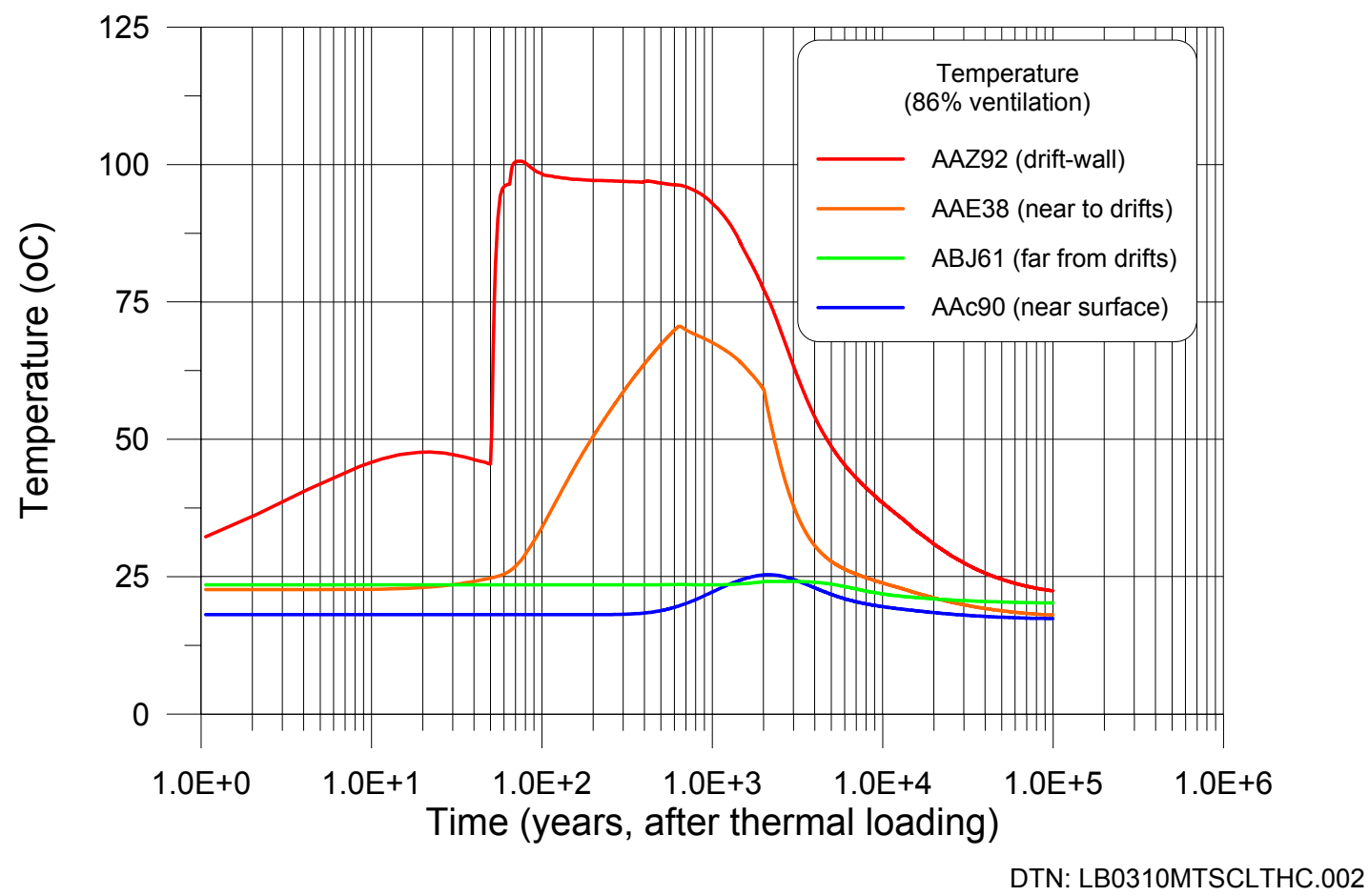

Note: The locations are shown in Figure 6.4-3.

Distance from the nearest drift: AAE38: $64.25 \mathrm{~m}$, ABJ61: $492.54 \mathrm{~m}, \mathrm{AAc} 90: 323.94 \mathrm{~m}$.

Figure 6.4-5. Long-Term Temperature Evolution Curves at Different Locations 

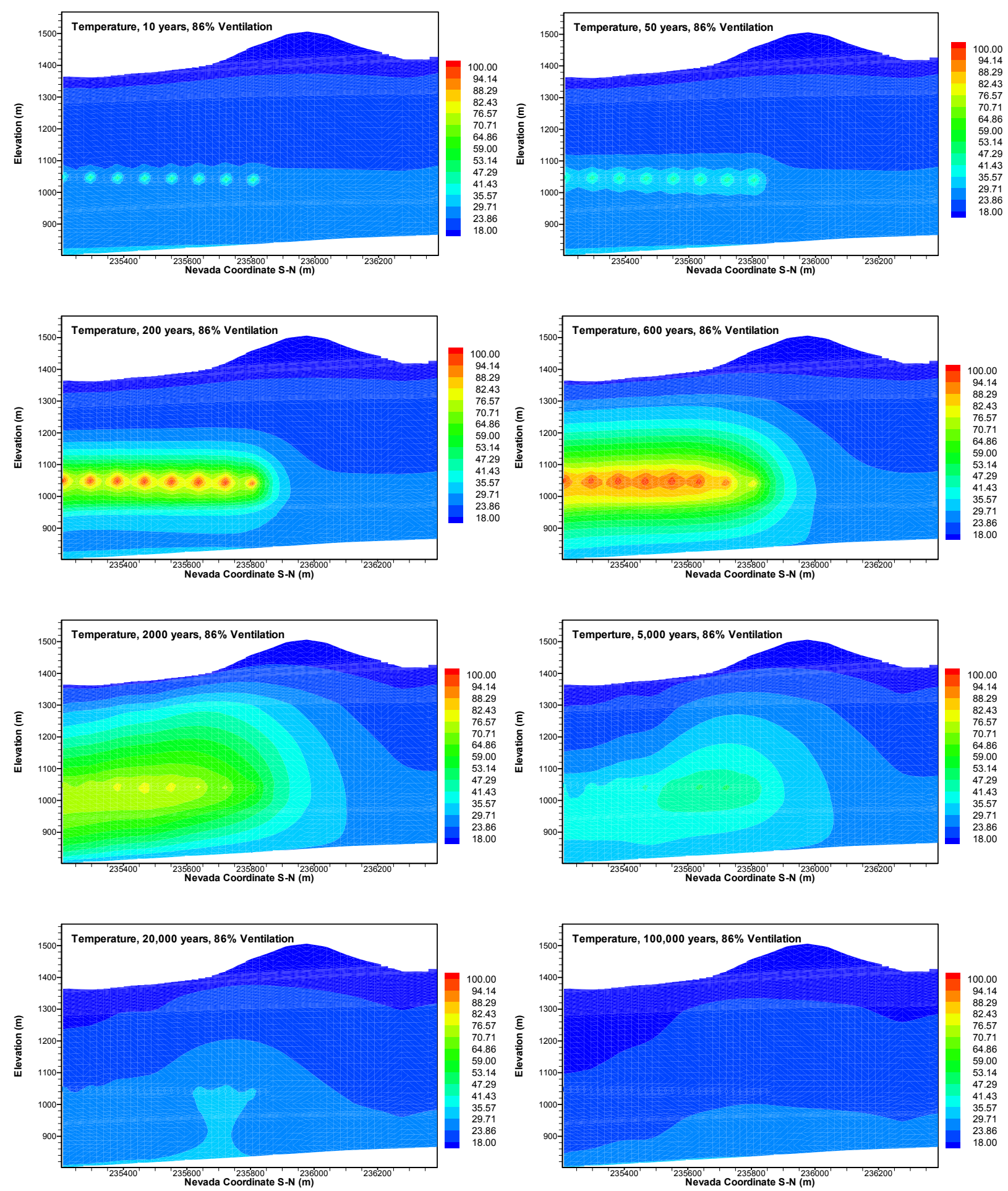

DTN: LB0310MTSCLTHC.002

Figure 6.4-6. Temperature Spatial Distribution at Different Times (86\% Ventilation) 


\subsection{Liquid Saturation}

During the ventilation period, the water saturation in the matrix is almost unchanged (Figure 6.47). A slight increase ( 4 years to 20 years) followed by a very gentle decrease (20 years to 50 years) can be seen at the drift-wall (curve AAZ92 in Figure 6.4-7). After the ventilation period, the matrix water saturation at the drift wall first increases slightly (50 years to 60 years) and then decreases sharply. From 400 years to 500 years, the rock matrix at the drift wall is completely dry. Afterwards, the liquid saturation increases until 100,000 years reaching nearly the ambient condition. In the near-drift area, the matrix saturation increases from 100 years to 3,000 years, due to vapor condensation from the evaporation of the drifts (can be seen from curve AAE38 in Figure 6.4-7). Saturation in areas far from the drifts is not affected by heating. However, the effects of infiltration-rate increases can be easily recognized in these areas (curve AAc90 and ABJ61). The final saturation profile (at 100,000 years) is controlled by the larger (glacial transition mean) infiltration (Figure 6.4-8).

The fracture saturation trend is similar to that of the matrix, but with some differences: (1) the fracture saturation is more sensitive to heating and (2) the affected areas are larger than those in the matrix. Figure 6.4-9 shows the fracture saturation distribution maps at different times. From this figure, one can see that the overall saturation profile is still controlled by the infiltration spatial distribution. The disturbance in the overall fracture saturation profile is recognizable from 50 years to1,000 years at the drifts and near drift areas (less than $100 \mathrm{~m}$ from the drifts).

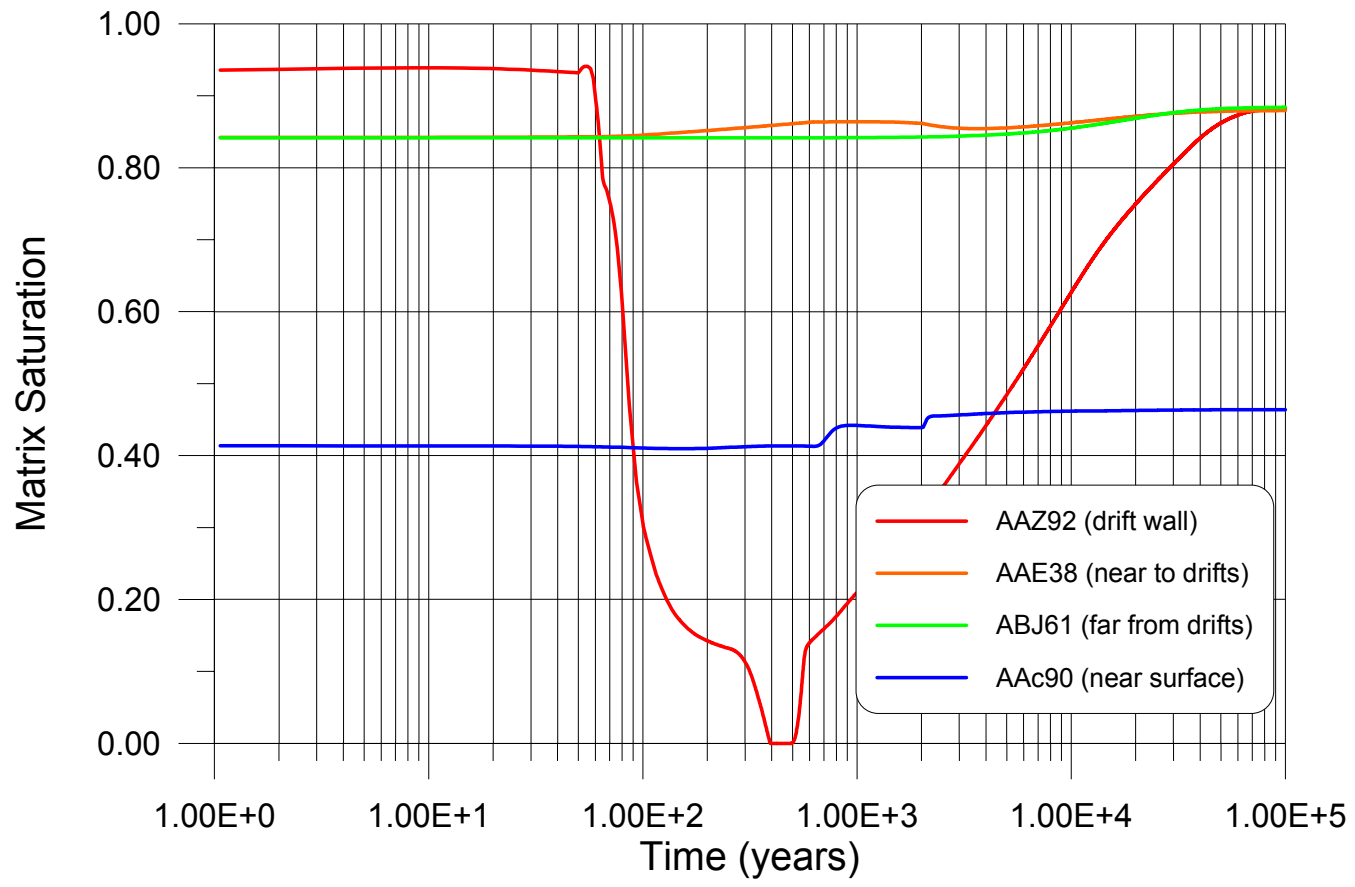

DTN: LB0310MTSCLTHC.002

NOTE: The locations are shown $\quad$ in $\quad$ Figure Distance from the nearest drift: AAE38: 64.25 m, ABJ61: 492.54 m, AAc90: 323.94 m.

Figure 6.4-7. Matrix Saturation Evolution Curves at Different Locations (86\% Ventilation) 

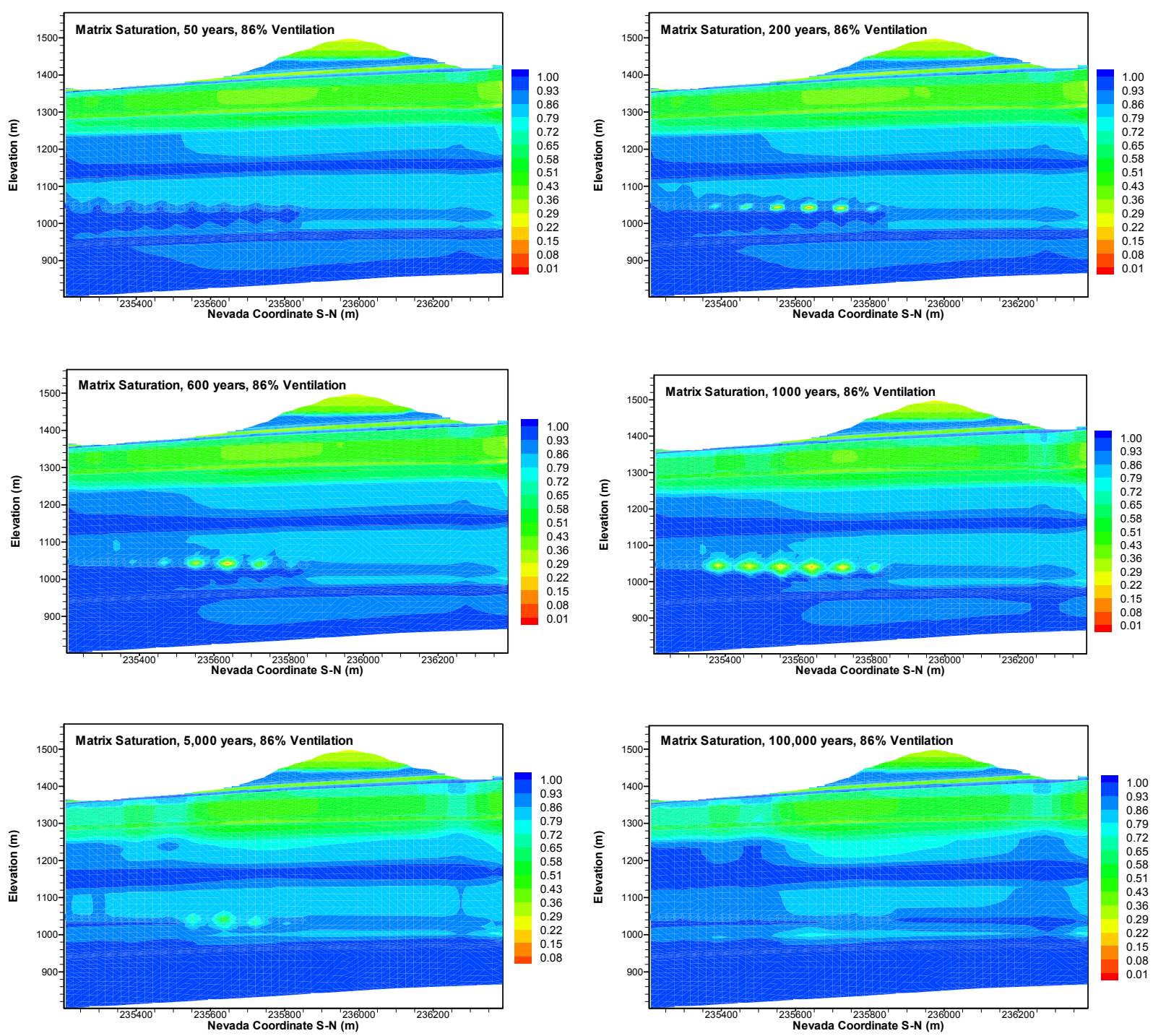

DTN: LB0310MTSCLTHC.002

Figure 6.4-8. Matrix Saturation Distribution Maps at Different Times (86\% Ventilation)

The shadow zone (drier region below drifts formed by diversion of percolating water around drifts) can be seen from fracture saturation distribution maps more easily than from matrix distribution maps. The shadow zone extends to CHn units in the fractures (Figure 6.4-9). They are different in size because of the strong spatial variation in infiltration rates. 

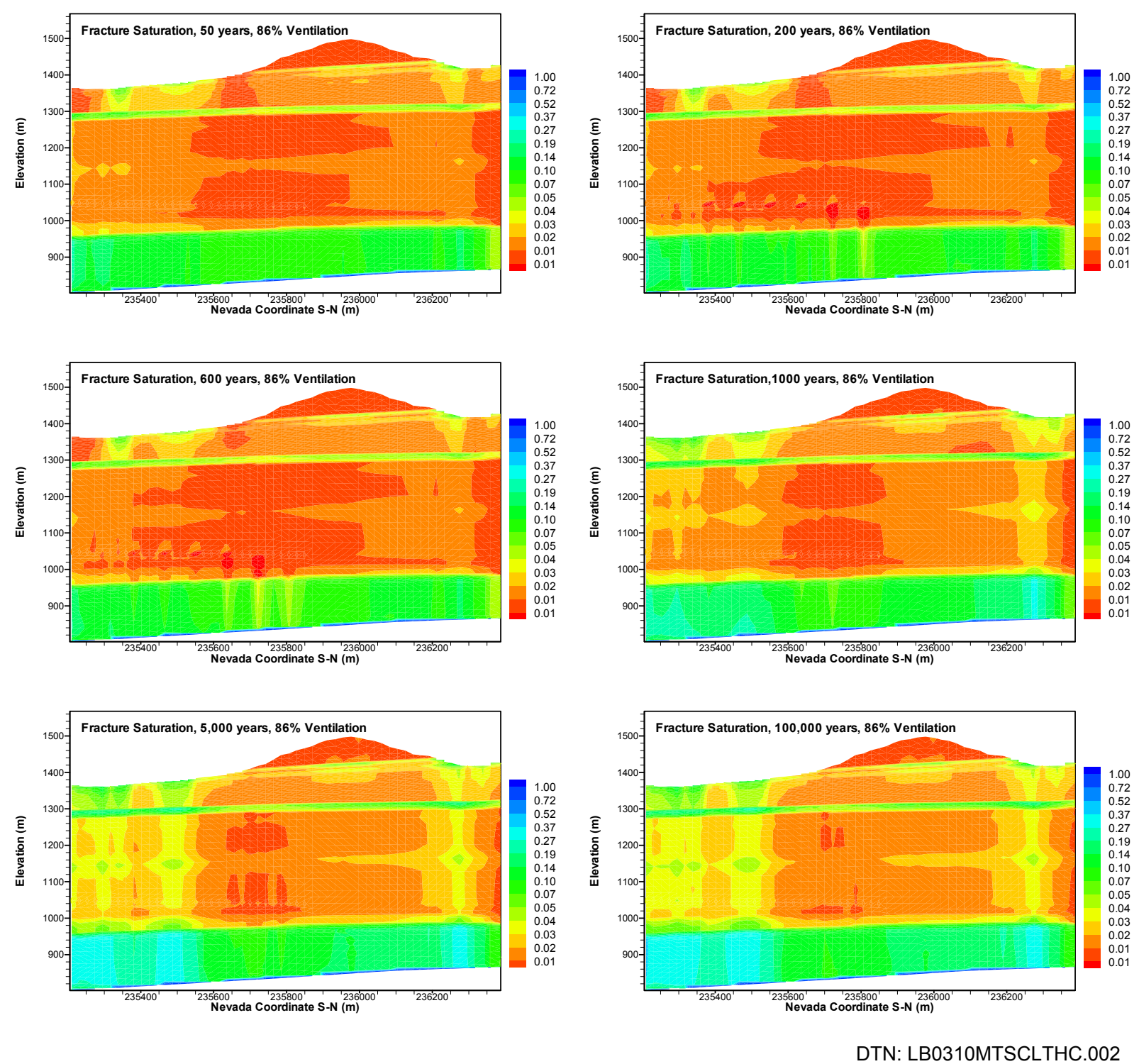

Figure 6.4-9. Fracture Saturation Distribution Maps at Different Times (86\% Ventilation) 


\subsection{Percolation Fluxes}

The rise in drift temperature drives moisture in the surrounding rock out into cooler regions, primarily through permeable fractures. Moisture in the drifts and the surrounding rock boils, and the fracture moisture around the drifts reaches a maximum, several meters to around $10 \mathrm{~m}$ from the drift center, from 200 years to 600 years, and almost no liquid water penetrates into the drifts (Figure 6.4-10). After 600 years, the percolation flux increases, mostly due to the infiltration rate increase (the infiltration rate is elevated to monsoon mean). The percolation flux increase is also contributed by water from the condensation zone. Simulation results show that from 1,000 to 2,000 years, the percolation flux is almost stable. After 2,000 years, the percolation flux increases, again in response to the infiltration increase (transition to glacial transition mean infiltration rate) and reaches a maximum. From 5,000 years to 100,000 years the percolation flux shows almost no change. The spatial variation of the percolation flux at the drift horizon is mainly caused by the infiltration distribution. Percolation flux in the near-drift rock is readjusted not only by the heating, but also by the drifts themselves, which act as capillary barriers diverting water into the surrounding rock. This diversion of flow is permanent. 

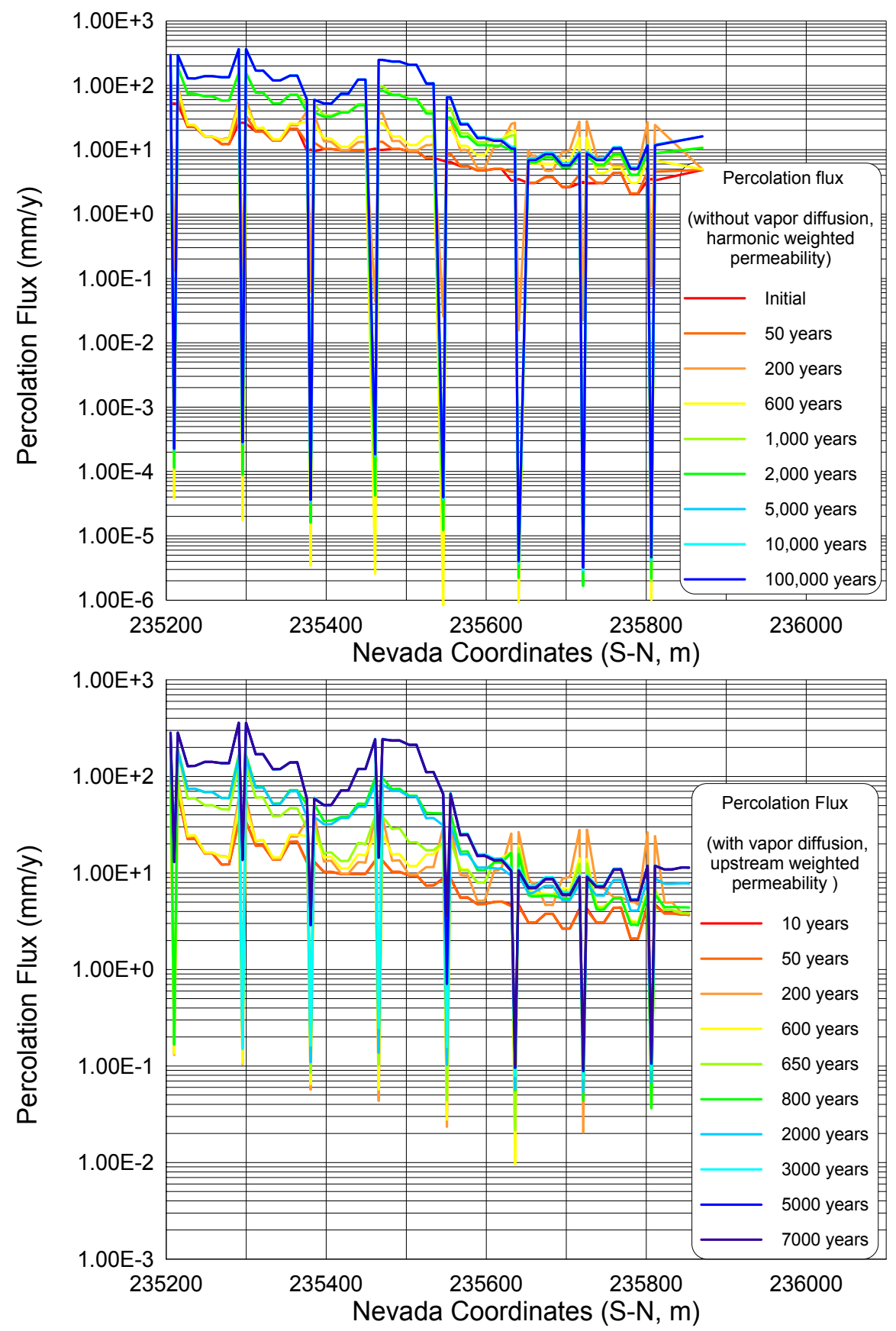

DTN: LB0310MTSCLTHC.002

NOTE: The locations are shown in Figure 6.4-3. The top plot shows percolation fluxes simulated with harmonic weighted permeability; vapor diffusion is not considered. The percolation flux shown in this figure is consistent with the 2-D TH model results (Figure 6.2-10a). The bottom plot shows the percolation fluxes simulated with upstream weighted permeability and consideration of vapor diffusion.

Figure 6.4-10. Percolation Fluxes at the Drift Horizon at Different Times (Simulated by Different Model Setups) 


\subsubsection{Chemical Steady State for Aqueous and Gaseous Species}

A simulation (Model 2, Table 6.4-3) was performed to obtain a chemical steady state under present day ambient condition for aqueous and gaseous species transport and gas-water equilibration (for $\mathrm{CO}_{2}$ ). This simulation serves two purposes. First, it allows for a better understanding of the role of spatial differences in infiltration, lateral flow, and the geothermal gradient in the transport of aqueous and gaseous species at the mountain-scale. Second, it serves as a potentially better set of initial conditions for simulations under repository thermal-loading conditions and for those simulations that include mineral-water reactions.

In this simulation, the measured pore-water concentrations at $25^{\circ} \mathrm{C}$ (Table 6.4.2) were assigned uniformly to the entire domain, as well as to the infiltrating water. No mineral-water reactions were considered, so that the only active processes were aqueous and gaseous species transport by advection and diffusion, along with equilibration of $\mathrm{CO}_{2}$ in the gas with bicarbonate in the aqueous phase. For this ambient steady-state simulation, the gridblocks are treated strictly as fractures at the locations of repository drifts. The system was then simulated, under the ambient temperature distribution, with the infiltrating water equilibrating with the $\mathrm{CO}_{2}$ gas in the atmosphere for about 10 million years. The infiltration rates were kept constant at the present day mean values.

The steady-state $\mathrm{PH}$ distribution is shown in Figure 6.4-11. The range in the $\mathrm{pH}(8.26-8.38)$ is rather small, and is related to the temperature gradient, the infiltration rate, and changing partial pressures of $\mathrm{CO}_{2}$. Differences in other aqueous species are negligible because the concentrations in infiltrating water were set to be spatially uniform.

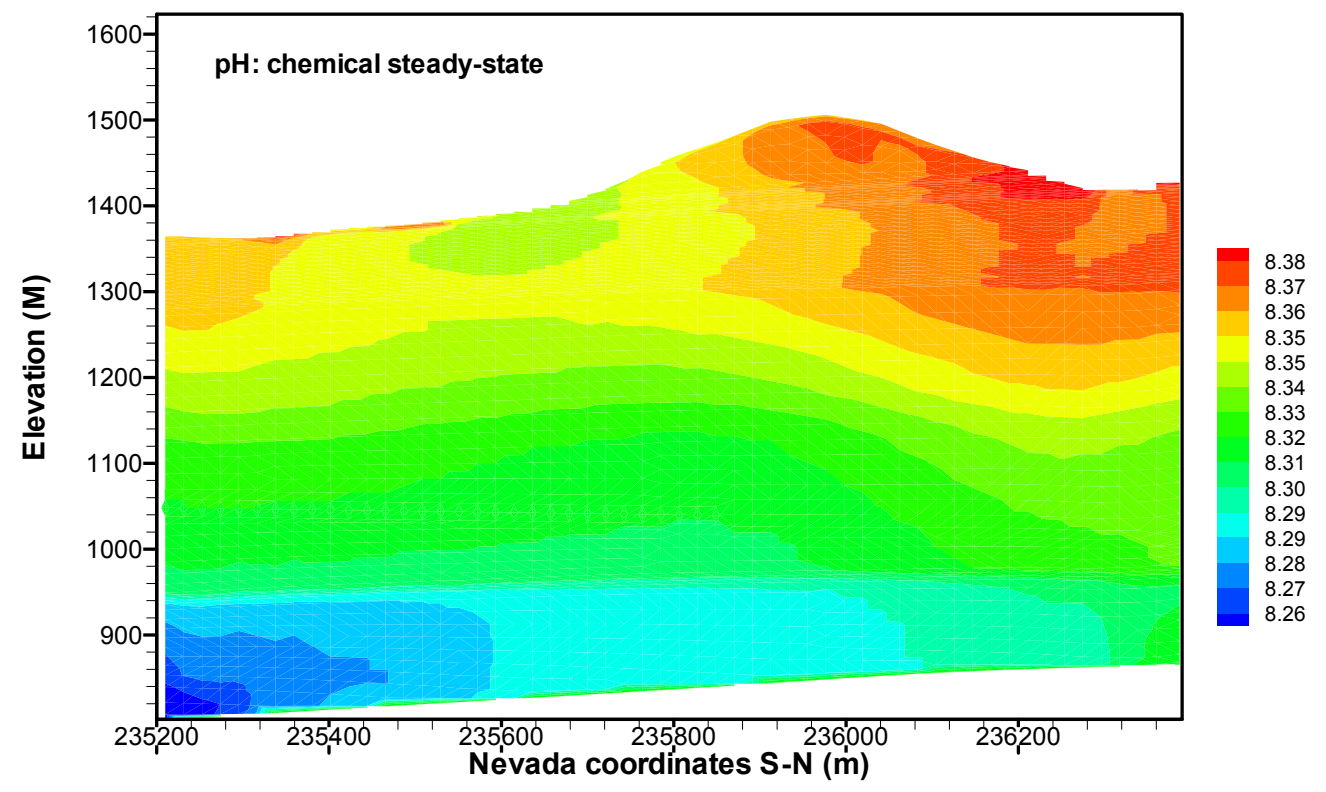

DTN: LB0310MTSCLTHC.002

Figure 6.4-11. Distribution of pH under Chemical Steady State (No Mineral-Water Reactions) 


\subsubsection{Effects of Thermal Loading on Aqueous and Gaseous Chemistry}

The main purpose of the analysis of mountain-scale changes in water and gas chemistry is to document potential spatial variations in chemistry resulting from large-scale spatial variations in infiltration rates, gas convection, and repository edge effects not considered in the Drift-Scale THC Seepage Model. Therefore, the purpose of this section is to analyze differences in major chemical indicators, rather than to provide detailed predictions of numerous chemical components in seepage waters.

The processes leading to changes in water chemistry are most pronounced during the peak thermal period, when condensation in fractures results in dilution of percolating waters, and boiling zones lead to evaporative concentration. Elevated temperatures also result in greatly enhanced reaction rates and in shifts in the thermodynamic stabilities of minerals. Heating of pore water causes the exsolution of $\mathrm{CO}_{2}$ out of the water and subsequent transport of gas via diffusion and advection. Exsolution and dissolution of $\mathrm{CO}_{2}$ can have a significant impact on $\mathrm{pH}$, with $\mathrm{pH}$ changes modifying mineral-water reactions and reaction rates.

\subsection{Simulation of Aqueous and Gaseous Chemistry: No Mineral-Water Reactions}

This simulation uses the steady-state flow and chemical concentrations obtained in the simulation described in Section 6.4.3.2. A thermal load, including $86 \%$ heat removal by ventilation, was then applied to the repository gridblocks. The stepwise climate scenario for infiltration rates was imposed, so that increasing rates were applied at 600 years and at 2,000 years. The simulation was run for 100,000 years.

Thermal loading affects aqueous chemistry by reducing the solubility of $\mathrm{CO}_{2}$ gas. The evolution of $\mathrm{CO}_{2}$ concentration in the gas phase (in ppmv) is shown in Figure 6.4-12. For the first few hundred years, the higher $\mathrm{CO}_{2}$ concentration regions are generally formed directly through degassing of matrix pore water. By 600 years, the zone of high $\mathrm{CO}_{2}$ concentration has migrated to close to the left boundary, where the percolation fluxes are highest as a result of lateral flow in the PTn. There, $\mathrm{CO}_{2}$ is generated primarily through heating of percolating water flowing down through fractures towards the repository. As those regions cool after the increase in infiltration rate at 2,000 years, the high $\mathrm{CO}_{2}$ concentration zone shifts back over to the drifts that are still hot.

The $\mathrm{CO}_{2}$ exsolved from the hotter rock, resulting in a $\mathrm{pH}$ increase in the remaining pore water, is transported along with water vapor to cooler regions, where it dissolves in local pore waters or in water formed by vapor condensation, causing a reduction in $\mathrm{pH}$. Figure 6.4-13 shows the matrix pore water $\mathrm{pH}$ evolution under thermal loading ( $86 \%$ heat removal by ventilation) and without any mineral-water reactions. 

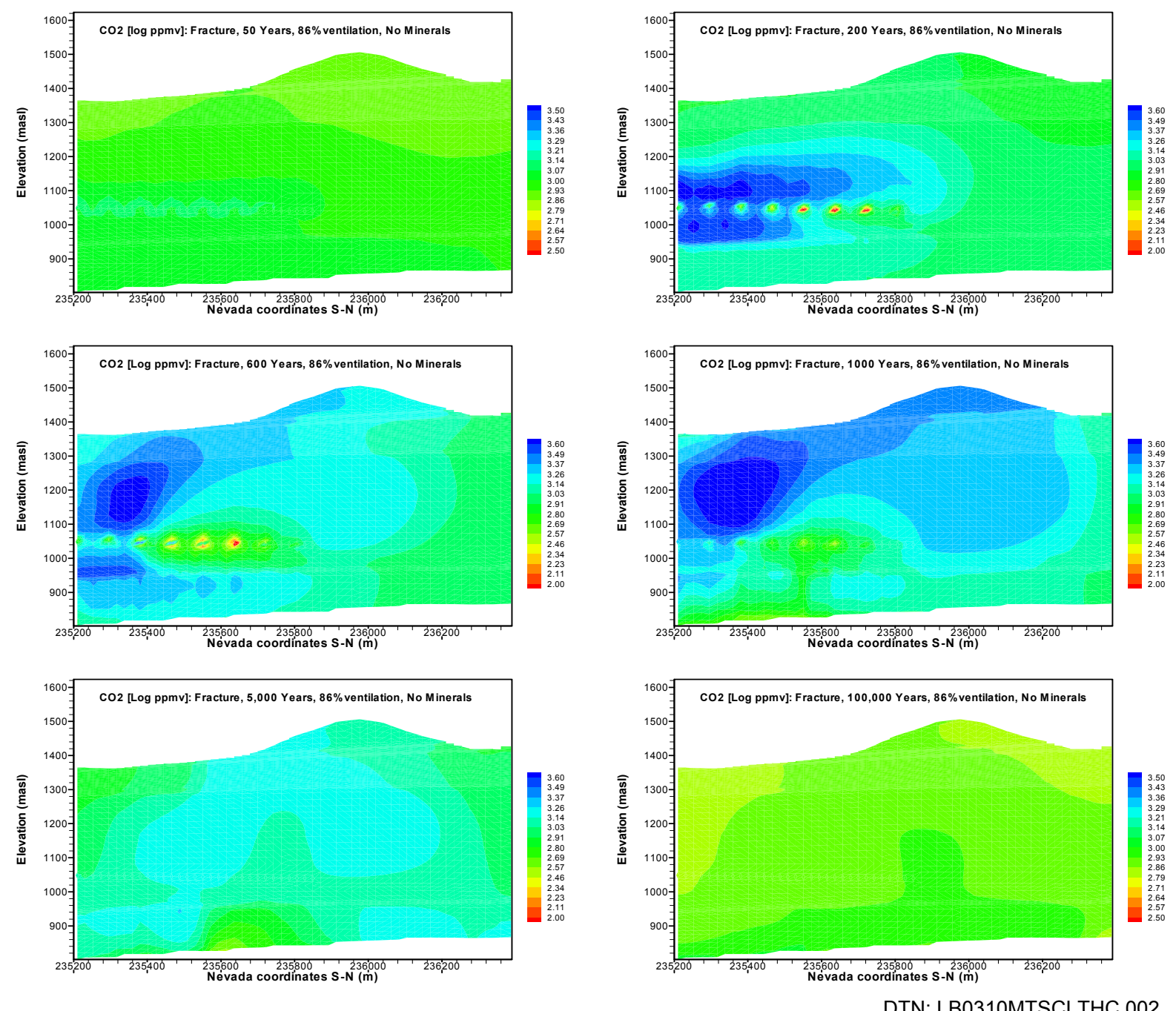

NOTE: Contour intervals change at different times. Aqueous and gaseous species transport; no mineral-water reactions.

Figure 6.4-12. Gas Phase $\mathrm{CO}_{2}$ Concentrations in Fractures over 100,000 Years (Thermal Loading with $86 \%$ Heat Removal by Ventilation) 

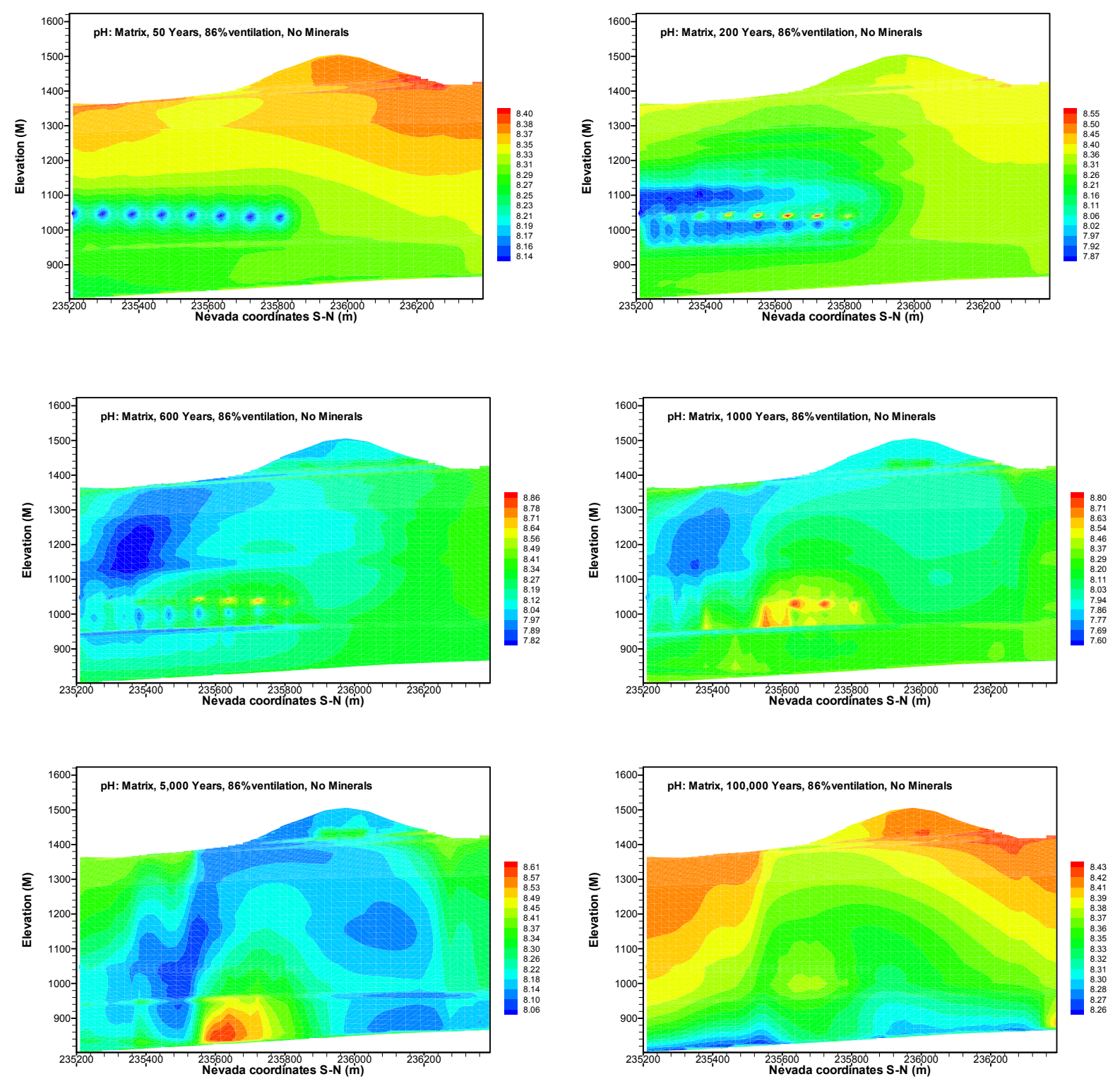

DTN: LB0310MTSCLTHC.002

NOTE: Contour intervals change at different times.

Figure 6.4-13. Matrix Pore Water pH Evolution under Thermal Impact without Mineral-Water Reactions 
Because matrix diffusion is slower than the changes imposed by heating, the matrix pore water $\mathrm{pH}$ response is slower and smoother than that in fracture. However, the distributions are similar, especially after long time periods (comparing Figures 6.4-13 and 6.4-14).
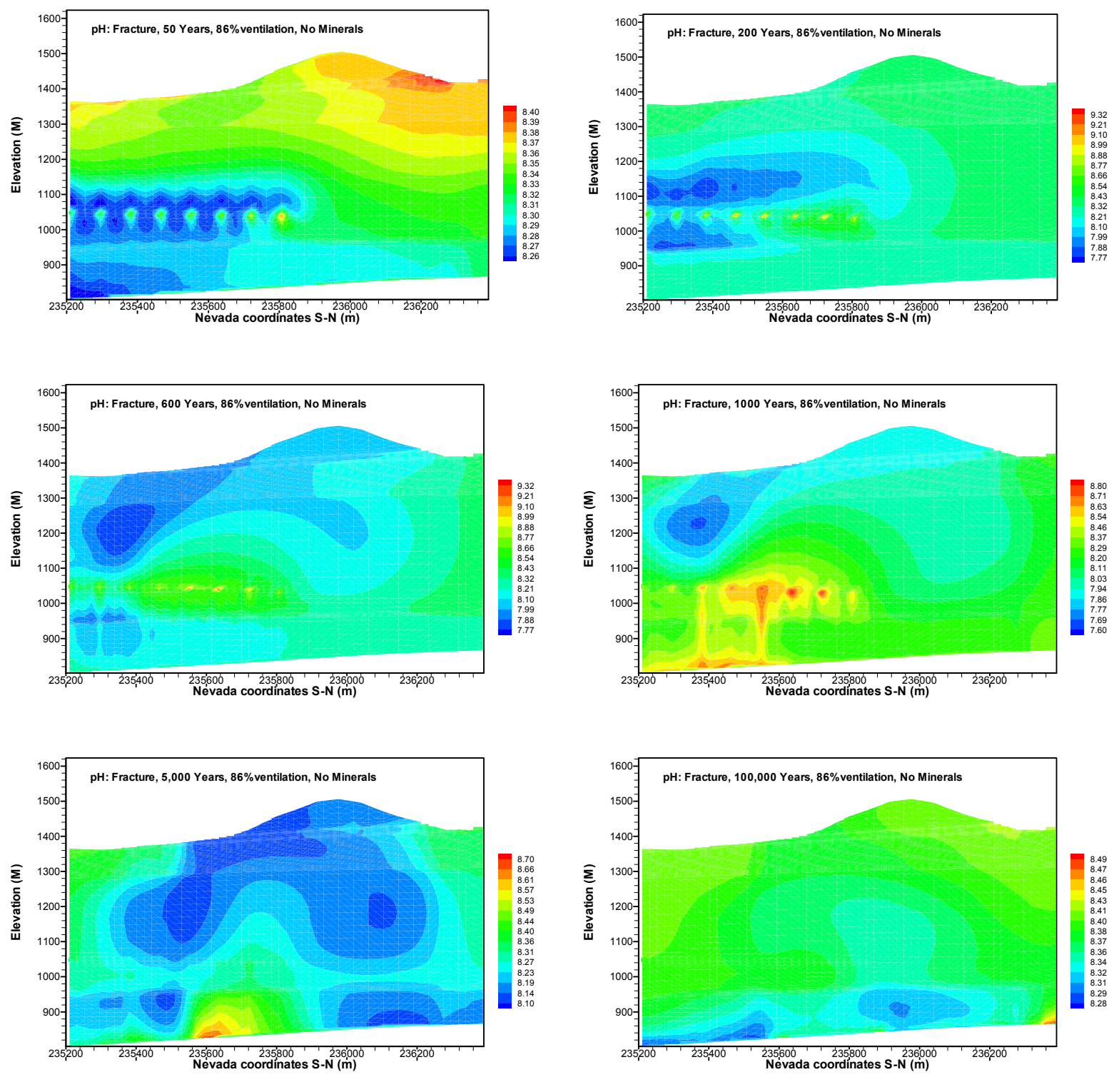

DTN: LB0310MTSCLTHC.002

NOTE: Contour intervals change at different times.

Figure 6.4-14. Fracture pH Evolution under Thermal Loading without Mineral-Water Reactions 


\subsection{Effects of THC Processes, Including Mineral-Water Reactions on Water and Gas Chemistry}

This section discusses the changes to water and gas chemistry for the case of full coupling between mineral-water-gas reactions, aqueous and gaseous species transport, and changes to flow owing to mineral precipitation and dissolution. The simulation discussed in this section utilized the full geochemical system of minerals, aqueous species, and gaseous species presented in Table 6.4-1, plus various salt phases. The heat load and ventilation efficiency employed were identical to that used in the previous section (6.4.3.2). The climate change scenario used was identical to the stepwise history used in Section 6.4.3.2.

First, the important effect of boiling and condensation-induced concentration changes are examined. The processes of condensation driving dilution, and evaporation resulting in higher concentrations, can be followed through the evolution of conservative species, such as chloride $\left(\mathrm{Cl}^{-}\right)$. Chloride concentrations in fracture water are shown at several times from 200 to 7,000 years in Figure 6.4-15. After only 200 years, a very small dryout zone and high concentrations can be seen at a few drifts. Surrounding the dryout zones are small regions of dilute fracture water where condensation is taking place. The region below the drifts is slightly drier, owing to the capillary barrier effect of the overlying drifts and vaporization of the fracture water. By 600 years, the condensation zones have grown, and drainage of the dilute water in the pillar regions has extended over $100 \mathrm{~m}$ below the drifts. The increased infiltration rate after 600 years enhances the elongation of the condensate drainage plumes, which are close to the water table by 1,000 years. In addition, the drier shadow zone regions are most prominent below the hottest drifts away from the boundaries. By 2,000 years, the highest chloride concentrations are only a factor of three greater than in the initial pore water, and by 3,000 years the differences are much less. A large, slightly elevated concentration region is present around the repository edge, formed as a result of large-scale evaporation and vapor transport. After 7,000 years, the entire system is nearly back to ambient chloride concentrations. 


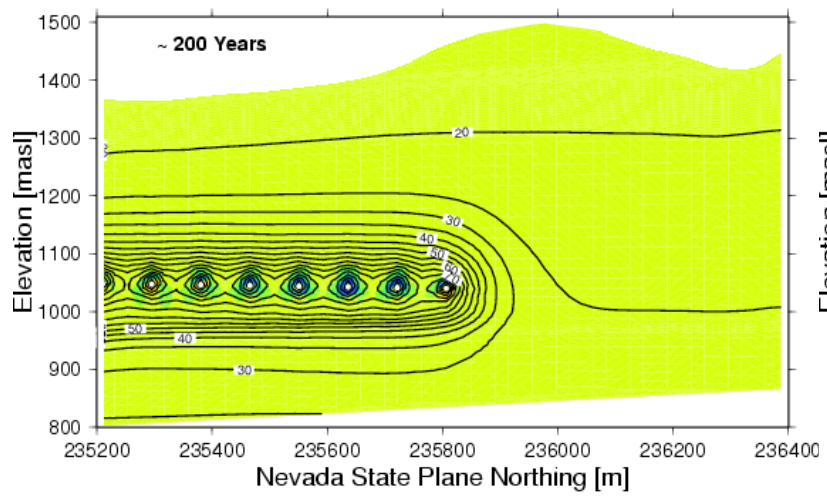

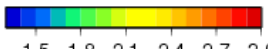

Fracture $\mathrm{Cl}[\log \mathrm{mg} / \mathrm{l}]$
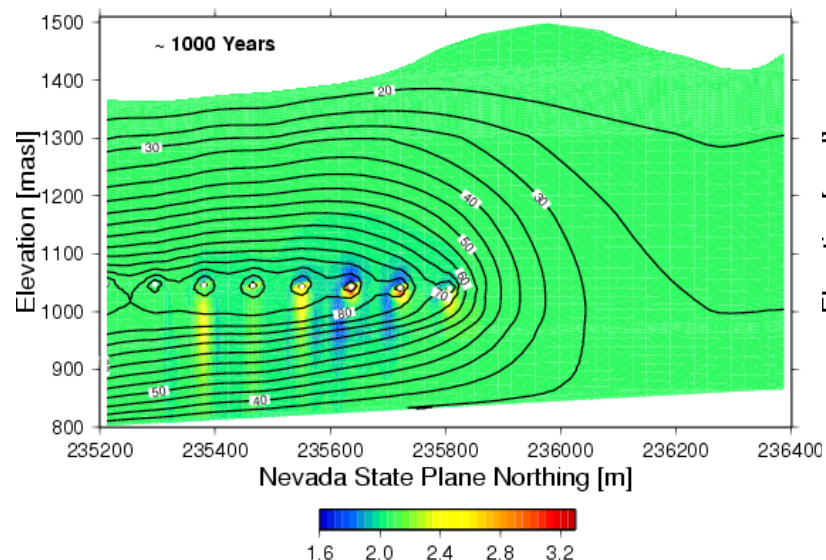

Fracture $\mathrm{Cl}[\log \mathrm{mg} / \mathrm{l}$

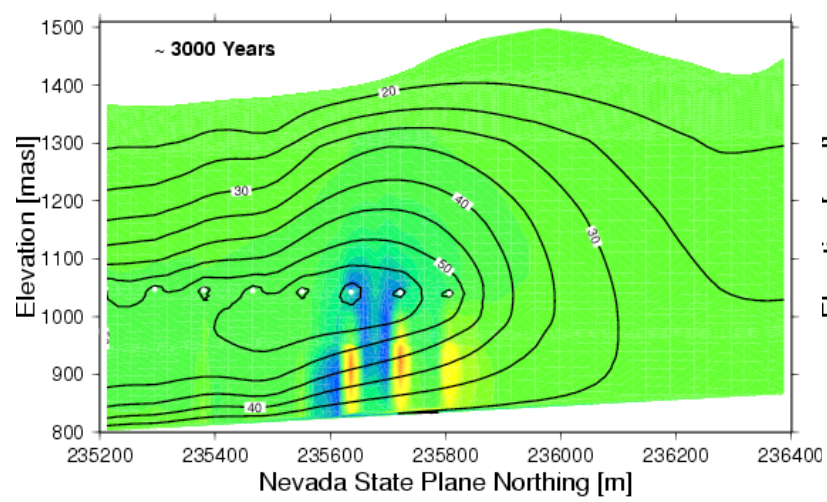

$\begin{array}{lllll}2.00 & 2.05 & 2.10 & 2.15 & 2.20\end{array}$

Fracture $\mathrm{Cl}[\log \mathrm{mg} / \mathrm{l}]$

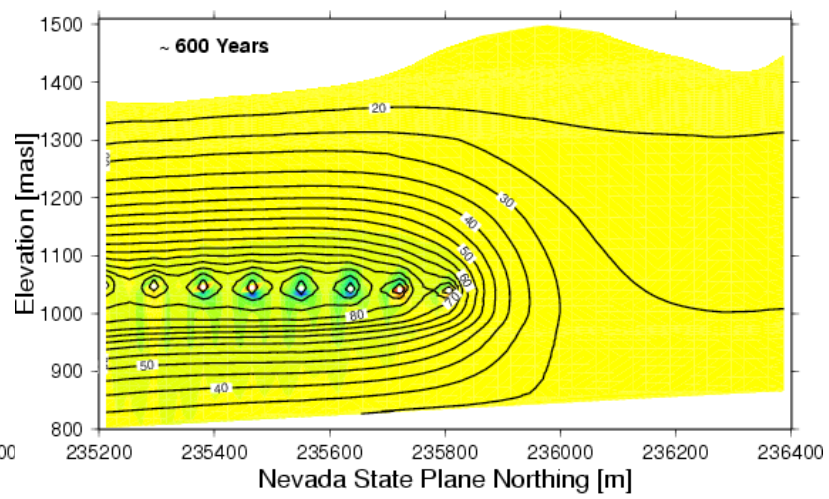

1,

1.21 .62 .02 .42 .83 .2

Fracture $\mathrm{Cl}$ [Log mg/l]

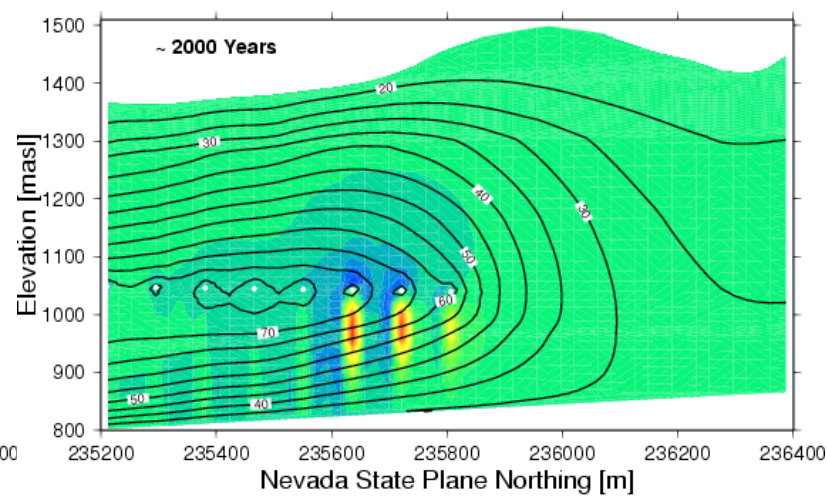

1.92 .02 .12 .22 .32 .42 .52 .6 Fracture $\mathrm{Cl}[\mathrm{Log} \mathrm{mg} / \mathrm{l}]$
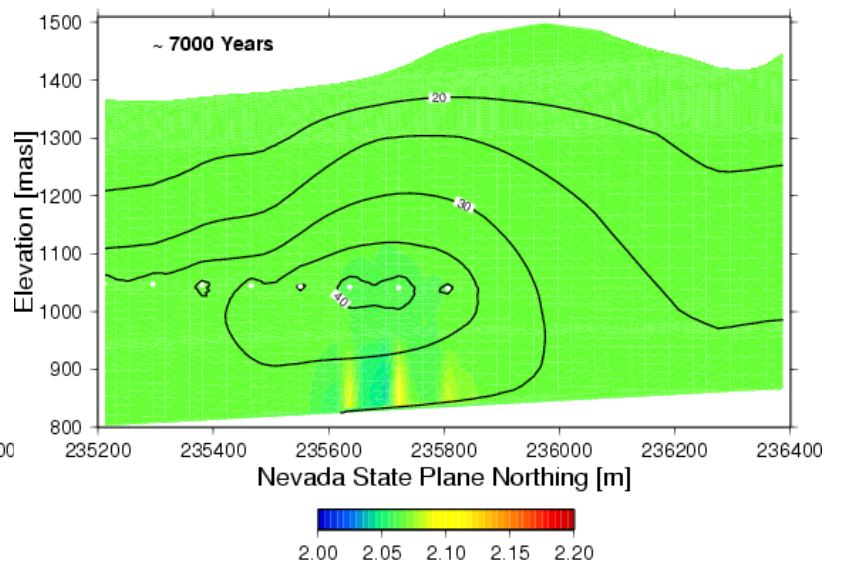

Fracture $\mathrm{Cl}$ [Log mg/l]

DTN: LB0310MTSCLTHC.001

NOTE: Concentration scale changes over time. Temperature contours are overlain.

Figure 6.4-15. Chloride Concentrations in Fracture Water at 200; 600; 1,000; 2,000; 3,000; and 7,000 Years 
The cooler drifts at the left edge of the model domain result from an increased infiltration rate in this area and a downward diversion of lateral flowing water above the repository (at the PTn$\mathrm{TSw}$ contact). Although the forced diversion of lateral flow at the left boundary is clearly enhanced as a result of the boundary, it is a realistic scenario for any location in the repository where there is focused flow owing to a fault, or as a result of runon and channelized flow in the central part of a stream channel. These differences in percolation fluxes and heat losses for repository drifts in different locations lead to spatial variations in the compositions of water potentially seeping into drifts at any particular time. Up to approximately 1,000 years, the differences in the chloride concentrations above the drifts are approximately one order of magnitude. As the drifts cool, and after percolating water rewets the dryout zones, the differences in the concentrations above the drifts become much less.

The evolution of $\mathrm{CO}_{2}$ concentrations over time is shown in Figure 6.4-16. After 200 years, there is an increase in $\mathrm{CO}_{2}$ concentrations that is confined to a zone extending up to about 200 meters above and 100 meters below the repository drifts. By 600 years, a plume-like zone of increased concentrations forms, with the plume center (maximum $\mathrm{CO}_{2}$ concentration) beginning close to the third drift from the left boundary after 600 years and migrating to the fourth drift after 2,000 years. This spatial shift is caused by the increase in the infiltration rate at 600 years, resulting in enhanced lateral flow and greater cooling of the drifts near the left boundary. Large-scale patterns of gas transport above and to the right of the repository are also clearly evident in the distribution of $\mathrm{CO}_{2}$ concentrations. Because the $\mathrm{CO}_{2}$ solubility is a strong function of the temperature, gas-phase $\mathrm{CO}_{2}$ concentrations remain perturbed as long as temperatures are elevated around the repository. Differences across the zone above the repository drifts are about two orders of magnitude in the first few hundred years and about one order of magnitude thereafter.

Compared to the $\mathrm{CO}_{2}$ distributions shown in Figure 6.4-13, the range in concentrations is much larger for the case with mineral reactions. This is particularly evident in the $\mathrm{CHn}$ unit below the repository, where calcite dissolution has taken place (see Figure 6.4-18). Compared to water-gas equilibriation by itself, mineral-water-gas reactions change both the range and distribution of $\mathrm{CO}_{2}$ spatially and over time. 

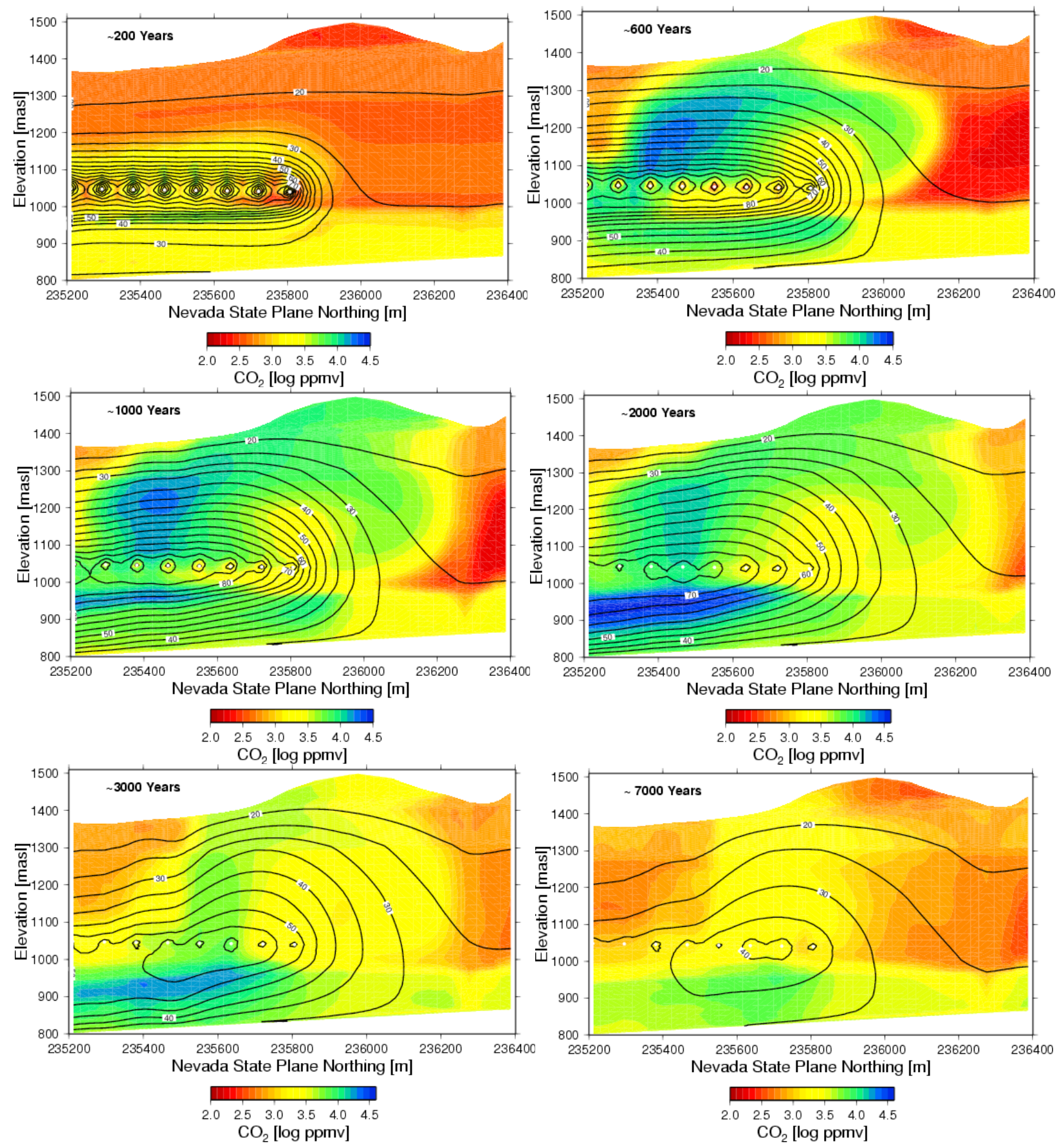

DTN: LB0310MTSCLTHC.001

Figure 6.4-16. Fracture Gas $\mathrm{CO}_{2}$ Concentrations and Temperatures at 200; 600; 1,000; 2,000; 3,000; and 7,000 Years 
As shown in Section 6.4.3.3.1, the evolution of $\mathrm{pH}$ in the waters surrounding repository drifts is strongly coupled to the exsolution of $\mathrm{CO}_{2}$ from pore waters during heating, followed by dissolution of the transported $\mathrm{CO}_{2}$ back into condensate water and cooler matrix pore water. The $\mathrm{pH}$ in fracture waters (Figure 6.4.17) shows a drop in $\mathrm{pH}$ from the initial value of about 8.3 to around 7 in the heated regions around the repository drifts.
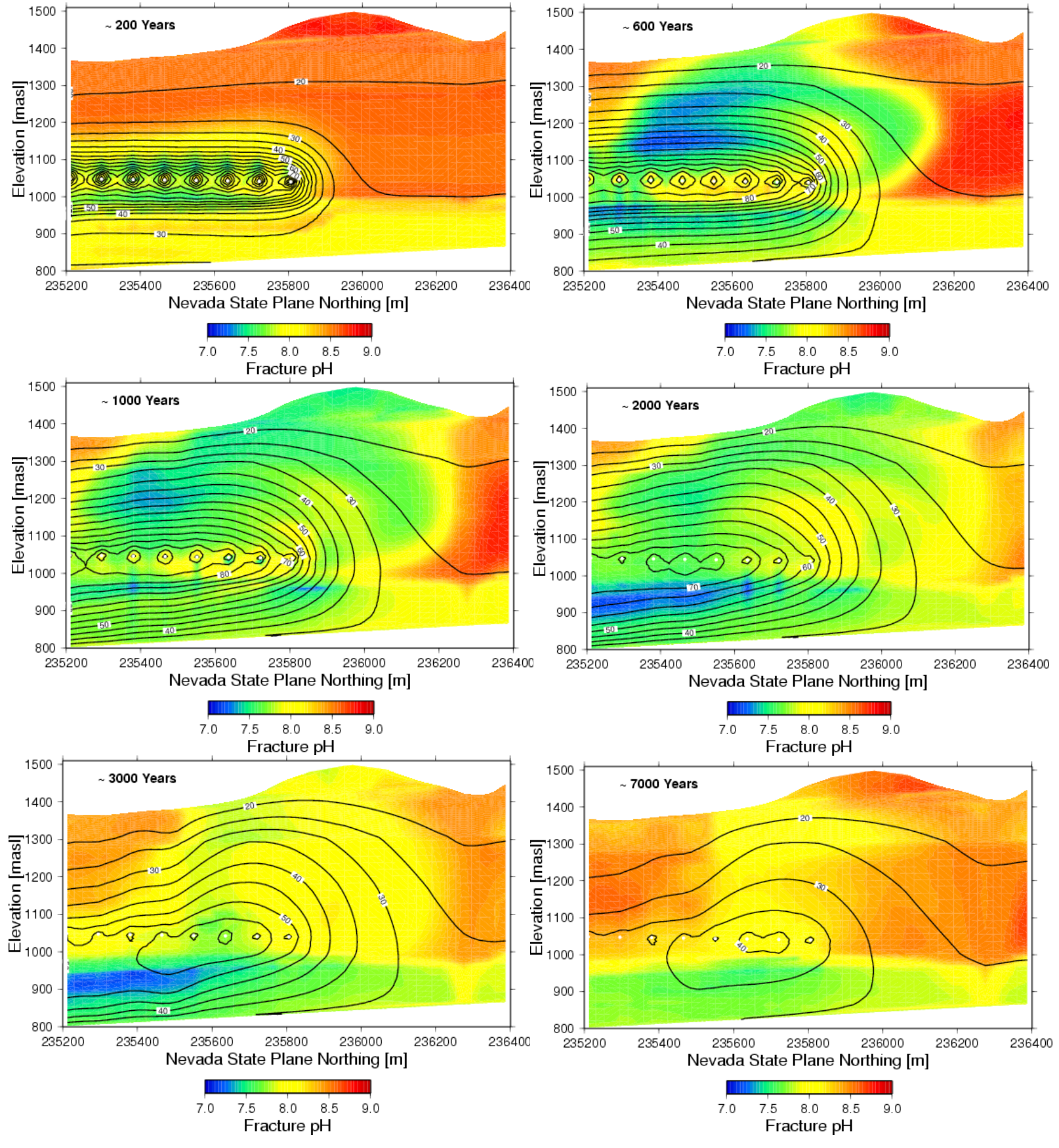

DTN: LB0310MTSCLTHC.001

Figure 6.4-17. Fracture Water pH and Temperature at 200; 600; 1,000; 2,000; 3,000; and 7,000 Years 
The $\mathrm{pH}$ distribution above the repository also changes from a broad area of lower $\mathrm{pH}$ waters to a more plume-like region extending above the hottest drifts after about 600 years. The plume-like distribution in $\mathrm{pH}$ seen in Figure 6.4-17 after 600 years can be directly attributed to the transport of exsolved $\mathrm{CO}_{2}$ above the repository drifts (Figure 6.4-16). A region of lower $\mathrm{pH}$ also extends through the PTn and to the surface after only about 600 years (Figure 6.4-17).

Differences across the zone above the repository drifts are about one $\mathrm{pH}$ unit at a given time, similar to the range in chloride concentrations. Higher $\mathrm{pH}$ waters tend to be in the area near the repository edge, where evaporation and vapor transport also resulted in slightly increased chloride concentrations. Below the repository, heating of the relatively confined $\mathrm{CHn}$ and Prow Pass units leads to a reduction in the $\mathrm{pH}$ to about 7. Areas still near ambient temperatures away from the repository show the $\mathrm{pH}$ remaining relatively stable in the range of 8 to 8.75 , indicating that the the geochemical system is roughly at steady-state, regardless of the climate change and increased infiltration rate.

\subsection{Effects of THC Processes on Mineralogy}

Mineral-water reactions may result from different major processes during repository heating. These include, but are not limited to: (1) boiling/evaporation-induced mineral precipitation as a direct result of increased concentration; (2) temperature effects on percolating waters, e.g. a decreased calcite solubility at higher temperatures; (3) changes in the thermodynamic stability of primary mineral phases (i.e., those minerals present prior to the onset of thermal loading) during heating or cooling; (4) fluid mixing resulting in a shift in mineral stability; and (5) exsolution/dissolution of $\mathrm{CO}_{2}$ and subsequent open-system advective or diffusive transport. Close to the repository drifts, boiling-induced precipitation in fractures is the most important process that could affect near-field percolation fluxes and seepage into drifts. Above the repository, in the PTn, alteration could affect any lateral flow or modify fast-path transport through fractures or faults. Below the repository, alteration of zeolitic or vitric layers could influence radionuclide transport velocities, as well as the extent of retardation by ion exchange or sorption.

Mineral precipitation and dissolution in the boiling and condensation zones around the drifts have the highest potential for changing percolation fluxes to the drift walls and modifying flow in the pillars between drifts. In simulations of drift-scale coupled THC processes (BSC 2003 [162050]), the most abundant phases precipitating in fractures, resulting in near-permanent changes to permeability, were amorphous silica and calcite. Other phases, such as gypsum and halite (only in dried-out gridblocks) also formed in proportions similar to calcite, but redissolved rapidly during rewetting. Similar mineral precipitation processes were observed in mountain-scale simulations, with some differences in the extent of alteration owing to the spatial variation of infiltration rates and flow diversion/focusing as a result of lateral flow in the PTn. Note that all mineral volume percentages are changes relative to the fracture or matrix volume.

Calcite is present as an initial fracture-lining mineral and within the matrix in some rock units. The evolution of calcite precipitation from 1,000 to 7,000 years is shown in Figure 6.4-18 (Note that all mineral volume percents are changes relative to the matrix or fracture volume). After 1,000 years, there is some calcite precipitation directly around the drifts, with dissolution most prominent in the adjacent condensation and drainage zones, where lower $\mathrm{pH}$ waters formed (see 
Figure 6.4-17). Regions of dissolution are more localized above the hottest drifts after 3,000 years, and precipitation of calcite has taken place in areas where at earlier times dissolution was evident. Dissolution of calcite progresses from 1,000 to 2,000 years in the zeolitic rocks below the repository, where there are increasing $\mathrm{CO}_{2}$ concentrations and decreasing $\mathrm{pH}$. Some calcite has formed above the repository in areas of high percolation fluxes, where infiltrating waters have undergone $\mathrm{CO}_{2}$ degassing and subsequent calcite precipitation in fractures. However, even after 5,000 years, the maximum amount of calcite formed in fractures is less than $0.2 \%$ of the fracture volume, and little change in the calcite abundances can be seen between 5,000 and 7,000 years.

1,000 years

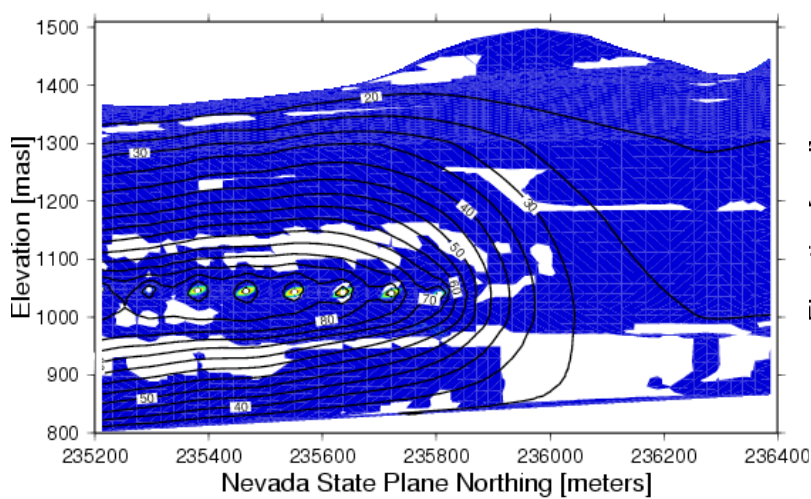

$\begin{array}{lllllll}0.00 & 0.04 & 0.08 & 0.12 & 0.16 & 0.20\end{array}$

Fracture Calcite Prec [\%]

5,000 years

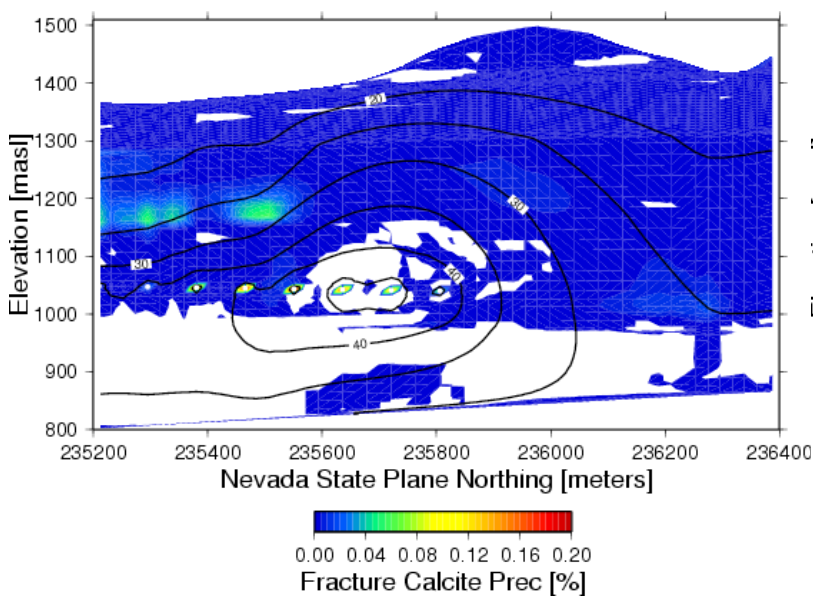

3,000 years

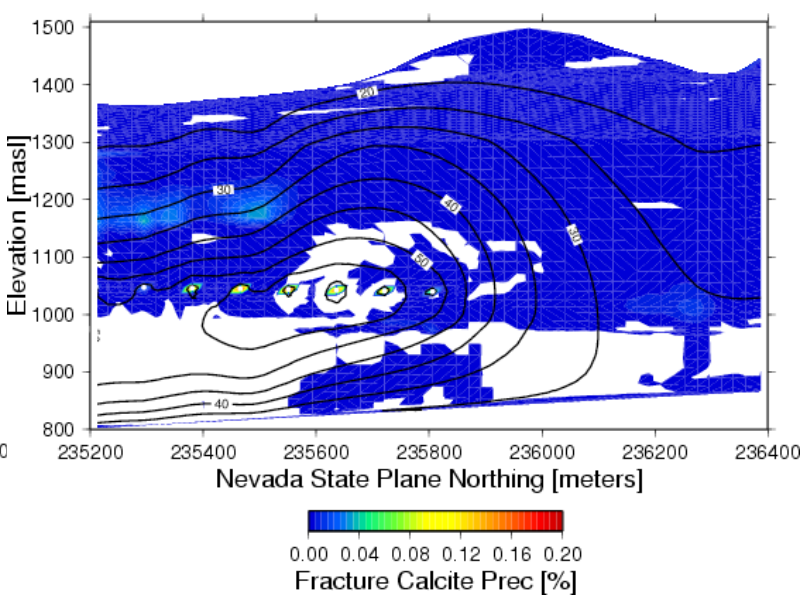

7,000 years

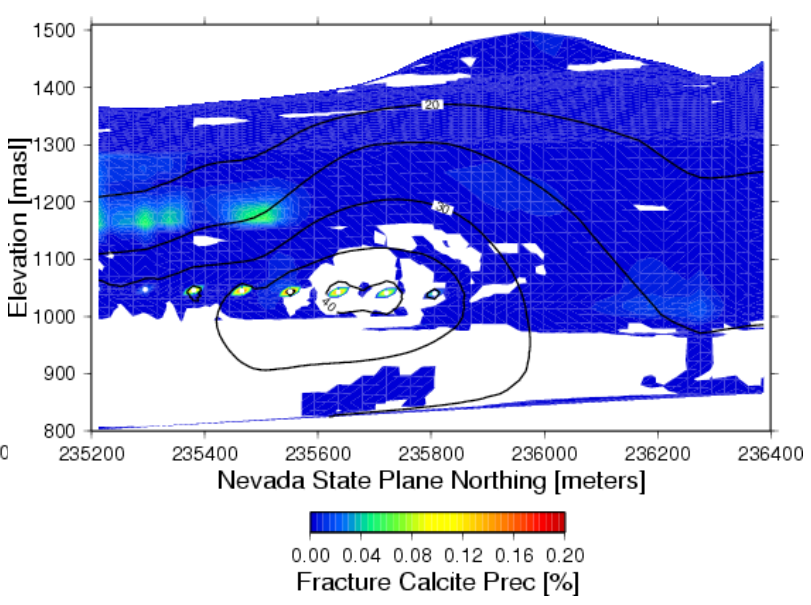

DTN: LB0310MTSCLTHC.001

NOTE: White areas represent regions where some dissolution has taken place.

Figure 6.4-18. Calcite Precipitation (Volume \%) in Fractures at 1,000; 3,000; 5,000; and 7,000 Years 
Amorphous silica is the dominant phase that precipitates in fractures in the boiling zones. However, because above-boiling conditions are encountered only in the regions directly adjacent to the hottest drifts, amorphous silica precipitation is limited to these areas (Figure 6.4-19). After 1,000 years, nearly all of the amorphous silica has precipitated, and at 2,000 years the distribution has remained the same. After much longer time periods, percolating waters later dissolve this mineral very slowly; however, the rate of amorphous silica dissolution is so slow at lower temperatures that it persists for tens of thousands of years or longer, even though it is undersaturated in the percolating waters. Therefore, the precipitation of amorphous silica can be considered as a permanent change with respect to the time scale of repository performance.

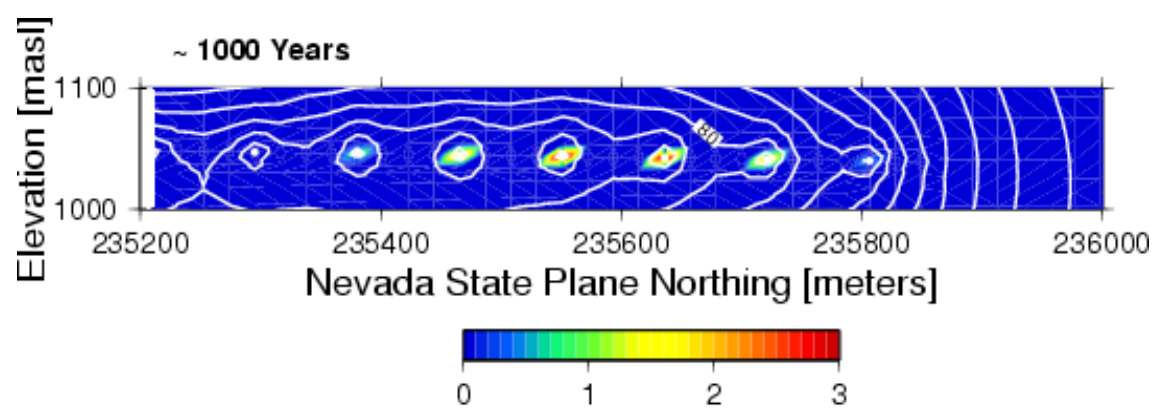

Fracture Amorphous Silica Prec [vol. \%]

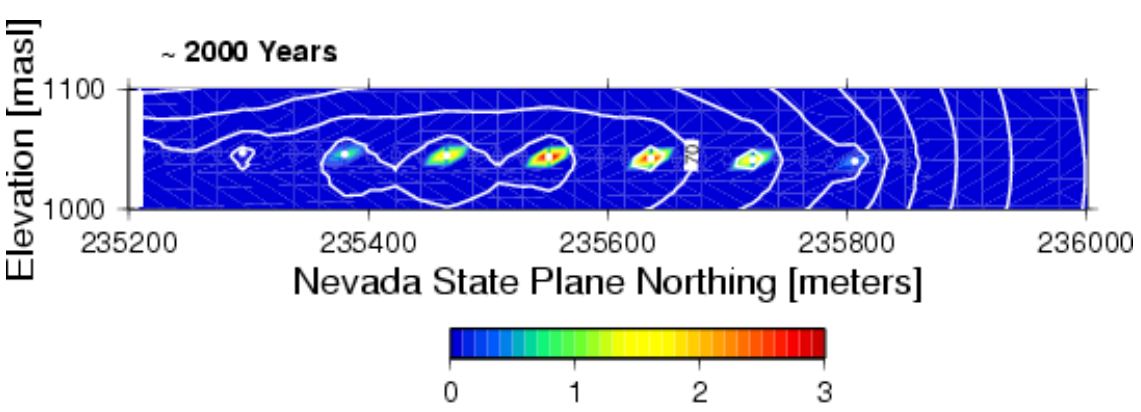

Fracture Amorphous Silica Prec [vol. \%]

DTN: LB0310MTSCLTHC.001

NOTE: Temperature contours are overlain.

Figure 6.4-19. Amorphous Silica Precipitated (Volume \%) in Fractures around Drifts after 1,000 and 2,000 Years

Away from the repository, the rocks that would likely be expected to undergo alteration at higher temperatures are those containing abundant volcanic glass and/or zeolites. These particular layers are the basal vitrophyre of the TSw, the vitric tuffs in the Calico Hills and the PTn, and the zeolitized tuffs (also often glass-rich) in the Calico Hills, Prow Pass, and Bullfrog units. Mineral-water reactions involving volcanic glass and complex silicate phases, such as zeolites, are extremely difficult to represent in geochemical models because of their complex chemical compositions and also because of uncertainties in their thermodynamic and kinetic properties. Zeolites, such as clinoptilolite, typically involve several endmembers in a solid solution series, are affected by simultaneously acting processes such as ion exchanges and reactions, and preferentially incorporate many trace components such as $\mathrm{Sr}$, all of which influence their composition and stability. Therefore, modeling results of the alteration of the vitric and zeolitic 
units can only be considered as qualitative in nature. Yet significant alteration of the glassy rocks at Yucca Mountain is evident, whereas the crystalline devitrified rocks are little altered. Hence, the rock record supports the tendency of the glassy units to alter preferentially. Furthermore, glass-rich bedded tuffs in the PTn show much less alteration to zeolites, indicating that the volcanic glass has not been significantly affected by ambient temperature reactions over millions of years. Therefore, qualitatively it should be expected that the Mountain-Scale THC Model results show some mineralogical alteration of the volcanic glass under modeled temperatures, and little change at near-ambient temperatures.

Model results show that in the rock matrix after 1,000 years over $5 \%$ of the volcanic glass in the basal vitrophyre of the TSw has reacted and by 7,000 years it has dissolved up to nearly $20 \%$ by volume (Figure 6.4-20). See Figures 6.4-1 and 6.4-3 for general locations of lithostratigraphic units. The zone of alteration progressed down into the $\mathrm{CHn}$ as temperatures increased, with significant glass alteration taking place at temperatures above approximately $50^{\circ} \mathrm{C}$. Much of the reaction has taken place by 3,000 years, with the alteration rate decreasing strongly as temperatures decline in the rocks below the repository. The extent of glass alteration is limited to the strongly heated regions directly below the repository drifts, with little effects elsewhere. The lack of significant alteration under ambient temperatures is qualitatively consistent with the observed preservation of glass in the PTn over the greater than 10 million years since the deposition of the tuffs. 

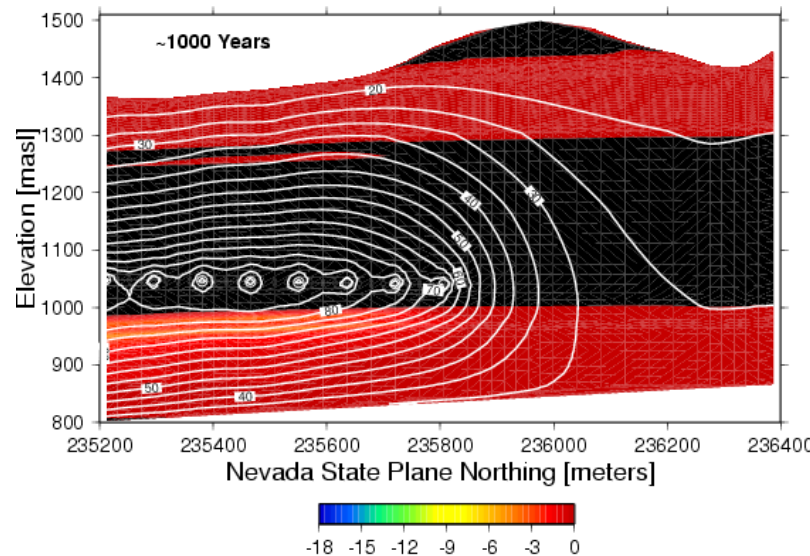

Matrix Glass Diss. [ vol. \%]

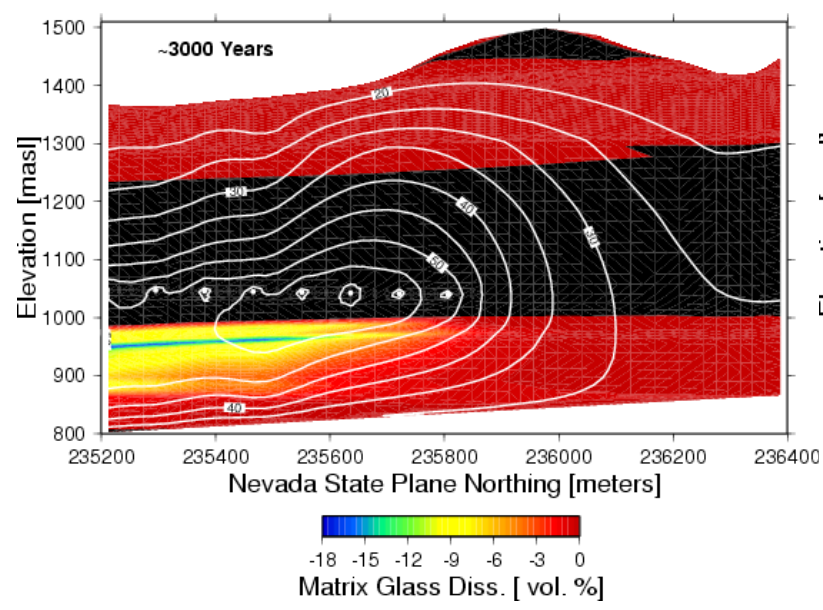

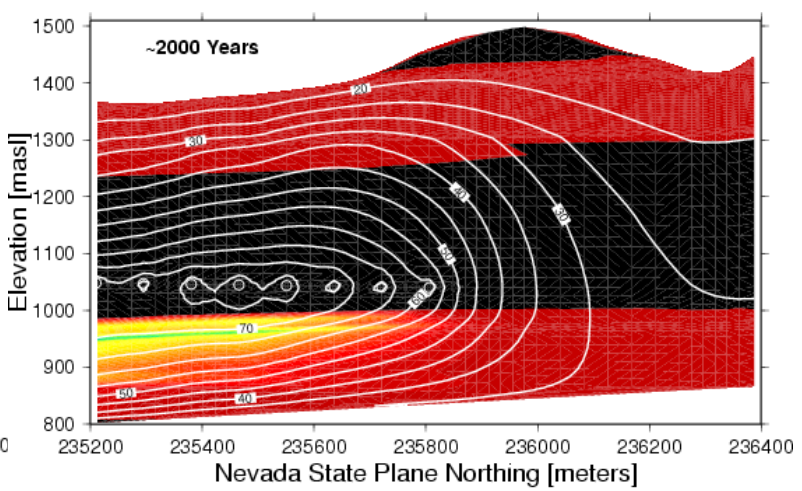

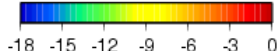

Matrix Glass Diss. [ vol. \%]

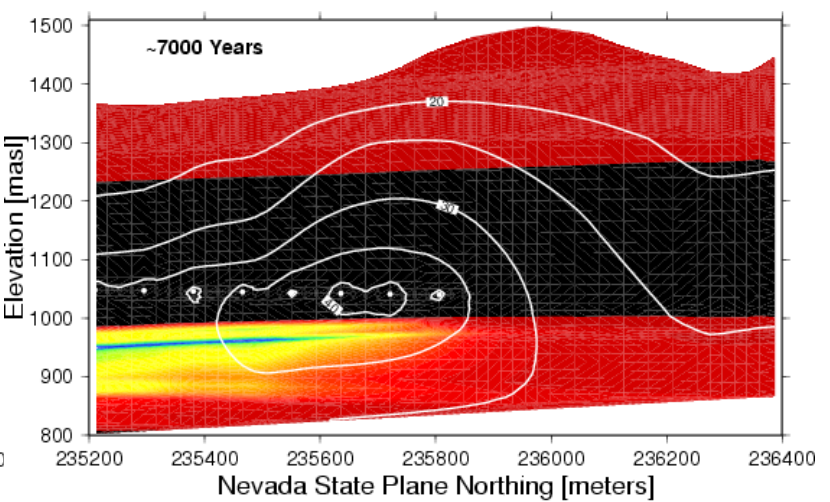

$\begin{array}{llllllll}-18 & -15 & -12 & -9 & -6 & -3 & 0\end{array}$

Matrix Glass Diss. [ vol. \%]

DTN: LB0310MTSCLTHC.001

NOTE: Black regions are areas where glass was absent from the rock or where no dissolution has taken place. Temperature contours are overlain. Percentage is relative to volume of matrix.

Figure 6.4-20. Volcanic Glass Dissolved (Volume \%) in the Rock Matrix after 1,000; 2,000; 3,000; and 7,000 Years 
The dominant phases formed by volcanic glass reactions with aqueous fluids are zeolites (i.e., stellerite; Figure 6.4-21), potassium feldspar (Figure 6.4-22; microcline in the thermodynamic data set), and albite (Figure 6.4-23).
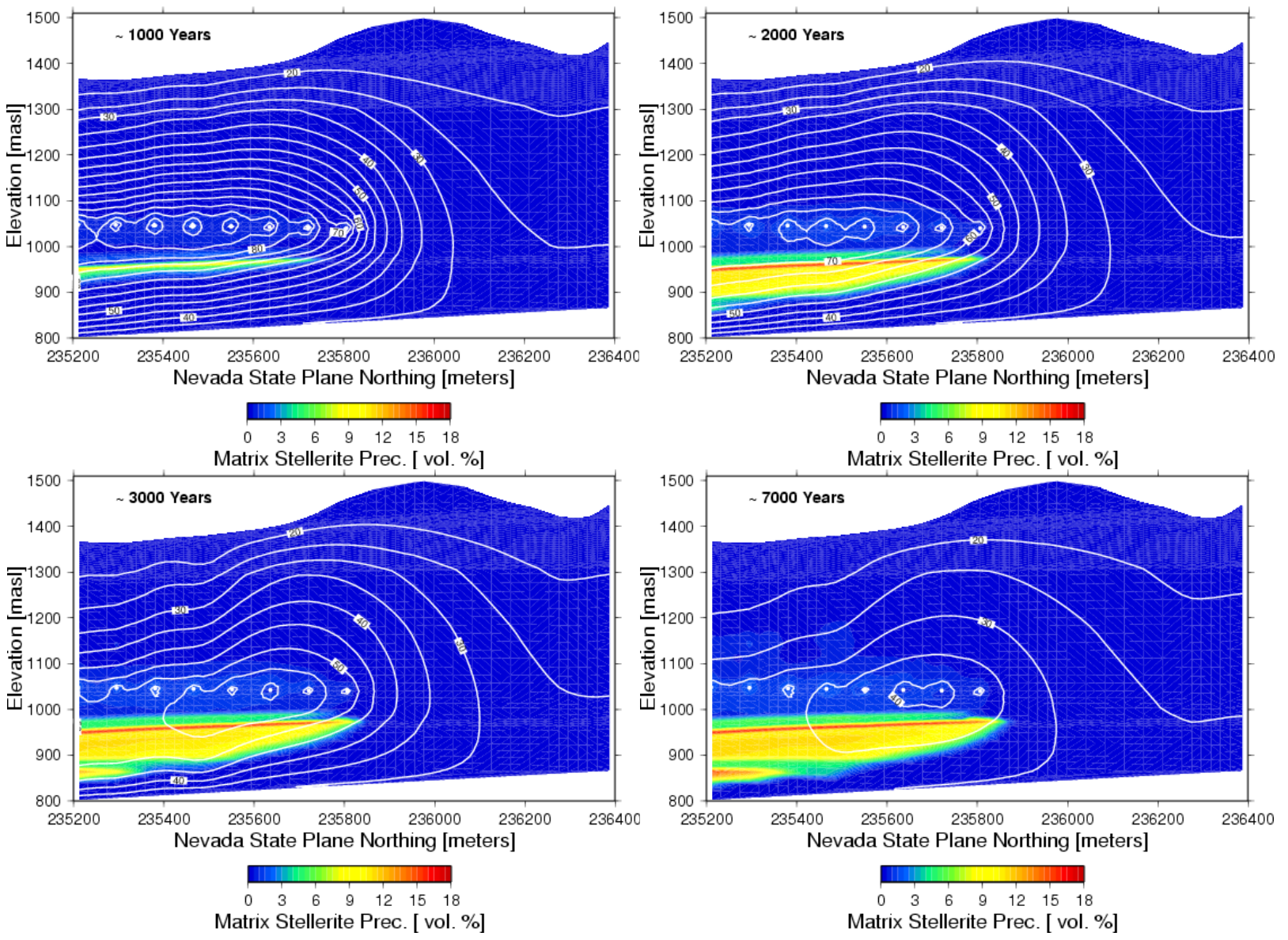

DTN: LB0310MTSCLTHC.001

NOTE: Temperature contours are overlain.

Figure 6.4-21. Stellerite Precipitation (Volume \%) in the Rock Matrix after 1,000; 2,000; 3,000; and 7,000 Years 

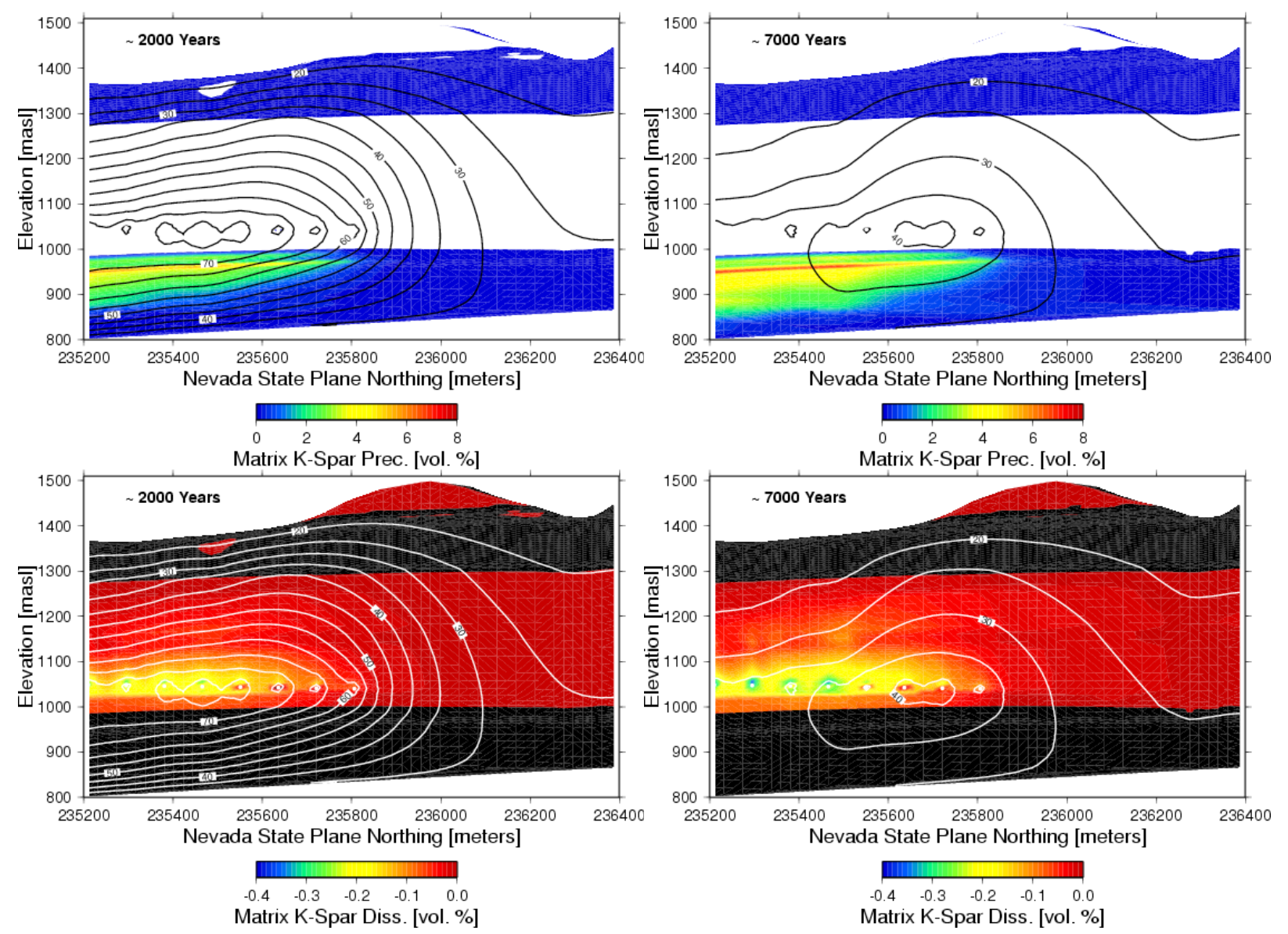

DTN: LB0310MTSCLTHC.001

NOTE: Temperature contours are overlain. White areas indicate dissolution and black areas indicate precipitation.

Figure 6.4-22. Potassium Feldspar (Microcline) Precipitation (Above) and Dissolution (Below) (Volume $\%$ ) in the Rock Matrix after 2,000 and 7,000 Years 

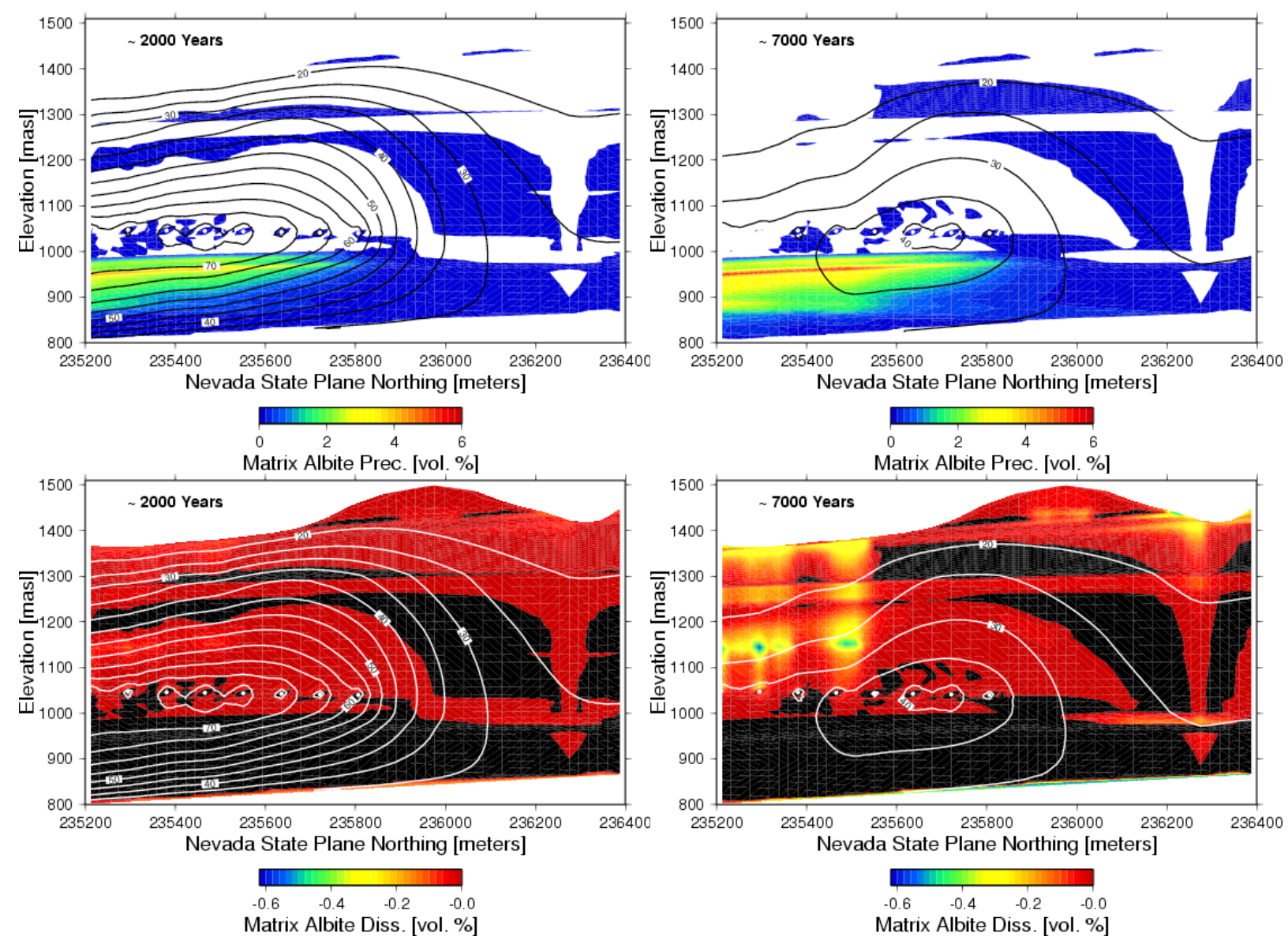

DTN: LB0310MTSCLTHC.001

NOTE: Temperature contours are overlain. White areas indicate dissolution and black areas indicate precipitation.

Figure 6.4-23. Albite Precipitation (Above) and Dissolution (Below) (Volume \%) in the Rock Matrix after 2,000 and 7,000 Years

The basal vitrophyre of the TSw and the underlying vitric units and glass-rich zeolitic units all contain abundant clinoptilolite, which (in the model simulations) breaks down at elevated temperatures (Figure 6.4-24) to form predominantly stellerite (Figure 6.4-21). Although stellerite is common in fractures in the devitrified tuffs in the TSw, it is not typical as an alteration product of glass in the vitric units. It is likely that the fixed composition of clinoptilolite used in the thermodynamic database limits its ability to form preferentially to stellerite under the changing calcium, sodium, and potassium concentrations in the aqueous fluid, thus reducing its relative stability to stellerite, potassium feldspar, and albite at elevated temperatures. At near-ambient temperatures, clinoptilolite is stable in the simulation and actually precipitates preferentially in the glass-rich layers (Figure 6.4-24). This trend is consistent with the observed mineral assemblage, although the $1 \%$ reacted in 7,000 years is probably greater than that actually formed in this short period of time.

Nevertheless, the general trend of glass reacting to form zeolites is captured, although the stable zeolite assemblage may not be representative of that occurring at higher temperatures. In addition, given the observed alteration of glass to predominantly clinoptilolite during earlier 
thermal events at Yucca Mountain, the reactions forming feldspars may be thermodynamically or kinetically unfavorable.
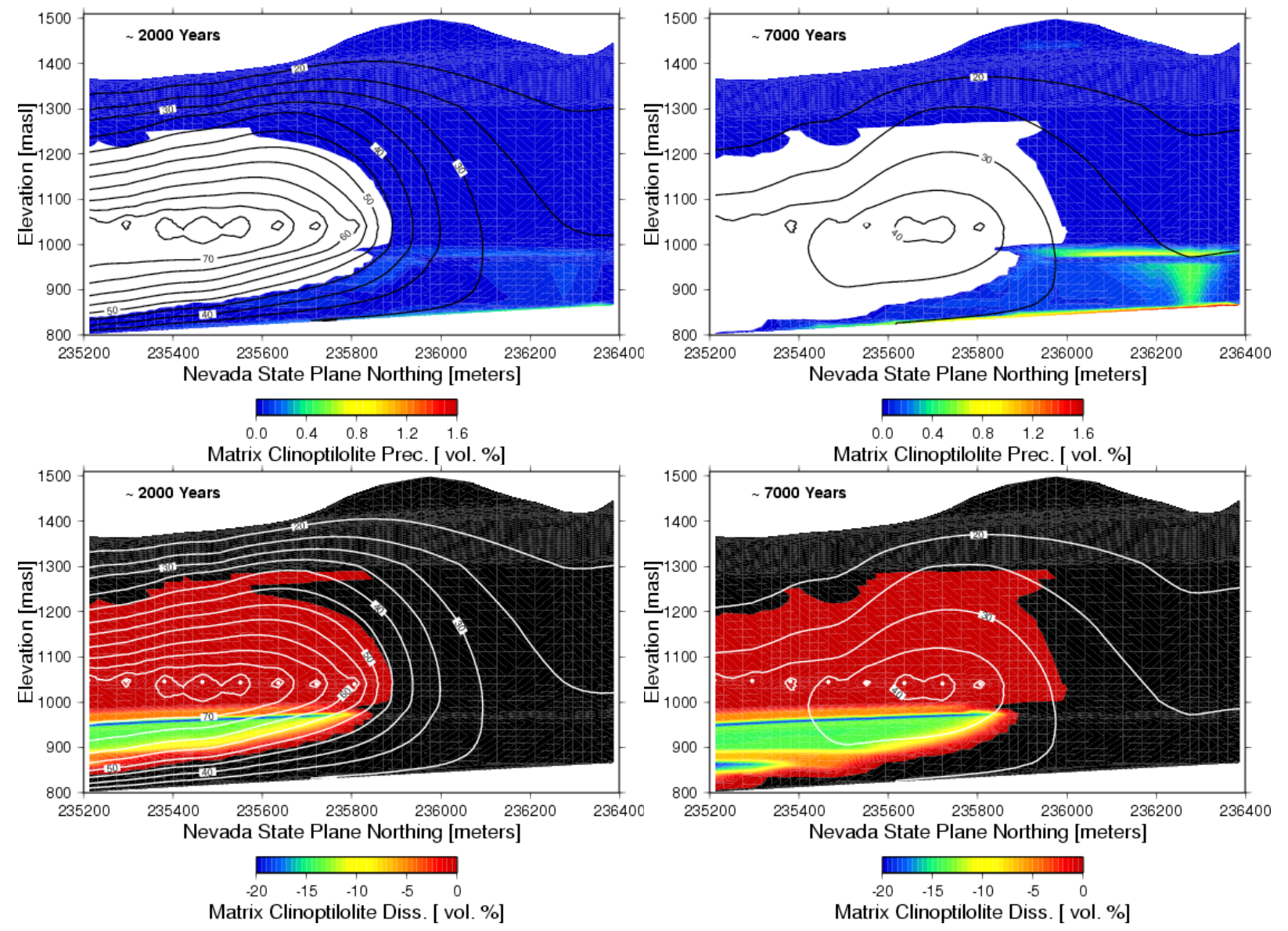

DTN: LB0310MTSCLTHC.001

NOTE: Temperature contours are overlain. White areas indicate dissolution and black areas indicate precipitation.

Figure 6.4-24. Clinoptilolite Precipitation (Above) and Dissolution (Below) (Volume \%) in the Rock Matrix after 2,000 and 7,000 Years

\subsection{Effects of THC Processes on Hydrological Properties and Percolation Fluxes}

Changes in porosity and hence permeability are related to the net effects of volume changes taking place via mineral dissolution/precipitation, as discussed in the previous section. Mineral precipitation takes place through several different mechanisms, and therefore the distribution in the changes in hydrological properties is related to the spatial distributions of the various processes. Near the repository drifts, changes in fracture porosity (Figure 6.4-25) and permeability (Figure 6.4-26) are related primarily to boiling-induced mineral precipitation, which is dominated by amorphous silica (Figure 6.4-19). Only minor changes in fracture porosity (about 6\%) are observed near the drifts. However, the spatial resolution of the mesh in these zones is not adequate to evaluate changes in a narrow boiling zone. Hence, the Drift-Scale THC Seepage Model predicts about twice this amount of porosity change (based on doubling the mineral amounts in Figure 6.8-43 (BSC 2003 [162050]) for a fracture medium initially having 
$50 \%$ rock). In the rock matrix, a small reduction in porosity of less than $1 \%$ is apparent in the repository horizon around the drifts (Figure 6.4-25), whereas in the CHn there is a modest increase in porosity of about $1 \%$, owing primarily to the reaction of clinoptilolite and glass to feldspars and stellerite. Such small fracture porosity changes do not significantly reduce the fracture permeability around the drifts (Figure 6.4-26). Permeability changes in the matrix of the $\mathrm{CHn}$ vitric and zeolitic units are minor because of the initially high porosity of these rocks (Figures 6.4-25 and 6.4-26). Therefore, the porosity and permeability values in the matrix are essentially the same as the initial values.

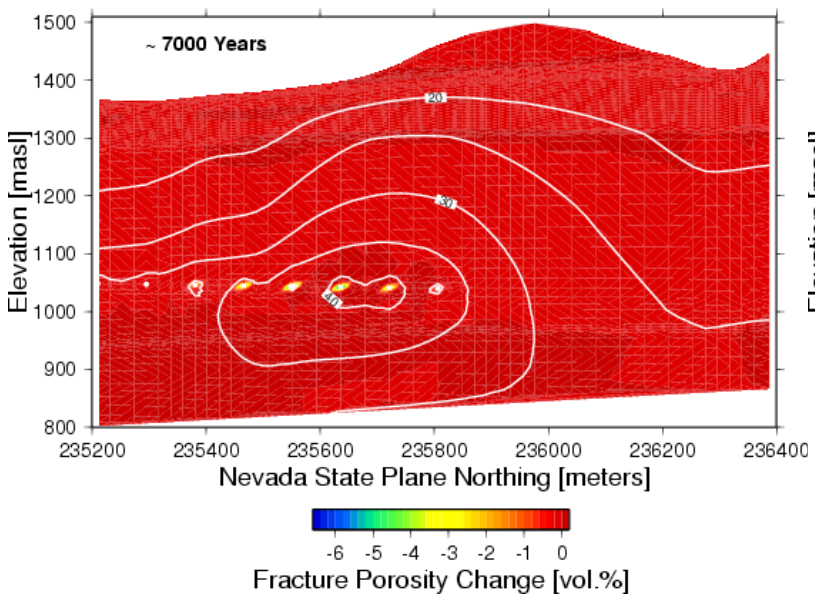

Figure 6.4-25. Fracture and Matrix Porosity Changes after 7,000 Years
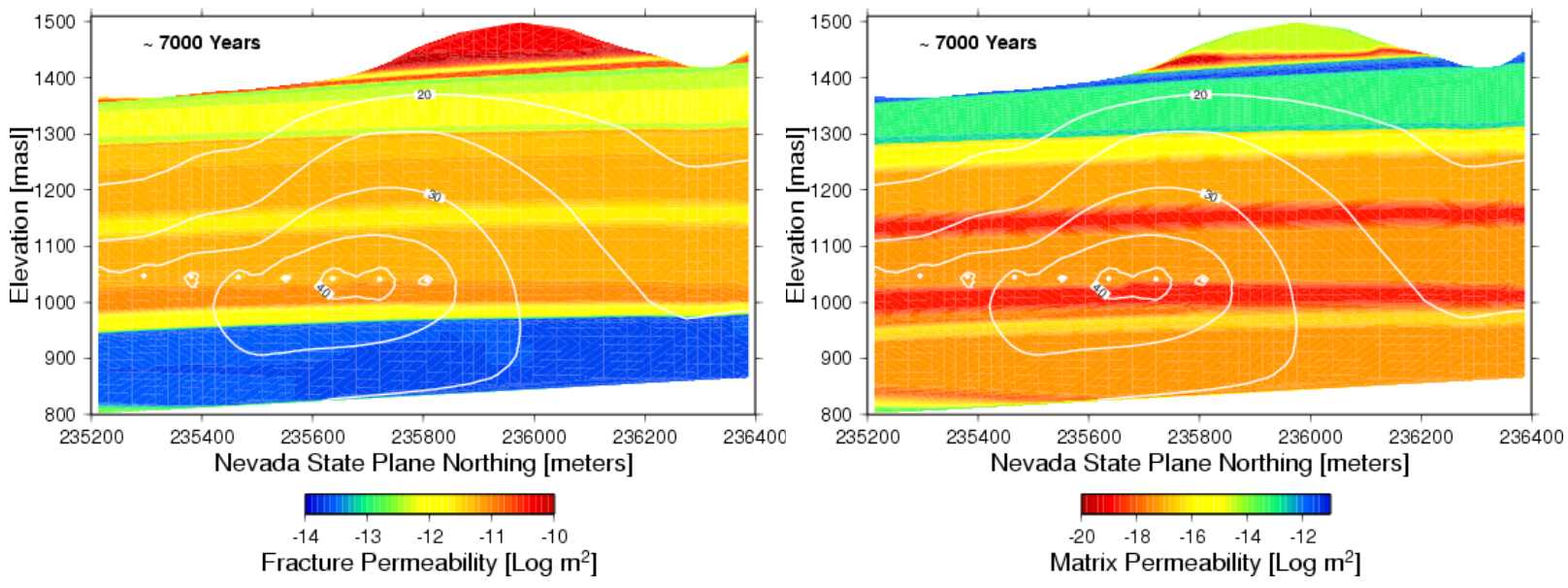

DTN: LB0310MTSCLTHC.001

Figure 6.4-26. Fracture and Matrix Permeability after 7,000 Years 
As a result of the relatively minor changes to hydrological properties, the percolation fluxes at the repository horizon are little different from the thermal-hydrological model fluxes (Figure 6.427). Although changes in the near-field hydrological properties and flow are limited by the lack of sufficient resolution in the Mountain-Scale THC Model, these results indicate that reactions taking place in the far-field above the repository (e.g., in the PTn) are not sufficient to affect percolation fluxes.
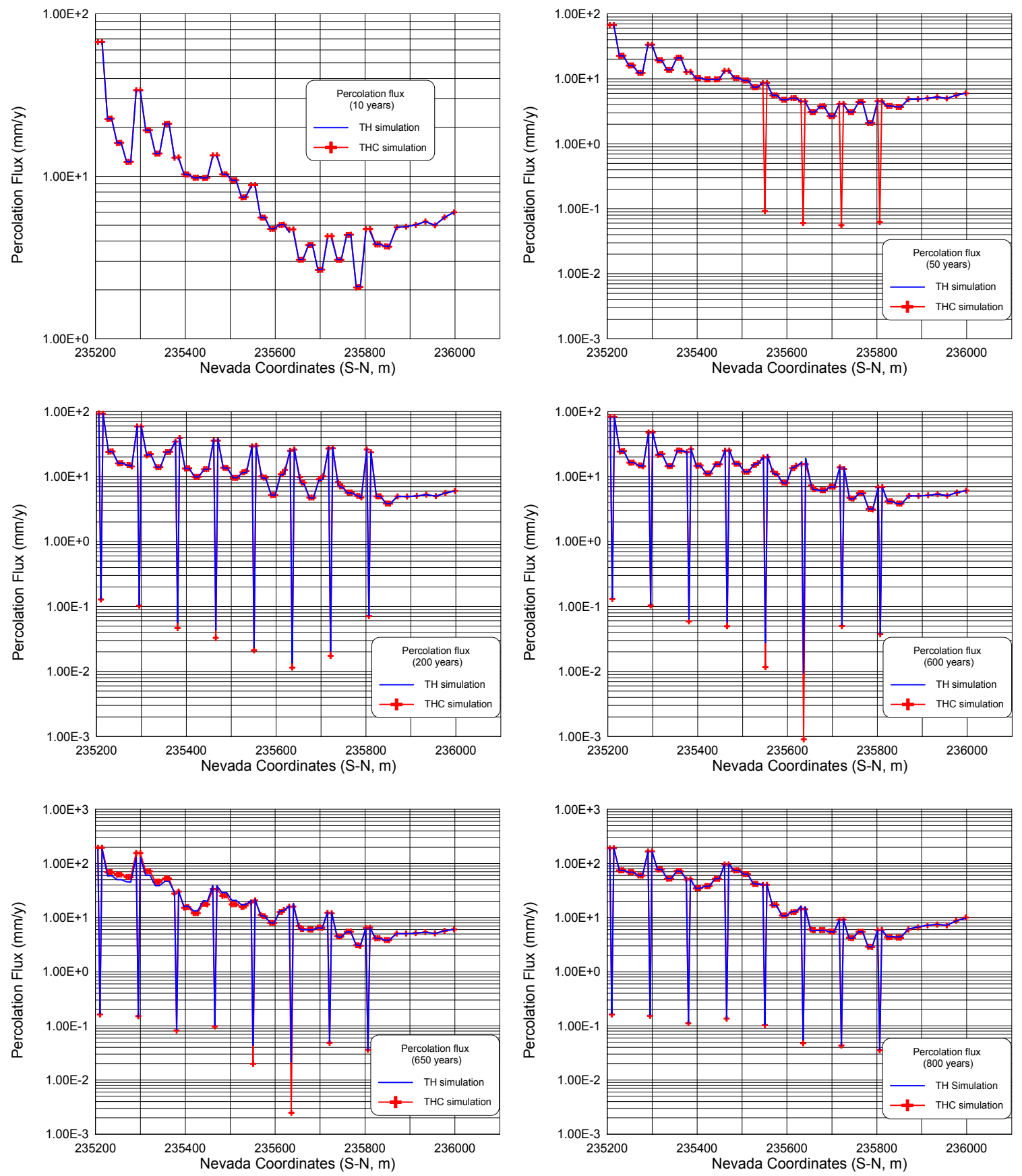

DTN: LB0310MTSCLTHC.001

Figure 6.4-27. Percolation Fluxes at the Repository Horizon from the TH and THC Models 

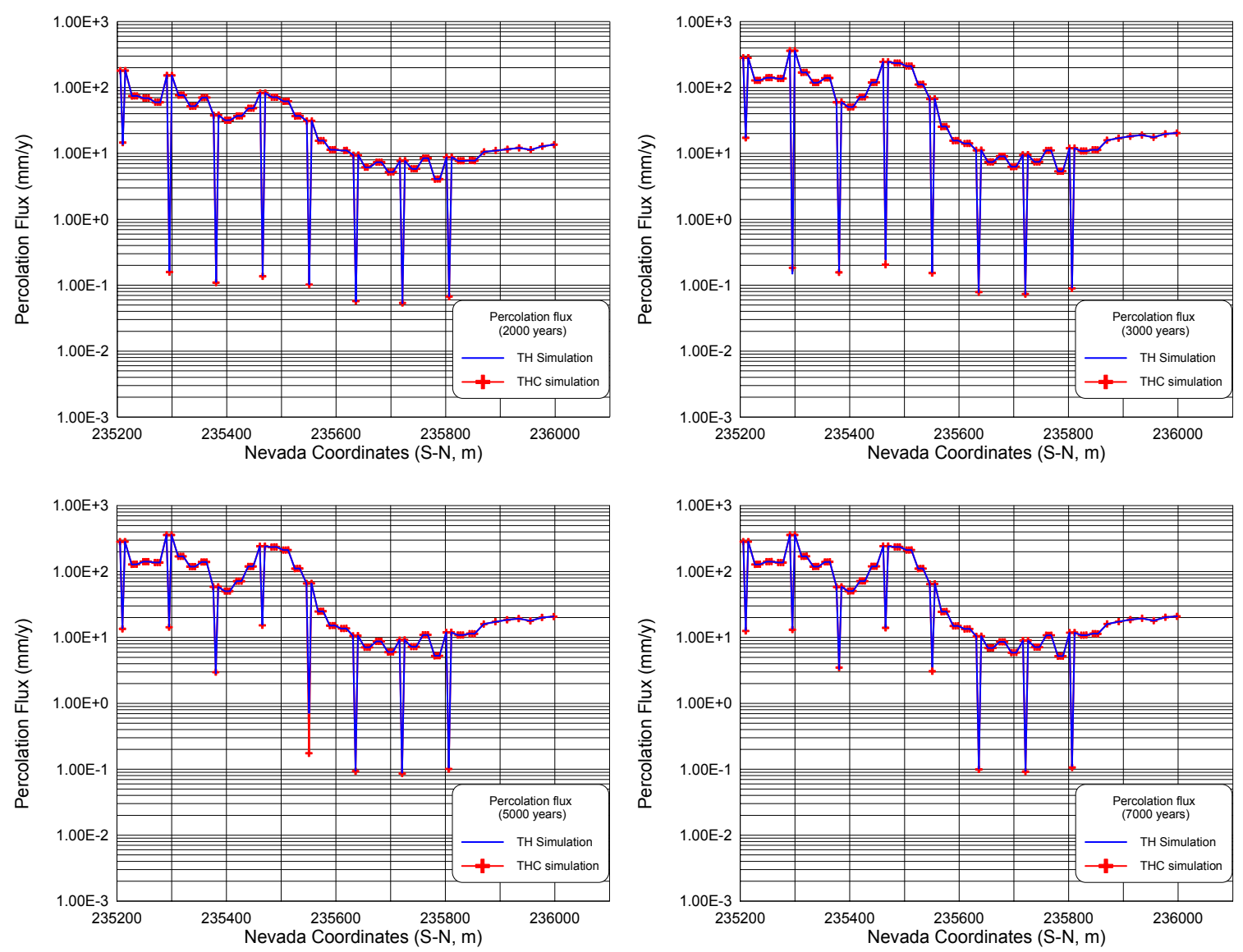

DTN: LB0310MTSCLTHC.001

Figure 6.4-27. Percolation Fluxes at the Repository Horizon from the TH and THC Models (Continued) 


\subsection{MOUNTAIN-SCALE THM MODEL}

The purpose of this section of the Model Report is to document mountain-scale modeling of coupled THM processes around the repository. Specifically, the impact of coupled THM processes on hydrological properties and mountain-scale fluid flow are examined over a time frame of 10,000 years. For this purpose, a Mountain-Scale THM Model is developed, based on the coupled THM simulator TOUGH2-FLAC3D (Rutqvist et al. 2002 [162048]). A similar analysis has been conducted for the Drift Scale THM Model Report (BSC 2003 [164890]) using the same conceptual model and same numerical simulator. For the sake of completeness, salient features of the coupled THM model, which can also be found in the Drift-Scale THM Model report (BSC 2003 [164890]), are described in Sections 6.5.1-6.5.5 below.

\subsubsection{Introduction to Coupled THM Analysis}

The heat generated by the decay of radioactive waste results in elevated rock temperatures for thousands of years after waste emplacement. These temperatures cause thermal expansion of the rock, with the potential of opening or closing fractures and thus changing fracture permeability close to the repository. Changes in permeability may impact the percolation flux around the repository and thereby impact the performance of the repository. It is necessary to estimate the impact of THM processes on the repository performance to find out whether a coupled THM analysis is necessary or whether some couplings can be neglected, leading to a simplified partially coupled analysis.

In this section, the impact of coupled THM processes on the mountain-scale hydrology of the repository at Yucca Mountain is assessed by comparing the result of a TH analysis to that of a THM analysis. In the partially coupled TH analysis, the coupling via mechanical processes is neglected, which means that changes in hydrological properties induced by mechanical processes are neglected in the fluid flow calculation. To assess the impact of the THM processes on the flow field, it is sufficient to calculate changes in the mean permeability value for the conservative case of relatively strong THM-induced changes in permeability. The conservative case is realized by adopting a conservative estimate of the coupled THM material properties. This includes a conservative estimate of the thermal expansion coefficient (leading to the maximum possible thermal stress) and a conservative estimate of the stress-versus-permeability function (leading to maximum possible permeability change). Thus, it is reasonable to use a homogeneous mean permeability for showing the difference between THM and TH analyses, which is the basis for conclusions drawn in this Model Report.

\subsubsection{Description of the Coupled THM Simulator}

The two computer codes, TOUGH2 V1.6 (LBNL 2003 [161491]) and FLAC3D V2.0 (LBNL 2001 [154783]), have been coupled for the analysis of coupled multiphase flow, heat transport, and rock deformations in fractured porous media (Rutqvist et al. 2002 [162048]). The TOUGH2 (Pruess et al. 1999 [160778]) code is designed for hydrological analysis of multiphase, multicomponent fluid and heat transport, while FLAC3D (Itasca Consulting Group 1997 [156788]) is designed for rock and soil mechanics. TOUGH2 has been successfully applied in the Yucca Mountain Project to predict the temperature and moisture distribution of field experiments, including the Single Heater Test (Tsang and Birkholzer 1999 [137577]) and the 
Drift Scale Test (DST) (BSC 2001 [157330], Sections 6.3.1, 6.3.2). TOUGH2 can simulate relevant coupled TH processes - including evaporation of liquid water to vapor with transfer of latent heat during boiling, advection of moisture and dissolved air with gas and liquid phase flow, heat convection with water transport, vapor diffusion, and condensation of vapor to liquid water upon cooling. With these capabilities, the TOUGH2 code can simulate the evolution of temperature and moisture around a repository drift, including the formation and resaturation of a dryout zone. FLAC3D has the capability to analyze coupled HM and TM responses of soil, rock, or other types of materials that may undergo plastic flow when their yield limit is reached. It contains various constitutive models suitable for mechanical analysis of geological materials. This includes Mohr-Coulomb elasto-plastic and ubiquitous joint models. Using appropriate mechanical constitutive models, it can simulate relevant rock mechanical aspects, including stress and strain redistribution and the possibility of rock-mass failure around a repository drift. In the present analysis, FLAC3D and TOUGH2 are coupled through external modules: one that calculates changes in effective stress as a function of multiphase pore pressure and thermal expansion, and one that corrects porosity, permeability, and capillary pressure as a function of stress (Figure 6.2-1). Because these coupling parameters are material-specific, specially designed coupling modules have been constructed and qualified for Yucca Mountain. The coupling modules are contained in qualified software routines tin V1.1 (LBNL 2002 [162038]), Delb.dat V1.0 (LBNL 2001 [154791]) and GPZones.dat V1.0 (LBNL 2001 [154792]), the functions of which are described in more detail below.

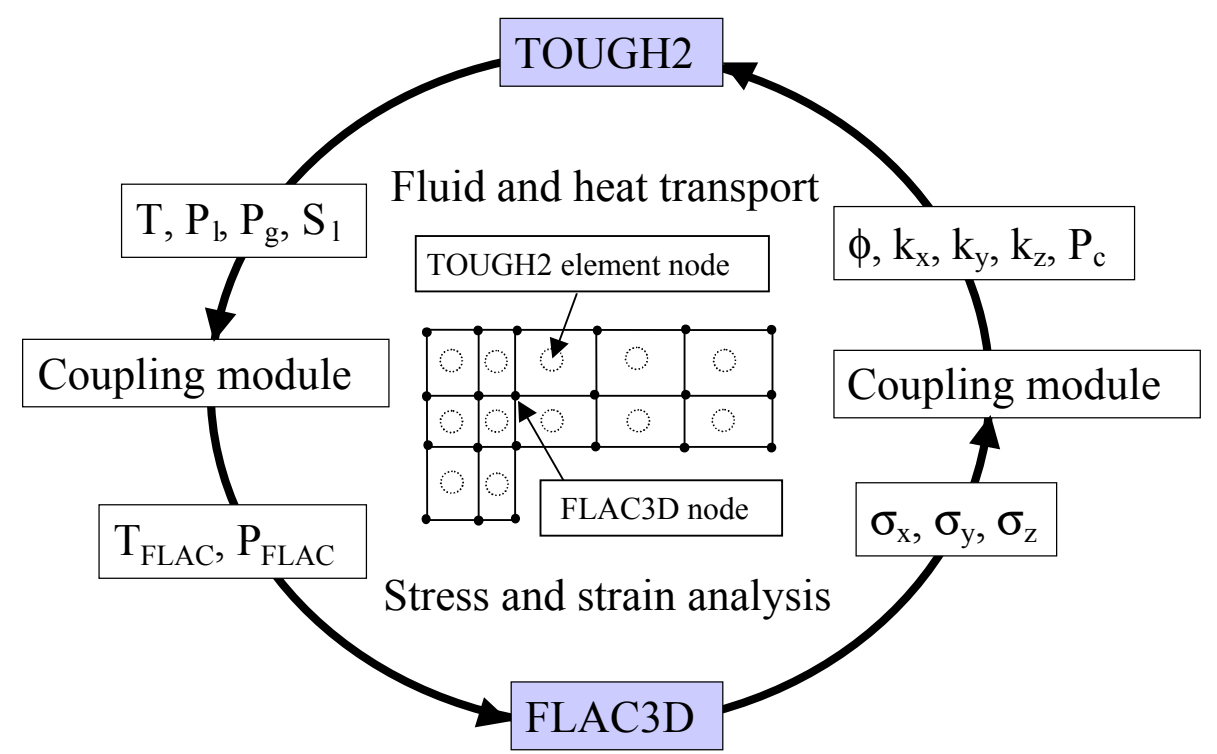

NOTE: $\mathrm{T}=$ Temperature, $\mathrm{P}_{\mathrm{I}}=$ liquid fluid pressure, $\mathrm{P}_{\mathrm{g}}=$ gas pressure, $\mathrm{T}_{\mathrm{Flac}}=$ temperature at FLAC3D node, $\mathrm{P}_{\mathrm{FLAC}}=$ pressure at FLAC3D node, $\phi=$ porosity, $\mathrm{k}_{\mathrm{x}}, \mathrm{k}_{\mathrm{y}}$, and $\mathrm{k}_{\mathrm{z}}$ are permeabilities in $\mathrm{x}, \mathrm{y}$, and $\mathrm{z}$-directions, respectively, $P_{c}$ is capillary pressure and $\sigma_{x}, \sigma_{y}$, and $\sigma_{x}$ are stresses in $x, y$, and z-directions, respectively. In the special case of Yucca Mountain, the illustrated transfer of multiphase fluid pressure from TOUGH2 to FLAC3D is not significant and therefore neglected. Only temperature has to be transferred from TOUGH2 to FLAC3D.

Figure 6.5.2-1. Schematic of Coupling between TOUGH2 and FLAC3D 


\subsubsection{Dual-Permeability Model for Analysis of THM Processes at Yucca Mountain}

The two main stratigraphic units in which the emplacement drifts may be located (middle nonlithophysal [Tptpmn] and the lower lithophysal [Tptpll] units of the Topopah Spring Tuff) are both highly fractured, and the fractures are well connected (BSC 2003 [163226], Section 6.3). In these rock units, three dominant sets of fractures are oriented almost orthogonal to each other (CRWMS M\&O 1998 [102679], Section 7.4.5), two subvertical and one subhorizontal, and the mean fracture spacing is on the order of or less than $0.4 \mathrm{~m}$ (BSC 2003 [162711], Tables IV-1, IV-2). Because of the high density and connectivity of the fracture network, the conceptual model used is a dual-permeability continuum model with interacting fractured and matrix continua consistent with the UZ flow model and other coupled analyses. The dual-permeability continuum model appropriately accounts for the difference in water retention between the fractures and matrix necessary to capture important fracture-matrix interaction processes such as matrix imbibition. Previous analyses of TM-induced displacements at two major heater tests at Yucca Mountain (the Single Heater Test [SHT and DST] have shown that mechanical deformations in the Tptpmn unit can be reasonably well captured with a linear-elastic or nonlinear-elastic mechanical model (Sobolik et al. 1998 [162049]; BSC 2001 [155957]; pp. 115125; Sobolik et al. 1999 [163202], p. 735). Furthermore, previous comparisons of the discretefracture approach and continuum approach for the modeling of mechanical displacements in the DST show only minor differences, indicating that the continuum approach is sufficiently accurate to represent in situ TM behavior at Yucca Mountain (BSC 2001 [155957], p. 125). This implies that the bulk-rock mass behavior is essentially elastic, although locally a small slip may occur on fracture planes. On the other hand, next to the wall of a repository drift, more significant inelastic shear slip or tensile fracturing may occur because of the strong stress redistribution and a lack of mechanical confinement in that region. Because the fractured porous medium is always in a static equilibrium, the three-dimensional stress is equivalent in the fracture and matrix continua. Therefore, the mechanical dual-continuum model reduces to a lumped fracture-matrix continuum model (equivalent continuum model). For fluid and heat transport, the dual continuum still exists, but with fracture and matrix continua that may not be in equilibrium and therefore can have different fluid pressure and temperature.

\subsubsection{TOUGH2 to FLAC3D Link for Yucca Mountain}

For modeling of the Yucca Mountain UZ, the linkage function from TOUGH2 to FLAC3D considers only thermally induced strain and stresses. The changes in effective stress caused by the multiphase fluid pressure and saturation changes are neglected. This is defensible considering that the fracture system is unsaturated, with a capillary pressure of less than $0.01 \mathrm{MPa}$. This is a very small pressure for a system that has in situ stresses and thermal stresses with magnitudes on the order of several to tens of MPa. Thus, the coupling module for the link from TOUGH2 to FLAC3D transfers the temperature field from TOUGH2 nodes to FLAC3D nodes. This coupling is provided by routine Tin V1.1 (LBNL 2002 [162038]) and with volume interpolation factors calculated by routine GPZones.dat V1.0 (LBNL 2001 [154792]). Both these qualified routines were developed in the FLAC3D FISH programming language. 


\subsubsection{FLAC3D to TOUGH2 Link for Yucca Mountain}

For Yucca Mountain, the linkage function between FLAC3D and TOUGH2 corrects hydrological properties for changes in the three-dimensional stress field, using a conceptual model of highly fractured rock shown in Figure 6.5.5-1. Although the fracture orientation in this cubic-block model is roughly consistent with common fracture orientations at Yucca Mountain, it is a simplified representation of the in situ fracture network. For example, in some rock units, the subhorizontal fracture set may be less frequent, and there may also be randomly oriented fractures. Furthermore, trace distributions of fractures mapped along ESF for the Tptpmn unit makes them discontinuous with fractures that frequently terminate against an intersecting fracture (BSC 2003 [162711], Section 6.1.4.1). However, the conceptual model shown in Figure $6.2-2 \mathrm{~b}$ is consistent with established hydrological and $\mathrm{TH}$ process models for the Yucca Mountain UZ. The hydrological properties of those models are largely derived directly from in situ permeability measurements and through model calibration against in situ hydrological data. The fracture density is used to derive parameters for the fracture-matrix interaction behavior, such as interface area and connection length between fracture elements and matrix blocks in the underlying conceptual model. Using this underlying conceptual model, the hydraulic properties, such as the water retention curve, are calibrated against field measurements. Thus, for deriving hydrological properties and for analysis of hydrological and $\mathrm{TH}$ processes in the Yucca Mountain UZ, detailed information on distribution of fracture length, orientation, and aperture are not explicitly incorporated, except for a generic value of mean fracture spacing for each rock unit. The underlying conceptual model for stress versus permeability coupling shown in Figure 6.5.5-1 is justified because it is consistent with the established hydrological models of the Yucca Mountain UZ. In these hydrological models, the permeability field is heterogeneous but isotropic, leading to an underlying conceptual model with equal fracture spacing and properties for vertical and horizontal fractures.

The conceptual model in Figure 6.5.5-1 is appropriate for estimating the impact of mechanical processes on the established hydrological models at Yucca Mountain. This is because it can capture all relevant THM processes observed at several in situ experiments conduced at Yucca Mountain (BSC 2003 [164890], Section 7). The simplified conceptual model can capture relevant THM processes because the rock at Yucca Mountain is highly fractured, forming a network that is well connected for fluid flow. This conceptual model may not be generally acceptable for all types of fractured rock (for example, at sparsely fracture rock sites where fluid flow is dominated by a few discrete conducting fractures). Thus, the conceptual model is selected specifically for Yucca Mountain based on field evidence of intense fracturing and a well-connected fracture network. For the main repository units, Tptpmn and Tptpll, a mean fracture spacing of less than 0.4 has been derived, using mappings of fractures with a trace length larger then a meter (DTN: LB0205REVUZPRP.001 [159525]). However, as pointed out in the Drift Degradation Analysis (BSC 2003 [162711], Section 6.1.4.1), 80\% of the fractures have a trace length of less than one meter, and therefore, counting all fractures, the fracture spacing should be less than $0.4 \mathrm{~m}$. The concept of a well-connected fracture network for fluid flow is confirmed by air-permeability measurements conducted at Yucca Mountain boreholes with short (1 foot) packer intervals at several excavated niches (BSC 2001 [158463], Section 6.1). In these tests, the permeability at each $0.3 \mathrm{~m}$ interval of the boreholes is several orders larger than the matrix permeability, indicating that at least one hydraulic conductive fracture 
intersects every $0.3 \mathrm{~m}$ and is connected to a network of hydraulic conducting fractures. For such intensely fractured rock, the detailed fracture geometry does not impact the coupled THM behavior significantly, and hence, the adopted conceptual model is appropriate.

Using the conceptual model in Figure $6.5 .5-1$, the porosity, $\phi$, permeability, $k$, and capillary pressure, $P_{c}$ in the fractured continuum are corrected for any change in the stress field according to:

$$
\begin{gathered}
\phi=F_{\phi} \times \phi_{i} \\
k_{x}=F_{k x} \times k_{i x}, k_{y}=F_{k y} \times k_{i y}, k_{z}=F_{k z} \times k_{i z} \\
P_{c}=F_{P c} \times P_{c i}
\end{gathered}
$$

where $F$ denotes various correction factors and subscript $i$ denotes initial conditions. Porosity and permeability correction factors are calculated from the initial and current apertures, $b$, in Fracture Sets 1, 2, and 3, according to:

$$
\begin{gathered}
F_{\phi}=\frac{b_{1}+b_{2}+b_{3}}{b_{1 i}+b_{2 i}+b_{3 i}} \\
F_{k x}=\frac{b_{2}^{3}+b_{3}^{3}}{b_{2 i}^{3}+b_{3 i}^{3}}, F_{k y}=\frac{b_{1}^{3}+b_{3}^{3}}{b_{1 i}^{3}+b_{3 i}^{3}}, F_{k z}=\frac{b_{1}^{3}+b_{2}^{3}}{b_{1 i}^{3}+b_{2 i}^{3}}
\end{gathered}
$$

where fractures in Fracture Sets 1, 2, and 3 are equally spaced and oriented normal to $\mathrm{x}, \mathrm{y}$, and $\mathrm{z}$ directions, respectively, and a parallel-plate fracture flow model (Witherspoon et al. 1980 [123506]) is adopted. The capillary pressure is corrected with porosity and permeability changes according to the Leverett (1941 [100588]) function:

$$
F_{P c}=\sqrt{\frac{F_{\phi}}{F_{k}}}
$$

where

$$
F_{k}=\sqrt[3]{F_{k x} \times F_{k y} \times F_{k z}}
$$

In this study, the current fracture aperture $b$ depends on the current effective normal stress $\sigma_{n}^{\prime}$, according to the following exponential function (Rutqvist and Tsang 2003 [162584]):

$$
b=b_{r}+b_{m}=b_{r}+b_{\max }\left[\exp \left(\alpha \sigma_{n}^{\prime}\right)\right]
$$

where $b_{r}$ is a residual aperture, $b_{m}$ is mechanical aperture, $b_{\max }$ is the maximum mechanical aperture, and $\alpha$ is a parameter related to the curvature of the function (Figure 6.5.5-2). This 
relationship can also be expressed in terms of an initial aperture, $b_{i}$, and changes in aperture, $\Delta b$, as:

$$
b=b_{i}+\Delta b=b_{i}+b_{\max }\left[\exp \left(\alpha \sigma_{n}\right)-\exp \left(\alpha \sigma_{n i}\right)\right]
$$

where $\sigma_{n i}$ is the initial stress normal to the fractures. This expression can be inserted into Equation (6.5.5-5) to derive expressions for rock-mass permeability-correction factors in $\mathrm{x}, \mathrm{y}$, and $\mathrm{z}$ directions. In this formulation, the permeability changes as a function of normal stress across each fracture set, while no shear-induced permeability changes are considered. It is expected to be sufficient because closure of vertical fractures caused by thermally induced horizontal stresses are expected to have a dominating impact on the permeability changes. Furthermore, the potential for shear-induced permeability changes can be evaluated indirectly from the results of the stress analysis. The calculation of fracture aperture changes is conducted in the qualified software routine Delb.dat V1.0 (LBNL 2001 [154791]), which is then transferred into the TOUGH2 code for the correction of hydrological properties.

The most important parameter for estimating stress-induced changes in hydraulic properties is the relationship between fracture aperture and stress, defined in Equation 6.5.5-8. For a wellconnected fracture network, fracture spacing and fracture orientation have little importance on the stress-versus-permeability relationship in comparison with the fracture-aperture-versus-stress function. The relationship between fracture hydraulic aperture and stress has been determined both in laboratory samples and in the field for various types of rock. This relationship depends on fracture characteristics such as roughness and degree of mineral filling. However, apertureversus-normal stress relationships derived from small-scale laboratory samples are generally not applicable in the field. The effect of size on the permeability and normal stiffness of fractures has been confirmed in both theoretical and experimental studies (Rutqvist and Stephansson 2003 [162583], p.15). Because of potential effects of size and nonrepresentative sampling, it is important to determine the stress-versus-aperture relationship in situ (Rutqvist and Stephansson 2003 [162583], p. 7). Such in situ determination seeks to determine the basic parameters $b_{\max }$ and $\alpha$ for fractures in the underlying conceptual model. The determination of the stress-versusaperture relationship for mountain scale is further discussed in Section 6.5.9. 


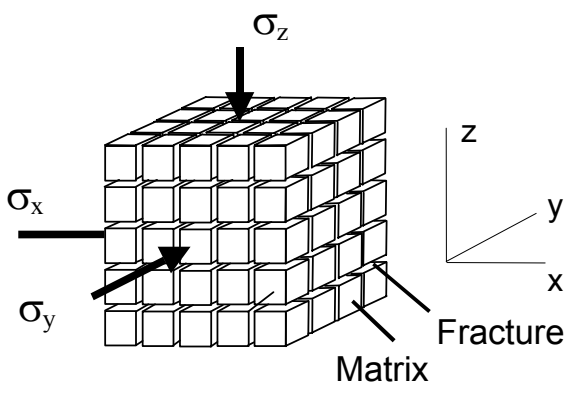

$$
\begin{aligned}
& \mathrm{k}_{\mathrm{x}}=\mathrm{k}_{\mathrm{x}}\left(\sigma_{\mathrm{y}}, \sigma_{\mathrm{z}}\right) \\
& \mathrm{k}_{\mathrm{y}}=\mathrm{k}_{\mathrm{y}}\left(\sigma_{\mathrm{x}}, \sigma_{\mathrm{z}}\right) \\
& \mathrm{k}_{\mathrm{z}}=\mathrm{k}_{\mathrm{z}}\left(\sigma_{\mathrm{x}}, \sigma_{\mathrm{y}}\right)
\end{aligned}
$$

NOTE: $\sigma_{x}, \sigma_{y}, \sigma_{x}$ and $k_{x}, k_{y}, k_{z}$ are stresses and permeabilities in $x, y$ and z-directions, respectively.

Figure 6.5.5-1. Conceptual Model Used for Calculation of Stress-Induced Changes in Hydraulic Properties

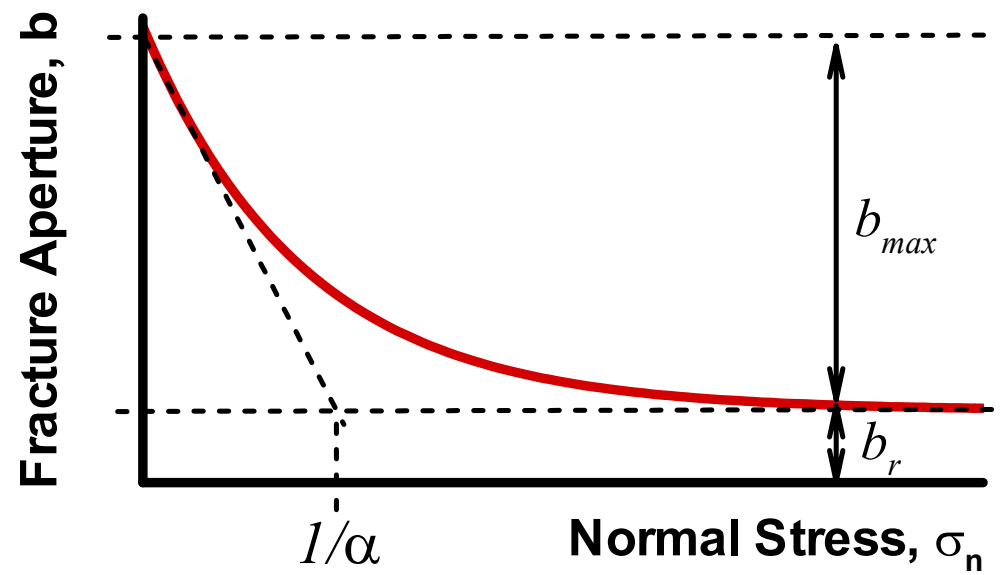

NOTE: $b_{\max }$ and $\alpha$ are parameters that determines the shape of the exponential function and $b_{r}$ is the residual aperture when the fracture is completely compressed from mechanical point of view at a high normal stress.

Figure 6.5.5-2. Schematic for Normal Stress vs. Aperture Relation

\subsubsection{Coupled THM Model Domain}

The Mountain-Scale THM Model is a vertical two-dimensional cross section extending from the ground surface down to the groundwater table (Figure 6.5.6-1). The model domain is designed by first taking a multiple-layered column extending vertically from the ground surface down to the water table. The vertical layering for the model is chosen to correspond to the vertical contacts at the Nevada State Plane Coordinates $170600 \mathrm{~m}$ (Easting) and $234017 \mathrm{~m}$ (Northing), near the center of the repository. (See Figure 6.1-1 for location in the 3D grid.) The geological data are derived from the "b58"column of the two-dimensional Yucca Mountain UZ model grid (DTN: LB030432DGRIDS.001 [163937], file mesh-ns.vf). The layers are extended horizontally 
to form a two-dimensional section that runs North-South along the UZ two-dimensional TH model (See Figure 6.1-1 for location of the two-dimensional section). The model is halfsymmetric, containing 21.5 waste emplacement drifts located at a depth of about $384 \mathrm{~m}(1065 \mathrm{~m}$ elevation) in the in the Tptpll unit. The current drift configuration, as given in Repository Design Drawing 800-IED-EBS0-00201-000-00A (BSC 2003 [164069], Repository Design Project, Repository/PA IED Emplacement Drift Configuration 1 of 2), calls for a drift diameter of $5.5 \mathrm{~m}$ and a drift spacing of $81 \mathrm{~m}$. However, along the two-dimensional section, the emplacement drifts are $85 \mathrm{~m}$ apart (because the two-dimensional model section is not exactly normal to the drift axes). The repository is represented by elements $5 \mathrm{~m}$ high and $5 \mathrm{~m}$ wide. In between the emplacements drifts, the distance is $80 \mathrm{~m}$ and elements with sizes of $5,10,25,25,10,5 \mathrm{~m}$ were used in these regions.

The boundary conditions applied to the Mountain-Scale THM Model and numerical values of domain are given in Figure 6.5.6-1a. The left boundary is closed to heat and fluid flow by symmetry and is allowed zero normal displacement mechanically (i.e., "on rollers"). The right boundary is set at a distance of $5 \mathrm{~km}$ from the right edge of the repository. At this boundary, a constant stress is maintained with a gradient according to Assumption 1 in Section 5.3, and no heat or fluid flow can cross it. The ground surface boundary was set at a constant temperature and atmospheric pressure, mechanically free, and the water-table boundary was set at constant temperature and mechanically fixed (Figure 6.5.6-1a and Table 6.5.6-1). The specific values of temperature, pressure, and saturation at the top and bottom boundary were extracted from column "b58" of the two-dimensional Yucca Mountain UZ model grid (DTN: LB030432DGRIDS.001 [163937], file incon_th_2d.dat). The pre-emplacement ambient thermal and hydrological conditions are derived by running a TH model to steady state, using the prescribed boundary conditions at the ground surface and the present-day infiltration rate of about $6 \mathrm{~mm} /$ year $(5.8043 \mathrm{~mm} /$ year according to Table 6.5.6-1). The infiltration rates for present-day, monsoon, and glaciating in the Mountain-Scale THM Model are the mean infiltration rates over the North-South 2-D TH model sections used in Section 6.2 (Table 6.5.61). Thus the mean infiltration rates used in the mountain-scale THM model simulation are consistent with mean infiltration rates of the mountain-scale TH model simulation in Section 6.2.

The initial stress field represents the best estimate of the stress field at the repository horizon (See Section 5.3, Assumption 1). The initial vertical stress is estimated based on the weight of the overburden rock mass, with an average saturated bulk rock density of $2,200 \mathrm{~kg} / \mathrm{m}^{3}$. This is the average value of the bulk rock density calculated for the rock mass overlying the repository drifts, using values of saturated rock densities given in 1999 TBV-332/TBD 325 Resolution Analysis: Geotechnical Rock Properties, Table 9 (DTN: MO9911SEPGRP34.000 [148524]). The magnitude of maximum and minimum principal compressive horizontal stresses are estimated to be a factor of about 0.6 (ranging $0.3-1.0$ ) and 0.5 (ranging 0.3 to 0.8 ) of the vertical stress, with the maximum stress oriented N32E (CRWMS M\&O 1997 [103564], Table 3-2, p. 323 ). Thus, the magnitude of the horizontal stresses are about $50 \%$ of the vertical and are nearly isotropic in the horizontal plane. The adopted initial stress field in this model simulation is shown in Figure 6.5.6-1 (See also Section 5.3 Assumption 1). The values of the horizontal stresses are within the range of those estimated in CRWMS M\&O (1997 [103564], Table 3-2, p. 3-23). This estimate of the initial stress is considered sufficiently accurate because this Model 
Report concerns itself with thermally induced stresses, which are largely independent of the initial stress field.

For all TH and THM simulations over the 10,000 year licensing period, a varying infiltration rate was applied at the ground surface according to the mean infiltration scenario described in AMR Simulation of Net Infiltration for Modern and Potential Future Climate (USGS 2001 [160355], Sections 6.9 and 6.11). In the Mountain-Scale THM Model, an average infiltration rate is applied uniformly over the two-dimensional section with the values given in Table 6.5.6-1. These are average values used in Section 6.2.

The thermal load is imposed on the 21.5 drift elements located along the 1,785 $\mathrm{m}$ long repository, at level $1,065 \mathrm{~m}$ in the Tptpll unit (the lower lithophysal unit of the Topopah Spring welded tuff). The half drift is located at the mid symmetry line on the left side of the model. The thermal line load of $1.45 \mathrm{~kW} / \mathrm{m}$ (initial heat power) and the 50 -year ventilation period with $86.3 \%$ ventilation efficiency is described in Section 6.1.5 of this Model Report. As modeled, emplacement of all waste occurs at once, followed by the 50 -year ventilation period. The condition that emplacement of all waste occurs at once provides a conservative case for estimating the impact of THM processes, because it leads to the highest possible heat load and therefore the highest possible thermal stress. 
Table 6.5.6-1. THM Model Boundary Conditions

\begin{tabular}{|c|c|c|}
\hline Boundary & Boundary Condition ${ }^{1}$ & Reference \\
\hline $\begin{array}{l}\text { Top of model domain, } \\
\text { which represents the } \\
\text { conditions at the ground } \\
\text { surface }\end{array}$ & $\begin{array}{l}\mathrm{T}=16.05^{\circ} \mathrm{C} \\
\mathrm{S}_{\mathrm{l}}=0.01 \\
\mathrm{P}=84089 \mathrm{~Pa} \\
\text { Infiltration rate: } \\
5.8043 \mathrm{~mm} / \text { year } 0-600 \text { years } \\
16.9535 \mathrm{~mm} / \text { year } 600-2000 \text { years } \\
28.8198 \mathrm{~mm} / \text { year }>2000 \text { years }\end{array}$ & $\begin{array}{l}\text { T, S, and P from } \\
\text { LB030432DGRIDS.001 [163937] file } \\
\text { incon_th_2d.dat column "b58" and } \\
\text { infiltration rates from DTN: } \\
\text { LB0310MTSCLTH2.001; files } \\
\text { GENER_PRESENT_VENT_0.863.2D } \\
\text { GENER_MONS_VENT_0.863.2D } \\
\text { GENER_GLACIAL_VENT_0.863.2D }\end{array}$ \\
\hline $\begin{array}{l}\text { Bottom of model } \\
\text { domain, which } \\
\text { represents the } \\
\text { conditions at the } \\
\text { groundwater table }\end{array}$ & $\begin{array}{l}\mathrm{T}=31.37^{\circ} \mathrm{C} \\
\mathrm{S}_{1}=0.99999 \\
\mathrm{P}=92000 \mathrm{~Pa}\end{array}$ & $\begin{array}{l}\text { T, S }, \text { and P from } \\
\text { LB030432DGRIDS.001 [163937] file } \\
\text { incon_th_2d.dat column "b58" }\end{array}$ \\
\hline $\begin{array}{l}\text { Waste package thermal } \\
\text { load }\end{array}$ & $\begin{array}{l}\text { Initial heat of } 1.45 \mathrm{~kW} / \mathrm{m} \\
\text { decreasing with time (due to } \\
\text { radioactive decay), and reduced } \\
\text { by } 86.3 \% \text { during the first } 50 \text { years } \\
\text { (due to removal by ventilation, see } \\
\text { Section } 6.1 .5 \text { ) }\end{array}$ & $\begin{array}{l}\text { Heat load: } \\
\text { 800-IED-EBS0-00201-000-00A (BSC } \\
\text { 2003 [164069]) } \\
\text { Thermal decay function: } \\
\text { DWG-MGR-MD-000003 (BSC } 2002 \\
\text { [159527]) } \\
\text { Ventilation efficiency: } \\
\text { BSC } 2003 \text { [166343], Section } 8.1\end{array}$ \\
\hline
\end{tabular}

NOTES: $1 \quad \mathrm{~T}=$ Temperature, $\mathrm{S}_{\mathrm{I}}=$ liquid saturation, $\mathrm{P}=$ pressure

2 The time-dependent thermal-line-load values used in the Mountain-Scale THM Model are from repository design drawing (BSC 2002 [159527]), which was superseded by BSC (2003 [164136]) during the writing of this report. These two decay curves are within $1 \%$ of each other and the heat output is slightly greater in BSC (2002 [159527]) than in (2003 [164136]), so use of the older decay curve is slightly conservative. 


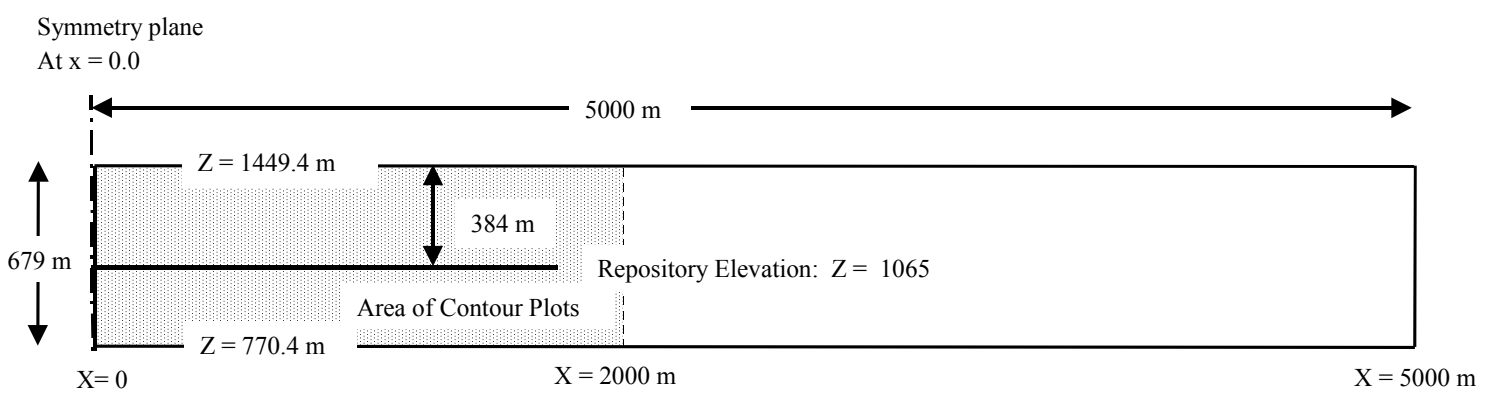

(a) Model Domain

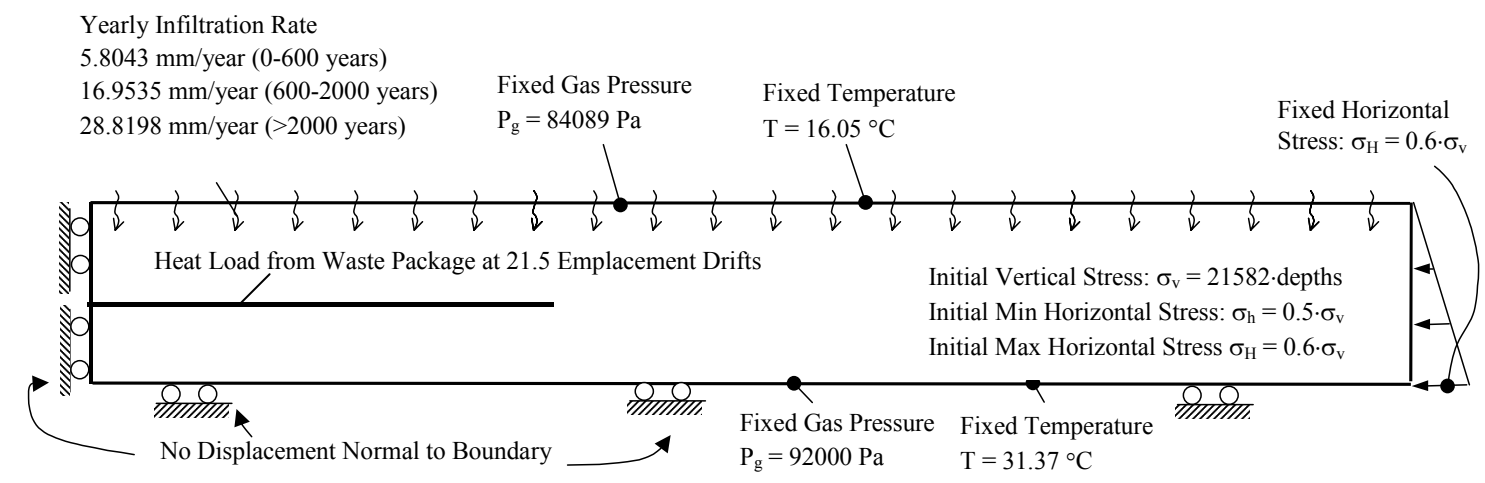

(b) Boundary and Initial Conditions

Figure 6.5.6-1. Domain and Boundary Conditions for the Mountain-Scale THM Model

\subsubsection{TH Rock Properties}

The thermal and hydrological properties used in the Mountain-Scale THM Model and their sources are the same as properties used for the mountain-scale TH analysis in Section 6.1.

\subsubsection{Mechanical Rock Properties}

The mechanical rock-mass properties used for the Mountain-Scale THM Model are identical with the ones used for the Drift-Scale THM Model (BSC 2003 [164890], Section 4.1.1.1). They are extracted from the qualified data set in the 1999 TBV-332/TBD 325 Resolution Analysis: Geotechnical Rock Properties (DTN: MO9911SEPGRP34.000 [148524], Tables 10 and 11) for $40 \%$ cumulative frequency. A Young's Modulus of $14.77 \mathrm{GPa}$ and Poisson's Ratio of 0.21 are extracted for TSw2 TM Unit (Tptpmn and Tptpll lithostratigraphic units). A Young's modulus of 14.77 GPa for the Tptpll unit closely represents a Young's modulus of Category 4 rock type in Drift Degradation Analysis (BSC 2003 [162711], Table 34). These elastic parameters, which represent the bulk rock mass (including the effect of fractures), have been estimated using an empirical method based on the Geological Strength Index. The adopted rock-mass Young's modulus for the rock in the repository units (Tptpmn and Tptpll) is about 50\% lower than the Young's modulus of intact rock determined on core samples from the site. Assumptions 2 and 3 in Section 5.3 justify the choice of mechanical properties for TSw3 and CHn TM units located 
below the repository drift. The elastic properties of the $\mathrm{CHn}$ are taken from measurements on intact core samples (DTN: MO9911SEPGRP34.000 [148524], Table 8), according to Approximation 3 in Section 6.5.1.

\subsubsection{Coupled TM and HM Rock Properties}

TM and HM properties of the rock mass were developed within the Model Report entitled DriftScale THM Model (BSC 2003 [164890], Section 6.4) and was validated in Section 7 of that report specifically through comparison of simulated and measured THM responses at the Yucca Mountain Drift Scale Test (DST). As described in Section 6.5.1 of this report, to assess the impact of the THM processes on the flow field, it is sufficient to calculate changes in the mean value of the permeability for a conservative case of relatively strong THM-induced changes in permeability. The conservative case is realized by adopting a conservative estimate of the coupled TM and HM material properties. This includes a thermal expansion coefficient that leads to the maximum possible thermal stress and a stress-versus-permeability function that leads to maximum-possible permeability change. However, because the TM and HM properties were developed for the drift scale, a scale dependency is considered when applying these properties for the mountain scale.

The temperature-dependent thermal expansion coefficient adopted for the Mountain-Scale THM Model was derived from laboratory measurements on intact rock samples as presented in DriftScale THM Model (BSC 2003 [164890]), Figure 6.4-1 as:

$$
\alpha_{T}=5+0.0583 \cdot T\left(10^{-6} /{ }^{\circ} \mathrm{C}\right)
$$

As noted in BSC (2003 [164890] Section 6.4), the thermal expansion coefficient in the field could theoretically be equal to or lower than the intact value because of the presence of fractures. However, analysis of the MPBX displacements at the DST by Sobolik et al. (1999 [163202], p. 741), BSC (2001 [155957], pp. 21 and 115-125), and BSC (2003 [164890], Section 7.4.2) have shown that the displacements are well predicted if an intact-rock thermal expansion coefficient is used. Adopting a thermal expansion coefficient that represents the intact rock values is considered a conservative estimate, because it leads to the highest possible thermally induced stress. This is because the intact rock value is the upper bound of the possible in situ thermal expansion coefficient. Figure 6.4-1 in BSC (2003 [164890]) shows that the adopted function closely represents intact-rock thermal expansion coefficients for various rock units at Yucca Mountain. Therefore, the linear function defined in Equation 6.5.9-1 is adopted for all rock units in the Mountain-Scale THM Model.

In this Model Report, the stress-permeability relationship derived for the Drift-Scale THM Model is applied to the Mountain-Scale THM Model, with corrections for possible scale effects. The parameters in the stress-aperture function (Equation 6.5.5-9) were estimated in the DriftScale THM Model report (BSC 2003 [164890], Section 6.4) through model calibration against air-permeability measurements conducted at several field experiments at Yucca Mountain. As noted in BSC (2003 [164890], Section 6.4), it is essential that $b_{\max }$ and $\alpha$ be determined in situ, at a relevant scale, because of the potential size dependency of the coupled HM properties of rock fractures (Rutqvist and Stephansson 2003 [162583], p. 15). Also, as noted in Section 7.10 of the 
Drift-Scale THM Model report (BSC 2003 [164890]), the thermal and mechanical properties at Yucca Mountain show little or no size dependency at meter size and larger. Hydraulic properties, on the other hand, have been shown to be dependent on the measurement scale (BSC 2003 [161773], Section 6.1.1.1). At Yucca Mountain, mountain scale calibrated fracture permeability is generally one to two orders of magnitude higher than drift-scale calibrated fracture permeability (BSC 2003 [160240], Sections 6.3.2 and 6.3.3). Specific values of drift-scale and mountain-scale fracture permeability values are given in Table 6.5.9-1. The associated aperture, $b$, is calculated from the mean fracture frequency, $f$, and the isotropic initial permeability, for an ideal cubic block model, leading to the formula:

$$
b=\sqrt[3]{6 \times k / f}
$$

In this Model Report, two methods are investigated for upscaling of drift-scale stress versus permeability function to that of the mountain-scale. The two methods were developed as part of an ongoing effort in the international cooperative project DECOVALEX (acronym for DEvelopment of COupled models and their VALidation against EXperiments in nuclear waste isolation). In the DECOVALEX project, the TOUGH2-FLAC3D simulator is applied in a benchmark test to the upscaling of THM properties at Sellafield, UK. The rock at Sellafield consists of welded tuff, a similar type of rock to the repository units at Yucca Mountain. The upscaling strategy adopted in this Model Report is the one used for the DECOVALEX project as described by Liu et al. (2003 [166017]).

In the first method of upscaling, Method 1, the parameters $b_{\max }$ and $\alpha$ are kept the same as at the drift scale, whereas the initial aperture $b_{i}$ (and hence the residual aperture $b_{r}$ ) is increased as a result of the higher initial permeability at mountain scale. The initial aperture for all rock units is calculated from Equation (6.5.9-2). In the second method, Method 2, the parameters $b_{\max }, b_{i}$, and $b_{r}$ are increased proportionally. The mountain-scale parameters are calculated based on Equation (6.5.9-2), leading to the following relationships:

$$
\frac{b_{\max }}{b_{\max }^{d}}=\frac{b_{r}}{b_{r}^{d}}=\frac{b_{i}}{b_{i}^{d}}=\left(\frac{k}{k^{d}}\right)^{1 / 3}
$$

where superscript $d$ denotes drift-scale parameters (note that no superscript indicates mountainscale parameters). Because all aperture parameters $b_{\max }, b_{r}$ and $b_{i}$ are increased proportionally, the parameter $\alpha$ becomes independent of scale and hence $\alpha=\alpha^{d}$. Given the mountain-scale and drift-scale fracture permeability, the ratio $\mathrm{k} / \mathrm{k}^{\mathrm{d}}$ is found to be 1.9 for both the Tptpmn and Tptpll units (Table 6.5.9-1). Therefore, the parameter $b_{\max }$ is upscaled by a factor 1.9. The resulting parameters for Tptpmn and Tptpll units are given in Table 6.5.9-1.

Arguments can be made for both Method 1 and 2. Method 1 agrees with the general observations at the niche excavation tests that for larger initial permeability, the permeability changes less upon excavation (BSC 2003 [164890], Figure 7.5-1). This essentially signifies that the hydraulic permeability (as represented by the initial aperture $b_{i}$ ) increases with size while mechanical "stiffness" of the fractures (as represented by the parameters $b_{\max }$ and $\alpha$ ) does not change from drift scale to that of mountain scale. This is in agreement with observations from other fractured 
rock sites, which indicate that permeable, highly conductive fracture zones are generally less sensitive to stress than zones of more competent rock (Rutqvist and Stephansson 2003 [162583]). The logic behind Method 2 is that large-scale fracture flow may be dominated by the largest and most open fractures, which may also be the roughest. As such, the residual aperture, $b_{r}$, and the maximum closure parameter, $b_{\max }$ (both of which may be a function of roughness), should increase proportionally to the increase in the initial aperture $b_{i}$.

Methods 1 and 2 reflect two extremes, with Method 2 giving the most sensitive stress-versuspermeability relationship at the mountain scale. Because Method 2 gives the most sensitive stress-versus-permeability relationship, it is the most conservative choice for investigation of the maximum possible impact of coupled THM processes in the mountain scale. Therefore, the parameters developed using Method 2 is adopted for further analysis and modeling in the Mountain-Scale THM Model.

Table 6.5.9-1. Summary of HM Parameters Developed in the Model Report

\begin{tabular}{|c|c|c|c|c|}
\hline & Geol. Unit > & Tptpmn & TptpII & Source \\
\hline $\begin{array}{l}\text { Drift-scale fracture } \\
\text { permeability }\end{array}$ & $k^{d}\left(\mathrm{~m}^{2}\right)$ & $0.3311 \cdot 10^{-12}$ & $0.9120 \cdot 10^{-12}$ & $\begin{array}{l}\text { Table 6.4-1 in Drift-Scale } \\
\text { THM Model Report (BSC } \\
2003[164890]) .\end{array}$ \\
\hline $\begin{array}{l}\text { Drift-scale maximum joint } \\
\text { closure }\end{array}$ & $b_{\text {max }}^{d}(\mu \mathrm{m})$ & 200 & 200 & $\begin{array}{l}\text { Table 6.4-1 in Drift-Scale } \\
\text { THM Model Report (BSC } \\
2003[164890]) .\end{array}$ \\
\hline Drift-scale exponent $\alpha$ & $\alpha^{d}(1 / \mathrm{Pa})$ & $5.2 \mathrm{E}-7$ & $5.2 \mathrm{E}-7$ & $\begin{array}{l}\text { Table 6.4-1 in Drift-Scale } \\
\text { THM Model Report (BSC } \\
2003[164890]) .\end{array}$ \\
\hline $\begin{array}{l}\text { Mountain-scale } \\
\text { permeability }\end{array}$ & $k\left(\mathrm{~m}^{2}\right)$ & $0.221 \times 10^{-11}$ & $0.608 \times 10^{-11}$ & $\begin{array}{l}\text { LB03013DSSCP3I.001 } \\
\text { [162379] }\end{array}$ \\
\hline Ratio of $k / k^{d}$ & & 1.9 & 1.9 & $\begin{array}{l}\text { Calculated based on values } \\
\text { of } k \text { and } k^{d} \text { given in this } \\
\text { table }\end{array}$ \\
\hline $\begin{array}{l}\text { Maximum joint closure for } \\
\text { upscaling method } 1\end{array}$ & $b_{\max }(\mu \mathrm{m})$ & 200 & 200 & Equal to $b^{d}{ }_{\text {max }}$ \\
\hline $\begin{array}{l}\text { Maximum joint closure for } \\
\text { upscaling method } 2\end{array}$ & $b_{\max }(\mu \mathrm{m})$ & 380 & 380 & $\begin{array}{l}\text { Calculated using Equation } \\
(6.5 .9-3)\end{array}$ \\
\hline $\begin{array}{l}\text { Mountain-scale exponent } \\
\text { for } \alpha \text { for both upscaling } \\
\text { methods } 1 \text { and } 2\end{array}$ & $\alpha(1 / \mathrm{Pa})$ & 5.2E-7 & $5.2 \mathrm{E}-7$ & Equal to $\alpha^{d}$ \\
\hline
\end{tabular}

\subsubsection{Evolution of Temperature at Yucca Mountain}

Figures 6.5.10-1 and 6.5.10-2 present calculated temperature evolution (see Section IV.4 of Attachment IV for details on post processing and plotting of the THM model results). Figure 6.5.10-1 shows that after emplacement of the waste in the excavated drift, the temperature in the drift wall rises rapidly and peaks at about 90 years, a few tens of years after the end of the forced ventilation period. The simulated temperature in the rock mass away from the drift continues to rise, and the mid-pillar temperature peaks at about $89^{\circ} \mathrm{C}$ after 900 years (see location of midpillar in Figure 6.5.3-1a). The temperature evolution shown in Figure 6.5.10-1 is consistent with 
the calculated temperature evolution in the Drift-Scale THM model (BSC 2003 [164890], Figure 6.5.2-1). Figure 6.5.10-2 shows that, although the temperature near emplacement drifts peaks at about 100 years after emplacement, the maximum average temperature at the repository level occurs at about 1,000 years. This is the time when the maximum impact of THM-induced changes in hydraulic properties and the flow field are expected to occur. After about 1,000 years, a general decline in temperature at the repository level takes place. At the same time, the thermal gradient around the repository becomes smaller with the declining temperature difference between the drift wall and the mid-pillar. However, at 10,000 years, the temperature is above $50^{\circ} \mathrm{C}$ at the repository level, which is still significantly higher than the initial temperature of $24^{\circ} \mathrm{C}$.

Figure 6.5.10-3 presents a comparison temperature profiles at the repository level for $\mathrm{TH}$ and THM models. The figure shows that the temperature evolution and peak temperature is almost identical for TH (red solid line) and THM models (blue dashed line). Thus, the THM coupling does not impact the evolution of temperature.
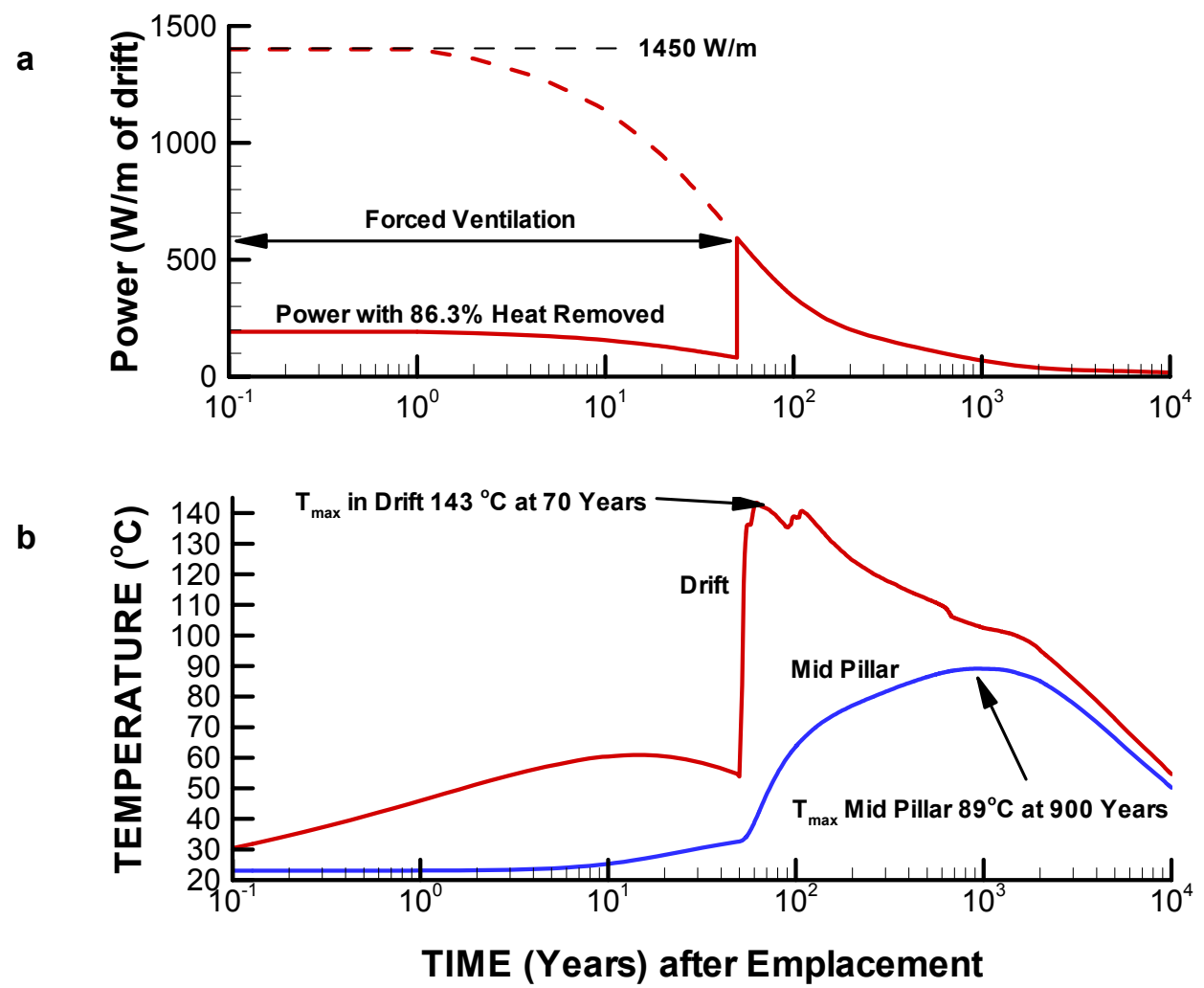

DTN: LB0310MTSCLTHM.002

NOTE: Mid-pillar is a point located at the mid-distance between neighboring repository drifts. Waste packages are emplaced at time for the entire repository.

Figure 6.5.10-1. Calculated Evolution of Thermal Power from Waste Package (a) and Temperature at Two Points on the Level of the Emplacement Drifts (b) 


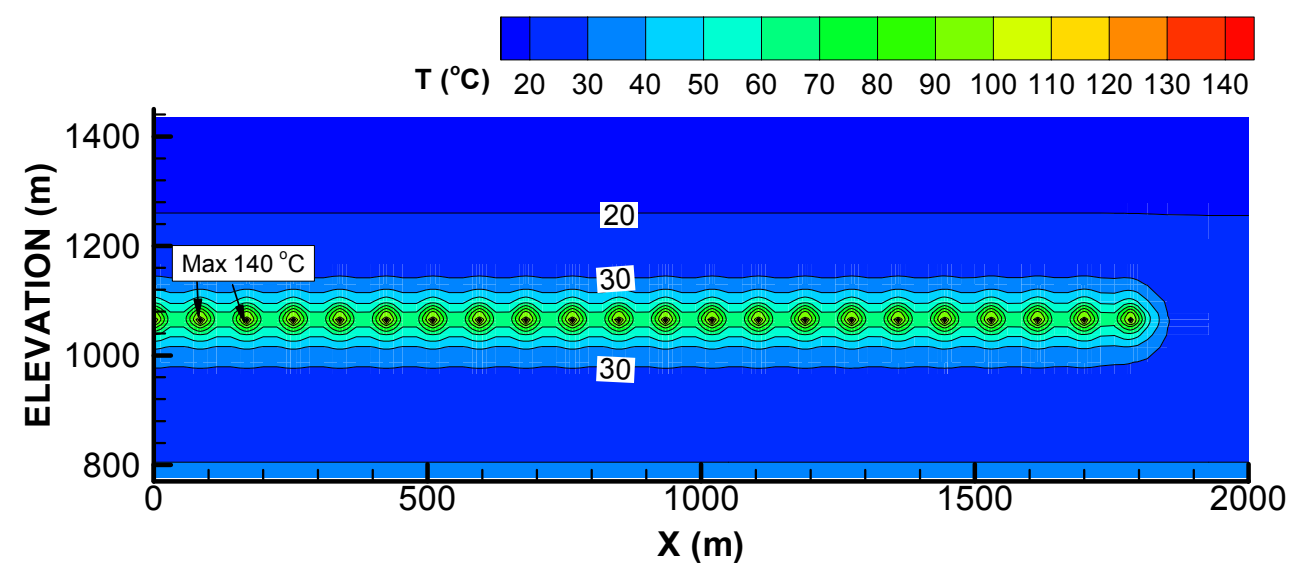

(a) 100 Years

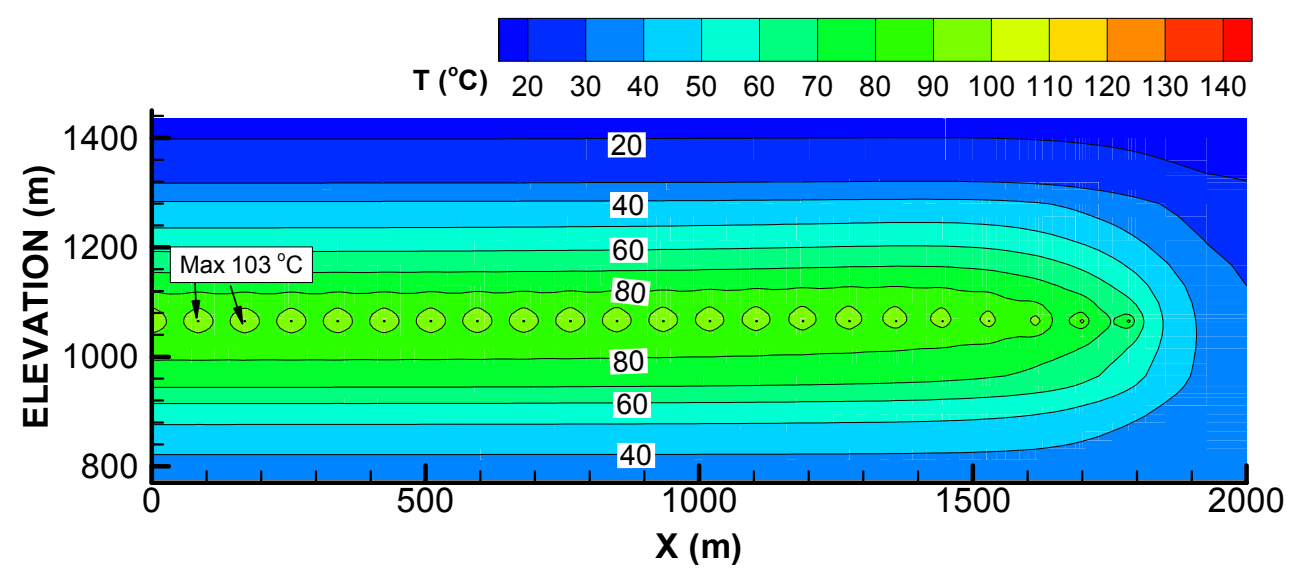

(b) 1,000 Years

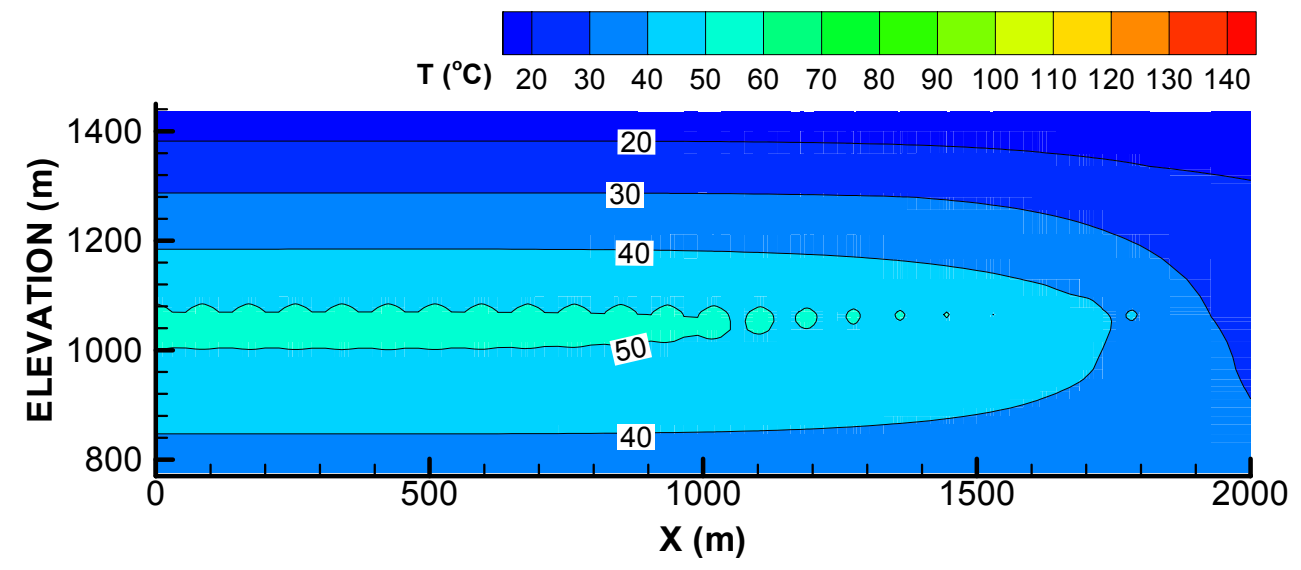

(c) 10,000 Years

DTN: LB0310MTSCLTHM.002

Figure 6.5.10-2. Calculated Temperature Distribution 


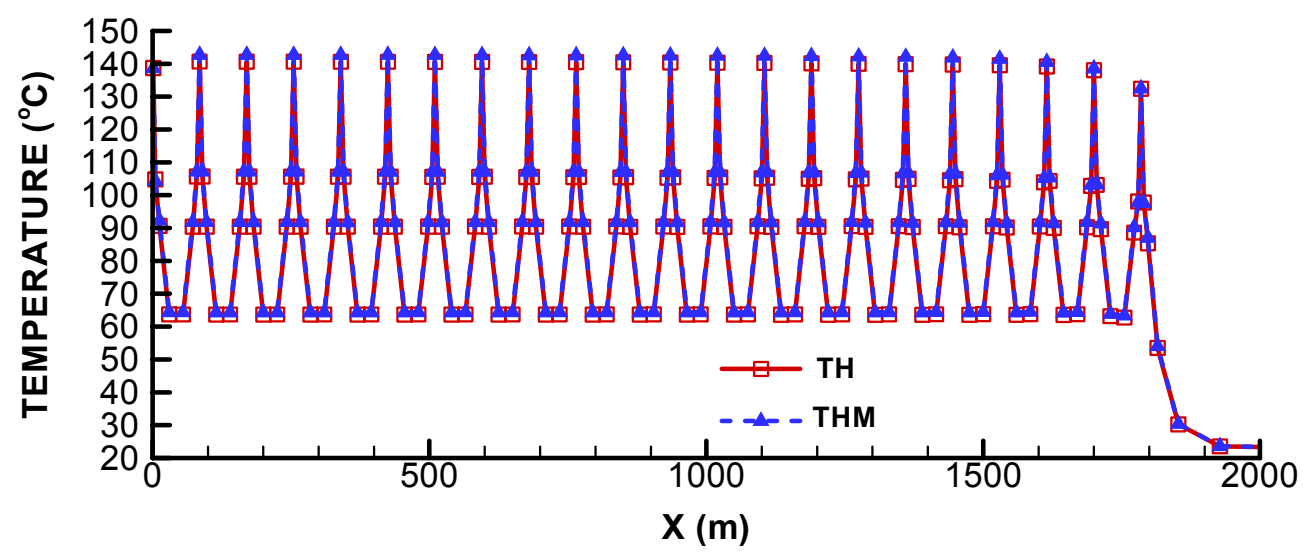

(a) 100 Years

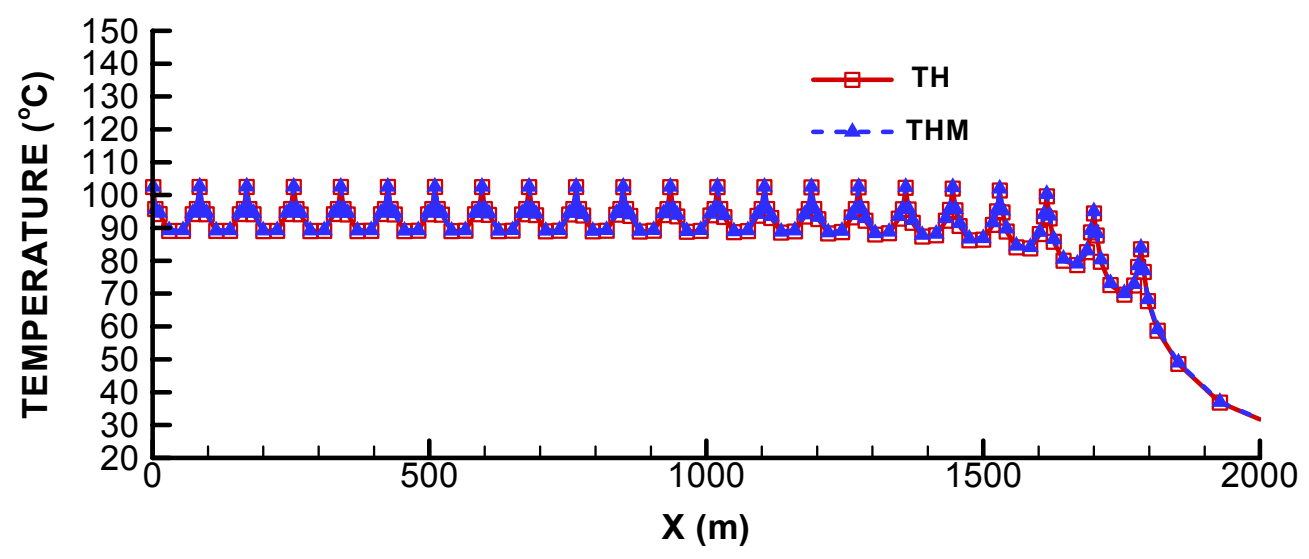

(b) 1,000 Years

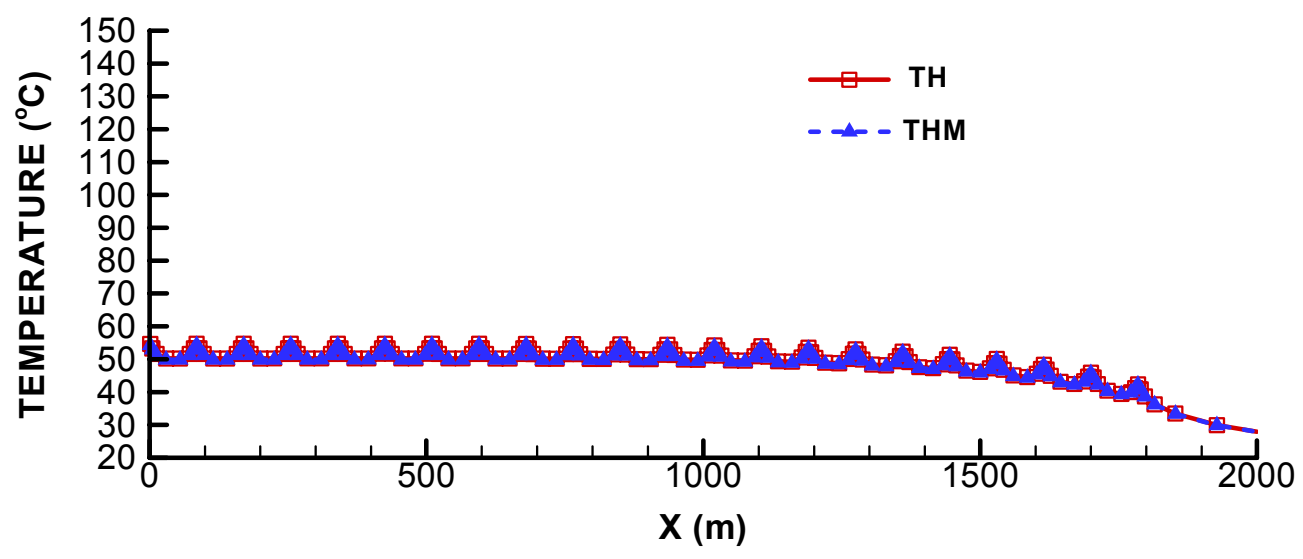

(c) 10,000 Years

DTN: LB0310MTSCLTHM.002

Figure 6.5.10-3. Temperature Profiles through the Repository for TH (solid red line) and THM (dashed blue line) Analyses 


\subsubsection{Evolution of Thermal Stress}

Figure 6.5.11-1 shows the distribution of mountain-scale horizontal stresses. Increased compressive stresses near the repository level are caused by thermal expansion of the rock mass. The magnitude of thermally induced stresses generally depends on the temperature and the distribution of the heat source, the rock-mass thermal expansion coefficient, and the rock-mass modulus of elasticity. The highest thermal stresses are created in the horizontal direction because of a larger extension of the heat source along the repository plane. At 100 years, the maximum compressive stress is about $18 \mathrm{MPa}$ near the emplacement drifts. At 1,000 years, a zone of increased horizontal stress extends more than a hundred meters below and above the repository, with a maximum stress of about $13 \mathrm{MPa}$ at the repository level. At 10,000 years, the compressive stresses at the repository level have generally declined as a result of decreasing temperature and decreasing thermal gradient. Smaller thermal stresses develop in the vertical direction (not shown). This is a result of the free-moving ground surface parallel to the extension of the heat source, and hence, a lack of mechanical confinement in the vertical direction.

Figure 6.5.11-1b shows that near the ground surface, a zone of tensile stresses exists. This zone of tension is caused by the redistribution of horizontal compressive stresses from the relatively cool regions near the ground surface towards hot regions near the repository level. This redistribution of stresses preserves the balance of horizontal force over the entire vertical extent of the model. The evolution of thermal stresses calculated for the Mountain-Scale THM Model is consistent with that of the Drift-Scale THM Model (BSC 2003 [164890], Section 6.5.2). The exception is for areas adjacent to the drift wall and for areas near the ground surface. The DriftScale Model contains more refined discretization gridblocks near the drift wall and is therefore more accurate for calculation of stresses within a zone of about one drift diameter. Far away from the drift, the Mountain-Scale Model is expected to be more accurate, since it can capture the redistribution of stresses from the cooler regions near the ground surfaces toward hotter regions near the heat source. The impact of near-surface tensile stress is discussed in Section 6.5.14. 


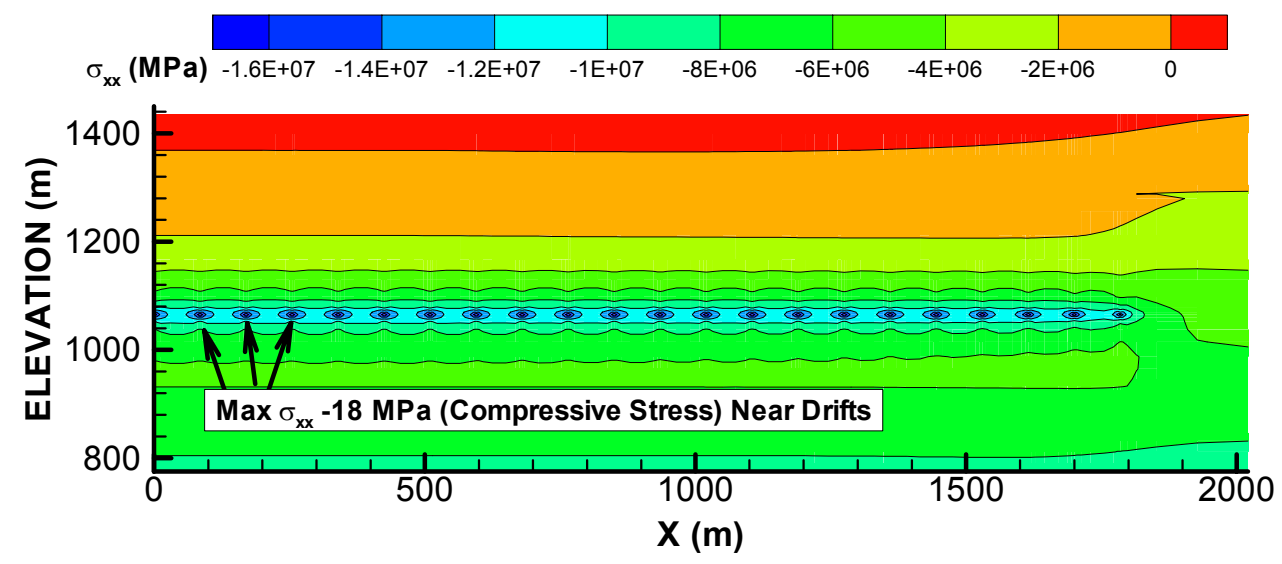

(a) 100 Years

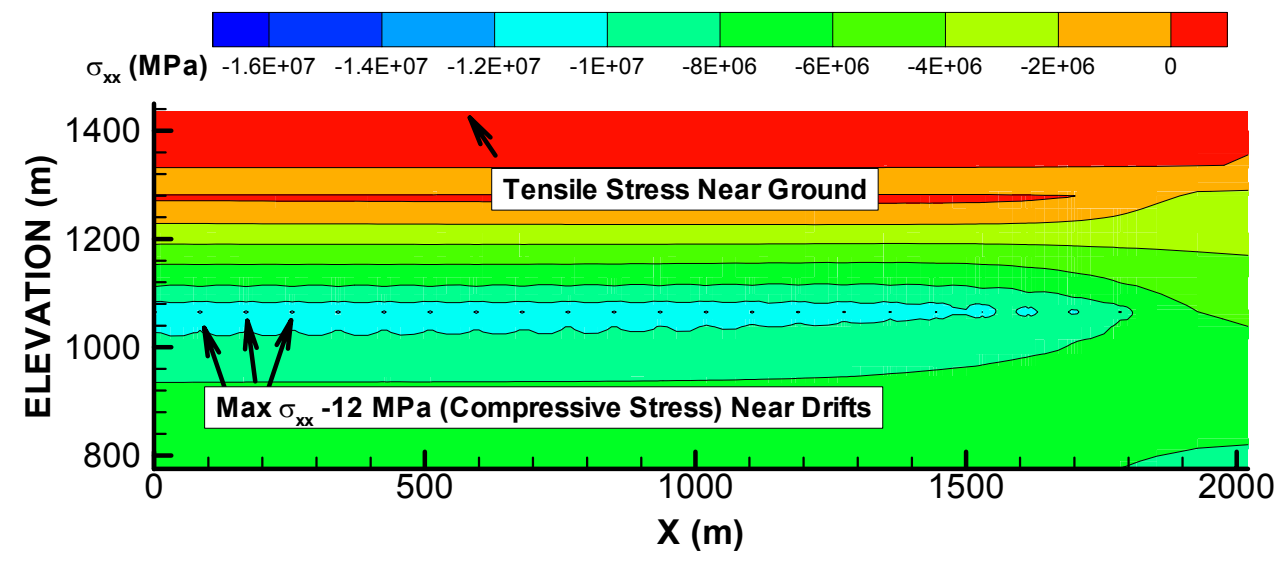

(b) 1,000 Years

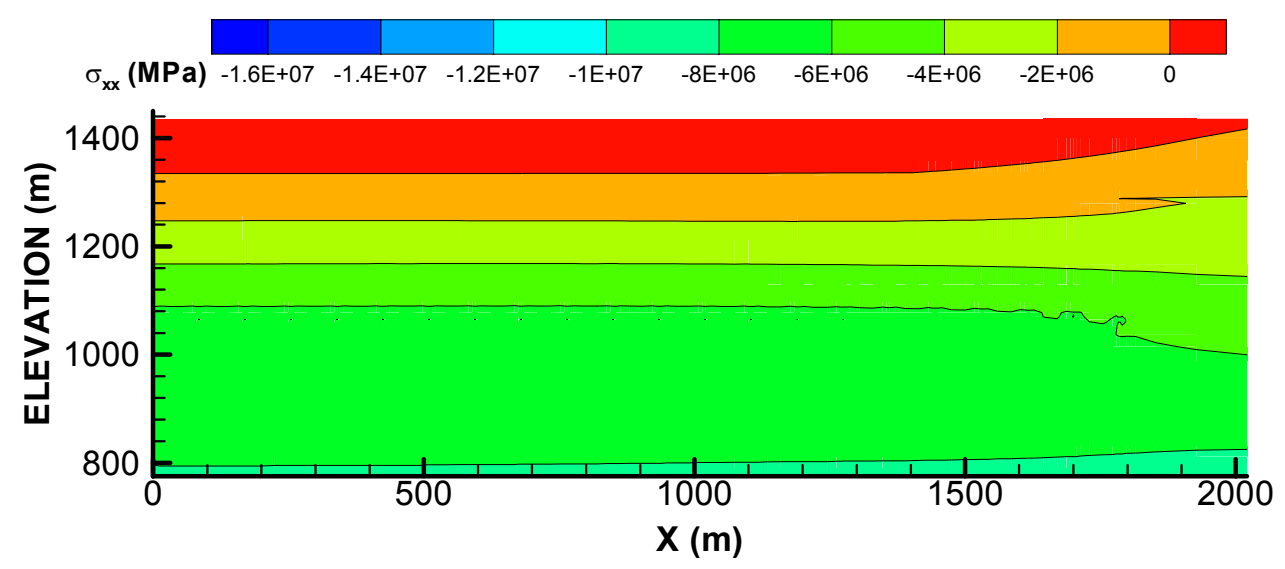

(a) 10,000 Years

DTN: LB0310MTSCLTHM.002

Figure 6.5.11-1. Evolution of Horizontal Stress $\left(\sigma_{x}\right)$ 


\subsubsection{Evolution of Hydraulic Properties}

Figures $6.5 .12-1$ to $6.5 .12-2$ presents vertical and horizontal permeability change factors at 100 , 1,000 , and 10,000 years for the case of $b_{\max }=380 \mu \mathrm{m}$. The general results of the coupled THM analysis presented in Figures 6.5.12-1 and 6.5.12-2 show that TM-induced compressive stresses around the repository level act across fractures, closing them to a smaller aperture, with an associated decrease in permeability and an increase in capillary pressure. Outside the heated region, towards the ground surface, reduction in horizontal stresses tends to open vertical fractures, with the result of a slight increase in the vertical permeability and reduction in capillary pressure. Such an increase in permeability immediately outside a heated region is consistent with observations at the Yucca Mountain DST (BSC 2003 [164890], Figure 7.4.3-2). The calculation shows that the vertical permeability (Figure 6.5.12-1) changes much more than the horizontal (Figure 6.5.12-2), corresponding to the result that horizontal fractures stay open during the entire heating cycle, whereas vertical fractures tighten to their residual aperture. The horizontal fractures remain open because no significant thermal stress can develop in the vertical direction, on account of the free-moving ground surface. Vertical fractures, on the other hand, close because thermal stresses develop in the horizontal direction. Throughout the entire 10,000year simulation time, the calculated changes in permeability are within a factor of 0.3 to 5 , whereas calculated changes in capillary pressure range between a factor of 0.7 to 1.2 . At the repository unit, the vertical permeability decreases by a factor of about 0.6 . These results are for the conservative case of $b_{\max }=380 \mu \mathrm{m}$, whereas smaller changes are obtained for the case of $\mathrm{b}_{\max }=200 \mu \mathrm{m}$.

Figure 6.5.12-3 presents vertical permeability change factors and permeability at 1,000 years along a vertical column at the left boundary of the model (representing the interior of the repository). The figure illustrates that a change factor ranging from 0.3 to 5 is relatively small compared to the general variability in permeability between different layers at the mountain.

The evolution of hydraulic properties calculated for the Mountain-Scale THM Model is consistent with that of the Drift-Scale THM Model (BSC 2003 [164890], Section 6.6.1), but with slightly smaller changes obtained for the former. Furthermore, the slight increase in permeability at the ground surface was not captured in the Drift-Scale THM Model (BSC 2003 [164890], Section 6.6.1) because no zone of tensile stress developed in that analysis. The modeling of permeability changes at the ground surface is likely to be more realistic in the Mountain-Scale Model, because it can capture the redistribution of stresses from the cooler regions near the ground surfaces toward hotter regions near the heat source (See Section 6.5.11). 


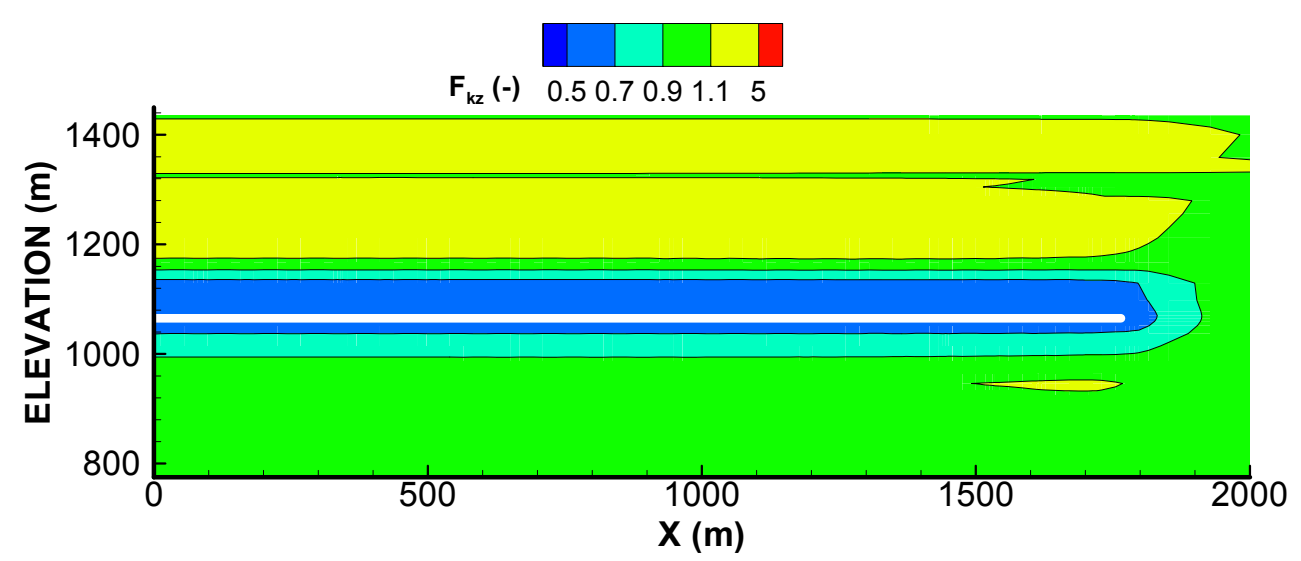

(a) 100 Years

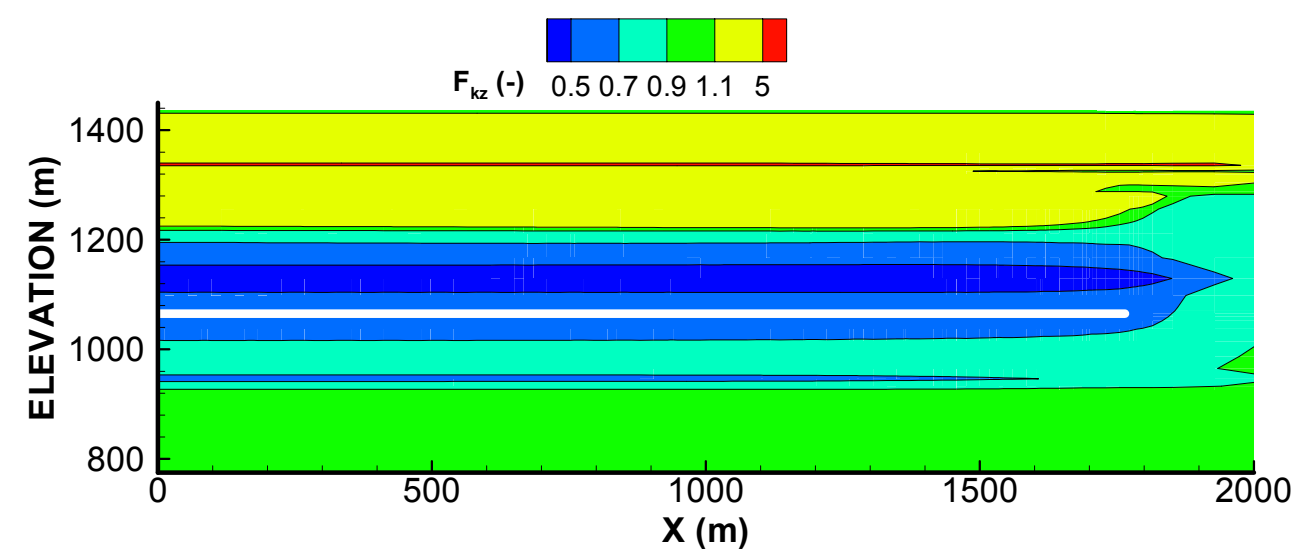

(b) 1,000 Years

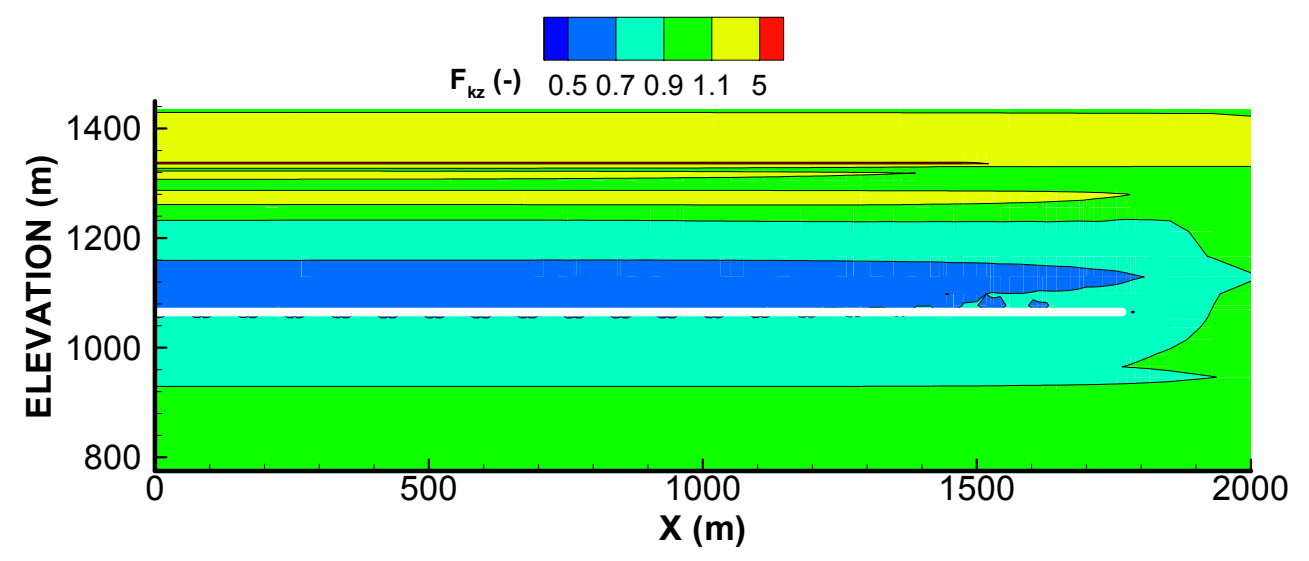

(c) 10,000 Years

DTN: LB0310MTSCLTHM.002

Figure 6.5.12-1. Evolution of Vertical Permeability Correction Factor $\left(F_{k z}=k_{z} / k i\right)$ Relative to PreEmplacement Permeability 


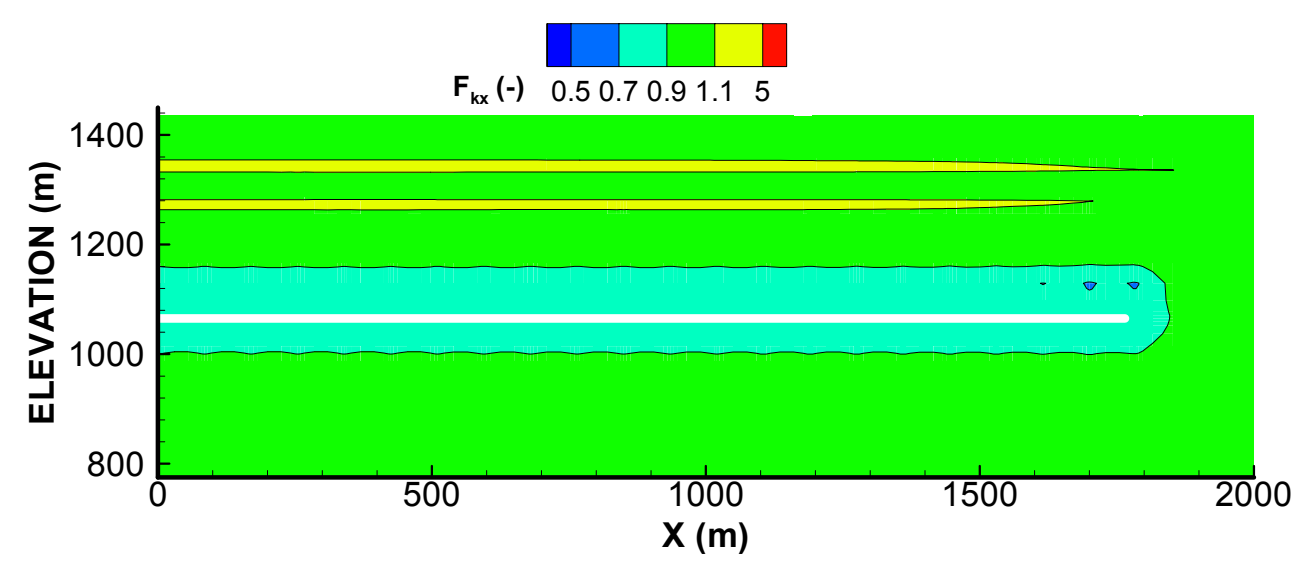

(a) 100 Years

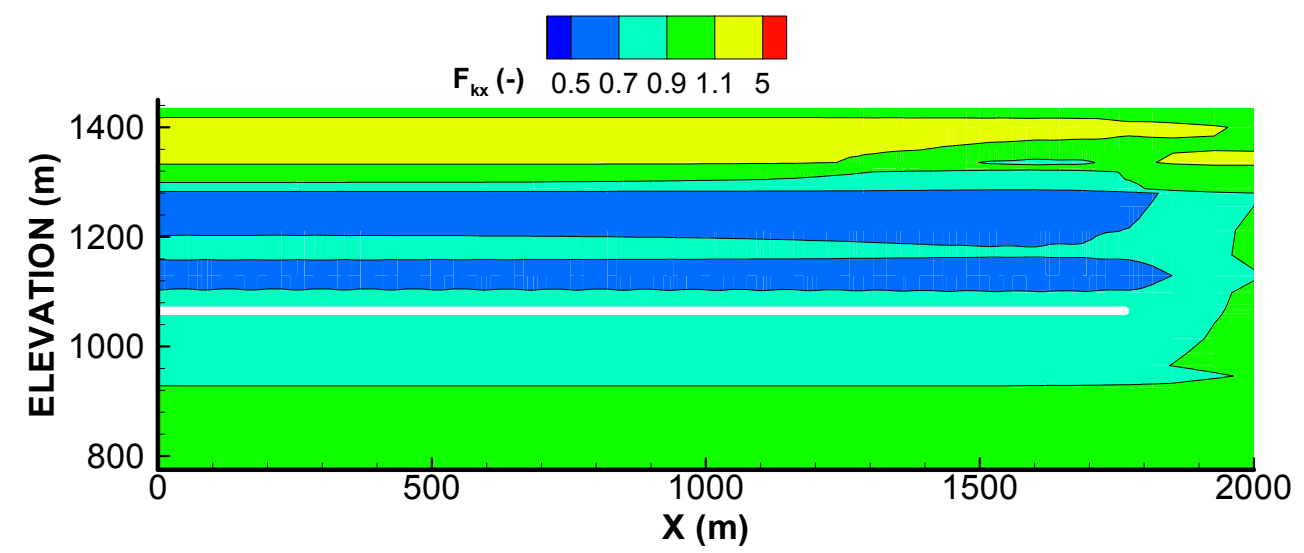

(b) 1,000 Years

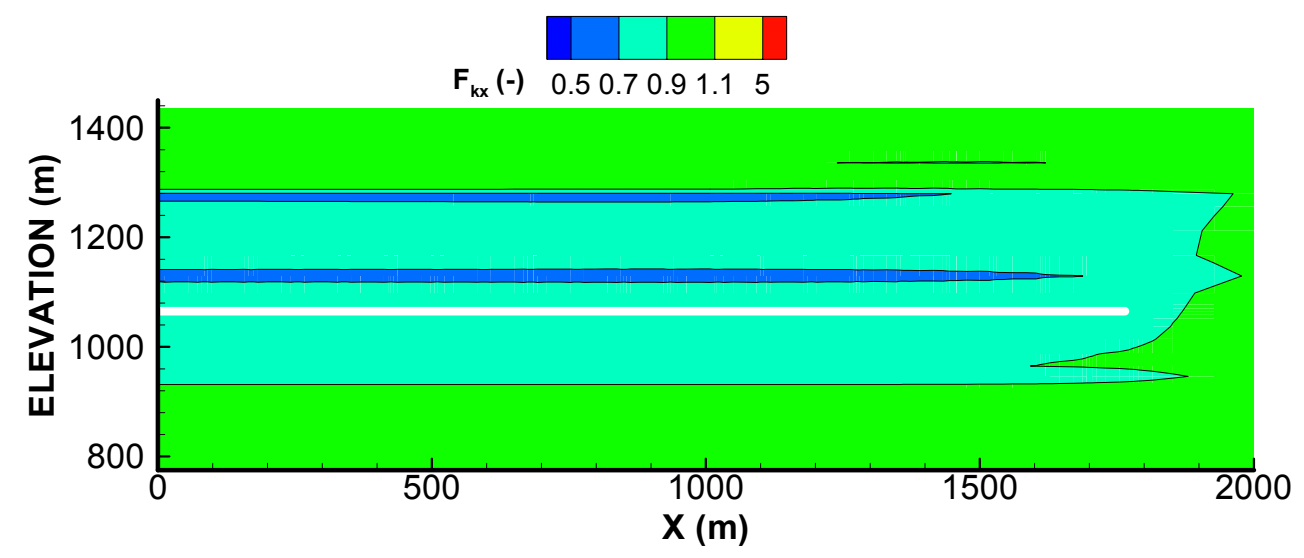

(c) 10,000 Years

DTN: LB0310MTSCLTHM.002

Figure 6.5.12-2. Evolution of Horizontal Permeability Correction Factor $\left(F_{k x}=k_{x} / k_{l}\right)$ Relative to PreEmplacement Permeability. 


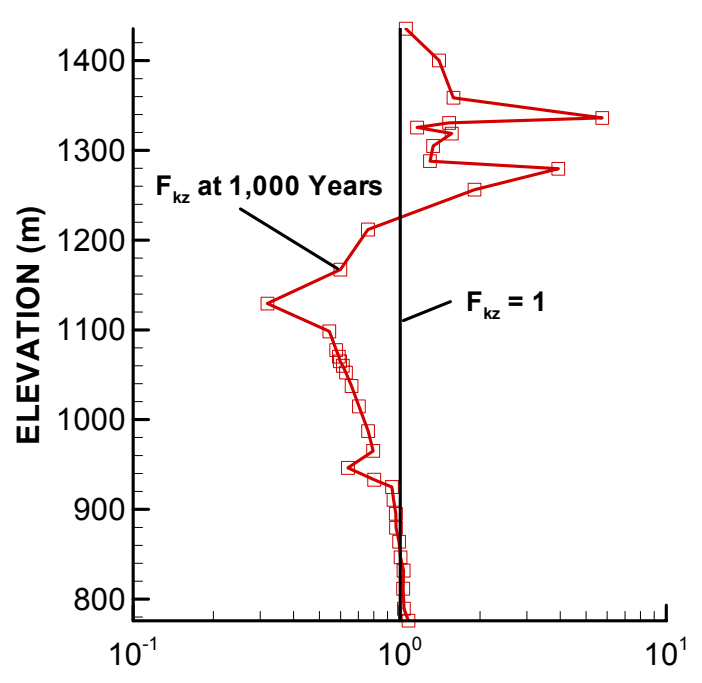

PERMEABILITY CORR. FACTOR, $F_{k z}\left(m^{2}\right)$

(a)

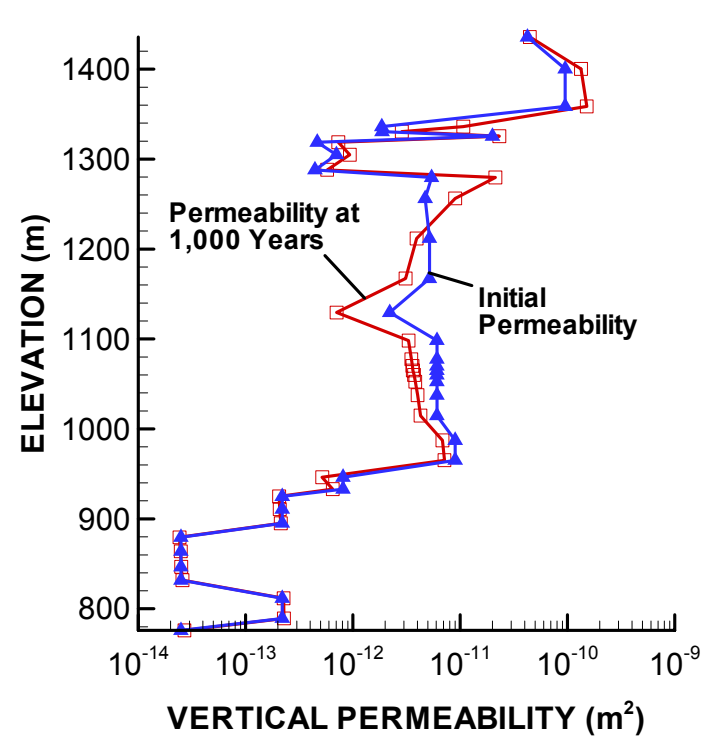

(b)

DTN: LB0310MTSCLTHM.002

Figure 6.5.12-3. Vertical Permeability at 1,000 Years along a Vertical Column at the Left Boundary of the Mountain-Scale THM Model Representing the Interior of the Repository: (a) Vertical Permeability Correction Factor $\left(F_{k z}=k_{z} / k_{i}\right)$ at 1,000 Years Relative to Pre-emplacement, (b) Vertical Permeability at 1,000 Years Compared to Pre-Emplacement (Initial) Permeability

\subsubsection{Fluid Flow Field}

Figures 6.5.13-1 through 6.5.13-6 present the evolution of vertical-percolation-flux distribution in the mountain for both the TH and THM models. In both cases, above-boiling temperatures near the emplacement drift cause drying of the rock around the emplacement drifts. A dryout zone is formed around each drift, and diversion of the vertical flux around the dryout zone is predicted between 100 and 1,000 years. At 10,000 years, the results of TH and THM models are identical, because rewetting has taken place and temperatures are close to ambient. The simulated results of vertical flux distribution from the ground surface to the groundwater table, and the flow diversion around the drifts, are consistent with simulation results obtained in the Drift-Scale THM Model (BSC 2003 [164890], Section 6.6.2).

Figure 6.5.13-7 presents a profile of vertical flux through the repository level, for a detailed comparison of the TH solution with the THM solution. As explained in Section 6.5.2, in the TH simulation, the hydrological properties of the rock mass are constant in time, which means that THM coupling is neglected in that case. Figure 6.5.13-7 shows that the vertical liquid flow is almost identical for TH (solid red lines) and THM (dashed blue lines). This indicates that that there is no significant impact from THM coupling on the mountain-scale fluid flow field. One reason for the similarity in the flow field for TH and THM simulation cases is that the reduced vertical permeability in the THM case is accompanied by a higher relative permeability from increased liquid saturation. Thus, a THM-induced reduction in vertical permeability may have been compensated for by a higher relative permeability, leading to an unchanged flow mobility. 
That THM coupling has little impact on the mountain-scale fluid flow field is consistent with results of the Drift-Scale THM Model (BSC 2003 [164890], Section 6.6.6).

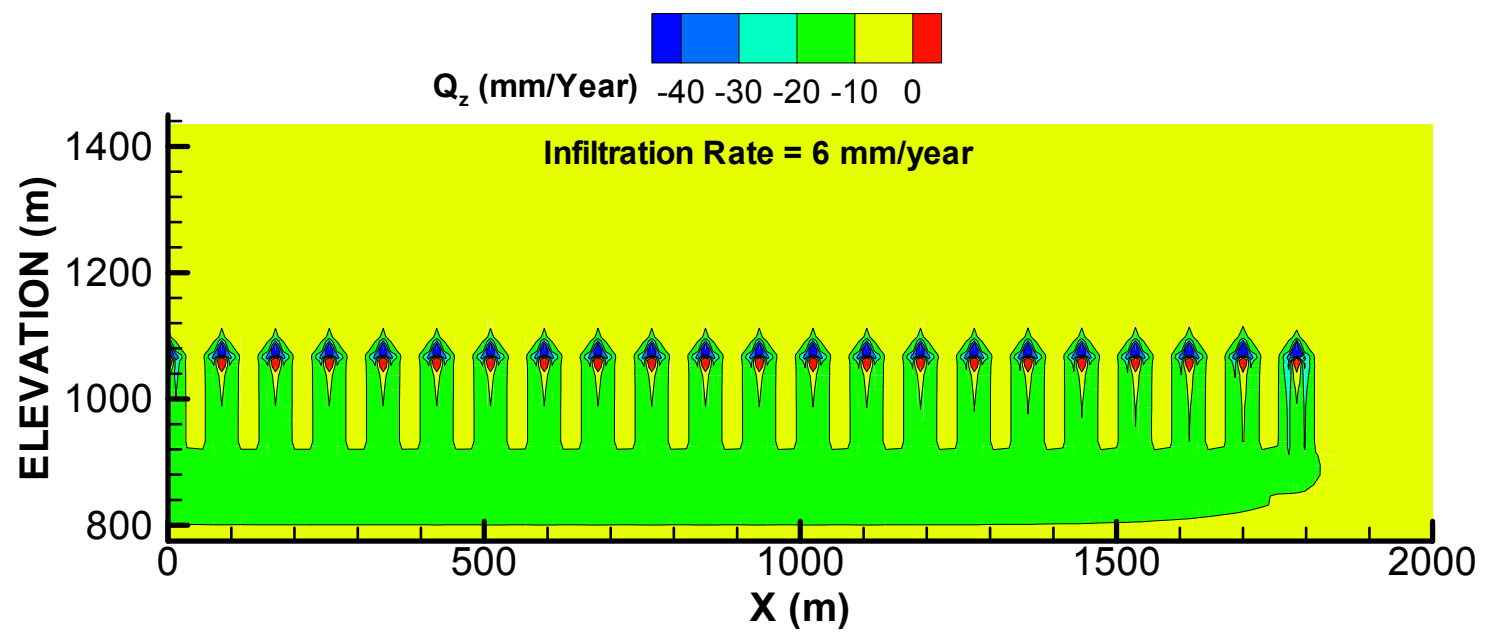

(a) TH Solution

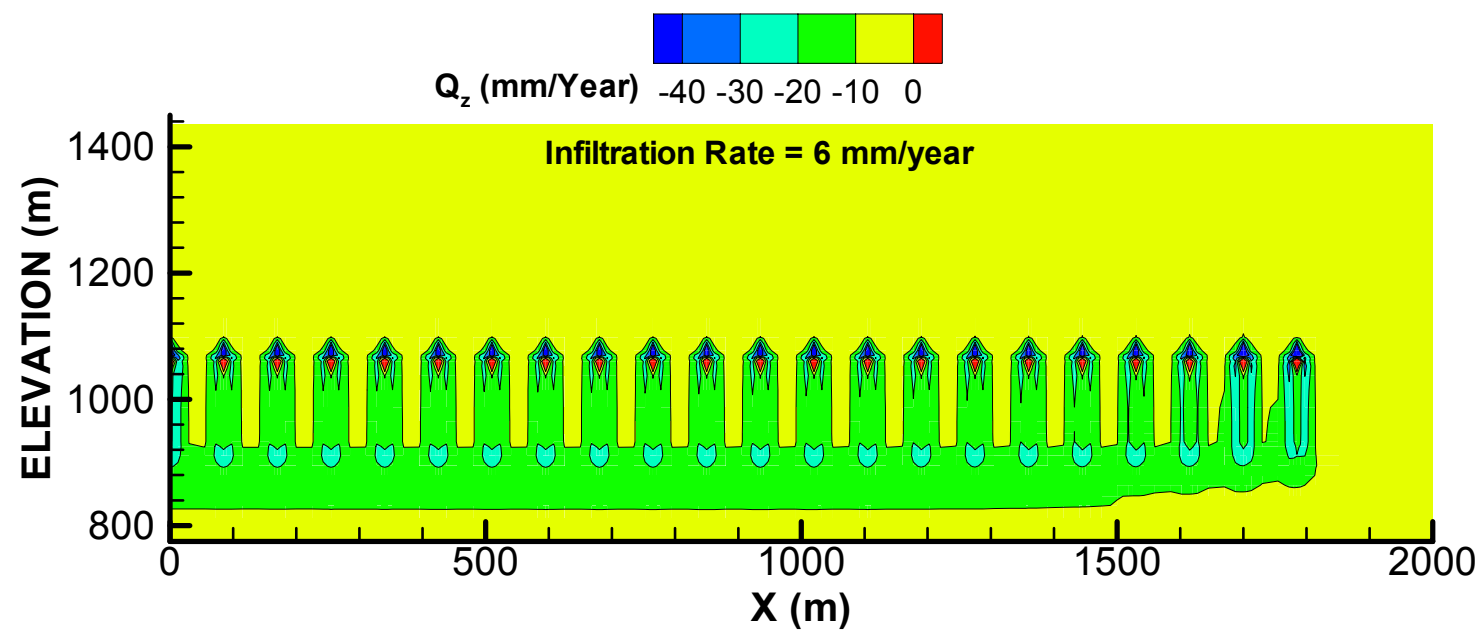

(b) THM Solution

DTN: LB0310MTSCLTHM.002

NOTE: See also Figure 6.5.13-4.

Figure 6.5.13-1. Distribution of Vertical Percolation Flux $\left(\mathrm{Q}_{\mathrm{z}}\right)$ at 100 Years after Emplacement for $\mathrm{TH}$ and THM Solutions 
$Q_{z}$ (mm/year) $\quad-40-30-20-10 \quad 0$

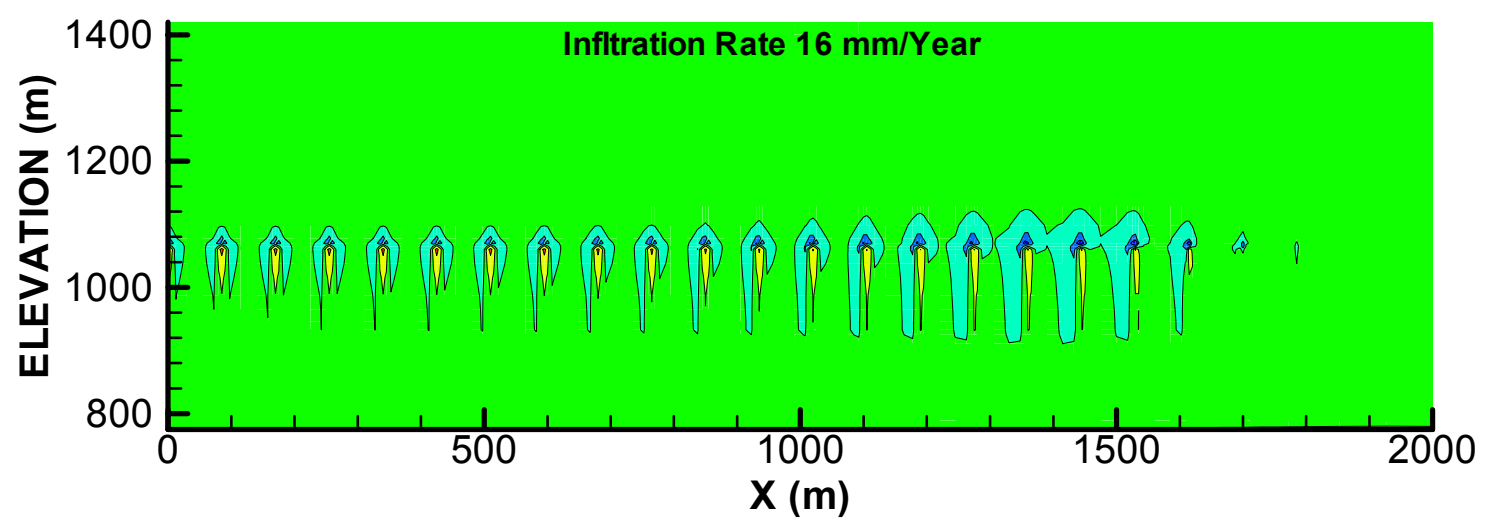

(a) TH Solution

$\mathbf{Q}_{\mathbf{z}}$ (mm/year) $\quad-40-30-20-10 \quad 0$

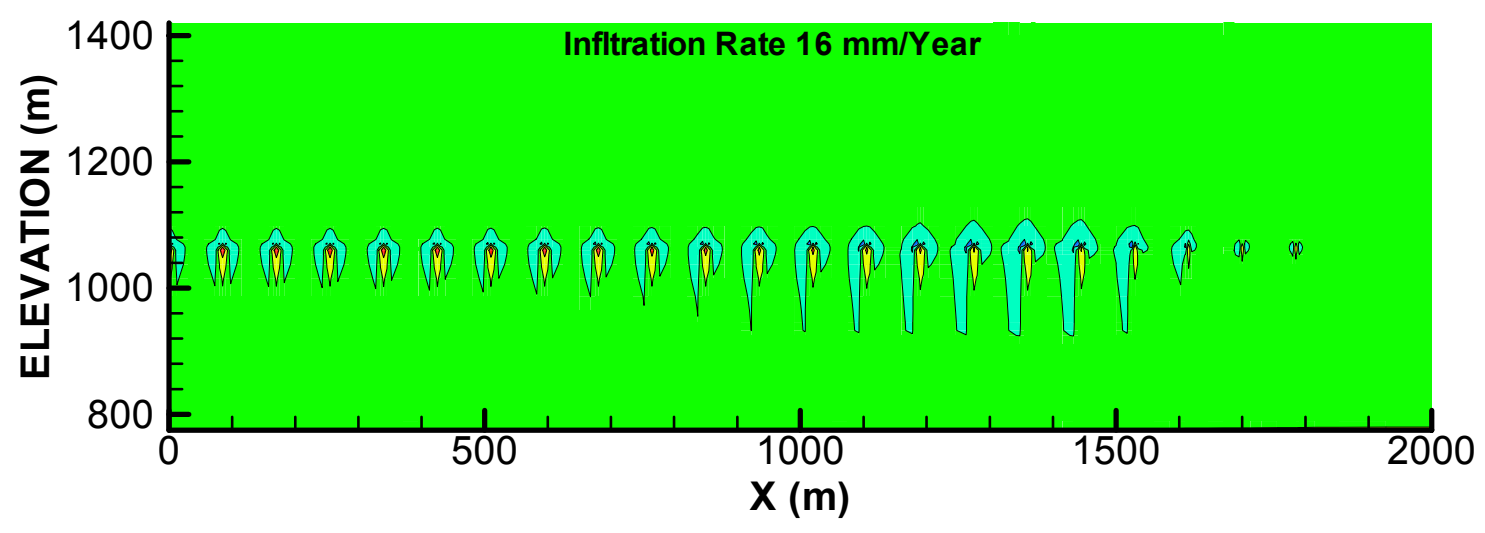

(b) THM Solution

DTN: LB0310MTSCLTHM.002

NOTE: See also Figure 6.5.13-5.

Figure 6.5.13-2. Distribution of Vertical Percolation Flux $\left(Q_{z}\right)$ at 1,000 Years after Emplacement for TH and THM Solutions 
$\mathbf{Q}_{\mathbf{z}}(\mathbf{m m} /$ Year) $-40-30-20-10 \quad 0$

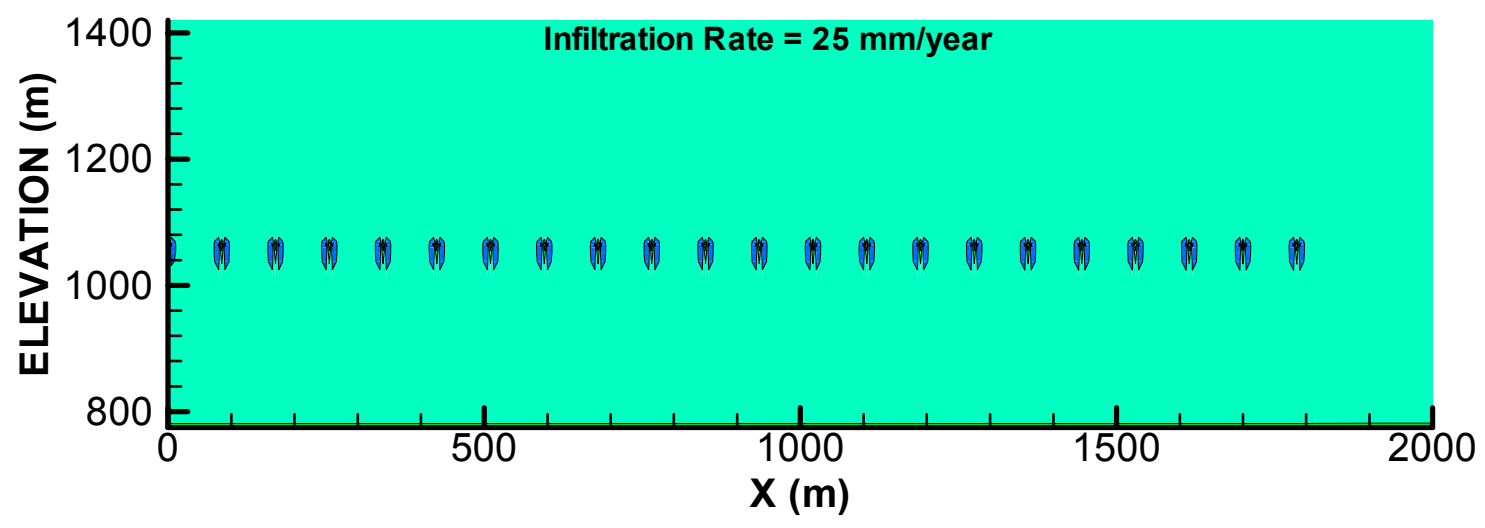

(a) TH Solution

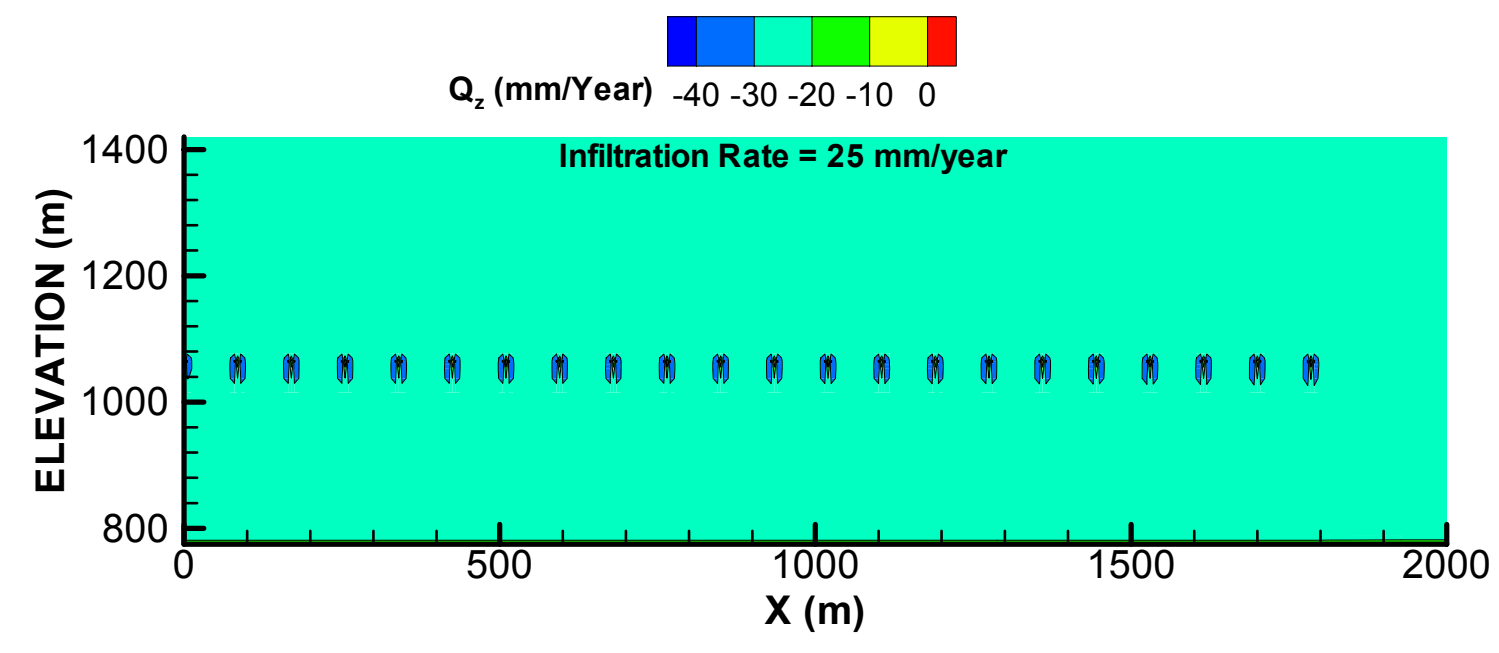

(b) THM Solution

DTN: LB0310MTSCLTHM.002

Figure 6.5.13-3. Distribution of Vertical Percolation Flux $\left(Q_{z}\right)$ at 10,000 Years after Emplacement for a TH and THM Solutions 


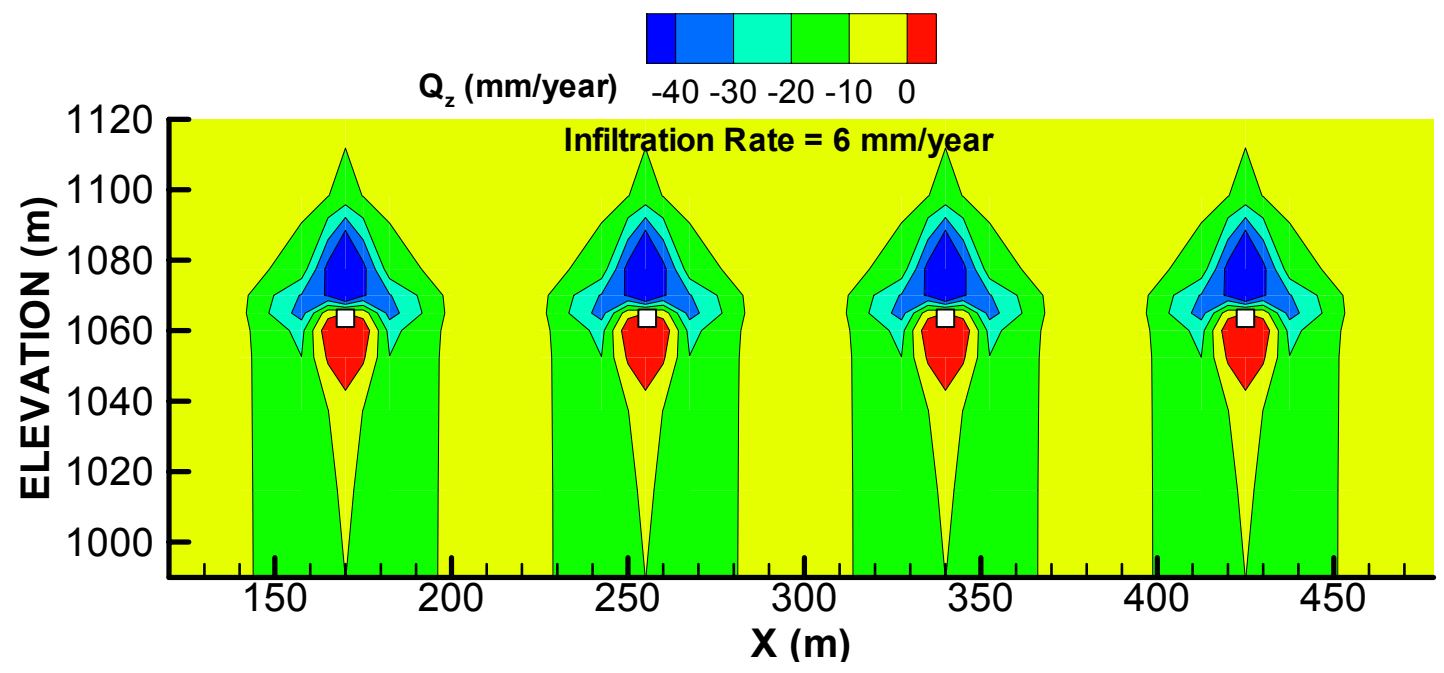

(a) TH Solution

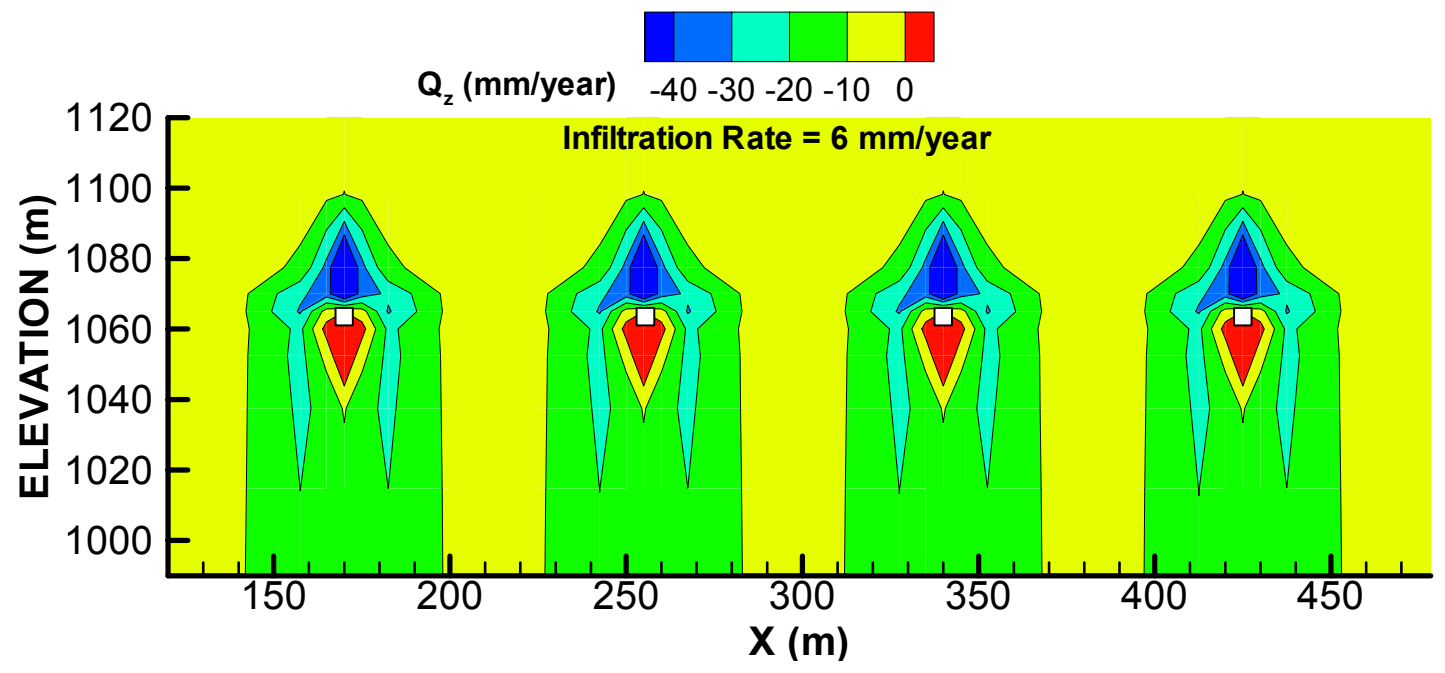

(b) THM Solution

DTN: LB0310MTSCLTHM.002

Figure 6.5.13-4. Distribution of Vertical Percolation Flux near four Emplacement Drifts in the Interior of the Repository $\left(Q_{z}\right)$ at 100 Years after Emplacement for TH and THM Solutions 


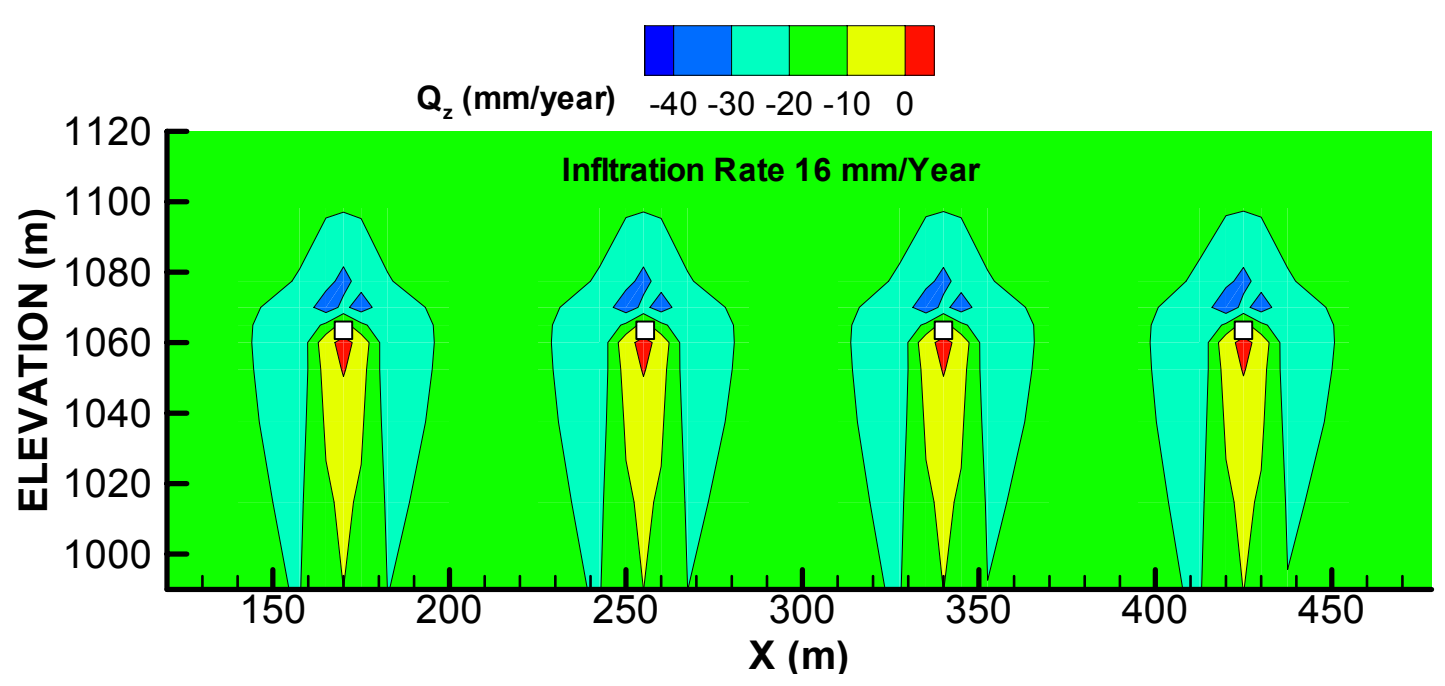

(a) TH Solution

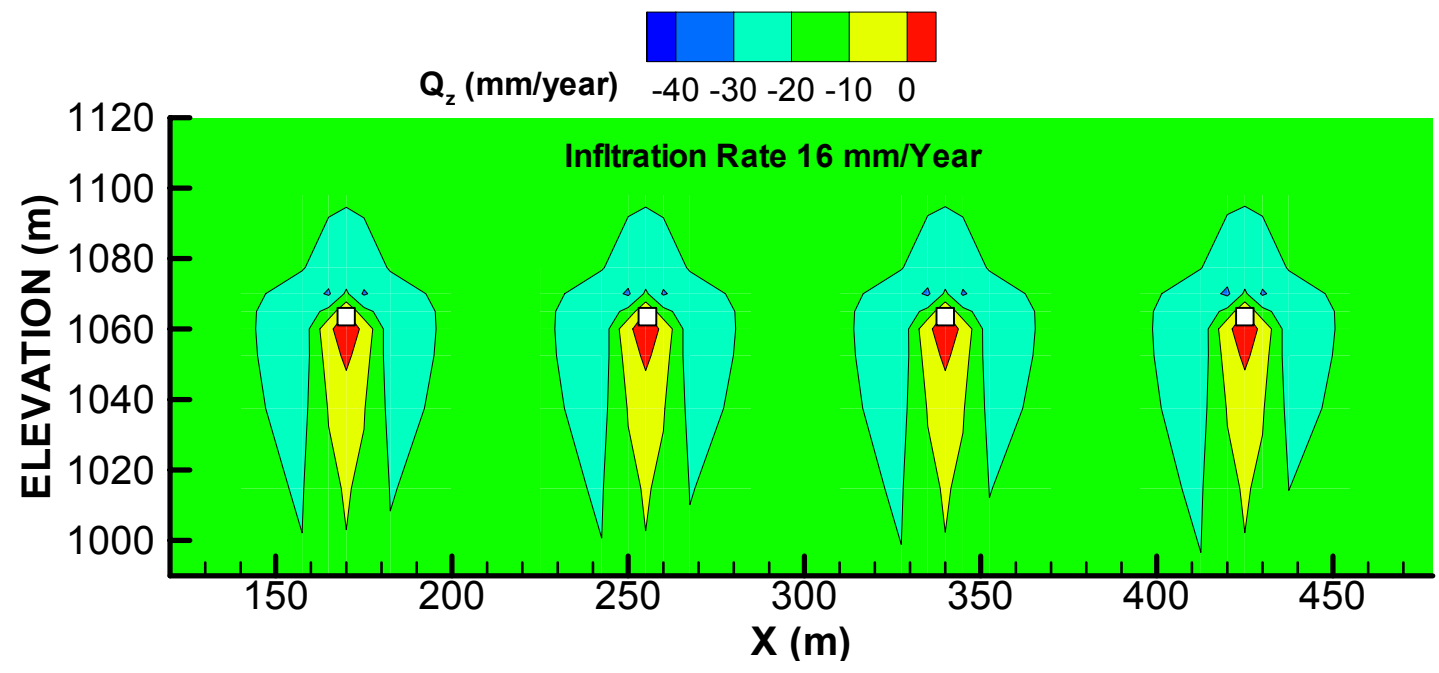

(b) THM Solution

DTN: LB0310MTSCLTHM.002

Figure 6.5.13-5. Distribution of Vertical Percolation Flux near Four Emplacement Drifts in the Interior of the Repository $\left(Q_{z}\right)$ at 1,000 Years after Emplacement for TH and THM Solutions 


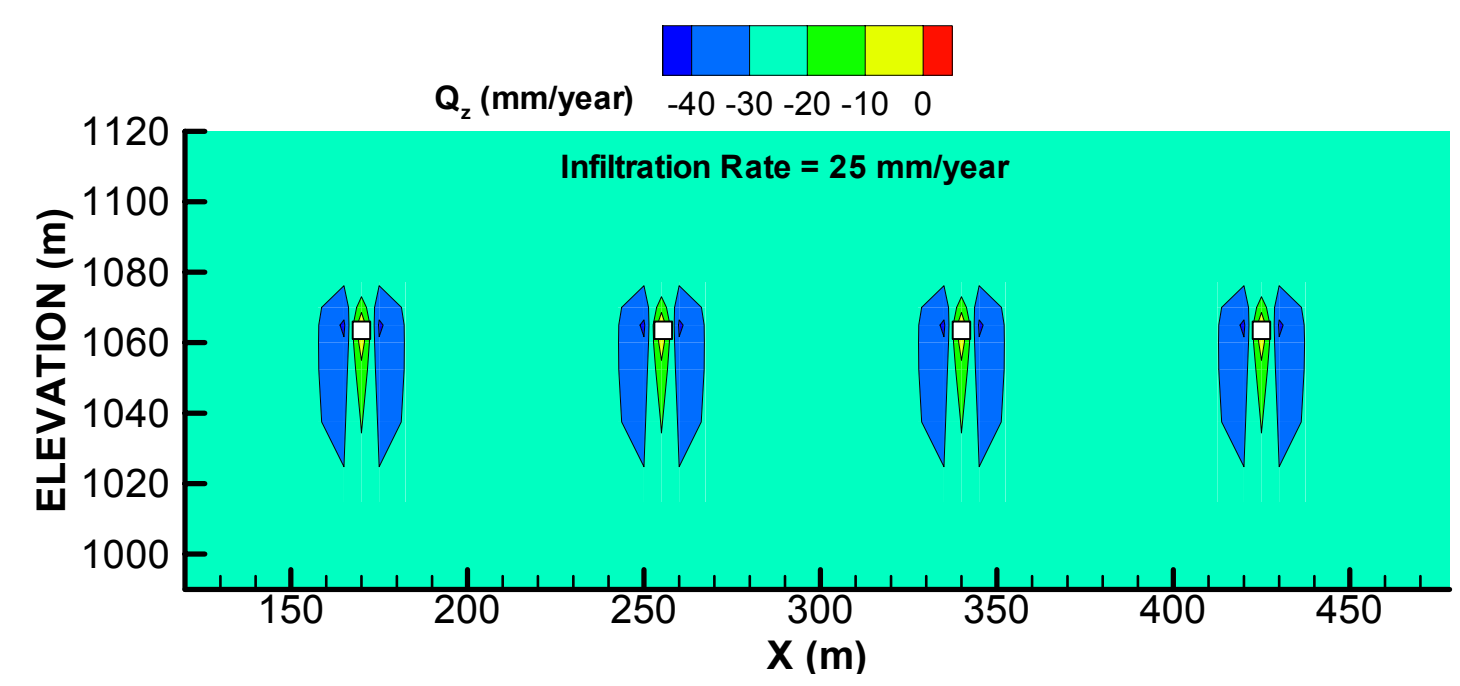

(a) TH Solution

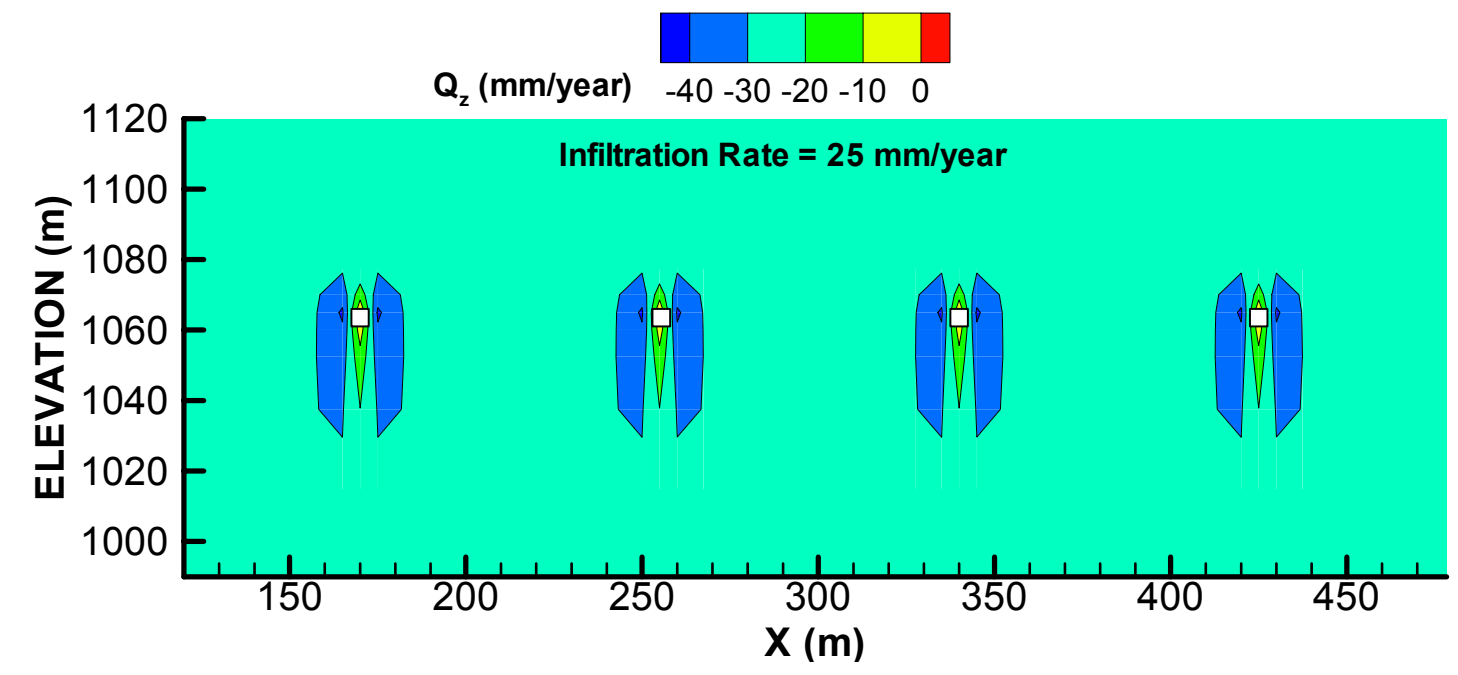

(b) THM Solution

DTN: LB0310MTSCLTHM.002

Figure 6.5.13-6. Distribution of Vertical Percolation Flux near Four Emplacement Drifts in the Interior of the Repository $\left(Q_{z}\right)$ at 10,000 Years after Emplacement for TH and THM Solutions 


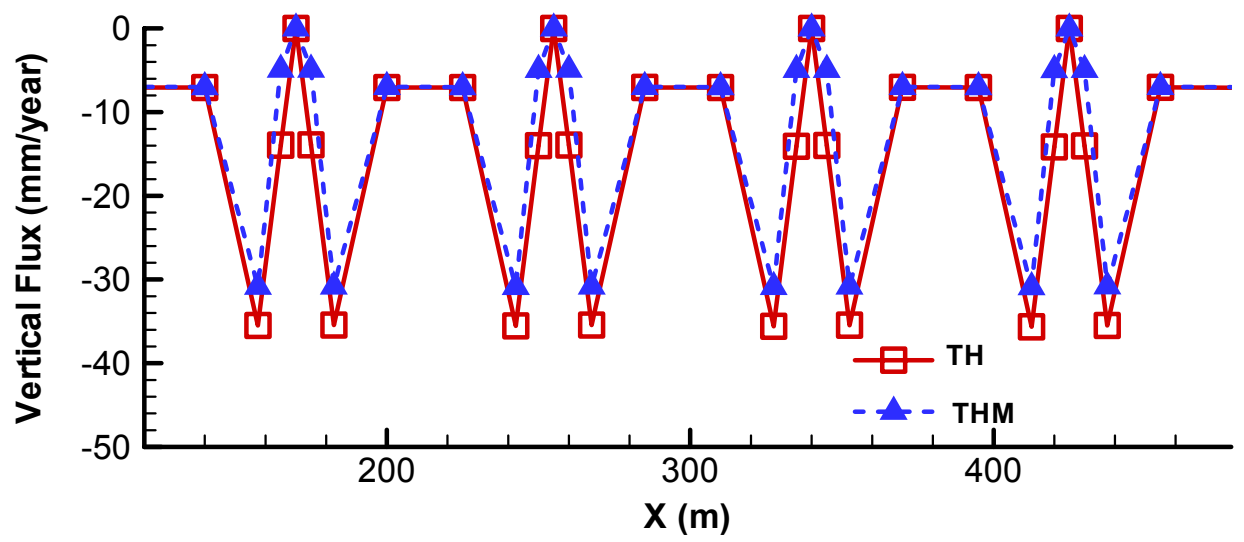

(a) 100 Years

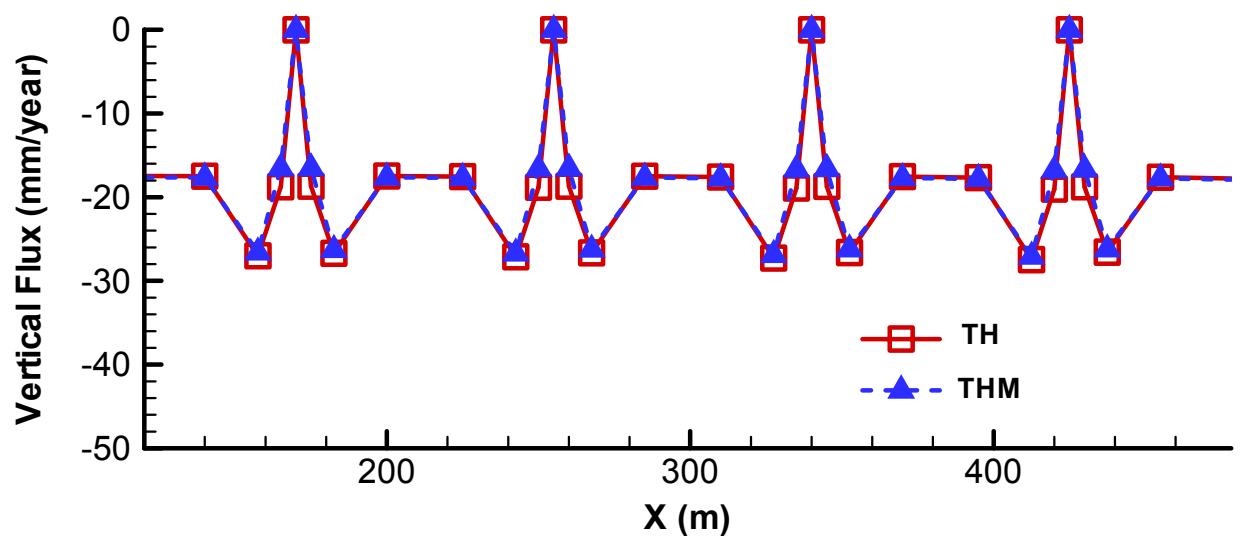

(b) 1,000 Years

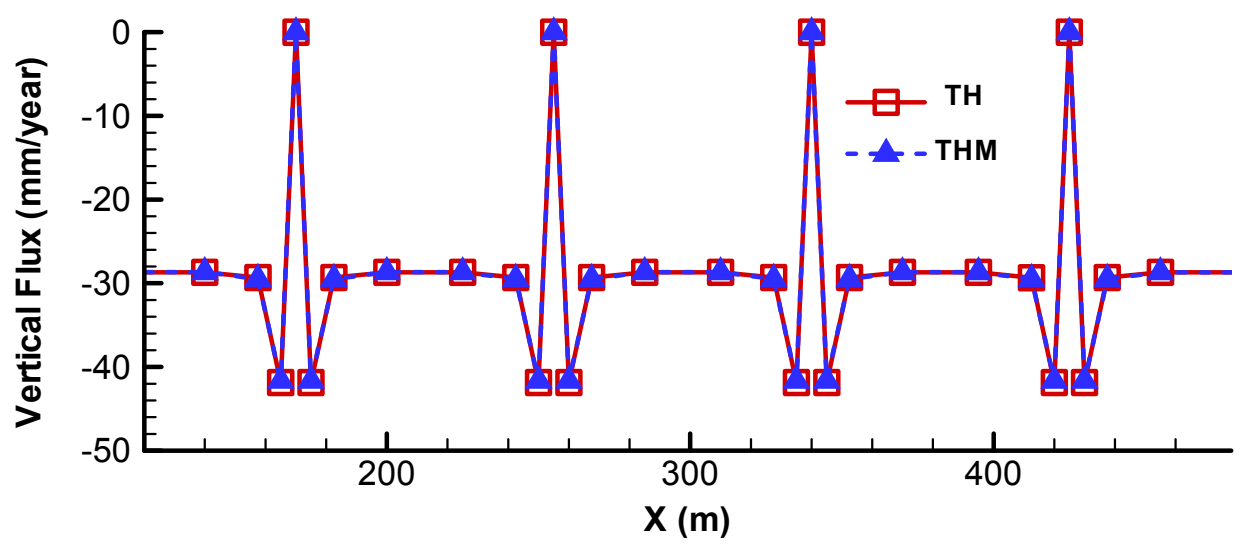

(c) 10,000 Years

DTN: LB0310MTSCLTHM.002

Figure 6.5.13-7. Vertical Percolation Flux $\left(Q_{z}\right)$ across the Repository Horizon near Four Emplacement Drifts for a TH Simulation (solid red lines) and a THM Simulation (blue dashed line) 


\subsubsection{Impact of Possible Fracturing and Shear Slip near Ground Surface}

The stress analysis presented in Section 6.5.11 showed that a zone of horizontal tensile stresses develops near the ground surface (Figure 6.5.11-1). In reality, tensile stresses would lead to fracturing and/or complete opening of pre-existing fractures. Furthermore, in this zone of complete unloading of compressive stresses (compressive stress relief), the shear strength along fractures will be reduced and as a result, shear slip could be triggered. Fracturing and shear slip along pre-existing fractures can lead to additional fracture opening and permanent (irreversible) changes in hydraulic properties. The possible permeability changes caused by such fracturing and shear slip near the ground surface were not fully accounted for in the coupled THM analysis of Sections 6.5.10 to 6.5.13 of this Model Report. Therefore, the possible effects of such changes are evaluated in this section.

The potential for shear slip can be evaluated from the ratio of shear stress to normal stress $\left(\sigma_{s} / \sigma_{n}\right)$. A high ratio (when the shear stress is large compared to the normal stress) means that the potential for shear slip is greater. Figure 6.5.14-1 presents the evolution of xz-shear stress in the xz-plane of the model. At 100 years, the highest shear stress develops near repository drifts and at the edge of the repository. The shear stresses are high near the repository drifts at 100 years because it is a few tens of years after the end of the ventilation period, when the temperature at the repository drift peaks and the thermal gradient is the highest. At 1,000 years, the shear stresses near the drifts have decreased, while the zone of high shear stress near the edge of the repository has expanded and propagated towards the ground. At 10,000 years, the shear stresses have decreased further, with some remaining at the edge of the repository.

The potential for shear slip was evaluated by contouring the $\sigma_{s} / \sigma_{n}$ ratio from stresses acting on vertical and horizontal fractures for 100, 1,000, and 10,000 years. The potential for shear slip along vertical fractures was evaluated by plotting the ratio $\sigma_{x} / \sigma_{x z}$, where $\sigma_{x}$ is the stress in the Xdirection (i.e., normal to vertical fractures) and $\sigma_{x z}$ is the shear stress along vertical fractures. Similarly, the potential for shear slip along horizontal fractures is evaluated by plotting the ratio $\sigma_{z} / \sigma_{x z}$. Figure 6.5.14-2 shows the results at 1,000 years, which is the time when the highest potential for shear slip occurs. In recent studies of crystalline rock, it has been found that highpermeability fractures are frequently oriented such that the ratio $\sigma_{s} \sigma_{n} \approx 0.6$ (Barton et al. 1995, [153826]). Thus, an $\sigma_{s} \sigma_{n}$ ratio above 0.6 is likely to induce shear slip with accompanying permeability enhancement. Figure 6.5.14-2 indicates that the highest potential for shear slip is along vertical fractures in regions near the ground surface. For horizontal fractures, on the other hand, $\sigma_{s} / \sigma_{n}$ is less than 0.6 , and therefore shear slip is not likely along horizontal fractures. Note that the red contours in Figure 6.5.14-2a generally coincide with areas of complete unloading of tensile stresses, which means that the shear strength goes to zero. 


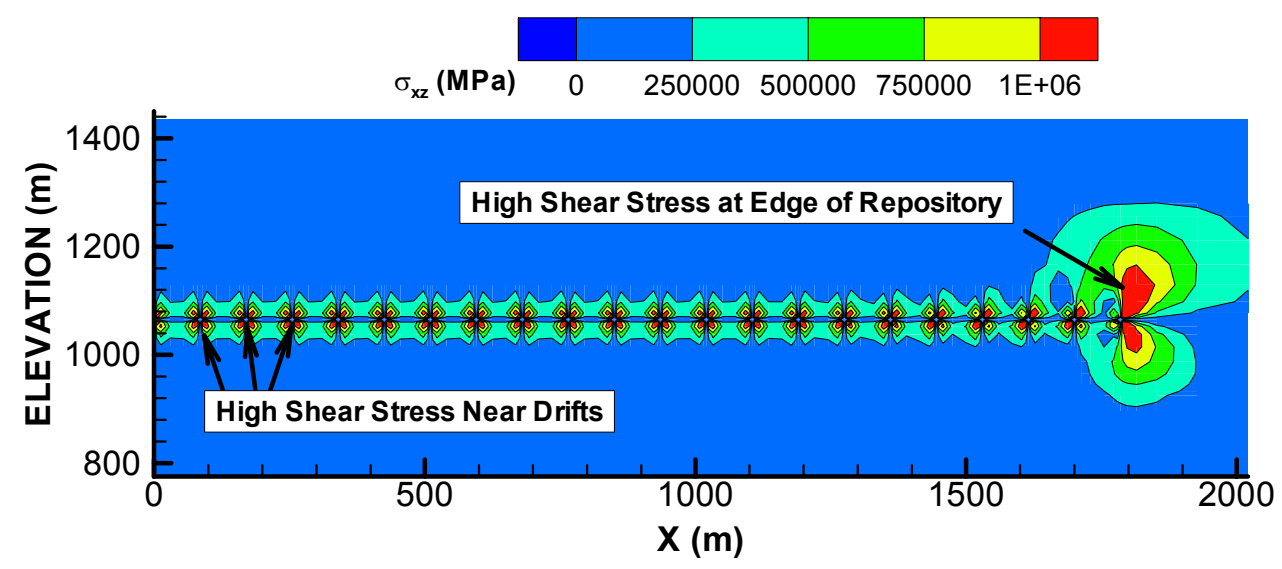

(a) 100 Years

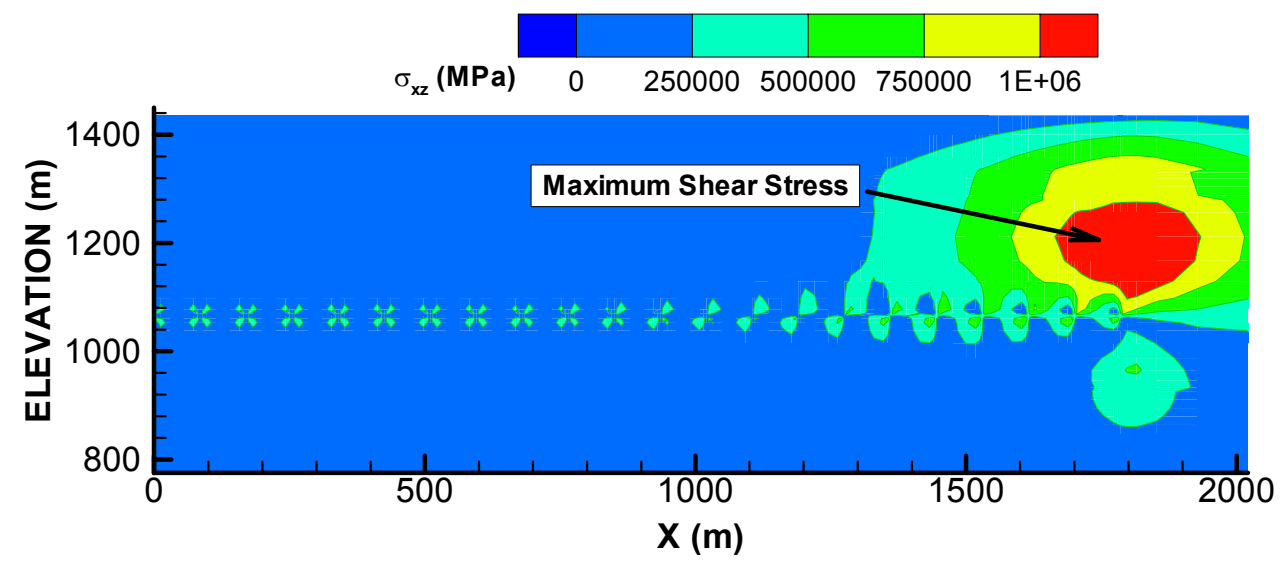

(b) 1,000 Years

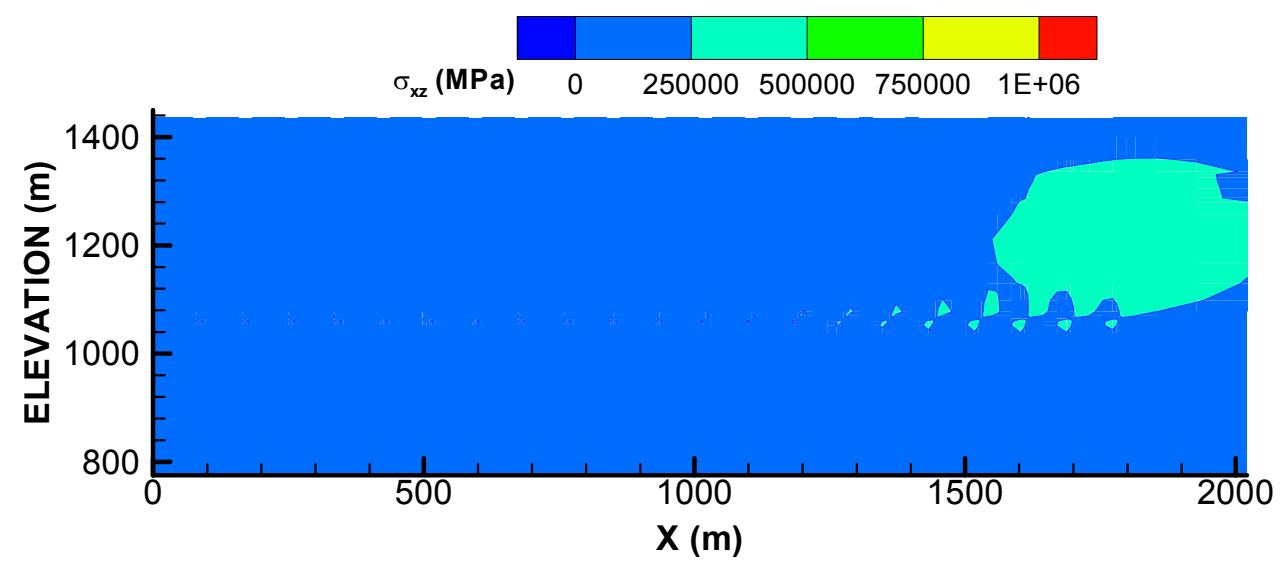

(c) 10,000 Years

Figure 6.5.14-1. Evolution of $x z$ Shear Stress $\left(\sigma_{x z}\right)$ 


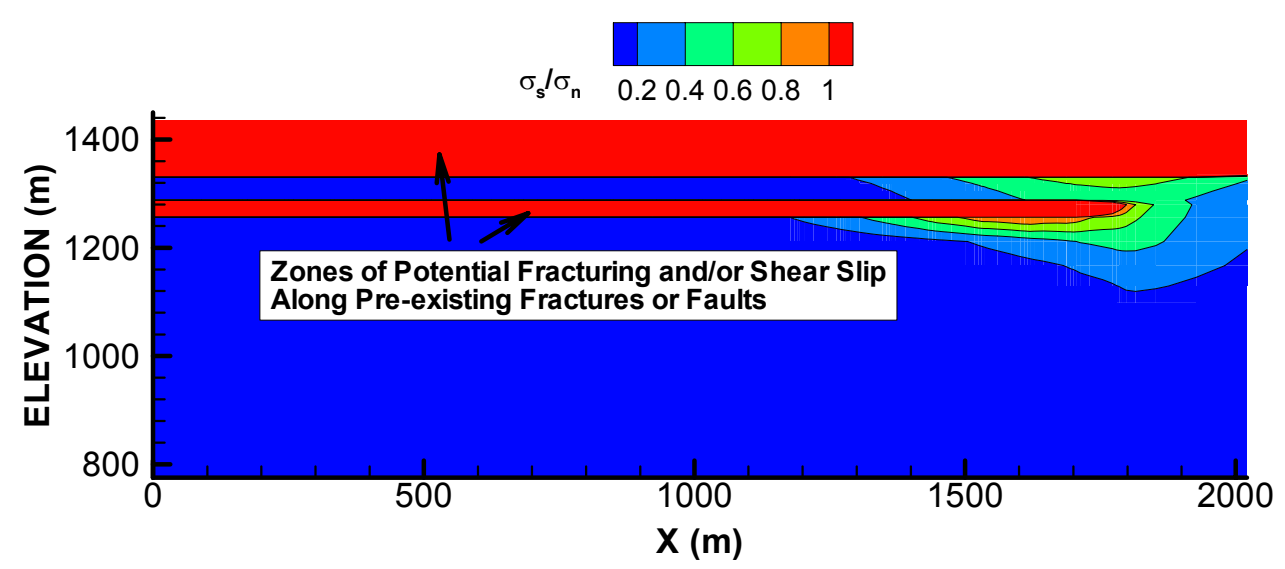

(a) Vertical Fractures

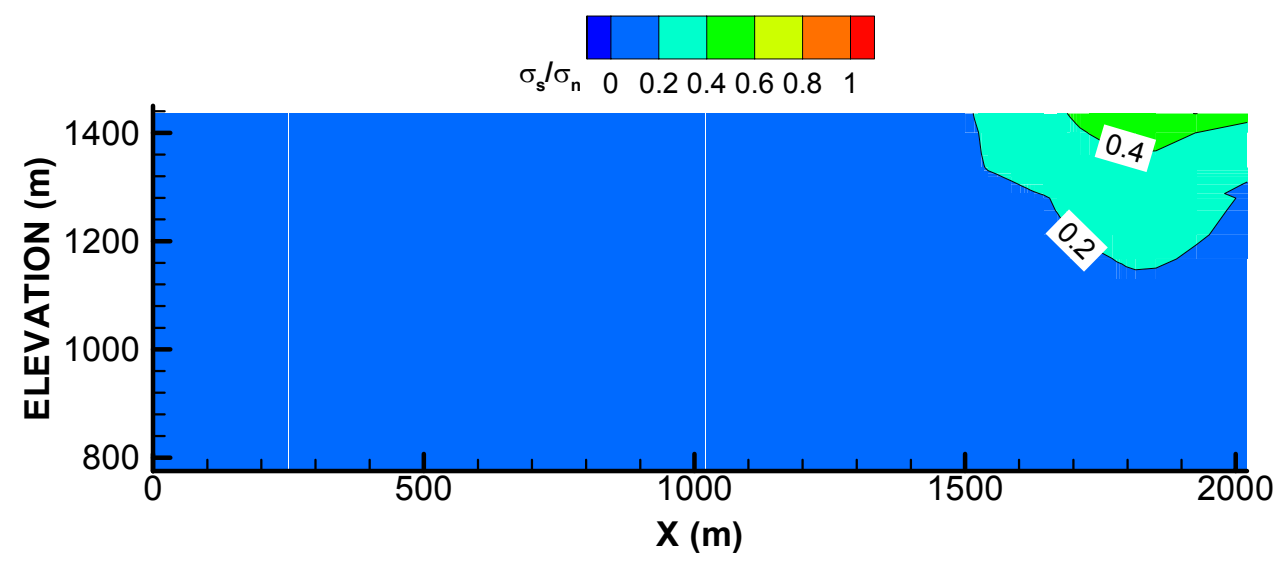

(b) Horizontal Fractures

DTN: LB0310MTSCLTHM.002

Figure 6.5.14-2. Ratio of $\sigma_{s /} \sigma_{n}$ from Stresses Acting on Vertical and Horizontal Fractures

Fracturing and shear slip at the ground surface could create permanent (irreversible) permeability changes that would last well over 10,000 years. The magnitude of permanent permeability increases is difficult to estimate because of lack of field evidence at a mountain scale. Laboratory tests of shear versus permeability generally show that permeability can increase by 1 to 2 orders of magnitude during shearing (Rutqvist and Stephansson [162583], p. 17). This would represent a fully dilated fracture during shear. A further estimate of the possible permeability increase may be derived from detailed air-permeability tests in niches conducted at Yucca Mountain (BSC 2001 [158463], Section 6.1). These tests shows that the small-scale fracture permeability ranges roughly over three orders of magnitude. The largest measured fracture permeability values are likely to represent fully dilated shear fractures that have unmated fracture surfaces. The variability of in situ fracture permeability would also be affected by fracture properties such a roughness and degree of mineral filling. However, a conservative estimate of possible increase during shear can be obtained by assuming that a three-order-of-magnitude variability in fracture permeability is caused by shear dilation of initial mated fractures. Thus, a conservative estimate of possible permeability increase in the completely unloaded zone at the ground surface is three orders of magnitude. 
An evaluation of the impact of a three-order-of-magnitude increase in permeability in the upper zones of Yucca Mountain is conducted through a steady-state flow simulation under 10,000 year conditions. The 10,000-year conditions are selected for this simulation because this represents the long-term conditions after the temperature has declined but permanent (irreversible) permeability changes in the upper part of the mountain would remain. The permeability imposed to increase by three orders of magnitude in layers of the red contour in Figure 6.5.14-2. The resulting vertical permeability distribution is depicted in Figure 6.5.14-3. In the zones of threeorders-of-magnitude permeability increase, the capillary pressure was reduced by one order of magnitude, which is a rough estimate based on Equation 6.5.5-6. Figure 6.5.14-4 shows a comparison of the vertical flow at the repository level, comparing this extreme case to the results of the partially coupled TH simulation presented in Figure 6.5.13-4c. It is indicated that the imposed extreme changes in permeability at the ground surface have no impact on the vertical flow field at the repository level. This shows that the infiltration rate and the hydraulic properties in the repository unit govern the flow field at the repository level.

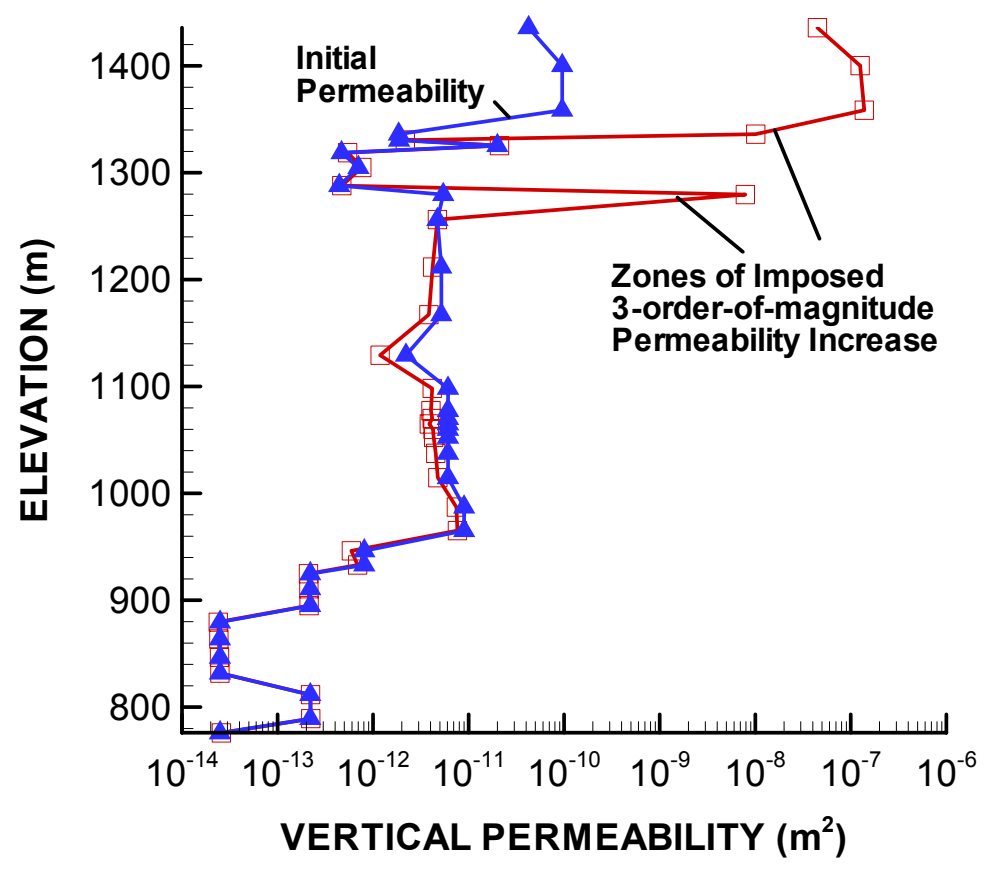

DTN: LB0310MTSCLTHM.002

Figure 6.5.14-3. Vertical Permeability at 10,000 Years along a Vertical Column at the Left Boundary of the Mountain-Scale THM Model, with an Imposed Three-Order-of-Magnitude Permeability Increase in Zone of Possible Fracturing near the Ground Surface 


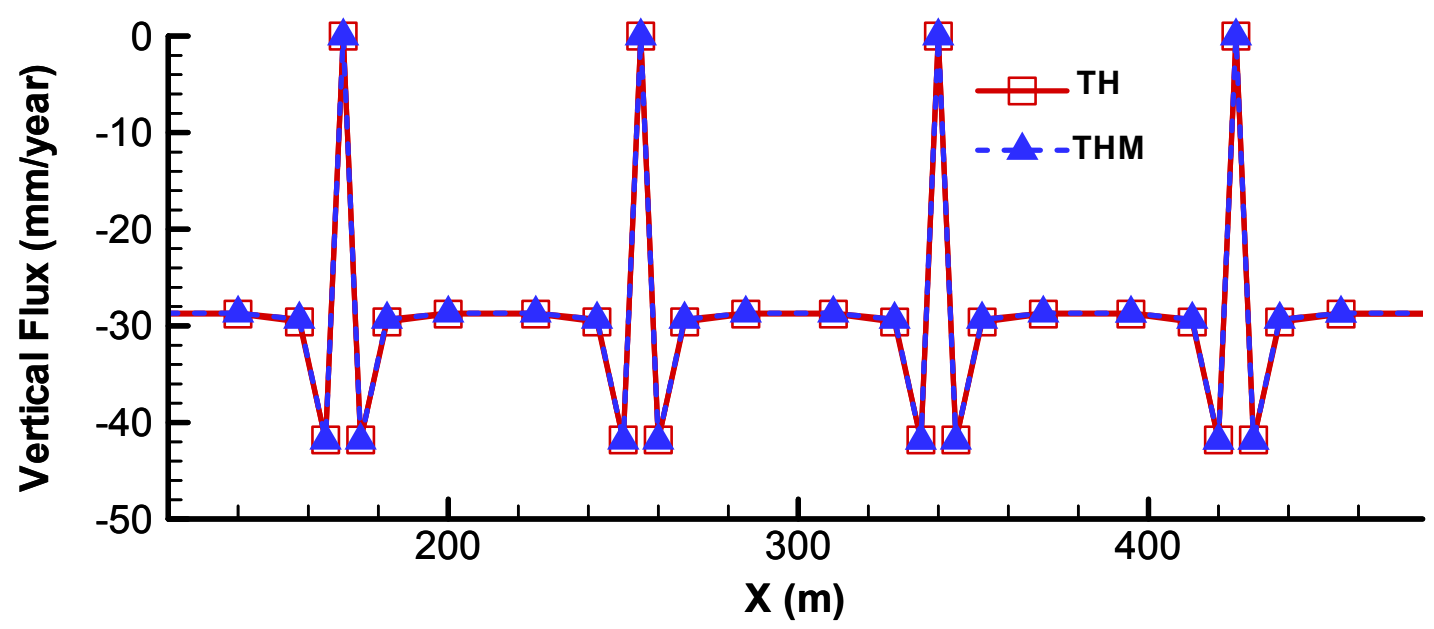

DTN: LB0310MTSCLTHM.002

Figure 6.5.13-4. Comparison of the Vertical Percolation Flux (Qz) across the Repository Horizon near Four Emplacement Drifts for a TH Simulation (solid red lines) and a Coupled THM Simulation, with Imposed Three-Order-of-Magnitude Permeability Change in Zone of Stress Relief Near Ground Surface (blue dashed line)

\subsubsection{Discussion of Uncertainties in the Mountain-Scale THM Results}

The model predictions in this analysis depend on a sufficiently accurate representation of TMinduced changes in hydraulic properties, and in particular changes in fracture permeability. In this context, potential sources for uncertainties were discussed in the Drift-Scale THM Model report (BSC 2003 [164890], Section 6.8): (1) simplified conceptualization of the fracture network geometry, (2) drift-wall inelastic behavior, (3) possible fracture-shear-induced permeability enhancement, (4) fracture stress-versus-permeability relationships, (5) effects of heterogeneous rock properties, and (6) mechanical properties of the Tptpll unit. Uncertainties related to hydrological and thermal properties, and to hydrological conditions such as infiltration rate, are most relevant for prediction of TH responses, whereas they are of secondary importance for estimating TM-induced changes in hydraulic properties. For example, uncertainties in the thermal conductivity will impact the temperature evolution and thereby the magnitude of the TM-induced stresses. However, in the Drift-Scale THM Model Report (BSC 2003 [164890], Section 6.8), it was concluded that the fracture normal stress-versus-permeability relationship is the most important for assessing the impact of coupled THM processes.

The relationship (discussed in Section 6.8.4 of BSC (2003 [164890]) is the key for an accurate assessment of possible stress-induced changes in hydraulic properties around the repository. The relationship provides limits for how much permeability can decrease or increase from the impact of stresses. In that study, the upper and lower limits of the normal stress-versus-permeability function were determined and validated against field experiments at Yucca Mountain. The stress-permeability function adopted for the predictive analysis with the Drift-Scale THM Model (BSC 2003 [164890], Section 6.4) was conservative, in the sense that it tends to result in larger permeability changes, and hence, have a larger impact on the percolation flux. It was concluded that model results in the Drift-Scale THM Model Report (BSC 2003 [164890], Sections 6.5 and 6.6) were obtained for a conservative estimate of input THM properties (thermal expansion 
coefficient and stress-versus-permeability function). This was deemed sufficient for bounding the possible impact of the THM processes on permeability and percolation flux at the drift-scale. An additional uncertainty for the Mountain-Scale THM Model is the upscaling of THM properties from drift scale to that of mountain scale. The upscaling of THM properties was discussed in Section 6.5.9. The adopted THM properties (thermal expansion coefficient and stress-versus-permeability relationship) for the mountain scale are based on a conservative upscaling from the already conservatively estimated drift-scale properties. Moreover, the flow simulation investigating the potential impact of fracturing and shear slip in areas of stress relief near the ground surface was conducted by imposing a conservative three-order-of-magnitude increase in permeability. Hence, the model results obtained in Section 6.5.10 through 6.5.14 of this Model Report are obtained for conservative estimates of the input THM properties, which are sufficient for bounding the possible impact of THM processes on permeability and percolation flux at the mountain scale. If thermal conductivity were lower, then the repository would be hotter and thermal stress would be greater. However, the fractures are already near residual aperture, so the effect on hydrology would be no greater. If thermal conductivity were higher, the repository would be cooler, and the effect would be less than predicted. 


\subsection{FEPS ADDRESSED IN THIS MODEL REPORT}

The features, events, and processes (FEPs) associated with this Model Report are described below and are taken from the LA FEP List (DTN: MO0307SEPFEPS4.000 [164527]). The LA FEP List is a revision to the previous project FEP list (Freeze et al. 2001 [154365]) used to develop the list of included FEPs in the Technical Work Plan for: Performance Assessment Unsaturated Zone (BSC 2002 [160819], Table 2-6). The selected FEPs are those taken from the LA FEP List that are associated with the subject matter of this report, regardless of the anticipated status for exclusion or inclusion in TSPA-LA as represented in BSC (2002 [160819]). The results of this model report are part of the basis for the treatment of FEPs as discussed in the Total System Performance Assessment-License Application Methods and Approach (BSC 2002 [160146], Section 3.2.2).

The results of this model report are used to support treatment of the FEPs for TSPA-LA. The UZ Department's documentation for the included FEPs is summarized in Table 6.6-1 from the supporting analysis reports and model reports, and can be found in the model abstraction reports as described in Sections 2.1.2 and 2.4 of the TWP (BSC 2002 [160819]) and the FEP report as described in Section 1.12 .10 of the TWP (BSC 2002 [160819]). Excluded FEPs are to be documented in the UZ FEPs analysis report BSC (2003 [164873]), as described in Section 1.12.10 of the TWP (BSC 2002 [160819]).

There are 27 FEPs in the LA FEP list for the UZ that are associated with this model report. These 27 FEPs are summarily described in Table 6.6-1. 
Table 6.6-1. FEPs Relevant to This AMR and Included into TSPA-LA

\begin{tabular}{|c|c|c|c|}
\hline $\begin{array}{l}\text { LA FEP } \\
\text { Number }\end{array}$ & FEP Name & YMP Description & $\begin{array}{l}\text { Sections Discussing } \\
\text { FEPs-Related Items In } \\
\text { this Model Report }\end{array}$ \\
\hline 1.1.02.02.0A & $\begin{array}{l}\text { Pre-closure } \\
\text { ventilation }\end{array}$ & $\begin{array}{l}\text { The duration of preclosure ventilation acts together with } \\
\text { waste package spacing (as per design) to control the } \\
\text { extent of the boiling front (zone of reduced water } \\
\text { content). }\end{array}$ & $6.1,6.2,6.3$ \\
\hline 1.2.02.01.0A & Fractures & $\begin{array}{l}\text { Groundwater flow in the Yucca Mountain region and } \\
\text { transport of any released radionuclides may take place } \\
\text { along fractures. The rate of flow and the extent of } \\
\text { transport in fractures are influenced by characteristics } \\
\text { such as orientation, aperture, asperity, fracture length, } \\
\text { connectivity, and the nature of any linings or infills. }\end{array}$ & $6.2,6.3,6.4 .3$ \\
\hline 1.2.02.02.0A & Faults & $\begin{array}{l}\text { Numerous faults of various sizes have been noted in } \\
\text { the Yucca Mountain Region and in the repository area } \\
\text { in specific. Faults may represent an alteration of the } \\
\text { rock permeability and continuity of the rock mass, } \\
\text { alteration or short-circuiting of the flow paths and flow } \\
\text { distributions close to the repository, and represent } \\
\text { unexpected pathways through the repository. }\end{array}$ & $6.1 .1,6.2,6.3$ \\
\hline 1.2.09.02.0A & $\begin{array}{l}\text { Large scale } \\
\text { dissolution }\end{array}$ & $\begin{array}{l}\text { Dissolution can occur when any soluble mineral is } \\
\text { removed by flowing water, and large-scale dissolution is } \\
\text { a potentially important process in rocks that are } \\
\text { composed predominantly of water-soluble evaporate } \\
\text { minerals, such as salt. }\end{array}$ & 6.4 .3 \\
\hline 1.3.01.00.0A & Climate change & $\begin{array}{l}\text { Climate change may affect the long-term performance } \\
\text { of the repository. This includes the effects of long-term } \\
\text { change in global climate (e.g., glacial/interglacial } \\
\text { cycles) and shorter-term change in regional and local } \\
\text { climate. Climate is typically characterized by temporal } \\
\text { variations in precipitation and temperature. }\end{array}$ & $6.1 .4,6.2,6.3$ \\
\hline 1.4.01.01.0A & $\begin{array}{l}\text { Climate modification } \\
\text { increases recharge }\end{array}$ & $\begin{array}{l}\text { Climate modification causes an increase in recharge in } \\
\text { the Yucca Mountain region. Increased recharge might } \\
\text { lead to increased flux through the repository, perched } \\
\text { water, or water table rise. }\end{array}$ & $6.1 .4,6.2,6.3$ \\
\hline 2.1.08.01.0A & $\begin{array}{l}\text { Water influx at the } \\
\text { repository }\end{array}$ & $\begin{array}{l}\text { An increase in the unsaturated water flux at the } \\
\text { repository affects thermal, hydrological, chemical, and } \\
\text { mechanical behavior of the system. Increases in flux } \\
\text { could result from climate change, but the cause of the } \\
\text { increase is not an essential part of the FEP. }\end{array}$ & $6.2,6.3$ \\
\hline 2.2.03.01.0A & Stratigraphy & $\begin{array}{l}\text { Stratigraphic information is necessary information for } \\
\text { the performance assessment. This information should } \\
\text { include identification of the relevant rock units, soils and } \\
\text { alluvium and their thickness, lateral extents, and } \\
\text { relationships to each other. Major discontinuities } \\
\text { should be identified. }\end{array}$ & 6.1 .1 \\
\hline 2.2.03.02.0A & $\begin{array}{l}\text { Rock properties of } \\
\text { host rock and other } \\
\text { units }\end{array}$ & $\begin{array}{l}\text { Physical properties such as porosity and permeability of } \\
\text { the relevant rock units, soils, and alluvium are } \\
\text { necessary for the performance assessment. Possible } \\
\text { heterogeneities in these properties should be } \\
\text { considered. Questions concerning events and } \\
\text { processes that may cause these physical properties to } \\
\text { change over time are considered in other FEPs. }\end{array}$ & 6.1 .6 \\
\hline
\end{tabular}


Table 6.6-1. FEPs Relevant to this AMR and Included into TSPA-LA (continued)

\begin{tabular}{|c|c|c|c|}
\hline $\begin{array}{l}\text { LA FEP } \\
\text { Number }\end{array}$ & FEP Name & YMP Description & $\begin{array}{l}\text { Sections Discussing } \\
\text { FEPs-Related Items In } \\
\text { this Model Report }\end{array}$ \\
\hline 2.2.07.02.0A & $\begin{array}{l}\text { Unsaturated } \\
\text { groundwater flow in } \\
\text { the geosphere }\end{array}$ & $\begin{array}{l}\text { Groundwater flow occurs in unsaturated rocks in most } \\
\text { locations above the water table at Yucca Mountain, } \\
\text { including at the location of the repository. See related } \\
\text { FEPs for discussions of specific issues related to } \\
\text { unsaturated flow. }\end{array}$ & $6.2,6.3$ \\
\hline 2.2.07.04.0A & $\begin{array}{l}\text { Focusing of } \\
\text { unsaturated flow } \\
\text { (fingers, weeps) }\end{array}$ & $\begin{array}{l}\text { Unsaturated flow can differentiate into zones of greater } \\
\text { and lower saturation (fingers) that may persist as } \\
\text { preferential flow paths. Heterogeneities in rock } \\
\text { properties, including fractures and faults, may } \\
\text { contribute to focusing. Focused flow may become } \\
\text { locally saturated. }\end{array}$ & $6.2,6.3$ \\
\hline 2.2.07.08.0A & $\begin{array}{l}\text { Fracture flow in the } \\
\text { UZ }\end{array}$ & $\begin{array}{l}\text { Fractures or other analogous channels act as conduits } \\
\text { for fluids to move into the subsurface to interact with } \\
\text { the repository and as conduits for fluids to leave the } \\
\text { vicinity of the repository and be conducted to the } \\
\text { saturated zone. Water may flow through only a portion } \\
\text { of the fracture network, including flow through a } \\
\text { restricted portion of a given fracture plane. }\end{array}$ & $6.2,6.3,6.4 .3$ \\
\hline 2.2.07.09.0A & $\begin{array}{l}\text { Matrix imbibition in } \\
\text { the UZ }\end{array}$ & $\begin{array}{l}\text { Water flowing in fractures or other channels in the } \\
\text { unsaturated zone is imbibed into the surrounding rock } \\
\text { matrix. This may occur during steady flow, episodic } \\
\text { flow, or into matrix pores that have been dried out } \\
\text { during the thermal period. }\end{array}$ & $6.2,6.3,6.4 .3$ \\
\hline 2.2.07.10.0A & $\begin{array}{l}\text { Condensation zone } \\
\text { forms around drifts }\end{array}$ & $\begin{array}{l}\text { Condensation of the two-phase flow generated by } \\
\text { repository heat forms in the rock where the temperature } \\
\text { drops below the local vaporization temperature. Waste } \\
\text { package emplacement geometry and thermal loading } \\
\text { will affect the scale at which condensation caps form } \\
\text { (over waste packages, over panels, or over the entire } \\
\text { repository), and to the extent to which "shedding" will } \\
\text { occur as water flows from the region above one drift to } \\
\text { the region above another drift, or into the rock between } \\
\text { drifts. }\end{array}$ & $\begin{array}{l}6.2 .1,6.2 .2,6.3 .1,6.3 .2 \\
6.4 .3\end{array}$ \\
\hline 2.2.07.11.0A & $\begin{array}{l}\text { Resaturation of } \\
\text { geosphere dryout } \\
\text { zone }\end{array}$ & $\begin{array}{l}\text { Following the peak thermal period, water in the } \\
\text { condensation cap may flow downward into the drifts. } \\
\text { Influx of cooler water from above, such as might occur } \\
\text { from episodic flow, may accelerate return flow from the } \\
\text { condensation cap by lowering temperatures below the } \\
\text { condensation point. Percolating groundwater will also } \\
\text { contribute to resaturation of the dry out zone. Vapor } \\
\text { flow, as distinct from liquid flow by capillary processes, } \\
\text { may also contribute. }\end{array}$ & $6.2,6.3,6.4 .3$ \\
\hline
\end{tabular}


Table 6.6-1. FEPs Relevant to this AMR and Included into TSPA-LA (continued)

\begin{tabular}{|c|c|c|c|}
\hline $\begin{array}{l}\text { LA FEP } \\
\text { Number }\end{array}$ & FEP Name & YMP Description & $\begin{array}{l}\text { Sections Discussing } \\
\text { FEPs-Related Items In } \\
\text { this Model Report }\end{array}$ \\
\hline 2.2.07.19.0A & $\begin{array}{l}\text { Lateral flow from } \\
\text { Solitario Canyon fault } \\
\text { enters drifts }\end{array}$ & $\begin{array}{l}\text { Water movement down Solitario Canyon fault could } \\
\text { enter waste emplacement drifts through lateral flow } \\
\text { mechanisms in the Topopah Spring welded } \\
\text { hydrogeologic unit. This percolation pathway is more } \\
\text { likely to transmit episodic transient flow to waste } \\
\text { emplacement locations due to the major fault pathway } \\
\text { through the overlying units. }\end{array}$ & 6.3 \\
\hline 2.2.10.01.0A & $\begin{array}{l}\text { Repository-induced } \\
\text { thermal effects on } \\
\text { flow in the UZ }\end{array}$ & $\begin{array}{l}\text { Thermal effects in the geosphere could affect the long- } \\
\text { term performance of the disposal system, including } \\
\text { effects on groundwater flow (e.g., density-driven flow), } \\
\text { mechanical properties, and chemical effects in the UZ. }\end{array}$ & $6.2,6.3$ \\
\hline 2.2.10.04.0A & $\begin{array}{l}\text { Thermal-Mechanical } \\
\text { Stresses Alter } \\
\text { Characteristics of } \\
\text { Fractures near } \\
\text { Repository }\end{array}$ & $\begin{array}{l}\text { Heat from the waste causes thermal expansion of the } \\
\text { surrounding rock, generating changes in the stress field } \\
\text { that may change the fracture properties (both } \\
\text { hydrologic and mechanical) of fractures in the rock. } \\
\text { Cooling following the peak thermal period will also } \\
\text { change the stress field, further affecting fracture } \\
\text { properties near the repository. }\end{array}$ & $\begin{array}{l}\text { Section } 6.5 .12 ; \text { A more } \\
\text { detailed discussion of the } \\
\text { effects of thermal- } \\
\text { mechanical stresses on } \\
\text { fracture characteristics } \\
\text { near waste emplacement } \\
\text { drifts is given in BSC } \\
(2003 \text { [164890], see Table } \\
6-2) .\end{array}$ \\
\hline 2.2.10.04.0B & $\begin{array}{l}\text { Thermal-mechanical } \\
\text { stresses alter } \\
\text { characteristics of } \\
\text { faults near repository }\end{array}$ & $\begin{array}{l}\text { Heat from the waste causes thermal expansion of the } \\
\text { surrounding rock, generating changes to the stress field } \\
\text { that may change the fault properties (both hydrologic } \\
\text { and mechanical) in and along faults. Cooling following } \\
\text { the peak thermal period will also change the stress } \\
\text { field, further affecting fault properties near the } \\
\text { repository. }\end{array}$ & 6.5 \\
\hline 2.2.10.05.0A & $\begin{array}{l}\text { Thermal-mechanical } \\
\text { stresses alter } \\
\text { characteristics of } \\
\text { rocks above and } \\
\text { below the repository }\end{array}$ & $\begin{array}{l}\text { Thermal-mechanical compression at the repository } \\
\text { produces tension-fracturing in the PTn and other units } \\
\text { above the repository. These fractures alter unsaturated } \\
\text { zone flow between the surface and the repository. } \\
\text { Extreme fracturing may propagate to the surface, } \\
\text { affecting infiltration. Thermal fracturing in rocks below } \\
\text { the repository affects flow and radionuclide transport to } \\
\text { the saturated zone. }\end{array}$ & 6.5 \\
\hline 2.2.10.06.0A & $\begin{array}{l}\text { Thermal-chemical } \\
\text { alteration in the UZ } \\
\text { (solubility, speciation, } \\
\text { phase changes, } \\
\text { precipitation/dissoluti } \\
\text { on) }\end{array}$ & $\begin{array}{l}\text { Thermal effects may affect radionuclide transport } \\
\text { directly by causing changes in radionuclide speciation } \\
\text { and solubility in the UZ or indirectly, by causing } \\
\text { changes in the host rock mineralogy that affect the flow } \\
\text { path. Relevant processes include volume effects } \\
\text { associated with silica phase changes, precipitation and } \\
\text { dissolution of fracture-filling minerals (including silica } \\
\text { and calcite), and alteration of zeolites and other } \\
\text { minerals to clays. }\end{array}$ & 6.4 .3 \\
\hline
\end{tabular}


Table 6.6-1. FEPs Relevant to this AMR and Included into TSPA-LA (continued)

\begin{tabular}{|c|c|c|c|}
\hline $\begin{array}{l}\text { LA FEP } \\
\text { Number }\end{array}$ & FEP Name & YMP Description & $\begin{array}{l}\text { Sections Discussing } \\
\text { FEPs-Related Items In } \\
\text { this Model Report }\end{array}$ \\
\hline 2.2.10.07.0A & $\begin{array}{l}\text { Thermal-chemical } \\
\text { alteration of the } \\
\text { Calico Hills unit }\end{array}$ & $\begin{array}{l}\text { Fracture pathways in the Calico Hills are altered by the } \\
\text { thermal and chemical properties of the water flowing } \\
\text { out of the repository. }\end{array}$ & 6.4 .3 \\
\hline 2.2.10.09.0A & $\begin{array}{l}\text { Thermal-chemical } \\
\text { alteration of the } \\
\text { Topopah Spring } \\
\text { basal vitrophyre }\end{array}$ & $\begin{array}{l}\text { Heating the Topopah Spring basal vitrophyre with water } \\
\text { available causes alteration of the glasses to clays and } \\
\text { zeolites. Possible effects include volume increases that } \\
\text { plug fractures, changes in flow paths, creation of } \\
\text { perched water zones, and an increase in the sorptive } \\
\text { properties of the unit. }\end{array}$ & 6.4 .3 \\
\hline 2.2.10.10.0A & $\begin{array}{l}\text { Heat from waste } \\
\text { generates two-phase } \\
\text { buoyant flow }\end{array}$ & $\begin{array}{l}\text { The vapor phase (water vapor) escapes from the } \\
\text { mountain. A heat pipe consists of a system for } \\
\text { transferring energy between a hot and a cold region } \\
\text { (source and sink respectively) using the heat of } \\
\text { vaporization and movement of the vapor as the transfer } \\
\text { mechanism. Two-phase circulation continues until the } \\
\text { heat source is too weak to provide the thermal } \\
\text { gradients required to drive it. Alteration of the rock } \\
\text { adjacent to the drift may include dissolution which } \\
\text { maintains the permeability necessary to support the } \\
\text { circulation (as inferred for some geothermal systems). }\end{array}$ & $6.2 .1,6.2 .2,6.3 .1,6.3 .2$ \\
\hline 2.2.10.12.0A & $\begin{array}{l}\text { Geosphere dryout } \\
\text { due to waste heat }\end{array}$ & $\begin{array}{l}\text { Repository heat evaporates water from the UZ rocks } \\
\text { near the drifts as the temperature exceeds the } \\
\text { vaporization temperature. This zone of reduced water } \\
\text { content (reduced saturation) migrates outward during } \\
\text { the heating phase (about the first } 1000 \text { years) and then } \\
\text { migrates back to the containers as heat diffuses } \\
\text { throughout the mountain and the radioactive sources } \\
\text { decay. This FEP addresses the effects of dry-out } \\
\text { within the rocks. }\end{array}$ & $6.2 .1,6.2 .2,6.3 .1,6.3 .2$ \\
\hline $2.2 .10 .14 .0 \mathrm{~A}$ & $\begin{array}{l}\text { Mineralogic } \\
\text { dehydration reactions }\end{array}$ & $\begin{array}{l}\text { Mineralogic dehydration reactions release water } \\
\text { affecting hydrologic conditions. Dehydration of zeolites } \\
\text { below the repository may lead to large-scale volume } \\
\text { changes affecting flow and/or drift stability. }\end{array}$ & 6.4 \\
\hline 2.3.11.03.0A & $\begin{array}{l}\text { Infiltration and } \\
\text { recharge }\end{array}$ & $\begin{array}{l}\text { Infiltration into the subsurface provides a boundary } \\
\text { condition for groundwater flow. The amount and } \\
\text { location of the infiltration influences the hydraulic } \\
\text { gradient and the height of the water table. Different } \\
\text { sources of recharge water could change the chemistry } \\
\text { of groundwater passing through the repository. Mixing } \\
\text { of these waters with other groundwaters could result in } \\
\text { precipitation, dissolution, and altered chemical } \\
\text { gradients. }\end{array}$ & 6.1 .4 \\
\hline
\end{tabular}




\section{VALIDATION}

Validation of a model normally requires testing model results against relevant data not used in the original model development. Direct validation of the mountain-scale coupled-processes TH/THC/THM models in this Model Report will require field data on a mountain scale over a long period of time (more than 1,000 years). Earliest data on mountain-scale coupled-processes may become available only after the repository is fully operational. Because no such data are available or are likely to become available soon, the validity of the models and modeling approaches is demonstrated using corroborative work in this field and the previously published UZ numerical modeling studies, journal papers, technical reviews, and drift-scale test.

Validation activities for the mountain-scale TH, THC, and THM models are carried out based on the Technical Work Plan for: Performance Assessment Unsaturated Zone (BSC 2002 [160819], Attachment I-3-1). According to this technical work plan (Section 2.7.3), this kind of indirect validation for the mountain-scale coupled-processes is acceptable and sufficient for the level I validation required for TH, THM, and THC models.

This Model Report consists of three coupled-processes models, i.e., TH, THC and THM models. Accordingly, the model validation efforts of this section consist of the following three parts:

1. Validation of the TH model

2. Validation of the THC model

3. Validation of the THM model.

\subsection{VALIDATION OF THE MOUNTAIN-SCALE TH MODEL}

The requirements for validation of this model are presented in Confidence Building during Model Development and Post-Development Validation Activities in BSC 2002 ([160819], Attachment I-3-1, pp. 32-34). The development of the model has been in accordance with the requirements of Section 5.3.3 (b) of AP-SIII.10Q. Confidence building will involve one or more of the following items:

- Discussion and justification of the use of input parameters and/or input data

- Discussion and justification of the approach for the establishment of the initial and boundary conditions

- Discussion and evaluation of the impact of the aggregate and input uncertainties on the model results, and sensitivity analysis to support the conclusions.

The TH models are validated - that is, confidence in the models is gained - by one or more of the following methods listed in AP-SIII.10Q, Section 5.3.3 (c). These methods are Method 2, Corroboration with Alternative Mathematical Models; Method 3, Corroboration with Data from Literature; which may be used when the relevant models and data become available; and publication in a refereed professional journal (for corroboration). The efforts of this section have 
provided validation of the mountain-scale $\mathrm{TH}$ Model for their accuracy and reliability in describing TH conditions under proposed thermal loading in the Yucca Mountain UZ.

\subsubsection{Validation of the Physical Processes}

Two-phase fluid flow and heat transfer in a fractured geological medium are the main focus of this Model Report. Such fluid flow and heat-transfer processes consist of some or all of the following physical processes: heat conduction, convective heat transfer, flow of liquid water and air/water vapor, vaporization and condensation, drainage through fractures and imbibition into matrix, and capillary effects. These processes have been routinely modeled and numerically simulated in the geothermal and petroleum reservoir engineering disciplines. Such numerical models of geothermal and petroleum systems have also been validated against a wealth of fieldscale tests and production data.

Aside from this, these same processes have been modeled at a smaller (space and time) scale in the Drift-Scale Coupled Processes (DST and TH Seepage) Model Report (BSC 2003 [161530]). The model results in that AMR were compared with measured temperature and saturation data from the Drift Scale Test (DST) at Yucca Mountain. The DST is the largest of the three thermal field tests performed at Yucca Mountain. The heating phase in the DST lasted slightly more than four years, and a large volume of rock was heated to temperatures close to and above boiling. Considerable high-quality TH/THM/THC data were collected from the DST. These data gave an adequate representation of the likely $\mathrm{TH} / \mathrm{THM} / \mathrm{THC}$ processes to be encountered in the nearfield of the emplacement drifts. Through a detailed comparison of measured and simulated TH/THM/THC data, it was concluded in BSC 2003 [161530] that the physical processes were adequately represented by the model. This builds confidence into the mountain-scale coupledprocesses models, since the underlying flow and heat transfer processes are identical both in the drift-scale and in the mountain-scale of this AMR. However, the thermal tests (including the DST) provide only limited data for calibration and validation of the numerical models. The small spatial and temporal scales limit validation of the mountain-scale models. The validation is also limited by the uncertainties arising from parameter estimates in a geologically complex system and the upscaling of drift-scale results to the UZ Mountain-Scale Model.

\subsubsection{Validation of the Numerical Modeling Approach}

In the absence of direct data to validate the mountain-scale coupled-processes models, validations of the modeling approach must rely mainly on the conceptual and mathematical validity of models. The analyses conducted in this AMR are intended to provide the mountainscale response to thermal loading under the proposed thermal-loading conditions. The numerical models are used to determine the effect of thermal loading on mountain-scale liquid and gas flux, temperature, and moisture distribution in the UZ. In these models, the relevant thermal-hydrological conditions at the potential repository are explicitly represented over the applicable time and space scale. Contemporary practice in modeling fluid-flow and heat-transfer processes has been incorporated in our approach. The formulation of simulation code TOUGH2 V1.6 (LBNL 2003 [161491]) allows numerical modeling of such processes. The following few paragraphs provide evidence of successful application of TOUGH2 in modeling two-phase flow and heat transfer in an unsaturated geological medium. 
Versions of TOUGH2 (Pruess et al. 1999 [160778]) have been used in a number of numerical models for evaluating the thermal-hydrological effects of thermal loading at Yucca Mountain (Pruess and Tsang 1994 [117451]; Buscheck et al. 1994 [105157]; Haukwa et al. 1999 [137562]; Haukwa et al. 2003 [165165]). Model conceptualizations have focused mainly on large-scale average behavior or on local simplified domains of two-dimensional representations. Both the ECM and dual-permeability methods have been used in previous applications of TOUGH2 in modeling two-phase flow and heat transfer through fractured rock. This present AMR considers only the dual-permeability approach for handling fracture-matrix interaction.

Various versions of the TOUGH2 code have also been used in sensitivity studies on thermalhydrological conditions near an infinite linear string of waste packages, as reported by Pruess and Wang (1984 [140912]). They modeled fluid and heat flow (including phase change effects) in a one-dimensional cylindrical geometry. They found that strong two-phase vapor-liquid counter flow (heat pipe) occurred in some cases. Tsang and Pruess (1987 [100688]) conducted repository-scale simulations with an emphasis on thermally driven natural convection. Nitao (1988 [109911]) considered details of temperature, saturation, and gas-phase composition in the hydrothermally disturbed zone. This was modeled using a $3 \mathrm{~km}$ diameter, disk-shaped repository to examine the thermal-hydrological responses. Pruess et al. (1990 [100818]; 1990 [100819]) used a previous version of TOUGH2 to perform a comprehensive modeling study of simultaneous transport of heat, liquid water, vapor, and air in a partially saturated fractured porous rock. They used a two-dimensional idealized model and included an explicit consideration of fracture effects. Their model included most of the physical effects that are important in multiphase fluid and heat flow in fractured media. They demonstrated the capability of modeling multiphase, nonisothermal flow of water and air with phase changes in a fractured medium.

The TOUGH2 family of codes has also been used in several numerical models of the natural state of geothermal systems (Bodvarsson et al. 1984 [137136]; 1986 [136386]; 1988 [138603]; Hanano 1992 [137307]; Ingebritsen et al. 1988 [137537]; O'Sullivan et al. 1990 [137409]) and in the predictions of their performance under exploitation (Bodvarsson et al. 1984 [137139]; 1987 [136391]; 1987 [136393]; 1990 [136384]; 1993 [138618]; Garg and Pritchett 1990 [137148]; Hunt et al. 1990 [137322]; Lam et al. 1988 [137338]; Menzies et al. 1991 [137923]). Mathematical models of the two-phase flow in such systems are identical to numerical modeling of $\mathrm{TH}$ response to thermal loading described in this Model Report. Major differences exist, mainly in equations correlating flow and saturation and the existence of preferential flow paths in UZ flow for heterogeneous media (e.g., fingering and flow channeling). The other major difference is in the time scale of modeled behavior. For example, evolution of the natural state of geothermal systems is typically modeled over a period of a few hundred to several hundred thousand years. The exploitation prediction is over a period of 30-50 years, the economic life of such systems based on measured field response. On the other hand, modeling of the mountainscale TH response requires numerical prediction for tens of thousands of years in a system for which limited field data exist. In many ways, however, the process for setting up the conceptual model, building the numerical grid, specifying boundary conditions, developing the natural state, and conducting numerical model predictions is the same, and is documented in the cited references as well as in this AMR. 
The modeling efforts described above demonstrate the capability of TOUGH2 to model TH processes on a mountain scale, in addition to the validity of process models and the assumptions used. Mass, momentum, and energy are inherently conserved in the mathematical formulation or numerical modeling results with the TOUGH2 family of codes. This adds further confidence to the numerical models.

\subsubsection{Confidence Building through Publication}

For corroboration, the mountain-scale impact of thermal loading at Yucca Mountain has also been published in the open scientific literature (Haukwa et al. 1999 [137562]; Haukwa et al. 2003 [165165]). These journal publications have gone through anonymous technical review and public scientific scrutiny. Since the processes modeled in those two papers occur at spatial and temporal scales similar to the ones in this MR, these publications corroborate, through independent technical review, the validation documented in this MR. Furthermore, the underlying physical processes and model validation with measured data have also undergone anonymous technical review in the open literature (Birkholzer and Tsang 2000 [154608]; Mukhopadhyay and Tsang 2003 [160790]), though these papers are concerned mainly with processes at a smaller time and space scale. Additionally, the basic formulations of physical processes implemented in this Model Report, as represented by two-phase flow equations (Pruess et al. 1999 [160778], pp. 144-145), the van Genuchten-Mualem model (Luckner et al. 1989 [100590], pp. 2191-2192), and an active fracture model (Liu et al. 1998 [105729]) for representation of preferential flow paths through selected fractures, are all in the open literature, have gone through proper technical review, and have withstood scrutiny of the scientific community since their dates of publication.

No further activities are needed to complete this TH model validation before LA for its intended use.

\subsection{MOUNTAIN-SCALE THC MODEL VALIDATION}

The Mountain-Scale THC model cannot be validated directly by experimental data over the relevant time and spatial scales of the system (millennia and kilometers). However, confidence in the Mountain-Scale THC Model results can be gained via the validation of the Drift Scale Test (DST) THC Model (Drift-Scale Coupled Processes (DST and THC Seepage) Models; BSC 2003 [162050], Section 7.1). Validity of the Drift-Scale THC Model gives confidence in the Mountain-Scale THC model because: (1) rock thermal properties are qualified data based on laboratory data and field surveys at the same location and are identical in values used in the Drift-Scale THC Model, where stratigraphic units are the same; (2) rock hydrological properties are qualified data based on field measurements and calibrated at an appropriate scale for Mountain-scale THC Model; (3) constitutive relationships are consistent with the one used for the Drift-Scale THC Model; and (4) the same THC conceptual and process model applies to both Drift-Scale and Mountain-Scale THC Models. In this section, the validity of the Mountain-Scale THC Model is demonstrated through reviewing the validation of the Drift-Scale THC Model and by demonstrating consistency in the model results output by the Mountain-Scale and Drift-Scale THC Models. 
This section describes models and data used to provide confidence in the Mountain-Scale thermal-hydrological-chemical (THC) Model. The following methods are used to evaluate mountain-scale THC effects on flow and geochemistry: the estimation of thermodynamic and kinetic parameters; testing and model validation using large-scale thermal test and laboratory experiments, and predictive process modeling. This approach was chosen because it provides the means to test the appropriateness of the conceptual model, to evaluate uncertainties in different conceptual models, and to provide predictions of potential effects on water and gas chemistry, as well as changes in hydrological properties that result in changes in flow.

The DST THC Model and validation of model simulation results to measurements are presented in Drift-Scale Coupled Processes (DST and THC Seepage) Models (BSC 2003 [162050]) and summarized below in Section 7.2.3. The validation of the THC models by comparison to chemical data on water and gas samples is subject to a variety of uncertainties. These uncertainties are discussed in detail throughout Section 7 of BSC 2003 [162050].

\subsubsection{Model Validation Methods, Criteria, and Limitations}

In the following sections, data and predictions are reviewed to demonstrate that the criteria specified in the TWP have been met for the Mountain-Scale THC Model. The Mountain-Scale THC Model uses the same conceptualization and mathematical treatment of THC coupledprocesses as the DST THC Model, including the same thermodynamic and kinetic data. Therefore, validation by comparison to the DST effectively corroborates the Mountain-Scale THC Model in the range of phenomena active at the scale a few hundred meters and a time scale of several years. It is important to recognize that although the DST THC Model validates the methodology and inputs used in the Mountain-Scale THC Model, the time scales of interest are different by several orders of magnitude, and thus the relative importance of various reactiontransport processes can lead to modifications in the long-term behavior.

The models were validated - that is, needed confidence in the models was gained - by the following methods listed in AP-SIII.10Q, Section 5.3.3 (c). These are: Method 1, Corroboration with Experimental Data; and publication in a refereed professional journal (for corroboration). These validation methods provide confidence in the conceptual and numerical models and their outputs.

\subsubsection{Validation Method 1-Corroboration with Experimental Data}

Data from the DST used for comparison consist of analyses of water and gas samples from borehole intervals between packers and observations of mineral precipitation in boreholes. Intervals were selected for comparison based upon the availability of a long, continuous sample record and the absence of confounding factors, such as the sampling interval being too long to compare with a particular gridblock or pair of gridblocks, or boreholes being near either end of the DST and affected by three-dimensional transport (see below). The locations of the hydrology boreholes, sampling intervals, and temperature sensors are shown in Figure 7.1-2 in BSC 2003 [162050].

Differences between the DST THC Model predictions and the DST measurements are important to this validation. There are several reasons (listed below) why observations may disagree with 
predictions, and yet be consistent with validation of the DST THC Model. Individual data points may not agree closely with model predictions, but model validation requirements can be met. It is important that these considerations are kept in mind when reviewing the model comparisons to measured data.

1. The DST THC model is a continuum model, using average hydrological, thermal, and mineralogical properties for individual hydrostratigraphic units at Yucca Mountain, rather than specifically for the DST.

2. The continuum model does not simulate individual fractures, which may intersect boreholes near sampling points, their aperture and frequency resulting in different flow rates and temperatures, thus affecting the chemistry of the gas and water samples in that interval.

3. All samples were taken from long borehole intervals (approximately $8-10 \mathrm{~m}$ long), which cross regions of large gradients in gas species concentrations (up to a few orders of magnitude) and exhibit temperature variations of tens of degrees. Furthermore, the samples are known to have been derived only from the borehole itself and may not have the same composition as the gas and liquid flowing in fractures. In addition, waters collected from boreholes have resided in the boreholes for different lengths of time, interacting with the surface of the borehole, interchanging components with the matrix, affected by gas flow and condensation in the borehole, and interacting with engineered materials. In contrast, the model results represent compositions in fractures or matrix at an instant in time.

4. The model represents a two-dimensional slice taken approximately at mid-length of the DST; it does not simulate transport in the third dimension. A 3-D model at the minimum resolution required for a reactive-transport simulation would have in excess of 100,000 gridblocks, which would be computationally infeasible (several months or more of computation time). Because the initial permeabilities and geochemical properties are unknown at every point inside the rock, a 3-D model would not be expected to significantly improve matches to geochemical data, because the model would still rely on average properties. Although a 3-D model would reduce some of the uncertainty because of slight improvements in capturing the distribution of heat, fluid, and chemical species transport, it would not yield any significant improvement in the conceptual understanding or validation of the model approach and input data.

5. The model does not consider all deviations from planned operation. These deviations include the exact time periods of power losses, variations or uncertainty in heat losses through the bulkhead, changes in pressure owing to forced ventilation, the effect of the many boreholes on the behavior of the system, and barometric pressure changes. Because of this, and reasons 1,2, and 4 above, the changes occurring at a particular time in the model may be shifted from that occurring in the DST by several months or more, depending on the time when the temperatures are similar or the point at which water completely evaporates.

6. Gas and water samples are affected by condensation of water vapor as the sample cools in the collection tubes from the borehole interval to the sample containers. This results in a variety of changes to the gas and water compositions. $\mathrm{CO}_{2}$ concentrations in the gas can 
increase dramatically as the water vapor is preferentially removed from the gas. Many aqueous species concentrations will become lower as the sample is diluted by pure water condensed in the tubes and mixed with the water being sampled. The $\mathrm{pH}$ of the water may drop as the pure condensate formed under elevated partial pressures of $\mathrm{CO}_{2}$ is mixed with the water from the borehole.

7. Given these considerations, and the model requirements in mind, the criterion for model validation is that any two of these three criteria be satisfied for a majority of the samples collected (but not all samples if conditions as given above are expected to be important).

8. Observed concentrations of gas and aqueous species match predicted concentrations within an order of magnitude (e.g., one $\mathrm{pH}$ unit). This range is reasonable because chemical potential is proportional to the logarithm of concentration.

9. The simulated trend of $\mathrm{CO}_{2}$ over time in the sampling interval is clearly followed. "Clearly followed" is understood to mean that model and observations show the same initial trend of increase or decrease, and any observed reversal is predicted. Simulated $\mathrm{CO}_{2}$ concentrations will be within one order of magnitude of measured data.

10. Observations of mineral precipitation will agree qualitatively with predictions of locations where mineral precipitation is most likely to occur.

\subsubsection{Confidence Building through Publication in Peer-Reviewed Journals}

Confidence building in the modeling approaches has been gained by publication in refereed technical journals as allowed by AP-SIII.10Q, Section 5.3.3 (d) (Xu et al. 2001 [161864]; Dobson et al. 2003 [165949], and Spycher et al. 2003 [162121]).

\subsubsection{Summary of Validation to DST Geochemical Data and Lab Experiments}

The following data and model results were examined in BSC 2003 [162050]. In this section, only data and model results pertaining to the DST are listed.

- Temperature measurements

- Gas-phase $\mathrm{CO}_{2}$ concentrations

- Evolution in the $\mathrm{pH}$ of waters from the DST

- Evolution of anion and cation concentrations

- Mineralogical changes

- Porosity and permeability changes

- Model corroboration using ${ }^{14} \mathrm{C}$ in $\mathrm{CO}_{2}$

- Plug-flow reactor experiment

- Fracture sealing experiment 


\subsubsection{Summary of the DST THC Model and Validation to Measured Data}

\subsubsection{Conceptual Model for THC Processes}

The evolution of the chemical regime in the unsaturated zone surrounding a heat source is closely related to the spatial distribution of temperature and the transport of water and vapor in the system. An important aspect of the unsaturated fractured tuff at Yucca Mountain is that the highly permeable fractures are nearly dry, and the low permeability and porosity rock matrix has a water saturation of about $90 \%$. Thus, heating of the rock induces boiling of the matrix pore water, vapor transport into fractures, and condensation along fracture walls. A numerical model for reaction-transport processes in the fractured welded tuffs must account for the different rates of transport in fractures, compared to a much less permeable rock matrix. Transport rates greater than the rate of equilibration via diffusion leads to disequilibrium between waters in fractures and matrix. Because the system is unsaturated, and undergoes boiling, the transport of gaseous species, especially $\mathrm{CO}_{2}$, is an important consideration. The model must also capture the differences in initial mineralogy in fractures and matrix and their evolution.

\subsubsection{Numerical Grid and Properties}

The two-dimensional dual-permeability grid for the DST represents a vertical cross section through the Heated Drift at a distance approximately $30 \mathrm{~m}$ from the bulkhead, separating the Heated Drift from the Access Drift (Figure 7.2-1).

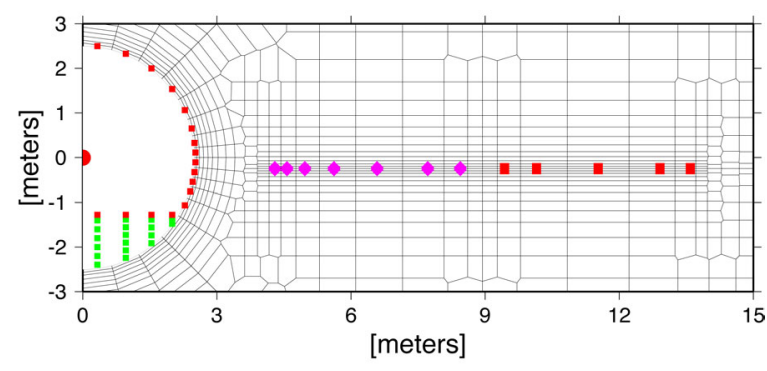

DTN: LB0307DSTTHCR2.001 [166054]

Figure 7.2-1. Enlargement of 2-D Numerical Mesh for the DST Showing Locations of Central Canister Heater (Red Circle), Wing Heater Locations (Purple Diamonds and Red Squares), Concrete Invert (Green Squares), and Drift Wall Blocks (Small Red Squares).

The top boundary is approximately $99 \mathrm{~m}$ above the drift center, with the bottom boundary at approximately $157 \mathrm{~m}$ below the center. Small gridblocks are employed adjacent to the wing heaters and drift wall to capture the strong gradients in temperature and liquid saturation in these regions. The Heated Drift gridblock is connected directly to the Heater Test Alcove gridblock and the connection area and distance were adjusted so that heat loss from the drift resulted in crown temperatures roughly similar to the maximum observed values. This was done to simulate heat and mass losses through the bulkhead, instead of reducing power by a set factor. In the approximate location of the observation drift, the gridblock volumes were increased to a large value to represent connection to the atmosphere. 


\subsubsection{Geochemical Model}

To handle separate yet interacting processes in fractures and matrix, the dual permeability method has been adopted, such that each gridblock is represented in both matrix and fracture continua, each characterized by its own pressure, temperature, liquid saturation, water and gas chemistry, and mineralogy. Simulations of THC processes include coupling between heat, water, and vapor flow; aqueous and gaseous species transport; kinetic and equilibrium mineral-water reactions; and feedback of mineral precipitation/dissolution on porosity, permeability, and capillary pressure.

Aqueous species included in the model are $\mathrm{H}^{+}, \mathrm{Ca}^{2+}, \mathrm{Na}^{+}, \mathrm{K}^{+}, \mathrm{SiO}_{2}(\mathrm{aq}), \mathrm{Mg}^{2+}, \mathrm{Al}^{3+}, \mathrm{Fe}^{3+}, \mathrm{SO}_{4}^{2-}$, $\mathrm{HCO}^{3-}, \mathrm{Cl}^{-}$, and $\mathrm{F}^{-}$, and $\mathrm{NO}^{3-}$. The initial pore water chemistry is based on a sample that was ultracentrifuged from the repository host rock (Tptpmn). Minerals considered include silica phases ( $\alpha$-cristobalite, quartz, tridymite, amorphous silica, and opal-CT), calcite, feldspars, smectites, illite, kaolinite, sepiolite, zeolites, fluorite, hematite, and gypsum. Treatment of $\mathrm{CO}_{2}$ includes gas-water equilibration, diffusion, and advection. Simulations were performed in BSC 2003 [162050] using TOUGHREACT V3.0 (LBNL 2002 [161256]).

\subsubsection{Gas-Phase $\mathrm{CO}_{2}$ Evolution}

The concentration of $\mathrm{CO}_{2}$ in the gas phase is a function of temperature, pressure, aqueous-phase chemistry, mineral-water reactions, and advective and diffusive transport. From a model validation standpoint, the strong effect of $\mathrm{CO}_{2}$ partial pressure on water $\mathrm{pH}$ and the final brine composition formed upon evaporation give importance to the analysis of $\mathrm{CO}_{2}$ concentrations. Simulation results are compared to concentrations measured in gas samples taken from boreholes during the heating phase of the DST. $\mathrm{CO}_{2}$ concentrations in gases collected from the DST also provide a qualitative measure of the influence of atmospheric gas on the system, because of the relatively low and constant value in the atmosphere ( $\approx 400 \mathrm{ppmv})$.

The modeled evolution of $\mathrm{CO}_{2}$ has been validated by comparison to over 4 years of measurements from the Drift Scale Test. Simulated $\mathrm{CO}_{2}$ concentrations in the fracture gas phase are shown after 3 years of heating in Figure 7.2-2. The results show the general outward migration of elevated $\mathrm{CO}_{2}$ concentrations as the boiling front moves outward. The peak in $\mathrm{CO}_{2}$ concentrations takes place at approximately $60^{\circ} \mathrm{C}$, above which the concentrations generally decline as a result of degassing and transport with water vapor to cooler regions. 


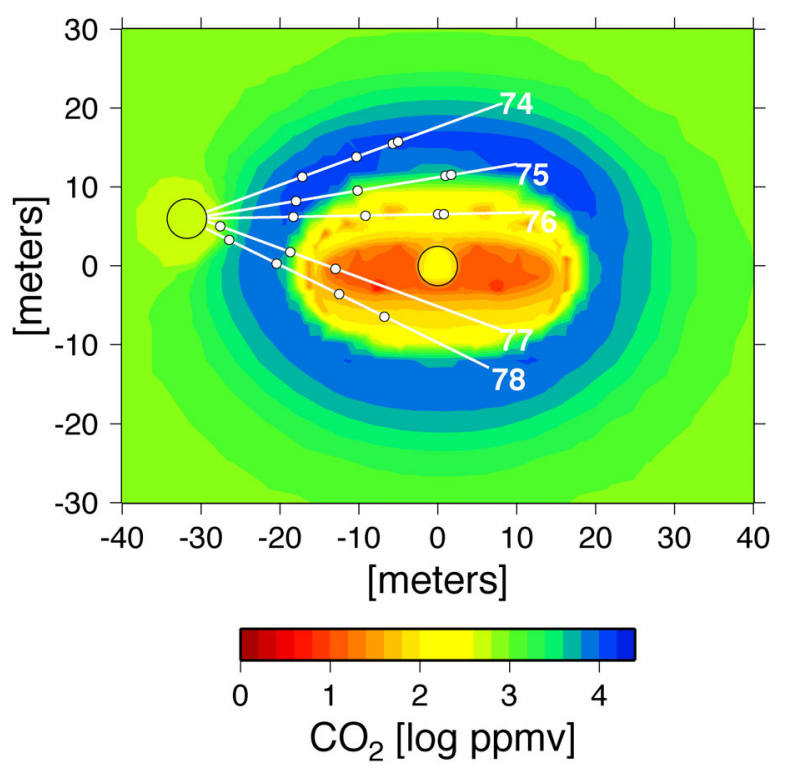

DTN: LB0307DSTTHCR2.001 [166054]

NOTE: Locations of boreholes collared in the Observation Drift (circular region at left).

Figure 7.2-2. Modeled $\mathrm{CO}_{2}$ Concentrations in Fractures after 3 years of Heating

Comparisons of modeled $\mathrm{CO}_{2}$ to measurements performed on gas samples from boreholes (shown in Figure 7.2-2) are presented in Figure 7.2-3. Samples were collected from zones a few meters (borehole interval 76-3) to about 15 meters away from the Heated Drift (borehole interval 74-3). Measured concentrations were corrected for water-vapor condensation that took place as part of the procedure for gas sampling. Zones closest to the heaters (interval 76-3) exhibit narrower and earlier peaks in concentration compared to zones further out in the rock (interval 74-3).

Simulated and measured concentrations are close in magnitude and in their trends. Differences between fracture and matrix concentrations are small, because of rapid equilibration by advection and diffusion of gas species and their local equilibration with pore water. 

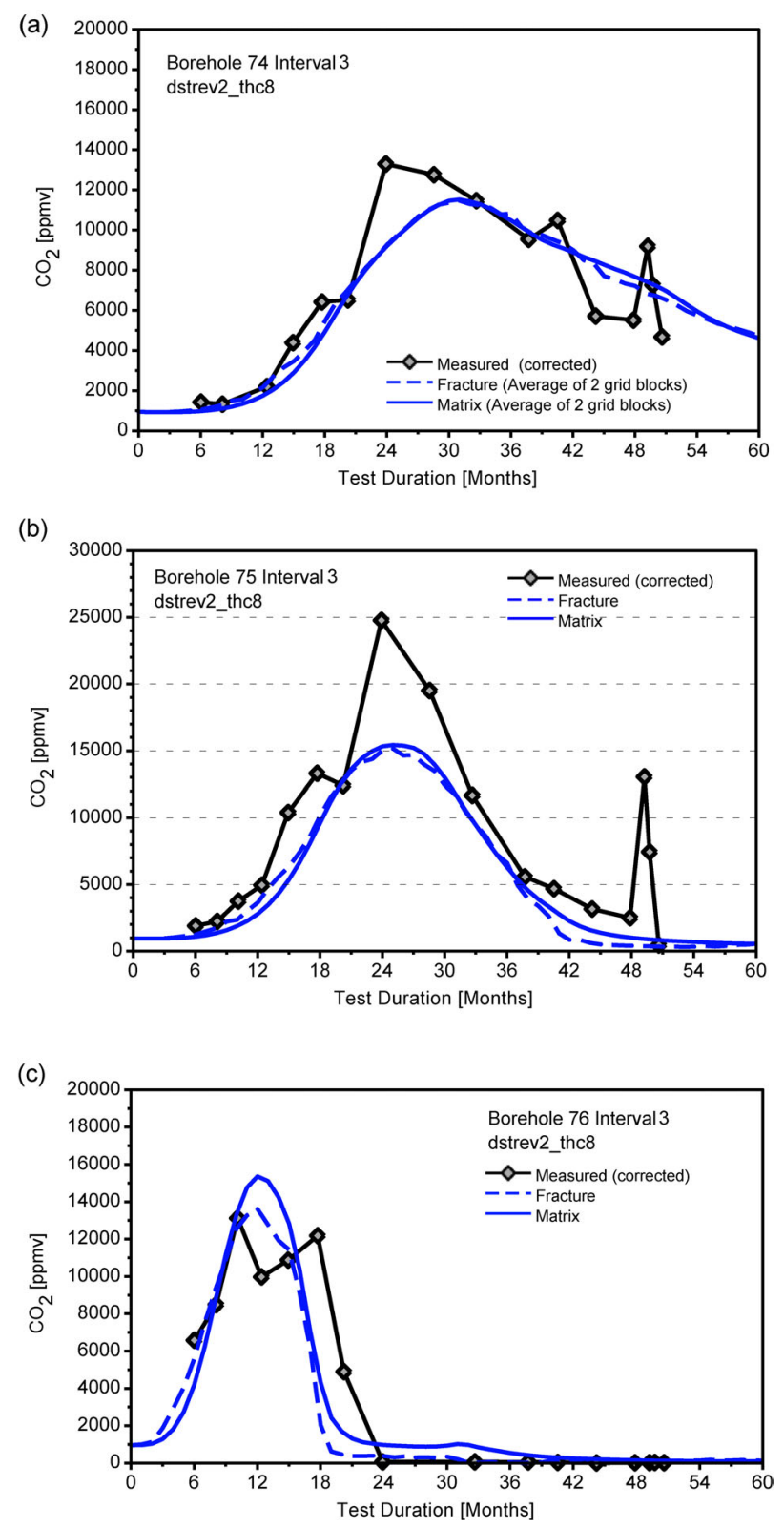

DTNs: LB0208ISODSTHP.001 [161638] (measured $\mathrm{CO}_{2}$ uncorrected); LB0310MTSCLTHC.001(modeled)

Figure 7.2-3. Modeled Gas Phase $\mathrm{CO}_{2}$ Concentrations in Fractures Compared to Measured Values (corrected for vapor condensation):(a) Borehole Interval 74-3 (average of bounding gridblocks); (b) Borehole Interval 75-3; (c) Borehole Interval 76-3.

\subsubsection{Aqueous Species Evolution}

The evolution of aqueous species in waters collected in the DST exhibit small reductions in $\mathrm{pH}$ (from about $\mathrm{pH} 8$ in the pore water to about 6-8 in condensate waters). The drop in $\mathrm{pH}$ is related to the local increases in $\mathrm{CO}_{2}$ concentrations. Figure 7.2-4 shows an example of the initial drop in $\mathrm{pH}$ during vapor condensation, followed by increasing $\mathrm{pH}$ as the zone is further heated and $\mathrm{CO}_{2}$ is diluted by water vapor. Note that the $\mathrm{pH}$ range is only about $1.5 \mathrm{pH}$ units (including the initial pore water $\mathrm{pH}$ ), with thermal waters collected in boreholes ranging from about $\mathrm{pH} 6.8$ to 8.0. 


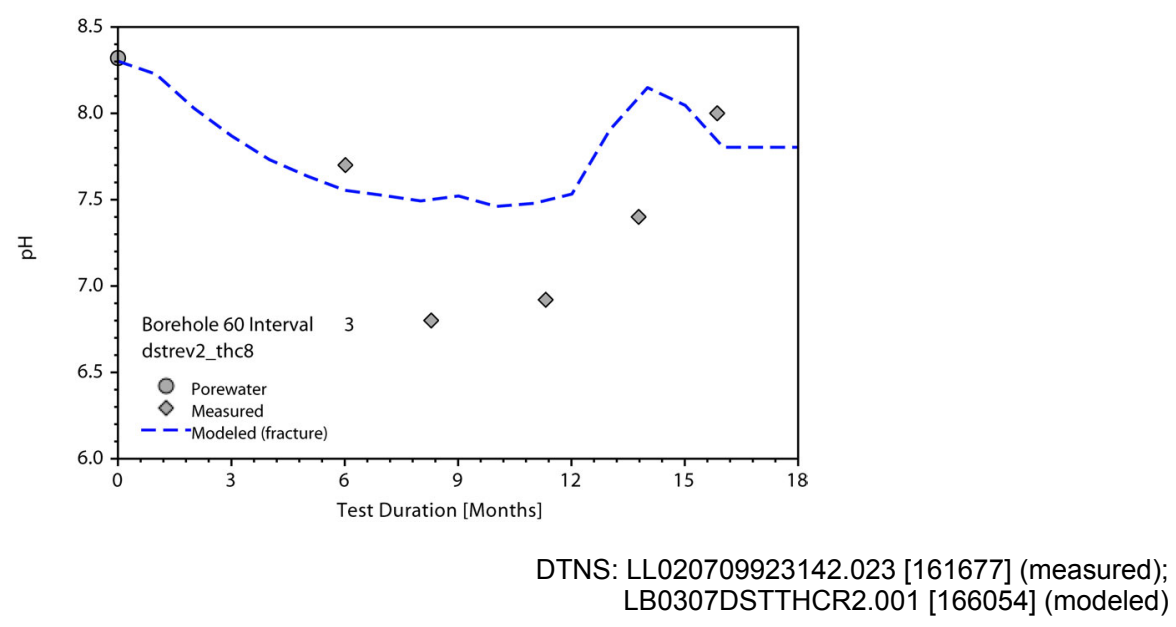

Figure 7.2-4. Measured and Modeled pH for Samples Collected from Borehole Interval 60-3, Located below the Heaters

Conservative species, such as chloride, exhibit concentrations much lower than in matrix pore waters, indicating that fracture-matrix interaction has been negligible. However, reactive species, such as silica and potassium, show significant effects of reaction with fracture-lining silicate minerals (see BSC 2003 [162050]).

\subsubsection{Mineral Precipitation and Dissolution}

Model predictions, followed by analyses of in situ sidewall core samples, showed that amorphous silica, calcite, and lesser amounts of gypsum are the dominant phases expected to precipitate in the boiling regions. The greatest amount of mineral precipitation is predicted to be above the heaters, where reflux of water condensed in fractures dissolves fracture-lining minerals and is boiled.

Simulations and measurements of amorphous silica and calcite, along with locations of observed mineralization, are shown in Figures 7.2-5 and 7.2-6. Amorphous silica forms only where strong evaporation by boiling takes place. In comparison, calcite originally present in fractures dissolves in the lower $\mathrm{pH}$ waters that formed in condensation zones around the boiling zone and in the drainage zones below the heaters. It also forms with amorphous silica and gypsum in the boiling zones. 


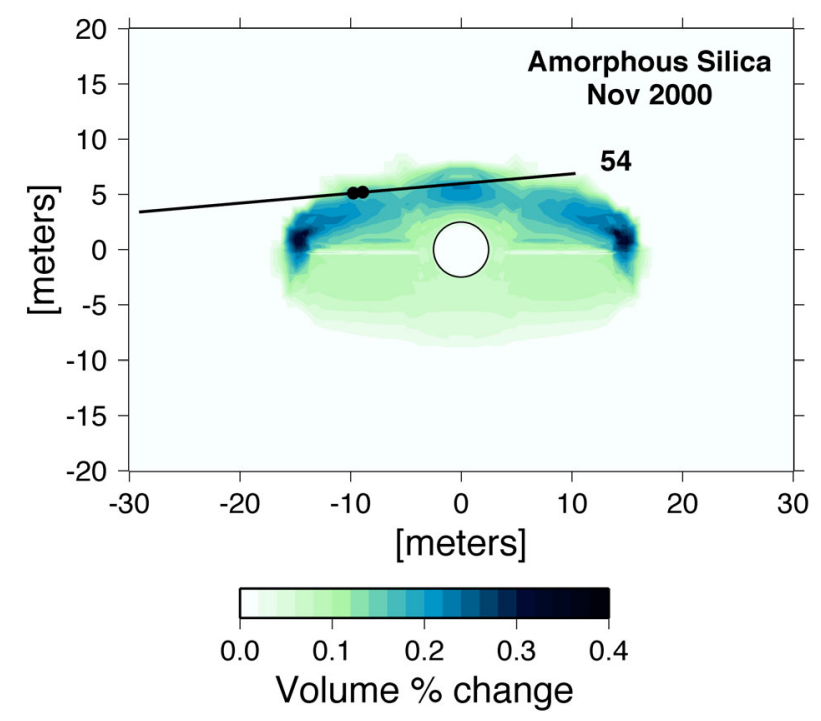

NOTE: Filled circle indicates sidewall core sample locations where change was observed.

Figure 7.2-5. Volume Percent Change in Amorphous Silica Abundance

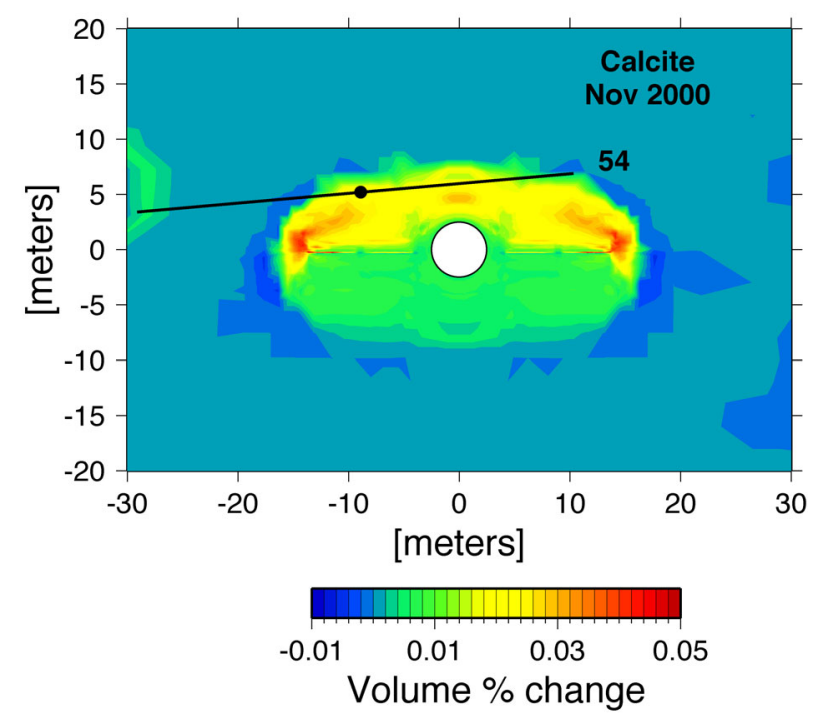

NOTE: Filled circle indicates sidewall core sample locations where change was observed.

Figure 7.2-6. Volume Percent Change in Amorphous Silica Abundance

\subsubsection{Summary of DST Model Validation Results}

Comparisons of modeled concentrations and the chemistry of water (e.g., $\mathrm{pH}, \mathrm{SiO}^{2}(\mathrm{aq}), \mathrm{Na}^{+}, \mathrm{K}^{+}$) and gas samples $\left(\mathrm{CO}_{2}\right)$ collected over a period of nearly 5 years show that the THC model captures the trends and magnitude of chemical changes. The precipitation zones of secondary mineral phases such as amorphous silica, calcite, and gypsum have also been successfully predicted. 
Because chemical changes in the rock are closely tied to $\mathrm{TH}$ processes and fracture-matrix interaction, modeling of several different chemical species having sensitivities to different processes provides an independent method for validating the Mountain-Scale THC model.

\subsection{Validation of the Mountain-Scale THM Model}

No data exist yet that can be used to validate the Mountain-Scale THM Model with corroboration to experimental data. Therefore, confidence in the Mountain-Scale THM Model is gained by reviewing the validation of the Drift-Scale THM Model, which was presented in the Drift-Scale THM Model report (BSC 2003 [164890], Section 7). The validity of the Drift-Scale THM Model gives confidence in the Mountain-Scale THM Model, because (1) rock thermal and mechanical properties are qualified data based on laboratory data and field surveys at the same location and are identical in values used in the Drift-Scale THM Model, where stratigraphic units are the same; (2) rock hydrological properties are qualified data based on field measurements and calibrated at an appropriate scale for the Mountain-scale THM Model; (3) the stresspermeability relationship is consistent with the one used for the Drift-Scale THM Model; and (4) the same THM conceptual and process model applies to both Drift-Scale and Mountain-Scale THM Models. In this section, the validity of the Mountain-Scale THM Model is demonstrated through reviewing the validation of the Drift-Scale THM Model and by demonstrating consistency in the model results between the Mountain-Scale and Drift-Scale THM Models.

In the Drift-Scale THM Model Report, the Drift-Scale THM Model was first tested by a coupled THM simulation of the Yucca Mountain Drift Scale Test (DST) and a coupled hydrologicalmechanical (HM) simulation of the Yucca Mountain niche experiments (BSC 2003 [164890], Sections 7.4 and 7.5). This was a model validation that aimed to test the underlying conceptual model for representing the fractured rock and to demonstrate that the Drift-Scale THM Model appropriately captures all THM processes relevant to the performance of the repository at Yucca Mountain. The validation of the Drift-Scale THM Model against the DST was conducted in the following steps:

1. Check that the simulated temperature field was in reasonable agreement with the observed temperature field to ensure that the THM model is properly implemented in terms of thermal behavior.

2. Check that simulated rock-mass displacements captured the general trends and average magnitudes of observed displacements (validation of TM processes).

3. Check that the simulated changes in air permeability captured the general trends and magnitudes observed in the field (validation of THM processes).

Additional validation was conducted by corroboration with results of an alternative conceptual model, and validation was also corroborated through publication in peer-review format (BSC 2003 [164890], Sections 7.6 and 7.7). Multiple lines of evidence were provided from natural analogues in the geothermal field and from other heater tests (BSC 2003 [164890], Section 7.8). Most validations discussed in the Drift-Scale THM Model report (BSC 2003 [164890], Section 7) are directly applicable to the Mountain-Scale THM Model. Specifically, the corroboration of validation through publication in peer-review format includes presentation of the TOUGH2- 
FLAC3D simulator in the International Journal of Rock Mechanics \& Mining Sciences (Rutqvist et al. 2002 [162048]). This paper includes the fundamental theories and underlying conceptual models for the TOUGH2 code, the FLAC3D code, and the coupling functions between the two codes. An application of the simulator for a drift-scale THM analysis of the repository at Yucca Mountain has been published in a special issue of the Journal of Contaminant Hydrology (Rutqvist and Tsang 2003 [162584]). This published analysis is similar to the one conducted in this model report, but does not include the recent extensive validation against the DST. The result and the general conclusions of the published analysis are consistent with the results presented in this Model Report. The TOUGH2-FLAC3D code has also been applied to problems related to HM processes in the geological sequestration of greenhouse gases (Rutqvist and Tsang 2002 [162587]).

As discussed in (Section 7.10 of BSC 2003 [164890]) a possible scale dependency of permeability, and hence a scale dependency of the stress-permeability relationship, should be considered when extending the validation of the Drift-Scale THM Model to that of the Mountain-Scale THM Model. The scale dependency of permeability and the upscaling of the stress-permeability relationship is discussed in Section 6.5.9 of this Model Report.

Consistency between the Mountain-Scale and Drift-Scale THM Models is demonstrated by the following specific comparisons of simulation results:

- The temperature evolution and calculated peak temperature are very consistent. Both models consistently predict a maximum temperature of about $140^{\circ} \mathrm{C}$ at about 80 to 90 years for an emplacement drift located in the Tptpll unit. Both models predict a maximum temperature of $89^{\circ} \mathrm{C}$ at the mid-pillar (between two repository drifts) occurring at 800 to 900 years.

- The vertical percolation flux pattern is consistent. Both models consistently predict the formation of a dryout zone around the drifts, which diverts liquid flow around itself. Both models predicts that this dryout zone will last for over 1,000 years. The magnitude of vertical fluxes is consistent throughout the models. Because of different mesh sizes near the drifts (mountain-scale element size at drift is $5 \mathrm{~m}$, whereas drift-scale element size at the drift wall is $0.25 \mathrm{~m}$ ), the flux pattern around the drift appears to be wider in the Mountain-Scale Model.

- The thermal-stress evolution is consistent. Both models consistently predict a substantial increase in horizontal stress, with a peak stress occurring at about 500 to 1,000 years. The magnitude of stress close to the drift is (as expected) higher in the Drift-Scale THM Model, because of detailed discretization of the emplacement drift in the Drift-Scale THM Model. The magnitude of maximum stress at the mid-pillar in the Mountain-Scale THM Model is $11 \mathrm{MPa}$, whereas the Drift-Scale THM Model predicts a maximum stress of about $13 \mathrm{MPa}$. The slightly higher peak stress (13 compared with $11 \mathrm{MPa})$ in the Drift-Scale THM Model is explained by a perfect confinement provided by lateral nodisplacement boundaries. 
- The evolution of stress-induced permeability changes is consistent. Both models consistently predict greatest reduction in vertical permeability at 1,000 years. Both models predict a vertical permeability reduction by a factor of about 0.6 around an emplacement drift located in the Tptpll unit.

The consistency between the Mountain-Scale and Drift-Scale THM Models presented in these four comparisons gives confidence in the implementation of thermal, hydrological, TM, and THM processes. Differences in model results between the Mountain-Scale and Drift-Scale THM modes, regarding stress near the ground surface and in the immediate vicinity of a drift, were discussed in Section 6.5.11 of the Model Report. Those differences are expected as a result of the different domain and discretization sizes of the two models. Hence, based on the extensive model validation of the Drift-Scale THM Model documented in BSC (2003 [164890], Section 7), and the consistency between model results from the Mountain-Scale and Drift-Scale THM Models, validity of the Mountain-Scale THM Model is demonstrated. 


\section{CONCLUSIONS}

This Model Report documents the development, results, and validation of the mountain-scale coupled TH, THC, and THM process models in accordance with the requirements of Section 5.2 of AP-SIII.10Q. These models and modeling analyses include the following:

- Mountain-scale 2-D model results and analyses

- Mountain-scale 3-D model results and analyses

- Mountain-scale THC model

- Mountain-scale THM model

- Model validation activities and results.

The mountain-scale TH/THC/THM process models are developed to assess mountain-scale hydrological/chemical/mechanical changes and predict UZ flow behavior in response to heat release by radioactive decay from the nuclear waste repository at the Yucca Mountain site. These $\mathrm{TH} / \mathrm{THC} / \mathrm{THM}$ coupled-processes models numerically simulate the impact of nuclear-waste heat release on the natural hydrogeological system, including a representation of heat-driven processes occurring at the repository drifts as well as in the far field. The mountain-scale $\mathrm{TH}$ model provides predictions for thermally affected liquid saturation, gas- and liquid-phase fluxes, and water and rock temperature. In particular, the TH model calculates the changes in water flux driven by evaporation/condensation and capillary processes, and drainage occurring between drifts. The mountain-scale THC coupled-processes model evaluates $\mathrm{TH}$ effects on water and gas chemistry, mineral dissolution/precipitation, and the resulting impact on UZ hydrological properties and flow and transport processes. By comparison, the THM component addresses issues concerning changes in permeability caused by mechanical and thermal disturbances in stratigraphic units above and below the repository host rock. The output data, simulation input files and results, and their associated data tracking numbers from these coupled-processes models are presented in Table 8-1. 
Table 8-1. Output Data and Data Tracking Numbers

\begin{tabular}{|c|c|c|c|c|}
\hline \multirow{2}{*}{ DTN } & \multicolumn{3}{|c|}{ Location in this report } & \multirow{2}{*}{ Remarks } \\
\hline & Text & Figure & Table & \\
\hline LB0310MTSCLTH2.001 & $\begin{array}{l}6.1 \\
6.2 \\
7.1\end{array}$ & $\begin{array}{l}6.1-2 \\
6.2-1 a----6.2-13\end{array}$ & & $\begin{array}{l}\text { Data for Mountain Scale 2D TH } \\
\text { Simulations: } \\
\text { Input/output files, mesh, and data } \\
\text { for post-processing. }\end{array}$ \\
\hline LB0310MTSCLTH3.001 & $\begin{array}{l}6.1 \\
6.3 \\
7.1\end{array}$ & $\begin{array}{l}6.1-1 \\
6.3 \cdot 1-1 a----6.3 \cdot 1-21 \\
6.3 \cdot 2-1---6.3 \cdot 2-11\end{array}$ & $6.3-1$ & $\begin{array}{l}\text { Data for Mountain Scale 3D TH } \\
\text { Simulations: } \\
\text { Input/output files, mesh, and data } \\
\text { for post-processing. }\end{array}$ \\
\hline LB0310MTSCLTHC.001 & 6.4 & $\begin{array}{l}6.4-2----6.4-3 \\
6.4-15----6.4-27\end{array}$ & & $\begin{array}{l}\text { Mountain Scale THC } \\
\text { Simulations: Input/output files for } \\
\text { TOUGHREACT simulations. }\end{array}$ \\
\hline LB0310MTSCLTHC.002 & 6.4 & 6.4-4----6.4-14 & & $\begin{array}{l}\text { Mountain Scale THC Predictions: } \\
\text { Data Summaries. } \\
\text { Extracted information from output } \\
\text { results in } \\
\text { LB0310MTSCLTHC. } 001 \text {. }\end{array}$ \\
\hline LB0310MTSCLTHM.001 & 6.5 & & & $\begin{array}{l}\text { Mountain Scale THM } \\
\text { Simulations: Input/output files. }\end{array}$ \\
\hline LB0310MTSCLTHM.002 & 6.5 & $\begin{array}{l}6.5 .10-1----6.5 .10-3 \\
6.5 .11-1 \\
6.5 .12-1---6.5 .12-3 \\
6.5 .13-1---6.5 .13-7 \\
6.5 .14-1----6.5 .14-4\end{array}$ & & $\begin{array}{l}\text { Mountain Scale THM } \\
\text { Predictions: Summary plots } \\
\text { Tecplot data extracted from } \\
\text { LB0310MTSCLTHM.001 }\end{array}$ \\
\hline
\end{tabular}

\subsection{TH MODEL}

In this Model Report, the Mountain-Scale TH Model consists of one 2-D and one 3-D submodel. Both TH submodels use the dual-permeability modeling approach and the same hydrogeological conceptual model developed in UZ Flow Models and Submodels (BSC 2003 [163045]). Specifically, the 3-D TH model employs the 3-D ambient TH Model results as its initial and boundary conditions. The 3-D TH Model grid, though using relatively coarse grid spacings, incorporates every repository drift explicitly by taking into account orientations, lengths, elevations, and spacings of the repository drifts, such that adjacent drifts are represented one-toone by adjacent gridblocks $81 \mathrm{~m}$ wide. In comparison, the 2-D model employs very refined lateral and vertical grids with an explicit drift representation along the north-south cross section. In the 2-D model, drifts and the space between them are represented by four gridblocks.

To account for future climates and their impact on TH behavior at the repository, the MountainScale TH Model implements three infiltration rates over three time periods, stepped up sequentially over themodeled period: present (0-600 years), monsoon (600-2,000 years), and glacial transition (2,000 and beyond). Both 2-D and 3-D models supply the reference-mode heat load $(1.45 \mathrm{~kW} / \mathrm{m}$ along the axis of an emplacement drift) as the initial thermal line load. During 
the preclosure period, a ventilation scenario of $86.3 \%$ heat removal for the first 50 years after emplacement is considered as the base case of thermal load. A no-ventilation case is also investigated for comparison and sensitivity analysis. In both cases, the thermal load is applied to the entire drift length (continuous/smeared heat source for each repository block).

The Mountain-Scale TH Model estimates the mountain-scale TH responses to the repository thermal load in the Yucca Mountain UZ system under present and future climates, as well as the effect of ventilation. The expected TH conditions in the fractured tuffs soon after emplacement of the wastes are predicted by the TH models. Sections 6.2 and 6.3 present the simulation results of the 2-D and 3-D models, respectively, in terms of spatial and temporal distributions and variations of simulated temperature, liquid saturation, and fracture-matrix percolation fluxes. In general, thermal loading at the repository results in significant changes in the temperature conditions and moisture distribution, both at the repository and at the zones directly above and below the repository, which have a large impact on fluid flow near repository drifts. These results can be summarized as follows:

At early times ( $\leq 100$ years) after waste emplacement, ventilation for 50 years with $86.3 \%$ heat removal has a significant impact on overall $\mathrm{TH}$ behavior at the repository and the immediate surrounding areas. With ventilation, it takes 50 and 80 years for boiling to occur (as predicted by the 2-D and 3-D models, respectively). As predicted by the base-case model, however, boiling develops within the northern, main repository block only and does not occur in the smaller southern repository block. The highest temperature at the repository is predicted to be $100^{\circ} \mathrm{C}$ after 100 years for the ventilation case and to reach more than $130^{\circ} \mathrm{C}$ after 10 years for the noventilation scenario. If no ventilation is carried out, both models estimate that boiling will occur at the repository in one to two years. However, both 2-D and 3-D base-case models predict that during this early period, TH changes are limited to the near field of the emplacement drifts. Far away $(\sim 100 \mathrm{~m})$ from drifts, conditions at these earlier times remain ambient.

The impact of 50-year ventilation becomes less significant for long times ( $\geq 1,000$ years) after waste emplacement. For example, the termination times of boiling are nearly the same with or without ventilation operations. The 2-D model predicts that the boiling period will end at 2,000 years for both ventilation scenarios, while the 3-D model estimates the boiling will terminate at 1,000 years with or without ventilation. For the base-case ventilation scenario, 2-D simulated peak temperatures near drifts are at $190^{\circ} \mathrm{C}$ at 60 years, whereas the $3-\mathrm{D}$ model predicts a peak temperature of $100^{\circ} \mathrm{C}$ occurring at 100 years. In addition, the 3-D TH models predict that either localized boiling zones will develop near the drifts, or no large-scale boiling will occur, with ventilation operations.

The 2-D model predicts consistently higher temperatures at and near the repository under the same infiltration and thermal-loading conditions (particularly for the first couple of hundreds of years) as those used by the 3-D model. This is primarily because the 2-D model does not account for heat transfer or thermal energy loss into the third dimension, which is equivalent to introducing more heat into the 2-D cross section than would the corresponding slice of the 3-D model under the same modeling conditions. Secondly, the 3-D model contains coarser gridblocks and larger-scale volume averages at and near repository drifts. These large gridblocks will average out peak temperature values, leading to lower predictions of elevated temperatures in the 
3-D TH Model. The peak temperatures predicted by the 3-D TH Model are also somewhat lower than those predicted by the Multiscale Thermal Hydrologic Model (BSC 2003 [165692]).

Higher temperature zones or heated regions around the repository drifts enlarge with time. The TH models predict that heated zones reach their maximum at about 2,000 years after waste emplacement. During the heating period, the temperatures at the middle pillar regions between two drifts are elevated significantly to above $80^{\circ} \mathrm{C}$, but never reach the boiling point. At 2,000 years, temperatures at the bottom of the PTn reach their highest values of $40-50^{\circ} \mathrm{C}$. At the same time, peak temperatures at the top of $\mathrm{CHn}$ are elevated to $70^{\circ} \mathrm{C}$. After 5,000 years, the repository and surrounding rock are significantly cooled down, and the TH effect diminishes.

Under repository heating, conditions become drier (with reduced liquid saturation in fracture and matrix systems) than they were under the ambient conditions. This drying effect is found to reach its maximum between 100 and 500 years. Without ventilation, the drying effect lasts 1,000 years. The TH model predicts that at mountain scale, no extensive dryout zones develop under the future climates with the current thermal load scheme. The most significant dryout occurs only in fractures within regions of several meters immediately surrounding the drifts. In almost all cases, the maximum reduction in matrix liquid saturation is about half its ambient value in the rock blocks directly connected to drifts, and overall dryout in matrix rock is insignificant. Even in fractures, drying is more prominent below the emplacement drifts than above. Laterally, drying in the fractures only extends a few meters from the emplacement drifts, and fractures in the pillar region are predicted to be at or near ambient saturation conditions.

Thermal loading at the repository has a significant impact on percolation fluxes near repository drifts for times $<1,000$ years. Strong liquid and gas flow fields, in particular for the noventilation case, are developed in local areas surrounding repository drifts. These flow fields, especially flow through the fractures surrounding drifts, are many times larger (with ventilation) to one order of magnitude larger (without ventilation) than the ambient conditions at repository drifts and at earlier times (100-500 years). The 2-D model results also show that downward flux through the fractures near repository drifts may decrease to zero during the strong dryout effect at 1,000 years. Furthermore, both 2-D and 3-D model results indicate that no fracture or matrix liquid fluxes flow directly into drifts, and that no seepage occurs during the entire thermalloading period, even with the much higher infiltration rates imposed by climate changes.

The 3-D TH model predicts that repository heating will have in general only a limited impact on far-field flow fields with ventilation. In this case, thermally enhanced flux zones are no more than $30 \mathrm{~m}$ in the regions directly above or below the repository blocks. Without ventilation, on the other hand, thermally impacted flux zones above the repository grow to as thick as $100 \mathrm{~m}$. In both modes of thermal operations, the TH model predicts much stronger TH effects along highly permeable columns of faults that intersect repository blocks, because of the stronger vapor flow and condensation.

The TH model predicts that repository heating will have only a small impact on flow through the pillar regions between two drifts. This is because boiling does not occur in these pillar areas, and moisture conditions there are not much changed from ambient status. Simulated vertical fluxes in the pillar regions show little variation in thermal activity at drifts. In fact, flow through the pillar regions is more affected by surface infiltration or climate changes than by repository heating. 


\subsection{THC MODEL}

The purpose of the Mountain-Scale THC Model was to evaluate the coupled THC processes that are influenced by variations in geology (structure and lithology), infiltration rate, and temperature at a mountain- or repository-scale. Mineral dissolution and precipitation, leading to changes in hydrological properties, can affect the percolation flux to the potential repository horizon (relevant to seepage), and flow below the potential repository (relevant to radionuclide transport in the UZ). Variability in lithology and infiltration rates may also affect the chemistry of waters percolating in the UZ and ultimately the composition of seepage waters. A partial 2-D cross section of the repository was selected from the 3-D Mountain-Scale TH Model and used for a series of TH and THC calculations having increasing complexity in terms of processes and chemical components.

The results of the simulations, presented in Section 6.4, indicate that mineral precipitation/dissolution will not significantly affect the hydrological properties and percolation flux, compared to the effects caused by TH processes alone. Glass-rich layers in the CHn show alteration to zeolites, with clinoptilolite breaking down to form stellerite at elevated temperatures. Changes in water chemistry, mineralogy, and hydrological properties in the ambient temperature regions are minimal over the 7,000 years of the simulation. The overall range in the water chemistry at a particular time above the drifts is about one order of magnitude. $\mathrm{CO}_{2}$ concentrations in the gas phase differ by about one to two orders of magnitude, with the range decreasing over time after the peak thermal period. The range in $\mathrm{pH}$ of about 7 to 9 is strongly linked to changes in gas-phase $\mathrm{CO}_{2}$ concentrations, relative to the ambient system away from the repository. Differences are smaller in the high-temperature potential repository center (and the $\mathrm{pH}$ is higher) compared to the edges (which have somewhat elevated values and $\mathrm{pH}$ values down to approximately 7). Results from the Mountain-Scale THC Model (presented in Section 6.4) have been submitted to the Technical Data Management System (TDMS) as output under DTNs listed in Section 9.4.

\subsection{THM MODEL}

The Mountain-Scale THM Model developed in Section 6.5 of this Model Report is capable of assessing the magnitude and distribution of changes in hydrological properties and of analyzing the impact of such changes on the mountain-scale vertical percolation flux through the repository horizon. Results from the Mountain-Scale THM Model presented in Sections 6.5.10 to 6.5.14 have been submitted to the Technical Data Management System (TDMS) as output under DTNs listed in Section 9.4. The result shows that maximum THM-induced changes in hydrological properties occur at around 1,000 years after emplacement, when average temperature in the mountain peaks. Near the repository level, thermal-elastic stresses tend to tighten vertical fractures to smaller apertures, leading to reduced permeability and increased capillary. At the ground surface, in a zone extending down about $100 \mathrm{~m}$, compressive stresses are completely relieved into tension. In this zone, fractures will open elastically, and fracturing or shear-slip along pre-existing fractures are possible.

Using a conservative estimate of input THM properties, changes in permeability by elastic closure or opening of pre-existing fractures are within a factor of 0.3 to 5 , whereas calculated changes in capillary pressure range between a factor of 0.7 to 1.2 . In addition, a conservative 
three-order-of-magnitude increase in permeability and one-order-of-magnitude reduction in capillary were imposed for the zone of possible fracturing and shear slip near the ground surface. Despite these conservative estimates of potential changes in hydrological properties, the main conclusion from the results of Sections 6.5.10 to 6.5.14 is that THM-induced changes in mountain-scale hydrological properties have no significant impact on the vertical percolation flux through the repository horizon. Again, these results were obtained for conservative estimates of the input THM properties, which are sufficient for bounding the possible impact of the THM processes on permeability and percolation flux at the mountain scale.

\subsection{MODEL VALIDATION}

Model validation efforts have been documented in this Model Report for the mountain-scale $\mathrm{TH} / \mathrm{THC} / \mathrm{THM}$ models, according to the requirements in Confidence Building during Model Development and Post-Development Validation Activities of the TWP (BSC 2002 [160819], Attachment I-3-1, pp. 32-34). The TH model is validated by corroboration with alternative mathematical models and corroboration with data from literature. Also, the validation is further corroborated by publication in a refereed professional journal.

The mountain-scale THC model is validated by confidence building with DST experimental data and validation was corroborated through publications in peer-reviewed journals. The following methods are used to evaluate mountain-scale THC effects on flow and geochemistry: the estimation of thermodynamic and kinetic parameters; testing and model validation using largescale thermal test and laboratory experiments, and predictive process modeling.

The model validation effort for the Mountain-Scale THM Model makes use of the validation results of the Drift-Scale THM model (BSC 2003 [164890]). The validity of the Drift-Scale THM Model gives confidence in the Mountain-Scale THM Model, because the same rock hydrological, thermal, and mechanical properties are used, and the same THM conceptual and process models applies to both Drift-Scale and Mountain-Scale THM Models.

\subsection{LIMITATIONS}

The mountain-scale coupled TH/THC/THM processes models provide appropriate numerical tools for simulating the impact of nuclear waste heat release on the natural hydrogeological system. The accuracy and reliability of these models and their predictions are critically dependent on the accuracy of estimated model properties, other types of input data, and hydrogeological conceptual models. These models are limited mainly by the current understanding of the mountain system, as developed from geological and conceptual models, the volume-average numerical modeling approach, and the available field and laboratory data.

By definition, models are idealizations of the real world. The TH/THC/THM models are continuum models, using averaged properties, and therefore are meant to represent overall changes in space and time. Input data summarized in Section 4 characterize the physical properties of the rock, but cannot include every detail of a natural system. In particular, the thermal effect on capillary pressure and relative permeability functions are ignored, and the infiltrating water chemistry is taken as laterally uniform over the model top boundary. As a result of such simplifications, the model results describe overall changes in space and time within the 
model domain, but must be applied with caution when predicting future conditions at any specific location.

One important limitation with these mountain-scale TH models is the use of the large-scale volume average modeling approach in numerical model grids. In addition, thermal-hydrological behavior within repository drifts is not explicitly modeled. Consequently, the mountain-scale TH model is not appropriate for investigating in-drift or small-scale near-field TH processes.

A limitation of the Mountain-Scale THC Model, as in all predictive models, is the increased uncertainty associated with predictions required for times far beyond the duration of field tests. The model is also limited by its mathematical formulations and associated assumptions (Section 5). For example, neither the Mountain-Scale THC Model nor the DST THC Model were designed for accurate computation of mineral precipitation from very saline waters (ionic strength $>4$ molal) resulting from evaporative concentration. The spatial resolution of the model near drifts is also much coarser than that used in drift-scale models. Therefore, the model cannot capture small-scale effects near drifts, especially those related to boiling, condensation, and evaporative concentration. However, the purpose of the Mountain-Scale THC Model is to capture the chemical changes expected at the mountain scale as opposed to detailed THC effects at the drift scale.

The predictions by the Mountain-Scale THM Model depend on a sufficiently accurate representation of TM-induced changes in hydraulic properties, and in particular changes in fracture permeability. In this context, the potential sources of uncertainties were discussed in Section 6.5.15 of this Model Report. It was concluded that the fracture normal stress-versuspermeability relationship is the most important aspect of this analysis. As discussed in Section 6.5.15, the adopted THM properties (thermal expansion coefficient and stress-versuspermeability relationship) for the mountain scale are based on a conservative upscaling from the already conservatively estimated drift-scale properties. Moreover, the flow simulation investigating the potential impact of fracturing and shear slip in areas of stress relief near ground surface was conduced with an imposed conservative three-order-of-magnitude increase in permeability. Hence, the predictive results of the Mountain-Scale THM Model are obtained for a conservative estimate of the input THM properties, and therefore, the possible impact of THM processes on percolation flux is adequately bounded, in concurrence with YMRP acceptance criteria as discussed in Section 4.2.

\subsection{SATISFACTION OF ACCEPTANCE CRITERIA}

In Section 4.2, seven NRC acceptance criteria were identified. How they are satisfied are discussed as follows.

For criteria from Section 2.2.1.1.3 of YMRP (NRC 2003 [163274])

- AC 1: System Description and Model Integration are adequate: The TH/THC/THM system is described in Sections 6.1, 6.4, and 6.5, respectively. This description is based on data from field and laboratory investigations and the UZ Flow Model (BSC 2003 [163045]), and is consistent with standard conceptual models of the UZ at Yucca Mountain. In addition, spatial variability of model parameters are adequately 
represented by the 3-D model grid, with more than 60 different types of fracture-matrix properties for spatial variability across the entire UZ formation. The model calibration and validation activities for the ambient TH model (BSC 2003 [163045]) show that the description is adequate for modeling UZ flow and transport.

- AC 2: Data are sufficient: Data from field and laboratory testing as well as 3-D model calibration (BSC 2003 [163045]) have been synthesized and used in the TH/THC/THM models. The model validation shows that these data are sufficient to justify the models for its intended use.

- AC3: Data uncertainty is characterized and propagated: Hydrological and thermal properties used in the TH/THC/THM Models have been calibrated (BSC 2003 [163045]) using different infiltration maps and field measured temperature data, thus capturing the uncertainty in model parameters.

- AC4: Model uncertainty is characterized and propagated: Two sets of thermal-loading scenarios were used to study the alternative TH model with or without ventilation.

For criteria from Section 2.2.1.1.3 of YMRP (NRC 2003 [163274]):

- AC1: Identification of barriers is adequate: The Mountain-Scale TH Model simulates UZ flow in the unsaturated tuffs above and below the repository horizon under repository heating. There are two natural barriers, the PTn unit and the lower permeability zeolitic zones in the CHn, identified in BSC (2003 [163045]).

- AC 2: Description of barrier capability to isolate waste is acceptable: Barrier capability is determined by the TH model results showing that no seepage into repository drifts occurs during the entire thermal-loading period. This will delay the release of radionuclides from drifts, leading to delay in their transport to the water table. These model results show that the description is acceptable.

- AC3: Technical basis for barrier capability is adequately presented: In Sections 6.2 and 6.3, Different 2-D and 3-D model results are used to analyze percolation patterns under repository thermal loading. 


\section{INPUTS AND REFERENCES}

The following is a list of the references cited in this document. Column 1 represents the unique six digit numerical identifier (the Document Input Reference System [DIRS] number), which is placed in the text following the reference callout (e.g., BSC 2002 [160819]). The purpose of these numbers is to assist the reader in locating a specific reference. Within the reference list, multiple sources by the same author (e.g., BSC 2002) are sorted alphabetically by title.

\subsection{DOCUMENTS CITED}

153826 Barton, C.A.; Zoback, M.D.; and Moos, D. 1995. "Fluid Flow Along Potentially Active Faults in Crystalline Rock." Geology, 23, (8), 683-686. [Boulder, Colorado: Geological Society of America]. TIC: 241579.

156269 Bear, J. 1972. Dynamics of Fluids in Porous Media. Environmental Science Series. Biswas, A.K., ed. New York, New York: Elsevier. TIC: 217356.

154608 Birkholzer, J.T. and Tsang, Y.W. 2000. "Modeling the Thermal-Hydrologic Processes in a Large-Scale Underground Heater Test in Partially Saturated Fractured Tuff." Water Resources Research, 36, (6), 1431-1447. Washington, D.C.: American Geophysical Union. TIC: 248278.

126590 Blum, A.E. and Stillings, L.L. 1995. "Feldspar Dissolution Kinetics." Chapter 7 of Chemical Weathering Rates of Silicate Minerals. White, A.F. and Brantley, S.L., eds. Reviews in Mineralogy Volume 31. Washington, D.C.: Mineralogical Society of America. TIC: 222496.

138603 Bodvarsson, G.S.; Bjornsson, S.; Gunnarsson, A.; Gunnlaugsson, E.; Sigurdsson, O.; Stefansson, V.; and Steingrimsson, B. 1988. "A Summary of Modeling Studies of the Nesjavellir Geothermal Field, Iceland." Proceedings, Thirteenth Workshop, Geothermal Reservoir Engineering, January 19-21, 1988, Stanford, California. Workshop Report SGP-TR-113. Pages 83-91. Stanford, California: Stanford University. TIC: 246824.

138618 Bodvarsson, G.S.; Gislason, G.; Gunnlaugsson, E.; Sigurdsson, O.; Stefansson, V.; and Steingrimsson, B. 1993. "Accuracy of Reservoir Predictions for the Nesjavellir Geothermal Field, Iceland." Proceedings, Eighteenth Workshop, Geothermal Reservoir Engineering, Stanford, California, January 26-28, 1993. Ramey, H.J., Jr.; Horne, R.N.; Kruger, P.; Miller, F.G.; Brigham, W.E.; and Cook, J.W., eds. Workshop Report SGP-TR-145. Pages 273-278. Stanford, California: Stanford University. TIC: 246821.

136386 Bodvarsson, G.S.; Pruess, K.; and Lippmann, M. J. 1986. "Modeling of Geothermal Systems." Journal of Petroleum Technology, 1007-1021. Richardson, Texas:

Society of Petroleum Engineers. TIC: 246733. 
136384 Bodvarsson, G.S.; Pruess, K.; Haukwa, C.; and Ojiambo, S.B. 1990. "Evaluation of Reservoir Model Predictions for Olkaria East Geothermal Field, Kenya." Geothermics, 19, (5), 399-414. [New York, New York]: Pergamon Press. TIC: 246739.

137136 Bodvarsson, G.S.; Pruess, K.; Stefansson, V.; and Eliasson, E.T. 1984. "The Krafla Geothermal Field, Iceland, 2. The Natural State of the System." Water Resources Research, 20, (11), 1531-1544. Washington, D.C.: American Geophysical Union. TIC: 246734.

137139 Bodvarsson, G.S.; Pruess, K.; Stefansson, V.; and Eliasson, E.T. 1984. "The Krafla Geothermal Field, Iceland: 3. The Generating Capacity of the Field." Water Resources Research, 20, (11), 1545-1559. Washington, D.C.: American Geophysical Union. TIC: 246737.

136391 Bodvarsson, G.S.; Pruess, K.; Stefansson, V.; Bjornsson, S.; and Ojiambo, S.B. 1987. "East Olkaria Geothermal Field, Kenya, 1. History Match with Production and Pressure Decline Data." Journal of Geophysical Research, 92, (B1), 521-539. [Washington, D.C.]: American Geophysical Union. TIC: 236629.

136393 Bodvarsson, G.S.; Pruess, K.; Stefansson, V.; Bjornsson, S.; and Ojiambo, S.B. 1987. "East Olkaria Geothermal Field, Kenya, 2. Predictions of Well Performance and Reservoir Depletion.” Journal of Geophysical Research, 92, (B1), 541-554. [Washington, D.C.]: American Geophysical Union. TIC: 246738.

155957 BSC (Bechtel SAIC Company) 2001. Coupled Thermal-Hydrologic-Mechanical Effects on Permeability Analysis and Models Report. ANL-NBS-HS-000037 REV 00. Las Vegas, Nevada: Bechtel SAIC Company. ACC: MOL.20010822.0092.

158463 BSC (Bechtel SAIC Company) 2001. In Situ Field Testing of Processes. ANL-NBSHS-000005 REV 01. Las Vegas, Nevada: Bechtel SAIC Company. ACC: MOL.20020108.0351.

157330 BSC (Bechtel SAIC Company) 2001. Thermal Tests Thermal-Hydrological Analyses/Model Report. ANL-NBS-TH-000001 REV 00 ICN 02. Las Vegas, Nevada: Bechtel SAIC Company. ACC: MOL.20011116.0025.

159527 BSC (Bechtel SAIC Company) 2002. Repository Design, Repository/PA IED Subsurface Facilities Plan Sht. 1 of 5, Sht. 2 of 5, Sht. 3 of 5, Sht. 4 of 5, and Sht. 5 of 5. DWG-MGR-MD-000003 REV A. Las Vegas, Nevada: Bechtel SAIC Company. ACC: MOL.20020601.0194.

160819 BSC (Bechtel SAIC Company) 2002. Technical Work Plan for: Performance Assessment Unsaturated Zone. TWP-NBS-HS-000003 REV 02. Las Vegas, Nevada: Bechtel SAIC Company. ACC: MOL.20030102.0108. 
160146 BSC (Bechtel SAIC Company) 2002. Total System Performance Assessment-License Application Methods and Approach. TDR-WIS-PA-000006 REV 00. Las Vegas, Nevada: Bechtel SAIC Company. ACC: MOL.20020923.0175.

160975 BSC (Bechtel SAIC Company) 2002. Ventilation Model. ANL-EBS-MD-000030 REV 01 ICN 01. Las Vegas, Nevada: Bechtel SAIC Company. ACC: MOL.20021106.0055.

161773 BSC (Bechtel SAIC Company) 2003. Analysis of Hydrologic Properties Data. MDL-NBS-HS-000014 REV 00. Las Vegas, Nevada: Bechtel SAIC Company. ACC: DOC.20030404.0004.

160240 BSC (Bechtel SAIC Company) 2003. Calibrated Properties Model. MDL-NBS-HS000003 REV 01. Las Vegas, Nevada: Bechtel SAIC Company. ACC:

DOC.20030219.0001.

160109 BSC (Bechtel SAIC Company) 2003. Development of Numerical Grids for UZ Flow and Transport Modeling. ANL-NBS-HS-000015 REV 01. Las Vegas, Nevada: Bechtel SAIC Company. ACC: DOC.20030404.0005.

162711 BSC (Bechtel SAIC Company) 2003. Drift Degradation Analysis. ANL-EBS-MD000027 REV 02. Las Vegas, Nevada: Bechtel SAIC Company. ACC: DOC.20030709.0003.

164890 BSC (Bechtel SAIC Company) 2003. Drift Scale THM Model. MDL-NBS-HS000017 REV 00 ICN 01. Las Vegas, Nevada: Bechtel SAIC Company. ACC: DOC.20031014.0009.

161530 BSC (Bechtel SAIC Company) 2003. Drift-Scale Coupled Processes (DST and TH Seepage) Models. MDL-NBS-HS-000015 REV 00. Las Vegas, Nevada: Bechtel SAIC Company. Submit to RPC URN-1087

162050 BSC (Bechtel SAIC Company) 2003. Drift-Scale Coupled Processes (DST and THC Seepage) Models. MDL-NBS-HS-000001 REV 02. Las Vegas, Nevada: Bechtel SAIC Company. ACC: DOC.20030804.0004.

164873 BSC (Bechtel SAIC Company) 2003. Features, Events, and Processes in UZ Flow and Transport. ANL-NBS-MD-000001 REV 02A. Las Vegas, Nevada: Bechtel SAIC Company. ACC: MOL.20031016.0004. TBV-5483

165692 BSC (Bechtel SAIC Company) 2003. Multiscale Thermohydrologic Model Report. ANL-EBS-MD-000049 REV 01E. Las Vegas, Nevada: Bechtel SAIC Company. ACC: MOL.20031009.0227. TBV-5533

165179 BSC (Bechtel SAIC Company) 2003. Q-List. TDR-MGR-RL-000005 REV 00. Las Vegas, Nevada: Bechtel SAIC Company. ACC: DOC.20030930.0002. 
164136 BSC (Bechtel SAIC Company) 2003. Repository Design Project, RDP/PA IED Typical Waste Package Components Assembly (4). 800-IED-WIS0-00204-000-00A. Las Vegas, Nevada: Bechtel SAIC Company. ACC: ENG.20030702.0004.

164069 BSC (Bechtel SAIC Company) 2003. Repository Design Project, Repository/PA IED Emplacement Drift Configuration 1 of 2. 800-IED-EBS0-00201-000-00A. Las Vegas, Nevada: Bechtel SAIC Company. ACC: ENG.20030630.0002.

161731 BSC (Bechtel SAIC Company) 2003. Repository Design, Repository/PA IED Subsurface Facilities. 800-IED-EBS0-00403-000-00B. Las Vegas, Nevada: Bechtel SAIC Company. ACC: MOL.20030109.0147.

163226 BSC (Bechtel SAIC Company) 2003. Seepage Model for PA Including Drift Collapse. MDL-NBS-HS-000002 REV 02. Las Vegas, Nevada: Bechtel SAIC Company. ACC: DOC.20030709.0001.

165572 BSC (Bechtel SAIC Company) 2003. Underground Layout Configuration. 800P0C-MGR0-00100-000-00E. Las Vegas, Nevada: Bechtel SAIC Company. ACC: ENG.20031002.0007.

163045 BSC (Bechtel SAIC Company) 2003. UZ Flow Models and Submodels. MDL-NBSHS-000006 REV 01. Las Vegas, Nevada: Bechtel SAIC Company. ACC: DOC.20030818.0002.

166343 BSC (Bechtel SAIC Company) 2003. Ventilation Model and Analysis Report. ANLEBS-MD-000030 REV 03 ICN 02. Las Vegas, Nevada: Bechtel SAIC Company. ACC: DOC.20031126.0003.

105157 Buscheck, T.A.; Nitao, J.J.; and Saterlie, S.F. 1994. "Evaluation of ThermoHydrological Performance in Support of the Thermal Loading Systems Study." High Level Radioactive Waste Management, Proceedings of the Fifth Annual International Conference, Las Vegas, Nevada, May 22-26, 1994. 2, 592-610. La Grange Park, Illinois: American Nuclear Society. TIC: 210984.

161770 Canori, G.F. and Leitner, M.M. 2003. Project Requirements Document. TER-MGRMD-000001 REV 01. Las Vegas, Nevada: Bechtel SAIC Company. ACC: DOC.20030404.0003.

103564 CRWMS M\&O (Civilian Radioactive Waste Management Management and Operating Contractor) 1997. Yucca Mountain Site Geotechnical Report. B00000000-01717-5705-00043 REV 01. Two volumes. Las Vegas, Nevada: CRWMS M\&O. ACC: MOL.19971017.0736; MOL.19971017.0737.

102679 CRWMS M\&O 1998. Geology of the Exploratory Studies Facility Topopah Spring Loop. BAB000000-01717-0200-00002 REV 01. Las Vegas, Nevada: CRWMS M\&O. ACC: MOL.19980415.0283. 
144454 CRWMS M\&O 2000. Mountain-Scale Coupled Processes (TH) Models. MDLNBS-HS-000007 REV 00. Las Vegas, Nevada: CRWMS M\&O. ACC:

MOL.19990721.0528.

165949 Dobson, P.F.; Kneafsey, T.J.; Sonnenthal, E.L.; Spycher, N.; and Apps, J.A. 2003. "Experimental and Numerical Simulation of Dissolution and Precipitation: Implications for Fracture Sealing at Yucca Mountain, Nevada." Journal of Contaminant Hydrology, 62-63, 459-476. New York, New York: Elsevier. TIC: 254205.

162903 DOE (U.S. Department of Energy) 2003. Quality Assurance Requirements and Description. DOE/RW-0333P, Rev. 13. Washington, D.C.: U.S. Department of Energy, Office of Civilian Radioactive Waste Management. ACC: DOC.20030422.0003.

135997 Doughty, C. 1999. "Investigation of Conceptual and Numerical Approaches for Evaluating Moisture, Gas, Chemical, and Heat Transport in Fractured Unsaturated Rock." Journal of Contaminant Hydrology, 38, (1-3), 69-106. New York, New York: Elsevier. TIC: 244160.

116801 Driscoll, F.G. 1986. Groundwater and Wells. 2nd Edition. St. Paul, Minnesota: Johnson Filtration Systems. TIC: 217555.

154365 Freeze, G.A.; Brodsky, N.S.; and Swift, P.N. 2001. The Development of Information Catalogued in REV00 of the YMP FEP Database. TDR-WIS-MD-000003 REV 00 ICN 01. Las Vegas, Nevada: Bechtel SAIC Company. ACC: MOL.20010301.0237.

137148 Garg, S.K. and Pritchett, J.W. 1990. "Cold Water Injection Into Single- and TwoPhase Geothermal Reservoir." Water Resources Research, 26, (2), 331-338. Washington, D.C.: American Geophysical Union. TIC: 247136.

137307 Hanano, M. 1992. "Reservoir Engineering Studies of the Matsukawa Geothermal Field, Japan." Geothermal Resources Council Transactions, 16, 643-650. Davis, California: Geothermal Resources Council. TIC: 247116.

137562 Haukwa, C.B.; Wu, Y-S.; and Bodvarsson, G.S. 1999. "Thermal Loading Studies Using the Yucca Mountain Unsaturated Zone Model." Journal of Contaminant Hydrology, 38, (1-3), 217-255. New York, New York: Elsevier. TIC: 244160.

165165 Haukwa, C.B.; Wu, Y-S.; and Bodvarsson, G.S. 2003. "Modeling ThermalHydrological Response of the Unsaturated Zone at Yucca Mountain, Nevada, to Thermal Load at a Potential Repository." Journal of Contaminant Hydrology, 62-63, 529-552. New York, New York: Elsevier. TIC: 254205. 
137322 Hunt, T.M.; Allis, R.G.; Blakeley, M.R.; and O’Sullivan, M. J. 1990. "Testing Reservoir Simulation Models for the Broadlands Geothermal Field Using Precision Gravity Data." 1990 International Symposium on Geothermal Energy, Transactions, Geothermal Resources Council, 1990 Annual Meeting, 20-24 August, 1990, KailuaKona, Hawaii. Volume 14, Part II. Pages 1287-1294. Davis, California:

Geothermal Resources Council. TIC: 246942.

137537 Ingebritsen, S.E. and Sorey, M.L. 1988. "Vapor-Dominated Zones Within Hydrothermal Systems: Evolution and Natural State." Journal of Geophysical Research, 93, (B11), 13635-13655. Washington, D.C.: American Geophysical Union. TIC: 247149.

156788 Itasca Consulting Group. 1997. FLAC \{superscript 3D\}, Fast Lagrangian Analysis of Continua in 3 Dimensions. Version 2.0 Five volumes. Minneapolis, Minnesota: Itasca Consulting Group. TIC: 251273.

137338 Lam, S.T.; Hunsbedt, A.; Kruger, P.; and Pruess, K. 1988. “Analysis of the Stanford Geothermal Reservoir Model Experiments Using the LBL Reservoir Simulator." Geothermics, 17, (4), 595-605. Oxford, United Kingdom: Elsevier. TIC: 247098.

100588 Leverett, M.C. 1941. "Capillary Behavior in Porous Solids.” AIME Transactions, Petroleum Development and Technology, Tulsa Meeting, October 1940. 142, 152169. New York, New York: American Institute of Mining and Metallurgical Engineers. TIC: 240680.

166017 Liu, H-H.; Rutqvist, J.; Zhou, Q.; and Bodvarsson, G.S. 2003. "Upscaling of Normal Stress-Permeability Relationships for Fracture Networks Obeying Fractional Levy Motion." GeoProc 2003, International Conference on Coupled T-H-M-C Processes in Geo-Systems: Fundamentals, Modelling, Experiments \& Applications, Stockholm, Sweden, October 13-15, 2003. Stephansson, O.; Hudson, J.A.; and Jing, L., eds. Part 1, 251-256. Stockholm, Sweden: Royal Institute of Technology. TIC: 255195.

160110 Liu, H.H. and Bodvarsson, G.S. 2001. "Constitutive Relations for Unsaturated Flow in a Fracture Network." Journal of Hydrology, 252, ([1-4]), 116-125. [New York, New York]: Elsevier. TIC: 253269.

105729 Liu, H.H.; Doughty, C.; and Bodvarsson, G.S. 1998. "An Active Fracture Model for Unsaturated Flow and Transport in Fractured Rocks." Water Resources Research, 34, (10), 2633-2646. Washington, D.C.: American Geophysical Union. TIC: 243012.

100590 Luckner, L.; van Genuchten, M.T.; and Nielsen, D.R. 1989. "A Consistent Set of Parametric Models for the Two-Phase Flow of Immiscible Fluids in the Subsurface." Water Resources Research, 25, (10), 2187-2193. Washington, D.C.: American Geophysical Union. TIC: 224845. 
137923 Menzies, A.J.; Granados, E.E.; Sanyal, S.K.; Merida-I, L.; and Caicedo-A, A. 1991. "Numerical Modeling of the Initial State and Matching of Well Test Data from the Zunil Geothermal Field, Guatemala." Proceedings, Sixteenth Workshop, Geothermal Reservoir Engineering, January 23-25, 1991, Stanford, California. Workshop Report SGP-TR-134. Pages 193-201. Stanford, California: Stanford University. TIC: 246832.

100161 Montazer, P. and Wilson, W.E. 1984. Conceptual Hydrologic Model of Flow in the Unsaturated Zone, Yucca Mountain, Nevada. Water-Resources Investigations Report 84-4345. Lakewood, Colorado: U.S. Geological Survey. ACC:

NNA.19890327.0051.

160790 Mukhopadhyay, S. and Tsang, Y.W. 2003. "Uncertainties in Coupled ThermalHydrological Processes Associated with the Drift Scale Test at Yucca Mountain, Nevada." Journal of Contaminant Hydrology, 62-63, 595-612. New York, New York: Elsevier. TIC: 254205.

109911 Nitao, J.J. 1988. Numerical Modeling of the Thermal and Hydrological Environment Around a Nuclear Waste Package Using the Equivalent Continuum Approximation: Horizontal Emplacement. UCID-21444. Livermore, California: Lawrence Livermore National Laboratory. ACC: NNA.19890317.0021.

163274 NRC (U.S. Nuclear Regulatory Commission) 2003. Yucca Mountain Review Plan, Final Report. NUREG-1804, Rev. 2. Washington, D.C.: U.S. Nuclear Regulatory Commission, Office of Nuclear Material Safety and Safeguards. TIC: 254568.

137409 O’Sullivan, M.J.; Barnett, B.G.; and Razali, M.Y. 1990. "Numerical Simulation of the Kamojang Geothermal Field, Indonesia." 1990 International Symposium on Geothermal Energy, Transactions, Geothermal Resources Council, 1990 Annual Meeting, 20-24 August, 1990, Kailua-Kona, Hawaii. Volume 14, Part II. Pages 1317-1324. Davis, California: Geothermal Resources Council. TIC: 246942.

100684 Pruess, K. 1987. TOUGH User's Guide. NUREG/CR-4645. Washington, D.C.: U.S. Nuclear Regulatory Commission. TIC: 217275.

100413 Pruess, K. 1991. TOUGH2-A General-Purpose Numerical Simulator for Multiphase Fluid and Heat Flow. LBL-29400. Berkeley, California: Lawrence Berkeley Laboratory. ACC: NNA.19940202.0088.

101707 Pruess, K. and Narasimhan, T.N. 1985. "A Practical Method for Modeling Fluid and Heat Flow in Fractured Porous Media." Society of Petroleum Engineers Journal, 25, (1), 14-26. Dallas, Texas: Society of Petroleum Engineers. TIC: 221917.

117451 Pruess, K. and Tsang, Y. 1994. Thermal Modeling for a Potential High-Level Nuclear Waste Repository at Yucca Mountain, Nevada. LBL-35381. Berkeley, California: Lawrence Berkeley National Laboratory. ACC: NNA.19940427.0248. 
140912 Pruess, K. and Wang, J.S.Y. 1984. "TOUGH - A Numerical Model for Nonisothermal Unsaturated Flow to Study Waste Canister Heating Effects." Scientific Basis for Nuclear Waste Management VII, Symposium held November 1417, 1983, Boston, Massachusetts. McVay, G.L., ed. 26, 1031-1038. New York, New York: Elsevier. TIC: 204393.

160778 Pruess, K.; Oldenburg, C.; and Moridis, G. 1999. TOUGH2 User's Guide, Version 2.0. LBNL-43134. Berkeley, California: Lawrence Berkeley National Laboratory. TIC: 253038.

100818 Pruess, K.; Wang, J.S.Y.; and Tsang, Y.W. 1990. “On Thermohydrologic Conditions Near High-Level Nuclear Wastes Emplaced in Partially Saturated Fractured Tuff, 1. Simulation Studies with Explicit Consideration of Fracture Effects." Water Resources Research, 26, (6), 1235-1248. [Washington, D.C.]: American Geophysical Union. TIC: 221923.

100819 Pruess, K.; Wang, J.S.Y.; and Tsang, Y.W. 1990. “On Thermohydrologic Conditions Near High-Level Nuclear Wastes Emplaced in Partially Saturated Fractured Tuff, 2. Effective Continuum Approximation." Water Resources Research, 26, (6), 12491261. [Washington, D.C.]: American Geophysical Union. TIC: 224854.

162583 Rutqvist, J. and Stephansson, O. 2003. "The Role of Hydromechanical Coupling in Fractured Rock Engineering." Hydrogeology Journal, 11, ([1]), 7-40. [New York, New York]: Springer-Verlag. TIC: 254245.

162587 Rutqvist, J. and Tsang, C-F. 2002. "A Study of Caprock Hydromechanical Changes Associated with $\mathrm{CO}$ \{subscript 2$\}$-Injection into a Brine Formation." Environmental Geology, 42, ([2-3]), 296-305. [New York, New York]: Springer-Verlag. TIC: 254244.

162584 Rutqvist, J. and Tsang, C-F. 2003. "Analysis of Thermal-Hydrologic-Mechanical Behavior Near an Emplacement Drift at Yucca Mountain." Journal of Contaminant Hydrology, 62-63, 637-652. New York, New York: Elsevier. TIC: 254205.

162048 Rutqvist, J.; Wu, Y.-S.; Tsang, C.-F.; and Bodvarsson, G. 2002. “A Modeling Approach for Analysis of Coupled Multiphase Fluid Flow, Heat Transfer, and Deformation in Fractured Porous Rock." International Journal of Rock Mechanics and Mining Sciences, 39, (4), 429-442. [New York, New York]: Pergamon. TIC: 253953.

100644 Sass, J.H.; Lachenbruch, A.H.; Dudley, W.W., Jr.; Priest, S.S.; and Munroe, R.J. 1988. Temperature, Thermal Conductivity, and Heat Flow Near Yucca Mountain, Nevada: Some Tectonic and Hydrologic Implications. Open-File Report 87-649. [Denver, Colorado]: U.S. Geological Survey. TIC: 203195. 
163202 Sobolik, S.R.; Finley, R.E.; and Ballard, S. 1999. "Thermal-Mechanical Measurements in the Drift Scale Test, Yucca Mountain, Nevada." Rock Mechanics for Industry, Proceedings of the 37th U.S. Rock Mechanics Symposium, Vail, Colorado, USA, 6-9 June, 1999. Amadei, B.; Kranz, R.L.; Scott, G.A.; and Smeallie, P.H.; eds. 2, 735-742. Brookfield, Vermont: A.A. Balkema. TIC: 245246.

162049 Sobolik, S.R.; Finley, R.E.; and Ballard, S. 1998. "Post-Test Comparison of Thermal-Mechanical Measurements vs. Analyses for the In-Situ Single Heater Test, Yucca Mountain, Nevada." International Journal of Rock Mechanics and Mining Sciences, 35, (4-5), 649. New York, New York: Pergamon. TIC: 253944.

162121 Spycher, N.F.; Sonnenthal, E.L.; and Apps, J.A. 2003. "Fluid Flow and Reactive Transport Around Potential Nuclear Waste Emplacement Tunnels at Yucca Mountain, Nevada." Journal of Contaminant Hydrology, 62-63, 653-673. New York, New York: Elsevier. TIC: 254205.

137577 Tsang, Y.W. and Birkholzer, J.T. 1999. "Predictions and Observations of the Thermal-Hydrological Conditions in the Single Heater Test." Journal of Contaminant Hydrology, 38, (1-3), 385-425. New York, New York: Elsevier. TIC: 244160 .

100688 Tsang, Y.W. and Pruess, K. 1987. “A Study of Thermally Induced Convection near a High-Level Nuclear Waste Repository in Partially Saturated Fractured Tuff." Water Resources Research, 23, (10), 1958-1966. Washington, D.C.: American Geophysical Union. TIC: 240715.

158378 USGS (U.S. Geological Survey) 2001. Future Climate Analysis. ANL-NBS-GS000008 REV 00 ICN 01. Denver, Colorado: U.S. Geological Survey. ACC: MOL.20011107.0004.

160355 USGS (U.S. Geological Survey) 2001. Simulation of Net Infiltration for Modern and Potential Future Climates. ANL-NBS-HS-000032 REV 00 ICN 02. Denver, Colorado: U.S. Geological Survey. ACC: MOL.20011119.0334.

100610 van Genuchten, M.T. 1980. "A Closed-Form Equation for Predicting the Hydraulic Conductivity of Unsaturated Soils.” Soil Science Society of America Journal, 44, (5), 892-898. Madison, Wisconsin: Soil Science Society of America. TIC: 217327.

165927 Wang, J.S. 2003. "Scientific Notebooks Referenced in Model Report U0105 Mountain-Scale Coupled Processes (TH/THC/THM), MDL-NBS-HS-000007 REV 01.” Interoffice correspondence from J.S. Wang (BSC) to File, December 4, 2003, with attachments. ACC: MOL.20031208.0371.

123506 Witherspoon, P.A.; Wang, J.S.Y; Iwai, K.; and Gale, J.E. 1980. "Validity of Cubic Law for Fluid Flow in a Deformable Rock Fracture." Water Resources Research, 16, (6), 1016-1024. [Washington, D.C.]: American Geophysical Union. TIC: 220088. 
153972 Wu, Y-S. and Pruess, K. 2000. "Numerical Simulation of Non-Isothermal Multiphase Tracer Transport in Heterogeneous Fractured Porous Media." Advances in Water Resources, 23, (7), 699-723. New York, New York: Elsevier. TIC: 249626.

117161 Wu, Y-S.; Haukwa, C.; and Bodvarsson, G.S. 1999. "A Site-Scale Model for Fluid and Heat Flow in the Unsaturated Zone of Yucca Mountain, Nevada." Journal of Contaminant Hydrology, 38, (1-3), 185-215. New York, New York: Elsevier. TIC: 244160.

160195 Wu, Y-S.; Pan, L.; Zhang, W.; and Bodvarsson, G.S. 2002. "Characterization of Flow and Transport Processes within the Unsaturated Zone of Yucca Mountain, Nevada, Under Current and Future Climates." Journal of Contaminant Hydrology, 54, ([3-4]), 215-247. [New York, New York]: Elsevier. TIC: 253316.

117167 Wu, Y.S.; Ritcey, A.C.; and Bodvarsson, G.S. 1999. "A Modeling Study of Perched Water Phenomena in the Unsaturated Zone at Yucca Mountain." Journal of Contaminant Hydrology, 38, (1-3), 157-184. New York, New York: Elsevier. TIC: 244160 .

161864 Xu, T.; Sonnenthal, E.; Spycher, N.; Pruess, K.; Brimhall, G.; and Apps, J. 2001. "Modeling Multiphase Non-Isothermal Fluid Flow and Reactive Geochemical Transport in Variably Saturated Fractured Rocks: 2. Applications to Supergene Copper Enrichment and Hydrothermal Flows." American Journal of Science, 301, (1), 34-59. New Haven, Connecticut: Yale University, Kline Geology Laboratory. TIC: 253949.

\section{Software Cited}

140944 LBNL (Lawrence Berkeley National Laboratory) 1999. Software Code: EXT. V1.0. Sun Workstation. 10047-1.0-00.

160768 LBNL (Lawrence Berkeley National Laboratory) 1999. Software Code: EXT. V1.1. SunOS 5.5.1. 10005-1.1-00.

147553 LBNL (Lawrence Berkeley National Laboratory) 1999. Software Routine: 2KGRIDV1.F. V1.0. Sun UltraSPARC w/SunOS 5.5.1. 10244-1.0-00.

153067 LBNL (Lawrence Berkeley National Laboratory) 2000. Software Routine Report: 2 kgridvla.for. V1.0. PC w/Windows OS. 10382-1.0-00.

147023 LBNL (Lawrence Berkeley National Laboratory) 2000. Software Routine: genincon-v0.f. V1.0. DEC Alpha w/OSF1 V4.0. 10220-1.0-00.

147025 LBNL (Lawrence Berkeley National Laboratory) 2000. Software Routine: get_a_layer_v0.f. V1.0. DEC Alpha w/OSF1 V4.0. 10221-1.0-00. 
147027 LBNL (Lawrence Berkeley National Laboratory) 2000. Software Routine: get_temp_v0.f. V1.0. DEC Alpha w/OSF1 V4.0. 10222-1.0-00.

147031 LBNL (Lawrence Berkeley National Laboratory) 2000. Software Routine: hsource_v0.f. V1.0. DEC Alpha w/OSF1 V4.0. 10225-1.0-00.

147030 LBNL (Lawrence Berkeley National Laboratory) 2000. Software Routine: toptemp_v0.f. V1.0. DEC Alpha w/OSF1 V4.0. 10224-1.0-00.

154783 LBNL (Lawrence Berkeley National Laboratory) 2001. Software Code: FLAC3D. V2.0. PC. STN: 10502-2.0-00.

154791 LBNL (Lawrence Berkeley National Laboratory) 2001. Software Routine: Delb.dat. V1.0. PC. STN: 10507-1.0-00.

154792 LBNL (Lawrence Berkeley National Laboratory) 2001. Software Routine: Gpzones.dat. V1.0. PC. STN: 10509-1.0-00.

154793 LBNL (Lawrence Berkeley National Laboratory) 2002. Software Code: infil2grid. V1.7. DEC-Alpha, PC. 10077-1.7-00.

162038 LBNL (Lawrence Berkeley National Laboratory) 2002. Software Code: Tin. V1.1. PC Windows 98. 10899-1.1-00.

161256 LBNL (Lawrence Berkeley National Laboratory) 2002. Software Code: TOUGHREACT. V3.0. DEC-Alpha with Unix OSF1 V5.1 and OSF1 V5.0, Sun UltraSparc w/Solaris 5.5.1, PC with Linux Redhat 7.2. 10396-3.0-00.

154785 LBNL (Lawrence Berkeley National Laboratory) 2002. Software Code: WINGRIDDER. V2.0. PC. 10024-2.0-00.

154787 LBNL (Lawrence Berkeley National Laboratory) 2002. Software Routine: 2kgrid8.for. V1.0. DEC-Alpha, PC. 10503-1.0-00.

161491 LBNL (Lawrence Berkeley National Laboratory) 2003. Software Code: TOUGH2. V1.6. PC/MS-DOS under Windows 98, Sun UltraSparc OS 5.5.1, DEC-Alpha OSF1 V4.0. 10007-1.6-01.

\subsection{CODES, STANDARDS, REGULATIONS, AND PROCEDURES}

15667166 FR 55732. Disposal of High-Level Radioactive Wastes in a Proposed Geologic Repository at Yucca Mountain, NV. Final Rule 10 CFR Part 63. Readily available.

AP-2.22Q, Rev. 1, ICN 0. Classification Analyses and Maintenance of the Q-List. Washington, D.C.: U.S. Department of Energy, Office of Civilian Radioactive Waste Management. ACC: DOC.20030807.0002. 
AP-SI.1Q, Rev. 5, ICN 2. Software Management. Washington, D.C.: U.S. Department of Energy, Office of Civilian Radioactive Waste Management. ACC: DOC.20030902.0003.

AP-SIII.10Q, Rev. 2, ICN 1. Models. Washington, D.C.: U.S. Department of Energy, Office of Civilian Radioactive Waste Management. ACC: DOC.20031126.0002.

\subsection{SOURCE DATA, LISTED BY DATA TRACKING NUMBER}

147613 GS000308311221.005. Net Infiltration Modeling Results for 3 Climate Scenarios for FY99. Submittal date: 03/01/2000.

105572 GS950208312232.003. Data, Including Water Potential, Pressure and Temperature, Collected from Boreholes USW NRG-6 and USW NRG-7A from Instrumentation through March 31, 1995. Submittal date: 02/13/1995.

106756 GS951108312232.008. Data, Including Water Potential, Pressure and Temperature, Collected from Boreholes UE-25 UZ\#4 \& UZ\#5 from Instrumentation through September 30, 1995, and from USW NRG-6 \& NRG-7A from April 1 through September 30, 1995. Submittal date: 11/21/1995.

105573 GS960308312232.001. Deep Unsaturated Zone Surface-Based Borehole Instrumentation Program Data from Boreholes USW NRG-7A, USW NRG-6, UE-25 UZ\#4, UE-25 UZ\#5, USW UZ-7A, and USW SD-12 for the Time Period 10/01/95 through 3/31/96. Submittal date: 04/04/1996.

113495 LA9908JC831321.001. Mineralogic Model "MM3.0” Version 3.0. Submittal date: 08/16/1999.

146447 LA9912SL831151.001. Fracture Mineralogy of Drill Core ESF-HD-TEMP-2. Submittal date: 01/05/2000.

146449 LA9912SL831151.002. Percent Coverage by Fracture-Coating Minerals in Core ESF-HD-TEMP-2. Submittal date: 01/05/2000.

159525 LB0205REVUZPRP.001. Fracture Properties for UZ Model Layers Developed from Field Data. Submittal date: 05/14/2002.

161638 LB0208ISODSTHP.001. Isotope Data and CO2 Analysis for the Heating Phase of the DST. Submittal date: 08/09/2002.

161243 LB0208UZDSCPMI.002. Drift-Scale Calibrated Property Sets: Mean Infiltration Data Summary. Submittal date: 08/26/2002.

160799 LB0210THRMLPRP.001. Thermal Properties of UZ Model Layers: Data Summary. Submittal date: $10 / 25 / 2002$.

162379 LB03013DSSCP3I.001. 3-D Site Scale Calibrated Properties: Data Summaries. Submittal date: 01/27/2003. 
165168 LB0303THERMESH.001. Thermal Model Mesh. Submittal date: 03/28/2003.

165167 LB0303THERMSIM.001. UZ Thermal Modeling: Simulations. Submittal date: $03 / 28 / 2003$.

163937 LB030432DGRIDS.001. Three 2-D Cross-Section Grids. Submittal date: 04/29/2003.

166054 LB0307DSTTHCR2.001. Drift-Scale Coupled Processes (DST Seepage) Model: Simulations. Submittal date: 07/24/2003.

164433 LB0307KNTDBRTM.001. Kinetic Database for Reactive Transport Modeling. Submittal date: 07/22/2003.

164434 LB0307THMDBRTM.001. Thermodynamic Database for Reactive Transport Modeling. Submittal date: 07/22/2003.

161677 LL020709923142.023. Aqueous Geochemistry of Borehole Waters Collected in the Heating Phase of the DST. Submittal date: 07/26/2002.

150930 MO0005PORWATER.000. Perm-Sample Pore Water Data. Submittal date: 05/04/2000.

154087 MO0007RIB00077.000. In Situ Rock Conditions. Submittal date: 07/18/2000.

153777 MO0012MWDGFM02.002. Geologic Framework Model (GFM2000). Submittal date: $12 / 18 / 2000$.

164527 MO0307SEPFEPS4.000. LA FEP List. Submittal date: 07/31/2003.

148524 MO9911SEPGRP34.000. Geotechnical Rock Properties. Submittal date: $11 / 10 / 1999$.

\subsection{OUTPUT DATA, LISTED BY DATA TRACKING NUMBER}

LB0310MTSCLTHM.001. Mountain Scale THM Predictions: Simulations. Submittal date: $10 / 21 / 2003$.

LB0310MTSCLTHM.002. Mountain Scale THM Predictions: Summary Plots. Submittal date: $10 / 21 / 2003$.

LB0310MTSCLTH2.001. Mountain Scale 2D TH Predictions: Simulations. Submittal date: $10 / 21 / 2003$.

LB0310MTSCLTH3.001. Mountain Scale 3D TH Predictions: Simulations. Submittal date: 10/21/2003. 
LB0310MTSCLTHC.001. Mountain Scale THC Predictions: Simulations. Submittal date: $10 / 21 / 2003$.

LB0310MTSCLTHC.002. Mountain Scale THC Predictions: Data Summaries. Submittal date: 10/21/2003. 


\section{ATTACHMENT I-INITIAL MINERAL VOLUME FRACTIONS}




\section{INTENTIONALLY LEFT BLANK}




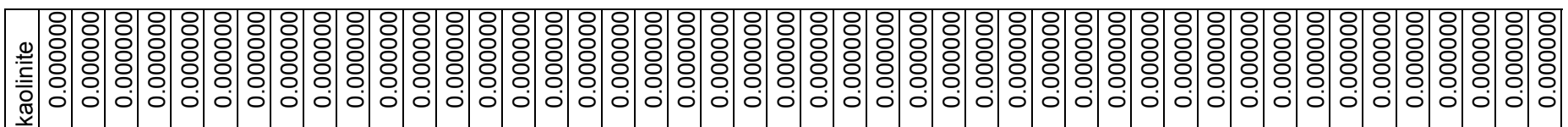

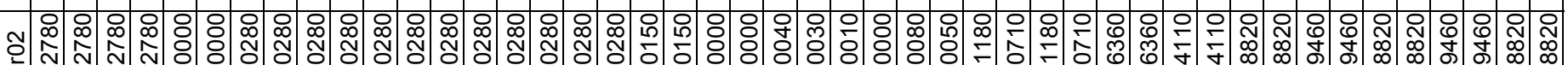

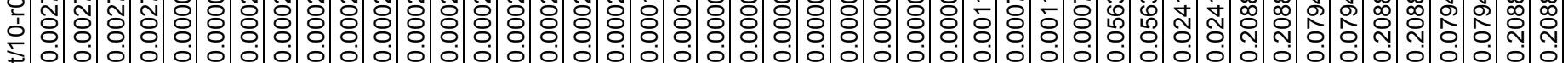

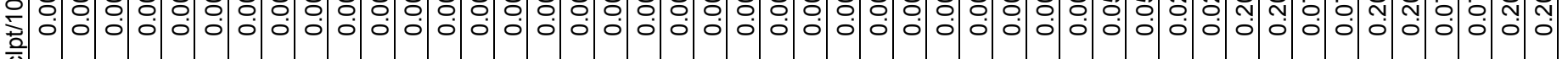

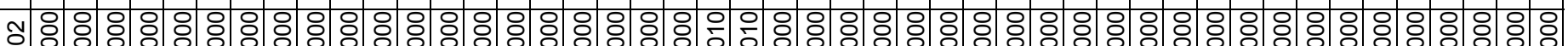

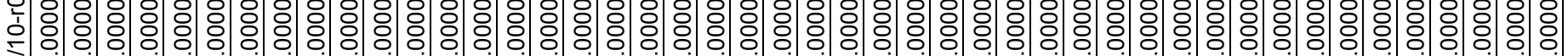
to

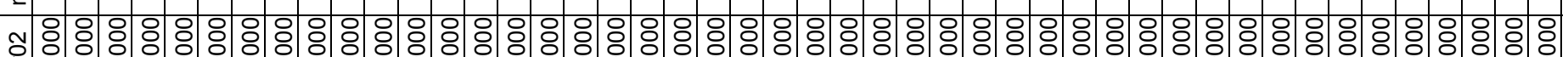

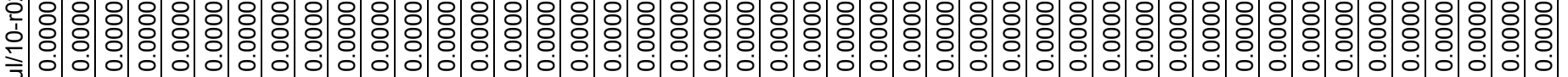
言

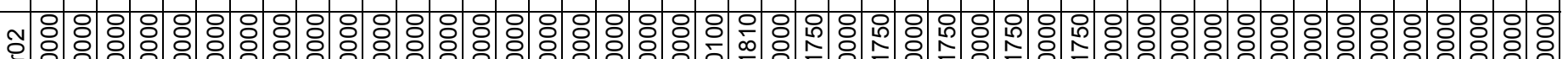

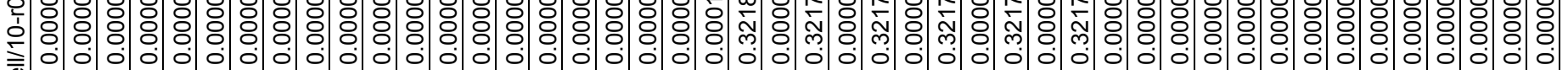

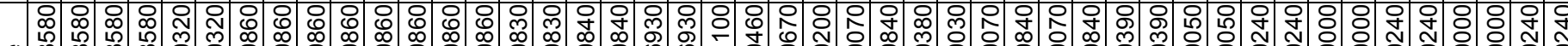

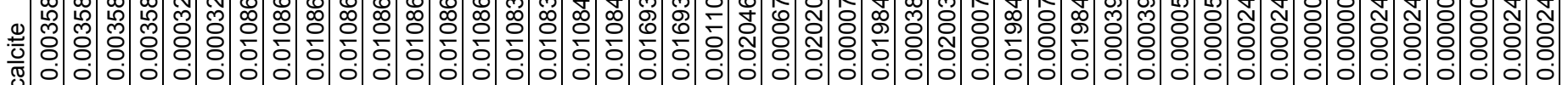

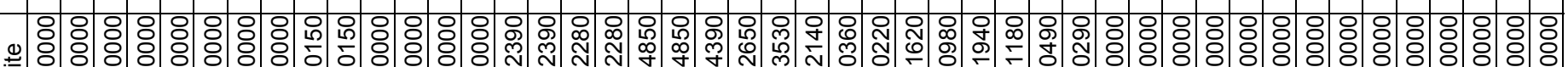
년: 气n

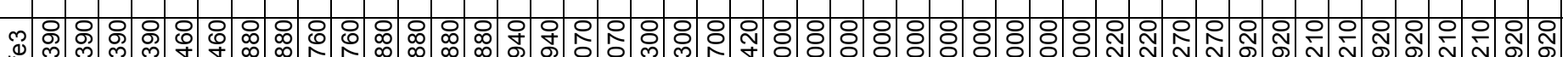

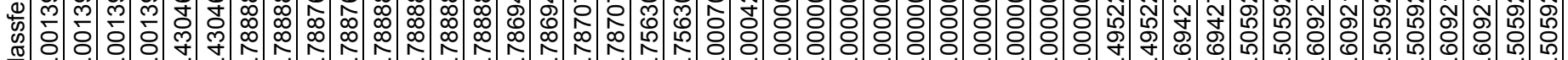

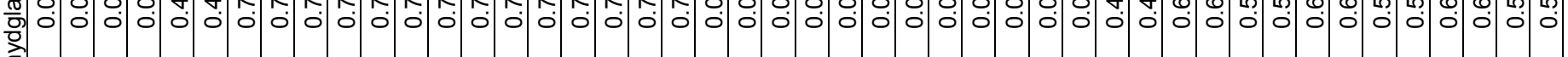

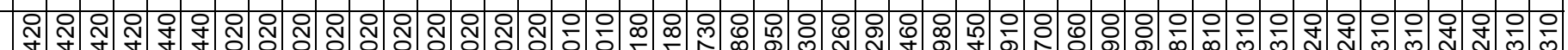

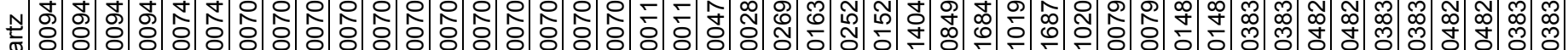
च

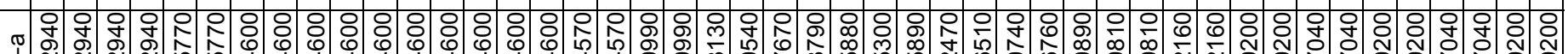

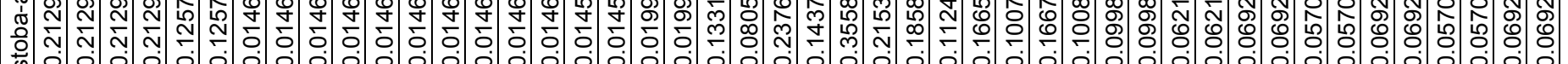

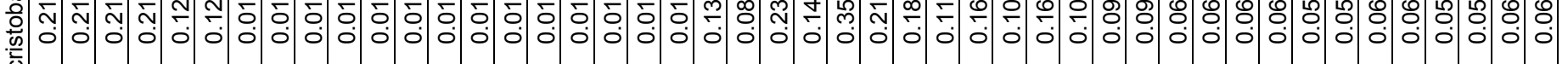

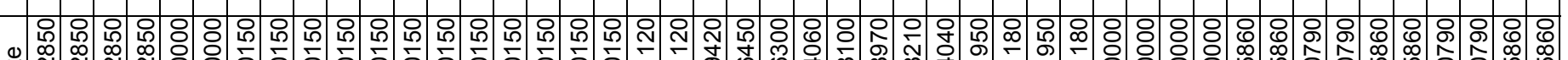

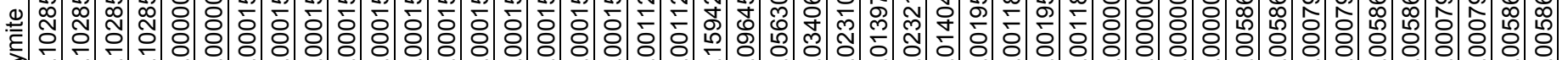
흘

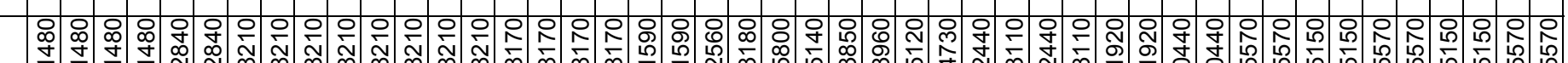

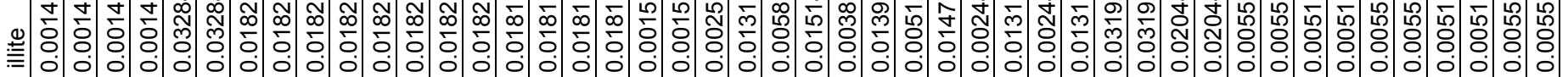

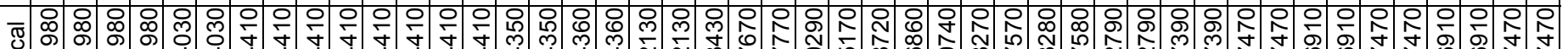

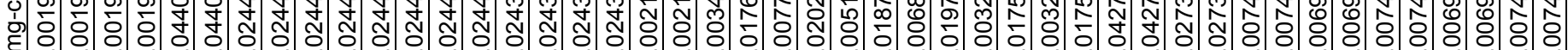

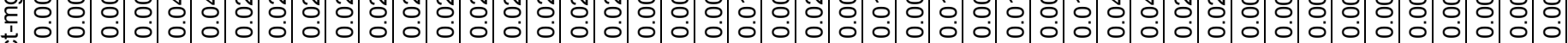

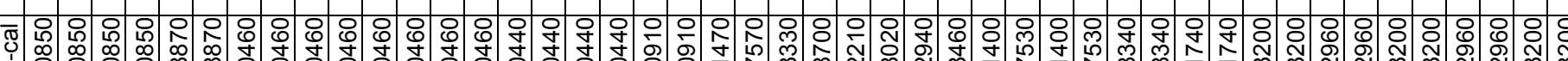

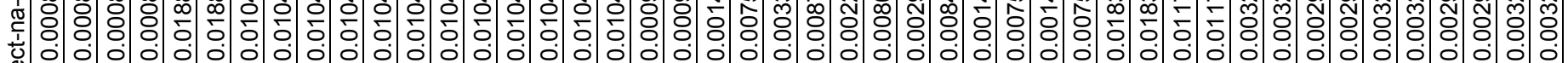

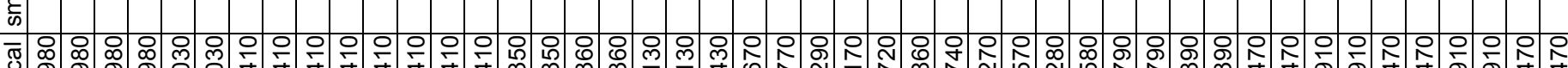

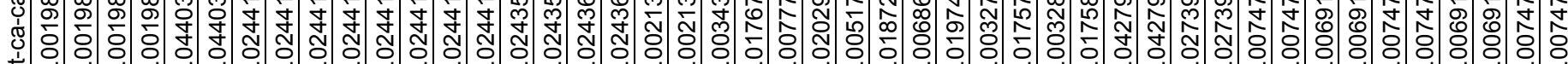

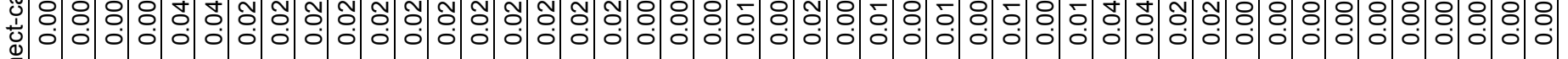

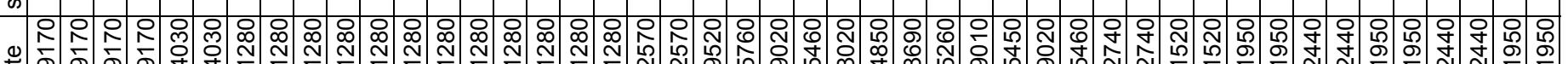

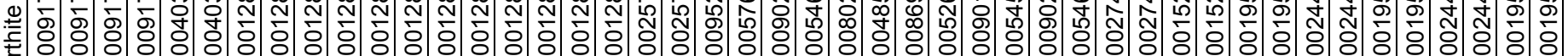

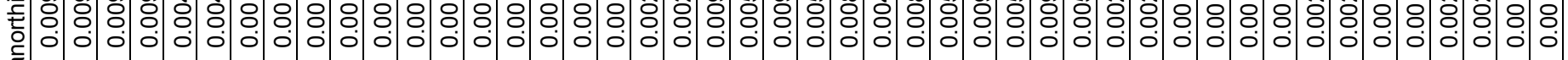

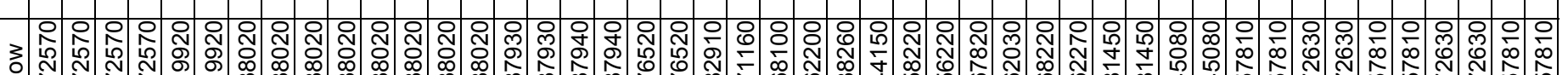

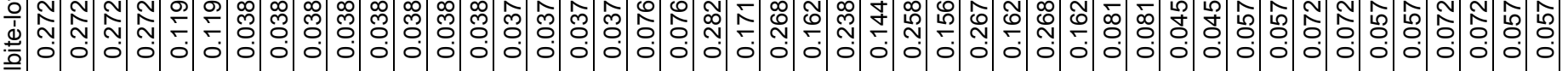

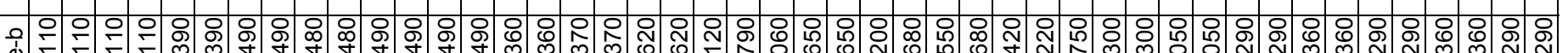

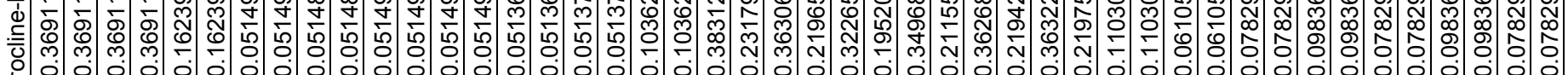

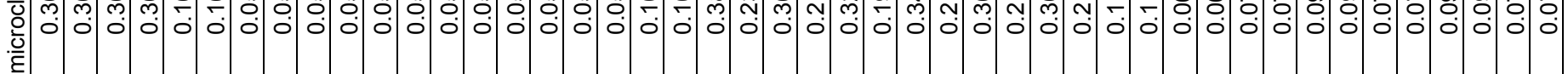

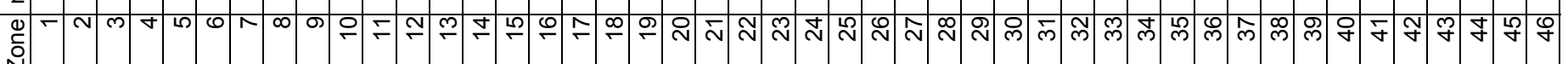

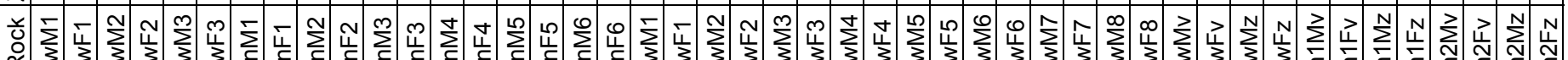




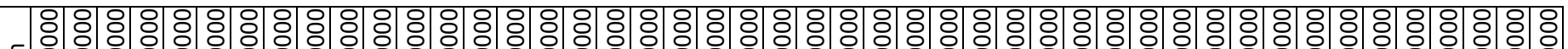

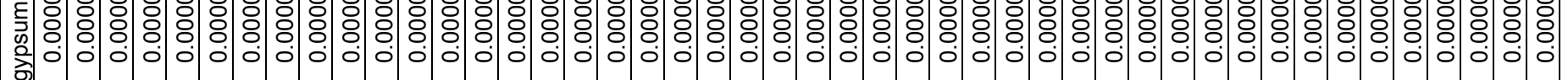

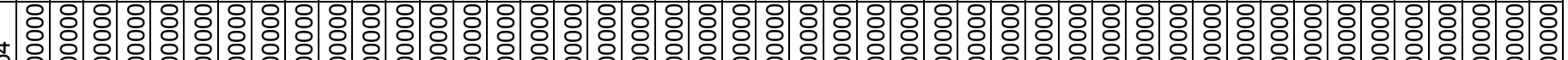
些

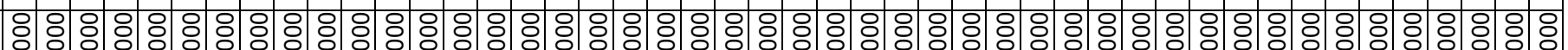

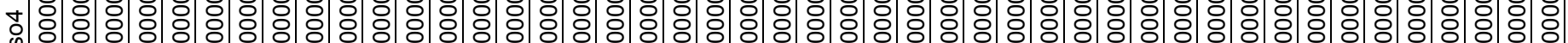

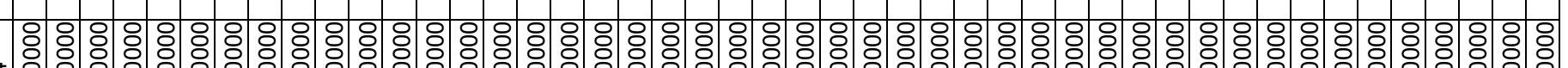

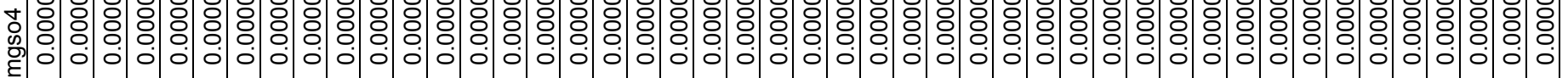

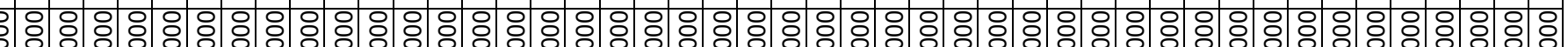

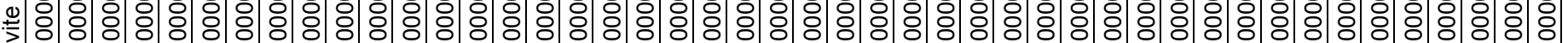

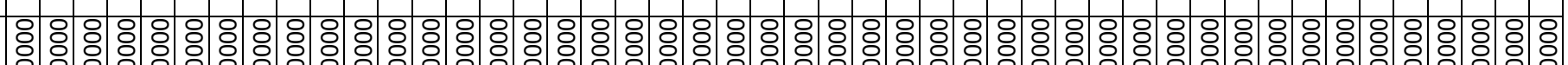

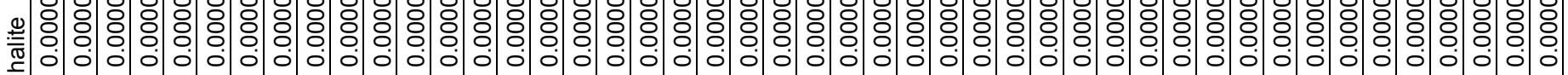

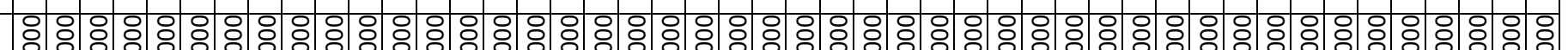

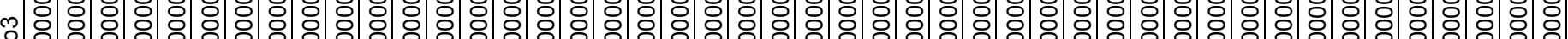

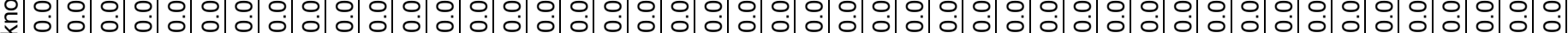

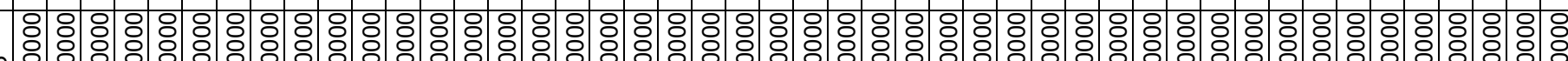
怘

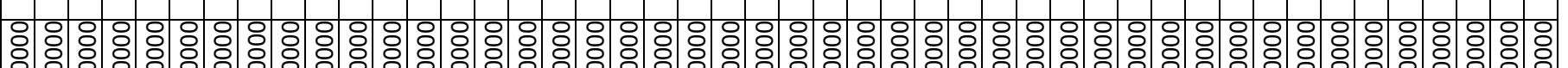

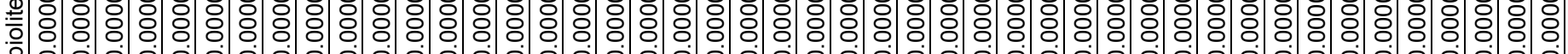

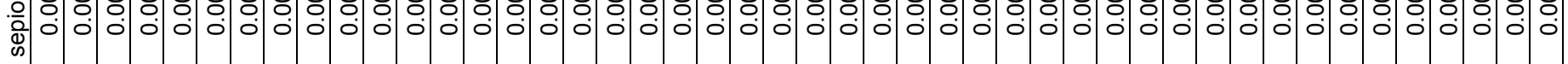

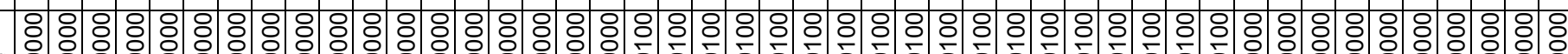

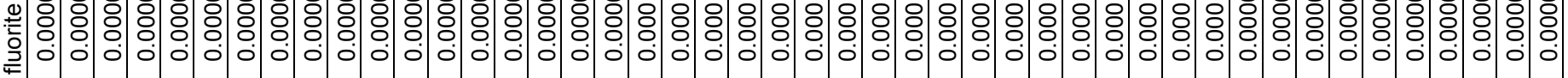

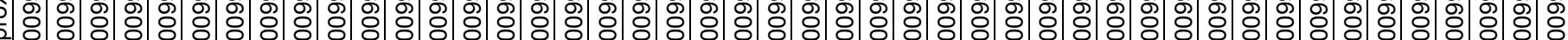

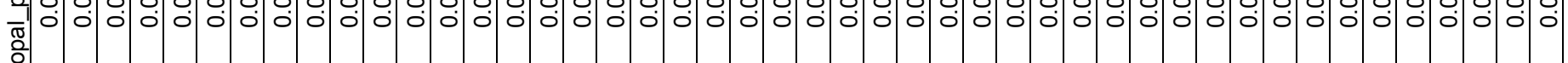

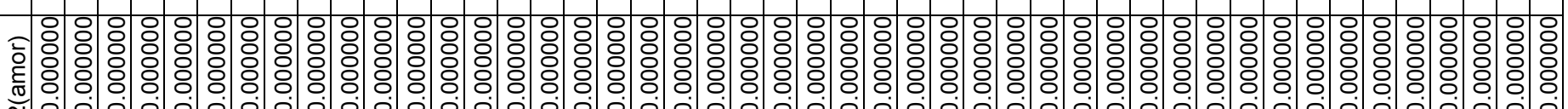
$\frac{\mathrm{m}}{\mathrm{m}}$

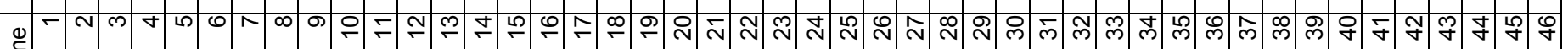

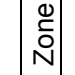

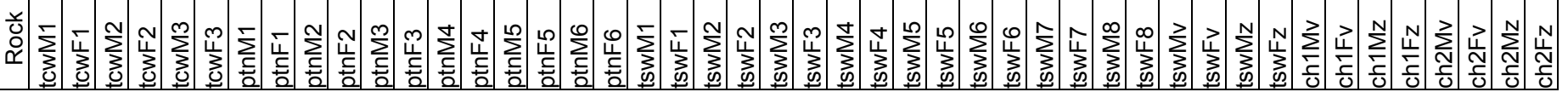




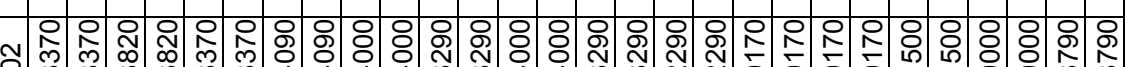

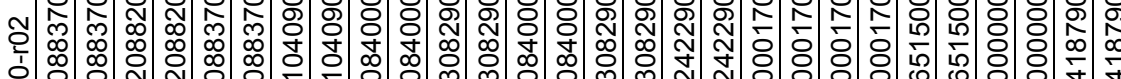

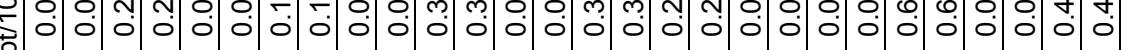

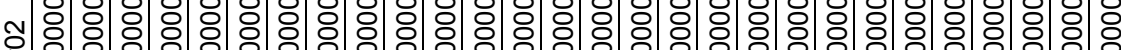
额: 항

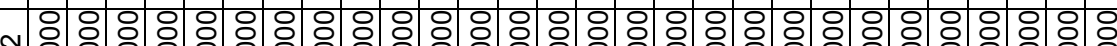

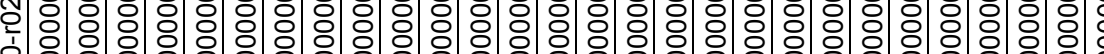

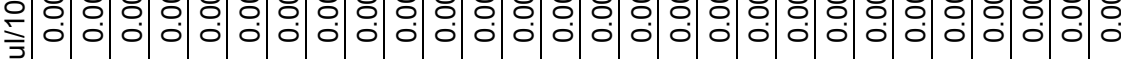

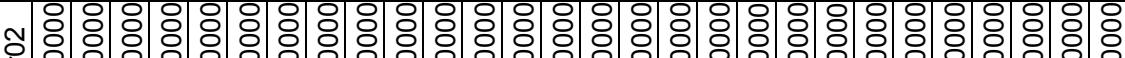

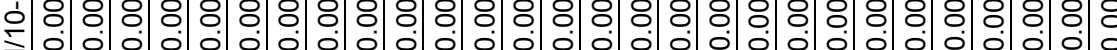
产

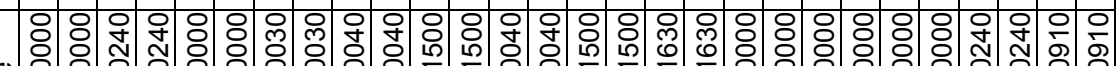

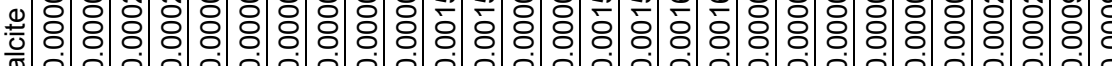

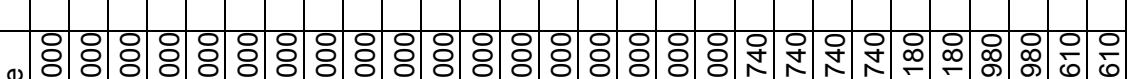
ڤ 莹

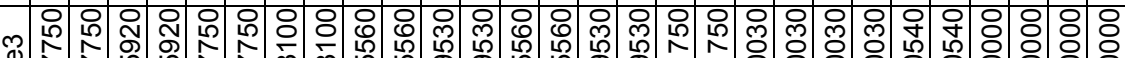

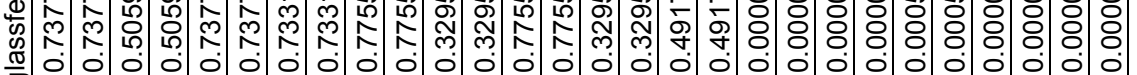
要

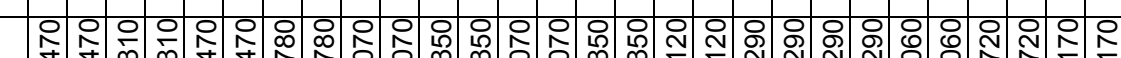
곤

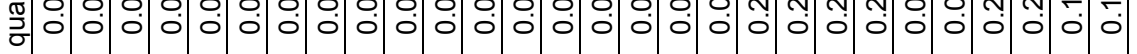

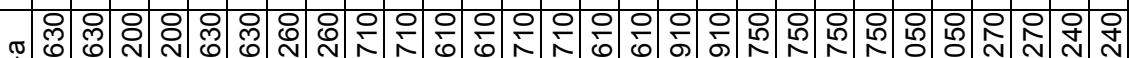

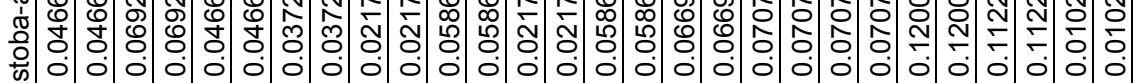

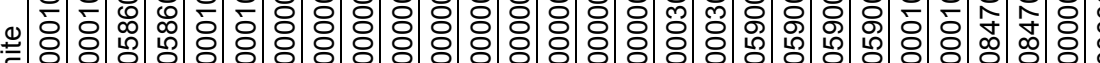

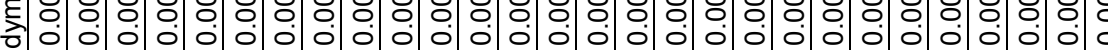
을

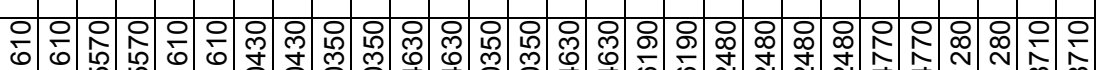

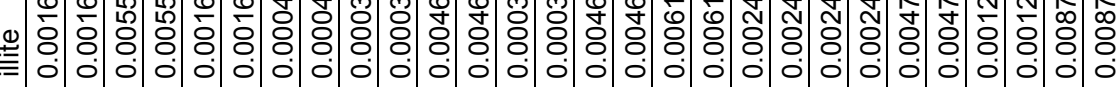

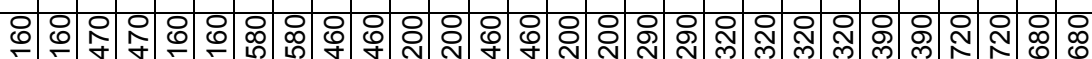

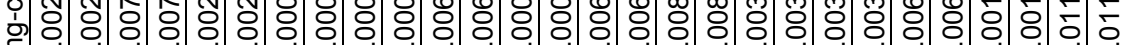

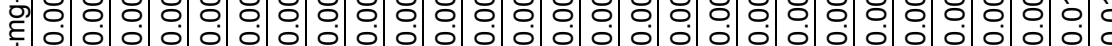
㟧

匹 市

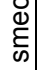

- 은연연:

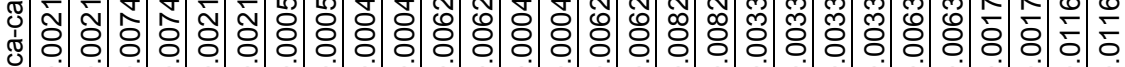
离

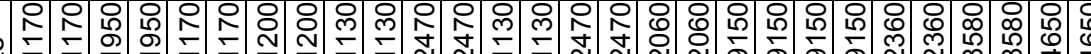

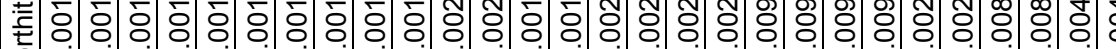

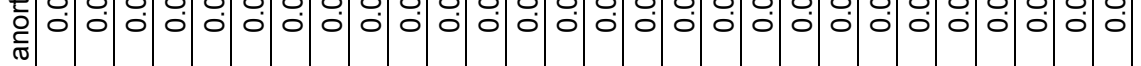

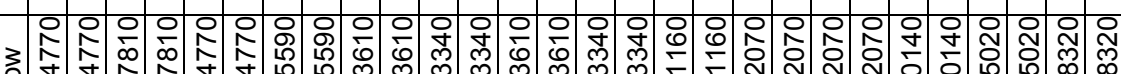

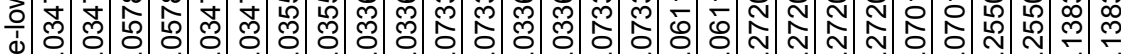
:

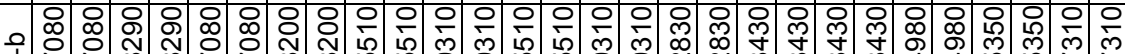

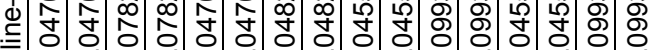

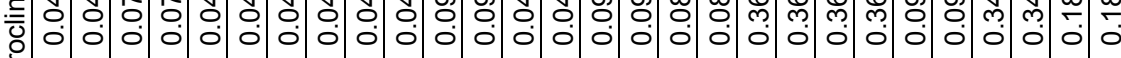
$\frac{. \overline{\mathrm{c}}}{\mathrm{E}}$

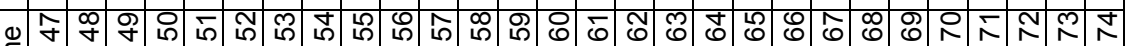
N 


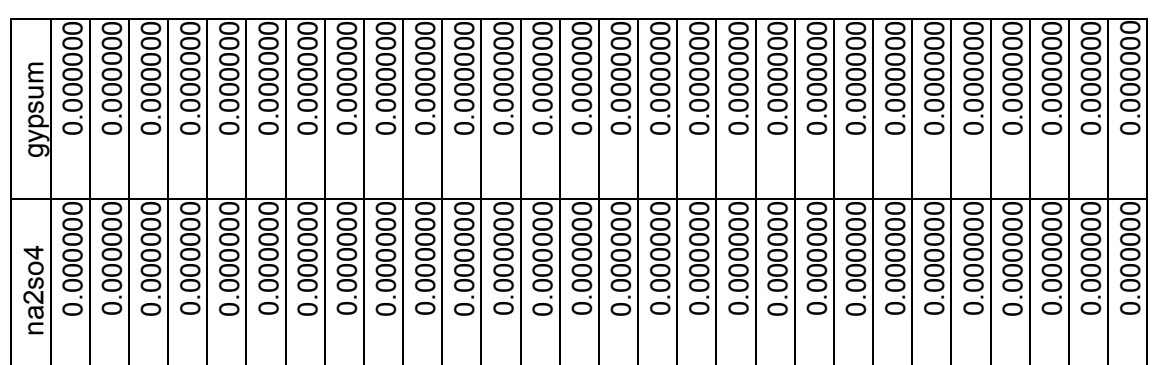

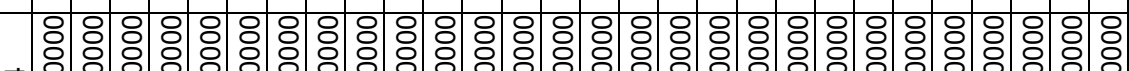

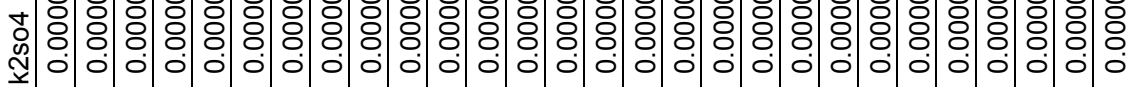

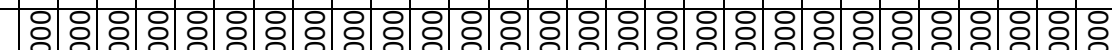

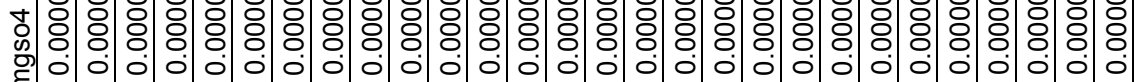

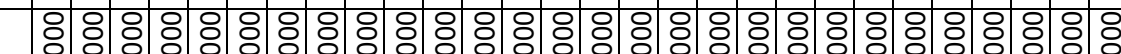

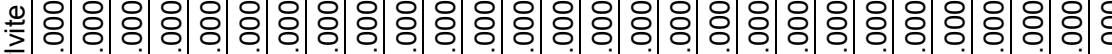

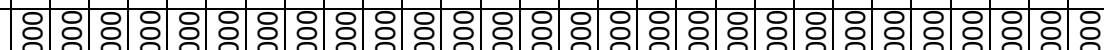

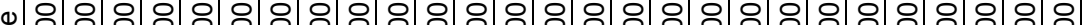

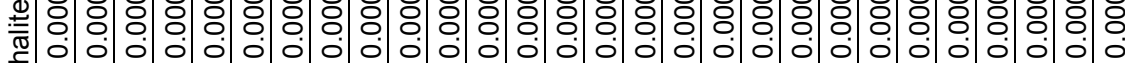

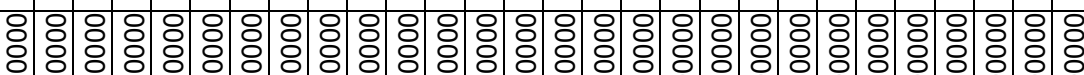

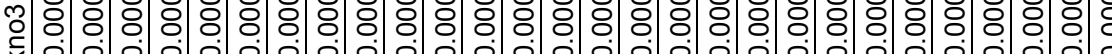

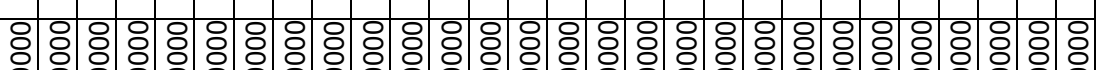

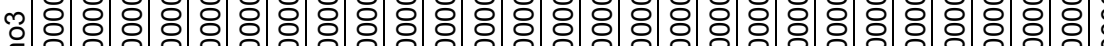
๘

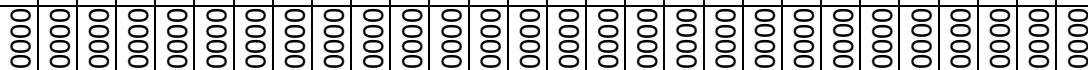
言第

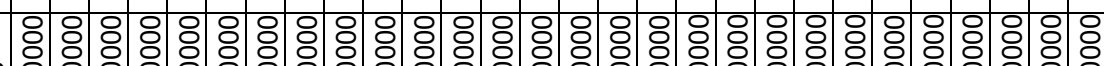

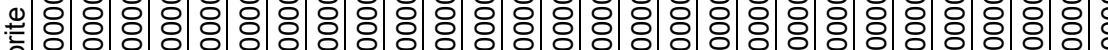
言: خ

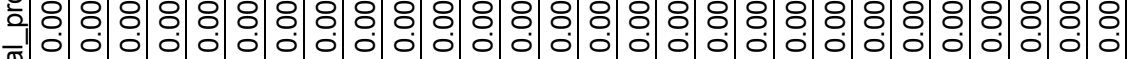
学 ๙ 훙유.

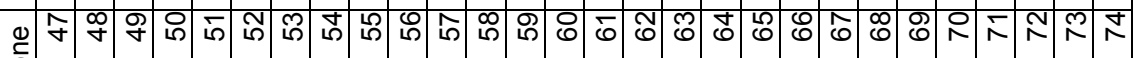
N 


\section{ATTACHMENT II-INITIAL MINERAL REACTIVE SURFACE AREAS $\left(\mathrm{cm}^{2} / \mathrm{g}\right.$ FOR} MATRIX, $\mathrm{m}^{2} / \mathrm{m}^{3}$ FOR FRATURES) 


\section{INTENTIONALLY LEFT BLANK}




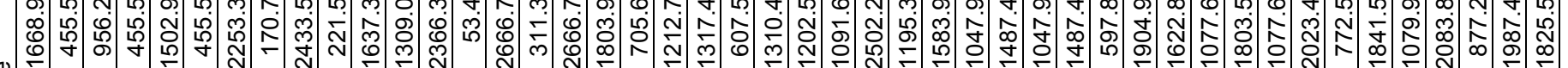

20
200

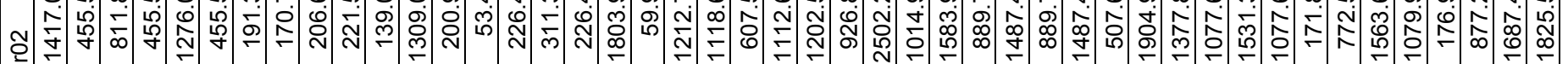

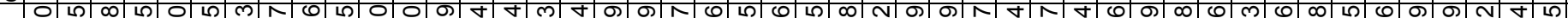

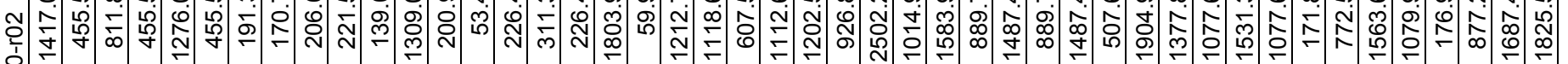
홓

D. L

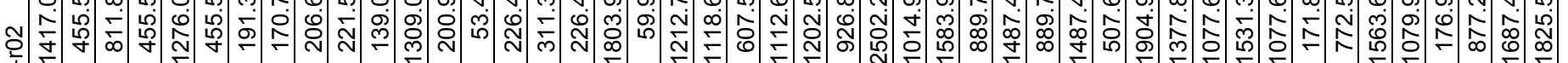

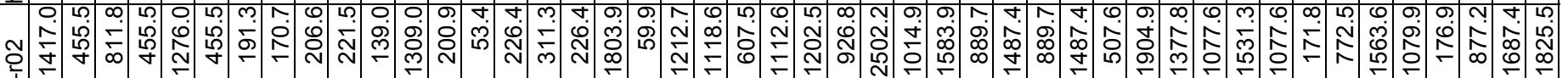
$\stackrel{1}{\equiv}$

0 n 0 n 0 m

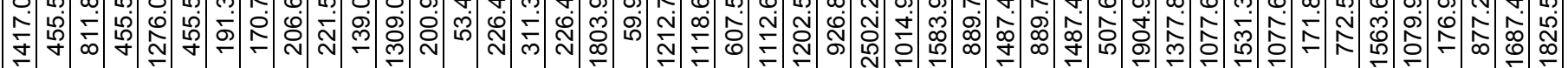
$\frac{\stackrel{2}{\frac{\pi}{\pi}}}{\frac{\pi}{\pi}}$

मे

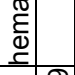

$\infty$ 在

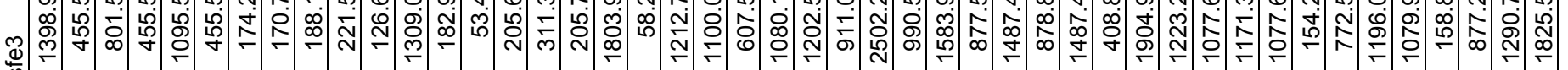
要

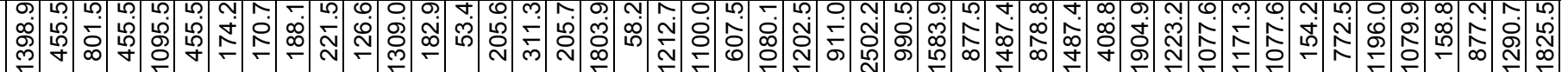

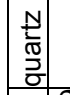

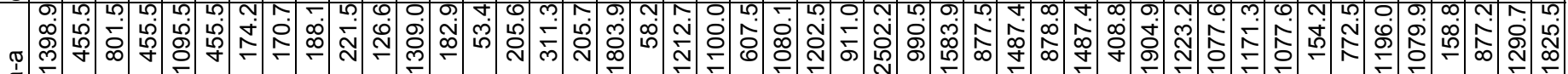

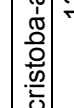

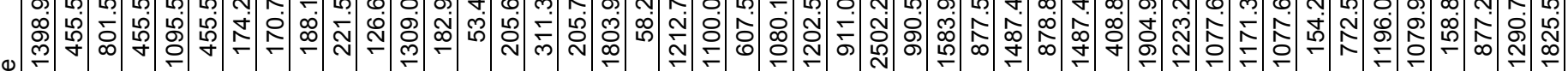

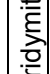

a n n क क

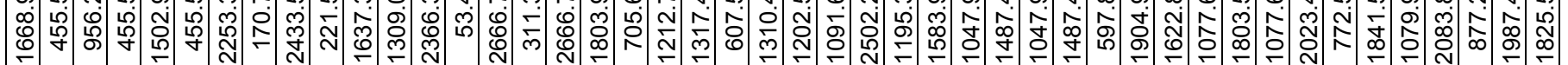

党

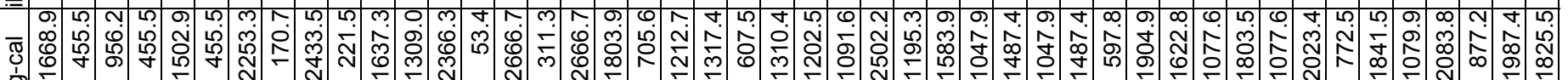
咅

क

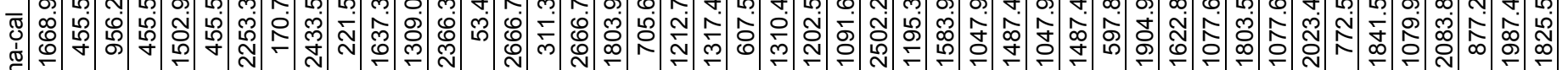
章

a

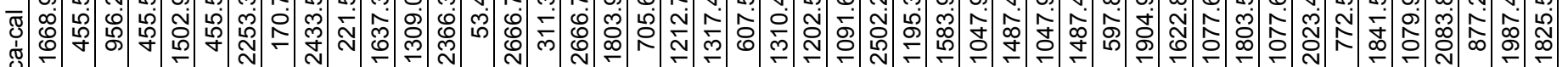
章

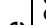

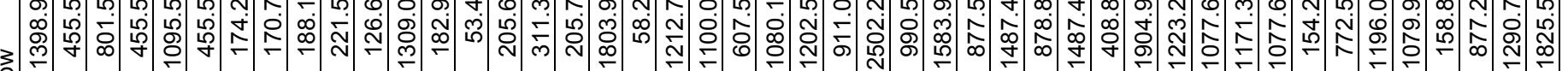
产

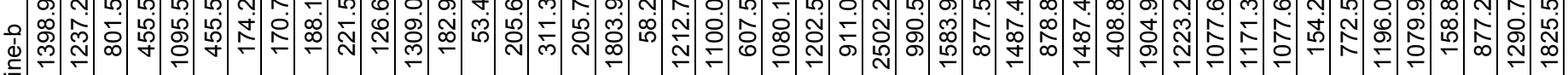
$\frac{\mathrm{O}}{\mathrm{O}}$ ๑ั 


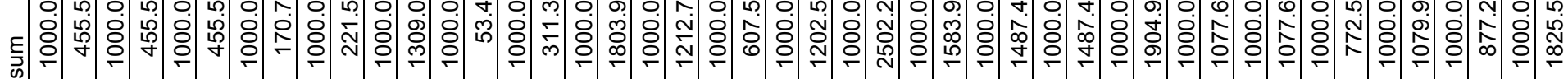
齐

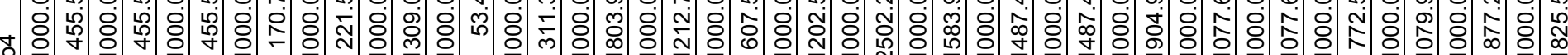

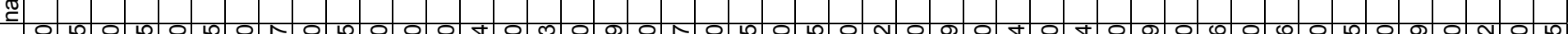

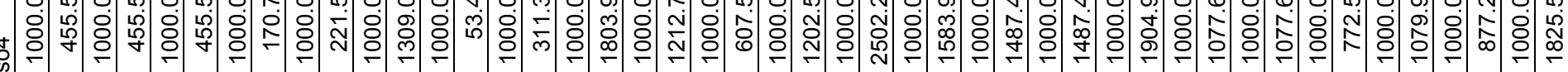

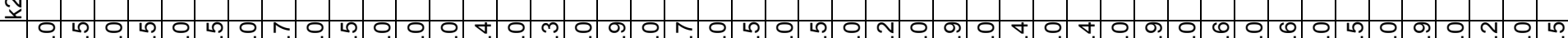

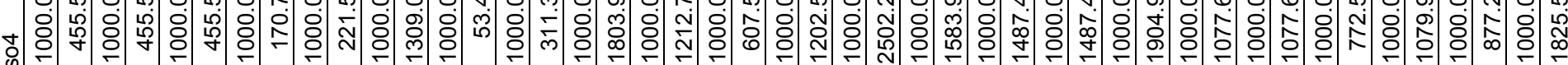
200

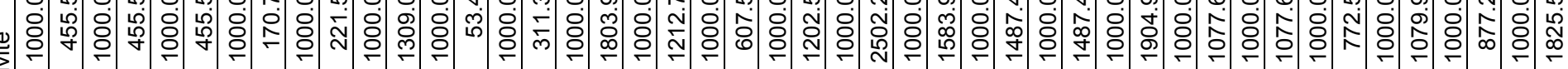
o lo lo lo ol ๔ ○

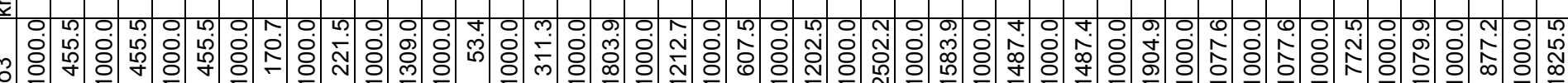
@ 응

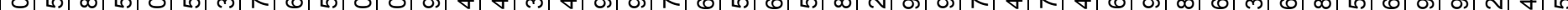

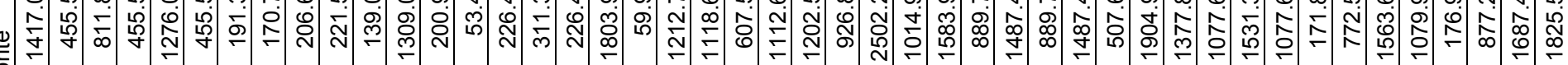




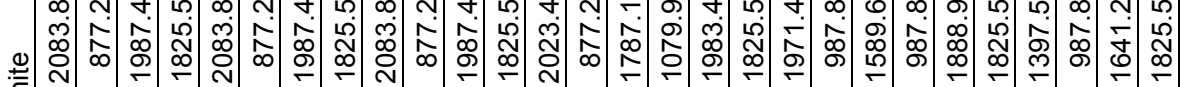

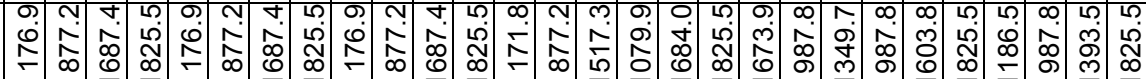

$0 \hat{10}$ (2) 항

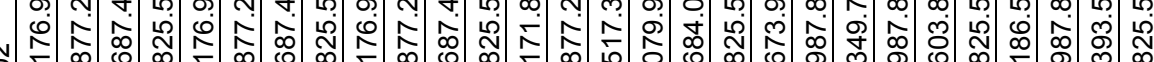
紊 \%

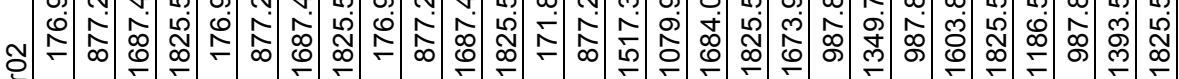
产

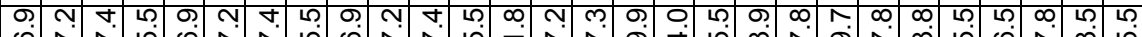

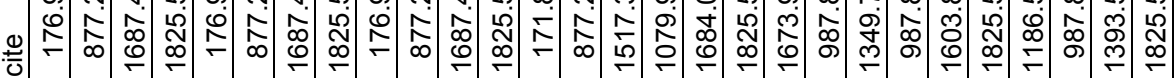

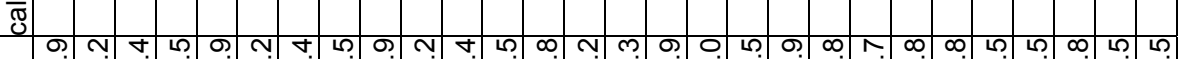
0 (2)

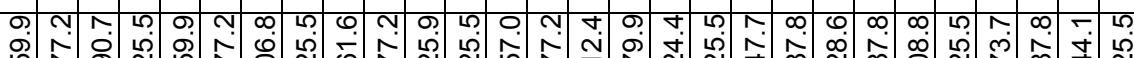

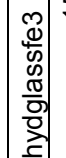

-

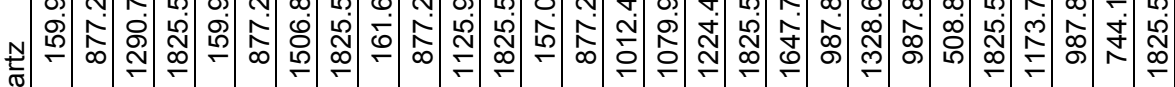

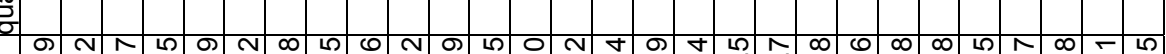

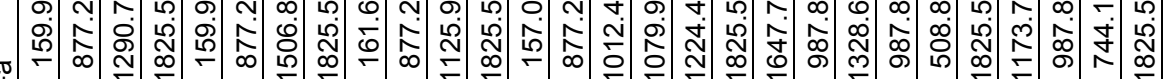
竞

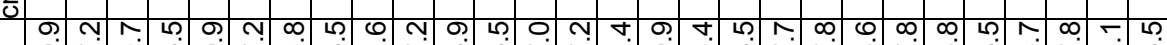

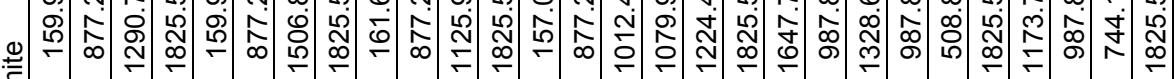
을

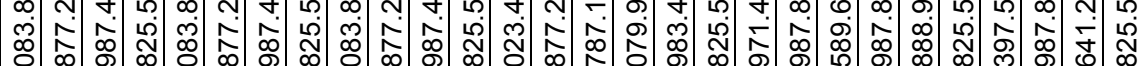
喜

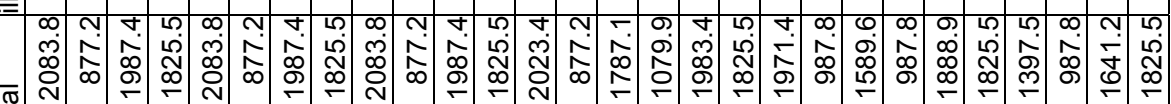
要 $\bar{\sigma}$ 离

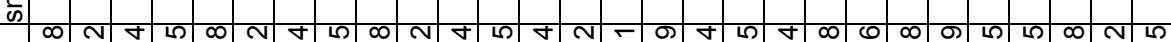

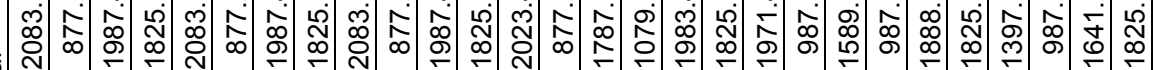
音

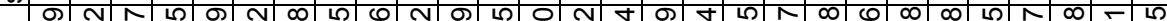

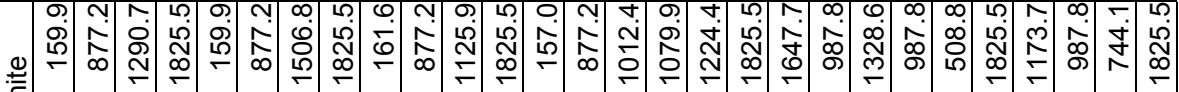
3.

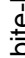
क क n क n

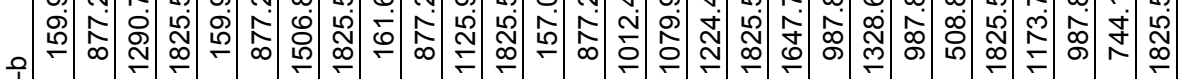
: 


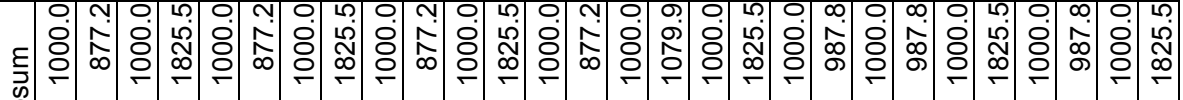

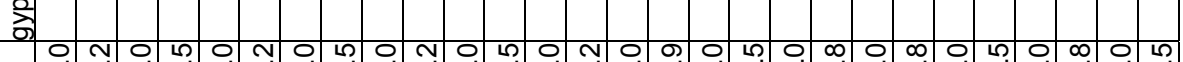

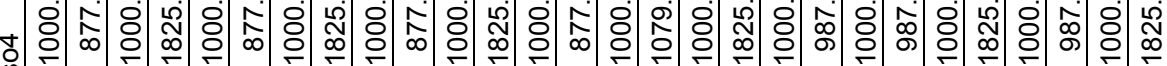
(1)

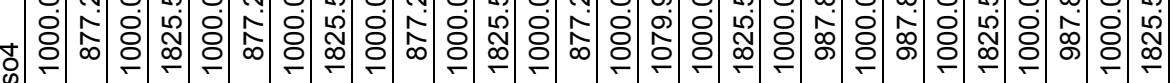
2.

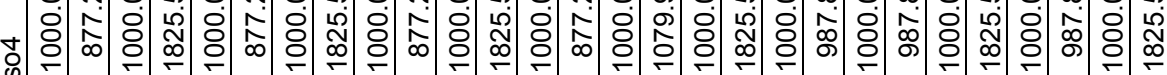

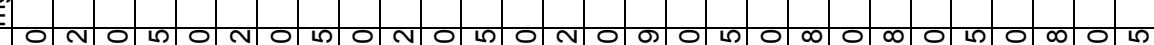
응 mon

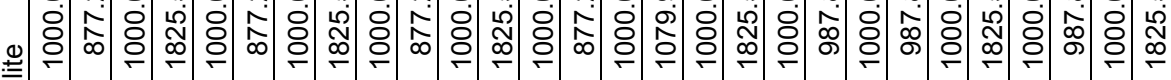
항

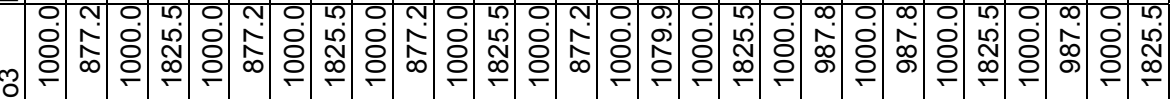

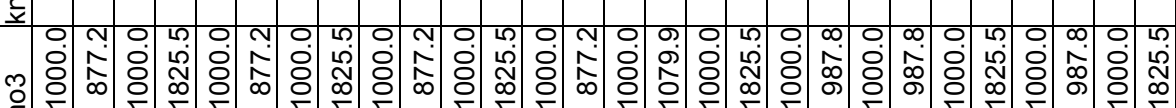

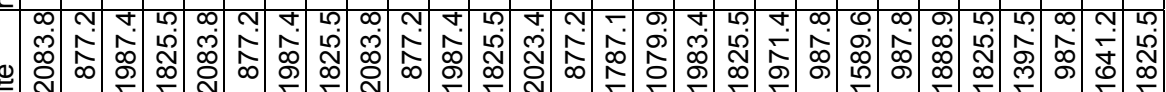
흥

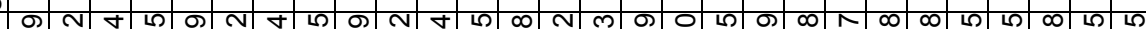
은

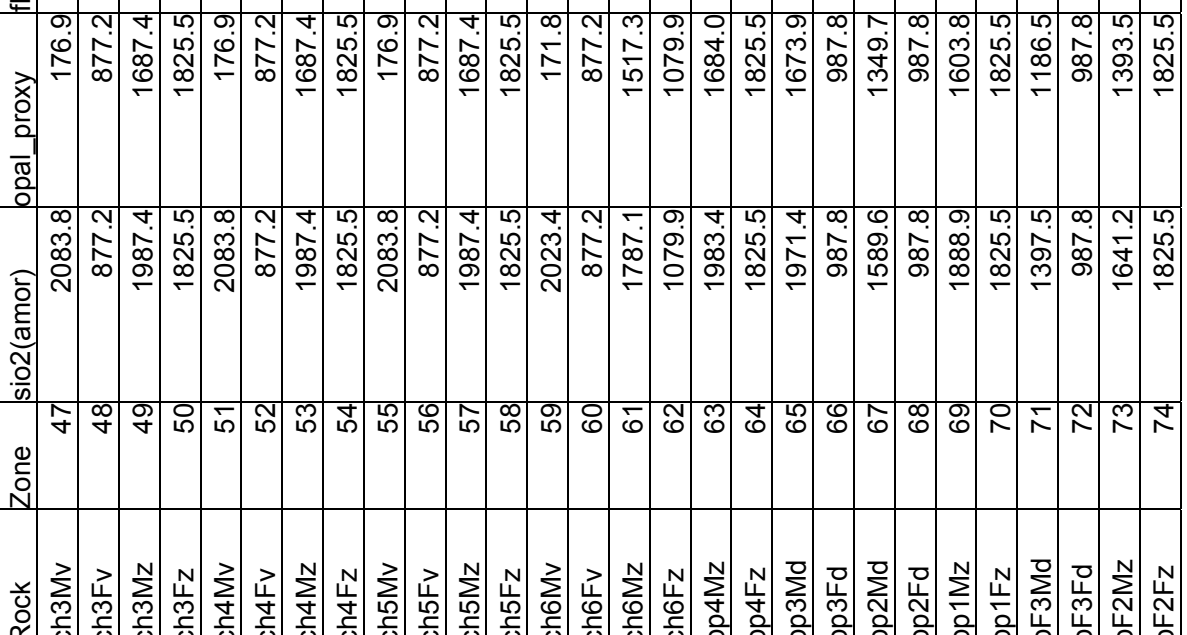




\section{ATTACHMENT III-PERMEABILITY MODEL PARAMETERS}




\section{INTENTIONALLY LEFT BLANK}




\begin{tabular}{|c|c|c|c|c|}
\hline Rock & Zone & Law & A-Par & B-Par \\
\hline tcwM1 & 1 & 1 & $0.00 E+00$ & $0.00 E+00$ \\
\hline tcwF1 & 2 & 4 & 1.54E-02 & $1.09 E+00$ \\
\hline tcwM2 & 3 & 1 & $0.00 \mathrm{E}+00$ & $0.00 \mathrm{E}+00$ \\
\hline tcwF2 & 4 & 4 & 1.27E-03 & 5.24E-01 \\
\hline tcwM3 & 5 & 1 & $0.00 E+00$ & $0.00 E+00$ \\
\hline tcwF3 & 6 & 4 & $3.45 \mathrm{E}-03$ & 3.58E-01 \\
\hline ptnM1 & 7 & 1 & $0.00 E+00$ & $0.00 E+00$ \\
\hline ptnF1 & 8 & 4 & $9.20 \mathrm{E}-03$ & $1.49 E+00$ \\
\hline ptnM2 & 9 & 1 & $0.00 E+00$ & $0.00 E+00$ \\
\hline ptnF2 & 10 & 4 & $7.09 \mathrm{E}-03$ & $2.17 \mathrm{E}+00$ \\
\hline ptnM3 & 11 & 1 & $0.00 E+00$ & $0.00 E+00$ \\
\hline ptnF3 & 12 & 4 & $1.20 \mathrm{E}-03$ & $1.75 \mathrm{E}+00$ \\
\hline ptnM4 & 13 & 1 & $0.00 \mathrm{E}+00$ & $0.00 E+00$ \\
\hline ptnF4 & 14 & 4 & $2.94 \mathrm{E}-02$ & $2.17 E+00$ \\
\hline ptnM5 & 15 & 1 & $0.00 E+00$ & $0.00 E+00$ \\
\hline ptnF5 & 16 & 4 & $5.05 \mathrm{E}-03$ & $1.92 \mathrm{E}+00$ \\
\hline ptnM6 & 17 & 1 & $0.00 \mathrm{E}+00$ & $0.00 E+00$ \\
\hline ptnF6 & 18 & 4 & $8.71 \mathrm{E}-04$ & $1.03 E+00$ \\
\hline tswM1 & 19 & 1 & $0.00 E+00$ & $0.00 E+00$ \\
\hline tswF1 & 20 & 4 & 1.30E-03 & 4.61E-01 \\
\hline tswM2 & 21 & 1 & $0.00 \mathrm{E}+00$ & $0.00 E+00$ \\
\hline tswF2 & 22 & 4 & $2.59 \mathrm{E}-03$ & 8.93E-01 \\
\hline tswM3 & 23 & 1 & $0.00 \mathrm{E}+00$ & $0.00 E+00$ \\
\hline tswF3 & 24 & 4 & $1.31 \mathrm{E}-03$ & $1.23 E+00$ \\
\hline tswM4 & 25 & 1 & $0.00 E+00$ & $0.00 \mathrm{E}+00$ \\
\hline tswF4 & 26 & 4 & $6.28 \mathrm{E}-04$ & 2.32E-01 \\
\hline tswM5 & 27 & 1 & $0.00 E+00$ & $0.00 \mathrm{E}+00$ \\
\hline tswF5 & 28 & 4 & 9.92E-04 & 3.17E-01 \\
\hline tswM6 & 29 & 1 & $0.00 \mathrm{E}+00$ & $0.00 \mathrm{E}+00$ \\
\hline tswF6 & 30 & 4 & 1.06E-03 & 2.49E-01 \\
\hline tswM7 & 31 & 1 & $0.00 E+00$ & $0.00 E+00$ \\
\hline tswF7 & 32 & 4 & $1.06 \mathrm{E}-03$ & $2.49 \mathrm{E}-01$ \\
\hline tswM8 & 33 & 1 & $0.00 E+00$ & $0.00 E+00$ \\
\hline tswF8 & 34 & 4 & $8.25 \mathrm{E}-04$ & $2.29 \mathrm{E}-01$ \\
\hline tswMv & 35 & 1 & $0.00 E+00$ & $0.00 E+00$ \\
\hline tswFv & 36 & 4 & 1.46E-03 & $1.04 \mathrm{E}+00$ \\
\hline tswMz & 37 & 1 & $0.00 \mathrm{E}+00$ & $0.00 E+00$ \\
\hline tswFz & 38 & 4 & $1.46 \mathrm{E}-03$ & $1.04 \mathrm{E}+00$ \\
\hline ch1Mv & 39 & 1 & $0.00 \mathrm{E}+00$ & $0.00 E+00$ \\
\hline ch1Fv & 40 & 4 & $2.03 E-03$ & $1.00 \mathrm{E}+01$ \\
\hline ch1Mz & 41 & 1 & $0.00 E+00$ & $0.00 E+00$ \\
\hline ch1Fz & 42 & 4 & $1.45 \mathrm{E}-03$ & $2.50 \mathrm{E}+01$ \\
\hline ch2Mv & 43 & 1 & $0.00 \mathrm{E}+00$ & $0.00 \mathrm{E}+00$ \\
\hline ch2Fv & 44 & 4 & 1.79E-03 & $7.14 \mathrm{E}+00$ \\
\hline ch2Mz & 45 & 1 & $0.00 E+00$ & $0.00 \mathrm{E}+00$ \\
\hline ch2Fz & 46 & 4 & 8.60E-04 & $7.14 \mathrm{E}+00$ \\
\hline
\end{tabular}




\begin{tabular}{|l|r|r|r|r|}
\hline Rock & \multicolumn{1}{l}{ Zne } & \multicolumn{1}{l|}{ A-Par } & B-Par \\
\hline ch3Mv & 47 & 1 & $0.00 \mathrm{E}+00$ & $0.00 \mathrm{E}+00$ \\
\hline ch3Fv & 48 & 4 & $1.79 \mathrm{E}-03$ & $7.14 \mathrm{E}+00$ \\
\hline ch3Mz & 49 & 1 & $0.00 \mathrm{E}+00$ & $0.00 \mathrm{E}+00$ \\
\hline ch3Fz & 50 & 4 & $8.60 \mathrm{E}-04$ & $7.14 \mathrm{E}+00$ \\
\hline ch4Mv & 51 & 1 & $0.00 \mathrm{E}+00$ & $0.00 \mathrm{E}+00$ \\
\hline ch4Fv & 52 & 4 & $1.79 \mathrm{E}-03$ & $7.14 \mathrm{E}+00$ \\
\hline ch4Mz & 53 & 1 & $0.00 \mathrm{E}+00$ & $0.00 \mathrm{E}+00$ \\
\hline ch4Fz & 54 & 4 & $8.60 \mathrm{E}-04$ & $7.14 \mathrm{E}+00$ \\
\hline ch5Mv & 55 & 1 & $0.00 \mathrm{E}+00$ & $0.00 \mathrm{E}+00$ \\
\hline ch5Fv & 56 & 4 & $1.79 \mathrm{E}-03$ & $7.14 \mathrm{E}+00$ \\
\hline ch5Mz & 57 & 1 & $0.00 \mathrm{E}+00$ & $0.00 \mathrm{E}+00$ \\
\hline ch5Fz & 58 & 4 & $8.60 \mathrm{E}-04$ & $7.14 \mathrm{E}+00$ \\
\hline ch6Mv & 59 & 1 & $0.00 \mathrm{E}+00$ & $0.00 \mathrm{E}+00$ \\
\hline ch6Fv & 60 & 4 & $1.79 \mathrm{E}-03$ & $7.14 \mathrm{E}+00$ \\
\hline ch6Mz & 61 & 1 & $0.00 \mathrm{E}+00$ & $0.00 \mathrm{E}+00$ \\
\hline ch6Fz & 62 & 4 & $1.45 \mathrm{E}-03$ & $2.50 \mathrm{E}+01$ \\
\hline pp4Mz & 63 & 1 & $0.00 \mathrm{E}+00$ & $0.00 \mathrm{E}+00$ \\
\hline pp4Fz & 64 & 4 & $8.60 \mathrm{E}-04$ & $7.14 \mathrm{E}+00$ \\
\hline pp3Md & 65 & 1 & $0.00 \mathrm{E}+00$ & $0.00 \mathrm{E}+00$ \\
\hline pp3Fd & 66 & 4 & $1.59 \mathrm{E}-03$ & $5.00 \mathrm{E}+00$ \\
\hline pp2Md & 67 & 1 & $0.00 \mathrm{E}+00$ & $0.00 \mathrm{E}+00$ \\
\hline pp2Fd & 68 & 4 & $1.59 \mathrm{E}-03$ & $5.00 \mathrm{E}+00$ \\
\hline pp1Mz & 69 & 1 & $0.00 \mathrm{E}+00$ & $0.00 \mathrm{E}+00$ \\
\hline pp1Fz & 70 & 4 & $8.60 \mathrm{E}-04$ & $7.14 \mathrm{E}+00$ \\
\hline $\mathrm{bF} 3 \mathrm{Md}$ & 71 & 1 & $0.00 \mathrm{E}+00$ & $0.00 \mathrm{E}+00$ \\
\hline $\mathrm{bF3Fd}$ & 72 & 4 & $1.59 \mathrm{E}-03$ & $5.00 \mathrm{E}+00$ \\
\hline $\mathrm{bF2Mz}$ & 73 & 1 & $0.00 \mathrm{E}+00$ & $0.00 \mathrm{E}+00$ \\
\hline $\mathrm{bF} 2 \mathrm{Fz}$ & 74 & 4 & $8.60 \mathrm{E}-04$ & $7.14 \mathrm{E}+00$ \\
\hline & & & & \\
\hline
\end{tabular}


ATTACHMENT IV-PREPARATIONS AND CALCULATIONS FOR POSTPROCESSING TH/THC/THM MODEL RESULTS 


\section{INTENTIONALLY LEFT BLANK}


This attachment presents the details and examples for preparing plotting files of postprocessing TH/THC/THM model simulation output results in this MR.

\section{IV.1 POSTPROCESSING OF 2-D TH MODEL RESULTS OF SECTION 6.2}

The 'grep' operation is carried out on a Unix platform (DEC Alpha Computer System with operating system OSF V4.0 or OSF V5.1). The Microsoft Excel operations and plotting with Tecplot8 were carried out on PC with Microsoft Windows98 operating system.

\section{IV.1.1 Preparing Contour Plots}

Contour plots have been developed for three variables, namely temperature $(T)$, matrix liquid saturation, and fracture liquid saturation. To develop contour plots for any one of these variables, follow the procedures given below. As an example, the procedure for the case where $86.3 \%$ of heat was removed by ventilation is described below.

i. There are a number of output files in that directory, as follows:

1. th_2dt.out_1: for output between 0 and 600 years.

2. th_600y_2000y_vent_0.863.out: for output between 600 and 1,500 years.

3. th_600y.out: use this output file if you want acontour plot at 2,000 years.

4. th_2000y.out_1: output between 2,000 and 5,742 (app.) years is recorded in this file.

5. th_2000y.out_2: provides output to the end of the simulation.

ii. First, decide the time (say, 100 years or $0.31557 \mathrm{e} 10$ seconds) at which the contour plot is to be placed. Then, select the output file from the list given in (iii) above. Using a text editor, separate the output (only the primary variables' portion) at that selected time from the rest of the output. Save this data in a file called (for example) out.0100y.

iii. Next, for temperature and matrix liquid saturation, grep the matrix elements out of that file. This can be accomplished by executing the command:

$$
>\text { grep }-\mathrm{v} \text { 'F' out.0100y }>\text { sim_0100y }
$$

In other words, this Unix command will remove the fracture elements (all starting with ' $F$ ') and direct the resulting output to sim_0100y (notice now sim_0100y has output information only for the matrix elements at $1 \overline{0} 0$ years).

iv. Similarly, for fracture liquid saturation, execute the following command

$$
\text { >> grep }-\mathrm{v} \text { 'M' out.0100y > sif_0100y }
$$

File sif_0100y will now contain output at 100 years for the fracture elements only.

v. Now, two TOUGH2 mesh files are required to go with these sim_0100y and sif_0100y files. To obtain these mesh files, do the following 


$$
\begin{aligned}
& >>\text { grep }-v \text { 'F' MESH }>\text { mesh_ns_th.mat } \\
& >>\text { grep }-v \text { 'M' MESH }>\text { mesh_ns_th.fra }
\end{aligned}
$$

The commands are self-explanatory. The first command extracts the matrix elements out of MESH and directs them to mesh_ns th.mat, which now contains only the matrix elements. Similarly, mesh_ns_th.fra contains only the fracture elements.

vi. To generate contour plots for temperature and matrix liquid saturation, open the two files sim_0100y and mesh_ns_th.mat in Microsoft Excel (with the fixed width option). First, copy the "y" and " $z$ " coordinates from mesh_ns_th.mat into the first two columns of a new sheet. Next, copy temperature (Column ${ }^{4}$ ) and liquid saturation (Column 6) from sim_0100y on to Columns 3 and 4 of the new sheet. Save this file with the name sim_0100y and with the option "Text (Tab delimited)" in Microsoft Excel (do not save in Excèl format).

vii. To generate contour plots for fracture liquid saturation, open the two files sif $0100 \mathrm{y}$ and mesh ns th.fra in Microsoft Excel (with the fixed width option). First, copy the " $y$ " and " $z$ " coordinates from mesh_ns_th.fra into the first two columns of a new sheet. Next, copy liquid saturation (Column 6) from sif_0100y on to Column 3 of the new sheet. Save this file with the name sif_0100y and with the option "Text (Tab delimited)" in Microsoft Excel (do not save in Excēl format).

Now, open Tecplot 8.0 for plotting. Load data file "sim_0100y" or "sif_0100y" and choose the "2D" plot option in Tecplot. Next, select "Triangulate" under "Data" in Tecplot. Select ZONE 001 and finish triangulation. Plotting from here on is straight-forward.

\section{IV.1.2 Preparing Line Plots along North-South Axis}

Line plots of temperature (or matrix liquid saturation or fracture liquid saturation) versus location (at various times) along the north-south axis of the 2D model grid have been developed for the following scenarios:

1. Just above the repository

2. Just below the repository

3. At the bottom of the PTn stratigraphic unit

4. At the bottom of the TSw stratigraphic unit.

Development of plots for the case where $86.3 \%$ of the heat is removed by ventilation is described here as an example. Also, only the process at the bottom of the Tsw will be described. Plots for the other cases can be obtained similarly.

1. At the bottom of the Tsw stratigraphic unit:

i. $\quad$ Locate the file "MESH", which contains the numerical grid used for 2D TH simulations.

ii. First those elements from "MESH" that lie at the bottom of the Tsw unit must be extracted. To do this, first a file is "MESH.ELE" is created (using a text editor) with only 
the 'ELEME' section of file 'MESH' (i.e., by removing the element connections in the 'CONNE' section of file 'MESH'). Next, the following Unix commands were executed:

$$
\begin{aligned}
& >>\text { grep 'tswFv' MESH.ELE }>\text { layer_tswFv_ele } \\
& >>\text { grep 'tswFz' MESH.ELE }>\text { layer_tswFz_ele } \\
& >>\text { cat layer_tswFv_ele }>>\text { layer_tswFz_ele } \\
& >>\text { grep 'tswMv' MESH.ELE }>\text { layer_tswMv_ele } \\
& >>\text { grep 'tswMz' MESH.ELE }>\text { layer_tswMz_ele } \\
& >>\text { cat layer_tswMv_ele }>>\text { layer_tswMz_ele }
\end{aligned}
$$

The first grep command produces a file with only the fracture elements; the second one produces a file with only the matrix elements.

iii. There are five output files from the 2-D TH simulations (they are listed under Item iii of Subsection a of Section A). As an example, select th_2dt.out_1. From this file, using a text editor, extract the output at 100 years $\left(=0.31557 \mathrm{e}^{-}+08\right.$ seconds $)$. Save this output in file out.0100y.

iv. Execute the following commands

$$
\begin{aligned}
& >>\text { fgrep }- \text { flayer_tswFz_ele out.0100y }>\text { prm_tswFz_0100y } \\
& >>\text { fgrep }- \text { flayer_tswMz_ele out.0100y }>\text { prm_tswMz_0100y }
\end{aligned}
$$

The first command extracts the primary variables out of the output file out.0100y for the elements listed in file "layer tswFz ele" into the output file prm tswFz 0100y. This file now has primary variables for all fracture elements just below the repository at 100 years. The second command similarly produces primary variables for all matrix elements at the bottom of the Tsw at 100 years.

v. For temperature and matrix liquid saturation, open file prm_tswMz_0100y in Microsoft Excel. Open also the file layer_tswMz_ele. Both these files should be opened as text files with the fixed width option.

vi. On the first column of a new worksheet, copy the 6th column ("y" coordinates) from "layer_tswMz_ele." Then copy columns 3,4, and 6 (pressure, temperature, and liquid saturation, respectively) from file "prm_tswMz_0100y into Columns 2 through 4 of the new worksheet.

vii. Save the new worksheet as prm_tswMz_0100y.txt with the "Text (Tab Delimited)" option of Microsoft Excel.

viii. For fracture saturation, repeat the above steps, but with files "prm_tswFz_0100y" and "layer_tswFz_ele." Save the file at the end of step vii as "prm_tswFz_0100y.txt" with the "Text (Tab delimited)" option of Microsoft Excel.

ix. For plotting, open either file "prm_tswMz_0100y" or file "prm_tswFz_0100y" and plot Column 1 ("y" coordinates, locations along the north-south axis of the repository) against cColumn 4 (for temperature) or Column 5 (for matrix liquid saturation) of 
"prm_tswMz_0100y.txt) or Column 5 (for fracture liquid saturation) of
"prm_tswFz_0100y."

x. Plots at other times can be obtained similarly by using an appropriate output file and following Steps ii through ix.

\section{IV.1.3 Preparing Line Plots along Selected Columns in the Numerical Grid}

Line plots of temperature (or matrix liquid saturation or fracture liquid saturation) versus depth (at various times) along selected columns of the 2D model grid have been developed for the following scenarios

1. Column a62 (location approximately $231972 \mathrm{~m}$ along Nevada North-South coordinate)

2. Column b62 (location approximately $234102 \mathrm{~m}$ along Nevada North-South coordinate)

3. Column c38 (location approximately $235721 \mathrm{~m}$ along Nevada North-South coordinate).

Below, procedures are described for developing these plots for Column b62; the procedures are similar for the other columns. Development of plots for the case where $86.3 \%$ of the heat is removed by ventilation is described here. Plots for the no ventilation case can be developed similarly.

\section{Line plot development for Column b62 is as follows:}

i. $\quad$ Locate the file "MESH", which contains the numerical grid used for 2D TH simulations. In the numerical grid, the elements along Column b62 have names ending with 'b62.' For fractures, these element names begin with ' $\mathrm{F}$ ' and, for matrix, they begin with ' $\mathrm{M}$.'

ii. First, those elements from "MESH" must be extracted. To do this, first a file is "MESH.ELE" is created (using a text editor) with only the 'ELEME' section of file 'MESH' (i.e., by removing the element connections in the 'CONNE' section of file 'MESH'). Next, the following Unix commands are executed:

$$
\begin{aligned}
& >>\text { grep ' } \mathrm{F}^{*} \mathrm{~b} 62 \text { ' MESH.ELE }>\text { column_b62_ele_F } \\
& >>\text { grep ' } \mathrm{M} * \mathrm{~b} 62 \text { ' MESH.ELE }>\text { column_b62_ele_M }
\end{aligned}
$$

The first grep command produces a file with only the fracture elements along Column 'b62'; the second one produce a file with only the matrix elements of the same column.

iii. There are fice output files from the 2-D TH simulations (they are listed under Item iii of Subsection 'a' of Section A). As an example, select th_2dt.out_1. From this file, using a text editor, extract the output at 100 years $\left(=0.31557 \mathrm{e}^{-}+08\right.$ seconds). Save this output in file out.0100y.

iv. Execute the following commands:

$$
\begin{aligned}
& >>\text { fgrep }- \text { f column_b62_ele_F out.0100y }>\text { prm_CFb62_0100y } \\
& >>\text { fgrep }- \text { f column_b62_ele_M out.0100y }>\text { prm_CMb62_0100y }
\end{aligned}
$$


The first command extracts the primary variables out of the output file out.0100y for the elements listed in file "column_b62_ele_F" into the output file prm_CFb62_0100y. This file now has primary variables for all fracture elements just above the repository at 100 years. The second command similarly produces primary variables for all matrix elements just above the repository at 100 years.

v. For temperature and matrix liquid saturation, open file prm_CMb62_0100y in Microsoft Excel. Open also the file column_b62_ele_M. Both these files should be opened as text files with the fixed width option.

vi. On the first column of a new worksheet, copy the $7^{\text {th }}$ column (" $z$ " coordinates) from "column_b62_ele_M." Then copy Columns 3, 4, and 6 (pressure, temperature, and liquid saturation, respectively) from file "prm_CMb62_0100y into Columns 2 through 4 of the new worksheet.

vii. Save the new worksheet as prm_CMb62_0100y.txt with the "Text (Tab Delimited)" option of Microsoft Excel.

viii. For fracture saturation, repeat steps (iv) through (vii) but with files "prm_CFb62_0100y" and "column_b62_ele F." Save the file at the end of step (vii) as "prm_CFb62_0100y.txt" with the "Text (Tab delimited)" option of Microsoft Excel.

ix. For plotting, open either file "prm_CMb62_0100y" or file "prm_CFb62_0100y" and plot Column 1 (" $z$ " coordinates, depth along column 'a62' of the numerical grid) against Column 3 (for temperature) or Column 4 (matrix liquid saturation) of "prm_CMb62_0100y.txt) or Column 4 (fracture liquid saturation) of "prm_CFb62_0100y."

x. Plots at other times can be obtained similarly by using an appropriate output file and following steps (ii) through (ix).

\section{IV.1.4 Time History Plots}

For plotting temperature as a function of time, the following postprocessing steps are needed. For illustration purposes, Column 'b58' of the numerical grid is selected as a representative column. Column b58 is located at $234017 \mathrm{~m}$ along the Nevada North-South coordinate.

There are 10 elements along Column ' $\mathrm{b} 58$ ' for which temperature versus time data were obtained from TOUGH2 simulations. These elements are (refer to the TOUGH2 input files):

1. M001Bb58 located at $\mathrm{z}=1428.8 \mathrm{~m}$

2. M0007b58 located at $\mathrm{z}=1321.1 \mathrm{~m}$

3. M009Bb58 located at $\mathrm{z}=1283.1 \mathrm{~m}$

4. M0010b58 located at $\mathrm{z}=1279.6 \mathrm{~m}$

5. M0011b58 located at $\mathrm{z}=1271.2 \mathrm{~m}$

6. $\mathrm{RP} 14 \mathrm{Db} 58$ located at $\mathrm{z}=64.6 \mathrm{~m}$ (a repository element)

7. M014Eb58 located at $\mathrm{z}=64.6 \mathrm{~m}$ (next to a repository element) 
8. M0017b58 located at $\mathrm{z}=952.1 \mathrm{~m}$

9. $\mathrm{M} 0019 \mathrm{~b} 58$ located at $\mathrm{z}=929.2 \mathrm{~m}$

10. $\mathrm{M} 0025 \mathrm{~b} 58$ located at $\mathrm{z}=832.0 \mathrm{~m}$

We describe postprocessing of data for each of these elements when $86.3 \%$ of the heat is removed by ventilation. Postprocessing of the no-ventilation case data can be done similarly.

i. There are altogether four files containing the temperature versus time data for all the elements specified in the TOUGH2 input file. These are:

1. GASOBS.DAT_th_2dt.out_1: Data through first 600 years.

2. GASOBS.DAT_th_600y.out: Data between 600 and 2000 years.

3. GASOBS.DAT_th_2000y.out_1: Data between 2000 years and 5742 years (app.).

4. GASOBS.DAT_th_2000y.out_2: Data beyond 5742 years.

ii. Element 'M001Bb58'

For temperature versus time evolution data in element 'M001B58', first execute the following commands:

$$
\begin{aligned}
& \text { > grep 'M001Bb58' GASOBS.DAT_th_2dt.out_1 }>\text { out.1 } \\
& >>\text { grep 'M001Bb58' GASOBS.DAT_th_600y.out }>\text { out.2 } \\
& >>\text { grep 'M001Bb58' GASOBS.DAT_th_2000y.out_1 > out.3 } \\
& >>\text { grep 'M001Bb58' GASOBS.DAT_th_2000y.out_2 }>\text { out.4 } \\
& >>\text { mv out.1 si_heat_M001Bb58.sen } \\
& >>\text { cat out.2 >> si_heat_M001Bb58.sen } \\
& >>\text { cat out.3 }>>\text { si_heat_M001Bb58.sen } \\
& >>\text { cat out.4 }>>\text { si_heat_M001Bb58.sen }
\end{aligned}
$$

File si heat_M001Bb58.sen now contains temperature versus time data for element 'M001 $\overline{\mathrm{B}} \mathrm{b} 58^{\bar{\prime}}$ from start to end of simulation.

iii. Element 'M0007b58'

For temperature versus time evolution data in element 'M001B58', first execute the following commands:

$$
\begin{aligned}
& >>\text { grep 'M0007b58' GASOBS.DAT_th_2dt.out_1 > out.1 } \\
& >>\text { grep 'M0007b58' GASOBS.DAT_th_600y.out }>\text { out.2 }
\end{aligned}
$$




$$
\begin{aligned}
& \text { > }>\text { grep 'M0007b58' GASOBS.DAT_th_2000y.out_1 }>\text { out.3 } \\
& >>\text { grep 'M0007b58' GASOBS.DAT_th_2000y.out_2 }>\text { out.4 } \\
& >>\text { mv out.1 si_heat_M0007b58.sen } \\
& >>\text { cat out.2 }>>\text { si_heat_M0007b58.sen } \\
& >>\text { cat out.3 }>>\text { si_heat_M0007b58.sen } \\
& >>\text { cat out. } 4>>\text { si_heat_M0007b58.sen }
\end{aligned}
$$

File si heat_M0007b58.sen now contains temperature versus time data for element 'M0007 b58' from start to end of simulation.

iv. Element 'M009Bb58'

For temperature versus time evolution data in element 'M001B58', first execute the following commands:

$$
\begin{aligned}
& >>\text { grep 'M009Bb58' GASOBS.DAT_th_2dt.out_1 > out.1 } \\
& >>\text { grep 'M009Bb58' GASOBS.DAT_th_600y.out }>\text { out.2 } \\
& >>\text { grep 'M009Bb58' GASOBS.DAT_th_2000y.out_1 > out.3 } \\
& >>\text { grep 'M009Bb58' GASOBS.DAT_th_2000y.out_2 }>\text { out.4 } \\
& >>\text { mv out.1 si_heat_M009Bb58.sen } \\
& >>\text { cat out.2 >> si_heat_M009Bb58.sen } \\
& >>\text { cat out.3 }>>\text { si_heat_M009Bb58.sen } \\
& >>\text { cat out.4 }>>\text { si_heat_M009Bb58.sen }
\end{aligned}
$$

File si heat M009Bb58.sen now contains temperature versus time data for element 'M009 $\overline{\mathrm{B}} \mathrm{b} 58^{\bar{\prime}}$ ' from start to end of simulation.

v. Element 'M0010b58'

For temperature versus time evolution data in element 'M001B58', first execute the following commands:

$$
\begin{aligned}
& >>\text { grep 'M0010b58' GASOBS.DAT_th_2dt.out_1 > out.1 } \\
& >>\text { grep 'M0010b58' GASOBS.DAT_th_600y.out }>\text { out.2 } \\
& >>\text { grep 'M0010b58' GASOBS.DAT_th_2000y.out_1 }>\text { out.3 } \\
& >>\text { grep 'M0010b58' GASOBS.DAT_th_2000y.out_2 }>\text { out.4 } \\
& >>\text { mv out.1 si_heat_M0010b58.sen }
\end{aligned}
$$




$$
\begin{aligned}
& >>\text { cat out. } 2>>\text { si_heat_M0010b58.sen } \\
& >>\text { cat } \text { out. } 3>>\text { si_heat_M0010b58.sen } \\
& >>\text { cat } \text { out. } 4>>\text { si_heat_M0010b58.sen }
\end{aligned}
$$

File si heat_M0010b58.sen now contains temperature versus time data for element 'M0010b58' from start to end of simulation.

vi. Element 'M0011b58'

For temperature versus time evolution data in element 'M001B58', first execute the following commands:

$$
\begin{aligned}
& \text { > } \text { grep 'M0011b58' GASOBS.DAT_th_2dt.out_1 > out.1 } \\
& >>\text { grep 'M0011b58' GASOBS.DAT_th_600y.out }>\text { out.2 } \\
& \text { > } \text { grep 'M0011b58' GASOBS.DAT_th_2000y.out_1 > out.3 } \\
& >>\text { grep 'M0011b58' GASOBS.DAT_th_2000y.out_2 > out.4 } \\
& >>\text { mv out.1 si_heat_M0011b58.sen } \\
& >>\text { cat out. } 2>>\text { si_heat_M0011b58.sen } \\
& >>\text { cat out.3 }>>\text { si_heat_M0011b58.sen } \\
& >>\text { cat out.4 }>>\text { si_heat_M0011b58.sen }
\end{aligned}
$$

File si heat_M0011b58.sen now contains temperature versus time data for element 'M001 1 b58' from start to end of simulation.

vii. Element 'RP14Db58'

For temperature versus time evolution data in element 'M001B58', first execute the following commands:

$$
\begin{aligned}
& >>\text { grep 'RP14Db58' GASOBS.DAT_th_2dt.out_1 }>\text { out.1 } \\
& >>\text { grep 'RP14Db58' GASOBS.DAT_th_600y.out }>\text { out.2 } \\
& >>\text { grep 'RP14Db58' GASOBS.DAT_th_2000y.out_1 > out.3 } \\
& >>\text { grep 'RP14Db58' GASOBS.DAT_th_2000y.out_2 > out.4 } \\
& >>\text { mv out.1 si_heat_RP14Db58.sen } \\
& >>\text { cat out.2 }>>\text { si_heat_RP14Db58.sen } \\
& >>\text { cat out.3 }>>\text { si_heat_RP14Db58.sen } \\
& >>\text { cat out.4 }>>\text { si_heat_RP14Db58.sen }
\end{aligned}
$$


File si heat_RP14Db58.sen now contains temperature versus time data for element 'RP14 $\overline{\mathrm{D}} \mathrm{b} 58^{\text {' }}$ from start to end of simulation.

viii. Element 'M014Eb58'

For temperature versus time evolution data in element 'M001B58', first execute the following commands:

$$
\begin{aligned}
& \text { > } \text { grep 'M014Eb58' GASOBS.DAT_th_2dt.out_1 > out.1 } \\
& >>\text { grep 'M014Eb58' GASOBS.DAT_th_600y.out }>\text { out.2 } \\
& \text { > } \text { grep 'M014Eb58' GASOBS.DAT_th_2000y.out_1 > out.3 } \\
& >>\text { grep 'M014Eb58' GASOBS.DAT_th_2000y.out_2 > out.4 } \\
& >>\text { mv out.1 si_heat_M014Eb58.sen } \\
& >>\text { cat out.2 >> si_heat_M014Eb58.sen } \\
& >>\text { cat out.3 }>>\text { si_heat_M014Eb58.sen } \\
& >>\text { cat out.4 }>>\text { si_heat_M014Eb58.sen }
\end{aligned}
$$

File si heat M014Eb58.sen now contains temperature versus time data for element

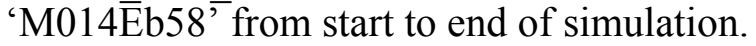

ix. Element 'M0017b58'

For temperature versus time evolution data in element 'M001B58', first execute the following commands:

$$
\begin{aligned}
& \text { > }>\text { grep 'M0017b58' GASOBS.DAT_th_2dt.out_1 > out.1 } \\
& >>\text { grep 'M0017b58' GASOBS.DAT_th_600y.out }>\text { out.2 } \\
& >>\text { grep 'M0017b58' GASOBS.DAT_th_2000y.out_1 > out.3 } \\
& >>\text { grep 'M0017b58' GASOBS.DAT_th_2000y.out_2 }>\text { out.4 } \\
& >>\text { mv out.1 si_heat_M0017b58.sen } \\
& >>\text { cat out.2 >> si_heat_M0017b58.sen } \\
& >>\text { cat out.3 }>>\text { si_heat_M0017b58.sen } \\
& >>\text { cat out.4 }>>\text { si_heat_M0017b58.sen }
\end{aligned}
$$

File si heat_M0017b58.sen now contains temperature versus time data for element 'M0017 b58' from start to end of simulation.

X. Element 'M0019b58' 
For temperature versus time evolution data in element 'M001B58', first execute the following commands:

$$
\begin{aligned}
& >>\text { grep 'M0019b58' GASOBS.DAT_th_2dt.out_1 > out.1 } \\
& >>\text { grep 'M0019b58' GASOBS.DAT_th_600y.out }>\text { out.2 } \\
& >>\text { grep 'M0019b58' GASOBS.DAT_th_2000y.out_1 > out.3 } \\
& >>\text { grep 'M0019b58' GASOBS.DAT_th_2000y.out_2 > out.4 } \\
& >>\text { mv out.1 si_heat_M0019b58.sen } \\
& >>\text { cat out.2 >> si_heat_M0019b58.sen } \\
& >>\text { cat out.3 }>>\text { si_heat_M0019b58.sen } \\
& >>\text { cat out.4 }>>\text { si_heat_M0019b58.sen }
\end{aligned}
$$

File si heat_M0019b58.sen now contains temperature versus time data for element 'M0019 b58' from start to end of simulation.

xi. Element 'M0025b58'

For temperature versus time evolution data in element 'M001B58', first execute the following commands:

$$
\begin{aligned}
& >>\text { grep 'M0025b58' GASOBS.DAT_th_2dt.out_1 > out.1 } \\
& >>\text { grep 'M0025b58' GASOBS.DAT_th_600y.out }>\text { out.2 } \\
& >>\text { grep 'M0025b58' GASOBS.DAT_th_2000y.out_1 > out.3 } \\
& >>\text { grep 'M0025b58' GASOBS.DAT_th_2000y.out_2 > out.4 } \\
& >>\text { mv out.1 si_heat_M0025b58.sen } \\
& >>\text { cat out. } 2>>\text { si_heat_M0025b58.sen } \\
& >>\text { cat out. } 3>>\text { si_heat_M0025b58.sen } \\
& >>\text { cat out.4 }>>\text { si_heat_M0025b58.sen }
\end{aligned}
$$

File si heat M0025b58.sen now contains temperature versus time data for element 'M0025 b58' from start to end of simulation.

xii. Now open any one of these files in Microsoft Excel with the fixed width open.

xiii. Copy the second through the last column on to a new worksheet. The first column of this new sheet is 'Time' (in days) and the third column is Temperature (in ${ }^{\circ} \mathrm{C}$ ).

xiv. Save this new worksheet with the same name but as a text file (with the Tab Delimited option in Microsoft Excel). 
xv. Open this file in Tecplot 8.0 and using the data alteration option in Tecplot (go to Data/Alter/Specify Equation) convert Time (in days) to Time (in years) by specifying $\mathrm{V} 6=\mathrm{V} 1 / 365.24$, and then plot V6 (as $\mathrm{x}$-axis) and V4 (temperature as y-axis).

xvi. Repeat the process for the other files representing the 10 elements.

\section{IV.2 POSTPROCESSING OF 3-D TH MODEL RESULTS OF SECTION 6.3}

The data extraction operations can be carried out on any Unix platform where the "grep" and "fgrep" are available. The Microsoft Excel operations and plotting with Tecplot9 were carried out on PC with the Microsoft Windows 2000 operating system.

\section{IV.2.1 Extraction of Temperature and Saturation at PTn Bottom, Repository Horizon, and CHn Top}

(1) Copy output data for a certain time from the original output file of the 3D TH model. For example, 500y_v.out represents ventilation model output results for time at 500 years.

(2) Grep data for different layers by:

fgrep -f ch1top_th.cel 500y_v.out $>$ chn_500y_v.dat

fgrep -f ptn_bot_th.cel 500y_v.out>ptn_500y_v.dat

fgrep - f repo_th.cel 500y_v.out $>$ repo_500y_v.dat

fgrep $-\mathrm{f}$ 3DTH_NSCross.cel 500y_v.out>ns_500y_v.dat

where

ch1top_th.cel contains the list of gridblocks located at the top of $\mathrm{CHn}$ unit.

ptn_bot_th.cel contains the list of gridblocks located at the bottom of PTn unit. repo_th.cel contains the list of gridblocks located at the repository horizon.

3DTH_NSCross.cel contains the list of gridblocks located at the N-S cross section.

(3) Use a text editor to edit the output file from above fgrep command. Delete columns and rows that are not needed.

(4) Use "grep" command to separate output results for fracture and matrix continuum.

(5) Use MS Excel or text editor to combine coordinates for each gridblock. The final file will contain three columns: $\mathrm{x}, \mathrm{y}$, and variable (can be temperature, saturation, or other parameters).

The following four files provide coordinates of all cells at different layers:

REPO_TH: $\mathrm{x}$ and $\mathrm{y}$ coordinates for gridblocks at the repository horizon.

PTN:xy: $x$ and y coordinates for gridblocks at the bottom of PTn unit.

CHN.xy: $x$ and y coordinates for gridblocks at the top of $\mathrm{CHn}$ unit.

3D_TH_NSCross.xy: $x$ and $y$ coordinates for gridblocks at the N-S cross section.

(6) Use "Tecplot" to plot the 2-D results on a 2-D contour map. 


\section{IV.2.2 Extraction of Vertical Flux at PTn Bottom, Repository Horizon, and CHn Top}

The same procedure is used as described in BSC 2001 ([163045], Attachment III.2).

\section{IV.2.3 Extraction of Temperature and Saturation with Time, or Profiles for Different Columns}

These results can be obtained by "greping" the gridblock name or a column "identification" from observation output files.

For example:

(1) Temperature or saturation change with time for the gridblock "DP12h47" can be obtained by

grep 'DP12h47' GASOBS.DAT_TH_V16.OUT_1>tem.dat grep 'F0' tem.dat $>$ DP12h47_t_F.dat (for temperature or saturation in fracture) grep 'M0' tem.dat> DP12h47_t_M.dat (for temperature or saturation in matrix)

Then use a text editor to remove unnecessary information from the above output file.

(2) Temperature, saturation, or vertical flux in the column " $h 47$ ".

All gridblocks in this column have a name with the last three characters of "h47".

Therefore, data can be abstracted for this column by:

grep 'h47' TH_V16.out_1>h47.dat.

h47.dat contains data for multiple years. Use a text editor to get the data required.

\section{IV.3 POSTPROCESSING OF THC MODEL RESULTS OF SECTION 6.4}

\section{IV3.1 Extraction of Temperature and Liquid Saturation Breakthrough Information from TOUGH2REACT Output Files}

Data extraction was carried out on a Unix platform where the "grep" and "fgrep" commands are available. Microsoft Excel operations and plotting with Tecplot were carried out on a PC with the Microsoft Windows 2000 operating system. 
(1) Output file

GASOBS.DAT

(2) Operation

Step 1: Apply the following UNIX commends to grep the temperature and gas saturation:

grep AAE38 GASOBS.DAT >AAE38

grep AAZ92 GASOBS.DAT >AAZ92

grep AAc90 GASOBS.DAT >AAc90

grep ABJ61 GASOBS.DAT >ABJ61

where AAE38 AAZ92 AAc90 ABJ61 are block names representing the position of where the temperature and saturation need to be extracted. These names are also used as the filename storing the information.

Step 2: Copy the second column (time), the fourth column (gas saturation) and the fifth column (temperature), from Files AAE38, AAZ92, AAc90 and ABJ61, respectively. Paste the time column and the saturation column, the time column and the temperature column onto two different intermediate files, respectively, for later plotting. Note that the gas saturation is converted into liquid saturation as follows:

$\mathrm{S}_{\mathrm{L}}=1-\mathrm{S}_{\mathrm{G}}$

where $\mathrm{S}_{\mathrm{L}}$ and $\mathrm{S}_{\mathrm{G}}$ are liquid and gas saturation, respectively.

The conversion is performed in a worksheet using command:

Column $\mathrm{C}=1-$ Column B

where Column B stores gas saturation and Column $\mathrm{C}$ gives the liquid saturation.

(3) Extracted information (files):

The extracted temperature and liquid saturation are stored in the following two files:

Temp_T.dat (temperature)

Sat_T.dat (Saturation)

\section{IV.3.2. Extraction of Temperature and Saturation Spatial Distribution Information from the TOUGH2REACT Output File}


(1) Output file:

flow.out

(2) Operation:

Step 1: Create files FRACTURE and MATRIX, storing the fracture and matrix blocknames, respectively. Open MESH file, copy digital column19 (should be F or M indicating fracture or matrix), paste it twice immediately after this column then. Tsing UNIX commands:

grep FFF MESH>FRACTURE

grep MMM MESH>MATRIX

Open FRACTURE and MATRIX, delete the connection rows and columns other than the block names, retrieve the coordinates of each block, and save them in files, Temp_pres.plt and file, Saturation_pres_F.plt and Saturation_pres_M.plt, respectively, as the first two columns.

Step 2: Applying the following UNIX commands to extract the fracture liquid saturation and matrix liquid saturation, respectively:

fgrep -f FRACTURE flow.out>flow_F.out

fgrep -f MATRIX flow.out>flow_M.out

Step 3: Delete the rows of iteration information and keep the rows of output information of each block. Copy the fourth column and paste it together with the coordinates into Temp_pres.plt. Note that the temperature of fracture blocks and the relevant matrix blocks are almost the same. Copy the sixth column (liquid saturation) from flow_F.out and flow_M.out, and paste them onto Saturation_pres_F.plt and Saturation_pres_M.plt, respectively. Add captions into the file, following the Tecplot format for the later plotting.

Step 4: Apply this operation also to the monsoon mean and glacial mean infiltration scenarios.

(3) Extracted information (files)

The extracted information are saved in the following files:

Temp_pres.plt (temperature, present mean, 0-600 years)

Saturation_pres_F.plt (fracture saturation, present mean, 0-600 years)

Saturation_pres_M.plt (matrix saturation, present mean, 0-600 years)

Temp_mon.plt (temperature, monsoon mean, 600-2,000 years)

Saturation_mon_F.plt (fracture saturation, monsoon mean, 600-2,000 years)

Saturation_mon_M.plt (matrix saturation, monsoon mean, 600-2,000 years)

Temp_gla.plt （temperature, glacial mean, 2,000-100,000 years) 
Saturation_gla_F.plt (fracture saturation, glacial mean, 2,000-100,000 years)

Saturation_gla_M.plt (matrix saturation, glacial mean, 2,000-100,000 years)

\section{IV.3.3 Extraction of Percolation Flux through the Repository Horizon from TOUGH2REACT Output}

(1) Output file

flow.out

(2) Operation

Step 1: Create files containing information of:

a) Fracture block names of the repository horizon:

Repo_Fblocks.dat

b) Matrix block names of the repository horizon:

Repo_Mblocks.dat

c) A downward vertical fracture connection of the repository horizon:

Repo_Fcon.dat (note: no space between two blocknames of each connection)

d) A downward vertical matrix connection of the repository horizon:

Repo_Mcon.dat (note: no space between two blocknames of each connection)

These files were manually created by just copy and paste operation from the MESH file.

Step 2: Using UNIX command to create files containing information of gridblock coordinates, connection areas:

Fgrep -f Repo_Fblocks.dat MESH>aa

Edit AA to get the coordinates of each block (pick up column51-80)

Apply the same operation for matrix blocks

Save the coordinates in:

Repo_Fcor.dat

Repo_Mcor.dat

Step 3: Using UNIX command to create files containing information of connection areas:

fgrep -f Repo_Fcon.dat Mesh>aa

edit aa to obtain connection area (picking up column 51-60) and save them in: 
Repo_Tarea.dat

Repo_Marea.dat

Note that the connection areas of fractures and matrix are set the same.

Step 4: Extract percolation flux

Open flow.out, delete rows regarding the blocks and keep only the rows of connections. Save the modified file as flux.out. Delete the space between the two block names in flux.out. Apply the following UNIX commands:

fgrep -f Repo_Fcon.dat flux.out>repo_Fflux.dat (fracture flux in $\mathrm{kg} / \mathrm{s}$ )

fgrep -f Repo_Mcon.dat flux.out>repo_Mflux.dat (matrix flux in kg/s)

Step 5: Combine the fracture flux and matrix flux and convert the unit from $\mathrm{kg} / \mathrm{s}$ to $\mathrm{mm} / \mathrm{year}$

Perform the following conversion in a worksheet:

Flux $(\mathrm{mm} /$ year $)=($ fracture flux $(\mathrm{kg} / \mathrm{s})+$ matrix flux $(\mathrm{kg} / \mathrm{s})) * 86400 * 365$

Step 6: Repeat the above operation for each simulation scenario and each time step of interestd.

(3) Extracted information (files)

The extracted information is stored in the following files:

XEPO 4.DAT (percolation flux through the repository horizon calculated with the harmonic scheme for permeability weighting and without vapor diffusion)

FLUX.DAT (percolation flux through the repository horizon calculated using TH and THC simulation with upstream scheme for permeability weighting with consideration of vapor diffusion)

All above-mentioned files are submitted in the following DTNs:

LB0310MTSCLTH2.001, LB0310MTSCLTH3.001, and LB0310MTSCLTHC.001

\section{IV.4 POSTPROCESSING OF THM MODEL RESULTS OF SECTION 6.5}

The postprocessing of results from the Mountain-Scale THM Model are described by the flow schemes given below. Yellow boxes contain input files for postprocessing, and blue boxes are outputs in the form of graphical presentations in Section 6.5 of this Model Report. Orange boxes represent data manipulations with standard functions in TECPLOT V8.0, and they are described in detail. Filenames marked with extension *.out and Gasobs.dat in yellow boxes denotes output 
files from TOUGH2 V1.6 (LBNL 2003 [161491]). Files marked *.sav in yellow boxes denotes FLAC3D V2.0 (LBNL 2001 [154783]) save files. Filenames marked with extension *.tec are TECPLOT formatted text files, which can be imported to TECPLOT V8.0 for graphical presentation. All these files have been submitted to the TDMS. Postprocessing of data with code Ext V1.0 (LBNL 1999 [140944]) was carried out on a Sun-Sparc workstation with operating system SunOs V5.5.1. Plotting by Tecplot V8.0 was performed on a PC with a Microsoft Windows 98 Operating System. 


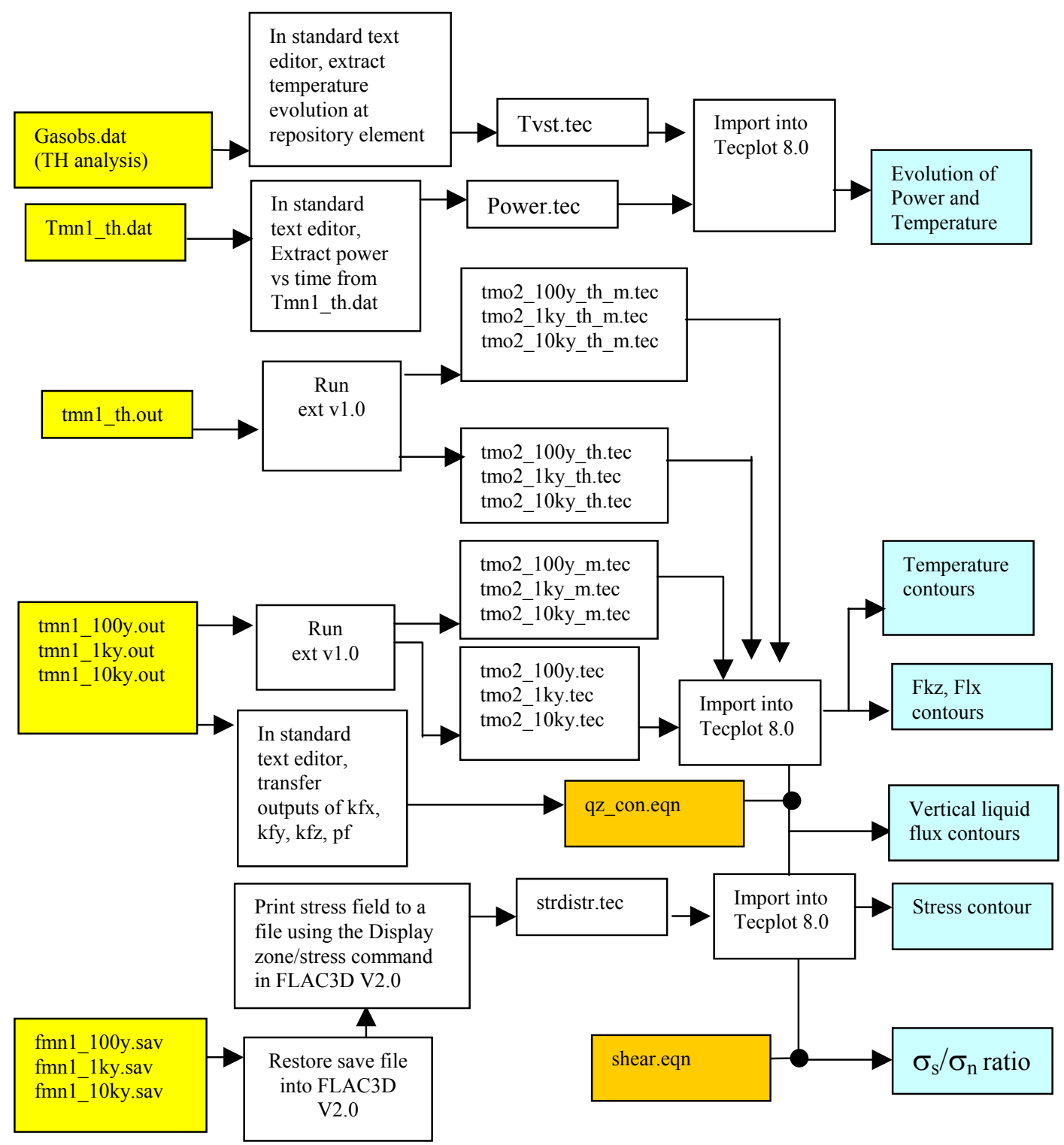



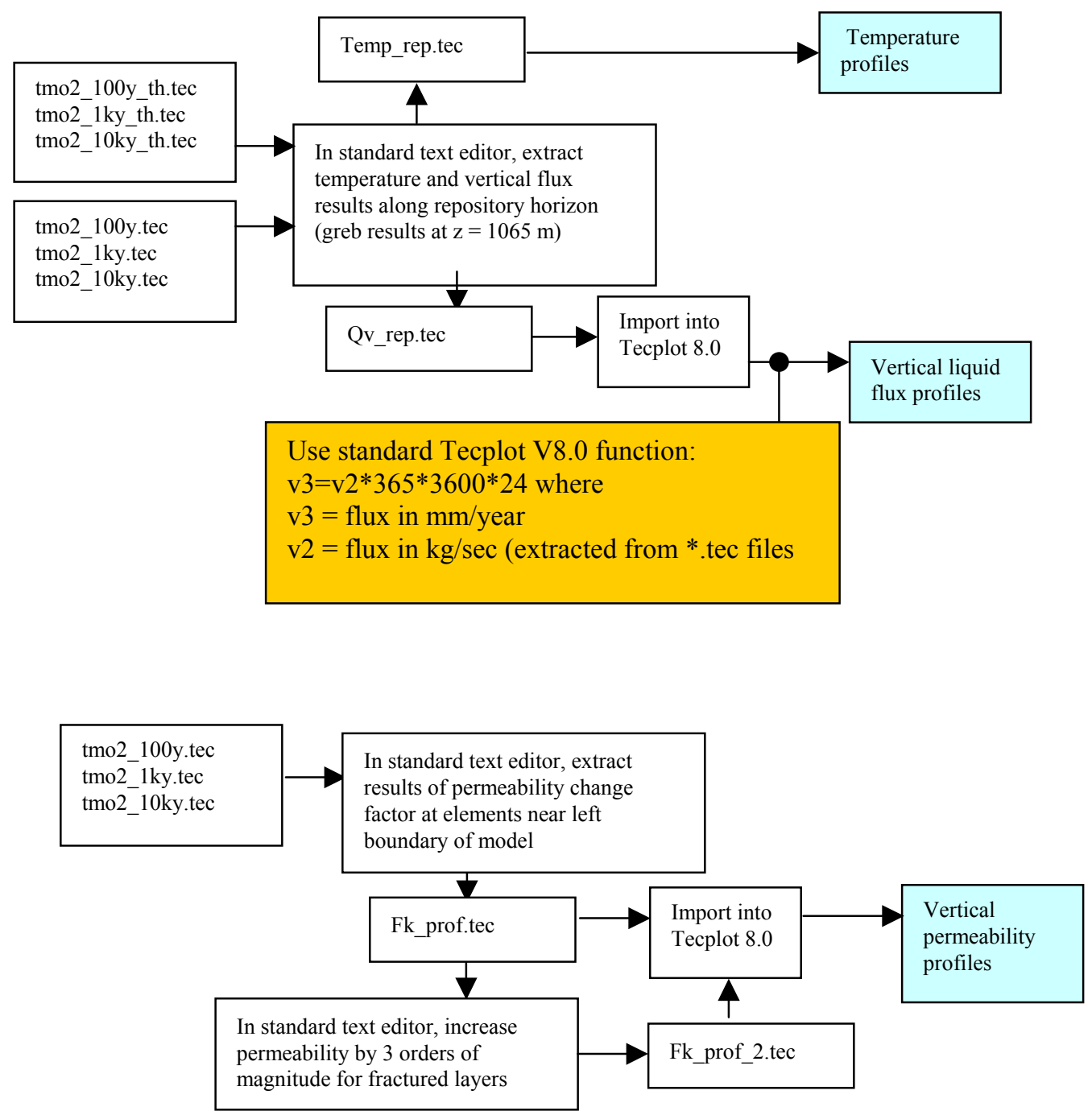


\section{Explanation to box}

qz_con.eqn contains standard Tecplot V8.0 functions:

$\mathrm{v} 4=\mathrm{v} 3 * 365 * 24 * 3600$

$\mathrm{v} 5=\mathrm{v} 4[1]+\mathrm{v} 4[2]$

where

v3 is vertical flux in $\mathrm{kg} / \mathrm{sec}$ (imported from *.tec files for both fracture and matrix in separate TECPLOT zones [1] and [2])

$\mathrm{v} 4$ is vertical flux in $\mathrm{mm} / \mathrm{year}$

$\mathrm{v} 4[1]$ is vertical flux in $\mathrm{mm} /$ year for TECPLOT zone [1] which is fracture vertical flux

$\mathrm{v} 4[2]$ is vertical flux in $\mathrm{mm} /$ year for TECPLOT zone [2] which is matrix vertical flux

$\mathrm{v} 5$ is the total vertical flux in $\mathrm{mm} / \mathrm{year}$ (including matrix and fracture) 
Explanation to box

on page 232 :

In shear.eqn the following standard TECPLOT V8.0 functions are used:

$\mathrm{v} 10=\mathrm{abs}(\mathrm{v} 9) /(\max (-\mathrm{v} 4,0.1))$

$\mathrm{v} 11=\operatorname{abs}(\mathrm{v} 9) /(\max (-\mathrm{v} 6,0.1))$

where

$\mathrm{v} 4$ is stress in $\mathrm{x}$-direction (imported from strdistr.tec file )

v6 is stress in z-direction (imported from strdistr.tec file )

v9 is xz-shear stress (imported from strdistr.tec file )

v10 is sigxz/sigx (with sigx limited to compression)

v11 is sigxz/sigz (with sigz limited to compression)

$\mathrm{v} 10$ and v11 is plotted as shear over normal stress ratio for vertical and horizontal fractures, respectively. 


\section{INTENTIONALLY LEFT BLANK}

